\title{
Der Städtedreieck-Typ
}

4.1

Michigan, Isl. Ms. 220

Isl. Ms. 220 besteht aus zwei Teilen: ${ }^{1}$ Teil I (Masse: $10.4-10.7 \times 89.5 \mathrm{~cm})$ ist deutlich jünger als Teil II (Masse: $11.1 \times 353.0 \mathrm{~cm}$ ). Teil I dürfte aus dem 18 . oder 19. Jh. stammen. Dieser jüngere Teil wurde dem alten Abschnitt (datiert 727/1327?) als Ergänzung bzw. neuer Anfang vorangestellt. Obwohl Teil I aufgrund seiner Gestaltung nicht zu den hier behandelten Dokumenten zählt, wird er der Vollständigkeit halber doch zusammen mit dem Rest der Rolle an dieser Stelle beschrieben. Das Dokument wurde in einem metallenen Behältnis aufbewahrt. $^{2}$

Teil I (АBB. 1): ${ }^{3}$ Auch dieser jüngere Teil ist am Anfang inzwischen nur noch fragmentarisch erhalten. Diese spätere Ergänzung des alten Dokuments zeigt, dass derartige Rollen über Generationen in Gebrauch waren. Auch aus Form und Inhalt dieser jüngeren Ergänzung ergeben sich wichtige Hinweise zur Kontextualisierung des gesamten Dokuments.

Ein Schriftband (Breite: $1.2 \mathrm{~cm}$ ) mit Text in Rollenrichtung fasst den jüngeren Teil auf beiden Seiten ein. ${ }^{4}$ Im Mittelstreifen (Breite ca. $4.8 \mathrm{~cm}$ ) wurde der Text zumeist auf horizontalen Linien notiert. Dies trifft insbesondere auf die drei Querbalken mit den Überschriften zu den einzelnen Abschnitten zu.

1 Diese Beschreibung stützt sich ausschliesslich auf digitales Abbildungsmaterial; das Dokument wurde nicht am Original untersucht. Der Aufwand einer Reise in die USA hätte wohl nur wenig zusätzliche Erkenntnisse gebracht; vgl. https://catalog.hathitrust.org/Record/ oo6795778 (Stand: 26. Juni 2017).

2 Vgl. Abb. 1-3 unter https://babel.hathitrust.org/cgi/pt?id= mdp.39015079126218; view=1up;seq=1.

3 Vgl. Abb. 6-7 (link in Anm. 2).

4 Vokalisiertes Nash von ca. 6-7 mm Höhe (alif). Dieses Schriftband wird von zwei feinen roten Linien eingefasst.
Der Kopist hat im linken und rechten Seitenband $^{5}$ Auszüge aus jenen Koranversen zusammengefasst, die den Begriff fath oder von dieser Wurzel abgeleitete Ausdrücke enthalten. ${ }^{6}$ Die Wurzel fataḥa bringt die Grundideen von „Öffnung, Eroberung, Sieg“ zum Ausdruck. Der Begriff fath bezeichnet auch jene Phase in der Geschichte der jungen muslimischen Gemeinde, die durch die nach Norden gerichteten Eroberungen gekennzeichnet ist. Allāh öffnete damals die neuen Gebiete für die Muslime. ${ }^{7}$

Im Mittelstreifen lassen sich in drei Querbalken die folgenden Überschriften erkennen:

I.A: Siegel des Propheten (صورة هر نبوت حضرت (رسالتيناهى (ر) Diese Figur selbst ist in ein Feld von ca. $4.8 \times 8.2 \mathrm{~cm}$ eingefügt worden. Eine feine rote Linie bildet einen oben spitz zulaufenden Tropfen. Im unteren Teil des Tropfens zweiteilige, hastenartige Verzierungen in schwarzer Tinte. Im oberen, spitzen Teil des Tropfens stehen folgende Einzelbuchstaben ohne unmittelbar ersichtlichen Sinn (rechts): ر و ر ر سا ط. Im Tropfen selbst stehen die Ausdrücke: نبوت | طعين | طلحلحح | صلعدح : Dieser Tropfen wird von drei Begriffen in unpunktier-

5 Linkes Schriftband: Text vorwärtslaufend; rechtes Schriftband: Text rückwärtslaufend.

6 Auf diesen seitlichen Schriftbändern liessen sich Auszüge aus folgenden Koranversen identifizieren: 1. Links, vorwärtslaufend: Q 2:76 (Anfang fehlt); 5:52; 4:141; 6:44; 6:59; 7:40; 7:89; 7:96; 8:19; 12:65; 2. Rechts, rückwärtslaufend (der Übergang erfolgt in Q 12:65; somit ist das Dokument hier vollständig); 15:14; 14:15; 21:96; 23:77; 26:118; 32:28-29; 34:26; 35:2 (Text bricht ab, da der Anfang des Dokuments fehlt).

7 Zum Fath-Konzept im Sinn von „Eroberung“ vgl. Auer Futūh, in $E I^{3}$. Es ist allerdings zu beachten, dass auch die Vorstellung des Öffnens bei der Interpretation dieser Koranstellen eine wichtige Rolle spielen dürfte; vgl. dazu Nünlist, Devotion and protection: Amuletic scrolls dating from the 14th century, 508-511.

8 Entzifferung nicht gänzlich gesichert. Die Folge Schluss der beiden letzten Begriffe wurde absteigend notiert.

(C) TOBIAS NÜNLIST, 2020 | DOI:10.1163/9789004429154_006

This is an open access chapter distributed under the terms of the CC BY-NC-ND 4.O license. 
ter Schrift eingerahmt, deren Entzifferung nicht

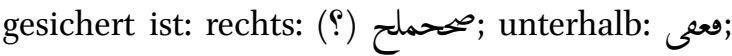
links: فعرور. Die Bedeutung dieser Ausdrücke liess sich nicht erschliessen.

I.B: Die Überschrift im zweiten Querbalken lautet نود و نه نام باري تعالى („Die 99 Namen Gottes, des Erhabenen“). ${ }^{9}$ Nach einer Einleitung in den vier ersten Zellen (هو الله / الذى / لا اله / الا هو ( in einem Gitter $(5 \times 20$ Zellen $)$ Epitheta, die aus Listen der Schönen Namen Gottes bekannt sind. Im vorliegenden Abschnitt können demnach aber nur noch 96 Namen enthalten sein. ${ }^{10}$

I.C: Der dritte Querbalken enthält die folgende Überschrift: دعا[ي] بازوبند حضرت شاه ولا يتيناه Am Oberarm getragenes Gebet des erhabenen Königs und Schutzherrn über die wilāyat"). Der Ausdruck „Ḥaḍrat-i Šāh-i wilāyat-panāh“ spielt auf 'Alī, den ersten Imam der Schiiten, an. Dieser jüngere Zusatz des Dokuments muss also in einem Umfeld entstanden sein, in dem 'Alī verehrt wird. Von Interesse ist sodann, dass dieses Gebet am Oberarm getragen wurde ( $b \bar{a} z \bar{u}-b a n d) .{ }^{11}$ Im Mittelstreifen dieses Abschnitts wurden zwei Gebete kopiert. Gebet 1 (Zeilen 1-8) appelliert im wesentlichen an den Schutz durch Gott. Gebet 2 (Zeilen 9-26) appelliert ebenso an den Schutz durch Gott. Es enthält wiederholt Anrufungen Gottes. ${ }^{12}$ Diese beiden Gebete sind auf arabisch abgefasst, was bei einem

9 Zu den Schönen Namen Gottes vgl. Kapitel 3.4, Anm. 464.

10 Beim Lesen verläuft der Text wie folgt: 1 . Zeile: rechts nach links; 2. Zeile: links nach rechts; 3 . Zeile: rechts nach links.

11 Vgl. dazu Dihhudā, Luġat-nāma, s.v. „bāzūband“.

12 Die beiden Gebete liessen sich als Ganzes anderweitig nicht nachweisen. Wiederholt liessen sich aber Ausschnitte daraus in andern Gebeten identifizieren: Gebet 1:

ا بسم الله الرحم الرحيم / تحصنت بذي الملك والملكوت واعتصمت بذي / العزة والجلال والجبروت وتوكلت على / الحي الذي لا ينام ولا يموت دخلت في حز الله / ه ووي حفظ الله وفي امان الله من شر كل بلية / اجمعين و.بكق كهيعص و.بكق معسق / لا حول ولا قوة الا بالله العلي العظيم وصلى الله / على سيدنا محد وآله اجمعين يا حفيظ.
Text frommen Inhalts aus dem islamischen Kulturraum nicht erstaunt. Die Überschriften zu den einzelnen Abschnitten in diesem ersten Teil sind aber persisch. Dieser erste Teil des Dokuments dürfte somit aus dem persischen Kulturraum stammen.

II. Teil (АВ B. 2): ${ }^{13}$ Diese Beobachtung ruft den Kolophon zum zweiten, älteren Teil der Rolle in Erinnerung. ${ }^{14}$ Der Schreiber des ursprünglichen Dokuments erwähnt hier auch seinen Namen: al-Abd Ḥusayn [b.] Ibrāhīm b. Muḥammad alHusaynī al-Hurāsānī. Dieser Schreiber liess sich anderweitig nicht belegen. Aus der nisba alHurāsānī geht allerdings hervor, dass er einen Bezug zu Nordostiran bzw. zum daran angrenzenden Zentralasien aufweist. Es ist davon auszugehen, dass der Schreiber seine Heimat verlassen hat, macht es doch keinen Sinn einen Bewohner Khorasans als Hurāsāni zu identifizieren. Eine solche Charakterisierung ist nur ausserhalb der engeren Heimat des Schreibers sinnvoll. Die nisba al-Hurāsānī lässt somit keine gesicherten Rückschlüsse darauf zu, wo das Dokument angefertigt wurde. Es dürfte allerdings nicht abwegig sein, auf diesem älteren Teil des Dokuments textliche und gestalterische Elemente zu erwarten, die sich

Gebet 2:

$$
\begin{aligned}
& 9 \text { بسم الله الرحمن الرحيم / • اللهم يا ذا العرش الكريم والملك / } \\
& \text { القديم والعطاء العظيم والصراط المستقيم / يا مرسل الرياح يا فالق } \\
& \text { الاصباح ويا باعث / الا رواح ويا ذالجود والسماح يا الله / يا الله } \\
& \text { يا الله يا رحمن يا رحمن يا رحمن يا رحيم / هايا رحيم يا رحيم يا احد } \\
& \text { يا صمد يا فرد يا وتر / يا حي يا قيوميا ذا الجلال والاكرام / ارحم } \\
& \text { ذلي وفقري وفاقتي وانفرادي / وخضوعي بين يديك واعتمادي } \\
& \text { عليك / وتضرعي اليك ربي سهل على كل / • r عسير وامنع عني شر } \\
& \text { كل ظالمر / حاسد وعاهة وافة ومرض وشدة / ووباء وزلزلة وعلى } \\
& \text { كل علة يا / سبوح يا قدوس يا رب الملائكة / والروح وصلى الله } \\
& \text { على سيدنا وبنينا / هץ محد وآله اجمعين الطيبين / الطاهرين برحتك } \\
& \text { يا ارحم الراحمين. }
\end{aligned}
$$

13 Vgl. Abb. 8-12 der Rolle (link in Anm. 2).

14 Vgl. Abb. 12 der Rolle (link in Anm. 2). Der Kolophon wird unten, II.C, nach Anm. 87, vollständig erfasst. 
im Osten der islamischen Welt auch anderweitig feststellen lassen. Es könnte auch sein, dass der Kopist im Rahmen der Wanderungsbewegungen im Nachgang des Mongolensturms nach Westen gelangt ist. Vielleicht hat er sich in Tabriz niedergelassen.

Der erhaltene Abschnitt des zweiten, älteren Teils misst $11.0-11.2 \times 353.0 \mathrm{~cm} .{ }^{15}$ Er gliedert sich in zwei grössere Abschnitte (II.A. und II.B.) und einen Schlussteil mit dem Kolophon (II.C). Unmittelbar vor Teil II.A lassen sich die spärlichen Überreste eines Achtecks erkennen. ${ }^{16}$

II.A (Schriftbänder, formal): ${ }^{17}$ Der erste Abschnitt ist etwa $79.5 \mathrm{~cm}$ lang; er weist die Form eines an beiden Enden abgerundeten Rechtecks auf. Am Anfang lässt sich ein Titelfeld (Höhe ca. $3 \mathrm{~cm})^{18}$ und eine auffällig gestaltete Basmala in schwarzem Zierkufi (Höhe ca. $7 \mathrm{~cm}$ ) erkennen. Die Höhe der Buchstaben alif und lām ist gegenüber jener von $b \bar{a}$, sin oder mìm stark überproportioniert ausgefallen (Verhältnis ca. 5 :1). Die Oberlängen von alif und lām sind als Hasten ausgebildet und mehrfach ineinander verschlungen. Sie verbreitern sich oben und werden durch eine feine weisse Linie voneinander getrennt. In ihrer unteren Hälfte sind die Zwischenräume zwischen den Oberlängen zur Verzierung durch ein mašrabiyyaähnliches Gitterwerk miteinander verbunden. ${ }^{19}$

Das oben und unten abgerundete Rechteck wird von zwei Schriftbändern eingefasst. Die Breite des innern Schriftbands beträgt ca. $2.3 \mathrm{~cm}$. Es enthält einerseits längliche Kartuschen mit Text in goldener Schrift, der in der Rollenrichtung verläuft

15 Diese Massangaben werden übernommen aus der Beschreibung unter: https://catalog.hathitrust.org/Reco rd/oo6795778 (Stand 9. September 2017). Bei den weiteren Massangaben handelt es sich um Annäherungen. Sie wurden anhand der Scans ermittelt und nicht am Original nachgemessen.

16 Allenfalls war es ein Sechseck; ein achteckiges Zierelement erscheint aber als wahrscheinlicher.

17 Vgl. Abb 8 der Rolle (link in Anm. 2).

18 Mit dem Text: Asmā Allāh ta'ālā.

19 Im Abschnitt II.B lässt sich die basmala drei Mal in weitgehend ähnlicher Gestaltung nachweisen. Siehe dazu unten nach Anm. 42 (rechts: vorwärts; links: rückwärts). Je zwei längliche Kartuschen werden von einem Kreis (Durchmesser: ca. $2.3 \mathrm{~cm}$ ) voneinander getrennt. In diesen Kreisen wurde Text in $\dot{G} u b \bar{a} r$-Schrift in goldener (bzw. goldbrauner; vereinzelt silberner) Tinte kopiert. Dieser mikroskopische Text lässt sich nur noch schwer entziffern. Ganz am Anfang des Rechtecks lassen sich in diesem Schriftband zur Linken und zur Rechten zwei Kreise mit Text in schwarzer Schrift erkennen. Diese beiden Kreise (Durchmesser ca. $2.3 \mathrm{~cm}$ ) enthalten Text auf 11 (links) bzw. 12 (rechts) Zeilen. Das ganze Rechteck wird aussen von einem zweiten Schriftband (Breite ca. $0.8 \mathrm{~cm}$ ) mit Text in rotem Nash eingefasst. Diese beiden Schriftbänder rahmen einen Mittelstreifen ein, der ca. $4.2 \mathrm{~cm}$ breit ist.

II.A (Schriftbänder, inhaltlich): Unmittelbar oberhalb des Titelfelds im Mittelstreifen lässt sich ein Halbkreis erkennen. Darin steht in schwarzer Schrift in verhältnismässig grossem Nash die Formel صدق الله العظيم وصدق رسوله [الكريك. Diese Formel markiert in der Regel den Abschluss einer Rezitation von Stellen aus dem Koran. ${ }^{20}$ Der erwähnte Halbkreis fasst ein Medaillon ein, das in roter Schrift zwei Anrufungen Gottes enthält, die an zwei seiner bekannten Eigenschaften appellieren. ${ }^{21}$ Die aufgrund der Șadaqa-Formel zu erwartenden Zitate von Stellen aus dem Koran sind in den Seitenbändern kopiert worden.

Dieses Koranzitat beginnt im roten Aussenband, wo sich oben ungefähr in der Mitte Q 6:135b erkennen lässt (Text nach rechts vorwärtslaufend). ${ }^{22}$ Kurz vor dem Ende dieses abgerundeten Rechtecks, wo das vorwärtslaufende Schriftband in den Bogen einmündet, der zum rückwärtslaufenden Teil überleitet, steht Q 6:141. Zurück am Anfang steht im roten Aussenband der Beginn von

$20 \mathrm{Zu}$ dieser Formel vgl. Melchert und Afsaruddin, Reciters of the Qur'ān, in EQ; Gade, Recitation of the Qur'ān, in EQ. Das abschliessende „al-karīm“ fehlt, da dafür kein Platz mehr vorhanden war. „Yā ḥayy, yā qayyūm“ - „O Lebendiger, o Beständiger“. 22 Q 6:135b:

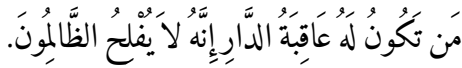


Q 6:146. ${ }^{23}$ Der Schreiber springt dann ins innere Schriftband, wo sich in der ersten horizontalen Kartusche in goldener Tinte die unmittelbare Fortsetzung von Q 6:146 erkennen lässt. ${ }^{24}$ Die Fortsetzung des Verses schliesst sich im Kreis unmittelbar rechts davon in schwarzer $\dot{G} u b \bar{a} r$-Schrift an. Der Kopist setzt die Abschrift von Q 6 danach fort. ${ }^{25}$ In der letzten länglichen Kartusche - sie mündet bereits in den Bogen ein, der dieses Rechteck unten abschliesst, steht Q 6:158 (Schluss). ${ }^{26}$ Q 6:159 steht vermutlich im anschliessenden Kreis zuunterst. Die Stelle lässt sich aber nur noch ansatzweise entziffern ( $\dot{G} u b \bar{a} r$-Schrift, Text in goldfarbener Schrift). Gewiss ist, dass in der nächsten länglichen Kartusche (jetzt rückwärtslaufend bzw. aufsteigend)

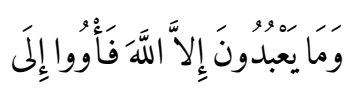

aus Q 18:16 steht. Die an dieser Stelle eigentlich erwartete Fortsetzung ( $Q$ 6:16o) steht erst ganz am Anfang dieses ersten Abschnitts auf der linken Seite im obersten Kreis mit Text in schwarzer $\dot{G} u b \bar{a} r$-Schrift. ${ }^{27}$ Die Schlussverse von Q 6 (vv. 162-

23 Q 6:146 lautet:

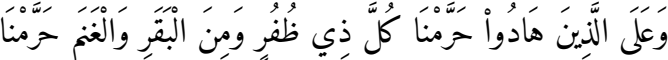

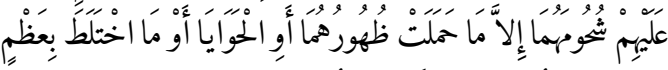

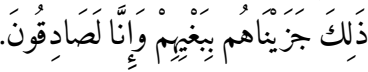

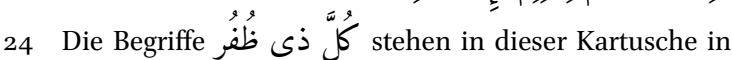
goldener Schrift aǘdem Kopf.

25 Der Text wurde am Anfang in $\dot{G} u b \bar{a} r$-Schrift in silber- und goldfarbener Tinte kopiert. Auf der Höhe der Basmala im Mittelstreifen ändert die Gestaltung: Auf eine längliche Kartusche mit goldbraunem Text in grosser Schrift folgt ein Kreis mit Text in $\dot{G} u b \bar{a} r$-Schrift in goldbrauner Tinte.

26 Erkennen lassen sich hier die fünf letzten Wörter von Q 6:158:

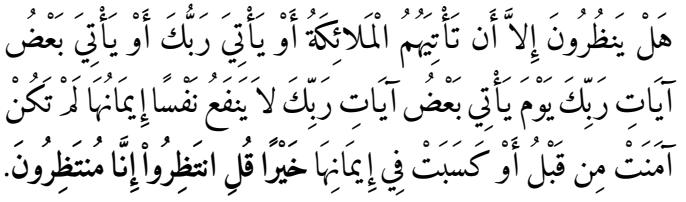

27 Dieser Kreis enthält Q 6:16o-161:

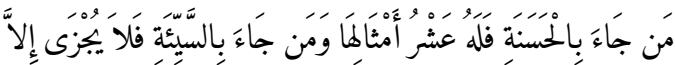

165) wurden erneut in $\dot{G} u b \bar{a} r$-Schrift in den drei anschliessenden Kreisen kopiert. Q 6 endet mit Vers 165 im zweiten Kreis mit Text im breiten Schriftband auf der linken Seite auf der Höhe des Titelfelds. ${ }^{28}$

Auf der Höhe der Basmala in grossem Zierkufi im Mittelstreifen folgt im linken seitlichen Schriftband ein Kreis mit Text in goldfarbenem $\dot{G} u b \bar{a} r$, der weitgehend unleserlich ist. Der Text in den länglichen Kartuschen in diesem breiten Teil des Seitenbands hingegen ist klar zu entziffern. In der ersten Kartusche zur Linken auf der Höhe der Basmala lässt sich der Ausdruck aṣ-ṣalihạat aus Q 18:2 erkennen. In den weiteren Kartuschen stehen folgende Stellen: 18:5b / 18:7b / 18:10 / 18:12 (Mitte) / 18:16a ${ }^{29}$. Die Kreise mit den Stellen in $\dot{G} u b \bar{a} r$-Schrift dazwischen müssen jeweils die restlichen Teile des Anfangs von Q 18 enthalten. Die Abschrift von Q 18 wird übrigens im nächsten Abschnitt fortgesetzt (II.B). ${ }^{30}$ Der Schreiber hat den Text von Q 18:1-16a grundsätzlich in der Rollenrichtung absteigend (vorwärtslaufend) kopiert. In den länglichen Kartuschen allerdings steht der Text aufsteigend (rückwärtslaufend). Das Vorgehen zwingt den Leser dazu, jeweils nach den Kreisen, ans untere Ende der Kartuschen zu springen und die Fortsetzung rückwärts zu lesen. Danach springt der Schreiber in den nächsten Kreis etc. Der Kopist wählte dieses Vorgehen offensichtlich, damit die Oberlängen des Texts in grosser Schrift im innern und äussern Seitenband nach innen gerichtet sind und dessen Grundlinien jeweils am Rand des Dokuments zu liegen kommen.

II.A (Mittelstreifen, formal; AB B. 2): ${ }^{31}$ Der Mittelstreifen dieses ersten Abschnitts ist ca. $4.2 \mathrm{~cm}$ breit. Er enthält Text in $\dot{G} u b \bar{a} r$-Schrift in schwar-

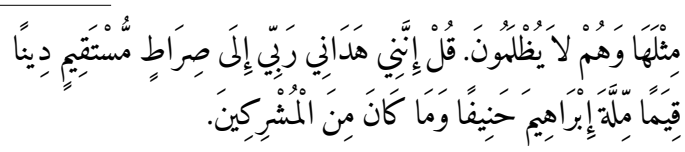

صدق :Nach dem Abschluss von Q 6:165 folgt die Formel الله العظيم وصدق رسوله الكريع.

29 Dies in der letzten Kartusche am unteren Ende des ersten Abschnitts.

30 Siehe dazu bei Teil II.B, vor Anm. 44.

31 Vgl. Abb. 8 der Rolle (link in Anm. 2). 
zer Tinte. Der Text wurde auf den neutralen Hintergrund des Dokuments geschrieben und ist derart angeordnet, dass ein Rankenmuster entsteht. ${ }^{32}$ Beim Betrachten fallen sechs rosettenartige Zierelemente auf. Im Zentrum der Rosette befindet sich ein golden umrandeter Kreis mit Text in roter Tinte (normale Schriftgrösse). Oberhalb, unterhalb, links und rechts von diesem Hauptkreis befindet sich je ein weiterer Kreis mit Text in $\dot{G} u b \bar{a} r$-Schrift in schwarzer Tinte. Zwischen diesen in der Vertikalen und Horizontalen ausgerichteten Kreisen lassen sich vier zusätzliche, etwas kleinere Kreise erkennen, die ebenso Text in $\dot{G} u b \bar{a} r-$ Schrift enthalten. Diese Rosette könnte auch als Blüte betrachtet werden. Die erste und sechste Rosette befindet sich am oberen bzw. am unteren Ende des Mittelstreifens. Die vier weiteren Rosetten sind gleichmässig dazwischen verteilt; es entstehen somit fünf Abschnitte. Beim Betrachten lässt sich ein Rankenmuster erkennen, das von unten nach oben steigt. Aus den Ranken geht zur Linken drei Mal und zur Rechten zwei Mal ein Blatt hervor, das Ähnlichkeiten mit einem Rebenblatt aufweist. Ranken und Blätter werden durch Textstellen in $\dot{G} u b \bar{a} r$-Schrift gebildet.

II.A (Mittelstreifen, inhaltlich): Der Mittelstreifen wird durch die sechs achtblättrigen Rosetten in fünf etwa gleich lange Abschnitte aufgeteilt. Der Kreis im Zentrum dieser Rosetten enthält Text in grosser roter Schrift. Es handelt sich um Anrufungen Gottes mit seinen Beinamen ya hayy, yā qayyūm. ${ }^{33}$ Die beiden Begriffe stehen einerseits aufrecht, anderseits auf dem Kopf. Die gegenläufig notierten Wörter sind ineinander verzahnt.

Der restliche Text in diesem Mittelstreifen wurde in $\dot{G} u b \bar{a} r$-Schrift kopiert; er liess sich nicht restlos entziffern. Die Schrift ist ausserordentlich klein und erreicht eine Höhe von ca. $1 \mathrm{~mm} .^{34}$

32 Es muss offen bleiben, ob die entstehende Figur als Baum interpretiert werden kann, Siehe zu dieser Vermutung: Nünlist, Rollen der Andacht aus dem Umfeld von Derwischorden $129 \mathrm{f}$.

33 „O Lebendiger, o Beständiger".

34 Eine Nachmessung im obersten Kreis in der ersten Rosette ergab folgende Werte: Durchmesser ca. $1.0 \mathrm{~cm}$,
Der Kopist ging bei der Abschrift an die äussersten Grenzen des Machbaren. Vokalisationszeichen fehlen in diesem Abschnitt zumeist; die Buchstaben sind vielfach unpunktiert. Der $\dot{G} u b \overline{a r}$-Text wurde hier ausschliesslich auf horizontalen Zeilen kopiert. Auf andern Belegstücken lässt sich beobachten, dass die Stellen in $\dot{G} u b a \bar{r}$-Schrift den Figuren entlang kopiert worden sind, in denen sie enthalten sind. Dies führt dazu, dass die $\dot{G} u b \bar{a} r-$ Stellen auf geschwungenen Zeilen, im Kreis etc. stehen. Auf dem vorliegenden Belegstück ist dies aber nicht der Fall.

Die vollständige Entzifferung der hier kopierten Texte in $\dot{G} u b a \bar{r}$ wäre mit einem unverhältnismässig hohen Zeitaufwand verbunden. Die weitere Darstellung hält die entsprechenden Passagen deshalb nicht vollständig fest. Sie beschränkt sich auf eine Identifikation der fraglichen Textstellen.

Die verderbte Überschrift dieses Abschnitts lautet Asmā’ Allāh tåălā („Die Namen Allāhs, erhaben ist er"). Der Text danach enthält in der Tat Anrufungen Allahs, die von den Eigenschaften Gottes gut bekannt sind. Das im vorliegenden Abschnitt enthaltene Gebet ist allerdings üblicherweise unter dem Titel $D u(\bar{a}$ al-Ğawšan al-kabir („Das grosse Gebet des Brustpanzers“ bzw. „Das Gebet des grossen Brustpanzers“) bekannt. ${ }^{35}$ Es

darin Text auf 10 Zeilen. Es ist also kaum noch Platz für Abstände zwischen den Zeilen vorhanden. Die Zeilen sind wiederholt ineinander verzahnt.

35 Der Text lässt sich nachweisen unter http://www.rafed .net/ramadan/aamal/o2.html (Stand 12. Oktober 2016). Es lassen sich allerdings wiederholt Abweichungen feststellen (z.B. geänderte Abfolge der einzelnen Anrufungen Gottes; modifizierter Wortlaut). Derartige Abweichungen sind in handschriftlichen Dokumenten allerdings üblich.

Das Gebet wird abgedruckt in al-Kaf'amī, Mișbāh 247f. (http://lib.eshia.ir/71570/1/247, Stand 21. Februar 2018); Ibrāhīm b. 'Alī al-Kaf'amī, Kitāb al-Miṣbāḥ. Qum, Dār ar-Riḍā (Zāhidī), 1405 h.q.;

$$
\begin{aligned}
& \text { ملاحظات: اين كتاب با خط ميرزا عبد الله حائرى تهرانى در }
\end{aligned}
$$

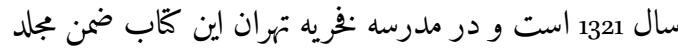

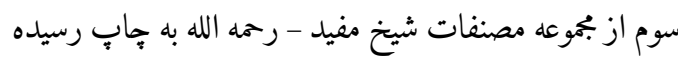

$$
\begin{aligned}
& \text { است ونسخه موجود ازروى همين طبع ججرى افست شده است. }
\end{aligned}
$$


soll über as-Sağğād ${ }^{36}$ auf den Propheten Muḥammad zurückgehen. ${ }^{37}$ Gemäss der Überlieferung hat es Gabriel dem Propheten übermittelt, als dieser auf einem Beutezug war. Er trug dabei einen schweren Brustpanzer, der ihn schmerzte. Gabriel forderte Muhammad auf, den Brustpanzer abzulegen und stattdessen dieses Gebet zu rezitieren. Es biete ihm und seiner Nation (umma) ausreichenden Schutz. Er bedürfe also seines Panzers nicht. Überhaupt seien mit dem Gebet zahlreiche positive Eigenschaften verbunden, die in der breiten islamischen Überlieferung zu diesem Text auch erörtert werden. ${ }^{38}$ Die hundert Abschnitte des Gebets fassen jeweils zehn Anrufungen Gottes bei seinen Beinamen zu Gruppen zusammen. Da das vorliegende Gebet auf den Namen Gottes aufbaut, ist auch nachvollziehbar, dass es mit der Überschrift Asmäà Allāh ta'ālā versehen ist. Am Schluss jedes Abschnitts folgt als Refrain folgende Anrufung Gottes:

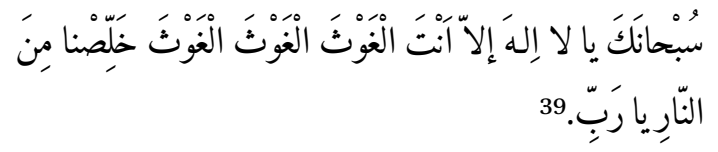

Die Textstellen werden auf dem Dokument nicht im einzelnen lokalisiert. Es sei hier aber festgehalten, dass das Gebet in der ersten Rosette im

Siehe auch Mağlisī, Bihār al-anwār, Bd. 94, S. $384 \mathrm{ff}$. (lib.eshia.ir/11008/94/384/) und Bd. 91, S. $384 \mathrm{ff}$. (lib.eshia .ir/7186o/91/384/); Mu'assasat al-Wafā', 2. Aufl.; 1403 (ohne Ort). Stand Internetquellen: 21. Februar 2018.

36 As-Sağğād ist der Beiname von 'Alī b. Husayn Zayn al'Ābidīn (658-713), dem vierten Imam der Schiiten.

37 Diese Angaben sind der in Anm. 35 zitierten Internetquelle entnommen: http://www.rafed.net/ramadan/ aamal/o2.html (Stand 12. Oktober 2016).

38 Vgl. dazu z.B. die Einleitung zum Gebet auf http://www .rafed.net/ramadan/aamal/o2.html (Stand 21. Februar 2018).

39 „Gepriesen seist Du, o jener, ausser dem es keinen Gott gibt. [Gewähr uns] Hilfe! [Gewähr uns] Hilfe! [Gewähr uns] Hilfe! Errette uns vor dem Höllenfeuer, oh mein Herr.“ Der Text auf dem hier diskutierten Belegstück aus Michigan ersetzt den Begriff al-gawt („Hilfe, Beistand“) durch das weitgehend synonyme al-amān („Schutz, Sicherheit"). obersten Kreis beginnt. Im grossen Kreis zur Rechten in der ersten Rosette lässt sich der zweite Abschnitt des Gebets al-Ğawšan al-kabir erkennen. ${ }^{40}$ Es lässt sich nicht abschliessend beurteilen, ob das Gebet auf dem vorliegenden Belegstück als Ganzes kopiert worden ist. Gewiss ist, dass der Refrain auch in den Kreisen der letzten Rosette zu erkennen ist.

II.B (formal): ${ }^{41}$ Die Länge des zweiten Abschnitts beträgt ca. $252 \mathrm{~cm}$. Es handelt sich auch dabei um ein Rechteck. Die beiden Teile II.A und II.B stossen zwar direkt aufeinander, ihre Schriftbänder sind aber nicht miteinander verbunden, wie sich dies auf andern Dokumenten aus dem 14. Jh. beobachten lässt. Während dieses zweite Rechteck oben abgerundet ist, ist sein Abschluss unten eckig. Danach schliesst sich der Schlussteil mit dem Kolophon an (siehe II.C).

In diesem zweiten Rechteck fallen drei Stellen mit Basmala und vorangehendem Titelfeld auf. Die Gestaltung der Basmala stimmt mit jener im ersten Rechteck überein (II.A). ${ }^{42}$ Diese drei Basmalas leiten jeweils ein Gebet ein, das im Mittelstreifen kopiert worden ist. Die Längenverhältnisse der drei Abschnitte betragen grob 1 (1. Gebet) :1 (2. Gebet) : 2 (3. Gebet).

Auch dieses zweite Rechteck wird auf seiner gesamten Länge von einem doppelten Schriftband eingefasst. Es wurde gegenüber jenem um das erste Rechteck (II.A) abweichend gestaltet. Die Breite des innern und äussern Bands ist in diesem Abschnitt nahezu identisch (je ca. $1.6 \mathrm{~cm}$ ). Die Gestaltung dieser beiden Schriftbänder lehnt sich an jene des inneren (breiteren) Schriftbands im

40 Jeweils mit Abweichungen im Wortlaut und Umstellungen in der Abfolge der einzelnen Anrufungen. Die Stelle lautet gemäss der Vorlage:

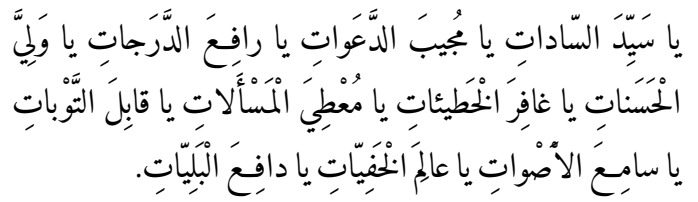

Vgl. Abb. 9-12 der Rolle (link in Anm. 2).

42 Vgl. die Beschreibung unter II.A (vor Anm. 19). 
ersten Rechteck an. Sie unterscheidet sich davon aber durch die häufige Verwendung von roter Tinte.

Der Mittelstreifen des zweiten Rechtecks wird durch geometrische Figuren gegliedert; er unterscheidet sich deutlich von jenem mit dem Rankenmuster in Abschnitt II.A. Die folgende inhaltliche Beschreibung erfasst zuerst den Text in den Schriftbändern und anschliessend den Inhalt des Mittelstreifens.

II.B Schriftbänder (inhaltlich): Im innern Schriftband lässt sich zuoberst verhältnismässig grosser Text in schwarzer Schrift erkennen, der auf dem Kopf steht. Unmittelbar darunter befinden sich zwei Zierelemente mit Text in silbergrauer $\dot{G} u b \bar{a} r$-Schrift. Es handelt sich um ein Zitat von Q 9:128-129, ${ }^{43}$ das am Schluss durch die Formel صدق الله العظيم وصدق رسوله الكريم abgeschlossen wird.

Unmittelbar darüber lässt sich im Aussenband ein Kreis mit Text in schwarzer $\dot{G} u b \bar{a} r$-Schrift erkennen. Es handelt sich um Q 18:16 (Mitte). Dieser Text setzt also Q 18:16a aus dem vorangehenden Abschnitt (II.A) unmittelbar fort. Die Fortsetzung von Q 18 (Sūrat al-Kahf) wurde danach auf dem vorwärtslaufenden äusseren Schriftband auf der rechten Seite des Dokuments kopiert. Der Schluss von Q 18 (Q 18:110) steht am Ende dieses Schriftbands unmittelbar vor dem Kolophon. ${ }^{44}$

Direkt über dem Kolophon befindet sich ein Streifen mit den Schlussversen von Q 19 (Q 19:9698). ${ }^{45}$ Im letzten Kreis (ganz auf der linken Seite) folgt eine Formel, die mutmasslich den

43 Q 9:128-129 (Schlussverse):

(ITN)

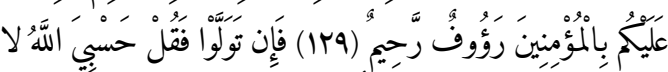

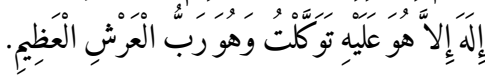

44 Deutlich erkennbar ist فمن كان يرجو aus Q 18:110. Die letzten Wörter aus Q 18:110 in weitgehend unleserlichem goldenem $\dot{G} u b \bar{a} r$.
Abschluss der Rezitation von Stellen aus dem Koran markiert. ${ }^{46}$

Im linken äussern Schriftband wurde Q 35:1-45 (Sūrat Fāțir, vollständig) kopiert. ${ }^{47}$ Die Abschrift beginnt bereits am Anfang von Teil II.B direkt oberhalb des Titelfelds mit der Überschrift Nawad wa nuh nām min asmā’ Allāh-i ta ālā. Hier lässt sich auf dem Aussenband in einem Kreis in silbergrauer $\dot{G} u b \bar{a} r$-Schrift Q 35:1 erkennen. In diesem Aussenband ist es zu Textverlust gekommen; das Dokument ist später repariert worden. Auf der deutlich erkennbaren Fehlstelle wurde zwischen Q 35:10 und 35:12 irrtümlich Q 3:126b ergänzt. ${ }^{48}$ Die Abschrift von Q 35 endet auf der Höhe der Basmala unterhalb des Titelfelds mit der Überschrift $A s m \bar{a}^{2}$ al-arba'ūn (sic) in silber-grauer Schrift (Gubār) ${ }^{49}$

Auf der Höhe der Basmala unterhalb des Titelfelds mit dem Eintrag Asmä’ al-arba'ūn (sic) beginnt im linken Aussenband die Abschrift von Q 34 (Sūrat Saba'). Die Basmala dazu wurde in roter Tinte notiert. ${ }^{50}$ Die Abschrift beginnt parallel zu Q 67:1 im Innenband und endet vor dem Kolophon mit Q 34:31 (mawqūuüna, aus Q 34:31 Mitte). Q 34:32-54 fehlen auf dem Dokument.

Im Innenband beginnt unterhalb des Titelfelds mit dem Text Nawad wa nuh nām min Asmā Allāh und der ersten horizontal ausgerichteten Basmala in Zierkufi ein Gebet in goldener Schrift. Die-

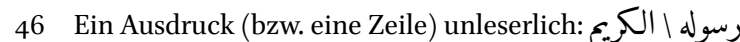

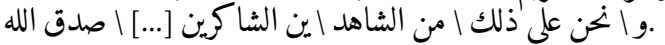
Vgl. Abb. 9 der Rolle (link in Anm. 2).

48 Q 3:126b lautet

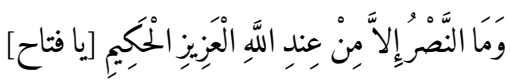

und spielt damit auf Gottes Eigenschaft als Verleiher von Sieg (bzw. Öffnung) an.

49 Man beachte die leichte Abweichung im Wortlaut gegenüber der Kairiner Ausgabe, in der der Begriff habiran fehlt:

$$
\text { فَإِنَّ اللَّهَ كَانَ بعبَادهِ [خبيزاًَ] بَصِيرًا. }
$$

Es schliesst sich die übliche Formel zur Markierung des Abschlusses eines Koranzitats an:

$$
\text { وصدق الله العظيم وصدق رسوله الكريم [....؟]. }
$$


ses Gebet umfährt den gesamten Abschnitt II.B.1 (Abb. 9-10). ${ }^{51}$ Beim hier kopierten Text handelt sich um das Gebet der Tasse (Du'ä al-Qadah $)$. Es lässt sich nachweisen bei Ibn Ṭāwūs (1193-1266), Muhağ ad-Da'wāt wa-manhağ al-ibādāt. ${ }^{52}$ Eine Variante des Gebets lässt sich auch aufrufen unter http://mawdoo3.com/دعاء_القدح (Stand 22. Februar 2018). Der Text in den zum Vergleich beigezogenen Quellen und jener auf der Rolle stimmen nicht in allen Einzelheiten überein. Die Parallelen sind aber zu zahlreich, als dass die Identifikation des Gebets nicht als gesichert gelten könnte. Der Text auf der Rolle liess sich anhand des Abbildungsmaterials auch nicht lückenlos entziffern. ${ }^{53}$ Anas b. Mālik soll dieses Gebet vom Propheten gehört haben, der es von Gabriel erhalten hat.

Unterhalb der zweiten horizontal ausgerichteten Basmala in Zierkufi beginnt im inneren Schriftband auf der rechten Seite Q 36 (Sūrat Yāsin) mit der Basmala. ${ }^{54}$ Auf dem innern Schriftband (rechts) lassen sich bis zum nächsten Titelfeld (und der Basmala darunter) vorwärtslaufend Q 36:1-28 erkennen. Der Kopist springt hier ins Innenband auf der gegenüberliegenden Seite und kopiert Q 36:29-49a aufsteigend, bis er erneut die Basmala zum ersten Teil (II.B.1) erreicht. Der Kopist setzt jetzt zu einem Sprung an: Q 36:49 steht erneut nach der Überschrift zu Abschnitt II.B.255

51 Vgl. Abb. 9 der Rolle (link in Anm. 2).

52 Ibn Ṭāwūs, Muhağ ad-Da'wāt wa-manhağ al-ibādāt 8990 (vgl. http://lib.eshia.ir/71561/1/89/ und http://lib.eshia .ir/71561/1/9o/; Stand 22. Februar 2018). Qum, Dār adDahāir, 1411 h.q. Beachte die Bemerkung zu dieser Ausgabe am Anfang des Texts (http://lib.eshia.ir/71561/1/1; Stand 22. Februar 2018):

ملاحظات: اين نسخه با طبع ججرى بسال 1323 ه ق درزمان مظفر الدين شاه قاجار مى باشد و آقا محد مهدى تاجر با خط محد حسن

كرمانى اقدام به نشر آن نموده است و اين نسخه با كّاب "المجتنى

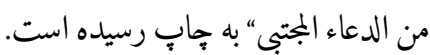

Dies trifft gerade auf die Stellen in mikroskopischer goldener Schrift zu.

54 Vgl. Abb. 10 der Rolle (link in Anm. 2).

55 Überschrift: „Asmā’ al-arba‘ūn (sic)“. in roter Tinte auf dem rechten Innenband. ${ }^{56}$ Der Schreiber setzt die Abschrift danach im Innenband bis an den Schluss der Rolle fort. In der vorletzten länglichen Kartusche mit Text in roter Schrift steht Q 36:82. Im letzten Zierelement steht mutmasslich Q 36:83 (Schlussvers) in goldenem $\dot{G} u b a \bar{r}$. Der Text ist hier allerdings nicht mehr zu erkennen. ${ }^{57}$

Unterhalb der zweiten horizontal ausgerichteten Basmala beginnt im inneren Schriftband auf der linken Seite Q 67 (al-Mulk) mit der Basmala. (Abschrift: rot). ${ }^{58}$ Dieser Text endet vor dem Kolophon, wo sich in der länglichen Kartusche in roter Schrift der Beginn von Q 67:18 erkennen lässt. ${ }^{59}$ Der Text in goldener $\dot{G} u b \bar{a} r$-Schrift im anschliessenden Zierelement lässt sich nicht mehr entziffern. Die restlichen Verse von Q 67 (Q 67:19-30) scheinen auf dem Dokument zu fehlen. ${ }^{60}$ Ausserdem ist eine Unregelmässigkeit in der Abschrift von Q 67 zu vermerken: Der Text zwischen Q 67:12 und 67:13 in den beiden länglichen Kartuschen auf dem innern Schriftband zur Linken dürfte nicht aus Q 67 stammen. Die längliche Kartusche mit Text in roter Schrift dazwischen stammt wahrscheinlich aus Q 36:12. ${ }^{61}$ Die Unregelmässigkeit beginnt bereits am Ende von Q 67:12. Die Gründe für diese Abweichungen vom Text der koranischen Offenbarung liessen sich nicht klären.

56 Vgl. Abb. 11 der Rolle (link in Anm. 2). Der Anfang von Q 36:49 wird wiederholt; der Vers lautet:

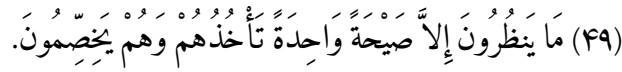

Vgl. Abb. 12 der Rolle (link in Anm. 2).

Vgl. Abb. 11 der Rolle (link in Anm. 2).

Vgl. Abb. 12 der Rolle (link in Anm. 2).

Unmittelbar vor dem Beginn von Q 67:18 lässt sich eine Unregelmässigkeit feststellen: Der Kopist hat hier offensichtlich Q 67:5-6 wiederholt (von Mitte zweitletzter bis Mitte letzter der beiden länglichen Kartuschen mit roter Schrift).

Der Text lautet:

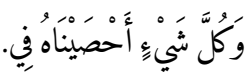

Dies gerade oberhalb des Quadrats mit dem Ausdruck al'adl in grosser schwarzer Schrift im Mittelstreifen. 
Die weitere Beschreibung befasst sich mit dem Mittelstreifen, der sich in drei Abschnitte einteilen lässt:

Mittelstreifen II.B.1 (formal): ${ }^{62}$ Der Mittelstreifen (Breite: ca. $2.8 \mathrm{~cm}$ ) mit dem ersten Gebet (bzw. der Aufzählung der Schönen Namen Gottes) enthält acht Rechtecke von etwa identischer Länge. Ausserdem lassen sich drei Quadrate mit Text in schwarzem Tulut erkennen. In zwei Rechtecken ist die Basmala aufgeführt worden, deren Gestaltung Elemente aus den Überschriften zu den einzelnen Gebeten übernimmt. Die Basmala ist vorwärtslaufend (rechts) bzw. rückwärtslaufend (links) notiert worden, wobei die Oberlängen von alif und lām ineinander verzahnt sind. Die restlichen sechs Rechtecke sind als Gitter gestaltet. Die Gitterstäbe werden durch die Aufzählung der Beinamen Gottes gebildet, die in $\dot{G} u b \bar{a} r$-Schrift in schwarzer Tinte notiert worden sind. Die Begriffe verlaufen in den diagonal angeordneten Stäben einerseits von rechts oben nach links unten und anderseits von rechts unten nach links oben. In den Zwischenräumen des Gitters lassen sich rote Verzierungen erkennen. Sie erinnern auf den ersten Blick an Buchstaben; es handelt sich aber einfach um Zierelemente (Striche, Winkel, Punkte).

II.B.1 (inhaltlich): Wie bereits erörtert lautet die Überschrift des ersten Abschnitts des alten Teils der Rolle (II.A) Asmā’ Allāh ta'ālā. Dieser Titel ist insofern gerechtfertigt, als das dort angeführte Gebet tatsächliche zahllose Eigenschaften Gottes aufzählt (100 Abschnitte mit der Erwähnung von je 10 Attributen Allahs). Das angeführte Gebet ist zumeist aber unter dem Namen $D u(\bar{a})$ al-Ğawšan al-kabir bekannt.

Aufzählungen der Eigenschaften Gottes enthalten nämlich zumeist 99 Attribute. Sie sind unter dem Begriff der Schönen Namen Gottes („al-asmā” al-ḥusnā“, eigentlich „die Schönsten Namen Gottes") bekannt. ${ }^{63}$ Derartige Listen umfassen gemäss der muslimischen Tradition 99 Beinamen. Auf den

62 Vgl. Abb. 9 der Rolle (link in Anm. 2).

63 Zu den Schönen Namen Gottes vgl. Kapitel 3.4, Anm. 464. untersuchten Rollen sind aber in den mit al-Asma $\bar{a}^{2}$ al-husnā überschriebenen Abschnitten oft deutlich mehr Qualitäten aufgezählt. Auch das vorliegende Belegstück enthält einen Abschnitt, der das Konzept der 99 Beinamen aufgreift (АВB. 3). Er ist mit der Überschrift Nawad wa nuh nām min asmā’ Allāh-i ta'ālā ("99 Namen von den Schönen Namen Gottes") versehen. Der erste Teil dieser Überschrift (Nawad wa nuh nām) ist persisch, was die bereits aufgrund der nisba des Kopisten (alHurāsānī $)^{64}$ geäusserte Vermutung stützt, dass der Schreiber ursprünglich aus dem persischen Kulturraum stammt.

Beim Betrachten fallen in diesem Abschnitt des Mittelstreifens auch drei quadratische Felder (Masse: ca. $2.4 \times 2.4 \mathrm{~cm}$ ) mit Begriffen in grossem, schwarzem Tulut auf. Der Text lautet hier: 1. La-hū al-asmā' al-ḥusnā („Ihm (Gott) sind die Schönsten Namen“); 2. al-awwal al-mu'ahhar: („Der Erste, der Letzte“); 3. Illā Allāh („[Es gibt keinen Gott] ausser Allāh“). Diese Hervorhebungen betonen die wichtigsten Aussagen des vorliegenden Abschnitts. Diese hervorgehobenen Ausdrücke in schwarzem Tulut sind zugleich Bestandteil der weiteren Aufzählungen in diesem Abschnitt, die in $\dot{G} u b a \bar{r}$-Schrift notiert wurden.

$\mathrm{Die}$ in den sechs gitterartig gestalteten $\mathrm{Ab}$ schnitten aufgeführten Eigenschaften Gottes werden hier nicht im einzelnen aufgeführt. Es sei aber festgehalten, dass diese Eigenschaften oft in kürzere Einheiten zusammengefasst werden. Das erste Gitterfeld hält einleitend drei Mal fest: هو الله الذى لا اله الا هو عالم الغيب والشهادة (؟) هو الرحمن الرحيم. In den Aufzählungen der Eigenschaften selbst lassen sich häufig Wiederholungen feststellen. Besondere Beachtung verdient das letzte Gitterfeld unmittelbar nach dem Quadrat mit dem Text illā Allāh. Hier beginnt auf der letzten Zeile des vorangehenden Gitterfelds die šahāda. Das letzte Gitterfeld enthält danach eine Abschrift von Q 112 (Sūrat al-Ihlāṣ $\left.{ }^{65}\right)$;

64 Siehe zum Kolophon nach Anm. 87.

65 Q 112 betont die Einheit und Beständigkeit Allāhs; sie wird auf den hier untersuchten Belegstücken auffällig häufig kopiert. 
am Schluss folgt eine Eulogie auf Muḥammad und seine Familie.

II.B.2 (formal; AB B. 4): ${ }^{66}$ Der Mittelstreifen des zweiten Gebets enthält acht Rechtecke. Sie werden von sieben annähernd quadratischen Vierecken voneinander getrennt. Im Zentrum der Rechtecke befindet sich ein Kreis; in jeder Ecke des Rechtecks befindet sich je ein deutlich kleinerer Kreis. Diese Kreise werden durch Text in $\dot{G} u b \bar{a} r$-Schrift gebildet. Der grosse Kreis im ersten Rechteck enthält Text auf 19 Zeilen (Durchmesser des Kreises ca. $2.1 \mathrm{~cm}$; dies entspricht einer Zeilenhöhe von etwas über $1 \mathrm{~mm}$ ). Der Text in den sieben Quadraten hingegen ist in grossem Tulut notiert worden. Er verläuft im zweiten Quadrat in horizontaler Richtung; er ist also so ausgerichtet wie der Text in den Titelfeldern der Rolle; in allen andern Quadraten verläuft er in der Richtung der Rolle selbst. Der gesamte Text in diesem Abschnitt wurde in schwarzer Tinte kopiert.

II.B.2 (inhaltlich): An den Abschnitt mit den 99 Namen Gottes schliesst direkt das nächste Titelfeld an. Es enthält in gold-gelben, schwarz umrandeten Buchstaben (Tulut ) die Überschrift $H \bar{a} \underline{d} \bar{a} D u^{\prime} \bar{a}^{\prime}$ Hirz al-[a]mān ${ }^{67}$ („Dies ist das Hirz al-amānīGebet $\left.^{\prime 68}\right)$. Am oberen Rand des Titelfelds befindet sich in der Mitte ein Zierelement. Es handelt sich um ein auf der Spitze stehendes Quadrat. Zwei Striche kreuzen sich in der Mitte des Quadrats. Die beiden Striche beginnen bzw. enden ausserhalb des Quadrats und unterfahren oder überfahren dessen Ränder. Alle Teile dieses Zierelements werden von Strichen gebildet, die den Buchstaben in der Überschrift gleichen. Es ist anzunehmen, dass mit diesem Zierelement bestimmte Bedeutungen verbunden sind, die sich allerdings nicht klären liessen. Das Element könnte einen Knoten darstellen. ${ }^{69}$

66 Vgl. Abb.9 (wo am Schluss Titelfeld) und Abb. 10 der Rolle (link in Anm. 2).

67 Der Schreiber notierte wohl irrtümlich al-mānī.

68 Der Ausdruck umniyya, Pl. amānin, bedeutet „Wunsch, Begehren, Verlangen“.

69 Vgl. zu dieser Vermutung ausführlicher Kapitel 3.4 (vor
Das Gebet ist zumeist in $\dot{G} u b \bar{a} r$-Schrift notiert worden, was seine Entzifferung erheblich erschwert. Sieben Stellen aus dem fortlaufenden Gebetstext werden allerdings in grosser Schrift hervorgehoben. Dies erleichtert die Orientierung innerhalb des Gebetstexts und ermöglicht die Identifizierung der Stellen in $\dot{G} u b \bar{a} r$-Schrift. Der vorliegende Text liess sich im Internet nachweisen. Er ist mit Abweichungen im Detail unter dem Titel Hizb al-Munāğāa hekannt ${ }^{70}$ und wird Aḥmad arRifā̄ì (gest. 578/1182), dem Begründer des Derwischordens der Rifā'iyya zugeschrieben. ${ }^{71}$

II.B.3 (formal; ABB. 5): ${ }^{72}$ Der dritte Abschnitt enthält ein weiteres Gebet; er ist etwa doppelt so

Anm. 50o) und Nünlist, Devotion and protection: Amuletic scrolls dating from the 14 th century, $507-512$.

70 Vgl. http://aldoaa.7olm.org/t78-topic (zum Vergleich herangezogene Version); im Schlussteil des Gebets sind die Abweichungen beträchtlich. Zuvor allerdings stimmen die beiden Texte (Vorlage und Text auf der Rolle) weitgehend überein. Das vorliegende Gebet lässt sich, oft mit Abweichungen im Detail, auch in folgenden Quellen belegen: http://www.knozalasrar.com/threads 1854-حزب-المناجاة-للشيخ-احمد-الرفاعي-الكبير/2ttps://alre faee.wordpress.com/about/ (unter Hizb al-Munāğāt; Stand beide 14. Oktober 2016). Siehe ausserdem http:// blackmagic-cure.com/topics/ara/ahzab.htm und http:// torjman.yoo7.com/t7-topic (Stand beide 23. Februar 2018).

Ahmad b. 'Abd ar-Rahīm aș-Șayādī (gest. 1271), Kitāb al-ma'ārif al-Muhammadiyya fi l-wazāif al-Ahmmadiyya; für derartige Gebete siehe darin S. 99-112 (der Text auf der vorliegenden Rolle liess sich in dieser Form darin aber nicht nachweisen). 'Izz ad-Dīn Ahmmad aṣ-Ṣayyād ar-Rifāî̀ al-Ḥusaynī, [al-Qāhira], Maṭba'at Muhammad Afandī Mușțafā al-Bahiyya, 1305 h.q./1888 (Universitätsbibliothek Basel, Meier I 186).

Auf der Website http://www.knozalasrar.com/archive /index.php/f-38.html findet sich eine Zusammenstellung von 121 in mystischen Orden wichtigen Gebeten (Stand 14. Oktober 2016). Man beachte auch: http://www.knozalasrar.com/archive/index.php und unbedingt http://www.knozalasrar.com (siehe zu dieser Website aber Kapitel 4 (Einleitung), zwischen Anm. 1 und 2; diese Website ist seit Herbst 2017 nicht mehr zugänglich).

71 Zu Aḥmad ar-Rifāè (1106-1182) siehe Margoliouth, alRifā̄ì', in $E I^{2}$; siehe ausserdem Bosworth, Rifā'īyya, in $E I^{2}$.

72 Vgl. Abb. 10 (wo am Schluss Titelfeld) und Abb. 11-12 der Rolle (link in Anm. 2). 
lang wie die soeben beschriebenen Abschnitte B.1 und B.2. Das nahezu quadratische Titelfeld enthält die Überschrift Asmä’ al-arba'ūn (sic) auf einem grünlich-goldenen ${ }^{73}$ Hintergrund. Danach schliesst sich als Einleitung zum Gebet die bereits zuvor beschriebene Basmala in Zierkufi an. ${ }^{74}$ Der Gebetstext wurde in schwarzer Tinte in eine Abfolge von Rechtecken und Quadraten notiert, die sich vierzehn Mal wiederholt. In den Rechtecken wurde der Text in kleinem Nash notiert, das aufgrund seiner Grösse (Höhe des alif ca. 3.5 mm) gerade nicht mehr als $\dot{G} u b \bar{a} r$ eingeordnet werden kann. ${ }^{75}$ Auf jedes Rechteck (Masse: ca. $2.3 \times 4.6 \mathrm{~cm}$ ) folgt ein Quadrat (Masse: ca. $2.3 \times 2.3 \mathrm{~cm}$ ) mit Text in verhältnismässig grossem $\underline{\text { Tulut }} .{ }^{76}$ Der Text in den Quadraten wird durch seine Grösse zwar optisch hervorgehoben. Allerdings handelt es sich bei diesen hervorgehobenen Begriffen einfach um Stellen aus dem fortlaufenden Gebet. Der Schreiber stellt sie aufgrund der gestalterischen Vorgaben gross dar.

II.B.3 (inhaltlich): Der Titel dieses letzten Gebets lautet Asmā'al-arbaūn (sic). Der Text ist punktiert und oft auch vokalisiert. Dieses Gebet ist üblicherweise unter den Titeln al-Asmä alarba'ūn, Du'ä' Hadrat Idrīs, Čihil Ism-i Idrīs oder ähnlich bekannt. ${ }^{77}$ Ibn Tāwūs, bei dem es sich

73 Die grünliche Farbe könnte als Folge von Oxydationsprozessen entstanden sein.

74 Vgl. die Beschreibung oben vor Anm. 19.

75 Als $\dot{G} u b \overline{a r}$ gilt eine Schrift, deren Höhe zwischen 1 und $3 \mathrm{~mm}$ beträgt. Da sich auf diesem Belegstück in unmittelbarer Nachbarschaft zu diesen Rechtecken auf den Seitenbändern Medaillons mit deutlich kleinerer Schrift befinden, kann die Schrift in den Rechtecken nicht mehr dem $\dot{G} u b \bar{a} r$-Typ zugeordnet werden. Es handelt sich einfach um kleines Nash.

76 Der Text ist in diesen Quadraten zumeist auf zwei Zeilen angeordnet; die Wörter auf der unteren und oberen Zeile greifen oft ineinander.

77 Vgl. für den Text (Stand jeweils 14. Oktober 2016): http://lib.eshia.ir/71561/1/304; der Text ist gedruckt nachweisbar in Ibn Ṭāwūs, Muhağ ad-da'wāt wa-manhağ al-ibādāt 365-366: Ausgabe Husayn al-A'lamī, Bayrūt, Mu'assasat al-A'lamī li-l-Mațbū'āt, 1414/1994. Siehe auch http://gheib.blogsky.com/tag/2عوت-اسماء-ادريسى und http://www.duas.org/idreesmafzaee.htm (mit Zugang zur Rezitation des Gebets). nachweisen lässt, äussert sich in einleitenden Bemerkungen dazu, wie das Gebet bekannt geworden ist. ${ }^{78}$ Seine Ausführungen stützen sich auf den bekannten Mystiker al-Ḥasan al-Bașrī (21-110/642728). ${ }^{79}$ Demnach habe Allāh Idrīs dieses Gebet gelehrt, als er ihn zu seinem Volk sandte. Als Idrīs das Gebet für sich (sirran) rezitiert habe, habe Gott ihn an einen hohen Platz emporgehoben. Allāh habe diese Namen danach ebenso Moses und Muhammad gelehrt. Muhammad habe dieses Gebet rezitiert, als er von den Qurayš und ihren Verbündeten beim Grabenkrieg (hier: Gazwat al$a h z \bar{a} b)$ angegriffen worden sei. Auch al-Hasan alBașrī war dieses Gebet nützlich. Er habe es rezitiert, als er vom Omeyyaden al-Hağğāg b. Yūsūf (661-714) verfolgt worden sei. Gott habe ihn deshalb vor den Blicken Ḥağğāğs und der Seinen verborgen. Al-Bașrī hält abschliessend fest, man solle dieses Gebet rezitieren, wenn man um Vergebung für seine Sünden bitte. Es sei auch nützlich, wenn man Gott um die Erfüllung von diesseitigen und jenseitigen Wünschen ersuche. In Übereinstimmung mit dem Titel handelt es sich beim Gebet um Anrufungen Gottes in vierzig kurzen Abschnitten. Die Zahl 40 entspreche den vierzig Tagen der Reue (ayyām at-tawba). Das Gebet soll inhaltlich nicht im Detail erörtert werden. Beachtenswert scheint allerdings die Anrufung Allāhs mit Yã ilāha al-āliha, „O Gott der Götter“. Sie stellt Allāh als Vorsteher eines Götterpantheons vor - eine sehr unislamische Vorstellung! ${ }^{80}$

Das Idrīs-Gebet endet im dritten Rechteck vor dem Kolophon mit einem Lob auf Gott, seinen Propheten Muhammad und dessen Angehörige. Es

Zu Ibn Ṭāwūs (1193-1266) siehe Kohlberg, Ebn Ṭāwūs, Rażì-al-Dīn 'Alī, in EIr.

78 Auch im Fall des vorliegenden Gebets stimmt der Wortlaut der Abschrift auf der Rolle weitgehend, aber nicht gänzlich mit jenem in den soeben aufgeführten Quellen überein.

79 Vgl. zu ihm Mourad, al-Ḥasan al-Bașrī, in $E I^{3}$.

8o So im ersten Rechteck dieses Gebets direkt unterhalb von Titelfeld und Basmala, Zeile 3-4. Diese Anrufung Gottes ist auch in den in Anm. 77 angeführten Quellen enthalten. Vgl. ebenso das Belegstück Ms. or. oct. 146 (Berlin): Kapitel 5.1, bei Anm. 22. 
schliesst sich danach ein kurzes letztes Gebet an, das die beiden letzten Rechtecke und Quadrate in diesem Mittelstreifen ausfüllt. Es wird im quadratischen Titelfeld davor mit Tāă-nāma-i Sulaymān überschrieben und lautet: ${ }^{1}$

$$
\begin{aligned}
& \text { تاج نامه سليمان:82 / بسم الله الرممن الرحيم / شهد الله انه } \\
& \text { لا اله / الا هو والملايكة / واولوا العلم لا اله / الا هو العزيز } \\
& \text { الحكيم / لله نور وحكمة وحول وقوة وبرهان / وقدرة وسلطان } \\
& \text { / وهيبة يا من لا ينام / لا اله الا الله آدم صفى الله //83 لا اله وله } \\
& \text { الا الله و84 / نوح نجى الله لا اله / الا الله ابرهيم / خليل الله }
\end{aligned}
$$

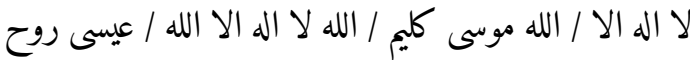

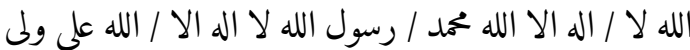

$$
\begin{aligned}
& \text { الله } 85 \text { / وصلـ[ي] الله على سيدنا / ونبينا وشفيع ذنوبنا / محمد } \\
& \text { وآله }
\end{aligned}
$$

II.C (Kolophon, formal): ${ }^{87}$ Die Höhe des Kolophons beträgt ca. $21 \mathrm{~cm}$. Er besteht aus sieben horizontalen Zeilen bzw. Streifen. Der mittlere Streifen ist am breitesten (Höhe ca. $3.8 \mathrm{~cm}$ ). Die andern Streifen sind je ca. $2.5 \mathrm{~cm}$ hoch und enthalten Text in Tulut in schwarzer (1., 3., 5. und 7. Streifen) bzw. roter Tinte (2. und 6. Streifen). Der Text im

81 Vgl. Abb. 12 der Rolle (link in Anm. 2). Die ebenso in Betracht gezogene Lesung Salmān wurde verworfen.

82 Auch Rasūl Ğafariyān liest Sulaymān anstelle von Salmān.; vgl. http://www.khabaronline.ir/detail/344807/ weblog/jafarian (Stand: 14. Oktober 2016).

83 In grosser Schrift.

84 In grosser Schrift.

85 Es wird hier auf die Erwähnung 'Alīs aufmerksam gemacht. Daraus lässt sich nicht notwendig ein SchiaBezug des Dokuments ableiten. Es fällt jedenfalls auf, dass 'Alī in der Šahāda am Ende des Gitters mit den 99 Namen Gottes (Nawad wa nuh nām) nicht erwähnt wird. Vgl. zur Frage allgemein Kapitel 3.3 "Alid loyalty“.

86 In grosser Schrift. Wahrscheinlich findet sich der Abschluss der Eulogie in den Kartuschen im Rahmen, der den Mittelstreifen unten abschliesst. Der Text im Kreis in der Mitte ist in goldenem $\dot{G} u b \overline{a r}$ notiert und lässt sich kaum noch entziffern. Rechts und links davon steht in grosser roter Schrift wa-l-ḥamd li-[A]llāh bzw. li-l-älamìn.
4. (breiteren) Streifen wurde in goldenen Buchstaben notiert, die von haarfeinen schwarzen Linien eingefasst werden. Dieser Teil musste Angaben zum Besitzer des Dokuments enthalten haben. Diese lassen sich aber kaum mehr ermitteln, da die Stelle stark verderbt ist.

\section{II.C (Kolophon, inhaltlich; Ав B. 6):}

$$
\begin{aligned}
& \text { (سطر 1) اللهم ابد وخلد دوله الامير الاعدل والاعظم } \\
& \text { (سطر r) الاعلم الاشجع الاكَم سلطان الامراء في العالم } \\
& \text { (سطر r) انك همه دولت از دولت او مىطلبند (؟) } \\
& 88 \text { [...] (سطر F) } \\
& \text { (سطر ه) خلد الله تعالى ملكه ودولته الى يوم الدين } \\
& \text { (سطر و) كتبه العبد حسين [بن] ابراهيم ابن محد الحسينى }
\end{aligned}
$$

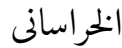

$$
\begin{aligned}
& \text { (سطر V) فى ذى الججة سنه سبع وعشرين وسبعمائة89 }
\end{aligned}
$$

Rückseite (Schluss): ${ }^{90}$ Auf der Rückseite des Dokuments befindet sich ganz am Schluss ein zusätzlicher Eintrag. Er stammt mit grosser Wahrscheinlichkeit von der Hand des Kopisten der jüngeren Ergänzung am Anfang der Rolle (Teil I). Der Eintrag umfasst vier Zeilen, wobei die erste Zeile weitgehend unleserlich ist. Am Schluss von Zeile 1 steht wohl der Namensteil Salār-zāda. ${ }^{91}$ Die nächsten drei Zeilen sind gut zu lesen: على فتح المهمات وفات وعلى دفع البليات وعلى شر \الساحر والساحة وعلى شر جميع الخلايق

88 Die vorliegende Zeile muss den Namen jenes Machthabers angeführt haben, für den dieses Belegstück hergestellt worden ist. Diese Zeile ist allerdings derart stark verderbt, dass sie sich kaum mehr lesen lässt. Ob die Stelle absichtlich oder zufällig beschädigt worden ist, muss offen bleiben. R. Ǧafariyān äussert die Vermutung, die Rolle könnte dem Îlhāniden-Herrscher Abū Saîd (gest. 1335) gewidmet gewesen sein, gesteht allerdings ein, dass sich die Stelle kaum noch lesen lässt (vgl. http://www.khabaronline.ir/detail/344807/weblog/ jafarian; Stand: 14. Oktober 2016).

89 Die Entzifferung dieser Zeile ist nicht gänzlich gesichert. 90 Vgl. Abb. 13 der Rolle (link in Anm. 2).

91 Mit Sicherheit lässt sich nur der Begriff $z a \bar{d} d a$ lesen; vor Salār-zāda allenfalls „zäida“ (?). 
92 Demnach verheissen die auf dem Dokument erwähnten Namen Erfolg in wichtigen Angelegenheiten (muhimmāt) und wenden Heimsuchungen ab. Das Belegstück neutralisiert ausserdem die üblen Machenschaften jedes Zauberers und jeder Zauberin (sāhir, sāḥira) ebenso wie jene aller weiteren Geschöpfe. Es schliesst sich danach eine Unterschrift an. Deutlich erkennen lässt sich Șāhibì (?) wa-mālik Yūsuf. Es folgt ein unklarer Begriff; in einer tuġra-ähnlichen Marke steht wohl der Name Muștafā. Rechts davon wurde ein Eintrag verwischt.

Schlussfolgerungen: Sollte die Datierung des vorliegenden Exemplars korrekt sein (D̄ū l-Hiğğga 727/Beginn 18. Oktober 1327$)^{93}$ wäre dessen alter Teil das älteste Dokument, auf das ich im Rahmen der vorliegenden Untersuchung gestossen bin. Es lassen sich verschiedene Hinweise darauf erkennen, dass das Belegstück im iranischen Kulturraum entstanden ist (nisba des Kopisten: alHurāsānī; mehrfach persische Elemente im Text). Es kann sein, dass das Exemplar für den ĪlhānidenHerrscher Abū Saīd (gest. 1335) angefertigt worden ist. Diese von R. Ǧa'fariyān ins Spiel gebrachte Hypothese lässt sich allerdings nicht beweisen, da die entsprechende Stelle im Kolophon zu stark verderbt ist. Aus den im Kolophon verwendeten Formeln geht aber hervor, dass dieses Belegstück für einen Angehörigen der herrschenden Eliten angefertigt worden ist.

92 Die Fehler, gerade das كحق | هذا الاسماء العظام, weisen darauf hin, dass der Zusatz nicht von einer im Arabischen sattelfesten Person verfasst wurde. Der Verfasser dürfte aus dem Osmanischen Reich stammen, wie auch aus der tugra-ähnlichen Unterschrift hervorgeht.

93 Die Zehner ('išrīn?) lassen sich nicht mit Sicherheit entziffern. 


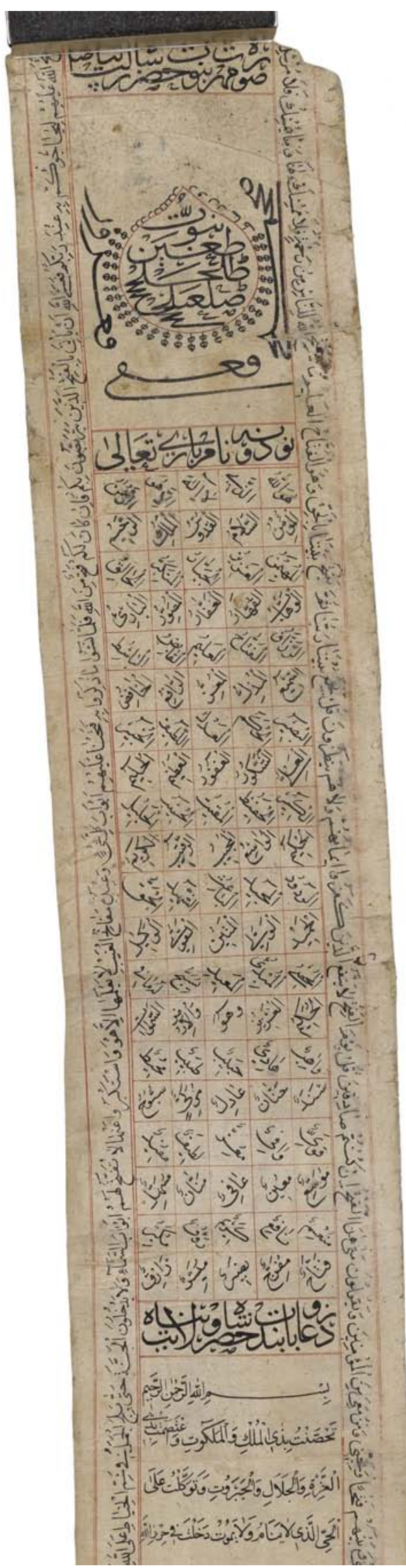

ABB. 1

Michigan, Isl. Ms. 220 (vgl. bei Anm. 3): Beginn der Rolle; dieser Teil I ist deutlich jünger als Teil II. Teil I dürfte aus dem 18. oder 19. Jh. stammen und wurde dem alten Dokument hinzugefügt, da dessen Anfang verloren gegangen war.

ISL. MS. 220, UNIVERSITY OF MICHIGAN LIBRARY (SPECIAL COLLECTIONS RESEARCH CENTER), ANN ARBOR

Tobias Nünlist - 9789004429154 


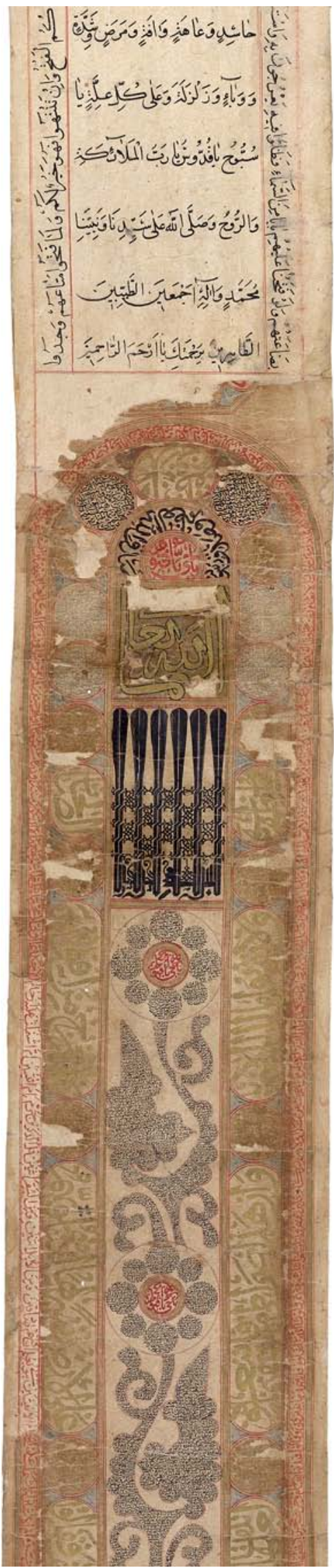

ABB. 2

Michigan, Isl. Ms. 220 (vgl. bei Anm. 13, 31): Schluss der jungen Ergänzung und Anfang des erhaltenen alten Teils der Rolle; der alte Teil stammt mutmasslich aus dem Jahr 727/1327. Die verderbte Überschrift im Mittelstreifen lautet Asmā Allāh $\operatorname{ta}^{\varsigma} \bar{a}[l \bar{a}]$. Der Text im Mittelstreifen wurde in die Formen von pflanzlichen Elementen eingepasst. Man beachte die auffällige Gestaltung der Basmala.

ISL. MS. 220, UNIVERSITY OF MICHIGAN LIBRARY (SPECIAL COLLECTIONS RESEARCH CENTER), ANN ARBOR 


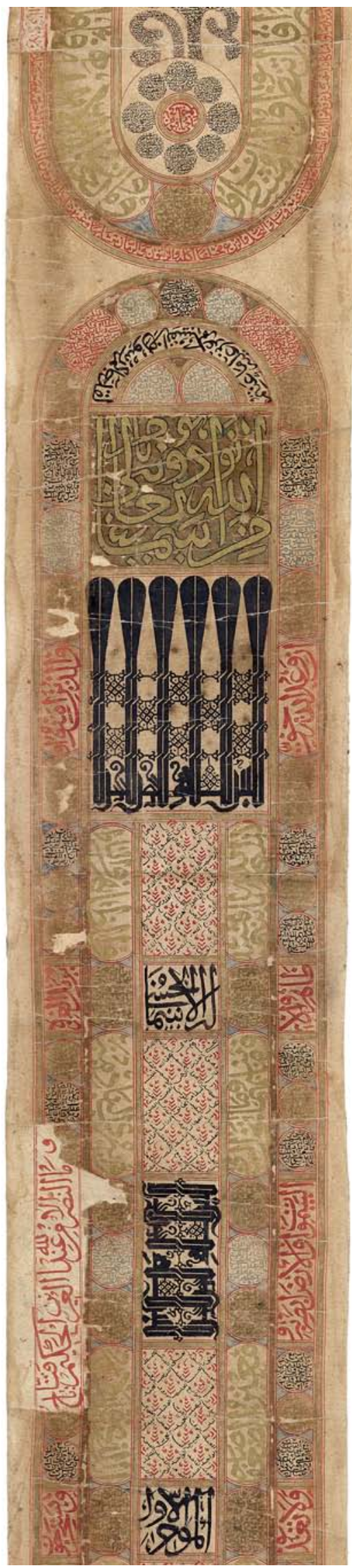

ABв. 3

Michigan, Isl. Ms. 220 (vgl. bei Anm. 41 und 63f.): Beginn der Aufzählung der 99 [Schönen] Namen Gottes (Nawad wa nuh nām min asmä’ Allāh ta'ālā). Die Namen Gottes werden im Mittelstreifen aufgeführt und sind in ein Gitter eingefügt.

ISL. MS. 220, UNIVERSITY OF MICHIGAN LIBRARY (SPECIAL COLLECTIONS RESEARCH CENTER), ANN ARBOR

Tobias Nünlist - 9789004429154 


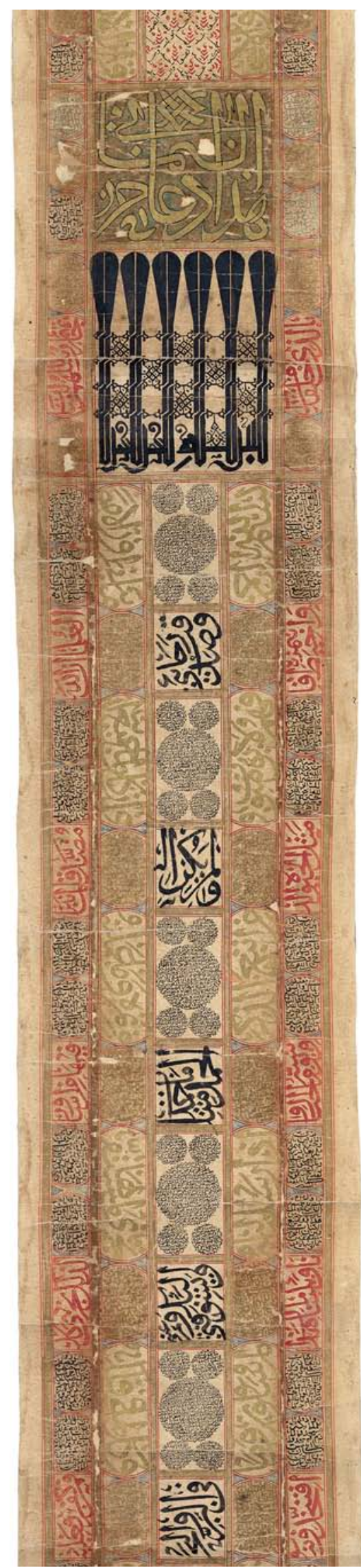

ABB. 4

Michigan, Isl. Ms. 220 (vgl. bei Anm. 66): Anfang des Gebets Hirz al-[a]mānī. Unter dem Titelfeld erneut die auffällig gestaltete Basmala.

ISL. MS. 220, UNIVERSITY OF MICHIGAN LIBRARY (SPECIAL COLLECTIONS RESEARCH CENTER), ANN ARBOR

Tobias Nünlist - 9789004429154 


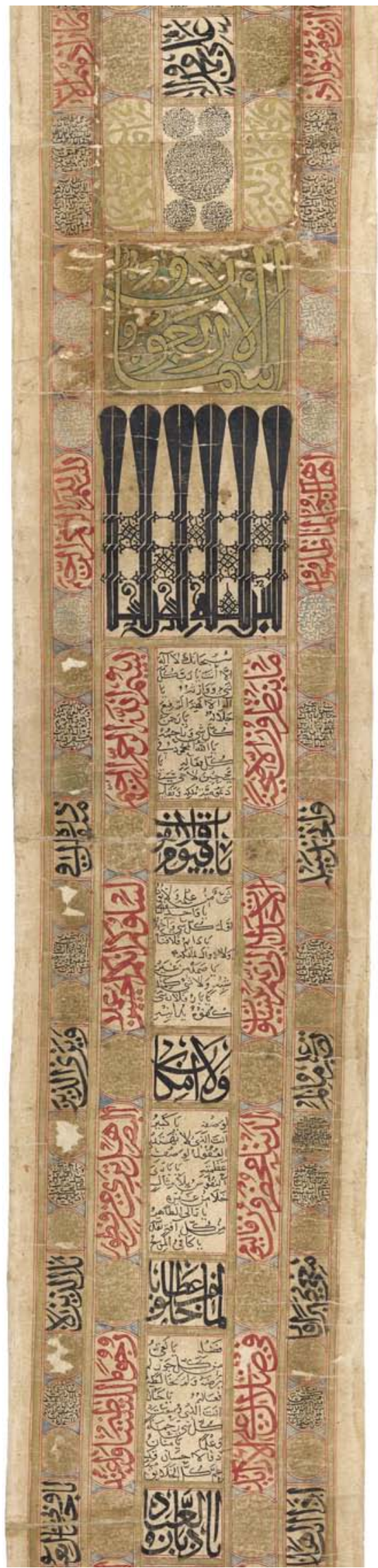

ABB. 5

Michigan, Isl. Ms. 220 (vgl. bei Anm. 72): Beginn des nächsten Gebets auf der

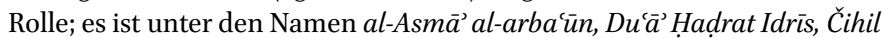
Ism-i Idrīs oder ähnlich bekannt.

ISL. MS. 220, UNIVERSITY OF MICHIGAN LIBRARY (SPECIAL COLLECTIONS RESEARCH CENTER), ANN ARBOR

Tobias Nünlist - 9789004429154 


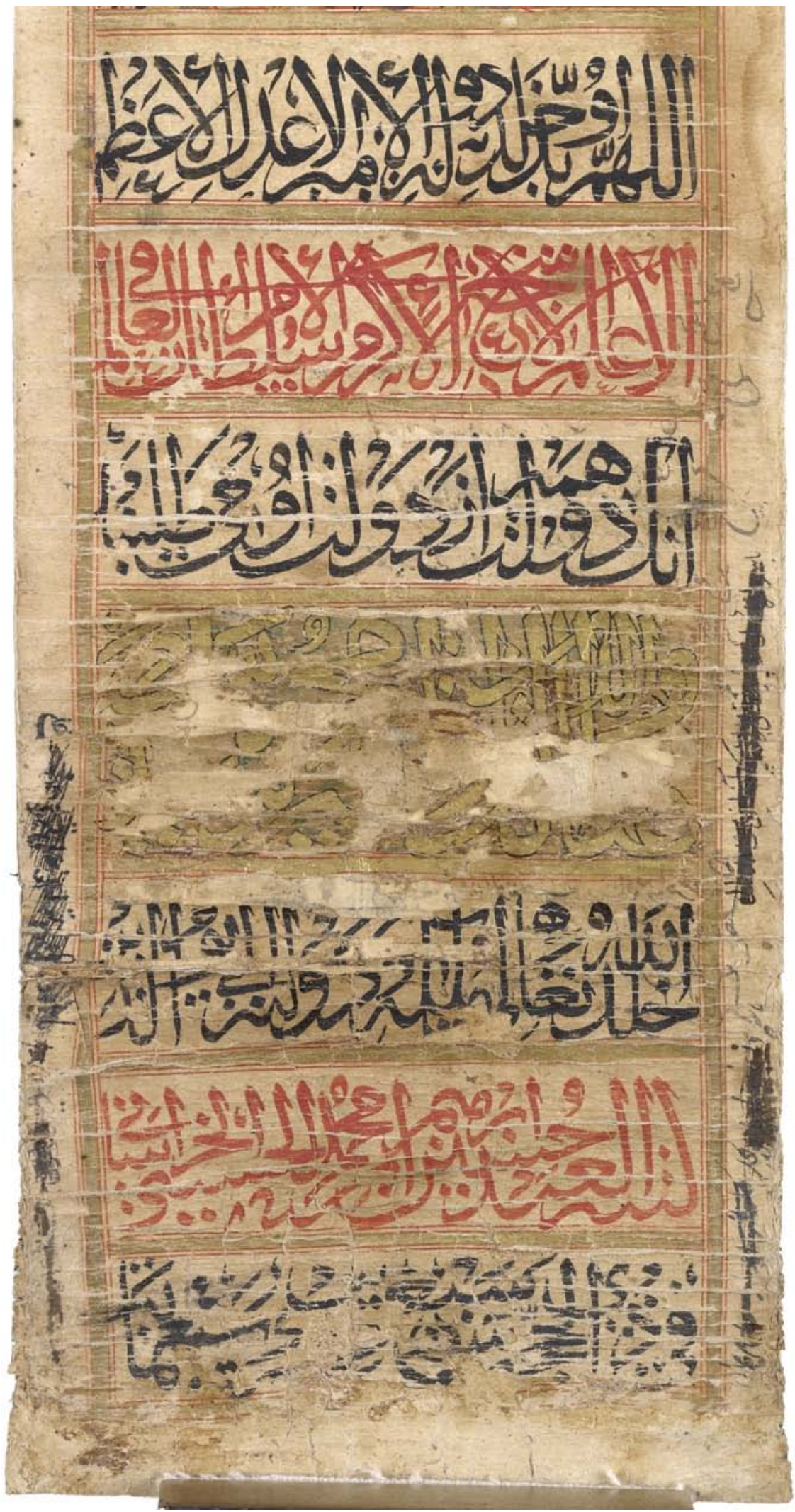

ABB. 6

Michigan, Isl. Ms. 220 (vgl. bei Anm. 87): Der Kolophon, dessen 4. Zeile wohl absichtlich beschädigt worden ist. Man beachte ausserdem die getilgten Einträge auf dem rechten und linken Rand. ISL. MS. 220, UNIVERSITY OF MICHIGAN LIBRARY (SPECIAL COLLECTIONS RESEARCH CENTER), ANN ARBOR 
David Collection, Kopenhagen, Nr. 37-1996. ${ }^{1}$ Masse: ca. $10 \times 755 \mathrm{~cm}$. Das Dokument dürfte vollständig oder nahezu vollständig erhalten sein, ist allerdings am Anfang beschädigt. Es ist zwar unwahrscheinlich, dass am Anfang ein oder mehrere Papierstreifen verloren gingen. Dies kann aber nicht gänzlich ausgeschlossen werden. Das Belegstück ist auf grünen Stoff aufgezogen. Es ist nicht datiert. Die David Collection bringt es mit Iraq oder Syrien in Verbindung und datiert es in die 1. Hälfte des 14. Jh. Diese Einordnung ist aufgrund von kunsthistorischen Vergleichen nachvollziehbar und dürfte sich mangels expliziter Einträge auf dem Dokument nicht weiter präzisieren lassen.

Formaler Aufbau: Das Dokument lässt sich in zwei Teile von ungleicher Länge gliedern. ${ }^{2}$ Teil I ist ca. $43 \mathrm{~cm}$ lang; er beeindruckt durch seine aufwendige Gestaltung. Teil II umfasst den Rest des Dokuments und misst etwa $712 \mathrm{~cm}$.

Teil I (Beschreibung; AB B. 7): ${ }^{3}$ Teil I lässt sich in drei Abschnitte gliedern. Am Anfang des Dokuments befindet sich ein Medaillon, das in ein

1 Vgl. dazu von Folsach, Art from the world of Islam 6o (Abb. 9). Man beachte auch die summarische Beschreibung und einige Abbildungen des Dokuments unter: https:// www.davidmus.dk/en/collections/islamic/materials/calli graphy/art/37-1996?image_index=3 (Stand: 27. September 2016).

Das Belegstück wird in der Dauerausstellung gezeigt (Besuch Juni 2015). Es befindet sich in einem gläsernen Schaukasten; eine Untersuchung am Original war daher nicht möglich. Die weiteren Ausführungen stützen sich auf Scans der gesamten Rolle, die die David Collection für das vorliegende Projekt anfertigte und zur Verfügung stellte.

2 Die Massangaben in der folgenden Beschreibung wurden anhand des Photomaterials ermittelt, auf dem auch ein Massstab abgebildet ist.

3 Vgl. die Abb. I.1-22 der David Collection. Diese Zahlenangaben haben folgende Bedeutung: Römische Ziffern (IVIII) verweisen auf die Ziffern auf den blauen Schildchen auf den von der David Collection 2016 vorbereiteten Scans; diese Schildchen enthalten die Längenangaben in Metern; bei Schildchen vi beginnt also der 6. Meter der Rolle. Die arabischen Zahlen 1-209 verweisen auf die einzelnen Scans.
Rechteck von etwa $10 \times 7.5 \mathrm{~cm}$ Seitenlänge eingepasst ist (I.A.1). Es schliesst sich ein Rechteck von ca. $26 \mathrm{~cm}$ Länge an (I.A.2). Darauf folgt ein Zierfeld (Masse: ca. $10 \times 9 \mathrm{~cm}$ ), in das ein Medaillon mit einem sechsstrahligen Stern eingefügt worden ist (I.A.3).

I.A.1 (Beschreibung): Medaillon (Durchmesser ca. $5 \mathrm{~cm})$ in einem Rechteck von etwa $10 \times 7.5 \mathrm{~cm}$ (Breite $\times$ Höhe). Es ist im oberen Teil beschädigt (reparierter Riss, Verlust von Verzierungen). Weitere Beschädigungen (Kupferfrass?) im unteren Teil des Rechtecks. Während die Verzierungen auf dem rechteckigen Hintergrund schlecht erhalten sind, hat das Medaillon weniger gelitten. Es wird von einem blauen Band (Breite ca. $0.5 \mathrm{~cm}$ ) mit einem Rankenmuster eingefasst. Im Medaillon selbst dominiert ein Rankenmuster auf bläulichem Hintergrund. Diese Ranken sind schwarz eingefasst und waren ursprünglich golden. ${ }^{4} \mathrm{Im}$ Zentrum des Medaillons befindet sich eine achtteilige Blüte mit rötlichen, anfänglich golden eingefassten Blättern. Diese Blüte befindet sich zugleich in der Mitte eines auf der Spitze stehenden Quadrats, dessen Seitenlinien von Ranken gebildet werden. Zusätzliche Ranken schmücken den weiteren Hintergrund des Medaillons. I.A.1 (Inhalt): Dieser Abschnitt weist keine textlichen Elemente auf.

I.A.2 (Beschreibung): Rechteck von ca. $26 \mathrm{~cm}$ Länge. Im Innern Kartusche (Breite ca. $3.6 \mathrm{~cm}$ ) mit Text; sie wird rundherum durch ein reich verziertes Band (Breite ca. $2.3 \mathrm{~cm}$ ) eingefasst. Der Hintergrund dieses Rahmens war ursprünglich blau, wie sich am Schluss des Abschnitts deutlich erkennen lässt. Die Farbpigmente haben sich aber oft vom Beschreibstoff gelöst. Die vier Ecken des Rechtecks werden durch eine kelchförmige Blüte mit vier blauen und vier roten Blättern markiert. Auf den beiden Seitenbändern des Rechtecks lassen

4 Reste der goldenen Farbe lassen sich in diesen Ranken oft noch erkennen. Die Farbpigmente lösten sich aber zumeist vom Beschreibstoff, sodass jetzt einfach das neutrale Papier zum Vorschein kommt. 
sich fünf Mal zwei rote Doppelblätter erkennen, die aus goldenen Ranken hervorgehen. Das zentrale gestalterische Element auf diesem Seitenband besteht aber aus einem Zierband mit einem Flechtmuster von ca. $3 \mathrm{~mm}$ Breite. Es fasst den Rahmen des Rechtecks innen und aussen ein. Es wechselt in regelmässigen Abständen von der innern auf die äussere Seite des Rahmens. Auf den beiden Längsseiten des Rechtecks bildet dieses Zierband je sechs kuppelförmige Figuren mit nach aussen gerichteter Spitze. Das Rechteck wird oben und unten durch je eine identisch ausgeführte dreistufige Kuppel abgeschlossen (insgesamt 14 dreistufige Kuppeln um das Rechteck herum). Diese Zierbänder sind übrigens golden eingefasst. Auch die weiteren rankenförmigen Verzierungen waren ursprünglich golden (Farbe jetzt oft verloren).

Im zentralen Mittelfeld des Rechtecks (Breite: ca. $3.6 \mathrm{~cm}$ ) dominiert Text in grossem schwarzem Nash mit Tendenz zu Tulut. Der Hintergrund wird durch ein engmaschiges rotes Gitter ausgefüllt. Auf der Höhe der sechs dreistufigen Kuppeln im Aussenband lassen sich im Innern des Rechtecks sechs wirbelförmige, ineinander übergehende Figuren erkennen, aus deren Ranken vereinzelt rote oder blaue Blätter oder Blüten hervorspriessen.

I.A.2 (Inhalt): Der Text lautet: هو الاول والآخ مie Aussage bezieht sich auf Gott und hält fest, dass Allāh der Erste und der Letzte, der Sichtbare und der Verborgene sei. Die angeführten Eigenschaften sind auch von den Schönen Namen Gottes bekannt.

I.A.3 (Beschreibung): Am Schluss ein Zierelement mit einem sechsstrahligen Stern. ${ }^{6}$ Dieser Stern ist in einen Kreis von ca. $6.6 \mathrm{~cm}$ Durchmesser eingepasst. Kreis und Stern werden durch ein dreiteiliges Band gebildet. Es ist aussen und innen golden und jeweils schwarz eingefasst. Der Mit-

5 Aus Q 57:3:

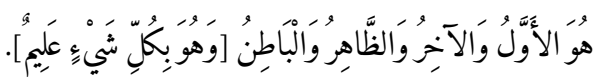

6 Zur Verwendung und Bedeutung dieses Ziermotivs (sechsstrahliger Stern) vgl. Baer, Metalwork 126-132, Abb. 107-110; Winkler, Siegel und Charaktere 127-133; Canaan, Decipherment v. a. 170, und Index dort, s.v. „hexagram“. telstreifen dieses Bands ist neutral belassen worden. Die Bänder über- bzw. unterfahren sich an den Schnittstellen gegenseitig. Die sechs Strahlen des Sterns sind durch nach innen geschwungene Bögen derart miteinander verbunden, dass die beiden einander jeweils gegenüberliegenden Spitzen miteinander verknüpft sind. Die Segmente zwischen Kreis und Stern sind mit einem engmaschigen roten Gitter ausgefüllt. Darüber ein goldenes Rankenmuster mit einer dreiteiligen blauen Spitze. Der Hintergrund der sechs Strahlen des Sterns ist blau und mit einem goldenen Rankenmuster versehen. Im Zentrum des Sterns eine blütenartige Verzierung mit je drei roten bzw. blauen v-förmigen Blättern. Identische Zierelemente in den vier Ecken des Rechtecks, in dem sich dieser Stern befindet. Der Kreis wird übrigens von einem blauen Kranz (Breite ca. $8 \mathrm{~mm}$ ) mit einem goldenen Rankenmuster eingefasst.

Teil II (Beschreibung): Teil II reicht bis ans Ende der Rolle. Er wird links, rechts und oben von einem Schriftband eingefasst, das ca. $1.6 \mathrm{~cm}$ breit ist. Ganz am Schluss der Rolle ein Kreis von ca. $8 \mathrm{~cm}$ Durchmesser. Das Schriftband umfährt diesen Kreis und wechselt dabei von der linken auf die rechte Seite der Rolle. Teil II bildet formal einerseits eine Einheit. Dies wird durch das Schriftband hervorgehoben, das den ganzen Teil II einfasst. Der Inhalt dieses Schriftbands wird im Abschnitt Teil II (Schriftband, Inhalt) dokumentiert. Anderseits lässt sich der von diesem Schriftband eingefasste Mittelstreifen in drei Abschnitte unterteilen (vgl. dazu Teil II.A-C, Mittelstreifen).

Teil II.A (Mittelstreifen, Beschreibung): ${ }^{7}$ In diesem ersten Abschnitt (Länge: ca. $16 \mathrm{~cm}$ ) dominiert eine Kartusche (Länge ca. $9 \mathrm{~cm}$ ), die oben und unten abgerundet ist (aussen) bzw. spitz zuläuft (innen). Diese Kartusche wird von einem ca. $9 \mathrm{~mm}$ breiten Band eingefasst, auf dem sich wellenförmige Verzierungen erkennen lassen. Dieses Band ist jetzt nahezu schwarz bzw. dunkelgrau. Es dürfte ursprünglich aber silbrig gewesen sein. Im Innern

7 Vgl. die Abb. I.22-26. 
ist der Hintergrund der Kartusche blau und mit einem goldenen Rankenmuster ausgefüllt. Sie ist mit einem Text von ca. $3 \mathrm{~cm}$ Höhe versehen, der in der Rollenrichtung verläuft. Oberhalb und unterhalb der Kartusche befindet sich je ein ca. $2.5 \mathrm{~cm}$ breiter rechteckiger und horizontal ausgerichteter Balken. Die beiden Balken sind ähnlich gestaltet wie der Mittelteil der Kartusche. Auch in diesen beiden Balken ist Text vorhanden; er ist hier allerdings horizontal, also in der Rollenbreite kopiert worden.

Teil II.A (Mittelstreifen, Inhalt): ${ }^{8}$ Der Text lau-

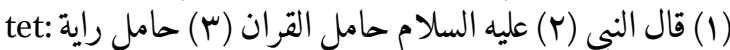
الاسلام. Diese dreiteilige Überschrift hält also fest: „(1) Es sprach der Prophet, / (2) Gruss über ihn, der Träger des Korans / (3) und der Träger des Banners des Islams." Sie dient offensichtlich als Einleitung zur Abschrift des Korans, die unmittelbar unterhalb dieses Abschnitts beginnt.

Teil II.B (Mittelstreifen, Beschreibung und Inhalt): ${ }^{9}$ Dieser Teil misst etwa $650 \mathrm{~cm}$ und bildet mit Abstand den längsten Abschnitt der Rolle. Er enthält eine wohl vollständige Abschrift des Korans. Die Abschrift wird durch 30 horizontal ausgerichtete Titelbalken unterteilt; sie markieren die Einteilung der islamischen Offenbarung in 30 Teile $\left(\check{g} u z^{\prime}\right)$. Die Abschrift jedes einzelnen $\check{g} u z^{\prime}$ weist eine Höhe von ca. $21-22 \mathrm{~cm}$ auf. Die Titelbalken messen $5.5 \times 2.1 \mathrm{~cm}$ (Breite $\times$ Höhe) und sind stets identisch gestaltet. Der Hintergrund dieser Titelbalken wird von einem Gitter aus roten Stäben ausgefüllt. Das Gitter ist hier nicht ebenso engmaschig wie jenes am Anfang der Rolle im Zierfeld mit dem Text هو الاول والآخر والظاهر والباطن In diesen 30 Titelfeldern lässt sich zusätzlich ein silbergraues Rankenmuster erkennen; es ist in zwei Wirbeln angeordnet. ${ }^{11}$ Auf diesem Hintergrund hat der

8 Vgl. die Abb. I.22-26.

9 Vgl. die Abb. I.26-VIII.19o.

10 Vgl. bei Anm. 5 (Abschnitt I.A.2; Beschreibung bzw. Inhalt).

11 Dieses Rankenmuster wird später durch einfachere silbrig-graue Zierelemente ersetzt. Wahrscheinlich sind diese Titelfelder nach der Abschrift des Korantexts ausgeführt worden. Beim Titelbalken zum 30. $\breve{G} u z^{\prime}$ deckt
Kopist in grossem, schwarzem Tulut die Einteilung des Korans in 30 ğ $u z^{\prime}$ festgehalten. Titelfeld 2 lautet al-ğuzw (sic) at-tāani; danach zählt der Kopist weiter bis zu al-ğuzw at-talātūun. Die Überschrift zum ersten ğuzw lautet allerdings Sūrat al-Fätiha, die selbstredend auch die Abschrift des Korans eröffnet. Q 2 (Sūrat al-Baqara) schliesst sich unmittelbar an Q 1 (Sure 1) an. Ihr Titel und die Anzahl ihrer Verse sind in roter Tinte festgehalten. ${ }^{12}$ Die Verse werden durch rote Trennzeichen (Punkte) voneinander getrennt. Die Abschrift des Korans wurde in schwarzer $\dot{G} u b \overline{a r}$-Schrift (Höhe des alif ca. $1.25 \mathrm{~mm}$ ) auf horizontal ausgerichteten Zeilen ausgeführt (7-8 Zeilen auf $1 \mathrm{~cm}$ Höhe). Der Text ist oft punktiert und teilweise vokalisiert.

Teil II.C (Mittelstreifen, Beschreibung und Inhalt; ABB. 8):13 Die Rolle endet nicht mit der Abschrift des Korans. Auf Q 114 folgt vielmehr ein weiteres horizontal ausgerichtetes Titelfeld, das ähnlich gestaltet ist wie die Überschriften zu den einzelnen $\check{g} u z^{\prime}$. Im Titelfeld lässt sich die Überschrift Asmā (sic) Allāh ta'ālā („Die Namen Allāhs, erhaben ist er") erkennen. Die Höhe dieses Abschnitts beträgt ca. $35 \mathrm{~cm}$ (inkl. Titelfeld). Die Textelemente in diesem Abschnitt sind in Kreisen notiert worden, die auf 29 Zeilen verteilt sind. Die Zeilen 1-6 enthalten auf den ungeraden Linien 4 Kreise; auf den geraden Linien sind es 2 Kreise. Auf den Zeilen 7-29 sind 4 (ungerade) bzw. 3 (gerade) Kreise (Durchmesser ca. $1.2 \mathrm{~cm}$ ) angeordnet worden. Der Abschnitt enthält insgesamt 99 Kreise. Die Zwischenräume zwischen den Kreisen wurden auf Zeilen 1-6 zur Verzierung mit stilisierten Blüten ${ }^{14}$ ausgefüllt. Ähnliche Verzierungen las-

jedenfalls eine schwarze Linie des Titelfelds die letzte Zeile der Abschrift von Q $77 \mathrm{zu}$.

12 Der Titel von Q 2 ist klar erkenntlich. Wahrscheinlich wurde er zu einem späteren Zeitpunkt neu geschrieben. Es fällt auf, dass andere Surentitel verblasst und zum Teil nicht mehr erkennbar sind. An anderen Stellen wiederum ist nur der Begriff Sūra klar lesbar; gerade am Schluss der Abschrift aber sind die Surentitel in rot wieder klar zu erkennen. Auch die roten Verstrenner sind stark verblasst; sie fehlen später.

13 Vgl. die Abb. viri.19o-20o.

14 Farben: rot, golden, vereinzelt blau. 
sen sich in diesem Abschnitt zusätzlich zwischen den Kreisen dem Rand entlang erkennen. Ab Zeile 7 sind die Zwischenräume zwischen den Kreisen im Innern aber nur noch mit kleinen Kreisen mit einem farbigen Punkt (zumeist rot) in der Mitte ausgefüllt. Der Text in diesen Kreisen ist in grossem, punktiertem und vokalisiertem Nash notiert worden.

Diese Kreise enthalten - wie aufgrund der Überschrift zu erwarten ist - eine Aufzählung der Schönen Namen Gottes. ${ }^{15}$ Der Abschnitt umfasst 99 Kreise. In den ersten sieben Kreisen steht zur Ein-

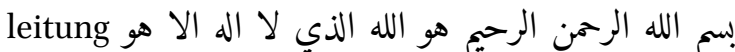
16 Danach beginnt die Aufzählung der Eigenschaften Allahs mit zumeist einem Beinamen pro Kreis. In der viertletzten bis zweitletzten Zeilen stehen zumeist zwei Eigenschaften pro Kreis. Der Abschnitt schliesst in den sechs letzten Kreisen mit der Schlussformel الذى ليس كمثله 年 17 Ob die Aufzählung - wie üblich - exakt 99 Namen enthält wurde nicht überprüft. Es ist bekannt, dass solche Aufzählungen durchaus deutlich mehr, aber auch weniger Beinamen enthalten können. ${ }^{18}$

Ganz am Schluss des Dokuments befindet sich ein Kreis, der vom Schriftband umfahren wird. In diesem Kreis befindet sich ein Stempel, der von M. Bayani analysiert worden ist. ${ }^{19}$ Sie datiert

15 Auch auf einem Belegstück aus der Sabancı Collection, Istanbul, werden die Schönen Namen Gottes in Kreisen aufgeführt. Die Gestaltung darauf weicht gegenüber dem vorliegenden Beispiel allerdings ab. Siehe die Abbildung in Sakıp Sabancı Museum Collection of the Arts of the book and calligraphy 153 (Nr. 6o).

16 Q 59:22.

17 Vgl. Q 42:11.

18 Siehe Kapitel 3.4, Anm. 464.

19 Der Inhalt des Stempels ist auf dem Abbildungsmaterial nur schlecht erkennbar. Die folgenden Angaben stützen sich auf eine unveröffentlichte Untersuchung dazu durch M. Bayani aus dem Jahr 1999, die dem Verfasser durch die David Collection zugänglich gemacht wurde. Demnach befindet sich am Ende des Dokuments der Abdruck eines grossen Siegels mit Text in Nasta liq. Im Zentrum des Siegels lässt sich allenfalls der Name Mūsā erkennen. Der Text dem Rand entlang ist in vier Kartuschen angeordnet, die je einen persischen Vers enthalten. M. Bayani schlägt ihn ins Ende des 16. Jh (1[o]o1/1592-1593). Da die Rolle selbst aber bereits in der ersten Hälfte des 14. Jh. entstanden sein dürfte, muss dieser Stempel nachträglich angebracht worden sein. Er dürfte einen älteren Eintrag verdecken. Dieser Stempel steht auch nicht exakt im Zentrum des Kreises.

folgende Entzifferung vor: „[Āy bar] huudā ba-ḥaqq hastī / [š̄̌š čìz ma-rā madad firistī / 'ilm wa 'amal wa [farahdast]ī / [īmān wa amān wa tandurustī]“ - „Oh God, by the truth of existence / would you send me six things as assistance / knowledge, and action, and openhandedness / faith, security, and health.“

In den Kartuschen erkennt M. Bayani in einem schmalen Textband Anrufungen Gottes: „Yā mannān, yā dayyān [...]“ - „Oh the Ever-bestowing One! / Oh the Everrequiting One! [...].“ Spuren von zusätzlichen Textstellen lassen sich ebenso zwischen den Kartuschen erkennen; es handelt sich wahrscheinlich ebenso um Anrufungen Gottes.

M. Bayani macht zur Ergänzung auf Parallelen zu diesem Stempel aufmerksam: Bei Inv. Nr. 4988 (Topkapi Saray Museum) handelt es sich wahrscheinlich um das Privatsiegel eines staatlichen Würdenträgers oder Wesirs. Abbildungen des Siegels fehlen. Die von M. Bayani konsultierte Quelle beschreibt es aber als „seal-ring, with silver handle. Engraved on a cornelian in taliq script. In the middle, Abduhu Feyzullah, and around that an identical quatrain in Persian. The date ist given as: [1]101/1689." In den Ecken dieses Vergleichsstücks befinden sich Anrufungen Gottes: „Yā ḥannān / yā mannān / yā subhạan / yā dayyān“. Dieses Siegel muss einen Vierzeiler enthalten, dessen Text mit jenem auf dem hier diskutierten Belegstück aus der David Collection identisch ist. M. Bayani vermutet allerdings, dass das Siegel aus dem Topkapı Saray früher anzusetzen ist und schlägt die Entzifferung 1[o]o1/1592-1593, anstelle von [1]101/1689, vor. Vgl. dazu I.H. Uzunçarşıl, Guide Book of the Seals Section of Topkapu Saray Museum 44 (englisch).

Ein undatiertes, längliches Siegel befindet sich sodann in der BNF, Paris. Es enthält denselben Vierzeiler und den Namen Mușțafā im Zentrum; vgl. dazu Kalus, Catalogue des cachets, bulles et talismans 45 (Nr. 2.2.19). Ein weiteres, undatiertes Siegel von ähnlicher Gestalt auch im Ashmolean Museum, Oxford. Es enthält denselben persischen Vierzeiler und den Namen „Hasan“ in der Mitte; vgl. Kalus, Catalogue of Islamic seals and talismans 24 (Nr. 2.2.18). Die beiden Belegstücke aus Paris und Oxford sind aber von anderer Gestalt und Qualität als der Stempel auf der Rolle. Gemäss M. Bayani dürfte es sich um eine Wiederaufnahme einer Tradition aus dem 16. Jh. handeln. 
Dies ist ein zusätzlicher Hinweis, dass es sich um eine spätere Hinzufügung handelt. ${ }^{20}$

Teil II (Schriftband, aussen, Inhalt): Teil II bildet formal aber auch eine Einheit, wie sich anhand des Schriftbands aufzeigen lässt. Es umfährt den ganzen Teil II und enthält Text in grossem, etwa $1.3 \mathrm{~cm}$ hohem Tulut. Die Schrift ist golden; sämtliche Buchstaben werden von haarfeinen schwarzen Linien eingefasst und sind gut zu lesen. Der Text ist punktiert und wiederholt auch vokalisiert. Das Schriftband beginnt ganz am Anfang von Teil II, wo sich horizontal die Basmala erkennen lässt. Auf dem Schriftband lassen sich noch zwei zusätzliche Basmalas nachweisen. Aus diesem Aufbau lässt sich schliessen, dass das Schriftband drei Textelemente enthält. Die drei Basmalas befinden sich an folgenden Stellen:

1. $\quad$.22 (links, Text vorwärtslaufend) ${ }^{21}$

2. VII.169 (links, Text zuerst vorwärtslaufend, dann rückwärtslaufend).

3. VI.141 (rechts, Text rückwärtslaufend).

Bei diesen Textelementen handelt es sich um drei Gebete, die sich teilweise auch anderweitig nachweisen liessen. Die Texte auf der Rolle stimmen nicht vollständig mit den Parallelen überein. Die Abweichungen betreffen v.a. die Abfolge der einzelnen Textelemente. Auch lassen sich wiederholt Ergänzungen feststellen.

1. Gebet (Teil I.22-VII.169; links, vorwärtslaufend): Dieses erste Gebet weist zahlreiche Übereinstimmungen mit einem Gebet auf, das in unterschiedlichen Quellen unter dem Namen Du'ầ Nūr

20 Beim Besuch in der David Collection befand sich die Rolle im Schaukasten (wie bereits erwähnt). Der Schlussteil mit dem Stempel war nicht sichtbar. Anhand des Abbildungsmaterials lässt sich nicht beurteilen, ob hier allenfalls ein älterer Eintrag überklebt wurde. Dies ist aber wahrscheinlich.

In den folgenden Transkriptionen haben die Zahlenangaben weiterhin folgende Bedeutung: Römische Ziffern (I-VIII) verweisen auf die Ziffern auf den blauen Schildchen auf den von der David Collection 2016 vorbereiteten Scans; diese Schildchen enthalten die Längenangaben in Metern; bei Schildchen 6 beginnt also der sechste Meter der Rolle. Die arabischen Zahlen 1-2og verweisen auf die einzelnen Scans. al-anwār al-kabīr verzeichnet ist. ${ }^{22}$ Es liess sich bis anhin in keiner gedruckten Gebetssammlung nachweisen. ${ }^{23}$ Der Text des Gebets auf der Rolle aus der David Collection lautet:

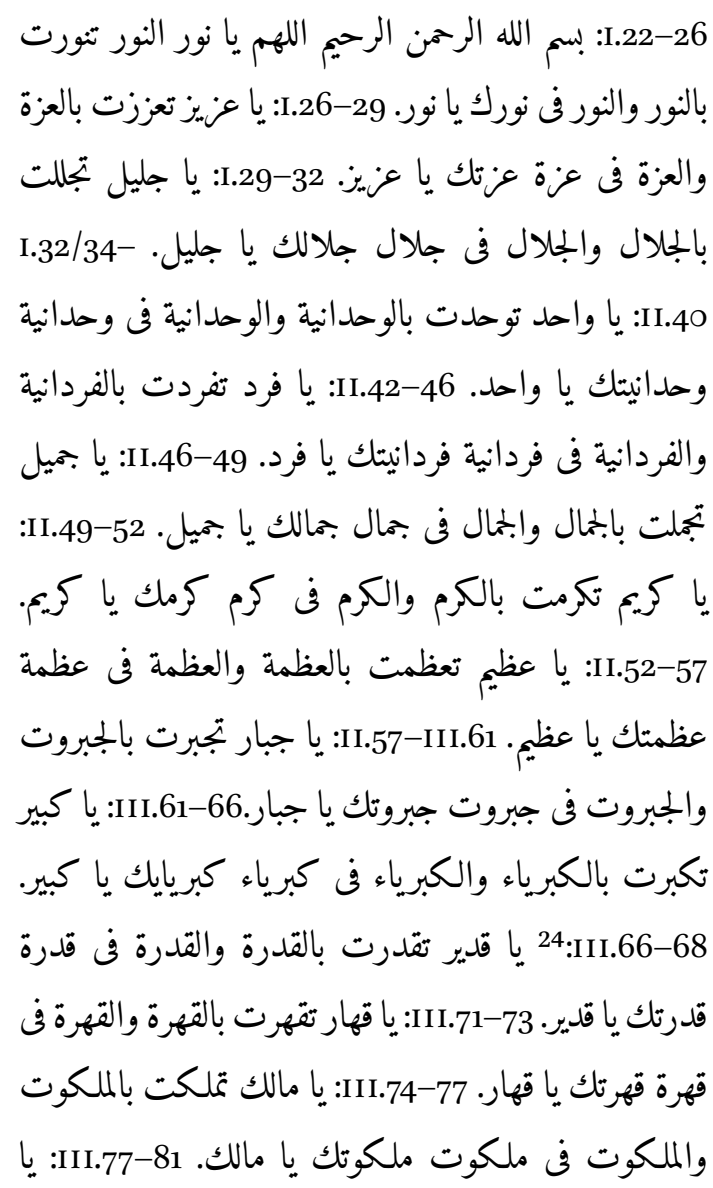

22 Vgl. dazu u.a. (alle Stand 18. Oktober 2016):

1. http://www.knozalasrar.com/threads/6oo-دعاء-نور(Website nicht zugänglich am 31. Dezember 2017);

2. http://www.niksalehi.com/din-andishe/archives/ 2168o7.php;

3. http://hamsafareasmani.blogfa.com/post/2;

4. https://ar-ar.facebook.com/Mahmoud.Essa.Roha ny/posts/480569368652074;

5. https://venuspell.blogspot.ch/2012/10/blog-post_7 .html.

23 Eine Handschrift mit einem Gebet dieses Namens befindet sich in der Universitätsbibliothek Leipzig (Signatur B. or. 315-02; 7 Bl.; vgl. IslamHSBook_islamhs_ooo10842 .pdf; Fleischer, Catalogus 444, 2).

24 Hier wurden beim Photographieren mutmasslich wenige Zentimeter ausgelassen. 
قدوس تقدست بالقدوس والقدوس في قدوس قدوسك يا قدوس. III.81-IV.87: يا رب تربيت بالربوبية والربوبية فى

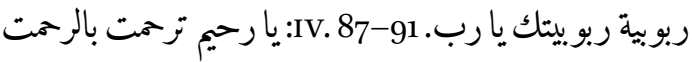
والرمت فى رحمت رحمتك يا رحيم. 95-IV.92: يا وهاب توهبت بالهيبة والهيبة في هيبة هيبتك يا وهاب. 99-IV.96: يا منان تمنيت بالمنة والمنة في منة منتك يا منان. 103-100 يا حكيم تحكت بالحكمة والحكمة في حكمة حكمتك يا حكيم. 25:IV.103-108 يا بجيد تيجدت بالمجد والمجد في مجد مجدك يا مجيد. IV.108-V.112: يا لا اله الا انت عليك توكلت واليك المصير. 115-V.112: بسم الله وبالله ومن الله وبرب ابرهيم. V.115-118: ورب اسمعيل واسحق وجبرئيل ومهكائل واسرفيل. 122-119: و.بكق التورية والانجيل والزبور والفرقان العظيم. 128-123: و.بحق كهيعص و.كقق حم عسق ويس والقران الحكيم 130-V.128: ان تيسر لنا امورنا وترزقنا خير الرازقين

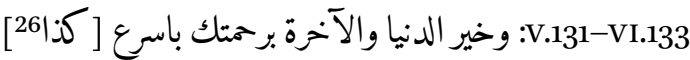
الحاسبين 143-VI.136:27 اللهم انى اسلمت نفسى اليك وفوضت امرى اليك والجأت ظهرى اليك لا ملجا ولا منجا منك الا اليك 146-144:VI.28 آمنت بكّابك انزلت [كذا] وبنبيك الذى ارسلت 151-VI.147: و.يحمد صلى الله عليه

25 Nach dieser Anrufung ändert die Struktur des Gebets. Die Fortsetzung dürfte aber nicht eigenständig sein; sie liess sich als Ganzes in dieser Abfolge sonst nicht nachweisen. Die Anrufungen Gottes sind sehr gängig und lassen eine Identifizierung kaum zu.

26 Recte: يا سريع الحاسبين.

27 Dieser Text liess sich nachweisen bei Buhārī, Sahị̄h, Hadīt Nr. 5952. Auf dem Belegstück aus Kopenhagen leicht gekürzt. Gemäss Buhārī soll der Gläubige diese Stelle rezitieren, bevor er sich schlafen legt bzw. wenn er die rituelle Waschung vollzieht. Vgl. http://www.al-islam .com $/$ Page.aspx?pageid $=695 \&$ BookID $=24 \& \mathrm{PID}=6052 \&$ SubjectID=24435; http://library.islamweb.net/newlibra ry/display_book.php?flag=1

\&bk_no $=0 \& I D=245$ (Stand 18. Oktober 2016).

28 Auch dies gehört noch zum Auszug aus dem in Anm. 27 angegebenen Prophetenwort.

$$
\begin{aligned}
& \text { وسلم عبدك ورسولك لا اله الا انت 156-151.29: تحصنت } \\
& \text { بذى الملك والملكوت واعتصمت بذى القدرة والجبروت } \\
& \text { VI.157-VII.169: وتوكلت على الحى الذى لا يموت وصل } \\
& \text { اللهم على محمد وآله اجمعين برحتك يا ارحم الراحمين. }
\end{aligned}
$$

Danach beginnt das nächste Gebet (Gebet 2) mit der Basmala:

2. Gebet 2a (VII.169-VI.142): Der Text beginnt nach einem kleinen Zwischenraum direkt in Anschluss an das Gebet Du'ä' Nūr al-anwār al-kabīr auf der Höhe des Titelfelds für den 27. 乌̆uz'.30 Im Lauf dieses Gebets umfährt das Schriftband das Medaillon ganz am Rollenende und wechselt dabei die Seite. Das Band fährt danach auf der gegenüberliegenden Seite zum Rollenanfang zurück. Dieses Gebet enthält eine Zusammenstellung weit verbreiteter Anrufungen und Lobpreisungen Gottes; es liess sich in dieser Abfolge anderweitig nicht identifizieren:

VII.169-173: Gebet, links, vorwärtslaufend الله الرحمن الرحيم لا حول ولا قوة الا بالله العلى العظيم VII.175-182 يا قدير يا فرد يا وتر يا احد يا صمد يا رحيم يا حى يا قيوم يا ذا الجلال والاكرام 186-182:VII.182 يا نور السموات والارض وما بينهما ورب العرش العظيم

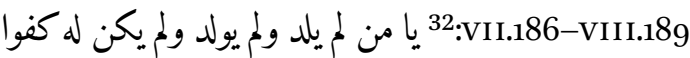
احد 192-VIII.189:33 يا كهيعص يا حم عسق يا كافى يا

29 Diese Stelle (und die erste Zeile im folgenden Abschnitt VI.157-169) lässt sich leicht modifiziert auch am Schluss eines Gebets nachweisen, das unter dem Titel Hizb atTult al-layl al-ahīr bekannt ist und auf Ǧìlānī zurückgeht. Die Aussage wird auch 'Alī b. Abī Ṭālib zugeschrieben. Vgl. https://www.msobieh.com/akhtaa/viewtopic.php?f $=4 \& \mathrm{t}=10658$ (Stand: 19 . Oktober 2016). In diesem Titelfeld ist das sin von sābic mit drei Punkten unterhalb der Zeile versehen. Diese Schreibweise des sin lässt sich auf dieser Rolle auch sonst häufig feststellen. Das sin in samawāt weist keine Punktierung unterhalb der Zeile auf.

32 Der folgende Auszug spielt auf Q 112:3-4 an.

33 Hier beginnt im Mittelstreifen der Abschnitt mit den Schönen Namen Gottes. 
هادى يا عالم يا صادق 196-VIII.193: يا رب الارباب يا

VIII.196-198: Gebet, سيد السادات يا ججيب الدعوات

Umfahrung des Medaillons am Schluss der Rolle

VIII.193-198: Gebet, يا قاضى الحاجات يا مقيل العثرات rechts, rückwärtslaufend VIII.190-193: Gebet, rechts, rückwärts- الكروب :laufend

Gebet $\mathbf{2 b}$ beginnt nach einem deutlichen Abstand (ca. $1.2 \mathrm{~cm}$ ). Die Stelle befindet sich auf der Höhe der Aufzählung der Schönen Namen Gottes im Mittelstreifen (Text rechts, rückwärtslaufend):

$$
\begin{aligned}
& \text { م4: 34:VIII.189-VII.184 اللهم انت اله من فى السموات واله } \\
& \text { من في الارض لا اله فيهما غيرك يا رب 178-VII.184: وانت }
\end{aligned}
$$

34 Bei Ibn 'Asākir, Ta'rīh Madīnat Dimašq, liess sich dazu (Abb. 184-165) folgende Belegstelle nachweisen (mit leicht modifiziertem Wortlaut). Es soll sich bei diesem Text um ein Gebet handeln, mit dem Jesus Kranke, v.a. chronisch Kranke, heilte. Auch Blinde und Wahnsinnige werden besonders erwähnt.

$$
\text { رقم الحديث: }
$$

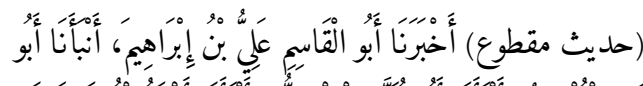

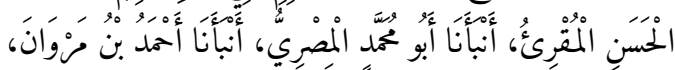

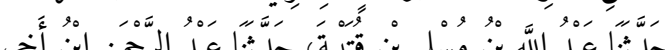

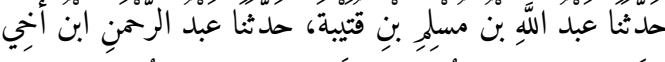

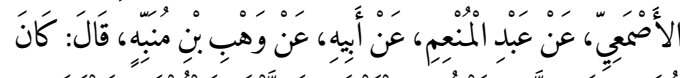

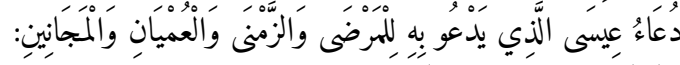

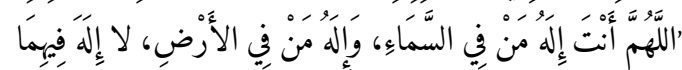

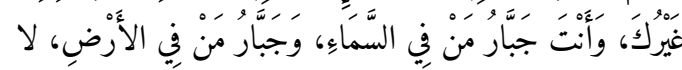

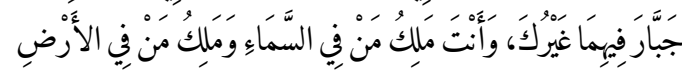

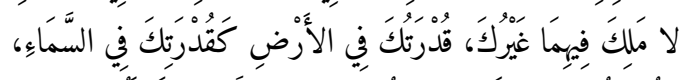

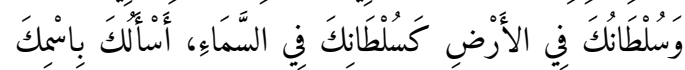

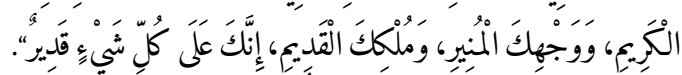

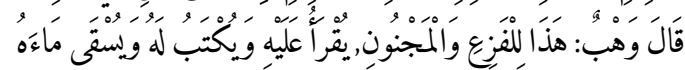
إِنْ شَاءَ اللَّهُ.

$$
\begin{aligned}
& \text { جبار من في السموات وجبار من فى الارض لا جبار فيهما } \\
& \text { غيرك يا رب 171-VII.177:35 وانت ملك من في السموات } \\
& \text { وملك من فن الارض لا ملك فيهما غيرك 165-VII.170: } \\
& \text { اسالك باسمك الكبير ووجهك المنير انك على كل شئ قدير }
\end{aligned}
$$

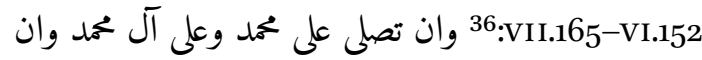

$$
\begin{aligned}
& \text { تقضى حاجتى من حوايج الدنيا والآخرة برحمتك يا ارحم } \\
& \text { الراحمين 142-VI.152:37 اللهم العالم بسرايرنا فاصلحنا وانت }
\end{aligned}
$$

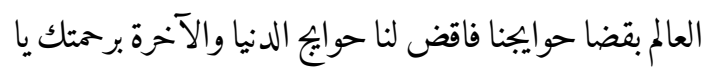

$$
\begin{aligned}
& \text { ارحم الراحين ويا احكك الحاكمين. }
\end{aligned}
$$

3. Das dritte Gebet (ab Abb. VI.141, rückwärtslaufend) liess sich - erneut mit Abweichungen, Auslassungen und Ergänzungen - in mehreren Quellen nachweisen. ${ }^{38}$ Es ist auch in der von

Siehe dazu: http://library.islamweb.net/hadith/display _hbook.phpbk_no=798\&pid $=388345 \&$ hid $=51083 . \quad \mathrm{Zu}$ Ibn 'Asākir, Ta'rīh Madinat Dimašq vgl. http://library islamweb.net/hadith/display_hbook.php?bk_no=798 \&pid $=375^{877}$ (Stand 10. September 2017).

35 Nach diesem Abschnitt erneut deutlicher Abstand (ca. $1.5 \mathrm{~cm})$.

36 Hier endet die Übereinstimmung mit der in Anm. 34 angeführten Stellen aus Ibn 'Asākir.

37 Nach dieser Stelle erneut ein grösserer Abstand, bevor das nächste Gebet mit der Basmala beginnt.

38 Man beachte die folgenden Internetquellen (Stand alle 18. Oktober 2016); Hinweise auf Druckausgabe in der übernächsten Anm.

1. http://www.mezan.net/mawsouat/ali/monajat/mo najat.html;

2. http://www.ansarh.com/maaref_details_2351_2350_ مناجاة_أمير_المؤمنين_عليه_السلام./mtml;

3. http://www.mowswoat-suhofe-alltyybeyyn.org/Soh foModaoanh/AlAsmaalhosniAlalihea/AdaetAlAsm aAlhosna/MolayYaMolayAnt.htm;

4. https://www.sibtayn.com/dua/index.php?option= com_content $\&$ view $=$ article $\&$ id $=683 \&$ catid $=20 \&$ Itemid $=61$;

5. https://duas.mobi/munajat/masjidkufa: mit englischer Übersetzung;

6. https://www.al-islam.org/articles/reflections-muna jat-imam-ali-mosque-kufa-mohammad-ali-shoma li;

7. https://www.youtube.com/watch?v=8z2lıGoUTzo. 
al-Kaf'amī (gest. 905/1499-1500) ${ }^{39}$ zusammengestellten Gebetssammlung al-Balad al-amin wa-ddir' al-hașinn verzeichnet. ${ }^{40}$ Das Gebet wird 'Alī b. Abī Ṭālib zugeschrieben. ${ }^{41}$ Damit weisen mehrere Faktoren darauf hin, dass dieses Gebet unter Schiiten beliebt war: a. 'Alī ist der erste Imam der Schiiten; b. Kaf'amī, der Kompilator der Gebetssammlung al-Balad al-amin aus dem 15. Jh., hat einen schiitischen Hintergrund; c. ausserdem fällt auf, dass die soeben angeführten Internetquellen nahezu ausschliesslich einen schiitischen Hintergrund haben. ${ }^{42}$ Das Gebet dürfte allerdings durchaus auch unter Sunniten im Umlauf gewesen sein.

39 „Taqī adِ-Dīn Ibrāhīm, b. 'Alī al-Āmilī al-Kaf'amī (Ara-

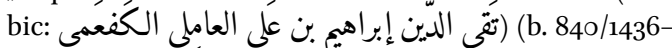
d. 905/1499) wás among Shi'a scholars of 9 th $/ 15^{\text {th }}$ century. He lived in Jabal 'Âmil, Lebanon, and his lineage reached Hāarith al-Hamdānī. Due to his expertise in different sciences of his time, al-Kaf'amī had miscellaneous works, and biographers have spoken highly of him. Al-Mișbāh and al-Balad al-amin are among his famous works in ziyāra and supplications." Zitiert aus http://en.wikishia.net/view/Ibrahim_b. _\%27Ali_al-Kaf\%27ami (Stand 31. Dezember 2017; daselbst weitere Angaben zu Kaf'amī).

Siehe al-Kaf'amī, al-Balad al-amin wa-d-dir al-hașin 319; Ausgabe Mu'assasat al-A`lamī li-l-Mațū'āt, Bayrūt, 1418/1997 (Nachdruck, der sich an einer Lithographie orientiert). Das Gebet liess sich in der elektronischen Fassung des Textes nachweisen: http://lib.eshia.ir/71752/ 1/319 (Stand 18. Oktober 2016). Es fehlt wahrscheinlich im Exemplar des Texts in der Bibliothek der Abteilung Islamwissenschaft, Universität Zürich, mit der Signatur PB II a 14. Dieses Zürcher Exemplar wurde ebenso im Jahr 1418 h.q./1997 bei al-A'lamī in Bayrūt gedruckt. Die Inhaltsverzeichnisse und die Seitenzahlen in der Druckausgabe und der elektronischen Fassung auf eshia.ir weichen jedoch deutlich voneinander ab (Druck: 734 S./elektronisch: $43^{2}$ S.). Die Druckausgabe gibt Kaf'amīs Todesjahr mit 900 h.q. an; lib.eshia.ir nennt 905 h.q. Diese Abweichungen liessen sich nicht klären. .ir/71752/1/434; es verzeichnet die 'Alī zugeschriebenen

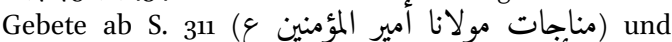

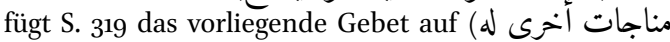
\&).

Vgl. Anm. 38.
Das Gebet umfasst zwei Hauptteile: ein erster Abschnitt enthält Anrufungen Gottes, die mit der Wendung beginnen اللهم إني أسألك الامان الامان يوم. An das yawm („Tag des Jüngsten Gerichts“) schliesst sich eine Aussage aus dem Koran zu gewissen Personen an, die an jenem Tag ihre früheren Handlungen bereuen. An die letzte dieser Anrufungen (Q 70:11 mit modifiziertem Wortlaut) schliesst sich die Feststellung aus Q 70:15-16 an

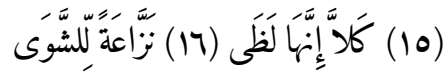

- „O nein! Sie ist das ,Flammenmeer, die Haut abziehend." Danach beginnt der zweite Teil des Gebets, in dem sich der Rezitierende mit stets identisch aufgebauten Anrufungen an Allah wendet. Sie sind nach folgendem Muster aufgebaut:

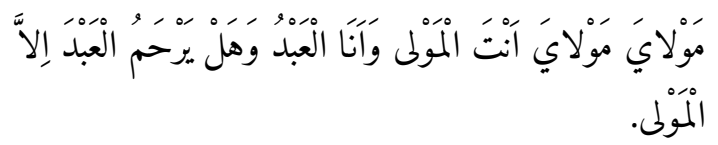

Die einzelnen Fassungen des Gebets variieren in Abhängigkeit von der Anzahl der Eigenschaften Gottes, die darin thematisiert werden.

Das Gebet Munāğāàt Amìr al-mu'mininn (VI.141I.22; alle auf dem rückwärtslaufenden Schriftband):

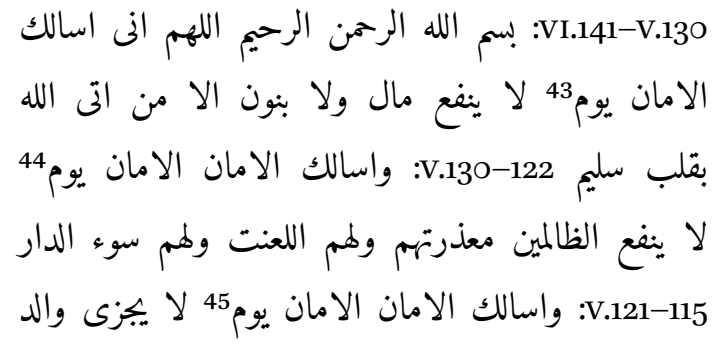

43 Vgl. dazu Koran, Q 26:88-89 (Sūrat aš-Šu'arā’):

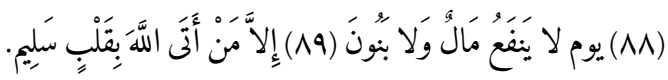

Vgl. dazu Koran, Q 40:52 (Sūrat Ġāfir):

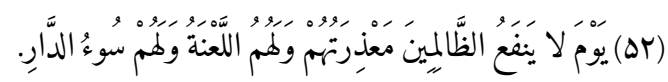

45 Vgl. dazu Koran, Q 31:33 (Sūrat Luqmān):

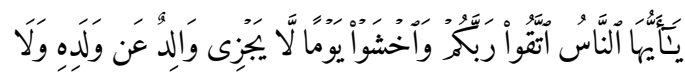


عن ولده ولا مول[ود عن وا]46 لده شيا ان وعد الله حق V.115-IV.107: واسالك الامان الامان يوم 47 يعض ولود وله الظالم على يديه يقول يا ليتنى اتخذت مع الرسول سبيلا

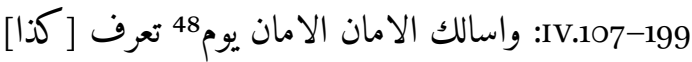
IV.99- المجرمون بسيماهم فيوخذ بالنواصـ[ى] والاقدام 91: اسالك الامان الامان يوم 49 يفر المرء من اخيه وامه هير وابيه وصاحبته وبنيه لكل امرء منهم يوميذ شان يغنيه IIV.9o-III.82: اسالك الامان الامان يوم50 لا تملك نفس لنفس شيأ والامر يوميذ لله 78-II.82:51. مولاي مولاي

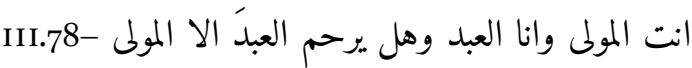

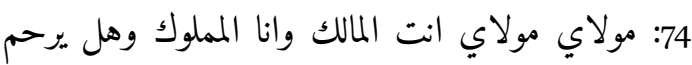

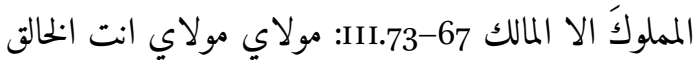
وانا المخلوق وهل يرحم المخلوقَ الا الخالق 61-67.67.

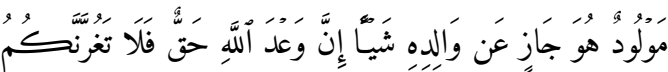

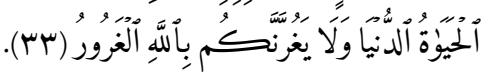

46 Hier Auslassung auf dem Photomaterial; der Text wurde anhand der zitierten Quellen (vgl. Anm. 27 und 29) ergänzt; er dürfte auf dem Original vorhanden sein.

gl. dazu Koran, Q 25:27 (Sürat al-Furqān):

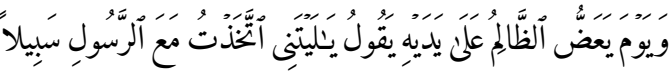

48 Vgl. dazu Q 55:41 (Sürat ar-Rahmmān):

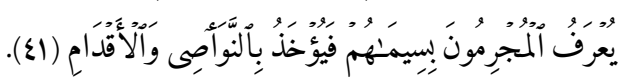

49 Vgl. dazu Q 8o:34 (Sūrat 'Abasa):

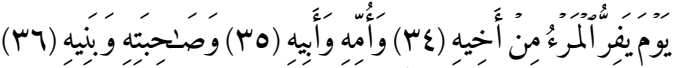

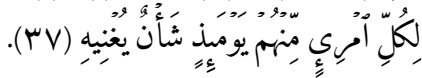

50 Vgl. dazu Q 82:19 (Sūrat al-Infițār):

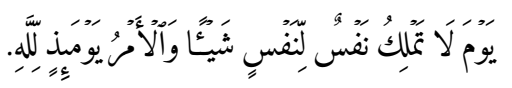

51 Hier beginnt der zweite Teil des Gebets mit den Anrufungen Gottes mit „Mawlāya, mawlāya!“
مولاي [مولاي52] انت الرازق وانا المرزوق وهل يرحم

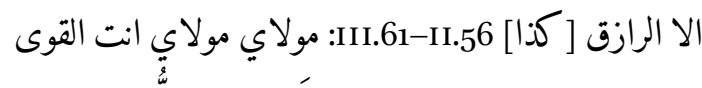
وانا الضعيف وهل يرحم الضعيف الا القوي 51-I.56: مولاي مولاي انت العزيز وانا الذليل وهل يرحم الذيليَ الإيل

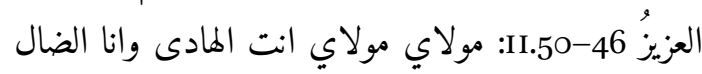
وهل يرحم الضال الا الهادى 40-4.46: مولايخ مولاي II.39- انت الغنى وانا الفقير وهل يرحم الفقير الا الغنى I.32: مولاي مولاي انت الباقى وانا الفانى وهل يرحم الفانى الا الباقى 28-I.32: مولاي مولاي انت الرمن وانا المرحوم وهل يرحم المرحومَ الا الرحمن 23-1.27: مولاي مولاي من مناي ارمتى برحمتك وبكرمك يا ذا الجلال والا كرام.53 

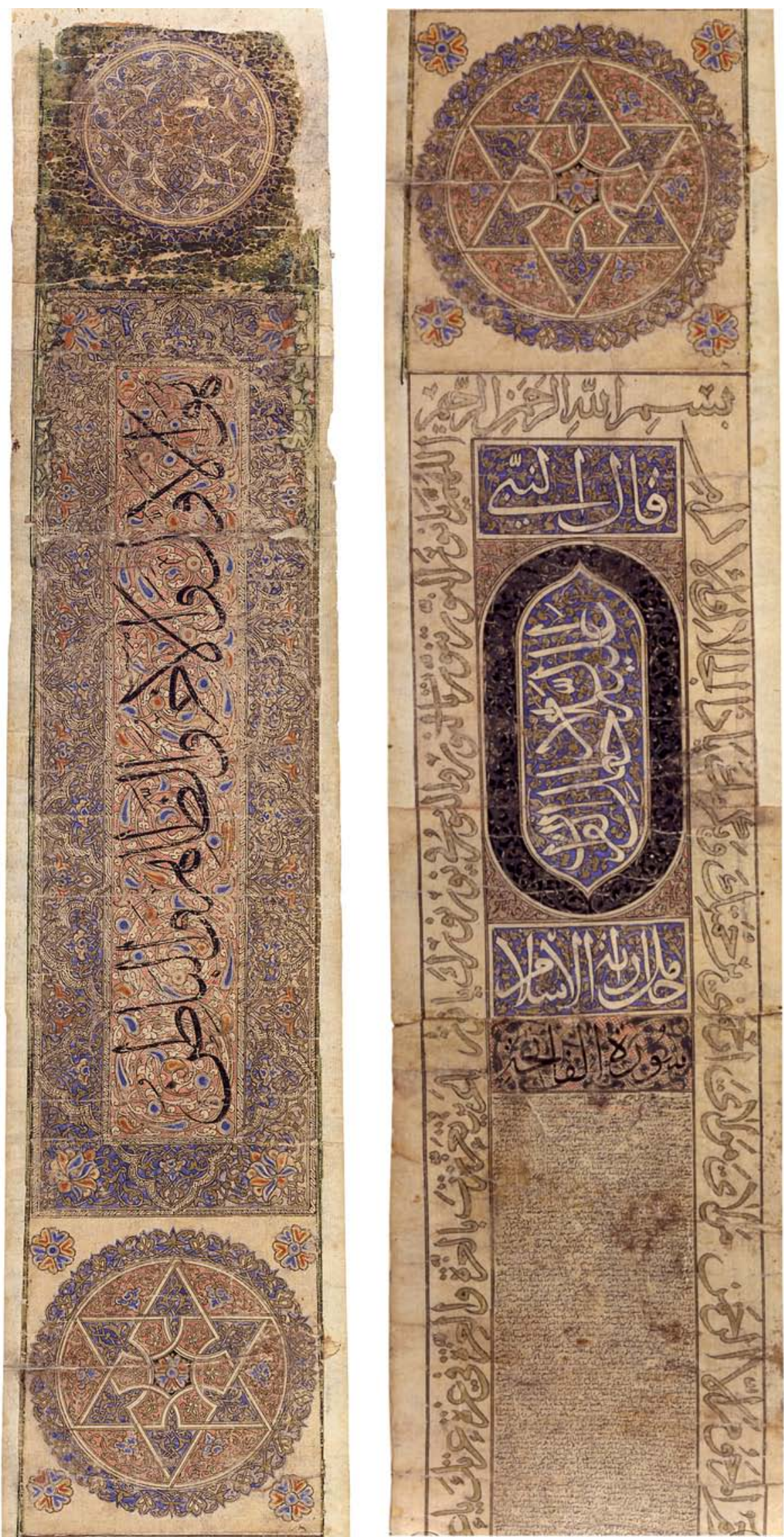

ABB. 7

Kopenhagen, David Collection, 37-1996 (vgl. bei Anm. 3-10): Die beiden Abbildungen zeigen den Anfang der Rolle. Nach den Kartuschen mit Text in grosser Schrift (Abb. links) beginnt der zweite Teil der Rolle. Im breiten Seitenband wurden Gebete kopiert. Im Mittelstreifen wurde auf horizontalen Zeilen der Koran in $\dot{G} u b \bar{a} r$-Schrift notiert (Abb. rechts). PHOTOGRAPH BY PERNILLE KLEMP AND ANNE-MARIE KEBLOW BERNSTED 


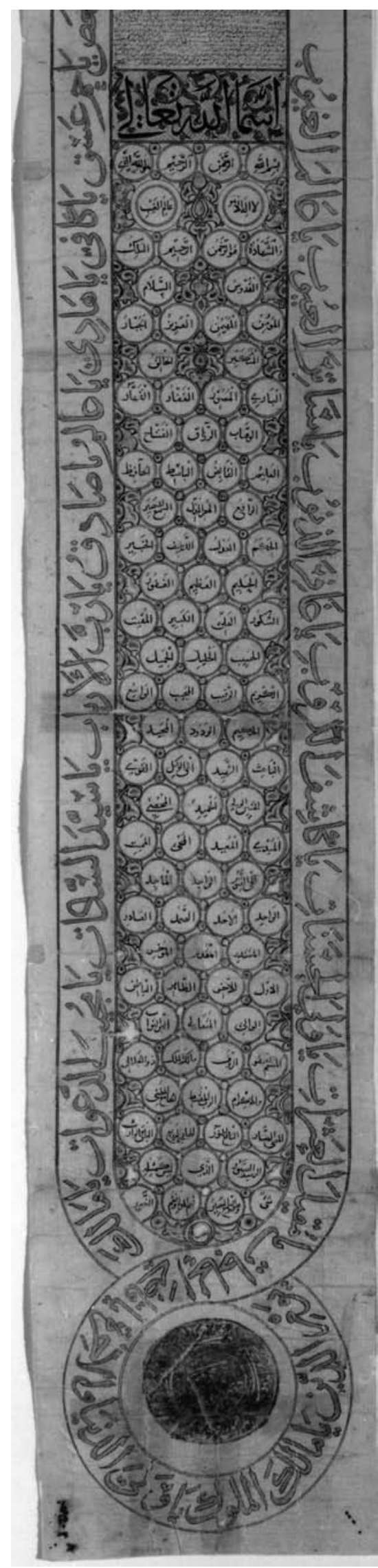

ABB. 8

Kopenhagen, David Collection, 37-1996 (vgl. bei Anm. 13-20): Beginn eines Abschnitts von ca. $35 \mathrm{~cm}$ Länge am Rollenende. Er ist mit der Überschrift Asmā (sic) Allāh ta'ālā versehen und zählt die Schönen Namen Gottes auf. Diese Namen Gottes sind in Kreisen angeordnet.

PHOTOGRAPH BY PERNILLE KLEMP AND ANNE-MARIE KEBLOW BERNSTED

Tobias Nünlist - 9789004429154 


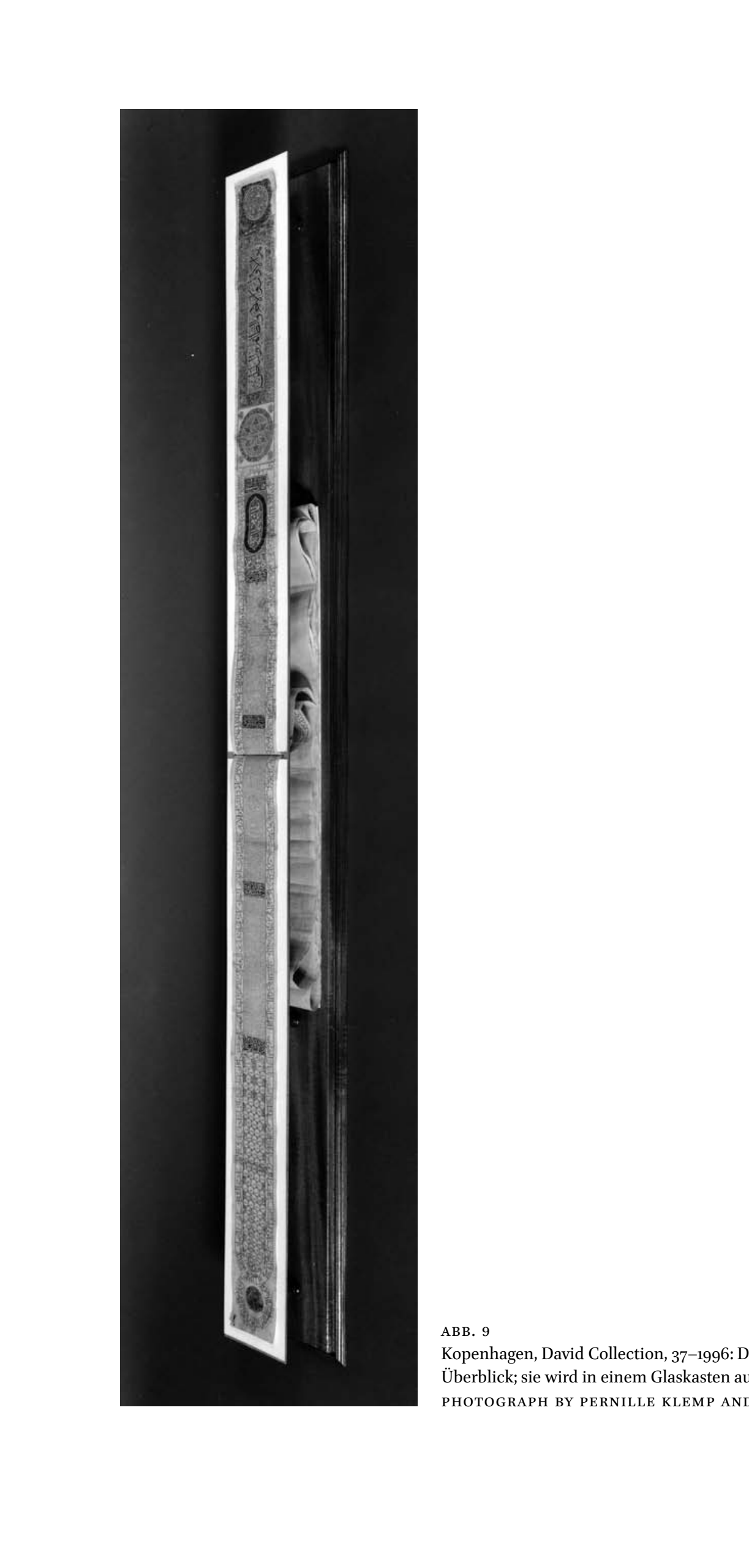


bezeichnet. ${ }^{3}$ Der Schreiber soll den Korantext diesen Angaben zufolge $184 \mathrm{Mal}$ als Ganzes rezitiert

Masse: $11 \times 846 \mathrm{~cm}$; kopiert auf eher starkes Papier, das auf weisse Leinwand aufgezogen ist. ${ }^{1}$ Papier am Schluss auf ein Rollholz von $2 \mathrm{~cm}$ Durchmesser geklebt. Die Abschrift datiert gemäss den Angaben im Kolophon vom Monat Rabī` I 775 (beginnt am 21. August 1373). Hier nennt der Schreiber auch seinen Namen: Muhammad b. Muhammad b. alBayțār aš-Šāfí̄i. Dieser Kopist liess sich anderweitig nicht belegen. Seinem Namen lässt sich einerseits entnehmen, dass er dem šāfíitischen Ritus folgte. Anderseits muss er als bayțār tätig gewesen sein; ein bayțār pflegte die Tiere, kümmerte sich um erkranktes Vieh und war als Hufschmied tätig. ${ }^{2}$ Angaben zum Entstehungsort fehlen auf dem Dokument. Es könnte aber gut in Syrien oder Iraq angefertigt worden sein.

Das Dokument ist am Schluss vollständig erhalten; am Anfang ging allerdings ein bedeutender Teil verloren. Das Exemplar enthält ausschliesslich Korantext; dies geht auch aus dem Kolophon hervor, der das Belegstück als al-muṣhaf al-karim

1 Dieses Dokument ist beschrieben in Ahlwardt, Verzeichniss der arabischen Handschriften der Königlichen Bibliothek zu Berlin I, Nr. 369. Die Verweise auf Abbildungen mit den Zahlenangaben beziehen sich auf die von der Staatsbibliothek angefertigten scans (1-8). Abbildungen der gesamten Rolle sind aufrufbar unter http://orient-digital .staatsbibliothek-berlin.de/receive/SBBMSBook_islamhs_ oooo4031 (Stand 28. September 2016).

Die Rolle wird in einem Lederköfferchen aufbewahrt; darin Zettel mit folgenden Angaben: „Auszüge aus dem Koran: Papierrolle in verschiedenen Richtungen sehr klein beschrieben und reich verziert. Abschrift vom Jahr 1373." Dazu Lederköfferchen vom Anfang des 19. Jh. mit Widmung „Dem Könige der Preußen.“ Es folgt Text desselben Inhalts auf Französisch; danach Eintrag: „Bibliothèque d'Etat / Marburg sur Lahn“. Auf der Rückseite des Zettels: Emblem (Adler der Bundesrepublik Deutschland) „Avec les compliments de l'Ambassade de la République Fédérale d'Allemagne / Rabat."

2 Der Kolophon wurde in Anm. 74 erfasst. Zur Tätigkeit eines bayțār siehe Kazimirski, Dictionnaire, s.v.: „médecin des animaux, artiste vétérinaire“; Lane, Lexicon, s. v., „A farrier; one who practices the veterinary art; one who treats beasts, or horses and the like, medically, or curatively.“

3 Vgl. Abb. 8 der Rolle; zweitletzte Zeile; siehe auch Abschrift des Kolophons in Anm. 74.

4 Bei der hatma handelt es sich um die Rezitation des gesamte Korantexts (als frommer Akt oder für einen Verstorbenen). Die Praxis war verbreitet, aber umstritten. Siehe Kazimirski, Dictionnaire, s. v.; Buhl, Khatma, Khitma, in $E I^{2}$; Denny, Tadjwīd, in $E I^{2}$; Melchert und Afsaruddin, Reciters of the Qur’ān (Abschnitt: „Devotional recitation“), in $E Q$.

5 Diese Gliederung in 8 Abschnitte (numeriert mit den römischen Ziffern I-VIII) stimmt nicht mit dem Inhalt der 8 Abbildungen (1-8) der Rolle in der in Anm. 1 genannten Internetquelle überein. 
kommt auf dem Dokument insgesamt sieben Mal vor. Am Ende von Abschnitt viI wechselt das Schriftband in einem Bogen einfach auf die gegenüberliegende Seite und läuft zum Anfang des Dokuments zurück. Beim Übergang zu Abschnitt viII fehlt ein weiteres Medaillon. Abschnitt VIII ist einfacher gestaltet als der Rest der Rolle; hier fehlen die seitlichen Schriftbänder. Dieser letzte Abschnitt (VIII) wird nur von einem einfachen Zierband eingefasst. ${ }^{6}$

Die Abschnitte I-VII davor hingegen werden vom bereits erwähnten fünfteiligen Schriftband umrahmt. Es weist eine Breite von insgesamt ca. $2.8 \mathrm{~cm}$ auf.

Das Mittelband ist am breitesten. Es wird innen und aussen von einem goldenen, von je zwei haarfeinen schwarzen Linien eingefassten Streifen umrahmt. Die Breite dieser goldenen Streifen beträgt ca. $1 \mathrm{~mm}$. Die Pigmente der goldenen Farbe sind oft verloren gegangen. Die Breite des Mittelbands (inkl. der beiden goldenen Streifen) beträgt ca. $9 \mathrm{~mm}$. Dieses Mittelband enthält Text in goldener Schrift (Nash), deren Höhe etwa $7 \mathrm{~mm}$ beträgt und somit gut lesbar ist. Sämtliche Buchstaben werden von haarfeinen schwarzen Linien eingefasst. Der Text ist punktiert und häufig vokalisiert.

Das breite Mittelband wird seinerseits innen und aussen durch zwei schmale Textbänder eingerahmt. Auch sie werden innen und aussen von einem goldenen, von je zwei haarfeinen schwarzen Linien eingefassten Streifen umrahmt. ${ }^{7}$ Die Breite dieser beiden schmalen Textbänder (inkl. den beiden goldenen Streifen) beträgt je ca. $2.5 \mathrm{~mm}$; die Breite des Schriftbands selbst beträgt etwa die Hälfte davon, also knapp mehr als $1 \mathrm{~mm}$. Der Kopist notierte den Text in diesen beiden Bändern mit schwarzer Tinte in $\dot{G} u b \bar{a} r$ (Höhe knapp 1 mm). Die Buchstaben sind oft unpunktiert; Vokalisationszeichen fehlen weitgehend.

6 Siehe die Beschreibung dazu unten nach Anm. 73 .

7 Dieser innere Streifen ist zugleich der äussere Streifen des breiten Mittelbands.
Das breite Mittelband und die beiden schmalen Seitenbänder werden ihrerseits innen und aussen von je einem Band mit Text in roter Schrift eingerahmt. Auch sie werden von einem schmalen goldenen Streifen eingefasst. Die Breite dieser beiden roten Textbänder misst ca. $6 \mathrm{~mm}$ (inkl. den beiden goldenen Streifen). Das Textband selbst erreicht eine Breite von etwa $4 \mathrm{~mm}$. Der Text wurde in rotem Nash kopiert und lässt sich gut lesen. Er ist zumeist punktiert und häufig vokalisiert.

Schriftbänder (Inhalt; ABB. 10): Die weiteren Ausführungen weisen auf den Inhalt der fünfteiligen Schriftbänder hin, die nahezu das gesamte Dokument einfassen (ohne Abschnitt viII). Sie äussern sich zuerst zum rechten Schriftband mit vorwärtslaufendem Text ganz am Anfang: ${ }^{8}$

Im breiten goldenen Band (in der Mitte) lässt sich Q 6:129 erkennen. ${ }^{9}$ Ebenso aus Q 6 stammt die Stelle im äusseren roten Schriftband (Q 6:12). ${ }^{10}$ Im innern roten Schriftband steht sodann $Q$ 5:32. ${ }^{11} \mathrm{Im}$ äusseren schwarzen Schriftband steht in mikroskopischer Schrift ( $\dot{G} u b \bar{a} r)$ Q 2:196. ${ }^{12}$

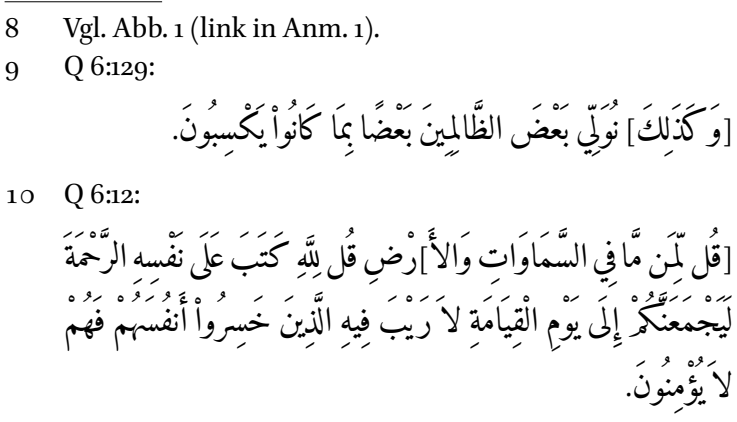

Q 5:32 (mit goldenem Verstrenner an falscher Stelle [·]):

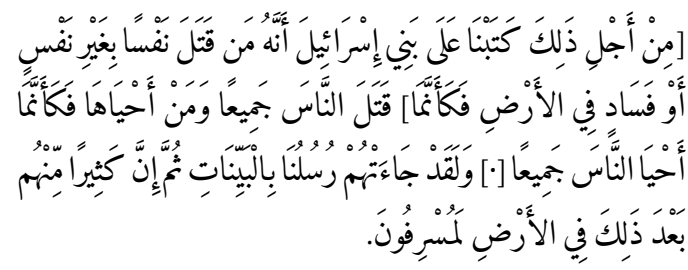

Q 2:196 (häufig stark verderbt, man beachte den Verstrenner beim Übergang des Bands ins Rechteck darunter, wo Q 2:197 beginnt):

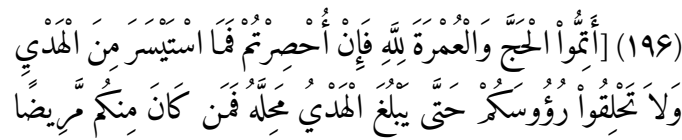


Auf dem innern schwarzen Schriftband steht Q 3:161. ${ }^{13}$

Die Stellen im linken, rückwärtslaufenden Schriftband auf der gegenüberliegenden Seite lassen sich wie folgt identifizieren: Auf dem breiten Band mit goldenem Text in der Mitte steht der Anfang von Q 7:31. ${ }^{14}$ Auf dem äusseren roten Schriftband steht Q 6:114. ${ }^{15}$ Auf dem innern roten Schriftband steht nach dem goldenen Verstrenner der Anfang von Q 5:114. ${ }^{16}$ Auf dem äussern schwarzen Schriftband steht der Übergang Q 3:117-118.17

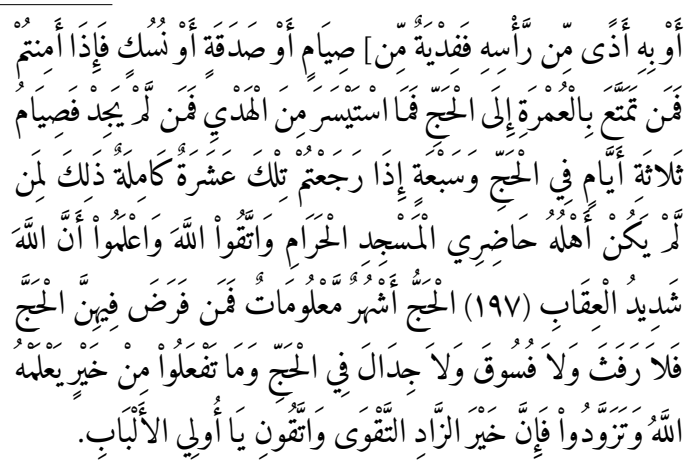

13 Q 3:161:

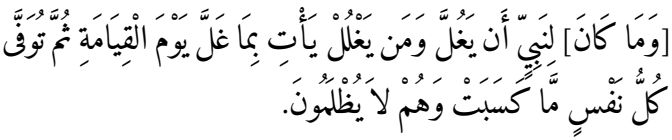

14 Davor der Schluss von Q 7:30:

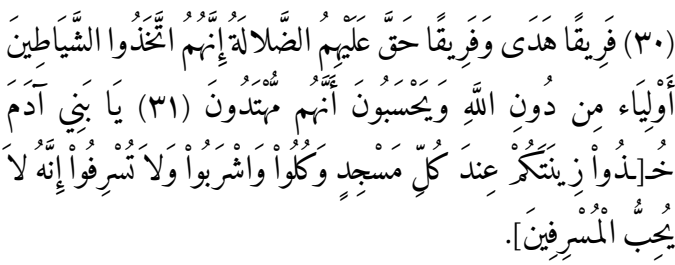

15 Die Stelle ist verderbt und weist Textverlust auf; Q 6:114:
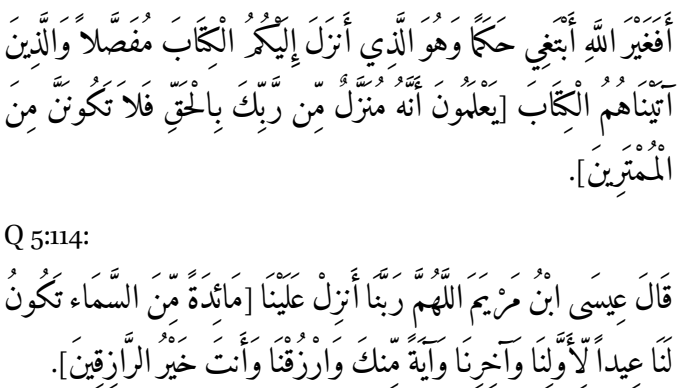

17 Q 3:117 lautet (der Beginn von Q 3:118 ist stark verderbt, mit Textverlust):

Auf dem innern schwarzen Schriftband endet in Gubār Q 4:176 (Schlussvers). ${ }^{18}$ Der Übergang zwischen Q 3 (Vers 200) und Q 4:1 befindet sich am Ende des vierten Rechtecks; es handelt sich um jenes mit dem mandelförmigen Muster, wo sich auf der linken Seite im vorwärtslaufenden Schriftband in roter Schrift der Titel Sūrat an-Nisā’ (Q 4) erkennen lässt. ${ }^{19}$

Aus dieser Zusammenstellung geht hervor, dass am Anfang Q 1 ganz und Q 2 teilweise (Verse 1195) fehlen. Ausserdem fehlt am Anfang u.a. die Stelle zwischen Q 7:31 ${ }^{20}$ und Q 8:2021. Beide Stellen nehmen in der Druckausgabe etwa 34 Seiten ein. Ausserdem fehlt der Abschnitt zwischen Q 3:117 und 3:161; diese Stelle umfasst gedruckt ca. 8 Seiten. Auch diese Beobachtungen zeigen auf, dass am Anfang der Rolle ein bedeutender Teil verloren ging. Aufbau und Gestaltung des Beginns dieses Belegstücks lassen sich nicht mit Sicherheit rekonstruieren. Es lässt sich aber vermuten, dass das Dokument ursprünglich über $10 \mathrm{~m}$ gemessen hat.

Das vorwärts- und das rückwärtslaufende Schriftband sind am Ende von Abschnitt vi durch einen Bogen miteinander verbunden. ${ }^{22}$ Hier im Rolleninnern blieb der Text besser erhalten als am Anfang. Es lassen sich folgende Textstellen erken-

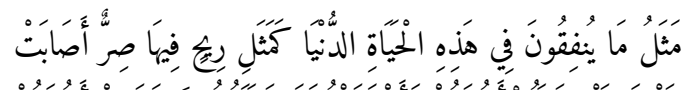

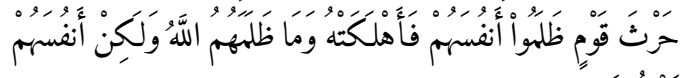

$$
\begin{aligned}
& \text { يَظِْمونَ. }
\end{aligned}
$$

18 Q 4:176 lautet (es fehlen die beiden Schlusswörter):

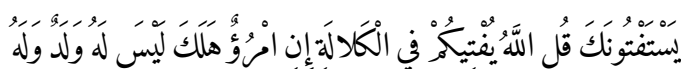

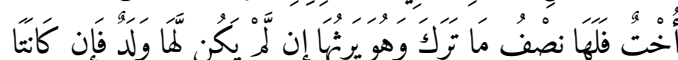

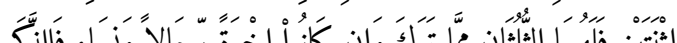

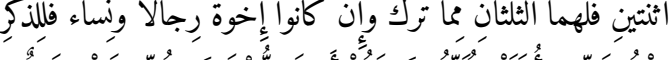

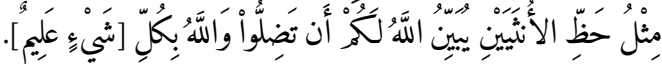

Abb. Nr. 3 .

Vgl. oben bei Anm. 14 .

Q 8:20 steht im Innern des ersten Medaillons auf einer horizontalen Zeile in schwarzem $\dot{G} u b a \bar{r}$.

Vgl. Abb. 8 (link in Anm. 1). 
nen: Im breiten Textband mit goldener Schrift steht Q 6:156 (АВ В 16). ${ }^{23}$ Auf dem äussern roten Band: Übergang Q 5:71-72. ${ }^{24}$ Auf dem innern roten Band: Q 6:68. ${ }^{25} \mathrm{Im}$ äusseren schwarzen Band in Gubār: Q 4:73-74. ${ }^{26}$ Im innern schwarzen Band steht sodann Q 2:282. ${ }^{27}$ Der Kopist setzte die Abschrift von Q 2 danach fort bis zum Schlussvers (Vers 286). Der Titel von Q 3 (Sūrat Āl Imrān) wurde in roter Tinte notiert. ${ }^{28}$

23 Q 6:156 lautet:

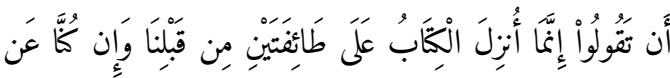

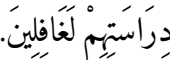

24 Q 5:71-72 lautet:

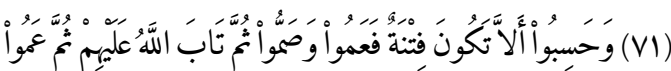

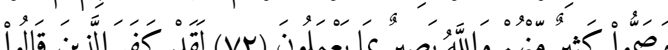

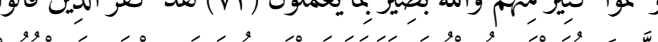

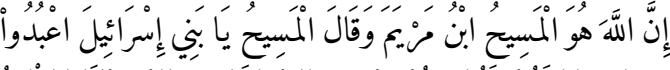

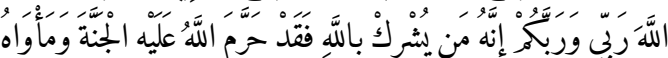

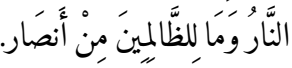

25 Q 6:68 lautet:

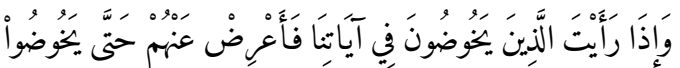

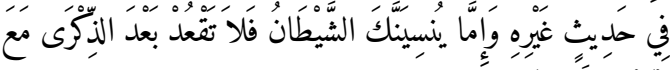
القّوْْم الظَّالمِين.

Q 4:73-74 lautet (der Übergang zwischen den beiden Versen wird durch einen goldenen Punkt markiert):

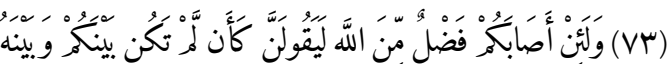

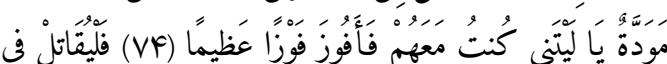

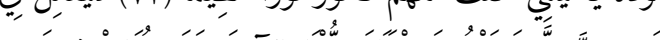

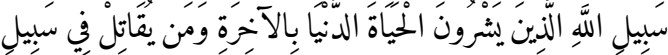

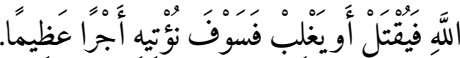

Q 2:282 (Auszug):

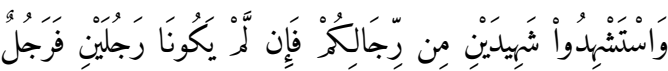

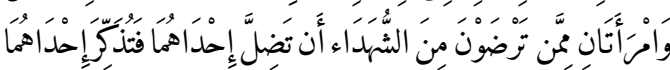
الأُخْرى

28 Rückwärtslaufendes Schriftband, inneres Band in $\dot{G} u b \bar{r} r$-Schrift, Titel rot, dann Basmala; vgl. Abb. 7 (link in Anm. 1).
Die weiteren Beschreibungen gehen auf die Gestaltung des Mittelstreifens ein, der sich in 8 Abschnitte einteilen lässt. Am Anfang jedes Abschnitts befindet sich ein zumeist rundes Element, das als Knoten interpretiert werden kann. ${ }^{29}$ Am Anfang von Abschnitt IV handelt es sich um eine mandelförmige Figur, auf die ein oben und unten abgerundetes Rechteck folgt.

Abschnitt I (AB B. 11): ${ }^{30}$ Masse ca. $10.5 \times 63 \mathrm{~cm}$. Dieser Abschnitt beginnt mit einem kreisförmigen Medaillon, das die gesamte Rollenbreite ausfüllt (Durchmesser ca. 10.5 cm). ${ }^{31}$ Danach schliesst sich ein Rechteck an, das oben und unten abgerundet ist (Länge ca. $53 \mathrm{~cm}$ ).

Der Innendurchmesser des Medaillons beträgt ca. $5 \cdot 3 \mathrm{~cm}$. Der Kopist hat hier auf 21 Zeilen Text in schwarzem $\dot{G} u b \bar{a} r$ kopiert. Zuoberst im Medaillon: der Schluss von Q 8:20; deutlich erkennbar sind danach Q 8:21 ff. Der Text ist zumeist punktiert und oft auch vokalisiert. Die einzelnen Verse werden durch gelb-braune (goldene) Verstrenner voneinander getrennt. Ganz zuunterst im Medaillon steht der Beginn von Q 8:33 (wa-mā kāna Allāh). Der Kopist springt darauf in den Mittelstreifen im Rechteck darunter und setzt dort Q 8:33 fort (schwarzes $\dot{G} u b \bar{a} r$ ).

Der Mittelstreifen in diesem Rechteck ist komplex gestaltet. Auf den ersten Blick fällt seine farbliche Gestaltung auf: Während der Text in der mittleren Textspalte in schwarzem $\dot{G} u b \overline{a r}$ kopiert wurde, ist er in den beiden Spalten zur Linken und Rechten in roter Tinte notiert worden. In diesem Mittelstreifen wiederholt sich ein komplexes Zierelement insgesamt zehn Mal. Es wird durch goldene (bzw. gelb-braune), schwarz eingefasste Linien gebildet, die teils gerade, teils geschwungen sind. Sie sind derart kombiniert, dass je nach Blickwinkel unterschiedliche Figuren entstehen (unvollständig eingefasste Kreise; Sterne bzw. Drei-

29 Zu einer Interpretation dieser Knoten vgl. Kapitel 3.4, vor Anm. 5 oo.

30 Vgl. Abb. 1 (link in Anm. 1).

31 Dieses Medaillon ist ganz am Anfang und auf der linken Seite verderbt (verbunden mit Textverlust). 
ecke; Sechsecke mit nach innen geschwungenen Seitenlinien; auch Fünfecke; in der Mitte der Kreise kreuzen sich diagonale Linien, die ihrerseits unterbrochen sind). Am linken und rechten Rand lassen sich auf einem schmalen Streifen Zierelemente (goldene Blätter) auf blauem Hintergrund erkennen. Hier auch weitere Textelemente.

In dieses Muster ist Text verteilt worden. In der Mittelspalte (schwarz) hat der Kopist den Rest von Q 8 (8:20-75) notiert. Jedenfalls lässt sich vor dem zweitletzten Kreiselement in roter Schrift der Titel von Q 9 (Sürat Barāaa) und davor der Schlussvers von Q 8 erkennen. ${ }^{32}$ Der Schlussvers von Q 9 (9:129) steht in diesem Rechteck ganz zuunterst links in roter Tinte (wa-huwa rabb al'arš al-'azìm). Daran schliesst sich in schwarzer Tinte die Überschrift von Q 10 (Sūrat Yūnus) an. Zuoberst im Medaillon des nächsten Abschnitts (II.) steht Q 10:38. Diese Beobachtung legt nahe, dass Q 9 (ganz) und Q 10:1-37 im ersten Rechteck verteilt sind. In der Mittelspalte des Mittelstreifens lässt sich zuunterst (schwarzes $\dot{G} u b \bar{a} r$ ) in der Tat der Schluss von Q 9:11 erkennen. ${ }^{33}$ Der Kopist steigt danach in den im schmalen Zierband mit den goldenen Verzierungen auf blauem Hintergrund eingestreuten Textfeldern wieder nach oben (also in Richtung Rollenanfang; Text in schwarzem $\dot{G} u b \bar{a} r$, rechte Seite der Rolle). ${ }^{34}$ Zuoberst im Rechteck angekommen wechselt der Schreiber in den Streifen mit rotem $\dot{G} u b \overline{a r}$ (rechts) und setzt die Abschrift fort, indem er in dieser Spalte wieder nach unten steigt. Der Text ist häufig diagonal (von rechts oben nach links unten) angeordnet. Im untersten Feld lässt sich in diesem Streifen Q 9:128 (Schluss) und Q 9:129 (Anfang) erkennen. Der Schluss von Q 9 (Vers 129) und der Titel von Q 10 folgen danach - wie bereits erwähnt - auf der gegenüberliegenden Seite (links). Hier setzt der

32 Vgl. Abb. 1 (scan) der Rolle.

33 Q 9:11 (Schluss):

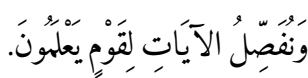

34 Im drittobersten Feld in diesem schmalen Zierband lässt sich Q 9:17-18 erkennen.
Kopist die Abschrift des Korans fort, indem er in der roten Aussenspalte (links) Feld um Feld nach oben steigt. Der Text steht auf dem Kopf und verläuft von rechts unten nach links oben. In dieser Spalte (links) steht zuoberst Q 10:29. ${ }^{35}$ Der Schreiber setzt den Text nun fort, indem er in den Textfeldern auf dem schmalen Band mit blauem Hintergrund wieder nach unten steigt, dem Rollenende entgegen (links). Wie ersichtlich hat auf diesem Dokument alles seine Logik: Auf dem schmalen Band mit den Zierelementen zuunterst angekommen springt der Schreiber einfach ins anschliessende Medaillon, das am Anfang von Abschnitt II steht.

Abschnitt II: ${ }^{36}$ Der zweite Abschnitt ist wesentlich einfacher gestaltet. Seine Länge misst etwa $59.5 \mathrm{~cm}$. Am Anfang befindet sich ein Medaillon (bzw. ein Knoten). Danach folgt ein Rechteck, das oben und unten durch das Schriftband abgerundet wird. Auf der Höhe des Medaillons lassen sich auf der rechten Seite goldene Verzierungen (Pflanzen, Blüten) mit blauen Einsprengseln erkennen. ${ }^{37}$ Der Text im Mittelstreifen ist in $\dot{G} u b \bar{a} r$ auf horizontalen Linien kopiert worden und mit goldenen (bzw. gelb-braunen) Verstrennern versehen.

Im Medaillon steht zuoberst Q 10:38 als direkte Fortsetzung des Abschlusses von Abschnitt I. ${ }^{38}$ Im Rechteck darunter lässt sich der Titel von Q 11 (Sūrat Hūd) identifizieren. Er wurde golden

Dieses oberste Feld beginnt mit Q 10:29:

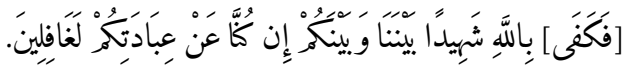

Kafā im vorangehenden Feld unmittelbar darüber.

Vgl. Abb. 1 der Rolle (link in Anm. 1).

37 Man beachte auf der linken Seite ein Fragment aus dem Schriftband, das bei einer Restaurierung fälschlicherweise hier aufgeklebt wurde (Länge ca. $2 \mathrm{~cm}$ ). Dieses Fragment befindet sich direkt unterhalb des Medaillons am Anfang von Abschnitt II (vgl. Abb. 1; link in Anm. 1).

38 Q 10:38 lautet:

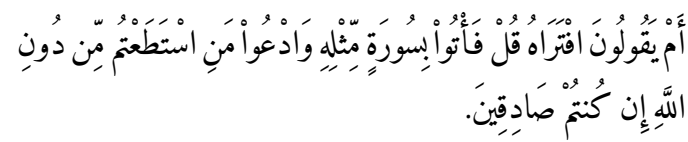


notiert. ${ }^{39}$ Kurz vor dem Ende des Rechtecks steht derTitel zu Q 12 (Sūrat Yūsuf, in goldener bzw. gelbbrauner Schrift). ${ }^{40} \mathrm{Q} 12$ folgt im wesentlichen in Abschnitt III.

Abschnitt III (ABB. 12-13): ${ }^{41}$ Länge ca. $51 \mathrm{~cm}$. Am Anfang erneut ein rundes Medaillon mit Text in schwarzem $\dot{G} u b \bar{a} r$. Es füllt die gesamte Breite des Dokuments aus. Zwischen Medaillon und Rollenrand Verzierungen, wie sie unter Abschnitt II beschrieben wurden..$^{42}$ Das Rechteck darunter enthält 8 Kreise; der unterste Kreis ist etwas kleiner als die sieben andern. Der Hintergrund dieses Rechtecks ist blau; er ist mit einem Muster mit Blüten und Ranken verziert. ${ }^{43}$ Die sieben grossen Kreise haben einen Durchmesser von ca. $5 \mathrm{~cm}$ (aussen) bzw. $3.8 \mathrm{~cm}$ (innen). Ein dreiteiliger Ring fasst jeden Kreis ein. Zuäusserst lässt sich ein schmaler goldener Ring erkennen, innen befindet sich ein breiter goldener Ring. ${ }^{44}$ Diese beiden Ringe rahmen ein Schriftband von knapp $5 \mathrm{~mm}$ Breite ein. Der Text im Schriftband wurde in flüssigem Nash notiert. Im obersten Kreis verläuft der Text einerseits nach links. Anderseits lässt sich Text erkennen, der auf dem Kopf steht und nach rechts verläuft.

Inhaltlich ist in diesem Abschnitt eine Abschrift von Q $12 \mathrm{zu}$ erwarten, deren Titel bereits am Schluss von Teil II erwähnt worden war. Im Medaillon steht zuunterst in der Tat Q 12:20. Auch in den Zeilen davor wurde Text aus Q 12 kopiert. Zuunterst im Medaillon angekommen springt der Kopist in den Aussenring des ersten Kreises. Er setzt die Abschrift von Q 12:20-21 hier nach links absteigend fort. Zuunterst im Ring angekommen springt er wieder nach oben. Er setzt dort die Abschrift von Q 12:21 im Aussenband fort; die

39 Mit Hinweis auf die Verszahl dieser Sure.

40 Vgl. Abb. 2 (link in Anm. 1).

41 Vgl. Abb. 2 (link in Anm. 1).

42 Vgl. bei Anm. 36.

43 V.a. oben, am Anfang des Rechtecks; aber auch in den Zwischenräumen zwischen den Kreisen und dem Rechteck.

44 Beide Ringe werden durch haarfeine schwarze Linien eingefasst.
Schrift steht anfänglich auf dem Kopf. Der Schreiber umfährt dann den ersten Kreis im Uhrzeigersinn und wechselt mit dem Schriftband am Anfang des zweiten Kreises auf die linke Seite und umfährt auch ihn, bis er zuunterst ankommt (jetzt im Gegenuhrzeigersinn). Der Kopist springt dort erneut an den Anfang des zweiten Kreises und umfährt auch ihn zuerst rechts; er wechselt dann mit dem Schriftband beim Übergang zum dritten Kreis auf die linke Seite. Und zuunterst im dritten Kreis springt er erneut nach oben. Im untersten Kreis umfährt das Schriftband den Kreis ganz. Im Aussenband des untersten Kreises lässt sich oben der Übergang Q 12:31-32 erkennen. ${ }^{45}$ Nachdem der Schreiber den untersten Kreis im Aussenband vollständig umfahren hat, springt er nach innen und setzt die Abschrift in roter Tinte fort, indem er den Kreis innen umfährt. ${ }^{46}$ Das Textband in roter Tinte ( $\dot{G} u b \bar{a} r)$ umfährt jetzt jeden dieser Kreise im Gegenuhrzeigersinn. Nachdem der Kopist den untersten Kreis derart umfahren hat und wieder an dessen oberen Ende angekommen ist, springt er in den zweituntersten Kreis. Er umfährt dann auch diesen Kreis im roten Schriftband. Der Schreiber setzt die Abschrift fort, indem er in diesem roten Text Kreis um Kreis wieder nach oben steigt. Im obersten Kreis lässt sich zuunterst im roten Schriftband eine Stelle aus Q 12:50 erkennen. Danach springt der Schreiber zuoberst ins Innere des Kreises und setzt dort die Abschrift von Q 12:50 auf den horizontalen Zeilen in schwarzem $\dot{G} u b \overline{a r}$ fort, indem er Kreis um Kreis nach unten steigt. ${ }^{47}$ Die Abschrift von Q 12 endet im

45 Der Beginn von Q 12:32 lautet:

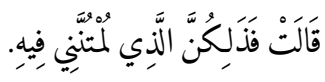

46 Beim Übergang des Textes vom Aussenring ins innere rote Schriftband lässt sich deutlich Josephs Aussage erkennen (Q 12:33):

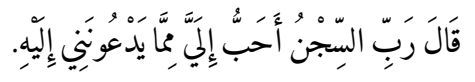

47

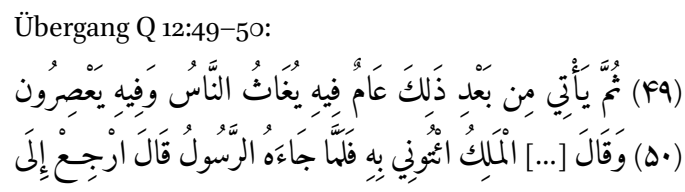


zweituntersten Kreis (Vers 111), wo sich die Überschrift zu Q 13 (Sürat $a r-R a^{\prime} d$ ) deutlich erkennen lässt. ${ }^{48}$

Abschnitt IV (AB B. 14): ${ }^{49}$ Länge ca. $53 \mathrm{~cm}$. Fortsetzung der Abschrift von Q 13; im Mittelstreifen lässt sich in schwarzem $\dot{G} u b \bar{a} r$ die Fortsetzung von Vers 7 und 8 erkennen. ${ }^{50}$

Die Gestaltung von Abschnitt IV ist besonders komplex ausgefallen. Im Gegensatz zu den andern Abschnitten befindet sich am Anfang dieses Teils kein Medaillon. Das fünfteilige Schriftband umfährt hier vielmehr eine mandelförmige Figur. ${ }^{51}$ Darunter folgt ein Rechteck, das am unteren Ende durch einen Bogen abgeschlossen wird. In diesem Rechteck lassen sich in der Vertikalen (Rollenrichtung) sieben sich überschneidende mandelförmige Figuren erkennen. Im Zentrum dieser mandelförmigen Figuren befindet sich ein Zierfeld, das von Kreissegmenten gebildet wird Die sieben Zierfelder sind golden ausgefüllt und waren mit einer blauen Verzierung versehen (jetzt stark verblasst). Der Abschnitt lässt sich auch aus einem andern Blickwinkel betrachten. Gemäss dieser zweiten Betrachtungsweise bilden sieben Halbkreise ${ }^{52}$ und ein zusätzlicher Viertelkreis am Anfang und am Schluss mandelförmige Figuren.

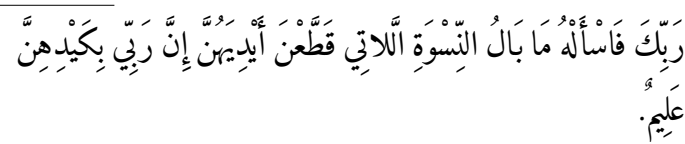

Der Text springt nach qāla zuunterst im obersten Kreis (rot) in die horizontalen Zeilen in schwarzem $\dot{G} u b \bar{a} r$ im Kreisinnern. Im obersten Kreis (Durchmesser innen ca. $3.6 \mathrm{~cm}$ ): 21 Zeilen, Text in schwarzem $\dot{G} u b \bar{a} r$, goldene Verstrennner, Schrifthöhe also etwa $1.7 \mathrm{~mm}$. Text oft punktiert, aber nicht vokalisiert.

48 Im untersten, kleineren Kreis am Schluss Q 13:7.

49 Vgl. Abb. 2-3 der Rolle (link in Anm. 1).

503 . Zeile in der mandelförmigen Figur, Beginn von Q 13:8:

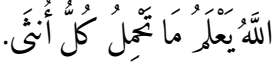

51 Höhe der mandelförmigen Figur ca. $14.3 \mathrm{~cm}$ (gemessen zwischen rotem Aussenband oben bzw. unten).

52 Es handelt sich nur annähernd um Halbkreise. Die imaginäre Grundlinie der Halbkreise läge im seitlichen Schriftband.
Diese Halbkreise sind entlang den beiden vertikalen Seitenlinien des Rechtecks angeordnet. Sie erreichen jeweils auf der Höhe der golden ausgefüllten Zierfelder die gegenüberliegende Seite des Rechtecks und steigen danach wieder ab. Vis-àvis des Kulminationspunkts des ersten Halbkreises beginnt in gleicher Weise der zweite Halbkreis etc. Die sich überschneidenden Halbkreise lassen ein komplexes Muster entstehen, das von mandelförmigen Figuren dominiert wird. Die soeben beschriebene Figur lässt sich auch als komplexe Anordnung ineinander verknoteter Stricke verstehen. Entlang den Figuren selbst, aber auch in ihren Zwischenräumen, ist Text in $\dot{G} u b \bar{a} r$ kopiert worden. In den Linien der Figuren ist der Text rot; in den Zwischenräumen ist er schwarz. Abgesehen von den sieben goldenen Zierfeldern ist das ganze Rechteck mit Text ausgefüllt. ${ }^{53}$

Die bisherigen Beobachtungen lassen vermuten, dass der Schreiber im Mittelstreifen dieses Abschnitts mit der Abschrift des Korans fortfuhr. In der grossen mandelförmigen Figur vor dem Rechteck lässt sich zuunterst Q 13:25 (Schluss) erkennen. ${ }^{54}$ Die nächste Stelle aus Q 13 befindet sich im anschliessenden Rechteck am rechten Rand. Hier entstehen zwischen dem fünfgliedrigen Schriftband und den geschwungenen Linien der mandelförmigen Figur kleine Freiräume. Darin steht der Beginn von Q 13:37. ${ }^{55}$ Gerade davor steht

53 Der Vollständigkeit halber sei hier auf eine Unregelmässigkeit hingewiesen: Im Rahmen des Rechtecks, der vom fünfteiligen Schriftband gebildet wird, findet sich oben rechts eine Abweichung vom üblichen Vorgehen. Im oberen rechten Winkel des Rechtecks wurde der Text im mittleren Teil des Schriftbands nicht in grosser goldener Schrift kopiert. Hier steht Text in kleiner roter Schrift (Q 7:22, Schluss).

54 Q 13:25 (Schluss):

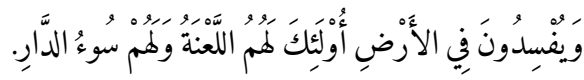

Q 13:37 lautet:

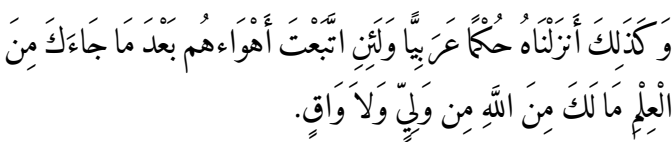


das Ende von Q 13:30.56 Die fehlenden Verse liessen sich nicht lokalisieren. Der Kopist setzt die Abschrift von Q 13 danach in diesem Aussenstreifen fort. Q 13 endet auf der Höhe des fünften goldenen Zierfelds. Zwischen dem 5. und 6. goldenen Zierfeld schliesst sich in rotem $\dot{G} u b \bar{a} r$ der Titel von Q 14 (Sürat Ibrāhìm) an, danach folgt der Text von Q 14. Im letzten Aussenfeld steht der Beginn von Q 14:2; die Fortsetzung des Verses 2 und die Verse 14:3-6 (und Anfang Vers 7) stehen in der Mitte über dem Bogen, der das Rechteck unten abschliesst. In der Fortsetzung der Abschrift steigt der Kopist nun in den Zwischenräumen auf der Gegenseite (links) wieder nach oben. Auf der Höhe des untersten goldenen Zierfelds steht $\mathrm{Wa}$ $q \bar{a} l a$ Mūsa (Anfang von Q 14:8). Zuoberst in diesem Rechteck steht dann in diesem Aussenfeld der Übergang Q 14:12-13.

Jetzt kommt es zum entscheidenden Übergang. ${ }^{57}$ Nachdem er das oberste Aussenfeld ausgefüllt hat (Text in schwarzem $\dot{G} u b \bar{a} r$ ), springt der Kopist in den Bogen der obersten mandelförmigen Figur, die hier auf der linken Seite beginnt, und setzt die Abschrift von Q 14.13 in rotem $\dot{G} u b a \bar{r} r$ fort; der Text steht vorerst auf dem Kopf. Die Fortsetzung der Abschrift folgt danach einfach den vorgegebenen geschwungenen Bögen, sodass sporadische Überprüfungen des Textverlaufs ausreichen. Zuunterst im Rechteck ist im letzten Bogen, der auf der Höhe des letzten goldenen Zierfelds auf der rechten Seite beginnt und dann auf der linken Seite der Rolle endet, eine weitere Stelle aus Q 14 zu erwarten. Hier steht dann in der Tat auch Q 14:22. Im letzten Bogen zuunterst links angekommen, setzt der Schreiber die Abschrift nach einer

56 Der Schluss von Q 13:30 lautet (nicht alles klar erkenntlich):

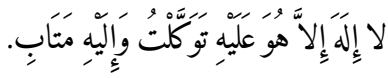

Die Übergangsstelle Q 14:13-14 lautet:

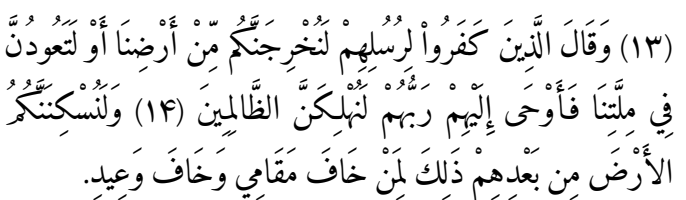

Spitzkehre in jenem Bogen fort, der nach oben aufsteigt. ${ }^{58}$ Der Kopist folgt beim Aufsteigen erneut dem vorgegebenen Muster und setzt die Abschrift nach oben Bogen um Bogen fort, wobei er zwischen linker und rechter Seite hin- und herpendelt. Am oberen Ende des Rechtecks befindet sich im Bogen auf der linken Seite Q 14:31. Der Schreiber springt jetzt auf die rechte Seite und setzt die Abschrift von Q 14:31 auf dem Kopf im Bogenabschnitt fort, der nach wenigen Wörtern den rechten Rand des Rechtecks erreicht. Dort macht der Schreiber eine Spitzkehre und setzt die Abschrift im hier beginnenden absteigenden Bogen fort. ${ }^{59}$ Danach folgt der Text erneut der durch die mandelförmigen Figuren vorgegebenen Logik und steigt in den geschwungenen Bögen nach unten. Zuletzt befindet er sich rechts unten und macht eine Spitzkehre, um erneut nach oben aufzusteigen. An dieser Übergangsstelle steht Q 14:39-40. ${ }^{60}$ Zuoberst im Rechteck lässt sich im letzten Bogen, der von der linken Rollenseite auf die rechte Seite wechselt, vor der senkrechten Mittellinie im Rechteck in der Tat Q 14.49-50 erkennen. ${ }^{11}$ Der Abschluss von Q 14 (Verse 51-52) steht sodann oben auf horizon-

58 Der Beginn von Q 14:22 (die Wendestelle) lautet:

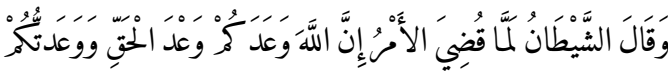

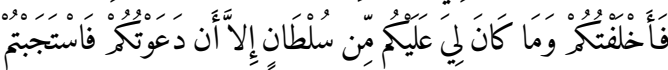

59

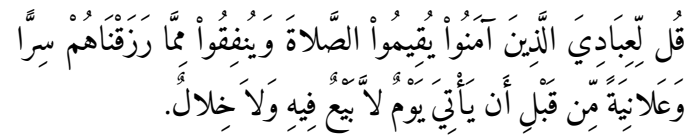

6o Q 14:39-40 lautet:

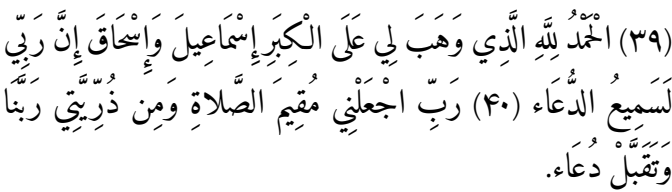

61 Q 14:49-50 lautet (von Vers 50 nur noch das erste Wort im Bogen):

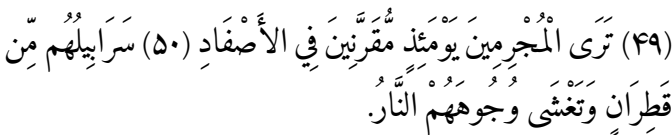


talen Zeilen in schwarzem $\dot{G} u b \bar{a} r$. Danach schliesst sich in roter Tinte der Titel von Q 15 (Sürat al-Hiğr) an.

Diese Überschrift lässt vermuten, dass im letztlich dreispaltigen Mittelstreifen zuerst Q 15 kopiert worden ist. Diese Vermutung findet darin ihre Bestätigung, dass unmittelbar oberhalb des fünften goldenen Zierfelds in diesem Abschnitt (links) der Titel von Q 16 (Sürat an-Nahl) in roter Tinte (Gubār) festgehalten wurde. Q 15 beginnt am Anfang dieses Abschnitts mit mandelförmigen Figuren direkt nach dem Titel. ${ }^{62}$ Vers 1 (Ende: mubin) und Vers 2 stehen im Zipfel zur Rechten. Der Kopist setzt die Abschrift darauf im Zipfel zur Linken fort (Verse 3-4). In der Spitze der vertikal ausgerichteten Mandel im Mittelstreifen ist deutlich Q 15:5 erkennbar. ${ }^{63}$ Die Schrift ist im Mittelteil der Figuren zuerst horizontal ausgerichtet; nach dem vierten goldenen Zierfeld verläuft die Schrift aber von rechts oben nach links unten. In den Feldern links und rechts davon ist der Text unterschiedlich angeordnet worden (teils horizontal, teils den Kreislinien entlang, teils senkrecht). Q 16 ordnet sich in gleicher Weise in die mandelförmigen Figuren ein. Zuunterst im Teil mit diesen Figuren angekommen springt der Kopist ins nächste Medaillon. ${ }^{64}$ Im untersten Flügel der mandelförmigen Figur zur Linken lässt sich die Abschrift von Q 16:43-44a erkenne. Q 16:44b folgt auf der obers-

62 Die Stelle ist verderbt und schlecht lesbar.

63 Q 15:5 lautet:

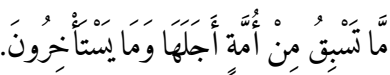

64 Es versteht sich von selbst, dass die Abschrift des Korantexts auf dieser Rolle nicht Wort für Wort überprüft wurde. Es sei aber festgehalten, dass die in Q $13 \mathrm{zwi}$ schen den Versen 25 und 37 festgestellte Fehlstelle auf diesem Rollenabschnitt an keiner andern Stelle nachgewiesen werden konnte. Kopistenfehler lassen sich auf diesen Dokumenten immer wieder feststellen.

Die Unstimmigkeiten lassen sich am oberen Ende des Rechtecks (rechts) gut erkennen. Hier wurde - gänzlich entgegen den Regeln - in rotem Ǵubār ein Teil von Q 13:25 eingefügt. Q 13:37 dann in den Randstellen auf der rechten Seite des Rechtecks. ten Zeile des Medaillons am Anfang des nächsten Abschnitts. ${ }^{65}$

Abschnitt v: ${ }^{66}$ Länge ca. $57 \mathrm{~cm}$. Der Abschnitt ist deutlich einfacher gestaltet als die vier vorangehenden Teile. Der Kopist setzt die Abschrift von Q 16 im Mittelstreifen in schwarzem $\dot{G} u b \overline{a r}$ fort. Die Verse werden durch goldene (bzw. gelbbraune) Trennzeichen voneinander getrennt. Nach dem kreisrunden Medaillon folgt auch in diesem Abschnitt ein Rechteck, das am oberen und unteren Ende abgerundet ist. Dieses Rechteck weist im Gegensatz zu den vorangehenden Abschnitten kein besonderes Muster auf. Der Surentext wurde in $\dot{G} u b \bar{a} r$-Schrift auf horizontalen Zeilen notiert. Das $k \bar{a} f$ ist hier oft stark gedehnt. In diesem Abschnitt stehen auch die Überschriften zu Q 17 (Sürat al-Isrā’) und Q 18 (Sūrat al-Kahf). Beide Stellen enthalten Angaben zur Verszahl in der jeweiligen Sure. Diese Titel in grossem Nash in goldener Schrift.

Die beiden nächsten Abschnitte der Rolle fallen auf, da sie ausgesprochen lang sind; Abschnitt vi ist deutlich länger als Abschnitt VII.

Abschnitt VI (AB B. 15): 67 Länge nahezu $308 \mathrm{~cm}$; es handelt sich um den längsten Abschnitt auf der Rolle. Er wird beidseits vom fünfteiligen Schriftband eingefasst. Im Mittelstreifen wurde der Text im wesentlichen auf horizontalen Zeilen in schwarzer $\dot{G} u b \bar{a} r$-Schrift notiert. Am Anfang ein Abschnitt von ca. $55 \mathrm{~cm}$ Länge mit einem Gittermuster. Dieses Gitter wird durch diagonal angeordnete Stäbe gebildet. Sie sind golden eingefasst und werden von einer haarfeinen schwarzen Linie eingerahmt. In den Stäben selbst Text in rotem $\dot{G} u b \bar{a} r$, der in unterschiedlichen Richtungen verläuft. Die Maschen dieses Gitters bzw. die Stäbe bilden auf der Spitze stehende Quadrate (abwech-

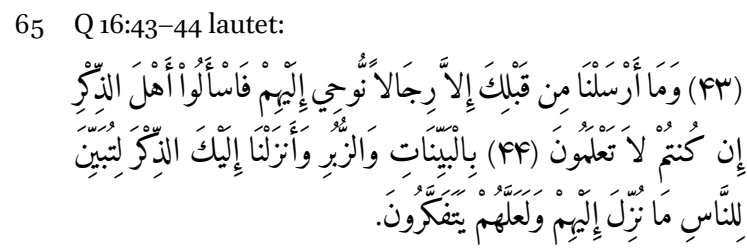

66 Vgl. Abb. 3 der Rolle (link in Anm. 1).

67 Vgl. Abb. 3-6 der Rolle (link in Anm. 1). 
selnd zwei bzw. drei Quadrate). Am Anfang und Ende dieses Rechtecks sind die auf der Spitze stehenden Quadrate gänzlich mit Text in schwarzem $\dot{G} u b \bar{a} r$ ausgefüllt. Dazwischen allerdings lassen sich im Zentrum der Quadrate goldene (bzw. gelb-braune) Zierpunkte erkennen. Darum herum Text in schwarzem $\dot{G} u b \bar{a}$.

In diesem Abschnitt ist die Fortsetzung der Abschrift des Korans (Rest von Q 18 und Fortsetzung) zu erwarten. Etwa in der Mitte des Abschnitts mit dem Gittermuster steht denn auch der Titel von Q 19 (Sūrat Maryam). Er wurde in einem Gitterstab in schwarzer Tinte von rechts unten nach links oben notiert. Kurz vor dem Ende des Gitters steht im Mittelstreifen in goldener (bzw. gelb-brauner) Tinte der Titel von Q 20 (Sürat Tă-hā).

Die bisherigen Beobachtungen lassen vermuten, dass das Layout dieses Abschnitts (Gitter) die Anordnung des Textes beeinflusst hat. Im Schriftfeld im Bogen, der dieses Rechteck oben abschliesst, steht auf der untersten Zeile Q 18:48. Der Schreiber springt jetzt in das Gitter darunter. Er setzt die Abschrift von Q 18:48 links von der Mitte an der Spitze des obersten vollständigen Quadrats fort. Er steigt in der Diagonalen zuerst links nach unten; am linken Rand des Rechtecks angekommen folgt er der durch die Gitterstäbe vorgegebenen Richtung. Er steigt weiter nach unten, wobei er stets von der einen auf die andere Seite des Rechtecks wechselt. Zuunterst steigt er wieder nach oben. Er verteilt so den Rest von Q 18 (Verse 48b-110) in rotem $\dot{G} u b \bar{a} r$ in diesen Gitterstäben. Er erreicht zuletzt etwa in der Mitte dieses Gitters die Stelle mit dem Titel von Q 19 (Sūrat Maryam; in schwarzer Tinte). Er erreicht am Schluss das obere Ende des Rechtecks und befindet sich an der Spitze des obersten vollständigen, auf der Spitze stehenden Quadrats rechts von der Mitte (Q 19:7a). Der Kopist setzt die Abschrift jetzt fort, indem er in die drei auf der Spitze stehenden Dreiecke am oberen Rand des Rechtecks wechselt. Darin lassen sich Q 19:7b-9a erkennen. Danach steigt der Schreiber in den auf der Spitze stehenden
Quadraten nach und nach abwärts und erreicht zuletzt die Stelle mit dem Titel Sūrat Ṭā-hā (Q 20), den er golden hervorhebt. Basmala und Q 20:12 lassen sich in schwarzem $\dot{G} u b \bar{a} r$ in den beiden seitlichen Dreiecken auf der Höhe des Titels erkennen. Darunter erreicht der Schreiber Quadrate mit einem goldenen Punkt im Zentrum. Der Text umfährt diese Punkte im Gegenuhrzeigersinn. Auf den horizontalen Linien unmittelbar unterhalb des Gitters steht zuletzt Q 20:35. Der Text umfährt darauf das horizontale Rechteck darunter im Gegenuhrzeigersinn und wechselt danach ins Rechteck selbst. Der Text wurde darin in rotem $\dot{G} u b \bar{a} r$ kopiert. ${ }^{68}$ Ab hier ordnet der Schreiber den Korantext nur noch vereinzelt in geometrischen Figuren an. Auf dem Rest von Abschnitt vi fallen neun horizontal angeordnete Rechtecke auf, die in regelmässigen Abständen die Abschrift auflockern. Die Höhe dieser Rechtecke beträgt ca. $3 \mathrm{~cm}$.

Ausserhalb der Rechtecke setzt der Kopist die Abschrift des Korans auf horizontalen Linien in schwarzem $\dot{G} u b \bar{a} r$ fort. Die Verse werden durch goldene Punkte voneinander getrennt. Die Surentitel werden golden hervorgehoben. Im dritten Rechteck hob der Kopist jene Stelle in goldener Schrift besonders hervor, die Gottes Qualität als Verleiher des Lebensunterhalts (rizq) thematisiert. ${ }^{69}$ Ansonsten setzt der Schreiber den Text Sure um Sure fort. Zuunterst steht in diesem Abschnitt Q 37:93.

Abschnitt VII: ${ }^{70}$ Länge ca. $195 \mathrm{~cm}$. Der Abschnitt beginnt mit dem letzten Wort von Q 37:93; danach folgt Q 37:94. Am Anfang des Abschnitts befindet sich erneut ein Medaillon, das vom fünfgliedrigen Schriftband umfahren wird. Der Schreiber

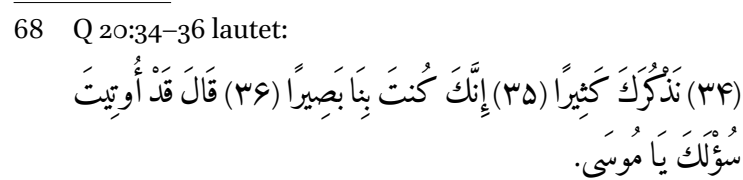

69 Q 22:58b lautet:

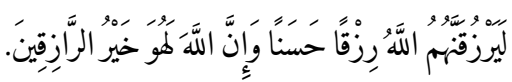

70 Vgl. Abb. 6-8 der Rolle (link in Anm. 1). 
setzt die Abschrift im Mittelstreifen fort (schwarzes $\dot{G} u b \bar{a} r$, goldene Verstrenner, hervorgehobene Surentitel). Verzierungen in den vier Spickeln um das Medaillon herum. Es handelt sich um eine zur Rollenmitte hin geöffnete weisse Blüte auf blauem Hintergrund. Zwei weisse, schwarz eingefasste Blätter verlaufen dem Rollenrand entlang nach oben bzw. unten. Nach dem Medaillon beginnt erneut der nach oben abgerundete Mittelstreifen. Beim Übergang vom Medaillon zum Rechteck steht Q 37:146. ${ }^{71}$ Wenig darunter folgt in goldener (bzw. gold-brauner) Schrift der Titel von Q 38 (Sürat Șād). Es schliesst sich die Abschrift der weiteren Suren an. Zuunterst steht der Titel von Q 68. Das nūn (Q 68:1) ist rot hervorgehoben (nūn wa-l-qalam).${ }^{72} \mathrm{Kurz}$ nach der Überschrift von Q 68 erreicht der Kopist das Ende jenes Teils der Rolle, der vom fünfgliedrigen Schriftband eingefasst wird (АВв. 16).

Abschnitt viII (AB B. 16-17): ${ }^{73}$ Der letzte Teil der Rolle misst etwa $60.5 \mathrm{~cm}$. Er wird den Rändern entlang von zwei goldenen, von haarfeinen schwarzen Linien eingefassten Bändern eingerahmt. Zwischen diesen zwei Goldbändern verläuft ein Streifen mit einfachen, aus schwarzen Linien bestehenden Verzierungen. Eine stark verblasste blaue Linie fasst diesen Rahmen aussen ein.

Der Schreiber setzt hier die Abschrift des Korans in der bekannten Art fort (schwarzes $\dot{G} u b \bar{a} r)$. Da die Suren am Ende der islamischen Offenbarung kürzer sind, folgen sich die Überschriften in immer geringeren Abständen. Auch scheint die Schrift etwas grösser zu werden und ist oft punktiert und teilweise vokalisiert. Der Abschnitt mit Q 93-98 wurde in roter Tinte kopiert. Bei Q 99 wechselt der Schreiber wie-

71 Q 37:146 lautet:

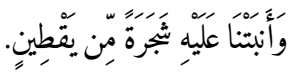

72 Dieser Abschnitt wurde eingehender überprüft, da auf derartigen Rollen Q 48 häufig eine Sonderstellung zukommt. Hier allerdings ist dies nicht der Fall. Q 48 (Sürat al-Fath) wurde hier ganz normal wie alle andern Suren kopiert.

73 Vgl. Abb. 8 der Rolle (link in Anm. 1). der zu schwarzer Schrift. Die Rolle endet mit der Abschrift von Q 114 (Sürat an-Nās), wie es sich für einen Koran gehört. Auf den letzten drei Zeilen folgt der Kolophon (АВ В. 17). ${ }^{74}$
74 Der Kolophon lautet (vgl. auch vor Anm. 2):

$$
\begin{aligned}
& \text { صدق الله العظيم وبلغ رسوله الكريم ا وافق الفراغ من كتابة هذا }
\end{aligned}
$$

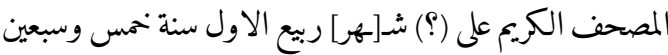

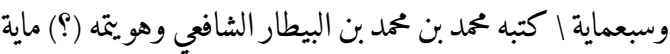

$$
\begin{aligned}
& \text { واربعة وثمانين ختمة شريفة. }
\end{aligned}
$$




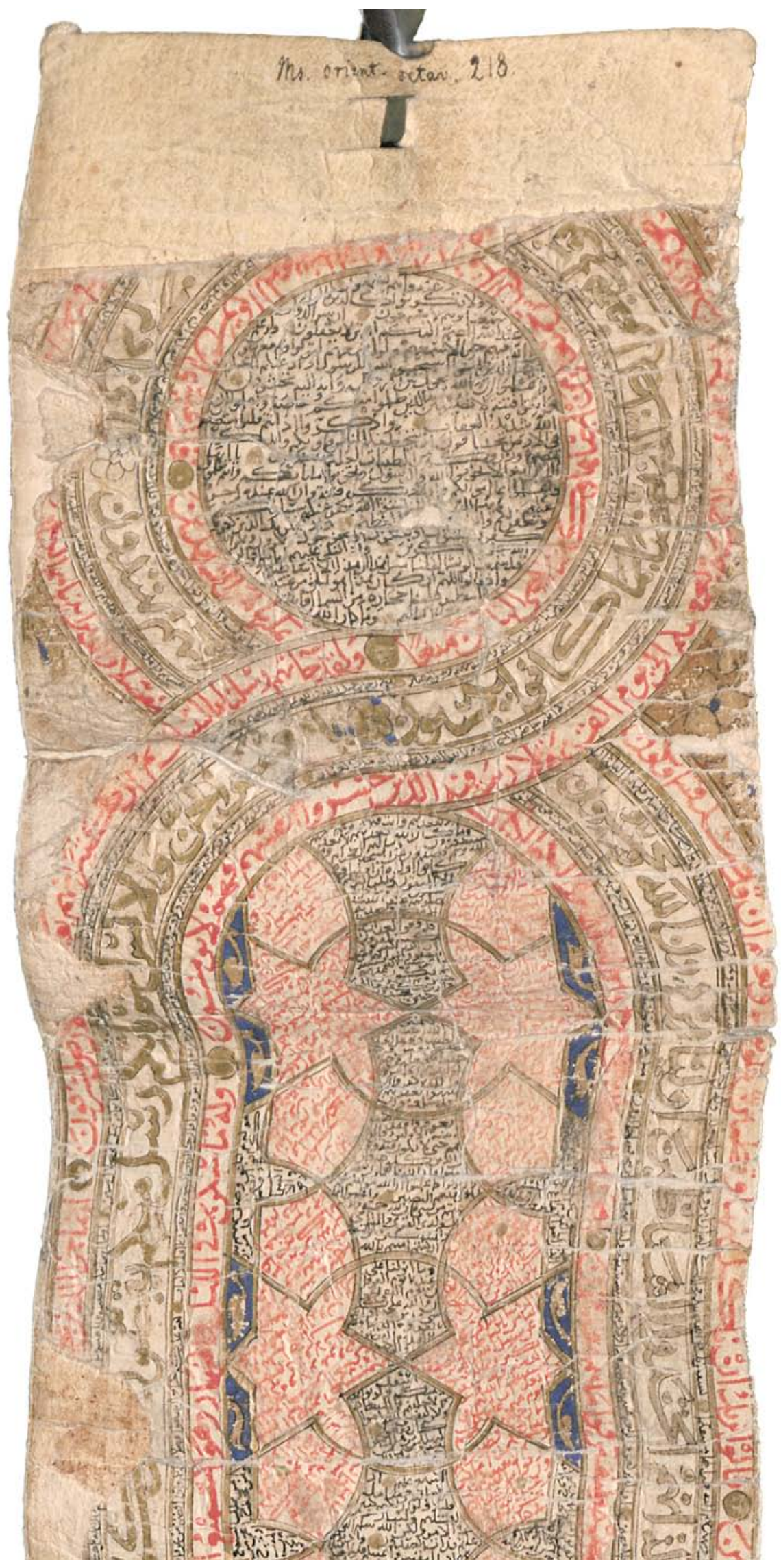

ABB. 10

Staatsbibliothek zu Berlin, Ms. or. oct. 218 (vgl. bei Anm. 8): Anfang des erhaltenen Teils der Rolle. Die Textstellen in den Schriftbändern liessen sich identifizieren; siehe für die Einzelheiten die Beschreibung nach Anm. 8.

STAATSBIBLIOTHEK ZU BERLIN-PREUSSISCHER KULTURBESITZORIENTABTEILUNG, MS. OR. OCT. 218 


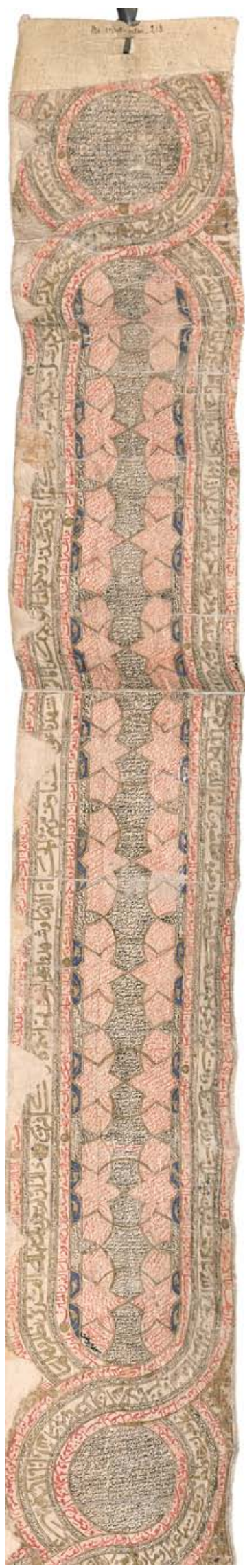

ABB. 11

Staatsbibliothek zu Berlin, Ms. or. oct. 218 (vgl. bei Anm. 30-36): Beginn Abschnitt I der Rolle. Das fünfteilige Schriftband umfährt hier ein Rechteck von ca. $63 \mathrm{~cm}$ Länge; es ist oben und unten abgerundet. Man beachte die komplexe Anordnung des Texts im Mittelstreifen; er wurde in roter und schwarzer Tinte in $\dot{G} u b \bar{r} r$-Schrift kopiert.

STAATSBIBLIOTHEK ZU BERLIN-PREUSSISCHER KULTURBESITZ-ORIENTABTEILUNG, MS. OR. OCT. 218 

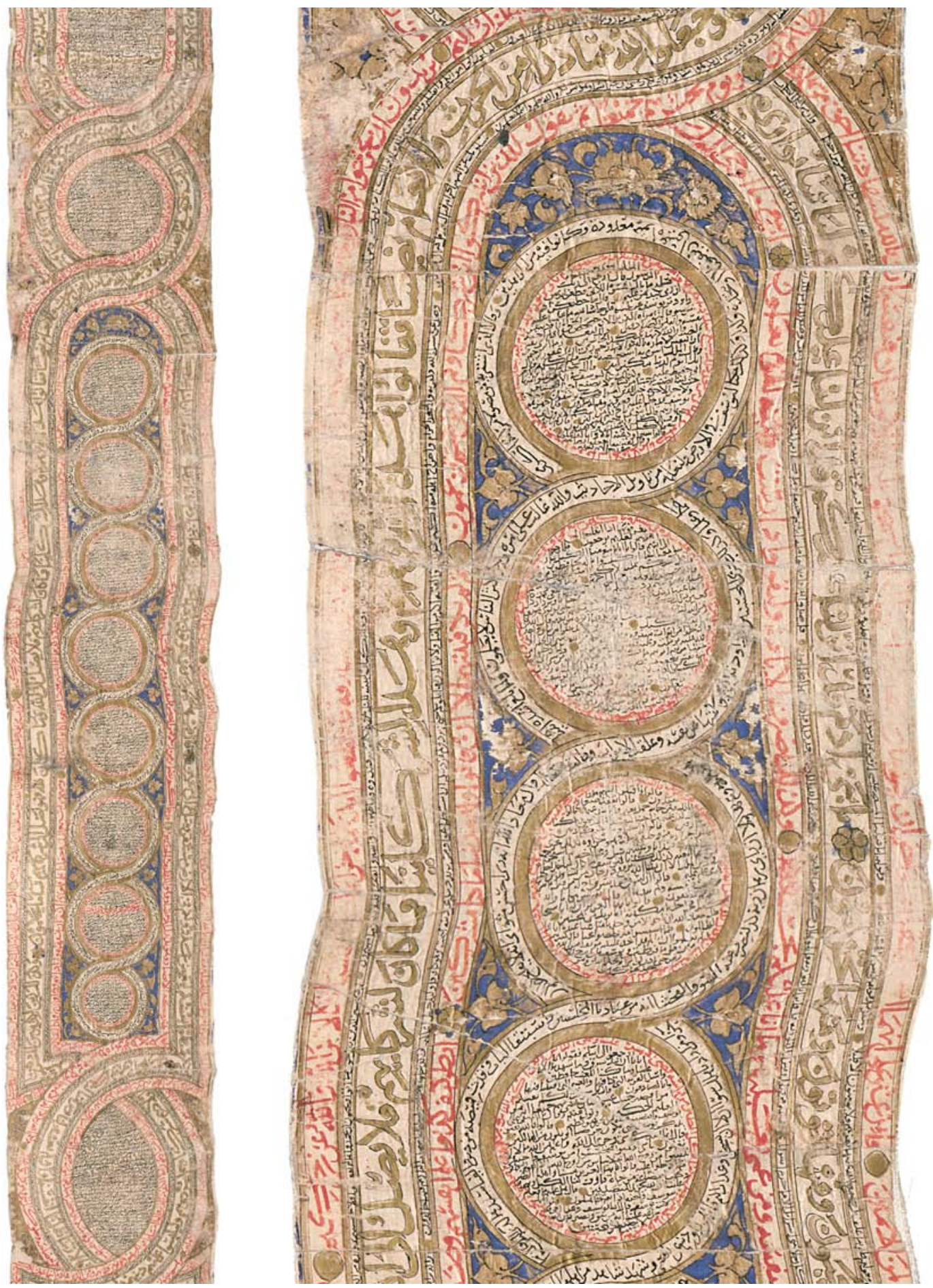

Ав B. 12-13 Staatsbibliothek zu Berlin, Ms. or. oct. 218 (vgl. bei Anm. 41-48): Abschnitt mit der Abschrift von Q 12 im Mittelstreifen. Die Überschrift von Q 12 (Sūrat Yüsuf) steht bereits am Ende des vorangehenden, unten abgerundeten Rechtecks. Die Abschrift wird im Medaillon in schwarzem $\dot{G} u b \bar{a} r$ auf horizontalen Zeilen fortgesetzt. Danach setzt der Schreiber den Text in 8 Kreisen im Rechteck darunter fort. ABB. 13 zeigt einen Ausschnitt aus dem Rechteck mit den 8 Kreisen. Im obersten Kreis lässt sich Q 12:21 erkennen. Der Text steigt im Ring zuerst nach links ab. Zuunterst im Ring angelangt springt der Schreiber nach oben und setzt die Abschrift im Ring rechts absteigend fort.

STAATSBIBLIOTHEK ZU BERLIN-PREUSSISCHER KULTURBESITZ-ORIENTABTEILUNG, MS. OR. OCT. 218 


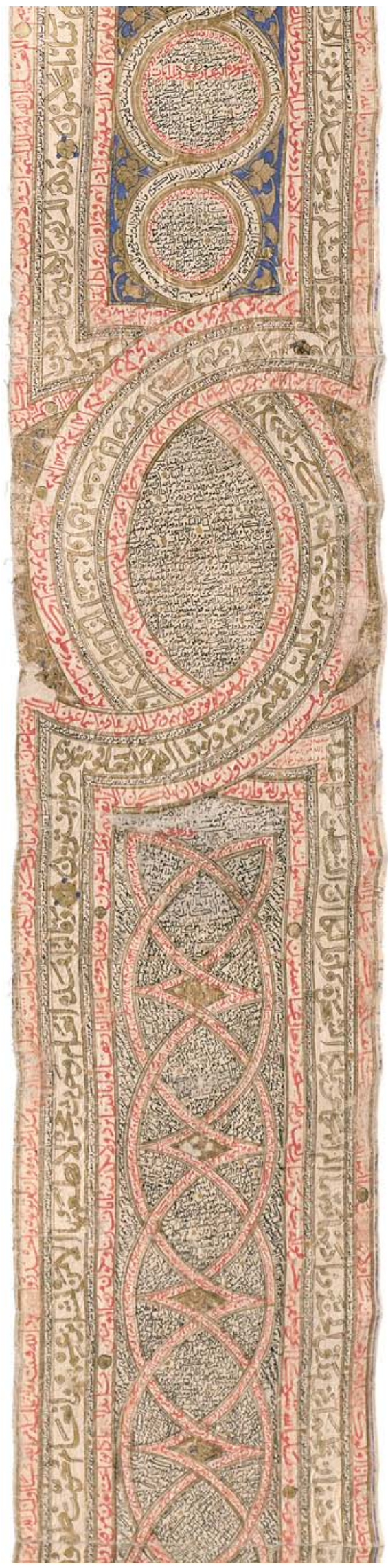

АBB. 14

Staatsbibliothek zu Berlin, Ms. or. oct. 218 (vgl. bei Anm. 49-65): Anfang des Abschnitts mit den mandelförmigen Figuren, in denen der Text besonders komplex angeordnet ist. Die Beschreibung hält das Vorgehen des Kopisten in diesem Abschnitt im einzelnen fest. Davor Schluss des Abschnitts mit der Abschrift von Q 12 (siehe ABB. 12-13). STAATSBIBLIOTHEK ZU BERLIN-PREUSSISCHER KULTURBESITZORIENTABTEILUNG, MS. OR. OCT. 218

Tobias Nünlist - 9789004429154 


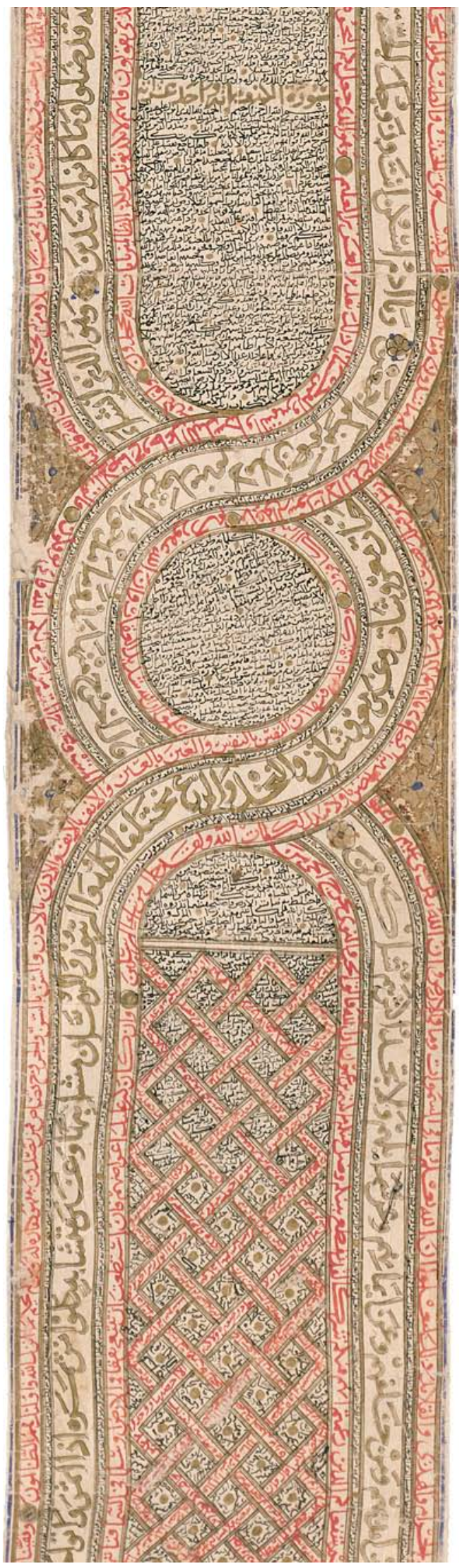

ABB. 15

Staatsbibliothek zu Berlin, Ms. or. oct. 218 (vgl. bei Anm. 6769): Die Abbildung zeigt das fünfteilige Schriftband, das unter Umfahrung von Medaillons von der linken auf die rechte Seite der Rolle bzw. vice versa wechselt. Im Mittelstreifen des oberen Rechtecks (unten abgerundet) lässt sich die Überschrift von Q 18 (Sūrat al-Kahf) erkennen. Im Rechteck darunter ordnete der Schreiber den Text in einem Gitter an.

STAATSBIBLIOTHEK ZU BERLIN-PREUSSISCHER

KULTURBESITZ-ORIENTABTEILUNG, MS. OR. OCT. 218

Tobias Nünlist - 9789004429154 

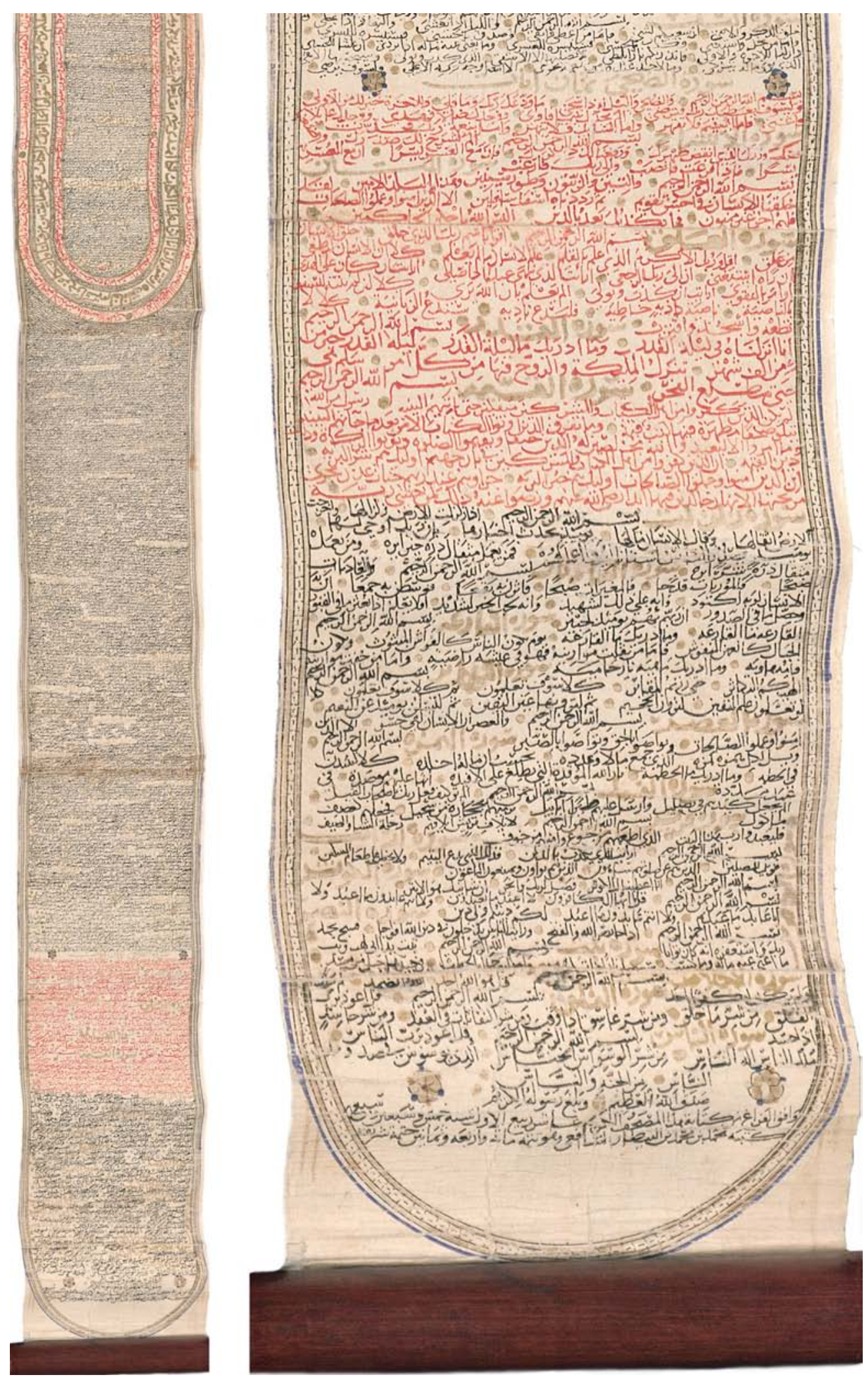

AвB. 16-17 Staatsbibliothek zu Berlin, Ms. or. oct. 218 (vgl. bei Anm. 70-74): Das fünfteilige Schriftband umfährt den Schluss der Rolle nicht. Im breiten mittleren Schriftband steht zuunterst Q 6:156 (ABB. 16; vgl. bei Anm. 23).

STAATSBIBLIOTHEK ZU BERLIN-PREUSSISCHER KULTURBESITZ-ORIENTABTEILUNG, MS.

OR. OCT. 218 
$4 \cdot 4$

Kopenhagen, The Royal Library, Cod. Arab. 53

Masse: $12.5 \times 813 \mathrm{~cm} ;{ }^{1}$ datiert: 11. Ramaḍān $803 / 25$. April 1401; Schreiber: 'Alī b. Ahmmad b. Muhammad al-Mahallī. Das Belegstück ist am Anfang unvollständig erhalten, wie sich anhand kodikologischer ${ }^{2}$ und inhaltlicher ${ }^{3}$ Kriterien feststellen lässt. Sehr gut geglättetes Papier. Rolle zusammengesetzt aus insgesamt 22 Papierstreifen von je ca. $37 \mathrm{~cm}$ Länge. ${ }^{4}$ Das vorliegende Exemplar enthält Angaben, die zumindest indirekt auf die Gegend hinweisen, wo es hergestellt worden ist. ${ }^{5}$ Zusammen mit den Angaben zum Kopisten und zum Zeitpunkt seiner Herstellung erlaubt dies eine recht präzise Einordnung dieses und vergleichbarer Belegstücke.

$\mathrm{Zu}$ diesem Exemplar sind zwei Parallelstücke aus der Dār al-Ātāār al-Islāmiyya (Kuwait) bekannt, die von Y. Alsaleh vorgestellt worden sind. ${ }^{6}$ Ausserdem ist auf ein fragmentarisch erhaltenes viertes Exemplar hinzuweisen, das 1988 in einer Ausstellung in Genf gezeigt wurde. ${ }^{7}$ Die weiteren Ausführungen befassen sich in erster Linie mit Cod. Arab. 53 aus Kopenhagen, das am Original

1 Dieses Exemplar wird beschrieben in Perho, Catalogue I, 159-161 (mit Abbildung). Die Bibliothek hat zu diesem Belegstück scans hergestellt, auf die bei der Beschreibung verwiesen wird.

2 Am Anfang des Dokuments lässt sich erkennen, dass es nachträglich zwei Mal auf anderes Papier aufgezogen worden ist.

3 Im ersten Medaillon lässt sich auf dem äussersten roten Schriftband Q 6:27-31 erkennen; das innere rote Schriftband führt Q 6:31-32 (Teile) auf. Das grosse schwarze Schriftband enthält Stellen aus Q 36:12-13. Daraus lässt sich schliessen, dass am Anfang jetzt verlorene Stellen vorhanden gewesen sein mussten.

4 Der erste Streifen misst $36.2 \mathrm{~cm}$; danach folgen Abschnitte, die stets ca. $37 \mathrm{~cm}$ messen.

5 Vgl. dazu unten bei Anm. 74-81 und 216.

6 Kuwait, Dār al-Ātār al-Islāmiyya, LNS 12 MS und LNS 25 Ms. Vgl. dazu Alsaleh, Licit Magic 240-259 (LNS 12 MS, mit Abb. 19-33) und 26o-287 (LNS 25 Ms, mit Abb. 34-51); siehe auch 122-178.

7 Vgl. dazu den Ausstellungskatalog Calligraphie islamique: Textes sacrés et profanes $98 \mathrm{f}$. (Nr. 22). untersucht werden konnte. Es unterscheidet sich von den meisten in diesem 4. Kapitel untersuchten Belegstücken, da es keine Stellen in $\dot{G} u b a \bar{r}$-Schrift enthält. Die Textstellen lassen sich somit leichter lesen.

Das Exemplar umfasst grundsätzlich zwei Teile, die als Abschnitt I bzw. II bezeichnet werden. Beide Abschnitte lassen sich weiter unterteilen. Abschnitt III enthält gemäss dieser Zusammenstellung sozusagen als Zusatz den Kolophon.

Abschnitt I (formal; A B B. 18): Die Länge des ersten Abschnitts misst ca. $156 \mathrm{~cm}$. Darauf lässt sich eine Abfolge von runden Medaillons und Rechtecken erkennen. Letztere sind am Anfang und Ende abgerundet. ${ }^{8}$ Sämtliche Figuren im ersten Abschnitt werden von einem dreiteiligen Schriftband eingefasst. Die sieben Figuren in diesem Abschnitt werden aussen zusätzlich von einem Band ohne Einträge umrahmt. Sie sind nicht miteinander verbunden. Das Schriftband umfährt jede Figur einzeln. Die Zwickel zwischen den abgerundeten Figuren und dem Rollenrand wurden golden ausgefüllt und werden von einer feinen blauen Linie eingefasst. Rechts und links befindet sich ein braun umrandetes Dreieck mit einer blütenförmigen Verzierung.

Abschnitt I (Mittelstreifen, inhaltlich; ABB. 18): ${ }^{9}$ Am Anfang der Rolle lässt sich drei Mal die Abfolge Medaillon-abgerundetes Rechteck feststellen. Diese Abfolge wird von einem weiteren Medaillon abgeschlossen. Das dritte abgerundete Rechteck ist am längsten und enthält eine Aufzählung der Schönen Namen Gottes, wie noch aufzuzeigen ist. ${ }^{10}$ Die restlichen Figuren am Rollenanfang enthalten im Mittelstreifen aber Text, der eine Einheit bildet. Es handelt sich um Auszüge

8 Die Form dieser abgerundeten Rechtecke erinnert an die im islamischen Kulturraum verbreiteten Federkästen; Alsaleh, op. cit. 351, spricht von einem pencase motif bzw. einem oblong medallion.

9 Die folgenden Ausführungen beziehen sich auf Abb. 1-9 der Rolle (Royal Library).

10 Vgl. sogleich anschliessend bei Anm. 14. 
aus Q 3:18-19 11 und Q 3:26; sie wurden im Mittelstreifen (Breite ca. $4.8 \mathrm{~cm}$ ) in der Rollenrichtung in grosser Zierschrift notiert (АВВ. 19). Es ist davon auszugehen, dass der Beginn von Vers 3.18 auf dem verlorenen Anfang der Rolle gestanden hatte. Dieser erste Auszug aus dem Koran weist auf Allahs Stellung als der eine und einzige Gott hin. Die Passage betont in der Fortsetzung ausserdem, dass der Islam die wahre Religion Gottes sei.

Der Auszug aus Q 3:26 schliesst sich direkt an das vorangehende Zitat an. Er ist über den Rest des ersten abgerundeten Rechtecks, das nächste runde Medaillon, das Rechteck mit dem blauen Hintergrund und das anschliessende Medaillon verteilt. Das Zitat überspringt dann das Rechteck mit den Schönen Namen Gottes und endet im Medaillon unmittelbar danach. ${ }^{12}$ Dieser Auszug preist Gott, der über alles herrscht. Er verleihe Herrschaft, wem er wolle, und entziehe sie, wem er wolle. Allah sei ausserdem jener, der stärke, wen er wolle. Die Fortsetzung des Verses mit der Feststellung, dass Gott erniedrige, wen er wolle, fehlt aber in diesem Auszug.

Bei der Gestaltung dieser Zierfelder wurde ein grosser Aufwand betrieben. Sämtliche Medaillons und abgerundeten Rechtecke (Durchmesser bzw. Breite ca. $4.8 \mathrm{~cm}$ ) weisen im Innern einen goldenen Ring auf (Breite ca. $6 \mathrm{~mm}$ ). Aussen werden diese Figuren von einem dreiteiligen Schriftband einge-

11 Q 3:18-19 lautet:

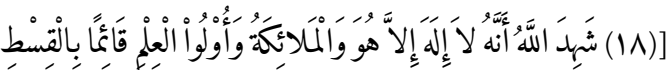

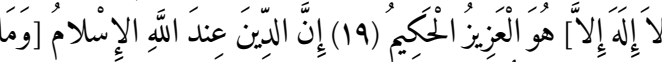

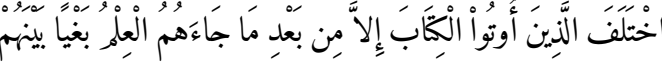

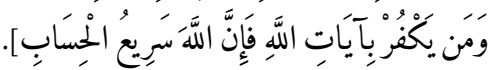

Der Text in eckigen Klammern fehlt auf der Rolle.

12

Q 3:26 lautet:

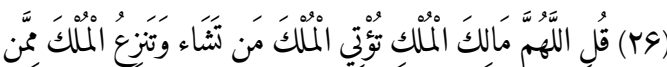

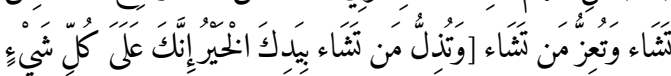

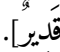

fasst, auf dessen Aufbau und Inhalt noch einzugehen sein wird.

Die drei ersten Zierfelder sind verderbt. DerText wurde auf einem goldenen, mit einem Rankenmotiv versehenen Hintergrund notiert. Die Buchstaben werden von feinen schwarzen Linien eingefasst. Sie dürften ursprünglich braun ausgefüllt gewesen sein; die Farbpigmente in den Buchstaben gingen allerdings oft verloren; viele Buchstaben sind jetzt einfach weiss. Das zweite, an beiden Enden abgerundete Rechteck dürfte allerdings weitgehend in seinem ursprünglichen Zustand erhalten geblieben sein. Es weist einen dunkelblauen Hintergrund auf, der mit goldenen Ranken verziert ist. Die Buchstaben selbst sind schwarz eingefasst und braun (bzw. bräunlich) ausgefüllt;13 sie werden aussen golden umrandet.

Das dritte abgerundete Rechteck ist abweichend gestaltet und enthält keinen Text aus Q 3:18 oder 3:26. Dieser Abschnitt enthält vielmehr eine Aufzählung der Schönen Namen Gottes, wie aus der Über- bzw. Unterschrift dazu hervorgeht. ${ }^{14}$ Die einzelnen Beinamen Gottes sind in ein Gitter von $4 \times 25$ Zellen eingefügt, die durch zwei feine rote Linien voneinander getrennt werden. An den Kreuzpunkten dieser Gitterlinien wurden abwechselnd zwei (auf den beiden äusseren Vertikalen) bzw. eine (auf der Vertikalen in der Mitte) goldene blütenförmige Verzierung angebracht. Die Beinamen Gottes wurden in schwarzem Nash in den einzelnen Kästchen kopiert. Die Schrift verläuft abwechselnd von rechts oben nach links unten bzw. von rechts unten nach links oben. Da das erste Kästchen die Aufzählung der Namen Gottes mit der Wendung Huwa Allāh einleitet, enthält dieses Gitter danach 99 Namen.

Das dreiteilige Schriftband: Das Schriftband um die Rolle herum und der Mittelstreifen der

13 Am Anfang dieses Zierfelds gingen die braunen Pigmente zumeist verloren.

14 Vgl. die Abb. 6-8 der Rolle, die von der Royal Library angefertigt worden sind. Die Überschrift lautet Wa-li[A]llāh al-asmā; in der Unterschrift folgt als Fortsetzung dazu: al-husnā und wahrscheinlich die Eulogie 'azza Allāh. 
vom Schriftband eingefassten Figuren enthalten Text. Die Textelemente im Schriftband um die Rollen herum und jene im Mittelstreifen gehören zusammen. Das Schriftband in der Mitte ist am breitesten (ca. 1.8cm). Es enthält Text in grosser, schwarzer Schrift (zu Tulut tendierendes Nash). Der Text ist punktiert und zumeist vokalisiert. Dieses breite Band mit schwarzem Text wird innen und aussen von je einem schmalen Band ${ }^{15}$ mit Text in roter Schrift (Nash, punktiert und vokalisiert) eingefasst. Aussen fasst eine blaue Linie diese Figuren ein.

Inhaltlich gehören der schwarze Text im breiten Mittelband und der rote Text in den beiden Seitenbändern zusammen. In der obersten Figur steht im breiten Schriftband Q 36:12-13 (Sürat $Y \bar{a}-\sin )$ im Gegenuhrzeigersinn. ${ }^{16}$ Die Verse werden von vierteiligen, golden ausgefüllten Verstrennern getrennt. Nachdem der Kopist den ersten Kreis umfahren hat, befindet er sich wieder an dessen obersten Stelle. Er springt jetzt in die Figur darunter (abgerundetes Rechteck) und setzt die Abschrift von Q 36 im schwarzen Mittelband fort. In dieser zweiten Figur steht Q 36:1417 (im Gegenuhrzeigersinn). Der Schreiber fährt mit der Abschrift von Q 36 auf diese Weise fort. Im schwarzen Schriftband um das Rechteck mit den Schönen Namen Gottes herum steht Q 36:24 (mubin) bis 36:31 (im Gegenuhrzeigersinn). Am Anfang von Abschnitt II (langes Rechteck, das bis ans Ende der Rolle reicht) steht Q 36:33b. ${ }^{17}$

15 Breite ca. $6-7 \mathrm{~mm}$. Zwei haarfeine rote Linien umfahren diese beiden schmalen Schriftbänder innen und aussen. Beim innern Schriftband allerdings sind die beiden innern Trennlinien schwarz.

16 Q 36:12-13 lautet (Text auf einem goldenen, mit einem Rankenmotiv versehenen Hintergrund):

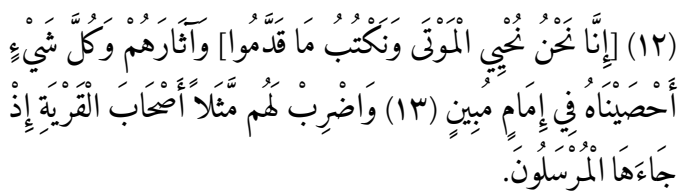

17 Q 36:33 lautet:

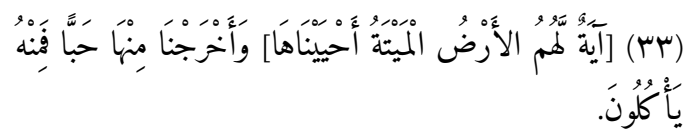

Der Schreiber setzt jetzt die Abschrift von Q 36 im linken, vorwärtslaufenden Schriftband fort. Im Bogen ganz am Ende des Dokuments, wo das vorwärtslaufende unter Wechseln der Rollenseite ins rückwärtslaufende Schriftband übergeht, steht Q 36:77-78.18 Die Abschrift von Q 36 endet auf dem rechten, rückwärtslaufenden Schriftband auf der Höhe des Abschnitts mit der Überschrift $L i$ ta'n ar-rumh im Mittelstreifen. ${ }^{19}$ Unmittelbar nach dem Ende von Q 36 beginnt Q 67 (Sürat alMulk) mit der Basmala. Der Kopist beendet die Abschrift von Q 67 wenig unterhalb des Anfangs dieses langen Rechtecks (Abschnitt II). ${ }^{20}$ Er befindet sich schliesslich wenige Zentimeter unterhalb des Anfangs des langen Rechtecks und füllt die letzten Zentimeter mit einer kurzen Lobpreisung Allahs. ${ }^{21}$

Aus diesen Beobachtungen ergibt sich, dass im breiten schwarzen Schriftband Q 36:12b-83 und Q 67:1-30 kopiert worden sind. Während Q 67 damit auf dem Schriftband vollständig enthalten ist, fehlt von Q 36 der Anfang (Verse 1-12a). Neben dem fragmentarisch erhaltenen Zitat von Q 3:18 im Mittelstreifen zeigt auch der fehlende Beginn von Q 36, dass der ursprüngliche Anfang der Rolle fehlt. ${ }^{22}$

Der Text in eckigen Klammern ist bereits im kreisrunden Medaillon davor enthalten; vgl. Abb. 9-10 (Royal Library).

18 Q 36:77-78 lautet (vgl. Abb. 40, Royal Library):

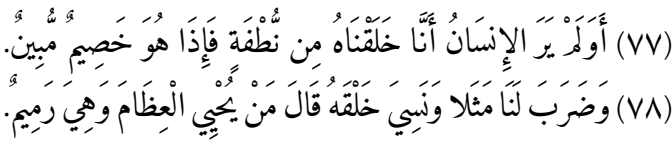

Vgl. Abb. 36 (Royal Library).

Q 67:30 (letzter Vers der Sure) lautet:

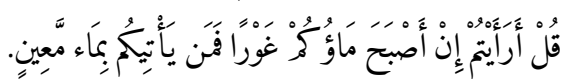

21 Vgl. Abb. 10 (Royal Library). Die Ergänzung zum Ausfüllen des Freiraums lautet:

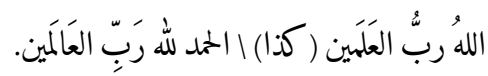

22 Die Länge des fehlenden Abschnitts lässt sich nicht bestimmen, da nicht klar ist, ob Q 36 direkt am Anfang der Rolle begann. 
Auch der rote Text in den beiden schmalen Schriftbändern, die das Mittelband mit schwarzem Text flankieren, beginnt nicht am Anfang einer Sure. ${ }^{23}$ Hier lässt sich im äussern Schriftband oben in der Mitte Q 6:27 erkennen. Der Schreiber umfährt dann das oberste Medaillon im Gegenuhrzeigersinn, bis er erneut den Ausgangspunkt erreicht (Stelle aus Q 6:30). Er springt jetzt in das innere Schriftband mit rotem Text und umfährt auch hier das Medaillon im Gegenuhrzeigersinn. Er springt danach in die nächste Figur darunter, das erste an beiden Enden abgerundete Rechteck, und setzt dort die Abschrift von Q 6:32 im Aussenband fort. Zurück am Anfang erreicht der Schreiber Q 6:37 und springt ins innere rote Schriftband, ${ }^{24}$ wo er die Abschrift von Q 6 fortsetzt. In diesem innern roten Schriftband stehen Q 6:37b41. Der Schreiber setzt Q 6 in derselben Art fort. Im Abschnitt mit den Schönen Namen Gottes steht im roten Aussenband Q 6:61 (Schluss) ${ }^{25}-\mathrm{Q}$ 6:70. Im roten Innenband folgt mit Q 6:71-78 (Anfang) die unmittelbare Fortsetzung.

Der Schreiber fährt mit der Abschrift im langen Rechteck in Abschnitt II auf dem roten Aussenband auf dieselbe Art fort. Zuunterst, wo das vorwärtslaufende Schriftband in einem Bogen von der linken auf die rechte Seite der Rolle wechselt und danach rückwärts läuft, lässt sich nach einem kleinen Abstand Q 6:135 erkennen. ${ }^{26}$ Die

23 Vgl. Abb. 1 (Royal Library).

24 Q 6:37 lautet:

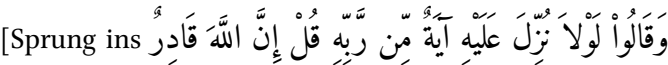
[Innenband

25 Der Übergang Q 6:61-62 lautet (vgl. Abb. 6 der Rolle, Royal Library):

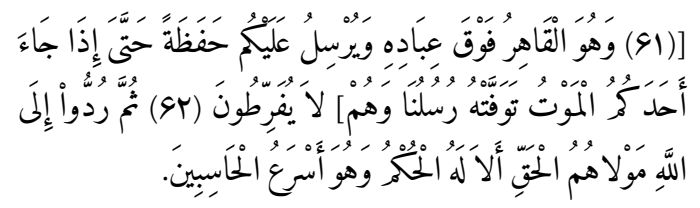

Q 6:135 lautet (vgl. Abb. 40, Royal Library):

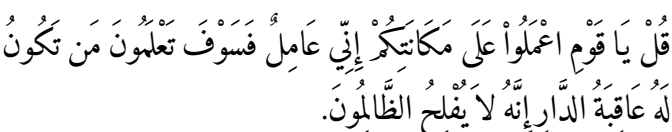

Abschrift von Q 6 endet mit deren letztem Vers auf der Höhe der Vierpässe im langen Rechteck (Abschnitt II). ${ }^{27}$

Danach beginnt nach einem kleinen Zwischenraum Q 48 (Sürat al-Fath, „Der Sieg“) ohne Basmala. ${ }^{28}$ Der Schreiber setzt die Abschrift in der bekannten Manier fort. Der Text erreicht am Anfang (oberes Ende) des langen Rechtecks in Abschnitt II Q 48.11 und springt in diesem Vers ins rote Innenband. ${ }^{29}$ Der Text von Q 48 steigt danach auf dem linken roten Innenband wieder nach unten. Die Abschrift dieser Sure endet mit dem Schlussvers (Q 48:29) auf der Höhe eines Titelbalkens im Mittelstreifen, der mit der Inschrift $\mathrm{Li}-\mathrm{l}$ hawf wa-l-faza' („Gegen Furcht und Schrecken“30) versehen ist. ${ }^{31}$ Kurz vor dem Schluss dieser Sure ist dem Kopisten beim Abschreiben von Q 48:29 ein Fehler unterlaufen. Mitten im Vers 48:29 beginnt ein Auszug aus Q 57:20, den der Kopist allerdings sogleich wieder durchgestrichen hat. ${ }^{32}$ Diese Fehlstelle dürfte darauf hindeuten, dass der Schreiber den Text auswendig kopierte.

27 Vgl. Abb. 15 der Rolle (Royal Library).

28 Q 48:1 lautet:

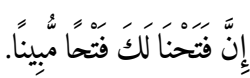

29 Vgl. Abb. 10 der Rolle (Royal Library). Q 48:11 lautet:

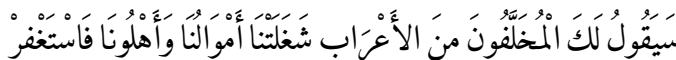

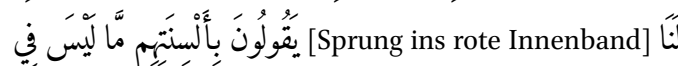

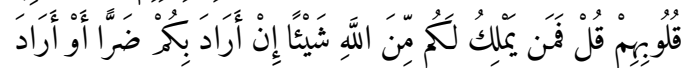

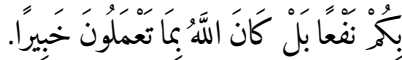

30 Vgl. zu diesem Abschnitt unten II.C.2 (bei Anm. 99).

Vgl. Abb. 27 der Rolle (Royal Library).

Vgl. Abb. 26 der Rolle (Royal Library). Q 57:20 lautet:

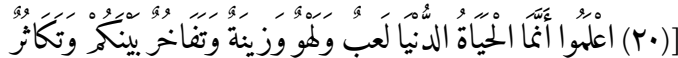

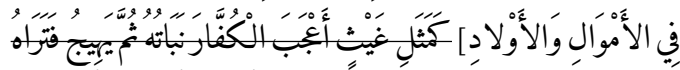

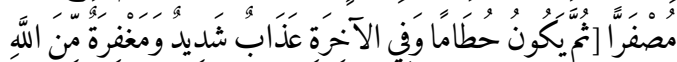

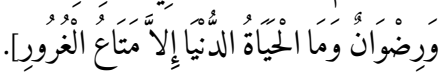

Der Text in eckigen Klammern fehlt auf der vorliegenden Rolle. 
Nach dem Abschluss von Q 48 beginnt auf der Höhe des Balkens mit der Überschrift Li-l-hawf wa-l-faza' nach einem kurzen Zwischenraum Q 76 (Sürat al-Insān) mit der Basmala. ${ }^{33}$ Der Text folgt weiterhin der vom Layout vorgegebenen Richtung und verläuft im roten Innenband. Die Abschrift endet mit dem letzten Vers der Sure (Q 76:31) auf der Höhe des Abschnitts mit der Darstellung von Moses' Stab im Mittelstreifen. ${ }^{34}$ Unmittelbar anschliessend beginnt die kurze Q 99 (Sūrat az-Zalzala) mit der Basmala. ${ }^{35}$ Wenig danach beginnt auf der Höhe des Abschnitts mit der Abbildung einer Hand ${ }^{36} \mathrm{Q} 102$ (Sūrat at-Takātur). ${ }^{37}$ Es schliesst sich darauf im roten Innenband des Bogens Q 109 (Sūrat al-Kāfirūn) an. ${ }^{38}$ Darauf beginnt im innern roten, rückwärtslaufenden Schriftband die Abschrift von Q 112 (Sürat al-Ihlāss). ${ }^{39} \mathrm{Q} 112$ wird besonders geschätzt, da sie die für den Islam bedeutende Ewigkeit, Einheit und Einzigartigkeit Allahs hervorhebt. Q 112 wird auf diesem roten innern Schriftband insgesamt 53 Mal wiederholt. Diese Wiederholungen hören erst auf, kurz bevor das rote Innenband das obere Ende von Abschnitt II erreicht. ${ }^{40}$ Auf dem

33 Q 76:1 lautet:

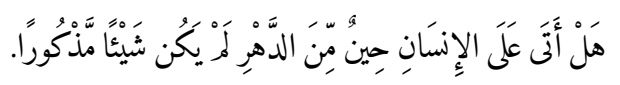

Vgl. Abb. 36-37 der Rolle (Royal Library) mit dem Titelfeld 'Așāt Mūsā.

Q 99:1 lautet:

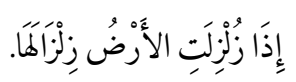

36 Vgl. dazu unten II.D.6 (vor Anm. 203).

37 Q 100 und Q 101 fehlen demnach.

38 Vgl. Abb. 4o der Rolle (Royal Library). Diese kurzen Suren wurden jeweils vollständig notiert. Q 109 lautet:

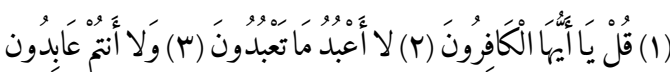

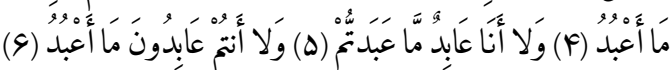

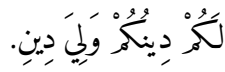

39 Q 112 lautet (vollständig):



Vgl. Abb. 12-10 der Rolle (Royal Library). hier noch verbleibenden Platz stehen mit Q 113 und Q 114 die beiden letzten Suren des Korans; sie sind auch unter dem Begriff al-Mu'awwidatān (die beiden Zufluchtgebenden) bekannt. ${ }^{41}$

Damit ist der Inhalt sämtlicher Stellen auf dem dreiteiligen Schriftband bestimmt worden, das sowohl Abschnitt I als auch Abschnitt II einfasst. Es enthält ausschliesslich Stellen aus der islamischen Offenbarung.

Abschnitt II (Mittelstreifen, formal und inhaltlich): Die weiteren Ausführungen stellen Aufbau und Inhalt des Mittelstreifens im zweiten Teil der Rolle vor. Er besteht aus einem sehr langen Rechteck, das an beiden Enden abgerundet ist. Daran schliesst sich, sozusagen als Abschnitt III, der Kolophon am Schluss der Rolle an. Die Länge des soeben erwähnten Rechtecks beträgt ca. $653 \mathrm{~cm}$. Abschnitt II lässt sich seinerseits in mehrere Unterabschnitte aufteilen:

II.A Vierpassgebet (formal; ABB. 20):42 Die Länge dieses Abschnitts misst etwa $195 \mathrm{~cm} .{ }^{43}$ Die Breite beträgt ca. $3.5 \mathrm{~cm}$. Der Abschnitt beginnt mit einem Medaillon, danach folgen 38 Vierpässe unmittelbar aufeinander. Nach jeweils vier Vierpässen sind die zwischen den beiden Schriftbändern zur Linken und Rechten und den Lappen der Vierpässe entstehenden Zwickel golden umrandet und blau ausgefüllt. Auf diesem Hintergrund lässt sich eine goldene, blattförmige Verzierung mit einer Blüte erkennen. Diese Verzierungen mit blauem Hintergrund sind gut erhalten. Auch die Zwickel bei den andern Vierpässen enthielten eine blattförmige Verzierung mit Blüte auf einem wohl ursprünglich bräunlichen Hintergrund. Bei all diesen Zwickeln sind die Konturen der Verzierungen verwischt und teilweise kaum noch erkenntlich. Die Vierpässe selbst werden von zwei feinen schwarzen Linien umrahmt. In ihrem Zen-

41 Siehe al-Mu'awwidhatān, in $E I^{2}$; Canaan, Decipherment 131.

42 Vgl. Abb. 9-19 der Rolle (Royal Library).

43 Diese Längenangabe wurde nicht am Original ermittelt, sondern anhand der Digitalisate berechnet. Sie dürfte aber auf einige Zentimeter mehr oder weniger korrekt sein. 
trum befindet sich eine golden ausgefüllte fünfoder sechsblättrige Blüte. Die Vierpässe enthalten Text in schwarzem Nash, der zumeist auf acht Zeilen angeordnet wurde. Der Text ist punktiert und oft vokalisiert. Die Höhe des Alif erreicht ca. 3 mm; der Abstand zwischen den Zeilen wird gut eingehalten. ${ }^{44}$

Beim ersten Zierelement in diesem Abschnitt handelt es sich nicht um einen Vierpass, sondern um ein Medaillon, das horizontal in zwei Halbkreise aufgeteilt wird. In der oberen Hälfte befindet sich ein Titelfeld; es ist golden eingefasst und hat einen blauen Hintergrund. Darin steht ein Titel in brauner Schrift, die golden hinterlegt ist. In der unteren Hälfte des Medaillons beginnt Text in schwarzem Nash.

II.A Vierpassgebet (inhaltlich; A B B. 20): ${ }^{45}$ Der im ersten Medaillon und den anschliessenden 38 Vierpässen kopierte Text wird im Titelfeld als Du'ā ['] as-Sayfı (sic) bezeichnet. Er lässt sich in unterschiedlichen Quellen nachweisen. Das Gebet ist ebenso unter dem Titel $D u^{\prime} \bar{a}^{’}$ al-Yamān̄ bekannt. Ibn Ṭāwūs (gest. 1266) ${ }^{46}$ führt es in seiner Gebetssammlung Muhağ ad-da'wāt wa-manhağ al-ibādāt auf. ${ }^{47}$ Es lässt sich mit kleineren oder

44 Als $\dot{G} u b \bar{a} r$ wird eine Schrift bezeichnet, deren Höhe zwischen 1-3 mm beträgt. Vorliegend handelt es sich also um einen Grenzfall.

Vgl. die Abb. 9-19 der Rolle (Royal Library).

Vgl. zu ihm und seinem Werk Kapitel 4.1, Anm. 77.

Siehe dazu die anschliessend angeführten Quellen (Der Text des Gebets folgt am Schluss dieses Abschnitts nach Anm. 218). Der folgenden Zusammenstellung ist die Bemerkung vorauszuschicken, dass der Wortlaut des Gebetstexts auf der Rolle und jener in den identifizierten Quellen nicht völlig identisch ist. Auch weichen die angeführten Quellen untereinander ab. Dies allerdings ist ein Problem der Textedition. Trotz dieser Abweichungen steht fest, dass es sich beim vorliegenden Gebet um die Du'ä’ al-Yamānī bzw. ad-Du'ā’ as-sayfí [al-kabìr] handelt. Siehe dazu:

Ibn Ṭāwūs, Muhağ ad-da'wāt wa-manhağ al-ibādāt 137-143; Überschrift: Wa-min dālika Du'ā’ li-Mawlānā Amìr al-mu'minīn Alī ('alay-hi s-salām) al-ma'rüf bidu'ā' al-yamānī. Bayrūt, Mu’assasat al-A'lamī li-l-Mațbū'āt, 1414/1994. Diese Textausgabe enthält auch zahlreiche Berichte über die Umstände, unter denen ein bestimmtes Gebet offenbart bzw. bekannt geworden ist. grösseren Abweichungen auch im Internet belegen. ${ }^{48}$

Die identifizierten Internetquellen stammen zumeist aus einem schiitischen Umfeld. Es ist auch bekannt, dass Ibn Ṭāwūs eindeutig der Schia zuzuordnen ist. Dies bedeutet allerdings nicht notwendigerweise, dass die hier diskutierte Rolle aus einem schiitischen Umfeld im engeren Sinn stammt. Im Vordergrund steht vielmehr eine Zuordnung zu mystischen Kontexten im allgemeinen. Gerade die Internetseite www .knozalasrar.com (für kunūz al-asrār) führt Gebete auf, die unter mystisch orientierten Gruppierungen beliebt waren. ${ }^{49}$ Diese Quelle hält fest, dass die ad-Du'ä’ as-Sayfı eines der bedeutendsten Gebete der Qādiriyya sei. Diese Bruderschaft geht auf 'Abd al-Qādir al-Ǧīlān̄ (470-561/1077-1166)

Diese Hintergrundberichte wurden in der folgenden Ausgabe aus Qum häufig weggelassen: Ibn Ṭāwūs, Muhağ adDa'wāt wa-manhağ al-ibādāt 114-119; Überschrift: Du'ā al-Yamānī bi-riwāya uhrā. Qum, Dār ad-Dahāir, 1411 h.q. (das Exemplar stimmt mit der Lithographie überein, die 1323 h.q. unter Nāṣir ad-Dīn Šāh angefertigt wurde). Dieses Exemplar ist im Internet zugänglich unter http://lib .eshia.ir/71561/1/1 (a. 71561: Signatur des Buchs, b. 1: Band 1; c. 1: Seite 1, in lib.eshia.ir; Stand 1. November 2016).

48 Ausserdem lässt sich das Gebet in zahlreichen Quellen im Internet nachweisen, hier eine Zusammenstellung (Stand alle: 1. November 2016):

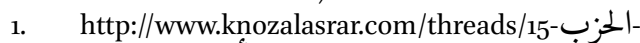
السيفي-للإمام-علي-ب-أبي-طالب-كرم-الله-وجهه Titel: alHizb as-sayfi. Der Zugriff ist auch ohne den Adressteil in arabischer Schrift möglich.

2. http://www.knozalasrar.com/threads/4429-دعاء اليماني-للنجاة-و-الخلاص-من-الظلمة-و-الأعداء. Titel: Dứác alYamānì.

3. https://al-3abbas.com/vb/showthread.php?t=1132 5o. Titel: ad-Du'ä’ as-Sayfı́ al-kabīr (al-Yamān̄̄); dieses Gebet soll rezitiert werden nach ad-Du'ä’ as-Sayfi as șaj̄ir (al-Qāmūs).

4. http://www.ghadeer.org/Book/92/14396 (Nr. 15): Titel: Dữà-i Yamān̄̄ (aus Ibn Ṭāwūs, Niyāyiš-hā az suwaydā-i dil, http://www.ghadeer.org/Book/92/1).

Siehe dazu Nr. 1 und 2 in der vorangehenden Zusammenstellung.. Die Website www.knozalasrar.com enthält sehr wertvolle Zusammenstellungen dieser Gebete. Sie war im Dezember 2017 und Januar 2018 nicht zugänglich. 
zurück. ${ }^{50}$ Diese Quelle nennt das Gebet einen hizb (al-Hizb as-sayfi ); auch diese Bezeichnung deutet darauf hin, dass es in einem mystisch ausgerichteten Umfeld beliebt war. ${ }^{51}$

Die angeführten Quellen beschränken sich nicht darauf, den Wortlaut des Gebets wiederzugeben, sondern halten auch die Umstände von dessen Bekanntwerden bzw. Offenbarung fest. A. Aydınl zeigte im Fall des Gebets alĞawšan al-kabir zwar auf, dass diese Erklärungen zumeist jeglicher historischer Plausibilität entbehren und unhaltbare Übertreibungen enthalten. ${ }^{52}$ Diese Berichte werden hier nicht im Detail erörtert; sie vermitteln im allgemeinen aber einen wichtigen Einblick in das Umfeld, in dem derartige erbauliche Erzählungen im Umlauf waren. Die weiteren Ausführungen stützen sich auf die bei Ibn Ṭāwūs (Muhağ, Bayrūt 1414/1994) enthaltenen Angaben:53

Das Gebet wird in der Druckausgabe durch einen isnād eingeleitet, der dem Text historische Glaubwürdigkeit verleihen soll. Er wurde nicht auf seine Plausibilität überprüft. Ibn Țāwūs gibt darin an, dass ihm ein gewisser Abū 'Abdallāh al-Ḥusayn b. Ibrāhīm b. 'Alī al-Fatā, bekannt als Ibn al-Huayāțt, das Gebet und die dazugehörende Überlieferungsberichte übermittelt habe. Dieser Ibn al-Hुayātț („Sohn des Schneiders"), liess sich nicht identifizieren. Er muss aber zur Zeit Ibn Țāwūs' gelebt haben, gibt dieser doch an, den Bericht von ihm gehört zu haben (ahbara-nā). Der isnād bezeichnet diesen Ibn al-Huayātț als fatā, also als Angehörigen der Futuwwa. Da Ibn Ṭāwūs beinahe sein ganzes Leben im Iraq verbrachte und zuletzt unter dem Īlhāniden Hülegü in Bagdad aktiv war, lie-

5o Zu 'Abd al-Qādir al-Ǧīlānī (al-Ǧīlī) siehe oben Kapitel 3.1.7 bei Anm. 166-167; vgl. Chabbi, 'Abd al-Qādir al-jīlānī, in $E I^{3}$.

$5^{1} \mathrm{Zu}$ den Hizb-Gebeten siehe Kapitel 3.4, zwischen Anm. 467 und 468; siehe ausserdem Padwick, Muslim devotions 12 und 23-25; für einzelne Hizb-Gebete siehe ihr Index s.v. hizb, 307, auch 299 f.

52 Vgl. zum Gebet al-Ǧawšan al-kabìr, Kapitel 4.1, bei Anm. 35-40.

53 Vgl. dazu Anm. 47. gen Abhängigkeiten von der dortigen FutuwwaBewegung nahe. Diese Bezüge würden auch durch die Angabe gestützt, dass der Vater dieses Garanten Schneider war (Ibn al-Hुayāțț). Angehörige von Futuwwa-Bünden waren verpflichtet einem Broterwerb nachzugehen. ${ }^{54}$

Das älteste Glied in diesem isnād ist 'Alī b. Abī Ṭālib, der einerseits als mawlāna, anderseits als amìr al-mu'minin bezeichnet wird. ${ }^{55}$ Gemäss dem anschliessenden Bericht habe Hasan seinen Vater 'Alī eines Tages wissen lassen, dass ein Fremder ihn zu sprechen wünsche. Ein angenehmer Moschusduft gehe von ihm aus, sein Aussehen erheische Respekt, er spreche gepflegt und trage das Gewand von Königen. Dieser Mann gibt gegenüber 'Alī an, er komme aus dem fernsten Teil des Jemens und gehöre zu den vornehmen (šarīf, Pl. àsrāf) Arabern. Auch leitet er seine Abstammung - ohne präzisere Angaben dazu - von 'Alī ab (intasaba $i l \bar{a})$. Er habe eine gewaltiges Königreich zurückgelassen und lebe in Wohlstand. Allerdings werde er von einem Feind heimgesucht, dessen er sich kaum erwehren könne. Eines Nachts habe ihn eine Stimme aufgefordert, aufzustehen und sich zu 'Alī zu begeben. Er solle 'Alī darum bitten, ihn jenes Gebet zu lehren, das er von Muhammad erfahren habe. Dieses Gebet enthalte den [grössten] Namen Gottes. Er solle dieses Gebet dann gegen seine Feinde im Jemen rezitieren. 'Alī habe darauf eingewilligt, dem Bittsteller das fragliche Gedicht mitzuteilen. Er habe nach Tinte und Papier verlangt und es aufgeschrieben. Nach dieser Einleitung schliesst sich das Gebet an, das sich mit Abweichungen im Detail auf der Rolle aus Kopenhagen nachweisen lässt. Der Mann sei darauf in den Jemen zurückgekehrt und habe dort das Gedicht gegen seine Widersacher rezitiert. Er habe seine Feinde danach in der Tat besiegt. Es wird auch angegeben, dass die Berge in Bewegung versetzen oder über das Meer gehen könne, wer dieses Gebet mit aufrichtiger Gesinnung und demütigen Her-

\footnotetext{
54 Vgl. zum Grundsatz des kasb haläl oben Kapitel 3.2, bei Anm. 284-287.

55 Ibn Țāwūs, op. cit. 138.5 .
} 
zens rezitiere. Nach vierzig Tage sei ein Schreiben aus dem Jemen bei 'Alī eingetroffen, in dem sich der Bittsteller für die Unterstützung bedankte. Er habe seinen Feind gänzlich vernichten können. Der Wortlaut des Gebets auf der Rolle wird ganz am Schluss dieses Abschnitts wiedergegeben. ${ }^{56}$

II.B Haykal-Gebet (formal): ${ }^{57}$ Die Länge des nächsten Abschnitts misst etwa $137 \mathrm{~cm} .{ }^{58}$ Er ist in sieben Teile von ungefähr gleicher Länge gegliedert.Jedem Abschnitt ist ein Titelbalken mit einem goldenen Rahmen vorangestellt. Der Hintergrund von Titelbalken 1 und 5 ist blau. In diesen Balken wurde die Überschrift zu den einzelnen Abschnitten notiert. Die einzelnen Abschnitte heissen stets al-Haykal und werden danach durchnumeriert; also al-Haykal al-awwal, aț-tānī, at-țālit, ar-rābi, al-hāmis, as-sādis und zuletzt al-Haykal as-sābi. Die einzelnen Abschnitte enthalten im Mittelstreifen nach dem Titel jeweils Text in gut lesbarem schwarzem Nash, das punktiert und zumeist vokalisiert ist. Jeder Abschnitt bildet ein Rechteck von ca. $20 \mathrm{~cm}$ Länge. Zur Verzierung wurden in diesem Rechteck in den beiden oberen und unteren Ecken je eine sechsblättrige goldene Blüte angebracht. Eine fünfte, identisch gestaltete Blüte lässt sich jeweils in der Mitte dieser Rechtecke erkennen.

II.B Haykal-Gebet (inhaltlich): Den weiteren Ausführungen ist die Bemerkung vorauszuschicken, dass nicht allein das vorliegende Belegstück aus der Royal Library ein siebenteiliges Gebet enthält, dessen einzelne Abschnitte als haykal bezeichnet werden. Siebenteilige HaykalGebete lassen sich auch auf folgenden weiteren Belegstücken feststellen: Basel M III $173,{ }^{59}$

56 Vgl. für das Gebet selbst: Ibn Ṭāwūs, op. cit., 139-143 (siehe Anm. 47, Ausgabe 1414/1994; auch Anm. 48). Der Text des Gebets folgt am Schluss dieses Abschnitts nach Anm. 218. Vgl. Abb. 19-26.

$5^{8}$ Dieser Wert wurde anhand des zur Verfügung stehenden Abbildungsmaterials der Rolle rekonstruiert und soll nur zur allgemeinen Orientierung dienen.
Dublin, Isl 1624, ${ }^{60}$ Sabancı Collection, ${ }^{61}$ Christie's, Eretna, ${ }^{62}$ und Dār al-Ātār al-Islāmiyya (zwei Belegstücke) ${ }^{63}$ Die siebenteiligen Haykal-Gebete auf den soeben angeführten Belegstücken stimmen miteinander nicht überein. Allerdings weisen sie abgesehen von ihrer siebenteiligen Struktur auch weitere Gemeinsamkeiten auf. Dazu zählt insbesondere, dass die Abschnitte $2-7$ nach der

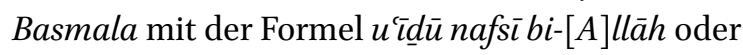
ähnlich beginnen. ${ }^{64}$ Aus dieser Einleitung geht hervor, dass es sich um ein Schutzgebet handelt.

Auch C. Padwick erwähnt den Begriff haykal in ihrer Untersuchung von Gebeten. Ihre Arbeit stützt sich auf Gebetshandbücher, die sie auf Märkten oder in Buchhandlungen zusammengetragen hat. ${ }^{65}$ Sie ist v.a. in Gebetshandbüchern auf Persisch oder Urdu auf Haykal-Gebete gestossen und ordnet sie den Schutzgebeten zu. Der Betende flehe darin Allah um Schutz vor allem Dämonischen an. Auch das persische Wörterbuch von Dihhudā führt unter dem Eintrag haykal die Bedeutung „Schutzgebet“ an; es feie besonders vor dem Bösen Blick. ${ }^{66}$

Die auf den beigezogenen Belegstücken enthaltenen siebenteiligen Haykal-Gebete unterschei-

6 V Vgl. Kapitel 4.6.

61 Inventar Nr. SSM 102-o396: Sakıp Sabancı Museum Collection of the arts of the book and calligraphy $150-153$ (Nr.6o).

62 Vgl. Auktion bei Christie's, London: lot 127, October 5 2010. Der Besitzer zog das Exemplar vor der Auktion zurück. Siehe hier Kapitel 4.10.

63 Vgl. die Quellenangaben in Anm. 6.

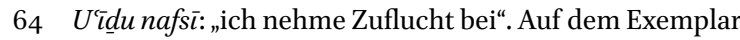

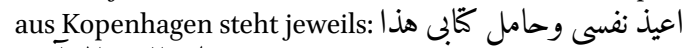
. بالله الذي الى آخره.

65 Padwick, Muslim devotions 86.

66 Vgl. Luġat-nāma-i Dihhudā, s.v. haykal: تعويذ. حرز. دعا كازونم به بازو بندند جشم زخم را

هedeutung haykal, aus Dihhudā, s.v. haft haykal: هفت

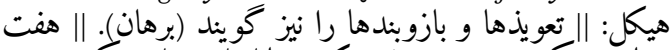

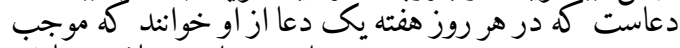
امن و سلامت باشد (غياث)

Man beachte den Hinweis, dass ein Haykal-Gebet gern am Oberarm festgebunden werde. Ähnlich auch

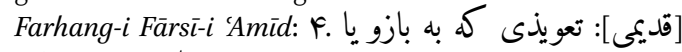
عضوى از بلدن مى بستند. 
den sich untereinander. Dies lässt es als unwahrscheinlich erscheinen, das Gebet auf dem Belegstück aus Kopenhagen tel quel in Gebetshandbüchern nachweisen zu können. Al-Kaf'amī ${ }^{67}$ allerdings führt in seiner Gebetssammlung alMișbāh ein siebenteiliges Haykal-Gebet auf, das mehr als nur vereinzelte Übereinstimmungen mit der Version auf dem Exemplar aus Kopenhagen aufweist. Die Parallelen fallen gerade im ersten Haykal (al-Haykal al-awwal) auf; mehrere Passagen haben denselben Wortlaut. ${ }^{68}$

Der erste Haykal (الميكل الاول) lautet auf dem Exemplar aus Kopenhagen (АВB. 21):69

$$
\begin{aligned}
& \text { بسم الله الرحمن الرحيم \الحمد لله الذى لا ينسى \ من ذكره }
\end{aligned}
$$

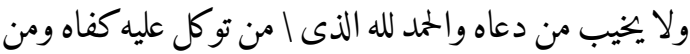

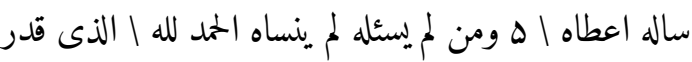

$$
\begin{aligned}
& \text { الارزاق والاقوات | والموت والحياه والحمد لله الذى يجزى | } \\
& \text { بالاحسان احسانا وبالسيات عفوا | وغفرانا والحمد لله الذى } \\
& \text { اعطانا من | •ا فضله واولانا من نعمه وارضانا | والحمد لله }
\end{aligned}
$$

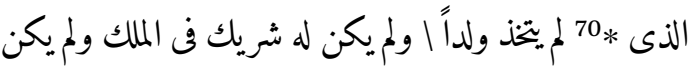

$$
\begin{aligned}
& \text { له | ولي من الذل وكبره تكبيراً الله | اكبر كبيراً واحمد كثيراً } \\
& \text { وسبحان الله | ها بكرة واصيلا سبحان الله والحمد لله | ولا اله } \\
& \text { الا الله والله اكبر ولا حول ولا اقوة الا بالله العلى العظيم }
\end{aligned}
$$

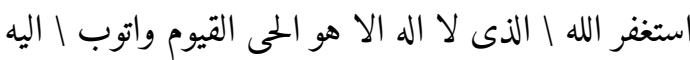

$$
\begin{aligned}
& \text { واسئله التوبه والمغفره والعفو ا •r والعافيه والمعافاة لدايمه }
\end{aligned}
$$

$67 \mathrm{Zu}$ al-Kaf'amī (gest. 905 h.q.) vgl. Kapitel 4.2, Anm. 39. Al-Kaf'amī lebte zwar erst im 15. Jh.; es ist aber klar, dass er als Kompilator tätig war und in seinen Gebetssammlungen Material aus älteren Quellen zusammentrug.

68 Vgl. dazu al-Kaf'amī, al-Miṣbāh, Qum, Dār ar-Riḍā (Zāhidī), 1405 h.q.; http://lib.eshia.ir/71570/1/1; darin S. 224-227: http://lib.eshia.ir/71570/1/224. Siehe auch alKaf'amī, al-Miṣbāh 26o-263; Bayrūt, Mu'assasat anNu'mān, 1412/1992.

69 Vgl. Abb. 20 der Rolle (Royal Library). Querstriche (\) kennzeichnen die Zeilenumbrüche.

70 Blüte zur Verzierung im Text.

$$
\text { في ا الدين والدنيا والآخرة | وصلى الله على سيدنا محد وآله }
$$

Die weiteren Haykal-Abschnitte auf der Rolle aus Kopenhagen werden hier nicht im Detail erörtert. Es wird bei dieser Gelegenheit aber festgehalten, dass der 2. Haykal den Thronvers (Q 2:255) aufgreift. ${ }^{71}$ Auch in den andern Abschnitten des Haykal-Gebets lassen sich wiederholt wörtliche Übereinstimmungen mit der gedruckten Version bei Kaf'amì feststellen; allerdings sind auch vielfach Abweichungen zu erkennen. So spielt der 6 . Haykal auf der Rolle auf Gottes Aufforderung an die Erde und die Himmel an, sich bei ihm freiwillig oder unter Zwang einzustellen (vgl. Q 41:11). In der gedruckten Fassung findet sich diese Anspielung bereits im 4. Haykal. ${ }^{72}$ Die gedruckte Fassung zählt die Muhammad vorangegangen Propheten sodann im 6. Haykal auf. Auf der Rolle folgt diese Zusammenstellung erst im 7. Haykal. Die Rolle schliesst im 7. Haykal mit denselben Lobpreisungen Gottes, die sich auch in der Druckausgabe an die Erwähnung der Propheten anschliessen. ${ }^{73}$

Von besonderer Bedeutung für die geographische Einordnung der vorliegenden Rolle ist der 6 . Haykal, der hier deshalb ausführlicher vorgestellt wird (АВB. 22-23): ${ }^{74}$

$$
\begin{aligned}
& \text { الهيكل السادس \ بسم الله الرحمن الرحيم \اعيذ نفسى }
\end{aligned}
$$

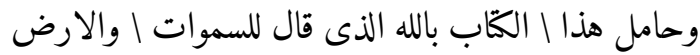

$$
\begin{aligned}
& \text { | ايتينا طوعاً او كرهاً } \\
& \text { سبع سموات في يومين واوحى فى الكل سماء امرها وزينا }
\end{aligned}
$$

71 In der Fassung auf lib.eshia.ir (vgl. Anm. 68) folgt der Thronvers im 3. Haykal (S. 225).

72 Vgl. den 4. Haykal in der Fassung auf lib.eshia.ir (Anm. 68): S. 226.

73 Vgl. den 6. und 7. Haykal in der Fassung auf lib.eshia.ir (Anm. 68): S. 227. Der 7. Haykal schliesst in der Druckfassung mit dem Lichtvers (Q 24:35); dieser fehlt auf der Rolle.

74 Vgl. Abb. 24-25, der von der Royal Library angefertigten Abbildungen.

75 Vgl. Q 41:11 


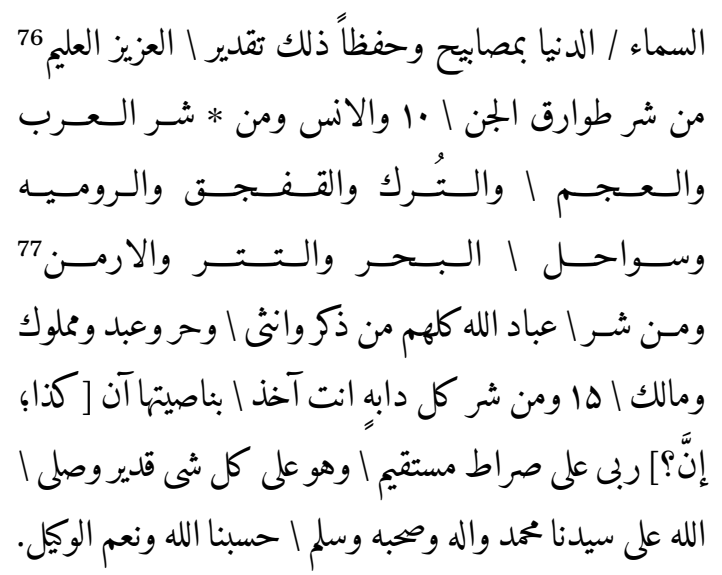

Teile aus diesem Haykal lassen sich ebenso in den zum Vergleich beigezogenen Druckausgaben nachweisen. Dies trifft gerade auf die Anspielung auf Q 41:11 zu. Allerdings scheinen Erwähnungen jener Völker in den konsultierten Druckversionen des Haykal-Gebets zu fehlen, die in der vorliegenden Fassung folgen. Der Betende ersucht hier Gott um Schutz vor allerhand Übel. Er will sich insbesondere schützen vor dem Übel der Araber und Perser (al-'ăğam), ${ }^{78}$ dem Übel der Türken und der Kiptschaken, der Byzantiner und der Bewohner der Meeresufer, ${ }^{79}$ ebenso wie vor dem Übel der Tataren ${ }^{80}$ und der Armenier. Der Betende fährt anschliessend mit der Aufzählung einiger weiterer Übel fort, vor denen er geschützt werden möchte (z.B. vor dem Übel jeglicher Männer und Frauen, von Dienern und Dienstherren etc.).

Diese weiteren Aufzählungen sind für die vorliegenden Belange nicht besonders relevant. Von grossem Interesse sind hingegen die Volksgruppen,

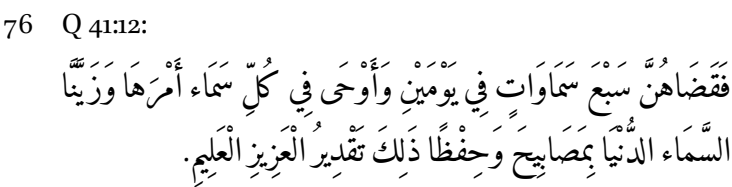

77 Diese Angaben sind zentral für die geographische Einordnung; vgl. bei Anm. $78 \mathrm{f}$.

78 Der Begriff 'ağam bezeichnet die Nichtaraber, also die Barbaren, im allgemeinen. Er dient besonders häufig zur Bezeichnung der Perser.

79 Allenfalls ist damit die Gegend am Schwarzen Meer (Nordostanatolien) gemeint.

80 Gemäss Kohlberg, Ibn Ṭāwūs 81, handelt es sich bei den Tataren um die Mongolen. vor denen der Betende Gott um Schutz ersucht. Sie unterstreichen, dass die Rolle für einen Träger aus einem bestimmten geographischen Kontext angefertigt wurde. Es fällt jedenfalls auf, dass die auf der Rolle angeführten Völker nahezu ausschliesslich im Norden der islamischen Welt beheimatet sind und die Dār al-Islām dort bedrohen. Diese Angaben erlauben Rückschlüsse auf die Gegend, wo das untersuchte Dokument hergestellt worden sein dürfte, nämlich mit grosser Wahrscheinlichkeit in Nordsyrien oder Nordiraq. ${ }^{81}$

Auf eine Herkunft aus Nordsyrien oder Nordiraq könnte, indirekt zumindest, auch der Begriff haykal hinweisen. Dieser Ausdruck bezeichnet in erster Linie ein Gebet, wie C. Padwick festgehalten hat. ${ }^{82}$ Es ist allerdings so, dass aus Harrān (heute in Südostanatolien, Türkei, gelegen) auch die Așhāb al-Hayākil, „die Leute der Tempel“, bekannt sind. ${ }^{83}$ Šahrastānī (gest. 548/1153) verwendet diesen Ausdruck zur Bezeichnung einer Untergruppe der Sabäer von Harrān. ${ }^{84}$ Bei der Erwähnung der Sabäer von Harrān selbst hält er

81 Würde das Dokument aus Ägypten stammen, würde man auch die Aufzählung von Völkern erwarten, die das Reich der Mamluken von Afrika aus bedrohen. Auch fehlen hier Bedrohungen durch Volksgruppen aus Indien. Dies gestattet ebenso Rückschlüsse auf den Entstehungsort dieses Dokuments.

82 Vgl. dazu bei Anm. 65-66.

83 Die weiteren Ausführungen machen allein auf den im arabischen Schrifttum mehrfach belegbaren Ausdruck der Așhāb al-hayākil bzw. ihres haykals (Pl. hayākil) aufmerksam. Sie zielen nicht darauf ab, die Frage nach der Identität der Sabäer von Harrān und den von ihnen vertretenen Auffassungen im einzelnen zu klären. Siehe zu den Sabäern von Harrān die ersten Hinweise bei Dodge, Fihrist of al-Nadìm II, 922, Eintrag Șābians (3), mit Hinweisen auf folgende weiterführende Literatur: Chvol'son (Chwolsohn), Ssabier (mit einer Übersicht über ihre Hauptquellen in Bd. 2, S. I-XXXIII; danach Hinweise auf Quellen: Šahrastānī, Mas'ūdī, Dimašqī, Bīrūnī); de Goeje, Mémoire posthume de M. Dozy. Siehe ausserdem Ibn an-Nadīm, The Fihrsit of Ibn an-Nadim [B. Dodge] II, 745-772.

84 Šahrastānī, Kitāb al-Milalwa-n-niḥal II, 49:صحاب الميا كل . والاشخاص: وهؤلاء من فرق الصابئة . Shl. Shahrastani, Livre des religions et des sectes [Jolivet et Monnot (Hg.)], II.159172. 
fest, dass sie den sieben Planeten geweihte Tempel (haykal) errichtet hätten. ${ }^{85}$ Auch Ibn al-Ǧawzì (1116-1201) geht auf diese Așhāo al-hayākil und ihre Auffassungen ein. ${ }^{86}$ Für unsere Belange von besonderem Interesse ist, dass Mas'ūdī (895-957) die Sabäer und ihre Tempel (haykal, Pl. hayākil) ebenso ausführlich erwähnt. ${ }^{87}$ Ausserdem weiss Dimašqī (gest. 727/1327) von ihnen und ihren Tempeln zu berichten. ${ }^{88}$ Es ist nicht das Ziel, den Kult dieser Sabäer aus Harrān hier im einzelnen zu beleuchten. Aus den vorangehenden Angaben lässt sich aber ableiten, dass die Sabäer in ihren Tempeln (haykal, Pl. hayākil) auch die sieben Planeten anbeteten. Diese Ausführungen bedeuten zwar nicht, dass dem Schreiber der vorliegenden Rolle dieser allfällige Bezug zu den Sabäern von Harrān und ihrem Sternenkult aktiv bewusst war. Aber die Verwendung des Begriffs haykal auf der Rolle dürfte indirekt auf die Sabäer von Harrān anspielen. Auch sie dürfte Rückschlüsse darauf zulassen, dass diese Rolle in Südostanatolien, Nordsyrien oder Nordiraq hergestellt worden sein könnte, wo Harrān liegt.

85 Šahrastānī, Kitāb al-Milal wa-n-nihal II, 54-57, v.a. 57; Übersetzung [Jolivet et Monnot (Hg.)] II, 167-172, v.a. 171f.: „Voici maintenant les temples [hayākil] que les sabéens ont construits sous les noms des substances intellectuelles et spirituelles, et selon les formes des astres du ciel:

Le temple de la Cause première et, en dessous d'elle, le temple de l'Intellect, le temple du Gouvernement, le temple de la Nécessité et le temple de l'Ame, qui sont de forme circulaire;

le temple de Saturne, hexagonal; le temple de Jupiter, triangulaire; le temple de Mars, rectangulaire; le temple du Soleil, carré; le temple de Vénus, un triangle dans un carré; le temple de Mercure, un triangle contenant un rectangle; le temple de la lune, octagonal.“ Der Ausdruck Tempel hier stets haykal.

86 Ibn al-Ǧawzī, Talbīs Iblīs 50-52.

87 Maçoudi [Mas'ūdī], Prairies d'or. Texte et traduction par Barbier de Meynard, IV.61-71. Auf diese Stelle macht sodann ausführlich aufmerksam Corbin, Temple et contemplation 143-149 (Kapitel: „Temple sabéen et ismaélisme").

88 Vgl. Dunlop, Dimashḳī, in $E I^{2}$; Textausgabe: Kitāb nuhbat al-dahrfí 'ağāib al-barr wa-l-baḥr; darin 39-45.
II.C Abschnitte mit Gebeten für bestimmte Situationen (formal): Der nächste Abschnitt des Dokuments ist ca. $170 \mathrm{~cm}$ lang ${ }^{89}$ und in $9 \mathrm{Ab}$ schnitte von ungefähr identischer Länge eingeteilt. Die Gestaltung dieser neun Abschnitte stimmt weitgehend mit jener überein, die vom HaykalGebet bekannt ist. Alle Abschnitte sind mit einem Titelbalken mit goldenem Rahmen versehen. Der Hintergrund des Titelbalkens ist bei Abschnitt 2 und 6 blau; in den andern Fällen lassen sich Reste von Verzierungen auf ursprünglich wohl goldenem Hintergrund erkennen. Zumeist sind diese Verzierungen aber kaum noch erkenntlich.

II.C Abschnitte mit Gebeten bzw. Bitten für bestimmte Situationen (inhaltlich):

II.C.1 (Abb. 26-27; A B B. 24): Der erste Abschnitt ist mit der Überschrift Mahabba wa-'atf ([Für] Liebe und Zuneigung) versehen und enthält in erster Linie Auszüge aus dem Koran, die dem Träger der Rolle die Sympathie seiner Mitmenschen garantieren sollen. Der Text lautet:90

$$
\begin{aligned}
& \text { بسم الله الرحن الرحيم |91 يحبونهم كحب الله * | والذين }
\end{aligned}
$$

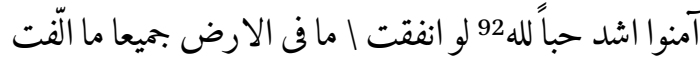

$$
\begin{aligned}
& \text { بين قلوبهم | (ه) ولكن الله اللف (كذا) بينهم انه عزيز } \\
& \text { حكيم } 93 \text { |اللهم اللف بين حامل كتابى هذا | وبين الخلق } \\
& \text { والبشر كما اللفت بين الملك لالذى نصفه نار ونصفه ثلج فلا }
\end{aligned}
$$

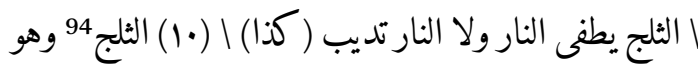

89 Die Länge wurde anhand des Abbildungsmaterials ermittelt.

90 Vgl. Abb. 26 der Rolle (Royal Library).

91 Blütenförmige Verzierung.

92 Aus Q 2:165:

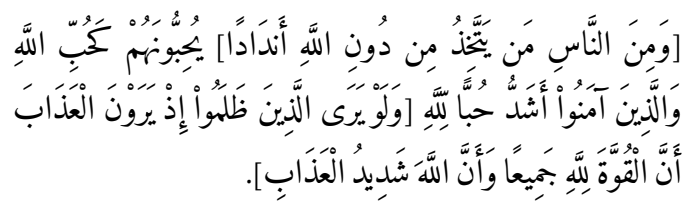

93 Aus Q 8:63:

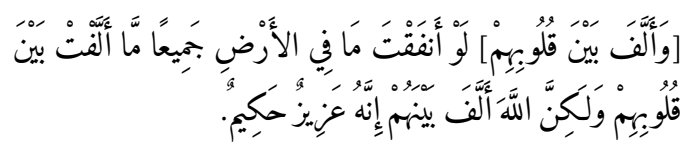


* ينادي يا قدار \اللف بين عبادك الابرار \مج البحرين *

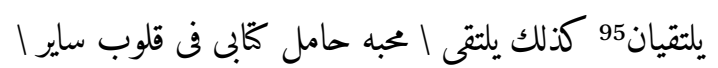

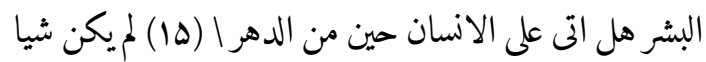

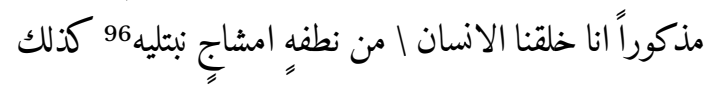

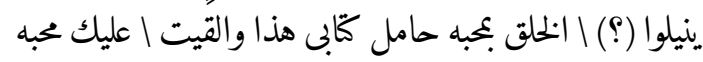

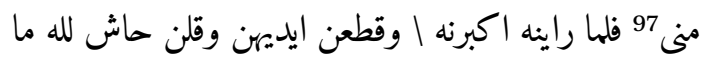

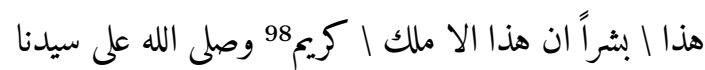

$$
\text { محمد واله وسلز. }
$$

Aus den Anmerkungen zu diesem Ausschnitt geht hervor, dass er nahezu ausschliesslich aus Auszügen aus dem Koran besteht, die auf die eine oder andere Art die Liebe thematisieren. Der Kopist ergänzt diese Auszüge mit dem Ersuchen an Gott, im Fall des Trägers der Rolle ebenso zu handeln, wie dies in den zitierten Koranversen der Fall ist. Der Abschnitt greift mit Q 12:31 auch einen Vers aus der Josefsgeschichte auf. Einzig der Bericht über den Engel, der je zur Hälfte aus Schnee bzw. Feuer besteht, fehlt im Koran.

auf einen Engel gestossen sein, dessen eine Hälfte aus Schnee, die andere aus Feuer bestand. Beide Hälften hätten ungehindert weiter bestanden. Für eine Abbildung dieses Engels siehe Séguy, Muhammeds wunderbare Reise Abb. 10 (S. 51 und 53); http://gallica.bnf.fr/ ark:/12148/btvıb8427195m/f28.image (Stand 14. September 2017).

95 Q 55:19.

96 Aus Q 76:1-2:

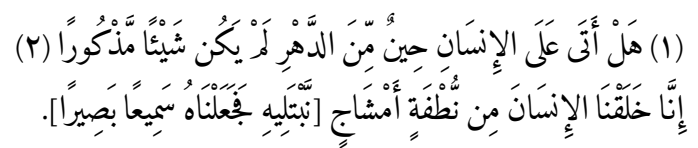

97 Aus Q 20:39:

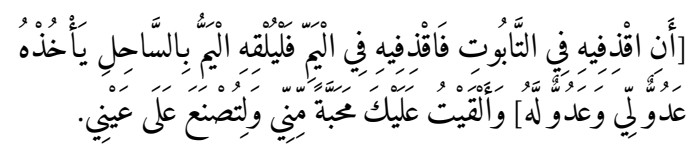

98 Aus Q 12:31:

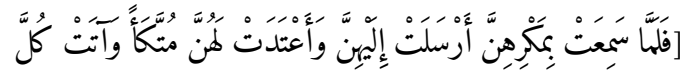

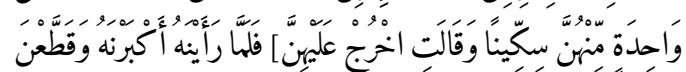

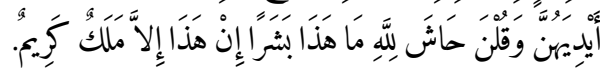

II.C.2 (Abb. 27-28): Der zweite Abschnitt ist mit der Überschrift Li-l-hawf wa-l-fazac („Gegen Furcht und Schrecken“) versehen. ${ }^{99}$ Er baut in erster Linie auf Koranzitaten auf, die gegen Furcht und Schrecken wirksam sein sollen:

$$
\begin{aligned}
& \text { للخوف والفزع || بسم الله الرمم الرحيم | اقبل ولا تخف | } \\
& \text { انك من الامينين } 100 \text { لا تخف نجوت من \القوم الظالمين } 101
\end{aligned}
$$

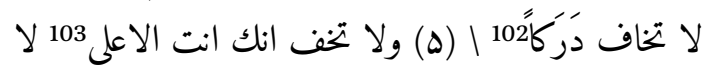

$$
\begin{aligned}
& \text { تخافا انتى معكما اسمع وارى104 لا تخف انى لا يخاف لدى }
\end{aligned}
$$

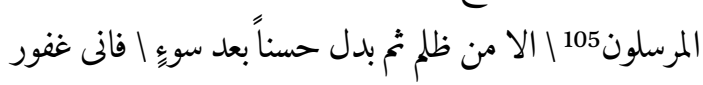

99 Text in einem Titelbalken mit blauem Hintergrund.

100 Aus Q 28:31 (Gott spricht zu Moses bei seiner Begegnung mit ihm):

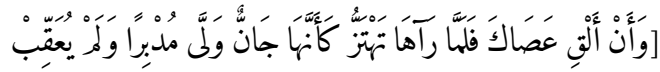

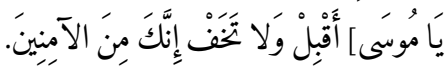

101 Aus Q 28:25 (Moses hütet das Vieh zweier Frauen; ihr Vater bedankt sich bei Moses und spricht ihn an):

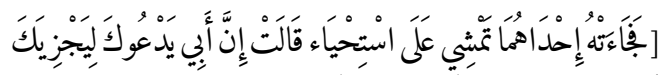

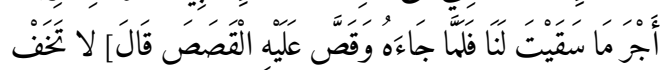

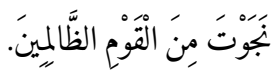

102 Aus Q 20:77 (Gott richtet die Rede an Moses, er solle sich nicht vor Verfolgung durch Pharao und die Seinen fürchten):

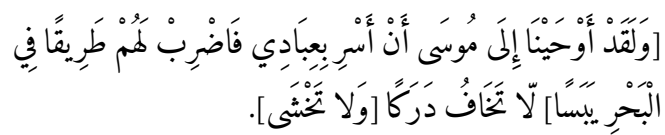

103 Q 20:68 (Gott richtet sich an Moses, als dieser von zwei Zauberern auf die Probe gestellt wird):

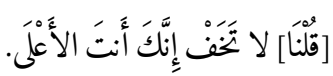

Aus Q 20:46 (Allah schickt Moses und seinen Bruder Aaron zu Pharao, um diesen auf die Probe zu stellen):

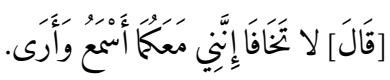

105 Aus Q 27:10 (Moses soll seinen Stab zu Boden werfen, der sich in eine Schlange ( $\breve{a} \bar{a} n n)$ verwandelt; Gott fordert Moses auf, sich nicht zu fürchten):

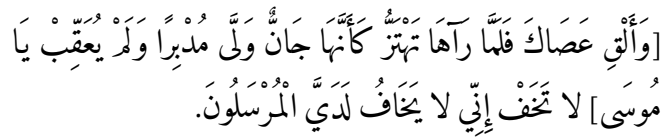




$$
\begin{aligned}
& \text { رحيم } 106 \text { اللهم يا حامل |(•) العرش عن مملة العرش عن }
\end{aligned}
$$

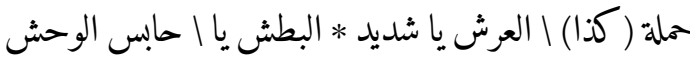

$$
\begin{aligned}
& \text { احبس عن حامل | كَّابى هذا من يظلمه واغلب له من | }
\end{aligned}
$$

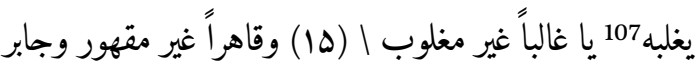

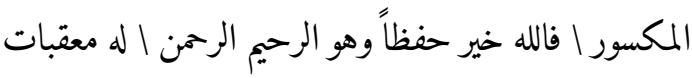

$$
\begin{aligned}
& \text { من بين يديه ومن خلفه | يحفظونه من امر الله } 108 \text { والله من } \\
& \text { ورايهم | محيط بل هو قرآن مجيد في لوح | (ب) محفوظ } 109 \\
& \text { وصلى الله على ا سيدنا محمد واله وصحبه وسلامه. }
\end{aligned}
$$

\section{II.C.3 (Abb. 28-29):}

$$
\begin{aligned}
& \text { عقد لسان } 110 \text { || بسم الله الرحمن الرحيم | *111 عُقِدَت السنه } \\
& \text { الخلق | والبشر عن حامل كنابى هذا | بكول الله وقوته }
\end{aligned}
$$

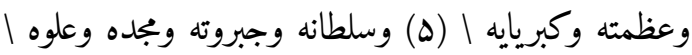

106 Q 27:11:

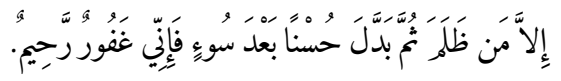

107 Ein Gebet dieses Inhalts lässt sich im Internet mehrfach belegen; es wird mit geringen Abweichungen im Wortlaut ar-Rifāî̄ zugeschrieben und als Hizb al-ḥiṣn bezeichnet; siehe http://www.sufi4.com/?app=article .show.53 (Stand: 3 November 2016; nicht zugänglich am 3. Januar 2018). Derartige Anrufungen sind häufig; eine Quelle mit exakter Übereinstimmung im Wortlaut liess sich nicht feststellen.

Q $13: 11$ (die Rede ist von Engeln, die den Menschen auf Geheiss Gottes von vorn und hinten beschützen):

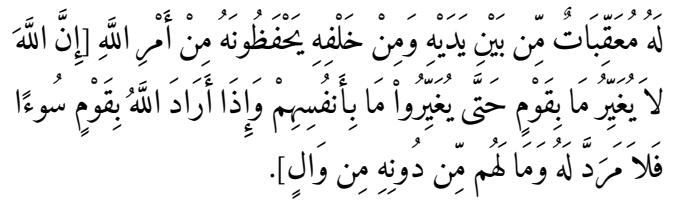
durch Gott anspielen:

$$
\text { مَّفوظٍ ظُ }
$$

Man beachte, dass diese Überschrift halbwegs persisch daherkommt: 'aqd-i lisān; auf arabisch würde man 'aqd al-lisān erwarten.

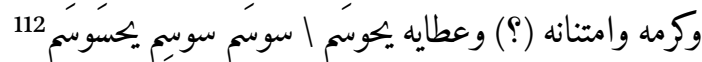
ياهيا | شَرَاهيا ادناى اصباوتِ ال ال شَداي 113 الله الرحمن وبه المستعان114 | (•1) وحامل كَّانى هذا في حرز الله وكنف \الله وجوار الله * في الليل والنهار | والنوم والقرار والظعن 115 والاسفار |Zeile mit Zeichen ${ }^{116}$ | توجه حيث شيت فانت المنصور | وسمطكسلططما118 | والله من ورايهم محيط بل هو اقران جيد في لوح محفوظ 119 | ولا حول ولا قوه الا بالله العلى العظيم | (·r) ولا حول ولا قوه الا بالله | وصلى الله على محلد واله وصحبه وسلم.

112 Der Text ist vokalisiert; die exakte Entzifferung ist nicht gänzlich gesichert.

113 Vgl. zu dieser Formel Canaan, Decipherment 146f. „In most books on magic, as in several talismans we find [this formula in one or another version]. It is clearly taken from the Hebrew (Exodus 3.14)." Mit Verweis auf Goldziher, Hebräische Elemente in muhammedanischen Zaubersprüchen 359. Auch Winkler, Siegel und Charaktere 20, 31-37, 78; Dorpmüller, Religiöse Magie 172 (Anm. 34). Siehe auch Kapitel 4.8 bei Anm. 475 .

114 „Und bei ihm ist der Ort, wo man um Zuflucht bittet“, passives Partizip in der Funktion eines ism makān.

115 Zain bedeutet „Aufbruch, Reise (besonders der Karawane)“, vgl. Wehr, Wörterbuch, s.v.

116 Bei den hier kopierten Zeichen handelt es sich um eine Abfolge von Charakteren, die Buchstaben bzw. Ziffern darstellen bzw. ähneln.

117 "Geh, wohin du willst, dir wird der Sieg verliehen." Vgl. dazu http://lib.eshia.ir/15192/1/404/توجه. Al-'Allāma atṬabāțabāì Sunan an-nabī I, 404, erwähnt diese Aussage. Qum Mu’assasat an-Našr al-Islāmī, Qum, 1416 h.q.

118 Vgl. zu dieser Art Zeichen Winkler, Siegel und Charaktere ${ }_{15}$ - -167 („Brillenbuchstaben“) und 114-119 („Die Formen der sieben Siegel“); Canaan, Decipherment 167-170.

119 Q 85:20-22 (Schlussverse), die ebenso auf den Schutz durch Gott anspielen:

محنَفوظٌ

Diese Stelle bereits am Schluss des vorangehenden Abschnitts (Li-l-hawf wa-l-fazac), vgl. oben bei Anm. 109. 
II.C.4 (Abb. 29):

لدخول الملوك120 || بسم الله الرحمن الرحيم | رجلان * | من الذين يخافون انعم الله عليهما ادخلوا | عليهم الباب فاذا دخلتموه فانكم | (ه) غالبون وعلى الله فتوكلوا ان

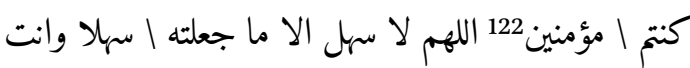

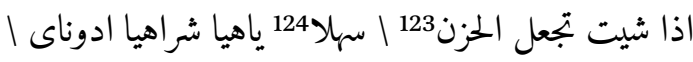
اصباُوتٍ * ال شداى 125 |(•إ) الله الرحمن وبه المستعان الذى | خلقنى فهو يهدين والذى هو يطعمنى ا ويسقين واذا مرضت فهو يشفين وا اذا قرات القران جعلنا بينك وبين |الذين لا يومنون بالاخرة ججاباً | (10) مستوراً وجعلنا على فرئل

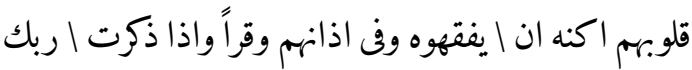
فى القران وحده ولوا على ادبارهم \نفور|اً 126 والله من ورايهم محيط ا وهو قران مجيد في لوح محفوظ.127

120 Für das Notieren der Überschriften in den Titelbalken dürfte ein Illuminator verantwortlich gewesen sein, der im klassischen Arabischen nicht ganz sattelfest war. Die Überschrift würde korrekt lauten: $L i$-d-duhūl 'alā $l$ mulūk.

Blütenförmige Verzierung.

Q 5:23:

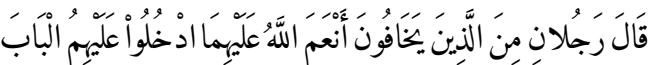

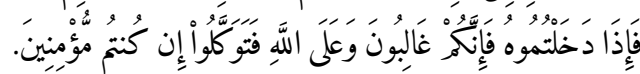

In der Handschrift wahrscheinlich al-hazn.

angebliches Prophetenwort. Es ist u.a. belegt be Abū Nu'aym al-Ișfahānī, Dikr ahbār Ișfahān II, 305 (Leiden, Brill, 1934; http://lib.eshia.ir/22015/2/305); weitere

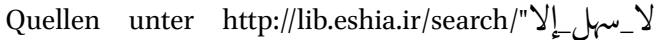
ما_جعلته (Stand beide 3. Januar 2018); vgl. http://www .ahlalhdeeth.com/vb/showthread.php?t=5919 (Stand 3 . November 2016).

125 Vgl. zu dieser Formel Anm. 113.

126 Vgl. Q 17:46:

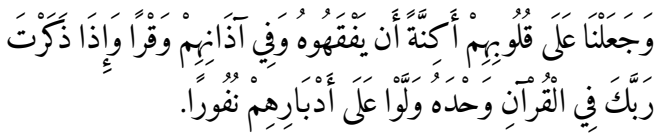

127 Q 85:20-22 (Schlussverse), die ebenso auf den Schutz durch Gott anspielen:
II.C.5 (Abb. 3o): Gemäss seiner Überschrift ( $L i$ ibțāl as-sihrr) soll dieser Abschnitt gegen Magie (sihr) wirksam sein. Der Abschnitt besteht eigentlich ausschliesslich aus Koranzitaten. Die angeführten Verse werden oft nur zum Teil zitiert. Die drei ersten Auszüge enden einfach mit der Verneinung lā; die Fortsetzung der Verse fehlt.

$$
\begin{aligned}
& \text { لابطال السحر || بسم الله الرحمن الرحيم | *128 قال موسى }
\end{aligned}
$$

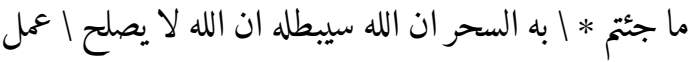

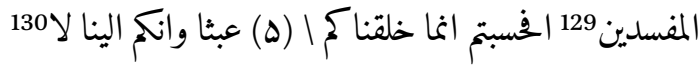

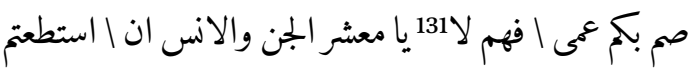

$$
\begin{aligned}
& \text { ان تنقذوا من اقطار السمو[ا]ت | والارض فانقذوا لا132 } \\
& \text { مَّم } \\
& \text { محفوظ: }
\end{aligned}
$$

Diese Stelle bereits am Schluss der beiden vorangehenden Abschnitte (Li-l-hawf wa-l-faza' und 'Aqd-i lisān), vgl. oben bei Anm. 109 und 119 .

Blütenförmige Verzierung.

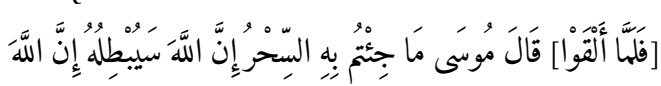

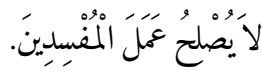

Beachte die Kritik an der Magie (sihr) in diesem Koranzitat; siehe zur Frage auch Kapitel 1.2 (bei Anm. 86).

Aus Q 23:115:

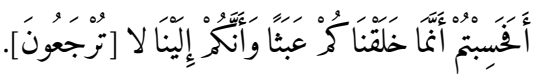

131 Aus Q 2:18:

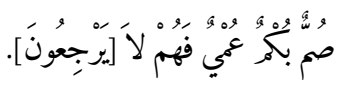

Die Verse werden hier nicht abgeschlossen; es werden nur Auszüge kopiert. Auch die Sinneinheiten scheinen nicht berücksichtigt zu werden. Die angeführten Auszüge brechen drei Mal mit der Verneinung $l \bar{a}$ ab. 
الله اذن لكم |ام على الله تفترون133 واذ صرفنا |(• (1) اليك

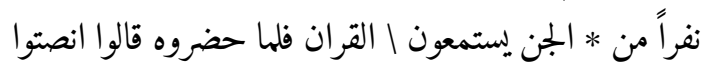

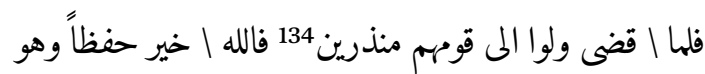

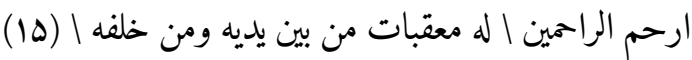

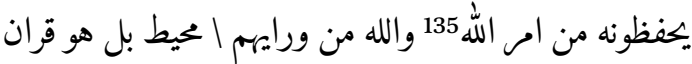

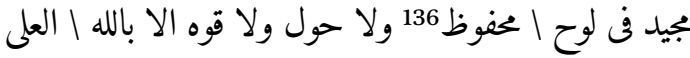
العظيم ا صلى الله على سيدنا محمد واله.

II.C.6 (Abb. 30-31): Aus der Überschrift dieses Abschnitts lässt sich ableiten, dass er bei Augenschmerzen hilft. Der Abschnitt enthält einerseits ein Zitat des Lichtverses (Q 24:35). Anderseits zitiert er Q 50:22, der die scharfe Sehkraft thematisiert. Gott solle dem Träger des vorliegenden Schriftstücks ebenso einen scharfen Blick verleihen. Dieser Abschnitt enthält ausserdem drei Zeilen mit einer Abfolge von Buchstaben und Ziffern. ${ }^{137}$

133 Aus Q 10:59:

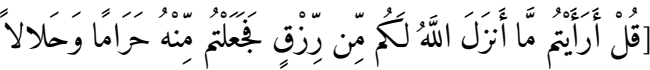

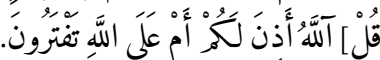

Q 46:29 (ganz):

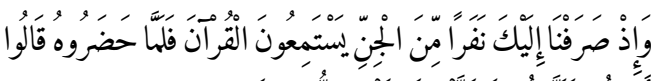

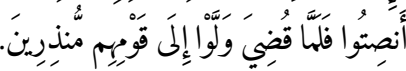

135 Aus Q 13:11:

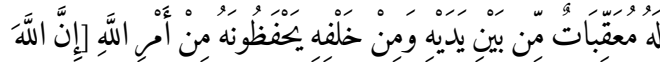

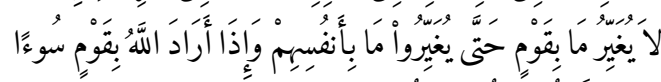

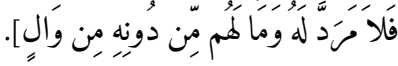

136 Q 85:20-22; diese Verse wurden bereits zuvor mehrfach zitiert (vgl. Anm. 109, 119, 127):

$$
\text { محَفوظٌ }
$$

137 Zu derartigen Abfolgen von Buchstaben und Ziffern vgl. Winkler, Siegel und Charaktere 77; Canaan, Decipherment $15^{2-166 . ~}$

لوجع العينين 138 || بسم الله الرحمن الرحيم | نور السموات | والارض مثل نوره كمشكوة | فيها مصباح

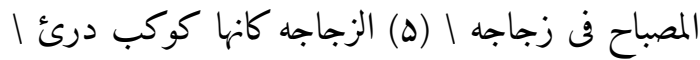
توقد من شجرة مباركة زيتونة | ولا شرقية ولا غربية يكاد |

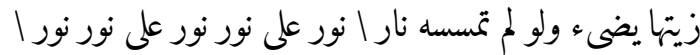

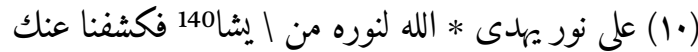

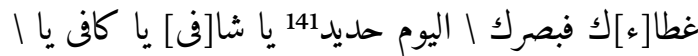
هادى اشف حامل كتانى هذا | بحق هذه الاسما كلها | (ه) Folge von Buchstaben und Zahlen \Folge von Folge von Buchstaben \Buchstaben und Zahlen und Zahlen

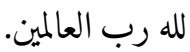

II.C.7 (Abb. 31-32): Dieser Abschnitt schützt gegen unterschiedliche Formen der Hitze, nämlich humma $\bar{a}^{142}$ und humra. ${ }^{143}$ Der Abschnitt wiederholt Q 21:69; die Stelle hält fest, dass Abraham von Nimrod ins Feuer geworfen wurde, Allah es aber für ihn angenehm und kühl gemacht habe. ${ }^{144}$

138 Diese Überschrift in einem Titelbalken mit blauem Hintergrund.

Blütenförmige Verzierung.

Aus Q 24:35 (Lichtvers):

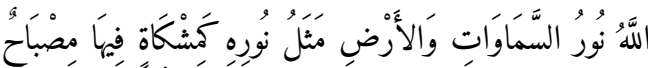

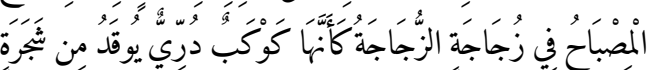

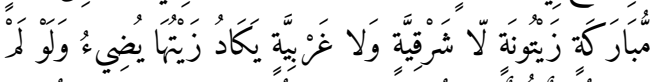

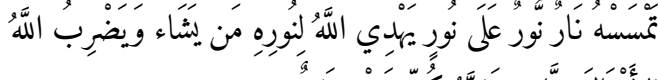

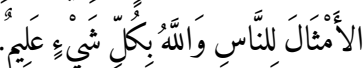

Aus Q 50:22:

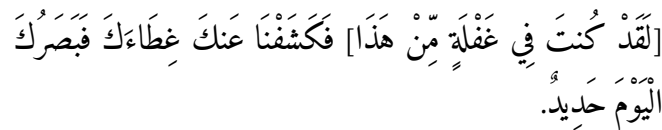

Zu ḥummā, Pl. ḥummayāt, vgl. Kazimirski, Dictionnaire, s.v. „Fièvre“.

Zu humra (?) vgl. Nünlist, Dämonenglaube 145 (Anm. 289: rịh aḥmar: eine Erkrankung von Magen und Darm).

Siehe zu diesem Vorfall auch Bocian, Lexikon der bibli- 


$$
\begin{aligned}
& \text { للمحما والحمره || بسم الله الرحمن الرحيم *145 | اوكد اوكد هرير } \\
& \text { | هرير سرير سرير هو هو | بطيح يطيخ فنلنال } 146 \text { قلنا يا نار | }
\end{aligned}
$$

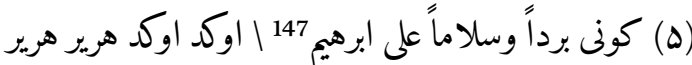

$$
\begin{aligned}
& \text { سرير اسرير هو هو يطيخ يطيخ| فتلتال148 قلنا يا نار كونى النى }
\end{aligned}
$$

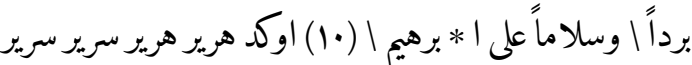

$$
\begin{aligned}
& \text { ا هو هو يطيخ يطيح فتلنال | قلنا يا نار كونى برداً وسلاماً إناً }
\end{aligned}
$$

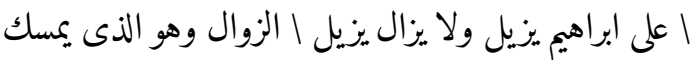

$$
\begin{aligned}
& \text { السما ان تقع | (ه1) على الارض الا باذنه ولا حول ولا قوه } \\
& \text { | الا بالله العلى العظيم وصلى الله على محد | واله وصحبه وسلم } \\
& \text { | والحمد لله رب العالمين. }
\end{aligned}
$$

II.C.8(Abb. 32-33): Dieser Abschnitt nützt gemäss der Überschrift bei Kopfschmerzen. Es fällt allerdings auf, dass der Abschnitt zuerst zwar Abhilfe bei heftigen Kopfschmerzen (dārib) in Aussicht stellt. Bald allerdings soll der Abschnitt auch allerhand andere Krankheiten heilen. ${ }^{149}$

$$
\text { لوجع الراس || بسم الله الرمن الرحيم *150 \اسكن ايها لمكا سكن عرش الرحمن وله ما سكن فى الليل }
$$

schen Personen 18; Busse, Abraham, in $E I^{3}$ (v. a. „1. Abraham in Ur"). Im Koran selbst wird Nimrod nicht als Widersacher Ibrāhīms genannt. In den Korankommentaren ist dies aber der Fall. Siehe auch Schützinger, Abraham-Nimrod-Legende.

Blütenförmige Verzierung.

Zeilen 2-4: immer wieder unpunktiert; genaue Lesung daher nicht gesichert.

Q 21:69:

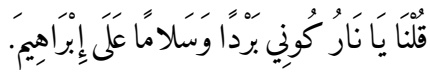

Immer wieder unpunktiert; genaue Lesung nicht gesichert.

Canaan, Decipherment 131 (mit Anm.), macht auf die $\bar{a} y \bar{a} t$ aš-šifä’’ (Verse mit heilender Wirkung) aufmerksam. Sie enthalten stets einen Ausdruck, der sich vom Verb šafā, „heilen“, ableitet. Es handelt sich um Q 9:14, 10:57, 16:69, 17:82, 26:8o und 41:44.

Blütenförmige Verzierung.

Zu ad-dārib: eine starke Form von Kopfschmerzen:

آيات التسكين: يستخدها الرقاه في تسكين الصداع ويقال معها
والهار وهو السميع العليم 152 \(ه) وهو الذى مد الظل ولو

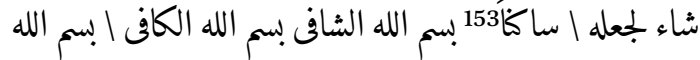

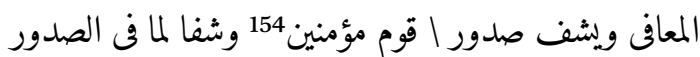
| ويخرج من بطونها شراب مختلف الوانه | (•1) فيه شفا للناس 155 * وينزل من القران / ما هو شفا ورحمه للمومنين واذا | مرضت فهو شافين قل هو للذين امنوا | هدى" وشفا رب الناس \اذهب الباس رب الناس اذهب \ل(ه (1) الباس رب الناس اذهب الباس الا شفا الا شفاوك اشفه وعافه | حامل كَابى هذا شفا لا يغادره | ستما وصلى الله على سيدنا

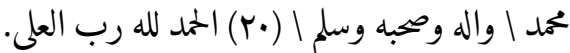

II.C.9 (Abb. 33-34): Gemäss seiner Überschrift enthält dieser letzte thematisch ausgerichtete Abschnitt Aussagen aus dem Koran zum Thema fath (Öffnung, Sieg). ${ }^{156}$ Der vorliegende Abschnitt

$$
\text { الدعاء "اسكن ايها الضارب بألف ألف لا حول ولا قوة الا بالله }
$$

Siehe http://www.roqyahsh.com/vb/archive/index.ph p/t-46705.html (Stand 21. Februar 2018). Q 6:13:

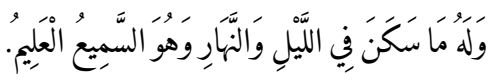

Auszug aus Q 25:45:

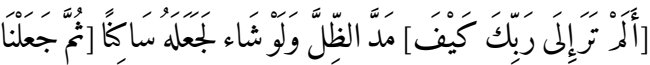

$$
\text { الشَّمس عَلَيَهِ دَرَيلا]. }
$$

Auszug aus Q 9:14:

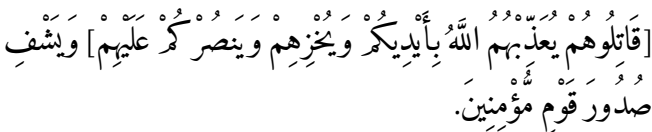

155 Auszug aus Q 16:69:

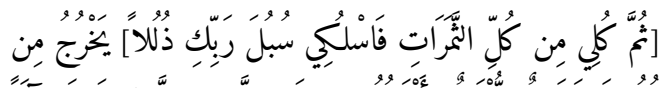

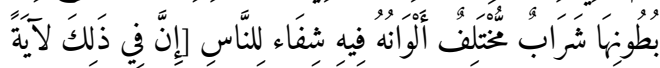

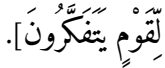

Die Grundbedeutung der arabischen Wurzel fataha bedeutet „öffnen“. Allāh öffnete (fataḥa) bei der Expansion des noch jungen Islams im 7. Jh. die nicht islamisierten Länder für die arabischen Erobe- 
lässt sich als Überleitung zum Teil II.D verstehen, der u. a. Abbildungen von Waffen enthält. Militärische Implikationen dürften damit im Vordergrund stehen.

باب الفتح || بسم الله الرحمن الرحيم *157 ربنا افتح بينتا وبين | قومنا بالحق وانت خير الفاتحين 158 | ان ان ينصركم الله فلا

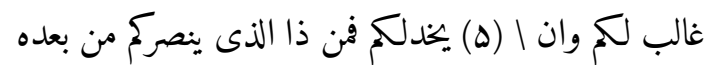
| وعلى الله فليتوكل المومنون159 وما | النصر الا من عند الله

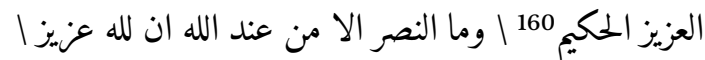
حكيم 161 رب انصرنى على القوم المفسدين 162 |(•) انـا فتحنا

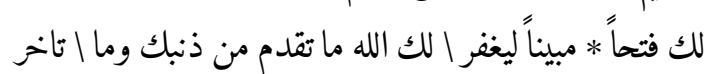

rer, indem er ihnen den Sieg ( fath) verlieh. Für weitere Implikationen des Fath-Konzepts siehe Nünlist, Devotion and protection: Amuletic scrolls dating from the 14th century 508-512.

157 Blütenförmige Verzierung.

$15^{8}$ Aus Q 7:89:

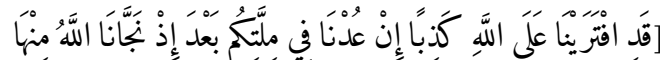

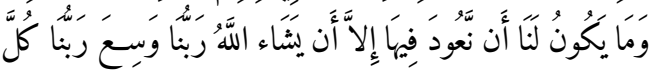

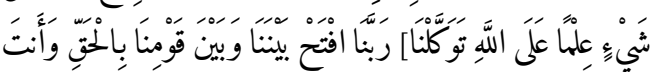

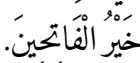

159 Vgl. Q 3:160:

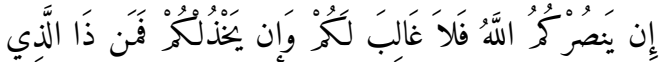

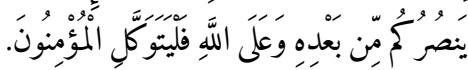

160 Auszug aus Q 3:126 (Schluss):

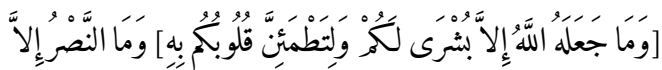

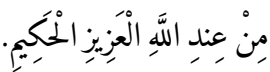

161 Auszug aus Q 8:10 (Schluss; die Stelle ist mit dem vorangehenden Zitat nicht gänzlich identisch):

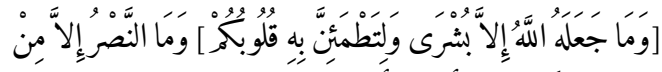

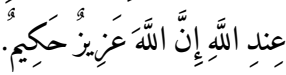

162 Auszug aus Q 29:30:

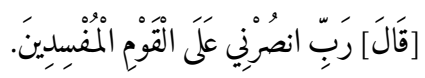

ويتم نعمته عليك ويهديك | صراطا مستقيماً 163 وينصرك الله

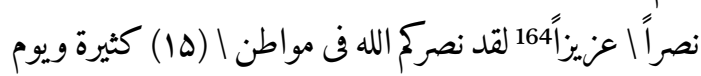
حنين 165 والله يعصمك \ من الناس 166 ويمكرون ويمكر الله والله | خير الماكرين 167 وصلى الله على سيدنا | محمد واله وصحبه

$$
\text { وسلم | الحمد لله رب العالمين. }
$$

II.D Gebete mit Abbildungen von Gegenständen: Dieser nächste längere Teil der Rolle misst ca. $140 \mathrm{~cm}$ und umfasst acht Abschnitte von ähnlicher Länge. Sie sind - ähnlich wie bei den vorangehenden Beispielen - mit golden umrahmten Titelbalken versehen. ${ }^{168}$ Die einzelnen Abschnitte enthalten Text in schwarzem Nash in normaler Grösse. Sie sind mit Abbildungen von Gegenständen (1-7) bzw. einem ğadwal (Abschnitt 8) versehen. Abschnitte 1-3 und allenfalls 4 enthalten Abbildungen von Waffen (Schwert, Pfeilbogen, Lanze, Stab). Dies könnte eine Fortsetzung

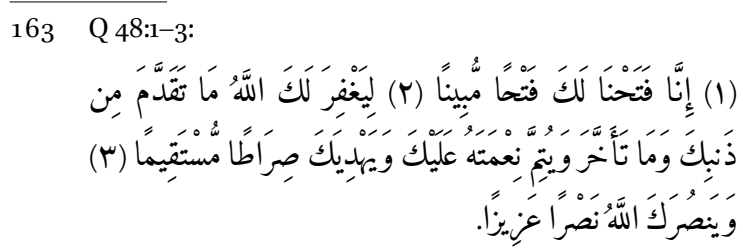

164 Wiederholung Q 48:3.

165 Q 9:25 (Anfang):

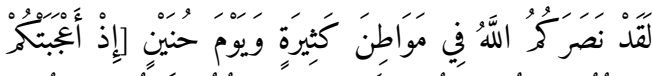

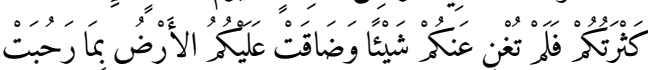

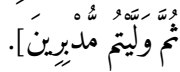

166 Auszug aus Q 5:67:

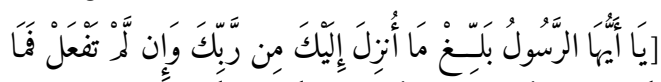

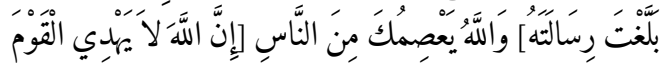

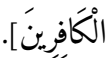

167 Auszug aus Q 8:30:

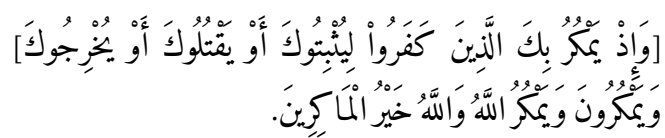

Der Hintergrund der Titelbalken 1 und 5 in diesem Teil der Rolle ist tiefblau. 
des Fath-Konzepts am Schluss des vorangehenden Abschnitts darstellen.

II.D.1 (Abb. 34-35; ABB. 25): In diesem Abschnitt ist ein Schwert abgebildet. Es weist nur eine Klinge auf. ${ }^{169}$ Es ist golden und wird von zwei feinen schwarzen Linien eingefasst. ${ }^{170}$ Gemäss der Überschrift (Li-ḍarb as-sayf) verleiht dieser Abschnitt Erfolg, wenn man im Kampf das Schwert zückt. Darauf weisen auch die Koranzitate hin, die diese Abbildung begleiten. Sie unterstreichen, dass Gott jene bestraft, die sich Ihm und seinem Gesandten im verborgenen verschliessen. Der Gläubige siege auch, wenn seine Feinde in der Überzahl seien.

$$
\begin{aligned}
& \text { لضرب السيف171 || بسم الله الرممن الرحيم *172 | انزلنا }
\end{aligned}
$$

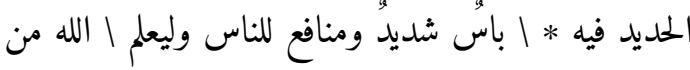

$$
\begin{aligned}
& \text { ينصره ورسله بالغيب | (ه) ان الله قوى عزيز173 فاضربوا } \\
& \text { فوق | الاعناق وا ||174 ضربوا منهم | كل بنانٍ || ذلك بانهم } \\
& \text { | شاقوا الله ورسوله || ومن شاقق | الله ورسوله فان || الله } \\
& \text { شديد ||(•) العقاب175* الان خفف الله | عنكم وان يكن } \\
& \text { || منكم مايه | صابره يغلبوا مئتين وان يكن منكم | الف يغلبوا }
\end{aligned}
$$

169 Zur Abbildung von zweiklingigen Schwertern auf Rollen vgl. Nünlist, Rollen der Andacht 127-129 und Abb. 3b; siehe auch München, BSB, Cod. arab. 204 und Cod. turc. 41.

Beginn der Abbildung des Schwerts.

Q 8:12-13:

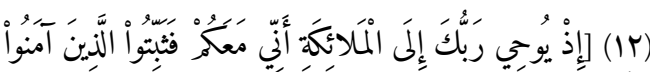

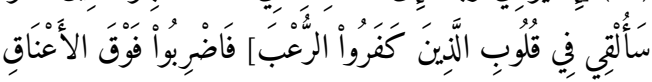

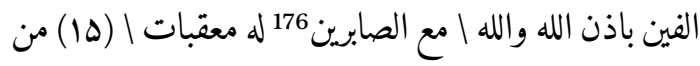

$$
\begin{aligned}
& \text { بين يديه ومن خلفه يحفظونه | من امر الله } 177 \text { والله من ورايهم } \\
& \text { | محيط بل هو قران مجيد في لوح محفوظ.178 }
\end{aligned}
$$

II.D.2 (Abb. 35; AB B. 26): Die Überschrift dieses Abschnitts lautet Li-ramy an-nuššāb. In Übereinstimmung mit dem Titel enthält der Abschnitt die Abbildung von drei Pfeilen und ausserdem von einem Bogen (zumeist golden, vereinzelt blau). Zwischen Pfeilen und Bogen lassen sich Einzelbuchstaben erkennen. Es handelt sich um Text aus Q 8:6o; die Stellen aus diesem Vers ausserhalb der Abbildung wurden in normal verbundener Schrift notiert. Dieser Vers fordert den Gläubigen auf, sich zum Kampf gegen seine Feinde und die Feinde Gottes zu rüsten. Allah werde ihm seine Ausgaben vergüten. Ausserdem enthält der Abschnitt einen Auszug aus Q 8:17, wonach Allah der eigentliche Schütze im Kampf sei. Dieser Vers schreibt dem Schützen einerseits Unterstützung im Kampf zu; er entledigt ihn aber zugleich jeglicher Verantwortung für die Konsequenzen seines Handelns, wozu Verletzungen und Todesfälle zählen.

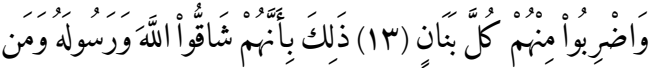

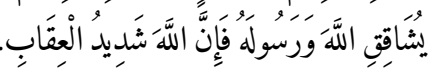

176 Vgl. Q 8:66:

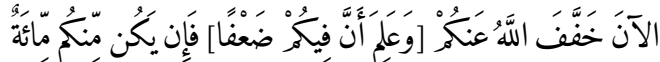

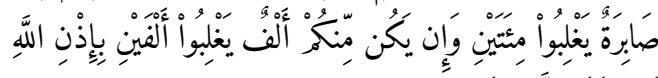

$$
\begin{aligned}
& \text { وَاللَّهُ مَعَ الصَّابرينَ. }
\end{aligned}
$$

177 Auszug aus Q 13:11:

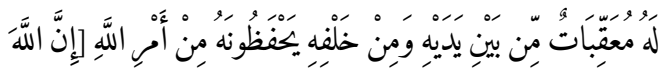

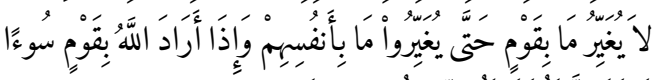

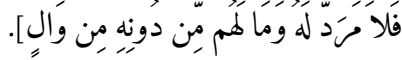

178

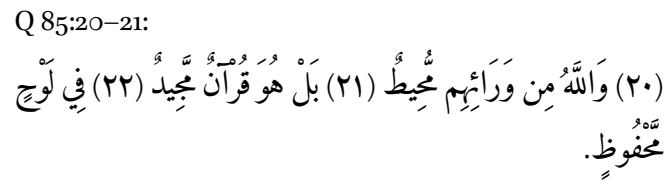




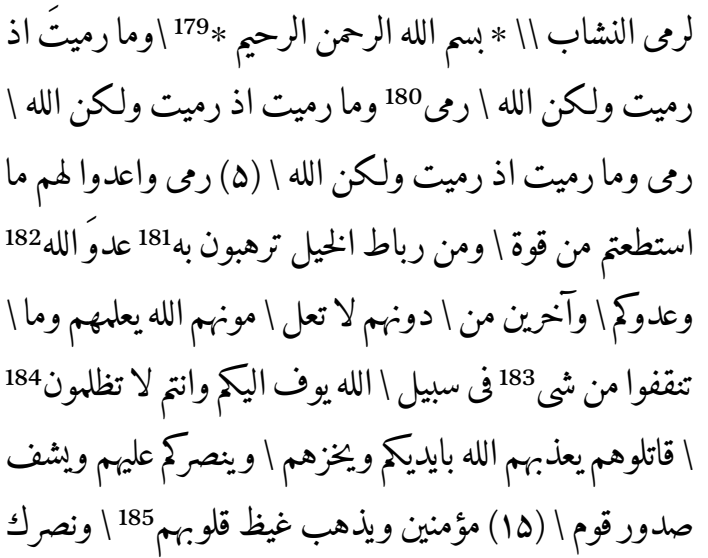
الله وهو خير \الناصرين والحمد لله وصلوة (؟).

179 Blütenförmige Verzierung.

180 Auszug aus Q 8:17, hier drei Mal wiederholt:

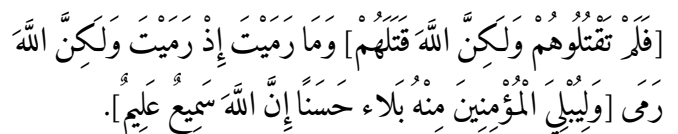

181 Q 8:60:

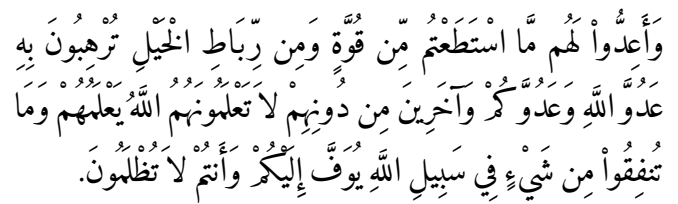

182 Hier beginnt die Abbildung von Pfeil und Bogen; die Begriffe aus Q 8:6o werden in der Fortsetzung zumeist in Einzelbuchstaben zwischen die drei Pfeile und den Bogen verteilt. Q 8:6o ist hier vollständig notiert worden.

Gerade im Umfeld der Magie wird darauf aufmerksam gemacht, dass das Notieren von Wörtern oder Sätzen in Einzelbuchstaben die Schutzwirkung der entsprechenden Stelle bzw. Koranpassage erhöhe (vgl. Canaan, Decipherment 152). Es sieht aber ganz danach aus, dass im vorliegenden Fall in erster Linie das Layout den Kopisten dazu veranlasst hatte, die Fortsetzung des Verses in Einzelbuchstaben zu notieren.

Ab hier werden die Begriffe aus Q 8:6o wieder als ganze Wörter geschrieben.
Auszug aus Q 9:14-15:

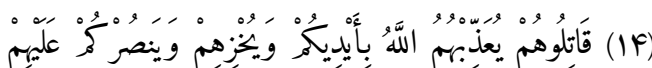

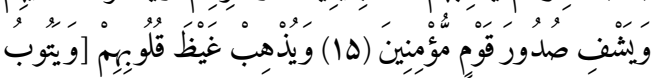

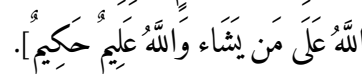

II.D.3 (Abb. 36): Die Überschrift dieses Abschnitts lautet Li-ța'n ar-rumh (Für das Durchbohren mit dem Speer). In Übereinstimmung mit diesem Titel enthält der Abschnitt die Abbildung eines Speers (golden und schwarz umrandet, mit grüner Spitze). Die angeführten Koranverse thematisieren einerseits das korrekte Verhalten, wenn man ein Beutetier (sayd) erlegt. Wer sich nicht korrekt verhalte, werde schwer bestraft (Q 5:94). Der Text fordert anderseits dazu auf, die Ungläubigen zu bekämpfen (Q 9:12). Ausserdem ruft der Kopist dem Träger der Rolle Muhammads Erfolg in der Schlacht von Badr in Erinnerung (Q 3:123). ${ }^{186}$ Auch werde Allah die Gottesfürchtigen durch das Herabsenden von Engeln unterstützen.

$$
\begin{aligned}
& \text { لطعن الرع || * بسم الله الرحمن الرحيم *187 \يا [ا]يها الذين } \\
& \text { امنوا ليبلونكم \الله بشيي من الصيد تناله ايديكم ورما-حكم } \\
& \text { ليعلم الله من يخافه بالغيب | (ه) فن اعتدى بعد ذلك فله } \\
& \text { عذاب اليم } 188 \text { | وطعنوا في دينكم || فقاتلوا ايمة | الكفر انهم }
\end{aligned}
$$

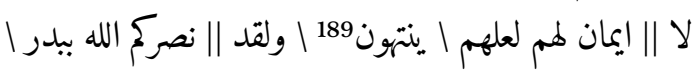

$$
\begin{aligned}
& \text { وانتم اذلة فاتقوا الله لعلكم (•) تشكرون } 190 \text { ان تصبروا وتتقوا }
\end{aligned}
$$

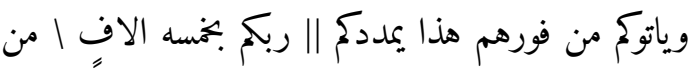

186 Die Schlacht von Badr fand 2/624 statt. Vgl. Athamina, Badr, in $E I^{3}$.

187 Blütenförmige Verzierung.

188 Q 5:94:

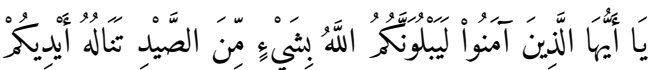

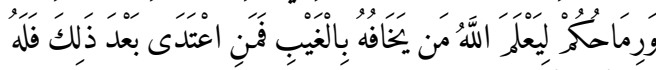

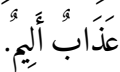

189 Auszug aus Q 9:12:

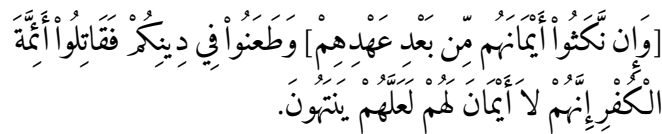

190 Dieser letzte Ausdruck wurde teilweise in Einzelbuchstaben zwischen Verzierungen und der Abbildung des Speers verteilt. Es handelt sich beim Zitat um Q 3:123:

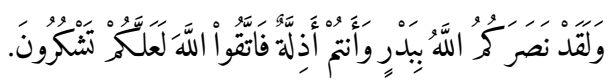


الملايكة || مسومين وما | (ها ) جعله الله الا بشرى [لكم]191

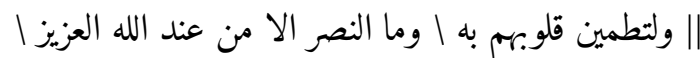

Es folgen zwei Zeilen mit Ziffern und الحكيم 192 193Buchstaben \الله الرممن المستعان وعليه التكلان |ولا

$$
\text { حول ولا قوة الا |(r) بالله العلى العظيم. }
$$

II.D.4 (Abb. 36-37): Die Überschrift lautet 'Așāt $M \bar{u} s \bar{a}$ (Moses' Stab). Moses' Stab wird in diesem Abschnitt golden dargestellt und ist an seinem untern Ende blau. Oben hat er einen Aufsatz, der an eine mehrblättrige Blüte erinnert. Dieser Aufsatz lässt sich allerdings auch als Kopf bzw. Mund einer Schlange interpretieren. Dies legt jedenfalls die blaue Zunge nahe, die aus dem goldenen Mund lugt. Auch könnte der kleine Kreis das Auge der Schlange darstellen (von der Seite betrachtet). Beim Begleittext handelt es sich um Q 20:17-29. Diese Stelle beschreibt Vorfälle aus Moses' Leben und schliesst sich an einen Hinweis auf Moses' Begegnung mit Gott im Ṭuwā-Tal an (Q 20:12). Gott verwandelt den Stab in eine Schlange, die Moses allerdings problemlos anfassen kann. Gott verwandelt sie nämlich zurück. Die Stelle spielt ausserdem auf das Wunder mit der Hand an, die weiss bleibt. ${ }^{194}$ Als Gott Moses zu Pharao schickt, bittet er seinen Herrn, ihm die Zunge zu lösen, damit er Pharao und die Seinen warnen könne und dabei auch verstanden werde.

191 La-kum: Dieser Ausdruck fehlt; er dürfte durch den Speer verdeckt sein.

192 Vgl. Q 3:125-126:

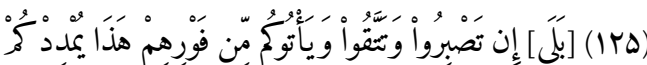

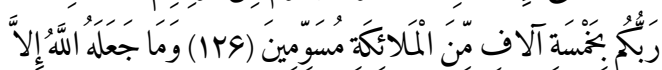

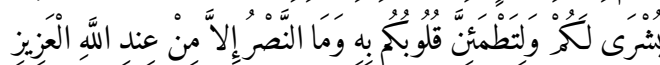

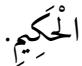

193 Es handelt sich wohl um eine Stelle aus dem Koran; die Ziffer $\mathrm{H}$ dürfte als w zu lesen sein. Die Stelle liess sich bis anhin aber nicht identifizieren.

194 Der Koran schildert diesen Vorfall in Q 7:108, 20:22, 26:33, 27:12, 28:32. Vgl. auch Heller und Macdonald, Mūsā, in $E I^{2}$ (2. Abschnitt).
عصاة موسى || * بسم الله الرحمن الرحيم *195 | وما تلك

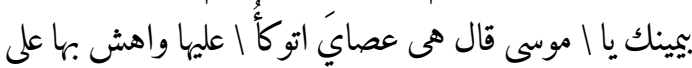
غنمى ولى فيها مارب | (ه) اخري قال القها يا موسى فالقاها | فاذا هى حيه تسعى || قال | خذها ولا تخف || سنعيدها | سيرتها الاولى || واضمم يدك الي | جناحك تخرج بيضا ||

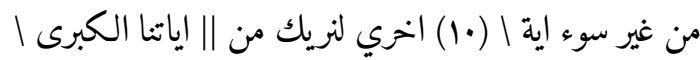

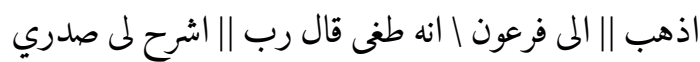
| ويسر لى امرى || واحلل عقده من السانى يفقهوا || قولى

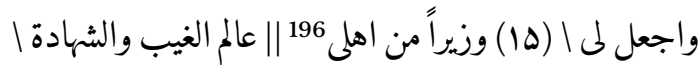

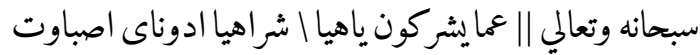
ال شداى \الله الرحمن وبه المستعان وصلى الله \على سيدنا

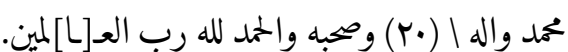

II.D.5 (Abb. 37-38): Die Überschrift dieses Abschnitts lautet $L i$-šs-šams wa-l-qamar (Für Sonne und Mond). In Übereinstimmung mit dieser Überschrift finden sich in diesem Abschnitt zwei Scheiben. Die obere Scheibe stellt die Sonne dar; sie ist golden. Dem Rand der Scheibe entlang verläuft ein goldener Ring. Im Innern der Scheibe lässt sich ein blütenförmiges Zierelement mit vier lanzettenförmigen Blättern erkennen. Im Zentrum befinden sich vier blaue Punkte. Darunter folgt die zweite Scheibe; sie stellt den Mond dar. Im unteren Teil der Scheibe lässt sich eine Sichel mit blauem Hin-

\footnotetext{
195 Blütenförmige Verzierung.

196 Aus Q 20:17-29:

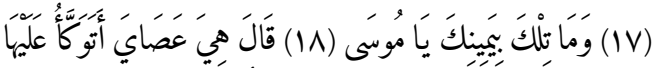

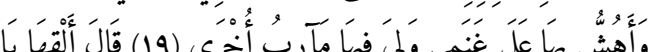

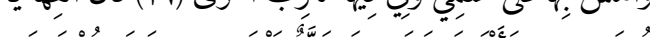

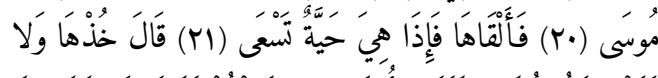

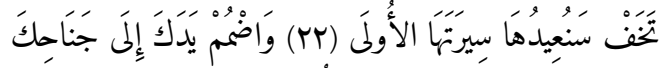

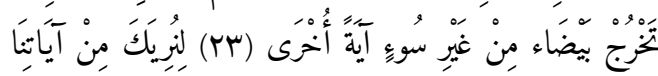

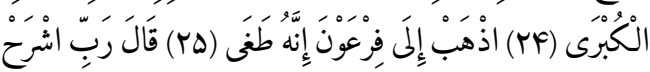

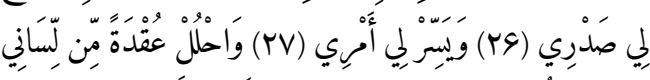

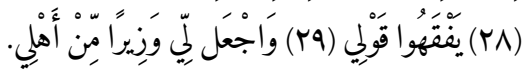


tergrund und goldenen Verzierungen erkennen. In diese Scheibe ist ein Kreis integriert, der von einem goldenen Ring eingefasst wird. Die Zitate aus dem Koran in diesem Abschnitt unterstreichen die Bedeutung von Sonne und Mond für den Fortbestand der Schöpfung.

$$
\begin{aligned}
& \text { للشمس والقمر || * بسم الله الرحمن الرحيم *197| والشمس } \\
& \text { تجرى لمستقر \لها ذلك تقدير العزير العليم ا والقمر قدرناه }
\end{aligned}
$$

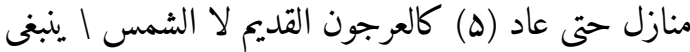

$$
\begin{aligned}
& \text { لها ان * تدرك القمر \ ولا الليل سابق النهار وكل في \الك الك }
\end{aligned}
$$

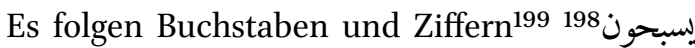
من | كل ما خلق (؟) || فيهما وهو | الذى ينزل الغيث

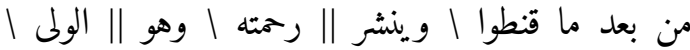
الحميد200 والله خير حفظاً | (ه) وهول وهو ارحم الراحمين 201

197 Blütenförmige Verzierung.

198 Q 36:38-4O:

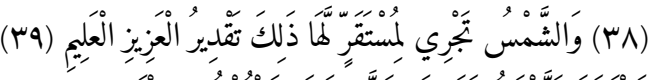

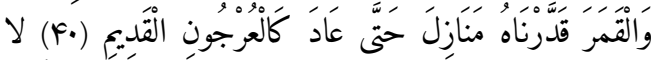

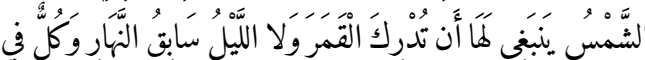

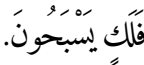

199 Es ist davon auszugehen, dass es sich letztlich um eine Stelle aus dem Koran handelt; sie liess sich allerdings nicht identifizieren. Die Buchstaben wurden hier unverbunden geschrieben. Die Ziffer $\uparrow$ dürfte für ein س bzw. ش stehen. Die Ziffer ץ steht mit grosser Wahrscheinlichkeit für das Buchstabenelement $\smile$. Je nach Punktierung kann es sich um die Buchstaben ث, ب, handeln. Das Ab̆̆ad-System dürfte bei der Erklärung dieser Zeichenfolge keine Rolle spielen.

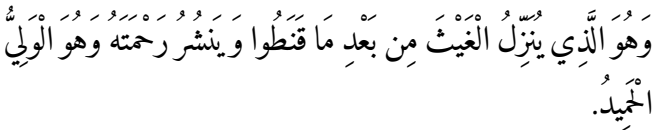

Vgl. Q 12:64 (Schluss):

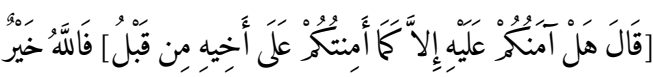

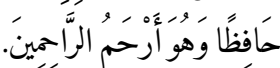

$$
\text { ولكن لا تفقهون اتسبيحهم انه كان حليماً |غفوراً } 202 \text { والحمد }
$$

II.D.6 (Abb. 38-39): Die Überschrift dieses Abschnitts lautet $L i$-ğalb ar-rizq; dieser Abschnitt soll dem Träger der Rolle den Lebensunterhalt sichern. Darauf weist gerade das Zitat von Q 3:27 hin. Gott ist sogar in der Lage, dem Gläubigen ausserordentliche Dinge zu verschaffen, wie das Zitat von Q 27:40 unterstreicht. In diesem Vers erklärt Āṣaf b. Barhiyā Salomon, dass er in der Lage sei, den Thron der Königin von Saba herbeizuschaffen. Allerdings kann Glück rasch in Unglück umschlagen, wenn sich der Gläubige nicht um die Unterstützung durch Gott bemüht und zu ihm betet (Q 94:5-8). Dieser Abschnitt enthält die Abbildung einer goldenen Hand mit fünf Fingern. In der Handfläche lässt sich ein goldener Kreis erkennen. Es dürfte sich um die Hand der Fāțima handeln. Sie steht auch für die fünf Angehörigen des Hauses des Propheten (ahl al-bayt: Muhammad, 'Alī, Fāțima, Ḥasan, Husayn) und wird als Schutzmittel geschätzt. ${ }^{203}$ Der vorliegende Abschnitt enthält überdies ein Gebet um Lebensunterhalt, das auf Ğa'far aṣ-Ṣādiq, den 6. Imām der Schiiten, zurückgeführt wird. Anhand dieser Elemente lässt sich aber nicht notwendigerweise auf einen schiitischen Hintergrund dieses Belegstücks schliessen.

$$
\begin{aligned}
& \text { لجلب الرزق ||* بسم الله الرحمن الرحيم *204 |وكفلهازكيا } \\
& \text { كلما | دخل عليها زكريا المحراب وجد عندها | رزقاً قال يا رديا } \\
& \text { مـيم انى لك هذا | (ه) قالت هو من عند الله ان اللهيرزق | } \\
& \text { من يشا بغير حساب205 \اللهم ان كان رزق صاحب | هذا }
\end{aligned}
$$

202 Auszug aus Q 17:44:

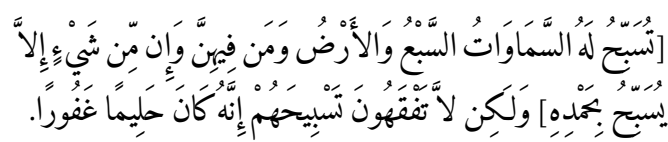

Zur Hand der Fāțima vgl. Kriss und Kriss-Heinrich, Amulette 2 f. und 5, Abb. 1-11.

204 Blütenförmige Verzierung.

205 Aus Q 3:37: 
الكتاب فن السما فانزله المى الارض ا وان كان قريباً فيسره

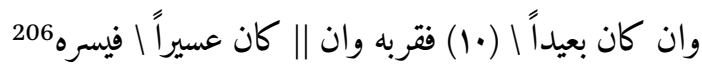
قال || الذى عنده | علم من الكّاب || انا اتيك | به قبل ان ||

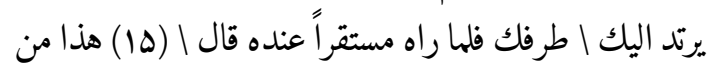
فضل ربى ليبلونى [ا]شكر ام | اكفر ومن شكر فانما شكر لنفسه

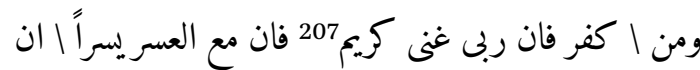
مع العسر يسراً فاذا فرغت فانصب ا والم ربك فارغب وصلى الله على سيدنا | (ب) محمد واله وصحبه وسلم | الحمد لله

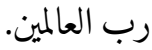

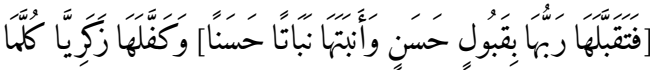

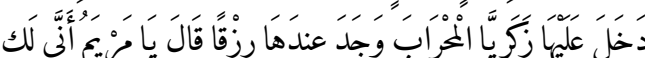

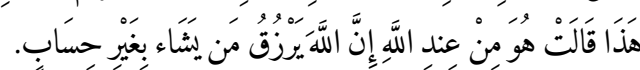

Der Vers spielt darauf an, dass Zakariyyā' Maryam nach der Geburt in den Tempel gebracht hatte. Wenn er sie dort jeweils besuchte, fand er bei ihr reichlichen Lebensunterhalt (rizq). Maryam antwortet ihm auf seine Frage, Gott gewähre ausreichenden Lebensunterhalt, wem auch immer er wolle, und tue dies unbesehen.

Es handelt sich um ein Gebet um Lebensunterhalt (rizq). Es lässt sich in modifizierter Form mehrfach nachweisen, siehe u.a.: Mağlisī, Miftāḥ al-ğinān 562, Bayrūt, Mu’assasat al-A'lamī li-l-Mațbū'āt, 1423 (vgl. http://lib.eshia.ir/71431/1/562); Mağlisī, Bihār al-anwār 95, 295, s. l., Mu'assasat al-Wafā', 1403 (țabca 2, vgl. http:// lib.eshia.ir/11008/95/295; Stand 7. November 2016). Diese zweite Quelle führt das Gebet auf Ǧācfar aṣ-Ṣādiq, den 6. Imam der Schiiten, zurück.

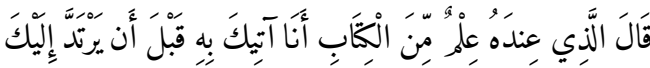

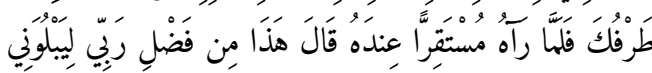

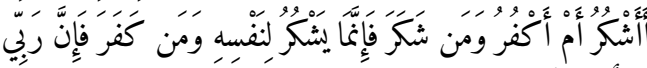

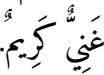

208

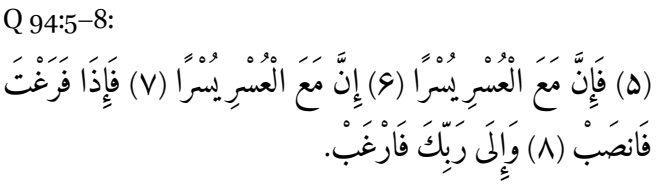

II.D.7 (Abb. 39; ABB. 27): Die Überschrift dieses Abschnitts lautet Li-l-haya wa-l-'aqrab (Gegen Schlange und Skorpion). Der Abschnitt enthält in Übereinstimmung mit seinem Titel die Abbildungen einer Schlange und eines Skorpions. Beide Tiere sind golden und weisen schwarze Konturen auf. Vereinzelte Teile werden durch rote Striche hervorgehoben.

$$
\begin{aligned}
& \text { للمية والعقرب | * بسم الله الرمن الرحيم *209 | الم ترا } \\
& \text { المى الذين خرجوا | من ديارهم وهم الوف | حذر الموت }
\end{aligned}
$$

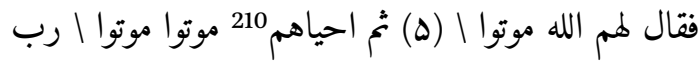

$$
\begin{aligned}
& \text { اوزعنى ان \اشكر نعمتك التى \انعمت علي وعلى والدي211 } \\
& \text { | ولا حول ولا قوة الا بالله العلى \العظيم والحمد لله رب المبل }
\end{aligned}
$$

II.D.8 (Abb. 40): Dieser letzte Abschnitt trägt die Überschrift Li-'usr al-wiläda (Gegen schwere Geburt). Er greift zwei Koranstellen auf. Die erste Stelle (Q 84:1-4) thematisiert, wie sich am [Jüngsten Tag] der Himmel spaltet und sich die Erde öffnet. Der Text weicht danach vom Wortlaut im Koran ab und nimmt Bezug auf die Situation einer schwangeren Frau. Sie solle ebenso wie die Erde das Kind aus ihrem Innern herauswerfen. Es werde, so Gott will, gesund und muslimischen Glaubens sein. Die zweite Stelle thematisiert,

209 Blütenförmige Verzierung.

210 Auszug aus Q 2:234:

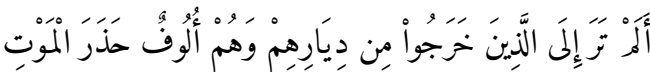

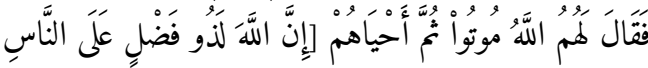

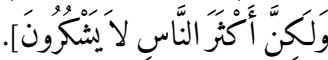

211 Vgl. Q 27:19 (hier zitiert, siehe auch Q 46:15):

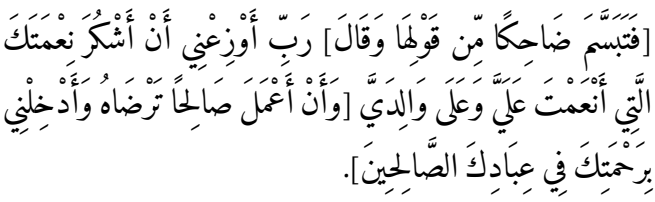

Die Stelle berichtet von Salomons Begegnung mit der Ameise; vgl. Nünlist, Dämonenglaube $448 \mathrm{f}$. 
wie Allah die Himmelstore öffnet und es heftig regnen lässt. Auch sprudle Wasser aus zahlreichen Quellen.

$$
\begin{aligned}
& \text { لعسر الولادة | * بسم الله الرحمن الرحيم *212 | اذا السما }
\end{aligned}
$$

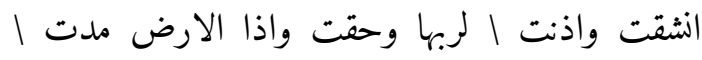

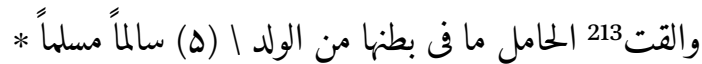

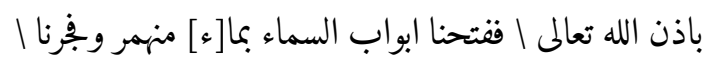

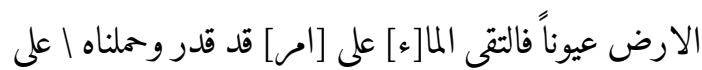

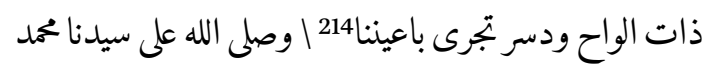

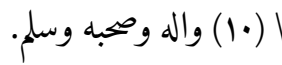

Dieser Abschnitt wird mit einem Quadrat mit $3 \times 3$ Zellen abgeschlossen. In diese Zellen sind Buchstaben eingefügt, nämlich: 1. Linie (von links

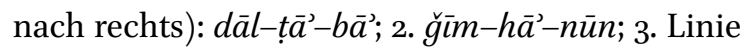
von links nach rechts: $h \bar{a}-$ alif-wāw. Ganz am

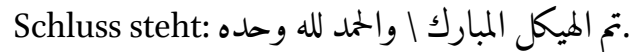

Abschnitt III (Kolophon; Abb. 40-41; AB B. 28):

Vor Kolophon (im Abschluss des abgerundeten Rechtecks): تح الميكل المبارك \والحمد لله وحده.

Kolophon:

$$
\begin{aligned}
& \text { وافق فراغ الميكل المبارك في يوم الاثنين المبارك } \\
& \text { من شهر رمضان المعظم قدره } \\
& \text { ومُمان ماية }
\end{aligned}
$$

212 Blütenförmige Verzierung.

213 Vgl. Q 84:1-5, mit Anpassungen in der Fortsetzung an die Situation einer schwangeren Frau bei der Geburt:

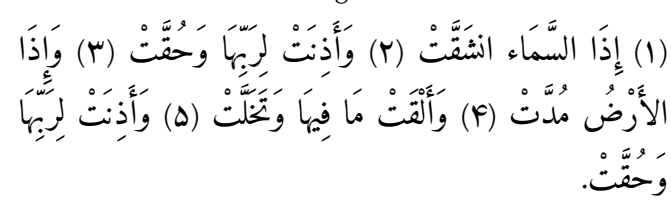

214 Q 54:1-14:

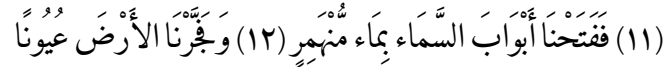

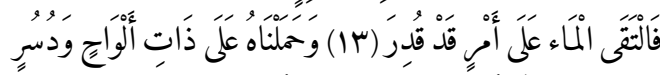

$$
\begin{aligned}
& \text { (1F) }
\end{aligned}
$$

215 Feste Wendung zum Preisen des Monats Ramaḍān.

$$
\begin{aligned}
& \text { احسن الله تعالى تقضيتها على يد اقل عبيد الله المسلمين }
\end{aligned}
$$

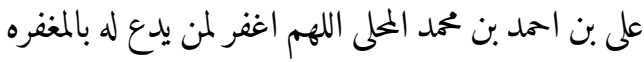

$$
\begin{aligned}
& \text { ونظر نظرا (؟) اليه }
\end{aligned}
$$

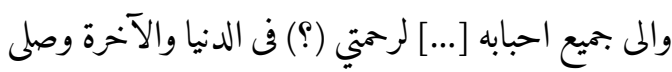

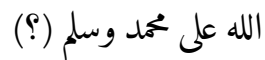

Datierung: Montag, den 11. Ramaḍān 8o3/25. April 1401; Schreiber: 'Alī b. Aḥmad b. Muḥammad alMahallī. Die Entzifferung der beiden letzten Zeilen des Kolophons ist nicht gesichert (Stelle teilweise verderbt).

Schlussfolgerungen: Dieses Dokument ist von grosser Bedeutung, da es klar datiert ist (803/1401). Aus der Aufzählung der Feinde im 6. Abschnitt des Haykal-Gebets (Araber, Perser, Türken, Kiptschaken, Byzantiner, Tataren [Mongolen], Armenier) lässt sich schliessen, dass dieses Dokument einen Bezug zu Südostanatolien, Nordsyrien oder Nordirak aufweist. ${ }^{216}$ In dieselbe Richtung könnte auch der Begriff haykal weisen. Er spielt indi-

\begin{tabular}{|c|c|c|}
\hline Abb. 26 & Mahabbawa-'atf & Liebe und Zuneigung \\
\hline Abb. 27 & Li-l-hawf wa-l-fazac & Gegen Angst und Schrecken \\
\hline Abb. 28 & 'Aqd lisān & $\begin{array}{l}\text { [Für] das Verknoten der } \\
\text { Zunge }\end{array}$ \\
\hline Abb. 29 & Li-duhūul al-mulūk & $\begin{array}{l}\text { Für das Eintreten bei } \\
\text { Königen }\end{array}$ \\
\hline Abb. 30 & Li-ibțāl as-siḥr & Gegen Zauberei \\
\hline Abb. $3 \circ f$. & $L i$-wağa'al-'aynayn & Gegen Augenschmerzen \\
\hline Abb. $31 \mathrm{f}$. & $\begin{array}{l}\text { Li-l-hummā wa-l- } \\
\text { ḥumra }\end{array}$ & $\begin{array}{l}\text { Gegen Fieber und } \\
\text { Hautrötungen }\end{array}$ \\
\hline Abb. 32 & Li-wağa'ar-ra's & Gegen Kopfschmerzen \\
\hline Abb. 33 & Bāb al-fath & Für den Sieg \\
\hline Abb. 34 & $L i$-darb as-sayf & Für Schwerthiebe \\
\hline Abb. 35 & Li-ramy an-nuššāb & $\begin{array}{l}\text { Für das Schiessen mit } \\
\text { Pfeilen }\end{array}$ \\
\hline Abb. 36 & $L i-t ̦ a \bar{c} n$ ar-rumḥ & $\begin{array}{l}\text { Für das Durchbohren mit } \\
\text { Lanzen }\end{array}$ \\
\hline 216 & Ghen bei Anm 79 & \\
\hline 217 & oben bei Anm. $82-8$ & \\
\hline
\end{tabular}
rekt auf die Sabäer von Ḥarrān an; unter ihnen gibt es eine Gruppierung, die als Așhāo al-hayākil bekannt ist. $^{217}$

Zur besseren Übersicht werden hier die Schutzgebete auf der Rolle nochmals zusammengestellt: 
Abb. $38 \mathrm{f} . \quad$ Li-ğalb ar-rizq

Abb. 39 Li-l-hayya wa-l-

$\begin{array}{ll}\text { Abb. } 40 \quad \text { Larab } & \text { Li-'usral-wilāda }\end{array}$

Für den Lebensunterhalt (Sold)

Gegen Schlangen und

Skorpione

Für eine leichte Geburt

Als Anhang wird hier ausserdem das $D \boldsymbol{u}^{\prime} \overline{\boldsymbol{a}}^{\prime} \boldsymbol{a s}$ Sayfi-Gebet aufgenommen (АВВ. 20): ${ }^{218}$

\section{دعا السيف / السيفى}

1. Medaillon (mit Titel und 3 Zeilen Text; Abb. 10)

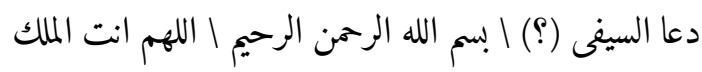

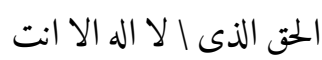

2. Vierpass

انت ربى وانا | عبدك عملتُ | سواٌُ وظلمت نفسى فاغفر لى |

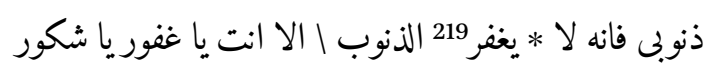

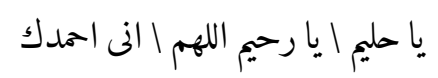

3. Vierpass

$$
\begin{aligned}
& \text { وانت للممد اهل | على ما اختصصتنى به | من مواهب } \\
& \text { الرغايب واوصلت } 220 \text { \اليَّ من فضايل * الصنايع واو اليتنى } \\
& \text { به من احسانك وبوا |تنى به من مظنة | الصدق }
\end{aligned}
$$

4. Vierpass (Abb. 10-11)

$$
\begin{aligned}
& \text { وانتنى \ من مننك الواصله (؟) \الي واحسنتَ الم \ من }
\end{aligned}
$$

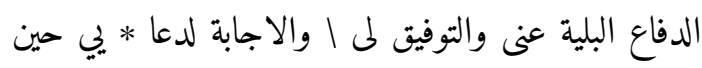

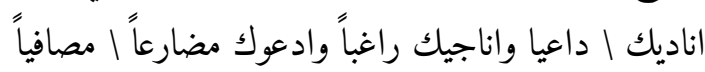

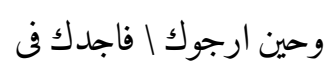

218 Vgl. dazu oben bei Anm. 45-56 (Vierpassgebet).

219 Siehe mit Abweichungen im Detail: http://lib.eshia.ir/ 71561/1/126 (unten; Stand 2o. Februar 2018).

220 Siehe mit Abweichungen im Detail: http://lib.eshia.ir/ 71561/1/127 (Stand 20. Februar 2018).
5. Vierpass (Abb. 11)

المواطن كلها | له حاضراً خفياً | مارًا وفى الامور ناصراً

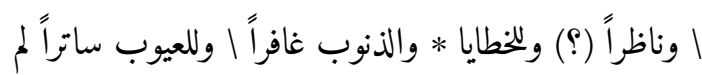

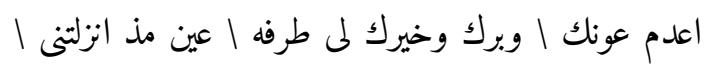
دار

6. Vierpass (Abb. 11)

الاختبار | لتنظر ما اقدم | لدار القرار فانا عتيقك | ايا

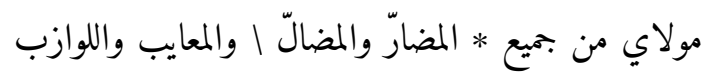
واللوازم | والمموم التى قد ساورتنى | فيها الغموم (؟) بمعا |

ريض

7. Vierpass (Abb. 11)

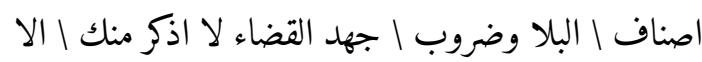

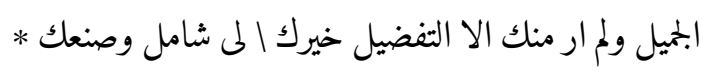

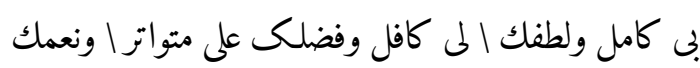
عندى متصله الم تحقر جوارى (؟)

8. Vierpass (Abb. 11)

وصدقت | جواري وصاحبت | اسفاري واكرمت | احضارى وشفيت امراضي وعافيت | منقلبي ومثواي * ولم تشمت بن اعدايى | ورميت من رمانى وكفيتنى شر من | عاداني لفمدي لك | واصب وثنائي | لك ومن ومنين متواتر

9. Vierpass (Abb. 12)

دايم من الدهر \الى الدهر بالوان انواع \التسبيح خالصاً

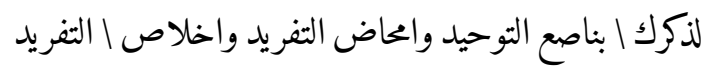

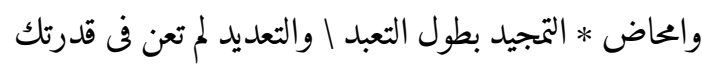
ولم تشارك | في الميتك ولم يعلم لك ماهية فتكون \ل للاشيا

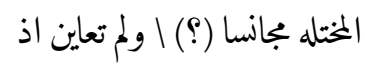


10. Vierpass (Abb. 12)

حبست الاشيا ا على العزايم المختلفات ا ولا خرقت الاوهام

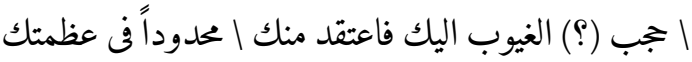
* ولا يبلغك بعد \الممم ولا ينالك غوص الفطن ولا ينتهى | اليك بصر ناظر في مجد | جبروتك ارتفعت | عن صفه

11. Vierpass (Abb. 12)

المخلوقين | صفات قدرتك | وعلا عن ذكر الذاكرين | كبريا

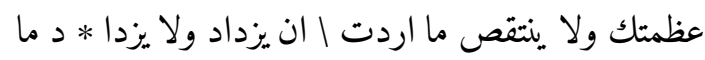
اردت ان | ينتقص (؟) ولا ضد حضرك حين فطرت الخلق

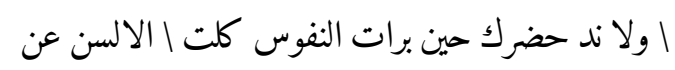

12. Vierpass (Abb. 13)

تفسير عظمتك | وانحسرت العقول | عن كنه معرفتك |

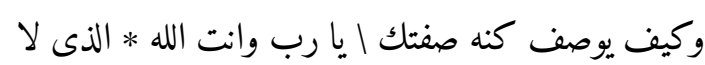

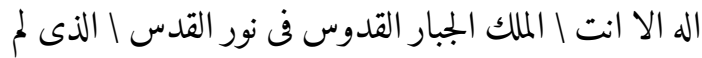

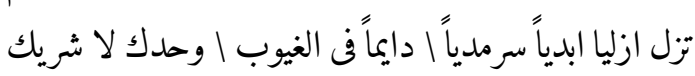
ك

13. Vierpass (Abb. 13)

ليس فيها احد | غيرك ولم يكن اله | سواك حارت في |

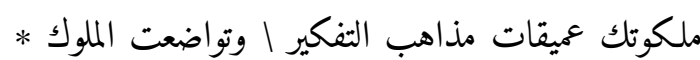
لميبتك وعنت الوجوه بذلة الاستكانه لعزتك وايقاد (انقاد؟) | كل شى لعظمتك | واستسلم كل شى القدرتك

14. Vierpass (Abb. 13)

وخضعت لك | الرقاب وكل ذلك | تحبير اللغات وضل

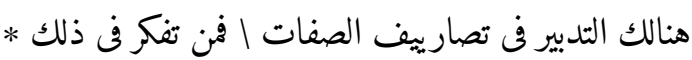

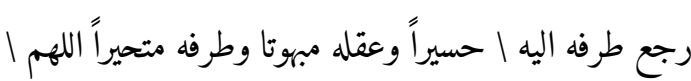

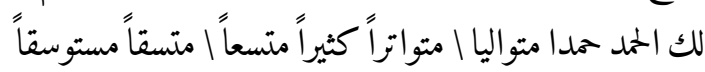
(مستوثقاً؟)
15. Vierpass (Abb. 13)

يدوم ولا يبيد (؟) \غير مفقود في الملكوت | ولا مطموس

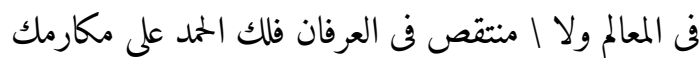

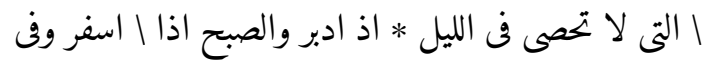
البروالبحار والغدو والاصال | والعشى والابكار والظهـيـ]رة لئيل

والاسحار وفى كل جزو (؟)

16. Vierpass (Abb. 14)

من اجزاء الليل | والنهار اللهم بتوفيقك قد احضرتنى النجاة وجعلتنى | منك فن ولاية العصمة فلم ابرح منك في سبوغ |

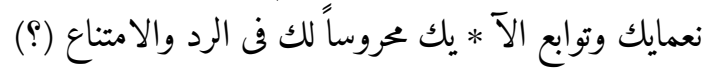
محفوظاً لك في المنعه والدفاع ا ولم تكلفنى فوق الطاقتى ولم تزض منى | [الا ] طاعتى

17. Vierpass (Abb. 14)

فانك انت الله \الذى لا اله الا انت الم تغب ولا تغيب عنك

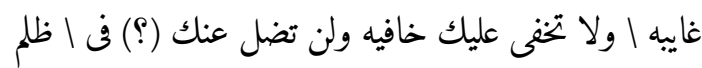
[الخفيات] ضاله * انما امرك اذا اردت الشيا ان تقول له كن فيكون اللهم لك المحد | مثل ما حمدت به نفسك | وحمدك به

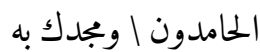

18. Vierpass (Abb. 14)

الممجدون | وكبرك به المكبرون | وهللك به المهللون | وعظمك به المعظمون حتى يكون لك منى وحدى ا في كل طرفه عين * واقل من ذلك مثل | حمد جميع الحامدين وتوحيد

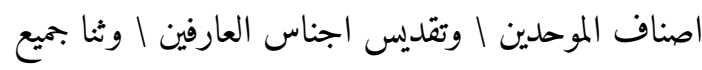
المهالين المصلين ا والمسبحين

19. Vierpass (Abb. 14)

ومثل ما انت | به عالم وهو محمود | ومحبوب ومحجوب من

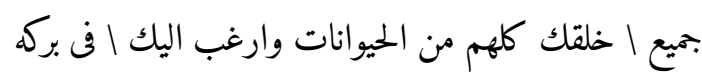


ما انطقتنى * به من حمدك \فا إسر ما كلفتنى من حقك

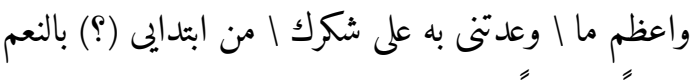
فضلاًا وطولاً مطاً

2o. Vierpass (Abb. 15)

وامتتنى بالشكر | حقاً وعدلاً [ووعدتنى] | عليه اضعافاً

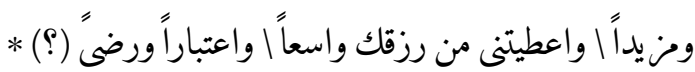

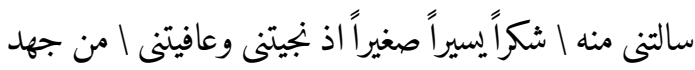
البلا ولم تسلمنى ابسوء (؟) فضايك ا وبلايك وجعلت

21. Vierpass (Abb. 14)

ملبسي العافيه | واوليتنى البسطة والرخا | وسوغت إسر

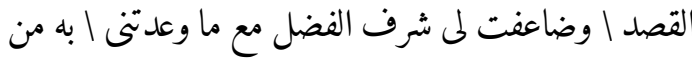
المحجة الشريفه * وبشرتنى به من \الدرجة الرفيعة واصطفيتنى

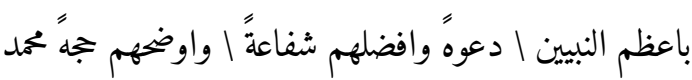

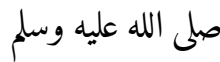

22. Vierpass (Abb. 14)

وعلى اله وعلى \جميع الانبيا والمرسلين \اللهم اغفر لى ما

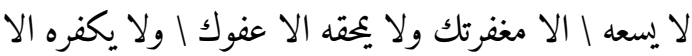
تجاوزك وفضلك | وهب وشهرى هذا وسنتى | هذه يقيناً صادقاً

23. Vierpass (Abb. 14)

يهون علي مصايب الدنيا ا والاخره واحزانهما | ويشوقنى اليك ويرغبنى رغبه فيما عندك \ا واكتب لى عندك * المغفرة

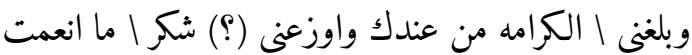
به عليَّ افانك انت الله

$221 \mathrm{Ab}$ hier siehe http://lib.eshia.ir/71561/1/131 (Stand 20. Februar 2018).
24. Vierpass (Abb. 16)

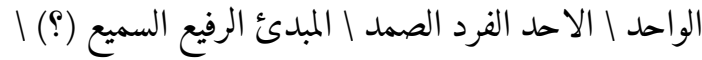

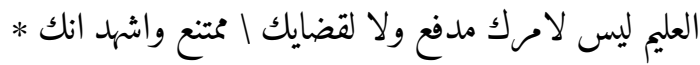

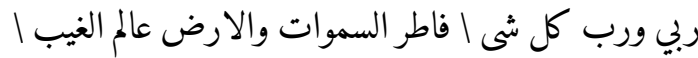
والشهادة العلى \الكبير المتعال

25. Vierpass (Abb. 15)

اللهم اني اسالك \الثبات في الامر والعزيمه \علي الرشد والشكر على نعمك | واعوذ بك من جور * كل جاير وبنى النى

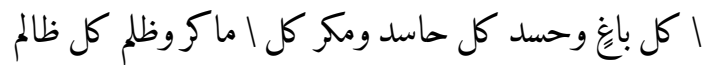
ا وسير كل ساحر اوشماته

26. Vierpass (Abb. 16)

كل كاثخ ابك اصول على الاعداء | واياك ارجو(ا) ولايه

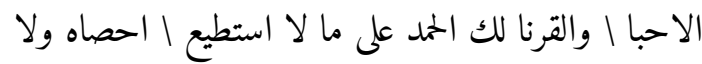

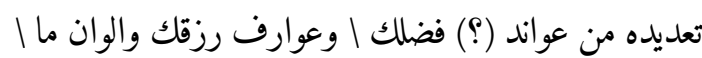

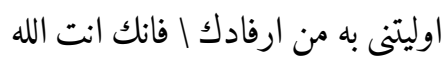

27. Vierpass (Abb. 16)

الذى لا اله الا \انت الفاشى فى الخلق | حمدك والباسط بالجود يدك الا تضاد في حكمك * ولا تنازع في سلطانك

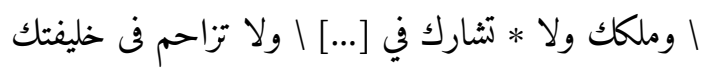

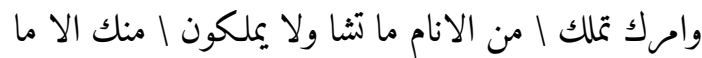
تريد اللهم ا انت المنعم

28. Vierpass (Abb. 17)

القادر \القاهر المقتدر \القدوس فى نور القدس \

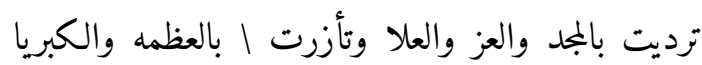

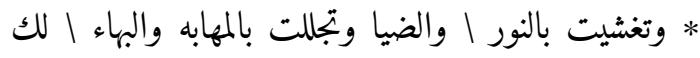

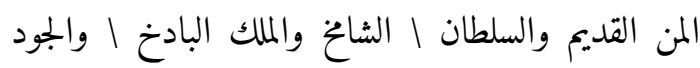

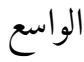


29. Vierpass (Abb. 17)

والحكمه البالغه | والقدره الكامله | ولك الحمد على ما جعلتنى

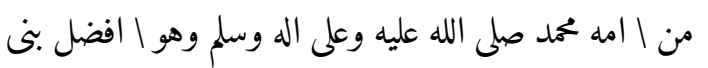

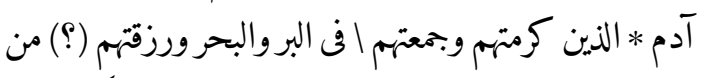
الطيبات | وفضلتهم على كثير من خلقت | تفضيلاً وخلقتنى

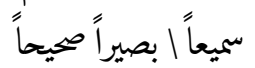

3o. Vierpass (Abb. 17)

سوياً سالماً | معافاً ولم تعِلّني | بنقصان فن بدنى | ولم

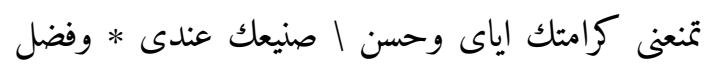

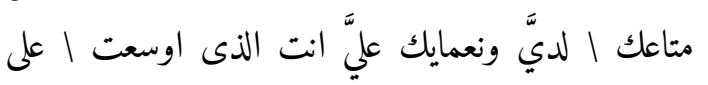

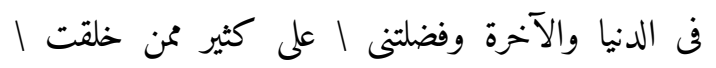

\section{تفضيلا}

31. Vierpass (Abb. 17)

وجعلت لى سمعا | يسمع اياتك وبصراً | يرى قدرتك وعقلا يفهم ايمانك وفوادا يعرف عظمتك | وقلباً يعتقد توحيدك فانى لفضلك | عليَّ حامد ولك نفسى شاكره وبحقك شاهد اهده | فانك 222 حي قبل كل حي | وحى بعد كل حى وحى | بعد

ک

32. Vierpass (Abb. 18)

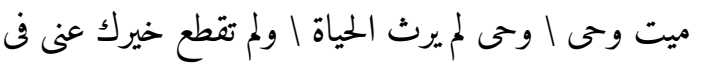

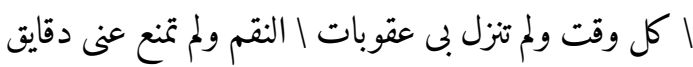

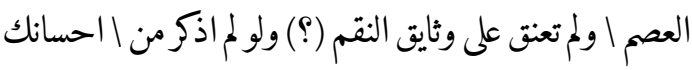
الا عفوك | عنى والتفيق

222 Vgl. ab hier http://lib.eshia.ir/71561/1/132 (Stand 20. Februar 2018); die Abweichungen zwischen dem Text auf lib.eshia.ir und jenem auf der Rolle sind hier aber beträchtlich.
33. Vierpass (Abb. 18)

والاجابه لدعايَ | حين رقعت صوتى | بتوحيدك وتيجيدك |

والا في تقديرك خلقى حين صورتنى ا فاحسنت صورتى والا

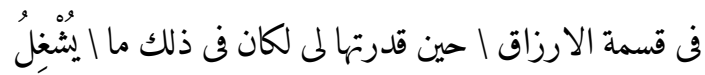

شكرى عن | جهدى فكيف | اذا (؟)

34. Vierpass (Abb. 18)

فكرت في النعم \العظام التى انقلب \ فيها ولا ابلغ شكري

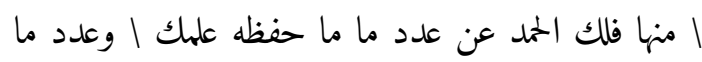

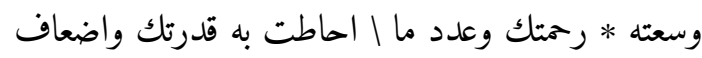
ما تستوجبه (؟) \ من خلقك اللهم فتمم احسانك اليَّ فيما | بقي من

35. Vierpass (Abb. 18)

عمرى كما احسنت | المَّ فيما مضى منه | اللهم انى اسالك

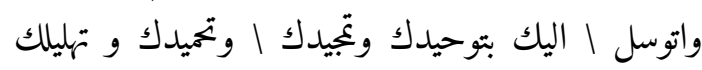

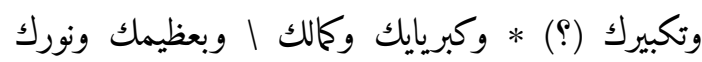

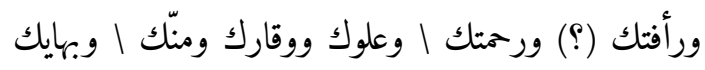
وبمالك | وجلالك

36. Vierpass (Abb. 19)

وسلطانك | وقدرتك واحسانك | وامتالك (؟) ونبيك وعترته | الطاهرين الا * تحرمنى رفدك | وفضلك وعوايد كراماتك وانه لا | يعتريك لكثيرة ما قد بشرت | من العطايا عوابق |

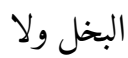

37. Vierpass (Abb. 19)

ينقض جودك | التقصير فى شكر | نعمتك ولا يخاف | ضيم املاق فشكوي (؟) ولا يلحقك |خوف عدم * فينقص من جودك \فيض فضلك اللهم ارزقنى قلباً اخاشعاً ضارعاً وبدناً | صابراً ويقيناً | صادقاً 
38. Vierpass (Abb. 19)

$$
\begin{aligned}
& \text { ولساناً ذاكراً اوحامداً ورزقاً ا واسعاً وعلهاً نافعاً وولداً صالحاً } \\
& \text { * وسناً طويلاً | وعملا صالحاً واسالك رزقاً حلالاً طيباً }
\end{aligned}
$$

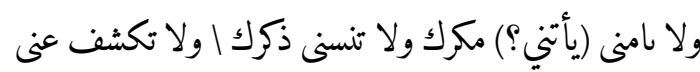

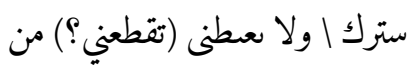

39. Vierpass (Abb. 19)

$$
\begin{aligned}
& \text { رحمتك ولا | تبعدنى من كرمك وجوارك | واعذنى من }
\end{aligned}
$$

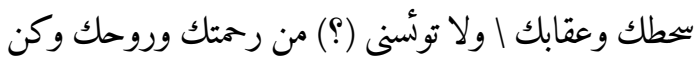

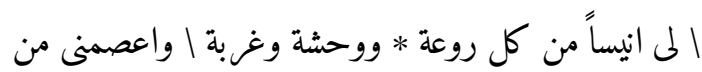

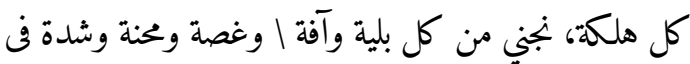

$$
\begin{aligned}
& \text { الدارين انك \لا تخلف الميعاد وصلى الله | على سيدنا محمد } \\
& \text { واله وسلم |الحمد لله رب العلمين. }
\end{aligned}
$$




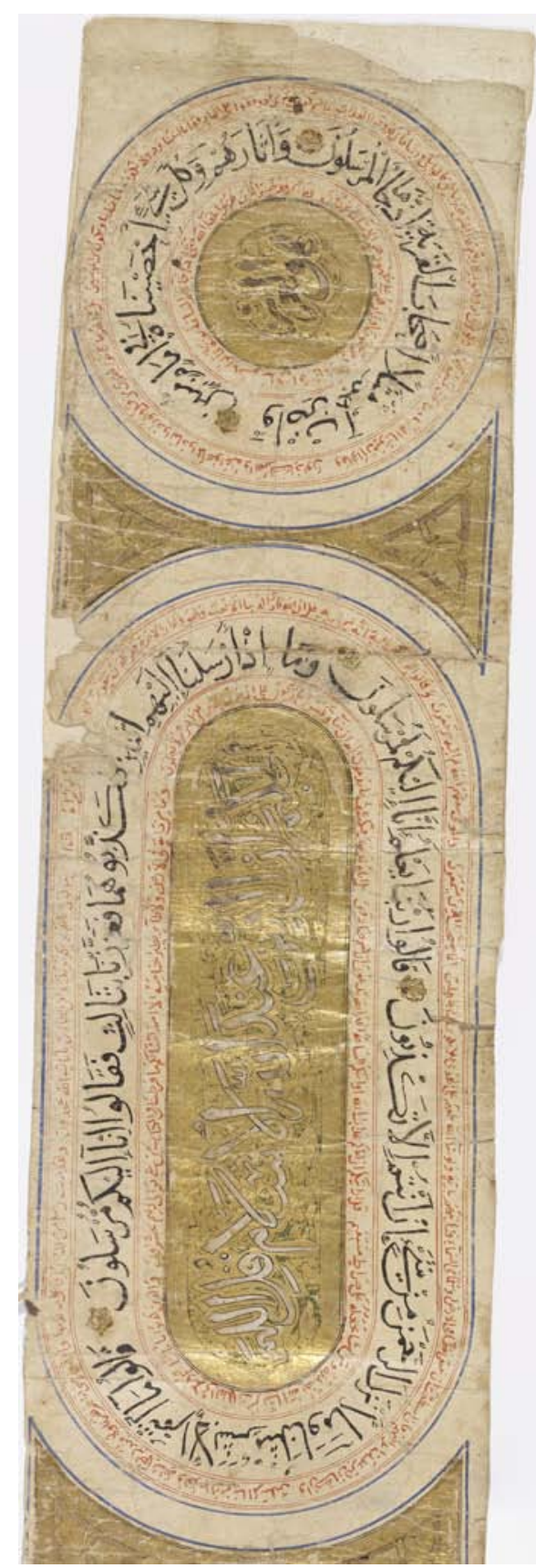

ABB. 18
Kopenhagen, The Royal Library, Cod. Arab. 53 (vgl. bei Anm. 89): Anfang des erhaltenen Teils der Rolle. Die Medaillons und abgerundeten Rechtecke werden von einem dreiteiligen Schriftband mit Text aus dem Koran umfahren. Diese Figuren sind untereinander nicht verbunden.

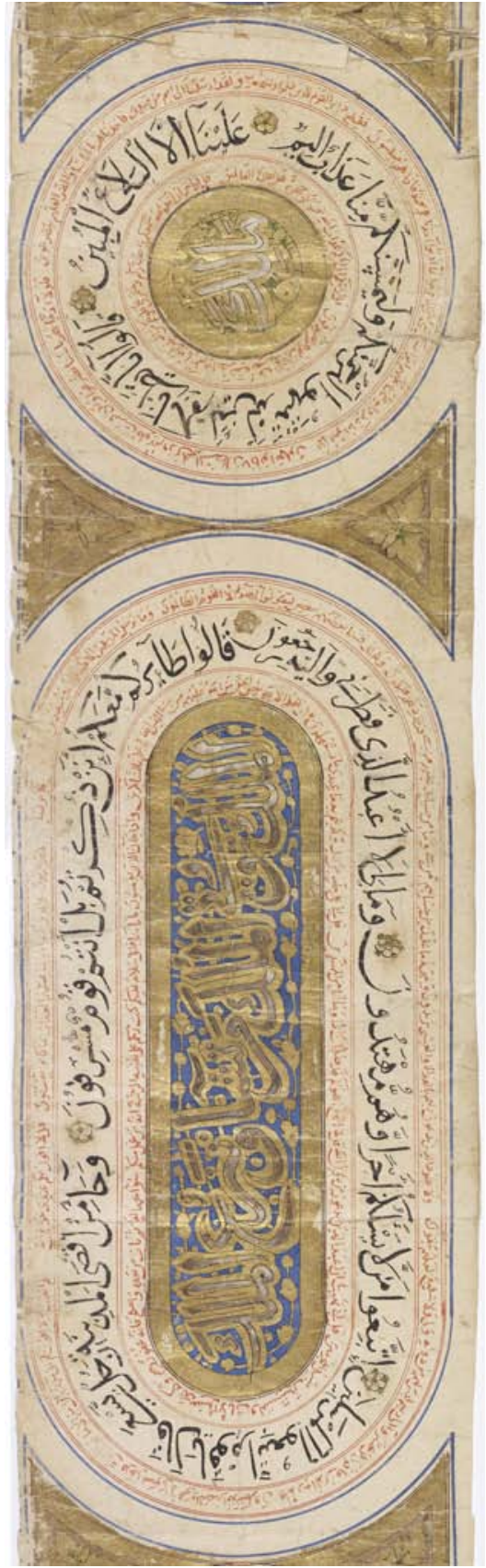

АВB. 19

Kopenhagen, The Royal Library, Cod. Arab. 53 (vgl. nach Anm. 11): Langes, an beiden Enden abgerundetes Rechteck. Auf dem blauen Hintergrund wurde in grosser, golden eingerahmter Zierschrift Q 3:26 kopiert. 


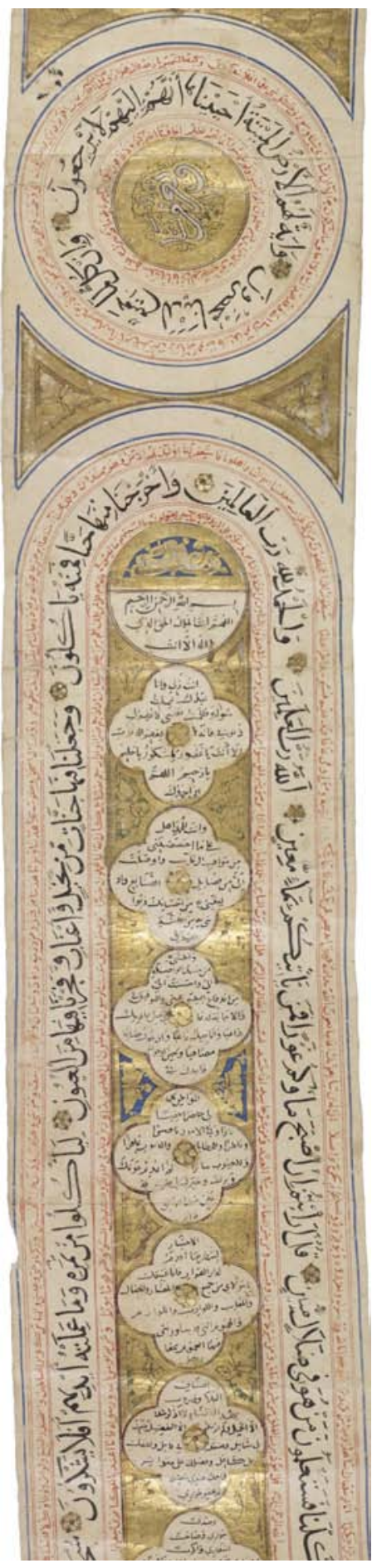

ABB. 20

Kopenhagen, The Royal Library, Cod. Arab. 53 (vgl. bei Anm. 42, 45-56, nach 218): Beginn des Vierpassgebets; es ist in 38 Vierpässen angeordnet und ist ca. $195 \mathrm{~cm}$ lang. 


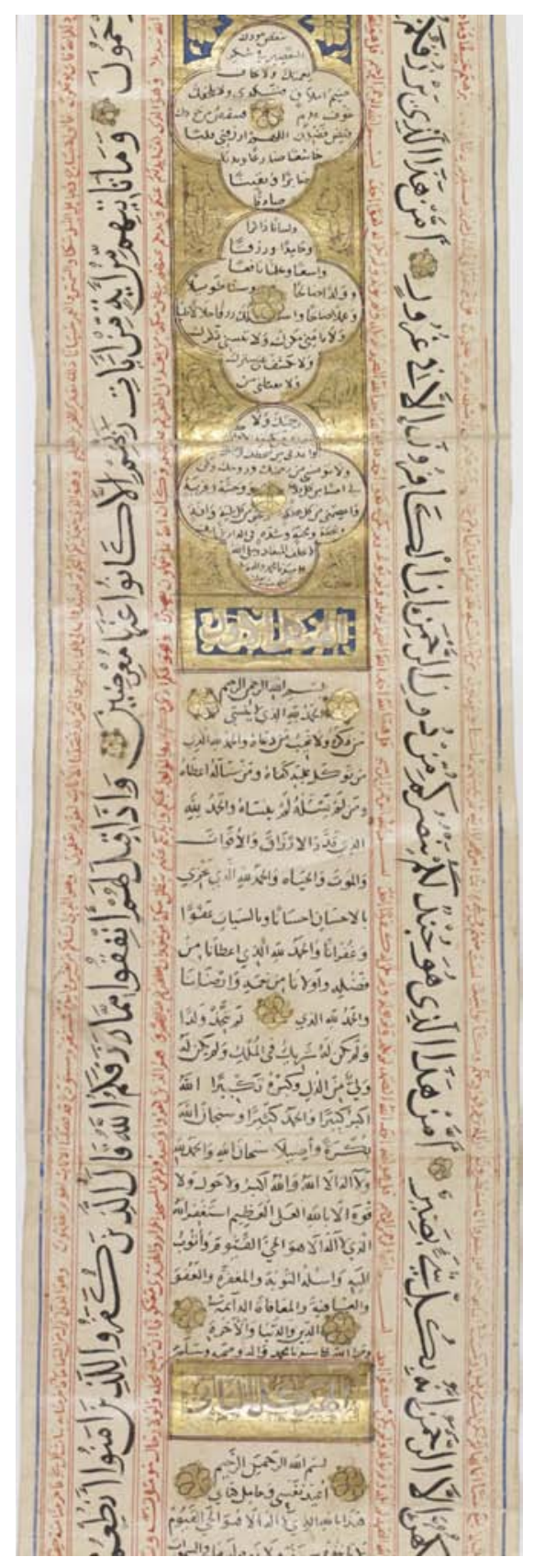

AвB. 21

Kopenhagen, The Royal Library, Cod. Arab. 53 (vgl. bei Anm. 69-71): Schluss des Vierpassgebets (vgl. AB B. 20) und Anfang des siebenteiligen HaykalGebets. Hier al-Haykal al-awwal (Überschrift auf blauem Hintergrund) und der Anfang des 2. Haykal (al-haykal at-tāāī; Titel auf goldenem Hintergrund). 

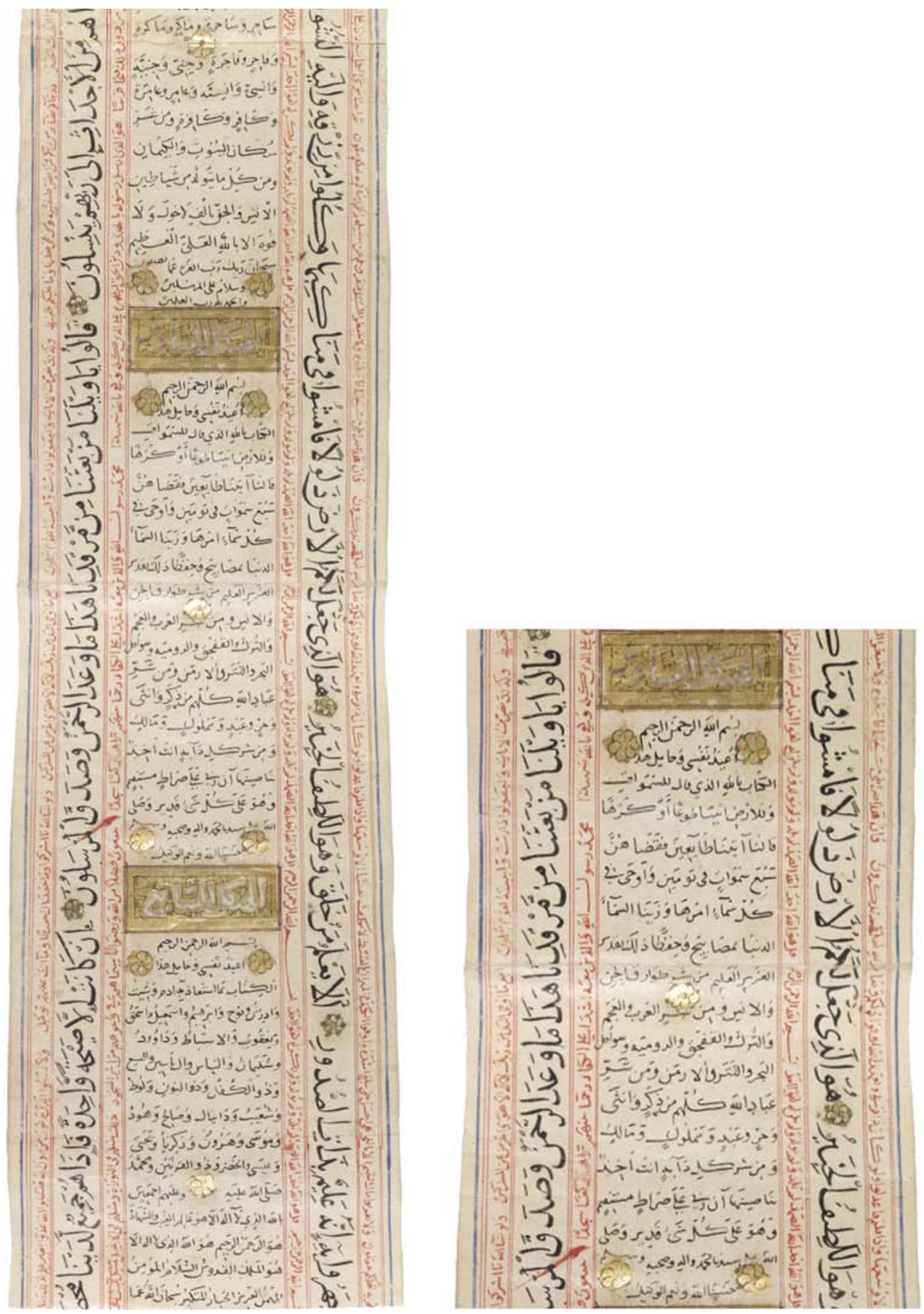

Авв. 22-23 Kopenhagen, The Royal Library, Cod. Arab. 53 (vgl. bei Anm. 74-81): Der 6. Haykal (al-Haykal as-sādis). Der Text zählt jene Völker auf, gegen die dieses Gebet im Krieg schützt. 

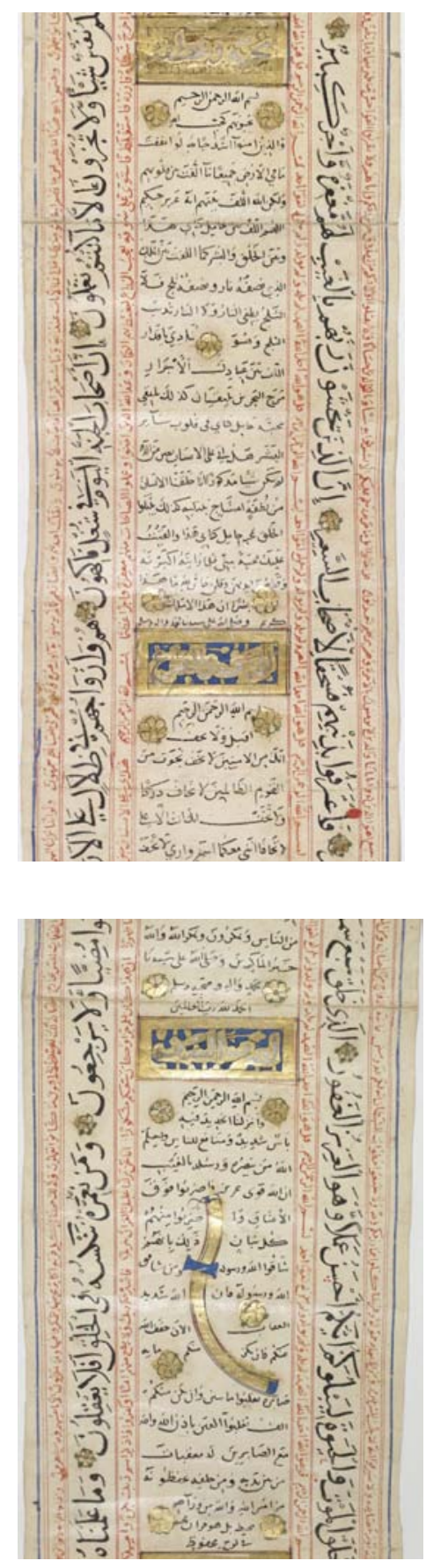

ABB. 24

Kopenhagen, The Royal Library, Cod. Arab. 53 (vgl. bei Anm. 90-99): Ein Gebet, das dem Träger der Rolle gemäss der Überschrift (Mahabba wa-'atf) die Liebe und Zuneigung der Menschen garantieren soll.
ABB. 25

Kopenhagen, The Royal Library, Cod. Arab. 53 (vgl. bei Anm. 169-178): Die Rolle enthält auch Abschnitte mit Abbildungen von Waffen; hier gezeigt der Abschnitt mit einem Schwert. Die Überschrift lautet Li-darb as-sayf. 

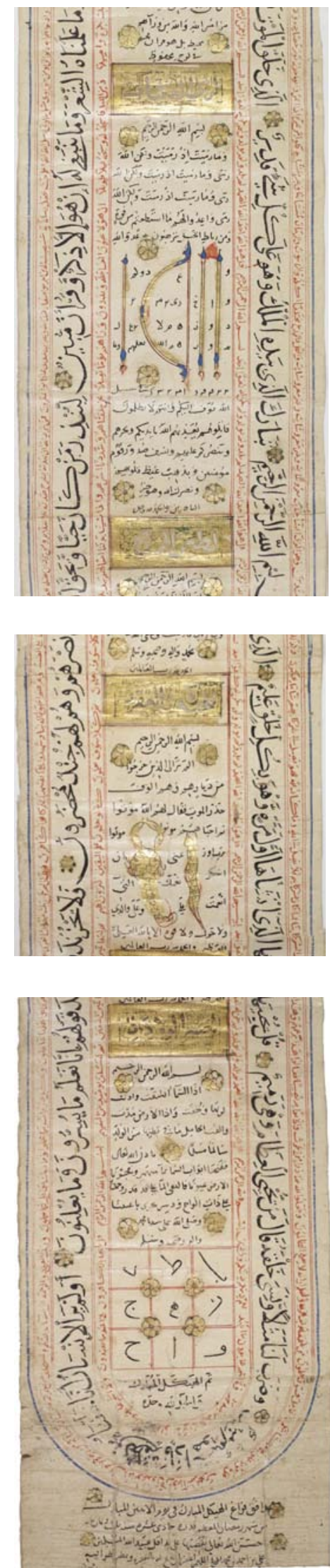

ABв. 26

Kopenhagen, The Royal Library, Cod. Arab. 53 (vgl. bei Anm. 178-185): Abschnitt mit der Abbildung von Pfeilen und Bogen; die Überschrift lautet Li-ramy an-nuššāa $b$.

ABB. 27

Kopenhagen, The Royal Library, Cod. Arab. 53 (vgl. bei Anm. 208-211): Abschnitt der Rolle zum Schutz gegen Schlangen und Skorpione; die beiden Tiere werden hier auch abgebildet.

ABB. 28

Kopenhagen, The Royal Library, Cod. Arab. 53 (vgl. bei Anm. 215): Der Schluss der Rolle mit dem Kolophon auf den letzten vier Zeilen. 
Paris, Bibliothèque Nationale de France, Arabe $6 \circ 88$

Das Dokument ist fragmentarisch erhalten; ${ }^{1}$ der Anfang fehlt. ${ }^{2}$ Es misst jetzt $10.0-10.3 \times 912 \mathrm{~cm}$ (9.12 m). Keine Datierung vorhanden. F. Déroche vermutet eine Entstehung um 1400. Das Dokument ist wahrscheinlich etwas älter (2. Hälfte 14. Jh.?). Es dürfte in Syrien oder Nordirak entstanden sein. Eine Anfertigung in Ägypten, wie von F. Déroche vermutet, lässt sich aber nicht ausschliessen. Aufgrund der Verzierungen ist ein mamlukischer Hintergrund wahrscheinlich. Diese Verzierungen wurden sehr sorgfältig ausgeführt. Das Dokument enthält eine Abschrift des Korans, dessen Text auf dem Belegstück ursprünglich vollständig enthalten gewesen sein muss. Gemäss Angaben der BNF messen die einzelnen Streifen zwischen 330 und $340 \mathrm{~mm} .^{3}$ Das ursprüngliche Papier lässt sich nur noch im zweiten Teil des Dokuments untersuchen. ${ }^{4}$ Wasserzeichen fehlen. Im ersten Teil wurde das Dokument später auf ein zweites Papier aufgezogen.

Zum Aufbau der Rolle: Das Dokument besteht aus zwei Hauptteilen. Teil $\mathrm{I}^{5}$ weist neben Textelementen aufwendig ausgeführte Verzierungen auf. Seine Länge beträgt ca. $267.5 \mathrm{~cm}$. Der Aufbau

1 Vgl. dazu Déroche, Les manuscrits du Coran du Maghreb à l'Insulinde 61-62 (Nr. 359); Blochet, Enluminures 138139 (mit Tafel XcviII); Les arts de l'Iran, l'ancienne Perse et Bagdad 172 (Nr. 105); Trésors d'Orient 65 (Nr. 174).

Abbildungen des gesamten Dokuments sind aufrufbar unter: http://gallica.bnf.fr/ark:/12148/btvib8419234m (Stand: 30 September 2016).

2 Das Dokument beginnt mit Q 2:83 (as-șalät) in der Mitte des horizontalen Schriftbands (rote Tinte). Q 1 und Q 2:182 (und Beginn 2:83) fehlen damit; sie müssen auf einem zusätzlichen Papierstreifen gestanden haben, der nicht mehr vorhanden ist. Im breiten Schriftband um die erste Kartusche steht Q 2:83-9o (in roter und schwarzer Tinte).

3 Aus konservatorischen Gründen wurde auf eigene Erhebungen verzichtet.

4 V.a. nach der Fehlstelle in Abschnitt II.e (mit Auslassung von $Q_{3}$ :122-129 bzw. 3:75-78 in den beiden Seitenstreifen).

5 Teil I umfasst die Abbildungen 1-10 (vgl. link. in Anm. 1). von Teil $\mathrm{II}^{6}$ unterscheidet sich deutlich vom Rollenanfang (Länge ca. $644.5 \mathrm{~cm}$ ). Er wird durch ein dreiteiliges Knotenband dominiert, das den ganzen zweiten Teil einfasst. Beide Abschnitte lassen sich weiter aufteilen.

Teil I.1 (formal, AB B. 29): ${ }^{7}$ Dieser Abschnitt misst $56 \mathrm{~cm}$. Es handelt sich um ein Rechteck, dessen Rahmen durch zwei Schriftbänder gebildet wird. Das äussere Band ist breiter (ca. $1.1 \mathrm{~cm}$ ) als das innere (ca. $0.6 \mathrm{~cm}$ ). Das breite Schriftband wird innen und aussen von einem goldenen Streifen eingefasst. Um das ganze Rechteck herum verläuft eine blaue Doppellinie. Das innere Schriftband wird gegen innen ebenso von einem goldenen Streifen eingefasst. Im Aussenband wurde der Text in roter und schwarzer Schrift kopiert. Die Stellen in roter Schrift überwiegen jene in schwarzer Schrift leicht. Der Text im Innenband wurde ausschliesslich in schwarzer Tinte notiert. Punktierter und vokalisierter Text. Schrifttyp: Nash mit einer Tendenz zu Tulut. Es fällt auf, dass die Unterlängen der Buchstaben in diesen beiden Aussenbändern stark nach links ausholen. Das $\sin$ wurde mit drei Punkten unterhalb des Buchstabens versehen, das šin weist drei Punkte darüber auf. 8

In Hinblick auf die zeitliche Einordnung ist ein Vergleich zwischen dem Text in der ersten Kartusche mit blauem Hintergrund auf Arabe 6088 und Or. Ms 848 aus der British Library hilfreich. ${ }^{9}$ Der Schaft des $k a \bar{f} f$ weist in beiden Fällen deutlich nach rechts. Der oberste Teil des $k a \bar{f}$ holt danach auffällig stark nach links aus und verbreitet sich dabei leicht. Bei BL Or. Ms 848 handelt es sich um eine für Farağ b. Barqūq ${ }^{10}$ um 1400 angefertigte Koran-

6 Teil II umfasst die Abbildungen 11-34 (vgl. link. in Anm. 1).

7 Vgl. Abb. 1-2 der Rolle (link in Anm. 1).

8 Man beachte das absteigende breite Schriftband links.

9 Für die folgenden Vergleiche beachte das Titelfeld auf Fol. 2a; vgl. die Abbildungen dazu unter imagesonline.bl .uk (https://imagesonline.bl.uk/?service=search\&action =do_quick_search\&language $=\mathrm{en} \& \mathrm{q}=848$; Stand 24 . September 2017).

10 Zum Mamluken-Sultan al-Malik an-Nāșir Farağ b. Barqūq (geb.1389; ermordet 1412 in Damaskus; reg. 1399-1412, 
handschrift. Auch der Buchstaben $f \bar{a}$ ' wurde auf beiden Dokumenten ähnlich ausgeführt. In beiden Fällen ruht der Kreis des $f \bar{a}^{3}$ auf einem Stiel. Auch das gayn wurde auf beiden Dokumenten ähnlich gestaltet. Da sich в L в Or. MS 848 chronologisch mit grösserer Sicherheit einordnen lässt, könnte dies Rückschlüsse auf die Datierung von Arabe 6 o88 aus der BNF gestatten.

Der Mittelstreifen im Rechteck ist hier besonders aufwendig gestaltet. Sein Hintergrund ist golden. Am Anfang, in der Mitte und am Ende lässt sich jeweils ein achtstrahliger Stern erkennen, der die Breite des Mittelstreifens ausfüllt." ${ }^{11}$ Dazwischen befinden sich zwei Rechtecke, die an beiden Enden von einem unvollständigen achtstrahligen Stern abgeschlossen werden. Diese Figuren auf dem Mittelstreifen werden von einem einfachen Zierband eingefasst. Der Hintergrund der angeführten Figuren ist blau und mit einem floralen Rankenmuster in goldener Farbe versehen. In diesen Figuren wurde Text in Zierkufi kopiert. In den drei achtstrahligen Sternen ist die Schrift golden. In den Rechtecken ist die Schrift jetzt weiss. In einzelnen Buchstaben lassen sich Reste von silberner (?) Farbe (jetzt oxydiert) erkennen. ${ }^{12}$

Teil I.1 (inhaltlich, AвB. 29): Der eigentliche Anfang der Rolle fehlt; bei der ersten Textstelle handelt es sich um Q 2:83b. Q 1 und Q 2:1-83a sind nicht mehr vorhanden. ${ }^{13}$ Es ist ausgeschlossen, dass eine Abschrift des Korans auf einem

mit einem Unterbruch von 70 Tagen im Jahr 1405) vgl. Wansbrough, Faradj, al-Malik al-Nāșir, in $E I^{2}$.

11 James, Qur'āns of the Mamlūks 22 (Fig. 6b), bezeichnet solche Figuren als achtstrahlige Sterne. Sie werden in islamischen Kontexten auch Rub`al-hizb genannt. Diese Figur besteht aus zwei Vierecken, die sich überlagern und gegeneinander um $45^{\circ}$ versetzt sind; vgl. dazu http:// www.wikiwand.com/en/Rub_el_Hizb (Stand 8. November 2016). Jetzt dunkel verfärbt.

Der Text beginnt in der Mitte des horizontalen Aussenbands mit Q 2:83b mit dem Begriff aṣ-ṣalät:

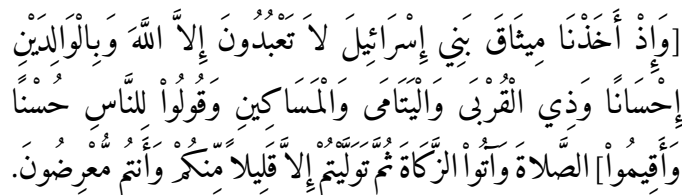

Dokument von derart hoher Qualität anfänglich nicht vollständig war. Der Aufbau der fehlenden Papierstreifen lässt sich nicht rekonstruieren. ${ }^{14}$

Auf dem breiten äusseren Schriftband wurde um das Rechteck herum Q 2:83b-9o kopiert. Q 2:90 steht wieder oben im horizontalen Band; hier springt der Text in Vers 9o ins innere Schriftband und umfährt das Rechteck im Gegenuhrzeigersinn. ${ }^{15}$ Das innere Schriftband enthält Q 2:90102. ${ }^{16}$

Im Mittelstreifen selbst wurde Q 48:1-2 in Zierkufi notiert. ${ }^{17}$ Die prominente Platzierung dieser beiden Verse eher am Anfang des Dokuments dürfte Rückschlüsse auf dessen ideologische Einordnung zulassen. ${ }^{18}$

Teil I.2 (formal): ${ }^{19}$ Der nächste Abschnitt (Länge ca. $78 \mathrm{~cm}$ ) beeindruckt durch seine aufwendige Gestaltung und die Verwendung von goldener und blauer Farbe. Es lässt sich eine Abfolge von acht Zierelementen erkennen; sie sind durch eine feine blaue Linie entlang der Zentralachse untereinander verbunden. Zwischen den einzelnen Zierelementen besteht jeweils ein Abstand von ca. 2$3 \mathrm{~cm}$.

14 Es dürften 2 oder 3 Papierstreifen fehlen (ca. 67 bzw. $100 \mathrm{~cm})$.

15 Der Übergang erfolgt in Q 2:9o (beachte die Markierung II):

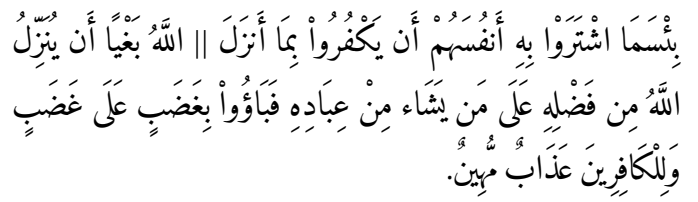

16 Die Fortsetzung von Q 2:102 folgt im nächsten Medaillon mit schwarzem Schriftband (vgl. Abb. 3 der Rolle, link in Anm. 1).

17 Q 48:1-2 lautet:

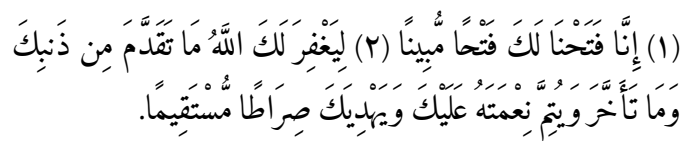

18 Vgl. zur Bedeutung von Q 48:1-2 bei Initiationszeremonien Nünlist, Devotion and protection: Amuletic scrolls dating from the 14th century, 508-512.

19 Beachte die Abbildungen 3-5 der Rolle. 
I.2.a: Zuoberst ein kleines Medaillon (Durchmesser $2.8 \mathrm{~cm}$ ), das von zwei blauen Kreisen und danach einem goldenen Ring eingefasst wird. Im Innern eine florale Verzierung in goldener Farbe auf blauem Grund. Zuinnerst eine achtblättrige Blüte.

I.2.b: Medaillon, das nahezu die gesamte Breite der Rolle $(10.0 \mathrm{~cm})$ einnimmt. Um das Medaillon läuft ein blauer Hastenkranz. Der Kreis im Innern (Durchmesser ca. $4.8 \mathrm{~cm}$ ) ist golden ausgefüllt. Es lassen sich Reste einer floralen Verzierung erkennen, die durch feine schwarze Linien strukturiert wird. Zwischen Hastenkranz und golden ausgefülltem Kreisinnern zwei weitere Bänder. Das äussere Band enthält auf blauem Hintergrund rankenartige Verzierungen, die zu den Hasten hin blattförmig zulaufen. Beim innern Kranz handelt es sich um ein Schriftband mit Text in schwarzer Schrift. ${ }^{20}$

I.2.c: Quer ausgerichtete Kartusche mit Zierband (Breite ca. $0.6 \mathrm{~cm}$ ), dessen lappenförmige Grundelemente eng aneinandergereiht um die Kartusche herumlaufen. Gegen innen schliesst sich ein rotes Schriftband an (Breite ca. $0.3 \mathrm{~cm}){ }^{21}$ Zuinnerst ein Schriftfeld (Höhe ca. $2.5 \mathrm{~cm}$ ) mit goldenem Rankenmuster auf blauem Hintergrund. Die hier enthaltenen beiden Begriffe wurden in Zierkufi notiert; die Buchstaben sind jetzt weiss.

I.2.d: Medaillon mit grossen Ähnlichkeiten mit jenem in Abschnitt I.2.b. Die Verzierungen auf dem äusseren $\mathrm{Kranz}^{22}$ mit blauem Hintergrund unterscheiden sich allerdings von jenem im vorangehenden Medaillon. Das Schriftband (Breite ca. $0.8 \mathrm{~cm}$ ) ist schmaler; es enthält Text in schwarzer Schrift. Das golden ausgefüllte Kreisinnere ist wie jenes im vorangehenden Medaillon gestaltet (vgl. I.2.b).

I.2.e (Авв. 3о): Achtlappiges Medaillon, aussen von zwei blauen Linie (schmal-breit) eingefasst. Gegen innen schliesst sich ein rotes Schrift-

20 Breite dieses Bands ca. $0.8 \mathrm{~cm}$; der Text ist punktiert und vokalisiert.

21 Bei der Schrift handelt es sich um $\dot{G} u b a \bar{r}$; der Text ist punktiert und teilweise vokalisiert.

22 Goldene Ranken mit Blättern und Blüten; mehrfach lassen sich Reste grüner Farbe erkennen. band (Breite ca. $0.3 \mathrm{~cm}$ ) an, das innen und aussen von einem schmalen goldenen Streifen eingefasst wird. Im Innern des Medaillons eine komplex aufgebaute Verzierung. Zuinnerst ein achtstrahliger Stern mit blauem Hintergrund und einer Verzierung mit goldenen Blättern und einer weissen Blüte. Die Verlängerungen der Strahlen dieses innern kleinen Sterns bilden einen zweiten grösseren Stern, der genau senkrecht ausgerichtet ist und dessen acht Strahlen golden ausgefüllt sind. Die Linien, die diese Strahlen bilden, sind über deren Spitze hinaus verlängert. Sie gehen in die Seitenlinien von zwei Quadraten über, die zusammen einen achtstrahligen Stern bilden. Dieser Stern füllt das Medaillon im Innern aus. Die weiteren Leerräume innerhalb des horizontal liegenden Quadrats weisen einen blauen Hintergrund auf und sind mit einem goldenen Blütenornament ausgefüllt. Zwei gegeneinander versetzte Vierpässe greifen die Rundungen des achtlappigen Medaillons auf und füllen den Raum zwischen Vierecken und Medaillonrand aus. Die Zwischenräume sind golden ausgefüllt.

I.2.f: Ein weiteres Medaillon; seine Gestaltung lehnt sich weitgehend an jenes an, das unter I.2.d beschrieben wurde.

I.2.g: Eine zweite horizontal ausgerichtete Kartusche (Federkastenform); ihre Gestaltung ist mit jener Kartusche identisch, die unter I.2.c beschrieben wurde.

I.2.h: Ein weiteres Medaillon; seine Gestaltung lehnt sich weitgehend an jenes an, das unter I.2.d beschrieben wurde (vgl. auch I.2.f).

Teil I.2 (inhaltlich): Einzelne der soeben beschriebenen Figuren enthalten Textelemente. ${ }^{23}$

I.2.b: Der Text im Schriftband beginnt oben etwas rechts von der Mitte mit dem Begriff Sulaymān aus Q 2:102. Der Anfang von Q 2:102 stand im innern schwarzen Schriftband am oberen Ende des rechteckigen Zierelements am Anfang des erhaltenen Teils der Rolle (Teil I.1). ${ }^{24}$ Jetzt folgt die direkte

\footnotetext{
23 Die Figuren ohne Text werden in der Folge einfach ausgelassen.

24 Vgl. bei Anm. 16.
} 
Fortsetzung von Q 2:102. Der Text umfährt den Kreis im Gegenuhrzeigersinn und endet mit den Begriffen mā yufarriqūna aus Q 2:102. ${ }^{25} \mathrm{Q}$ 2:102 gilt als locus classicus zur Stellung der Magie (sihr) im Islam. ${ }^{26}$

I.2.c: Die Fortsetzung von Q 2:102 schliesst sich im roten Schriftband in der nächsten Figur oben in der Mitte an (bi-hīmin al-mar'). Die Stelle endet mit den Ausdrücken min 'indi aus Q 2:103. ${ }^{27}$

Auf dem blauen Hintergrund im Innern der Kartusche steht Text in Zierkufi. Der Text ist zusammen mit seiner Fortsetzung in der identisch gestalteten Kartusche (I.2.g) zu lesen und lautet: wa-la-hū al-asmā / al-husnā. Diese Stelle weist also auf das Konzept der Schönen Namen Gottes hin. ${ }^{28}$

I.2.d: Fortsetzung der Abschrift von Q 2:103 oben in der Mitte (erster Begriff: Allāh; letzter Begriff: min rabbi-kum aus Q 2:105b).

I.2.e (АВB. 30): In Übereinstimmung mit dem bereits beobachteten Prinzip folgt hier der weitere Text aus Q 2:105b im roten Schriftband: waAllāhu yahtașșu; der Text endet mit Q 2:10g: law yaruddūna-kum min ba'di.

I.2.f: Der Text im Schriftband beginnt mit ìmānikum (Q 2:109) und endet mit bi-mā talamūna (Q 2:110).

25 Q 2:102 lautet (der Text in eckigen Klammern ist in diesem Medaillon nicht enthalten; er stand bereits zuvor bzw. folgt in der nächsten Figur):

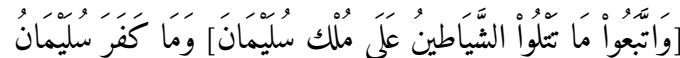

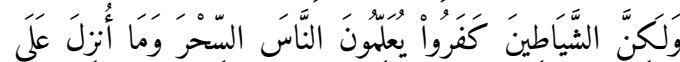

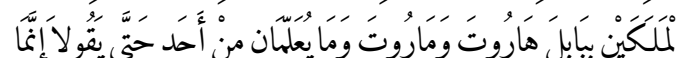

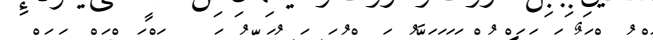

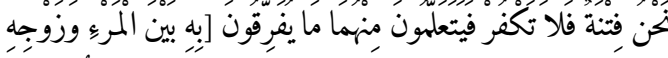

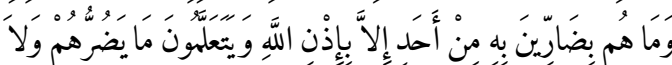

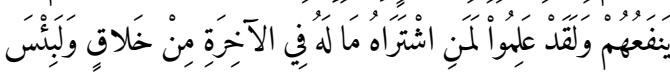

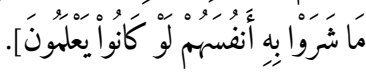

Vgl. dazu Bürgel, Allmacht und Mächtigkeit 199.

Q 2:103 lautet:

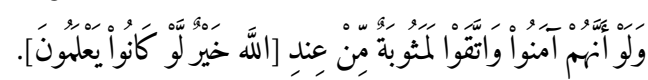

Vgl. auch unten vor Anm. 33 .
I.2.g: Der letzte Ausdruck aus Q 2:11o (bașīr) folgt in der horizontalen Kartusche. Das rote Schriftband endet mit Q 2:113 (laysat al-Yahūd 'alā šay'in wa-hum).

In der Kartusche im Innern dieser Figur steht in weissem Zierkufi der Begriff al-ḥusnā als Fortsetzung zu wa-lahū al-asmā aus Figur I.2.c.

I.2.h: Es folgt die Fortsetzung (Q 2:113: yatlüna alkitāb). Das Zitat in dieser Figur endet mit Q 2:114 ( mā kāna la-hum 'an yadhulū-hā).

Anmerkung zum Innern der Figuren I.2.b, d, f, h: Diese Medaillons sind im Innern golden ausgefüllt; auf diesem goldenen Hintergrund lassen sich Reste einer schwarzen Verzierung (Rankenmuster mit Blüten) erkennen. Wahrscheinlich war im Innern dieser Medaillons kein Text enthalten.

I.3 (formal, AB B. 31): ${ }^{29}$ Die Länge des nächsten Abschnitts beträgt ca. $48 \mathrm{~cm}$ (ohne Verbindungshasten). Oben und unten durch einen Bogen abgerundetes Rechteck (Federkasten). Eine feine blaue Linie verbindet dieses Rechteck mit der vorangehenden bzw. folgenden Figur. Das Rechteck selbst wird aussen von einer feinen und anschliessend einer breiteren blauen Linie eingefasst. Gegen innen folgt ein goldener Streifen. Die ganze Figur wird danach von zwei Schriftbändern eingefasst. Das äussere Schriftband ist breiter (ca. $1 \mathrm{~cm}$ ) und enthält Text in roter und schwarzer Schrift (punktiert und vokalisiert). Das innere Schriftband ist schmaler (ca. $0.35 \mathrm{~cm}$ ) und enthält Text in schwarzer Tinte.

Der Mittelstreifen im Innern ist oben und unten golden ausgefüllt. Auf diesem Hintergrund sind Reste eines schwarzen Rankenmusters erkennbar. Ausserdem steht in diesen beiden goldenen Bögen Text in weisser Schrift. Im Rechteck im Innern befinden sich kleine Sechsecke, die durch goldene, beidseits schwarz eingefasste Stäbe voneinander getrennt sind. Sie sind in drei Spalten angeordnet. Zwischen diesen kleinen Sechsecken entstehen kleine Dreiecke, die mit blattförmigen Zierelementen in blauer Farbe ausgefüllt sind. In den kleinen Sechsecken Text in $\dot{G} u b \bar{a}$, der von

29 Vgl. Abb. 6-7 der Rolle (link in Anm. 1). 
rechts unten nach links oben verläuft. Die Gestaltung lässt sich auch dahingehend erklären, dass jeweils sechs kleine Sechsecke (mit Text in roter Tinte) um ein kleines Sechseck (Text in schwarzer Tinte) angeordnet wurden. Die Figur enthält insgesamt acht grosse Sechsecke. Die zwei kleinen Sechsecke zur Linken und Rechten zwischen zwei grossen Sechsecken enthalten Text in roter Farbe.

I.3 (inhaltlich; Ав B. 31): Fortsetzung der Abschrift des Korans. Im roten Aussenband lässt sich die Fortsetzung von Q 2:114 (illā hẳifin) erkennen. Im Aussenband steht zuletzt Q 2:122. Der Kopist springt in diesem Vers ins schwarze Innenband und setzt die Abschrift oben in der Mitte fort. ${ }^{30}$ Der Text folgt dem schwarzem Schriftband; am Schluss Q 2:133. Der Kopist springt jetzt in den Mittelstreifen und setzt die Abschrift oben rechts fort. ${ }^{31}$ Zuunterst lässt sich im letzten Feld der Schluss von Q 2:196 und das erste Wort von Q 2:197 (al-ḥaǧğ) erkennen. ${ }^{32}$ Die Sechsecke enthalten Text in $\dot{G} u b \bar{a} r$ auf fünf oder sechs Linien.

Der in diesen Sechsecken kopierte Text überrascht insofern, als die weisse Überschrift bzw. Unterschrift auf goldenem Hintergrund in die-

30 Q 2:122 lautet (die Markierung || zeigt die Übergangsstelle an):

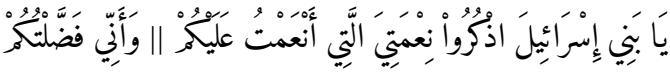
عَلَى الَْالمَينَ.

31 Q 2:133 lautet (die Markierung || zeigt die Übergangsstelle an):

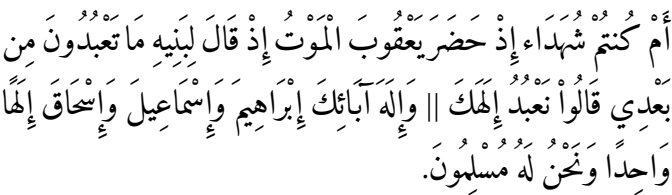

32 Die Übergangsstelle lautet (Q 2:196-197):

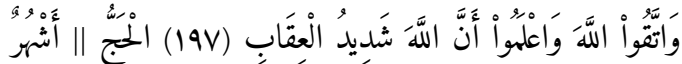

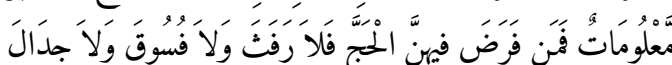

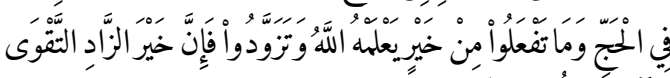

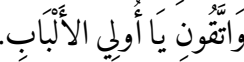

sem Abschnitt lautet wa-li-[A]llāh al-asmā // alhusnā. Dies liesse eine Aufzählung der Namen Gottes erwarten, die dann allerdings nicht folgt. Der Kopist begnügte sich offensichtlich mit einer Anspielung auf das Konzept der Schönen Namen Gottes, das er ja bereits zuvor (I.2.c und g) aufgegriffen hatte.

I.4 (formal): ${ }^{33}$ Länge ca. $85.5 \mathrm{~cm}$. Abschnitt mit sieben ausgesprochen sorgfältig gestalteten Figuren $(\mathrm{a}-\mathrm{g})$. Zwischen den einzelnen Figuren ein Abstand von $2-3 \mathrm{~cm}$; die Figuren sind allerdings durch eine feine blaue Linie entlang der Zentralachse miteinander verbunden:

I.4.a: Ein Medaillon, das nahezu die ganze Breite der Rolle ausfüllt. Seine Gestaltung erinnert an jene der vier Medaillons in Abschnitt I.2 (b, d, f, h).

I.4.b. Medaillon mit ausgesprochen komplexem Aufbau; keinerlei Textelemente. Im Zentrum ein sechsstrahliger Stern. Zwei seiner Spitzen kommen exakt in die Horizontale zu liegen. Die vier weiteren Strahlen des Sterns befinden sich dementsprechend links bzw. rechts der Zentralachse. Zwischen den Strahlen dieses Sterns und dem Medaillonrand sechs kleine Sechsecke. Sie markieren die Eckpunkte eines grossen Sechsecks, dessen Seitenlinien nicht vollständig ausgeführt worden sind. Die Eckpunkte dieses grossen Sechsecks sind durch nach innen gewölbte Doppelbögen miteinander verbunden; es entstehen sechs Doppel- bzw. zwölf Einzelbögen. Die sechs Spitzen des Sterns im Innern werden durch zwei Dreipässe miteinander verbunden, die gegeneinander verschoben sind und sich überlagern. Ganz zuinnerst ein blütenförmiges Ornament mit zwölf Spitzen. Ausserdem treffen sechs nach innen gewölbte Kreisbögen vom Medaillonrand her auf die sechs Strahlen des Sterns im Zentrum. Die Linien, die dieses Muster bilden, sind mit schwarzen Strichen und Punkten ausgefüllt. Abgesehen vom Zentrum der Figur, das einen neutralen Hintergrund aufweist, wurden die Flächen hier golden und blau ausgefüllt. In den Flächen dem Rand entlang: goldenes Rankenmuster auf blauem Hintergrund.

33 Beachte die Abb. 8-10 der Rolle (link in Anm. 1). 
I.4.c (Авв. 32): Die dritte Figur baut auf drei Kreiselementen auf, die sich gegenseitig überschneiden. Der mittlere Kreis ist am grössten und weist im Zentrum ein goldenes Ziermuster (v.a. Ranken) auf blauem Hintergrund auf. Auch das Zentrum des oberen und unteren Kreises ist blau und mit einer sechsteiligen goldenen Verzierung versehen. Der restliche Hintergrund der Kreise ist jetzt zumeist goldig; es lassen sich aber Reste eines schwarzen Ziermusters, teilweise auf blauem Grund, erkennen. In diese dreiteilige Figur sind zwei Schriftbänder (Knotenbänder) von identischer Breite eingepasst.

I.4.d: vgl. dazu I.4.a.

I.4.e (Авв. 33): Erneut eine komplex aufgebaute Figur. Blau eingefasstes Achteck; seine Seitenlinien sind mit kurzen Hasten verziert. Im Zentrum ein grosser Stern, dessen acht Strahlen auf die Ecken des Achtecks ausgerichtet sind. Im Innern dieses grossen Sterns ein kleinerer Stern mit blauem Hintergrund und einer blütenförmigen Verzierung. Die Strahlen dieses kleinen Sterns sind gegenüber jenen seines grossen Gegenstücks versetzt. Zwischen die Strahlen des grossen Sterns wurden gegen aussen acht Sechsecke eingepasst, an deren Spitze sich jeweils ein kleines Viereck befindet. Zwischen jeweils zwei Sechsecke wurde eine Figur eingefügt (goldenes Blatt auf blauem Grund), deren Spitzen auf die Ecken des grossen Achtecks hinweisen. In der Mitte der Seitenlinien lässt sich die Grundlinie einer Figur erkennen, von der aus in der Form eines Doppelbogens eine Verbindung ins Innere der Sechsecke startet. Dieses Band erreicht an der übernächsten Seitenlinie jeweils wieder den Rand des Achtecks. Alternierend starten auf den dazwischenliegenden Seiten Linien, die identische Figuren bilden. Die Wendepunkte dieser Linien im Innern lassen sich fiktiv derart miteinander verbinden, dass zwei gegeneinander versetzte Vierecke entstehen (bzw. ein achtstrahliger Stern). Die soeben beschriebenen Figuren werden durch Linien gebildet, die Text in $\dot{G} u b a \bar{r}$-Schrift enthalten. Der Text wurde entweder in roter oder schwarzer Tinte kopiert.

I.4.f: vgl. dazu I.4.a und d.
I.4.g: Eine horizontal ausgerichtete Kartusche, die von zwei blauen Linien eingefasst wird. Im Innern drei grosse, sich überschneidende Kreise. $\mathrm{Zu}$ beiden Seiten ist ein kleinerer Kreis hinzugefügt worden. Diese Kreise weisen goldene Ränder und einen blauen Hintergrund auf. Auf dem blauen Hintergrund ein goldenes Rankenmuster. Teilweise sind die Kreise golden ausgefüllt. Der schmale Zwischenraum zwischen diesen Kreisen und dem äussern Rand der Figur ist mit feinem weissem Blattwerk auf schwarzem Hintergrund verziert. Diese Figur enthält keinerlei textliche Elemente.

I.4 (inhaltlich): ${ }^{34}$ Einzelne der soeben beschriebenen Figuren enthalten Textelemente. ${ }^{35}$

I.4.a: Im schwarzen Schriftband schliesst sich die unmittelbare Fortsetzung von Q 2:197 an; der erste Begriff (al-haǧğ) stand bereits in der vorangehenden Figur mit Text. Der Text beginnt oben in der Mitte. Die Abschrift von Q 2:197 wird in dieser Figur abgeschlossen. ${ }^{36}$

I.4.c (АВВ. 32): Figur mit zwei Knotenbändern mit schwarzem bzw. rotem Text (Breite der Bänder: ca. $0.6 \mathrm{~cm})$. Im schwarzen Knotenband beginnt oben in der Mitte Q 2:198 (erster Begriff: laysa). Der Text läuft dem Band entlang, bis er wieder oben ankommt (Q 2:201; vorletztes Wort: 'a $\underline{a} a \bar{a} b)$. Hier springt der Kopist ins rote Knotenband und setzt die Abschrift fort (erster Begriff: an-nār; letztes Wort in Q 2:201). Der Schreiber erreicht zuletzt Q 2:205 (li-yufsida fi-hā). ${ }^{37}$

34 Beachte die Abb. 8-10 der Rolle (link in Anm. 1).

35 Die Figuren ohne Text werden in der Folge einfach ausgelassen.

36 Vgl. dazu oben bei Anm. 32. Q 2:197 lautet:
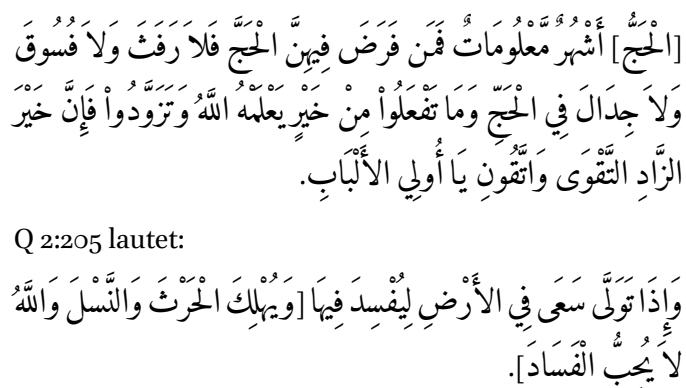
I.4.d: Direkte Fortsetzung von Q 2:205. Dieses Schriftband endet mit Q 2:207 (Allāh ra'üfun bi-l‘ibād).

I.4.e (АВв. 33): Diese Figur enthält Q 2:208224. Der Text beginnt im schwarzen Schriftband zuoberst in der Mitte und läuft nach links. Wenn der Leser der Struktur des Labyrinths folgt (schwarze Schrift), gelangt er am Schluss wieder an die oberste Ecke des Achtecks, wo sich die Ausdrücke al-ḥarām wa-ihrāăg ahli-hī aus Q 2:217 erkennen lassen. Im Vers 217 wechselt der Schreiber ins rote Schriftband, wo oben in der Mitte die unmittelbare Fortsetzung des Verses steht; der Text steigt, immer der roten Schrift folgend, zuerst nach links unten. ${ }^{38}$ Der Schreiber erreicht zuletzt erneut die oberste Ecke des Achtecks. Hier steht am Schluss al-mușlih wa-law šăa Allāh aus Q 2:220. Da die nächste Figur aber mit Vers 2.225 beginnt, muss in der vorliegenden Figur noch der Rest von Q 2:220 und Q 2:221-224 enthalten sein. Dies ist in der Tat der Fall: Der Schreiber springt jetzt nämlich nach links zur zweiten Ecke des Achtecks und setzt dort die Abschrift von Q 2:220 fort. ${ }^{39}$ Die rote Schrift ist häufig verblasst. Wenn man aber der Schriftrichtung genügend Aufmerksamkeit schenkt, findet man den Weg durch das Labyrinth und erreicht zuletzt wieder die zweite linke Ecke des Achtecks. Hier steht im roten, aus dem Innern der Figur kommenden Schriftband wa-tuṣlihū bayna

$38 \quad$ Q 2:217 lautet:

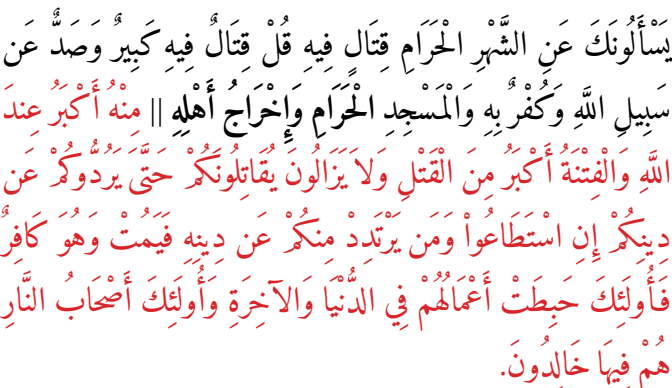

Q 2:220 lautet (die Übergangsstelle ist durch || markiert):

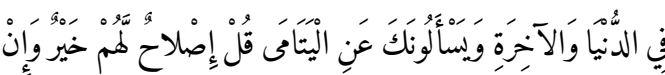

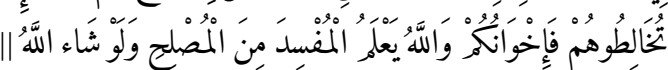

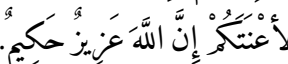

an-nās wa-Allāhu samī 'alìm (die letzten Wörter aus Q 2:224). ${ }^{40}$

I.4.f: Das Schriftband beginnt mit dem ersten Wort aus Q 2:225. ${ }^{41}$ Es endet in der Mitte von Q 2:227.42

Teil II (formal, ABB. 34):43 Der zweite Teil der Pariser Rolle unterscheidet sich deutlich vom Anfang. Beim zentralen Gestaltungselement dieses zweiten Abschnitts handelt es sich um ein dreiteiliges Knotenband mit Text. Auch im Mittelstreifen ${ }^{44}$ zwischen dem vorwärts- und rückwärtslaufenden Knotenband wurde Text, und zwar in mikroskopischer Schrift $(\dot{G} u b \bar{a} r)$, kopiert. Das dreiteilige Knoten- bzw. Schriftband umfährt den gesamten zweiten Abschnitt und wechselt bei den Knoten jeweils von der einen auf die andere Seite der Rolle. Diese Knoten werden durch Medaillons gebildet, die die gesamte Breite der Rolle ausfüllen. Zwischen jeweils zwei Knoten entstehen längere Rechtecke, die an beiden Enden abgerundet sind. Auch am Anfang und Ende dieses zweiten Abschnitts befindet sich je ein Medaillon. Insgesamt lassen sich auf diesem Teil der Rolle neun solche rechteckigen Abschnitte von ähnlicher Länge erkennen. ${ }^{45}$ Das erste und letzte Medaillon weisen einen goldenen Hintergrund auf. Ansonsten lässt sich eine Abfolge goldenes Medaillon-

40 Q 2:224 lautet:

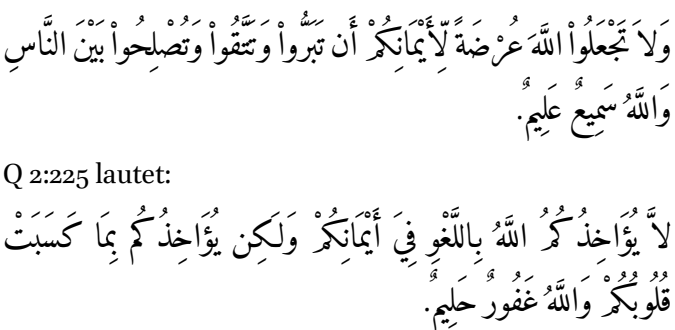

Q 2:227 lautet:

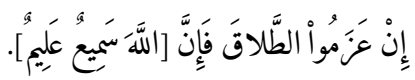

43 Beachte die Abb. 11-34 der Rolle (link in Anm. 1).

44 Mittelstreifen: die Stellen in den abgerundeten Rechtecken selbst.

45 Die Länge dieser einzelnen Rechtecke ist allerdings nicht identisch. Sie misst jeweils ca. $60-65 \mathrm{~cm}$. 
Rechteck-blaues Medaillon ${ }^{46}$ erkennen. Bei den Abschnitten 5 und 6 folgen allerdings zwei goldene Medaillons aufeinander. Diese formale Unregelmässigkeit legt nahe, dass das Dokument auch an dieser Stelle unvollständig erhalten ist. Überprüfungen des Inhalts bestätigten diese Vermutung. ${ }^{47}$ An dieser Stelle muss ein Abschnitt verloren gegangen sein, der mindestens ein ganzes Rechteck enthielt. Ausserdem sprechen kodikologische Anhaltspunkte (Unregelmässigkeiten im Schriftbild) dafür, dass es an dieser Stelle zu Verlusten gekommen ist. Somit dürfte dieser zweite Abschnitt der Rolle ursprünglich mindestens zehn, allenfalls auch elf, Rechtecke enthalten haben.

Es ist müssig über den Inhalt des jetzt fehlenden Teils zu spekulieren. Es könnte aber durchaus sein, dass dieser Abschnitt bewusst entfernt wurde, um Angaben missliebigen Charakters verschwinden zu lassen. Der jetzt fehlende Abschnitt war vielleicht deutlich anders gestaltet als die neun noch vorhandenen Rechtecke. Die weiteren Ausführungen stellen die einzelnen Abschnitte eingehender vor.

Vorerst ist allerdings auf das dreiteilige Schriftband (АВ В. 34) zurückzukommen, das den gesamten zweiten Abschnitt der Rolle umfährt. Das mittlere Schriftband ist am breitesten (ca. $1.2 \mathrm{~cm}$ ). Es enthält grossen Text, der in schwarzer Tinte kopiert wurde und punktiert und vokalisiert ist (Nash mit Tendenz zu Rayhāāì). Dieses mittlere Schriftband wird innen und aussen von je einem schmaleren Band mit rotem Text flankiert (Breite je ca. $0.6 \mathrm{~cm}$ ). Auch dieser rote Text ist punktiert und zumeist vokalisiert. Dieses dreiteilige Schriftband läuft auf der einen Seite der Rolle vorwärts. Bei den Knoten umfährt es jeweils das Medaillon und verläuft auf der andern Rollenseite weiter. Am Ende der Rolle umfährt es das letzte Medaillon und läuft danach zum Rollenanfang zurück. Am Anfang des zweiten Abschnitts trifft es auf das erste Medaillon bzw. den ersten Knoten.

46 Blaues Medaillon bedeutet hier, dass es einen blauen Hintergrund hat.

47

Vgl. dazu unten bei Anm. 70-78 bzw. II.e-f (inhaltlich).

Das Innere der Medaillons bzw. Knoten ${ }^{48}$ ist auf zwei Arten gestaltet. Auf ein Medaillon mit goldenem folgt jeweils eines mit blauem Hintergrund. ${ }^{49}$ Auch das Medaillon am Anfang von Teil II weist einen goldenen Hintergrund auf. Darauf lassen sich schwarze Linien erkennen, die ein Blütenund Rankenmuster bilden. Ausserdem lassen sich Überreste von blauen Verzierungen feststellen. Die blaue Farbe ist jedoch zumeist verloren gegangen.

Auf ein Medaillon mit goldenem folgt jeweils ein solches mit blauem Hintergrund. Darauf lässt sich ein Blüten- und Rankenmuster in goldener Farbe erkennen, das achsialsymmetrisch angeordnet ist. In der Mitte befindet sich eine grosse Blütenknospe, um die Ranken angeordnet sind. Diese Zierelemente werden von feinen schwarzen Linien eingefasst.

Teil II (inhaltlich, A B B. 34): Den weiteren Ausführungen sei vorausgeschickt, dass auch dieser zweite Teil der Rolle ausschliesslich Korantext enthält. Die Abschrift ist dabei derart aufgebaut, dass der Text zunächst im dreiteiligen Schriftband kopiert wurde, das diesen gesamten zweiten Teil einfasst. Erst danach geht der Kopist in den Mittelstreifen über und setzt die Abschrift dort fort. Die weitere Beschreibung folgt diesem Aufbau der Rolle:

Dreiteiliges Schriftband (inhaltlich, ABB. 34): Der Kopist erreichte im letzten Medaillon von Teil I (I.f) Q 2:227. ${ }^{50}$ Dies lässt erwarten, dass der Schluss von Q 2:227 am Anfang des zweiten Teils der Rolle folgt. Der Schluss von Q 2:227 und Q 2:228 lassen sich hier tatsächlich in der Mitte des roten Innenbands des ersten Medaillons feststellen. ${ }^{51}$

\footnotetext{
48 Durchmesser ca. $5 \mathrm{~cm}$.

49 Auf die Unregelmässigkeiten zwischen den Rechtecken 5 und 6 ist bereits hingewiesen worden.

50 Vgl. dazu oben bei Anm. 42 (I.4.f).

51 Q 2:227-228 lautet:

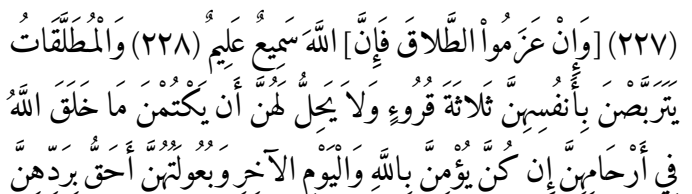


Der Kopist folgt danach dem von der Geometrie vorgegebenen Verlauf dieses Bandes, das im ersten Rechteck links aussen weitergeht. ${ }^{52}$ Im letzten Medaillon ganz am Schluss der Rolle steht auf dem roten Innenband Q 2:272.53 Q 2 endet mit Vers 286 auf Abb. 26 der Rolle im roten Aussenband rechts. Unmittelbar darauf folgt die basmala zu Q 3. Kurz vor dem ersten Medaillon beginnt auf dem rechten Aussenband im Rechteck darunter Q 3:49. Im Medaillon setzt sich dieses rote Aussenband als Innenband fort. Der Kopist erreicht dann die Mitte des roten Innenbands im obersten Medaillon, wo bereits Q 2:227 (Schluss) steht. Er springt deshalb in den breiten Mittelstreifen und setzt dort die Abschrift von Q 3:49 in grosser schwarzer Schrift fort. ${ }^{54}$ Auch hier folgt der Kopist stets dem Verlauf des schwarzen Schriftbands. Im letzten Medaillon am Ende der Rolle steht im schwarzen Mittelband Q 3:101. ${ }^{55}$ Die Geometrie führt den Schrei-

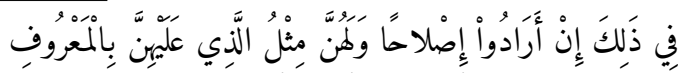

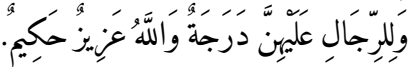

52 Vgl. dazu Abb. 11 der Rolle (link in Anm. 1).

53 Q 2:272 lautet (Vers beginnt auf dem Dokument auf der rechten Seite des Medaillons):

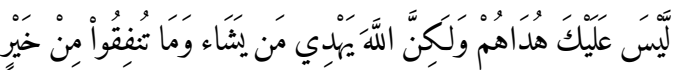

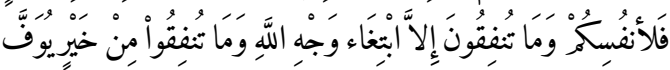

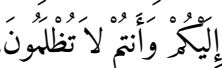

54 Q 3:49 lautet:

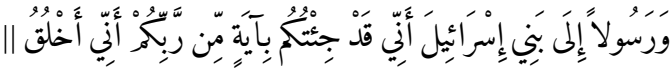
لَكُم مِّنَ الطَّينِ (Übergang ins Medaillon, rotes Innenband)

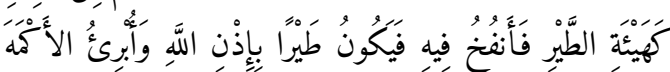

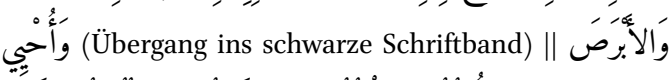

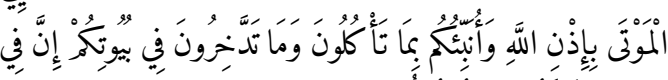

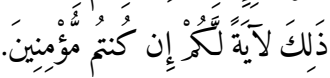

55 Q 3:101 beginnt im untersten Medaillon ziemlich genau in der Mitte:

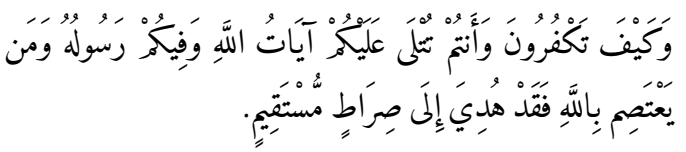

ber an den Anfang des Abschnitts zurück, wo im schwarzen Mittelstreifen Q 3:153 steht. In diesem Vers springt der Text vom schwarzen Mittelband ins rote Aussenband. ${ }^{56}$ Q 3:200 (Schlussvers) endet beim Medaillon vor dem sechsten Rechteck (rotes Aussenband, rechts). Unmittelbar darauf beginnt Q 4 mit der Basmala. ${ }^{57}$ Im letzten Medaillon lässt sich auf dem roten Aussenband der Schluss von Q 4:23 erkennen.58 Der Schreiber setzt die Abschrift des Texts fort und nähert sich dann wieder dem Rollenanfang. Dort lässt sich am oberen Ende des Rechtecks auf dem roten Innenband rechts der Schluss von Q 4:86 erkennen. Im Medaillon selbst folgt auf dem roten Aussenband links Q 4:87-88, womit der Kopist wieder zuoberst in der Mitte des äusseren roten Schriftbands angekommen ist. ${ }^{59}$ Damit ist das dreiteilige Schriftband um den zweiten Teil der Rolle herum vollständig ausgefüllt.

$5^{6} \quad$ Q 3:153 lautet:

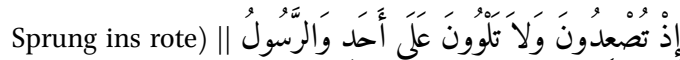

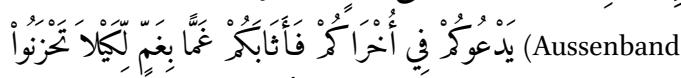

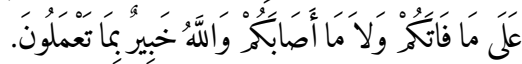

57 Vgl. dazu Abb. 24 der Rolle (link in Anm. 1).

$5^{8}$ Q 4:23 lautet (Vers 23 endet auf der linken Seite gerade bevor das Schriftband wieder ins vorangehende Rechteck wechselt; vgl. Abb. 34 der Rolle, link in Anm. 1):

年 حرِمت عليكم امهاتكم وبناتكم واخواتكم وعماتكم وخالاتكم

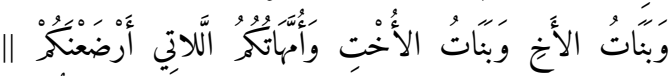

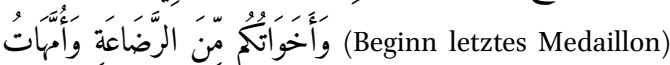

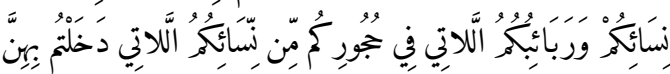

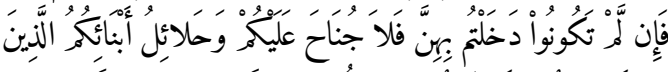

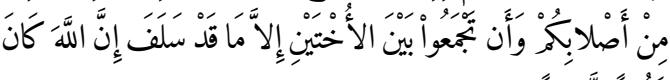
غَفُورا رَّحِيمًا (Medaillon Ende).

59 Q 4:86-88 lautet (vgl. Abb. 11, link in Anm. 1):

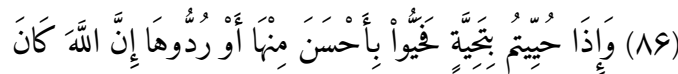

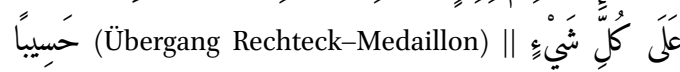

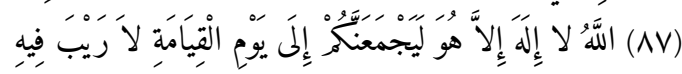


Der Schreiber springt jetzt in den Mittelstreifen im Innern der einzelnen Rechtecke von Teil II der Rolle. Zuerst wird die Gestaltung dieser Rechtecke beschrieben; anschliessend wird ihr Inhalt erfasst: Während das erste Rechteck (II.a) eine komplexe Gliederung aufweist, sind die acht weiteren Rechtecke (II.b-i) einfach aufgebaut und wurden identisch ausgeführt.

II.a (ABB. 34): ${ }^{60}$ Der Mittelstreifen im ersten Rechteck weist im Gegensatz zu den acht weiteren Rechtecken eine komplexe Gestaltung auf. Es lassen sich ineinander verknotete Schriftbänder in schwarzer und roter Farbe erkennen. Am Anfang und am Schluss befindet sich ein Kreis, der durch ein rotes Schriftband (Breite ca. $0.4 \mathrm{~cm}$ ) gebildet wird. Er wird von einem blauen Ring mit weissen Verzierungen (Blätter und Blüten) eingefasst. In diesem Rechteck folgen drei weitere solche Kreise mit einem blauen Ring in exakt kalkulierten Abständen (insgesamt fünf Kreise mit blauem Ring). Dieses rote Schriftband verläuft unter Bildung komplexer Figuren durch den gesamten Abschnitt hindurch und erreicht am Schluss wieder den Anfang. Das Schriftband geht nach dem ersten Kreis in eine mandelförmige Figur über und wechselt die Seite der Rolle. Auf die mandelförmige Figur folgt eine Serie von drei Kreisen, die durch das rote Schriftband gebildet werden (kleiner-grosser-kleiner Kreis). An den letzten kleinen Kreis in dieser Abfolge schliesst sich erneut eine mandelförmige Figur an. Danach folgt der nächste Kreis mit rotem Schriftband und blauem Ring. Ab hier wiederholt sich das soeben beschriebene Muster des roten Schriftbands noch drei Mal.

Zugleich lässt sich auf diesem Abschnitt ein schwarzes Schriftband (Breite ca. $0.4 \mathrm{~cm}$ ) erkennen. Es bildet vier an beiden Enden abgerundete Rechtecke, die zwischen den soeben beschriebe-

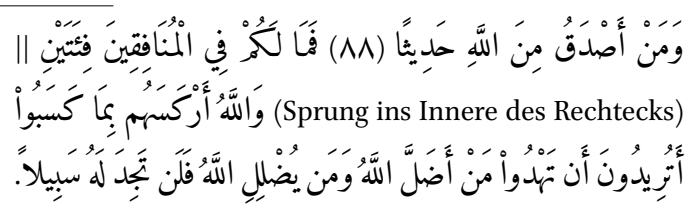

6o Vgl. die Abb. 11-13 der Rolle (link in Anm. 1). nen Kreisen mit rotem Schriftband und blauem Ring eingepasst worden sind. Dieses schwarze Schriftband umfährt die Kreise mit blauem Ring und wechselt dort von der einen auf die andere Seite der Rolle. In diese durch das schwarze Schriftband gebildeten Rechtecke ist übrigens die Abfolge aus kleinem-grossem-kleinem Kreis eingepasst, die durch das rote Schriftband gebildet wird. Auf der Höhe des mittleren grossen roten Kreises holt das schwarze Schriftband gegen innen aus und überschneidet sich mit dem roten Schriftband. Überhaupt lässt sich feststellen, dass sich rotes und schwarzes Schriftband auf diesem Abschnitt mehrfach derart überschneiden, dass ein komplex aufgebautes Knotenmuster entsteht.

Der Text auf dem roten und schwarzen Schriftband folgt stets dem durch die soeben beschriebenen Figuren vorgegebenen Muster. Bei der Schrift in diesen Bändern handelt es sich um kleines Nash; es kann aber nicht als $\dot{G} u b \bar{a} r$ charakterisiert werden. Auch im Innern der durch die Schriftbänder gebildeten Figuren ist übrigens Text in schwarzer Schrift kopiert worden. Dieser Text ( $\dot{G} u b \bar{a} r)$ wurde auf horizontalen Linien angeordnet.

II.b-i: ${ }^{61}$ Die Rechtecke $2-8$ sind identisch gestaltet. Hier wurde Text in sehr kleinem $\dot{G} u b \bar{a} r$ in schwarzer Tinte auf horizontalen Zeilen kopiert (Schrifthöhe alif: ca. 1mm, oft punktiert, vereinzelt vokalisiert) ${ }^{62}$ Beim kopierten Text handelt es sich weiterhin um eine Abschrift des Korans. Die goldenen (bzw. gelb-braunen) Punkte stellen die Verstrenner dar. Die Surentitel in goldener Schrift. Nach dem Titel wird jeweils die Anzahl Verse der Sure aufgeführt. Häufig folgen Angaben zum Offenbarungsort. Da die Suren am Ende des Korans kurz sind, folgen sich die Titel am Ende der Rolle dementsprechend in kurzen Abständen.

61 Vgl. die Abb. 13-34 der Rolle (link in Anm. 1).

62 Wiederholt lässt sich feststellen, dass die schwarze Schrift in gewissen Passagen eine höheren Sättigungsgrad aufweist als an andern Stellen. Die Gründe dafür liessen sich nicht ermitteln (Ersetzen der Feder; Wechsel zu anderer Tinte?). Eher unwahrscheinlich dürfte ein Kopistenwechsel sein (vgl. zur Frage z.B. Abb. 18 unten, link in Anm. 1). 
Teil II Mittelstreifen (inhaltlich): II.a (Mittelstreifen, Ав B. 34): Auf dem dreiteiligen Schriftband (zuoberst, rot, aussen) stand als letzte Stelle Q 4:87-88. Da der Kopist auf diesem Belegstück die islamische Offenbarung als Ganzes kopieren wollte, muss er seine Abschrift im Rechteck II.a also mit dem Schluss von Q 4:88 fortsetzen. Diese Stelle lässt sich im Mittelstreifen im schwarzen Schriftband zuoberst in der Mitte erkennen und verläuft von dort immer diesem schwarzen Schriftband entlang nach rechts unten. Dieses absteigende schwarze Schriftband trifft auf der rechten Seite wenig später auf ein aufsteigendes schwarzes Schriftband. Es unterfährt dieses, holt unmittelbar anschliessend in einem Bogen gegen innen aus und kommt nach aussen zurück. Beim zweiten Kreis mit blauem Ring wechselt es auf die linke Seite des Mittelstreifens. Der Kopist folgt in seiner Abschrift stets der Geometrie des schwarzen Bands. Er erreicht im aufsteigenden schwarzen Schriftband Q 4:94 und wechselt auf die linke Seite des Mittelstreifens. Im äusseren schwarzen Schriftband, das den obersten Kreis mit blauem Ring umfährt lässt sich Q 4:95 erkennen. Hier trifft der Kopist wieder auf die Stelle mit Q 4:88. Der Schreiber macht an dieser Stelle einen Sprung und setzt die Abschrift auf der rechten Seite im schwarzen Schriftband fort, das dort die oberste mandelförmige Figur durchquert und auf die linke Seite des Mittelstreifens wechselt. ${ }^{63}$ Der Kopist folgt

63 Q 4:95 beginnt in der Mitte der obersten mandelförmigen Figur im Mittelstreifen und steigt dann auf; der Vers lautet:

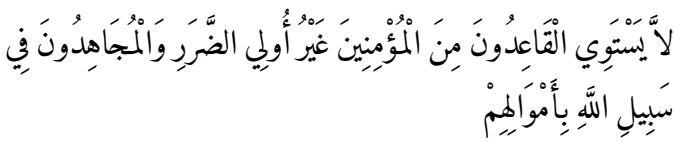

(zuoberst in der Mitte, dann Sprung ins absteigende schwarze Schriftband links, das durch die mandelförmige Figur hindurchfährt und auf die linke Seite wechselt)

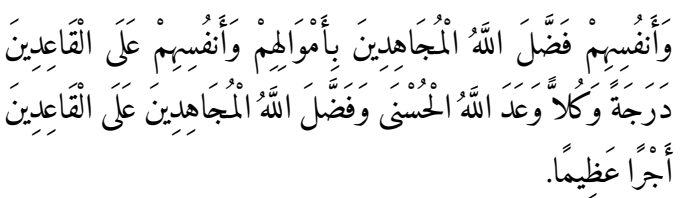

danach erneut dem Schriftband. Er erreicht zuletzt Q 4:103 im aufsteigenden schwarzen Schriftband auf der linken Seite und springt an dieser Stelle ins rote Schriftband. Er setzt dort zuoberst in der Mitte des ersten Kreises die Abschrift von Q 4:103 fort. ${ }^{64}$ Auch hier gibt der Verlauf des roten Schriftbands dem Kopisten die Schreibrichtung vor. Er erreicht im obersten Kreis im roten Schriftband links zuletzt Q 4:125 und springt in diesem Vers ins Kreisinnere. ${ }^{65}$

Jetzt fährt der Schreiber auf den horizontalen Zeilen mit der Abschrift in schwarzer $\dot{G} u b \bar{a} r-$ Schrift fort. Er erreicht am Ende dieses obersten Rechtecks (II.a) im Innern des letzten grossen Kreises mit rotem Schriftband den Schluss von Q 4 (Vers 176). Die Basmala von Q 5 lässt sich danach deutlich erkennen.

II.b (Mittelstreifen): ${ }^{66}$ Am Schluss des ersten Rechtecks springt der Schreiber ins nächste Rechteck und setzt die Abschrift von Q 5 auf den horizontalen Zeilen in schwarzer $\dot{G} u b \bar{a} r$-Schrift fort. ${ }^{67}$ In diesem zweiten Rechteck lassen sich auch die Titel von Q 6 und 7 erkennen.

II.c (Mittelstreifen): ${ }^{68}$ In diesem Abschnitt stehen die Überschriften von Q 8 und 9 und der dazugehörende Korantext. Der Schreiber setzt die Abschrift in sehr kleinem $\dot{G} u b \bar{a} r$ fort.

64 Q 4:103 lautet:

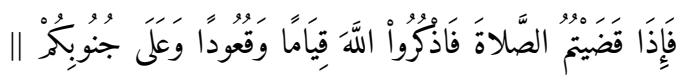
(rotes Schriftband, zuoberst in der Mitte, absteigend)

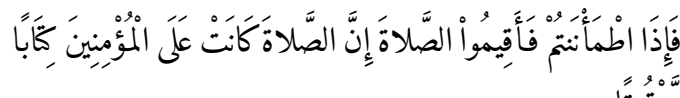

65 Q 4:125 lautet:

و

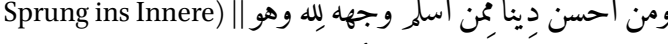
(des obersten Kreises

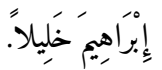

66 Vgl. die Abb. 13-15 der Rolle (link in Anm. 1).

67 Der Wechsel erfolgt in Q 5:3.

68 Abb. 16-18 (link in Anm. 1). 
II.d (Mittelstreifen): ${ }^{69}$ Am Anfang des vierten Rechtecks folgt der Titel von Q 10 (Yünus). Es schliessen sich Überschriften und Text von Q 11-14 an.

II.e (Mittelstreifen): ${ }^{70}$ Dieses Rechteck enthält als erste Überschrift den Titel von Q 15 (Sürat alHiğrr); zuletzt folgt Q 25 (Sūrat al-Furqān). Allerdings ist es in diesem Abschnitt zu grösseren Verlusten gekommen. Die Titel von Q 17-22 und der dazugehörende Text fehlen. Dieser Verlust eines ganzen Abschnitts lässt sich auch im Seitenband nachweisen. Im aufsteigenden schwarzen Textband steht an der auch auf der Abbildung erkennbaren Bruchstelle ${ }^{71}$ zuletzt Q 3:122; ${ }^{72}$ der Text fährt erst mit Q 3:129 ${ }^{73}$ weiter. ${ }^{74}$ Auf der Gegenseite fehlen im breiten Schriftband Q 3:74 (letztes Wort) ${ }^{75}$ bis Q 3:78 (letzter Teil des Verses wieder vorhanden) ${ }^{76}$ Selbstverständlich lassen sich auch in den schmalen roten Schriftbändern entsprechende Fehlstellen nachweisen.

Es fällt auf, dass die beiden Stellen 3.122-129 und 3.75-78 eher kurz sind, im Mittelstreifen aber

69 Abb. 18-21.

70 Abb. 21-23.

71 Die Stelle ist auf der Rückseite mit einem jüngeren Papier geklebt worden.

72 Q 3:122 lautet:

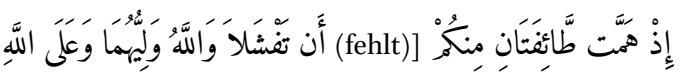

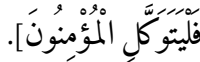

73 Q 3:129 lautet:

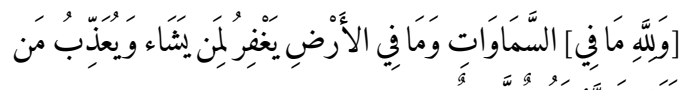

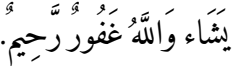

74 Abb. 22-23 (link in Anm. 1).

75 Q 3:74 lautet:

76

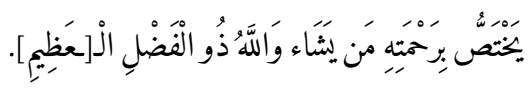

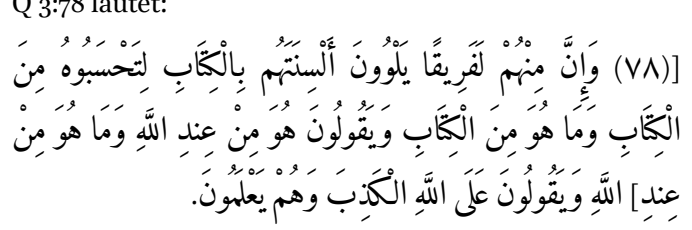

doch mehrere Suren (Q 17-22) gänzlich fehlen. ${ }^{77}$ Die Gestaltung dieser Stelle lässt sich zwar nicht rekonstruieren. Vieles spricht aber dafür, dass der jetzt fehlende Abschnitt bewusst entfernt wurde. Es könnte sein, dass diese Stelle Elemente enthielt, die einem späteren Besitzer nicht mehr opportun erschienen. Immerhin spielt Q 17:1 auf Muhammads Himmelfahrt (mi'rā $\breve{g}$ ) an. Q 18 thematisiert das Erlebnis der Siebenschläfer (Ahl al-Kahf). Es handelt sich in beiden Fällen um Erfahrungen, die auch in mystischen Kreisen Beachtung gefunden haben. Mutmassungen über Aufbau und Inhalt des jetzt fehlenden Abschnitts wären aber reine Spekulation.

I I.f (Mittelstreifen): ${ }^{78}$ Hier setzt der Schreiber die Abschrift des Korans auf horizontalen Zeilen in schwarzer $\dot{G} u b \bar{a} r$-Schrift fort. Der Abschnitt enthält die Überschriften und den Text von Q 26-33.

II.g (Mittelstreifen): ${ }^{79}$ Der Abschnitt enthält den Rest von Q 33. Es folgen die Überschriften und der Text von Q 34-42 (Anfang).

II.h (Mittelstreifen): ${ }^{80}$ Der Abschnitt enthält den Rest von Q 42. Es folgen die Überschriften und der Text von Q 43-58 (Anfang).

II.i (Mittelstreifen):81 Der Abschnitt enthält den Rest von Q 58. Es folgen die Überschriften und der Text von Q 59-114.

Schlussfolgerung: Diese Zusammenstellung legt die Annahme nahe, dass die islamische Offenbarung auf diesem Belegstück ursprünglich vollständig enthalten war. Die jetzt fehlenden Stellen am Anfang des Dokuments und im Abschnitt II.e hätten wahrscheinlich Hinweise enthalten, die eine präzisere ideologische Einordnung gestattet hätten. Ebenso fehlt ein Kolophon, der allenfalls weitere hilfreiche Angaben enthalten hatte. $\mathrm{Ob}$ er ursprünglich vorhanden gewesen war, muss dahingestellt bleiben. Diese Möglichkeit lässt sich jedoch nicht a priori ausschliessen. Am Schluss könnte ein Papierstreifen verloren gegangen sein.

77 Ca. 8o Seiten in Druckausgaben des Korans.

78 Abb. 24-26 (link in Anm. 1).

79 Abb. 27-29.

8o Abb. 29-31.

81 Abb. 32-34. 
Beachtung verdient, dass C. Hamès in einem Aufsatz Medaillons mit den aus dem indischen Kulturraum bekannten Mandalas vergleicht. Er macht dabei gerade auch auf Darstellungen aus dem Kitāb ad-Diryāq aufmerksam. ${ }^{82}$ Seine Perspektive könnte auch bei der Auseinandersetzung mit der vorliegenden Rolle (Arabe 6o88) von Interesse sein. ${ }^{83}$ Arabe 6088 enthält mehrfach Medaillons, die an Mandalas erinnern. ${ }^{84}$

82 Vgl. v.a. http://gallica.bnf.fr/ark:/12148/btvib842296om/ f42.image (Stand 16. Februar 2018). Es handelt sich um die Handschrift Arabe 2964 (BNF Paris), Traité de la thériaque; datiert 1198.

83 Hamès, Mandalas et sceaux talismaniques musulmans.

84 Vgl. die Abb. 3-5 und 8-10 der Rolle (link in Anm. 1). 


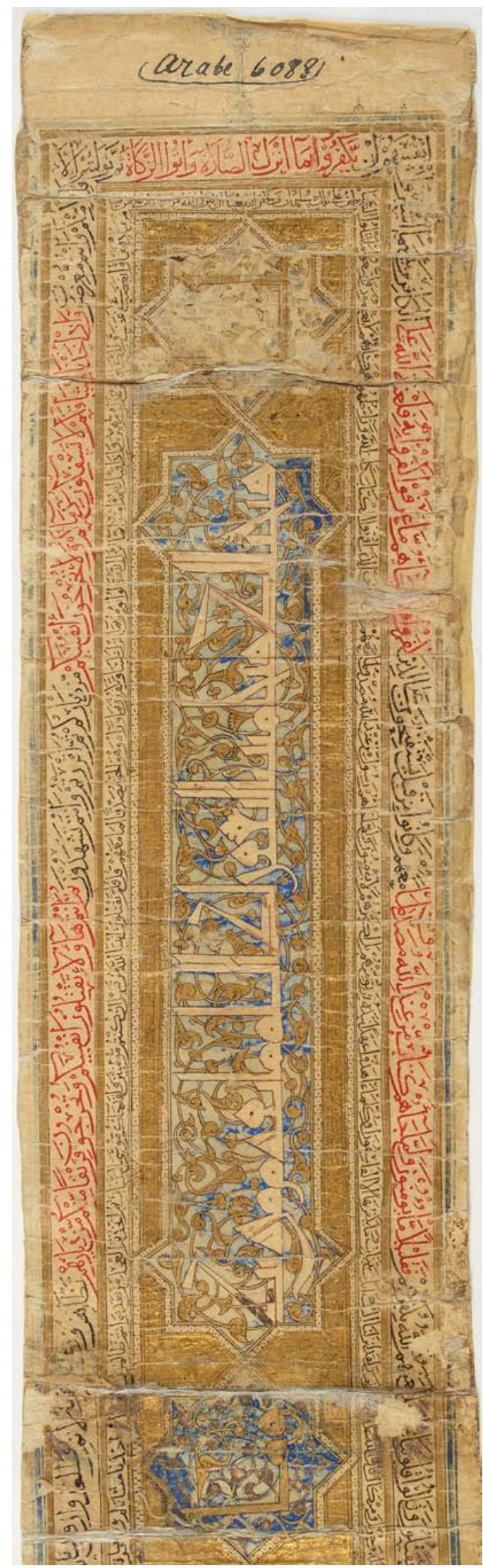

ABB. 29

Paris, Bibliothèque Nationale de France, Arabe 6088 (vgl. bei Anm. 7 f. und 13-18): Anfang des erhaltenen Teils der Rolle. Im Aussenband lässt sich in der Mitte der Begriff aṣ-șalāt aus Sure 2.83 erkennen. Im breiten Mittelstreifen steht auf blauem Hintergrund Sure 48.1.

Tobias Nünlist - 9789004429154 


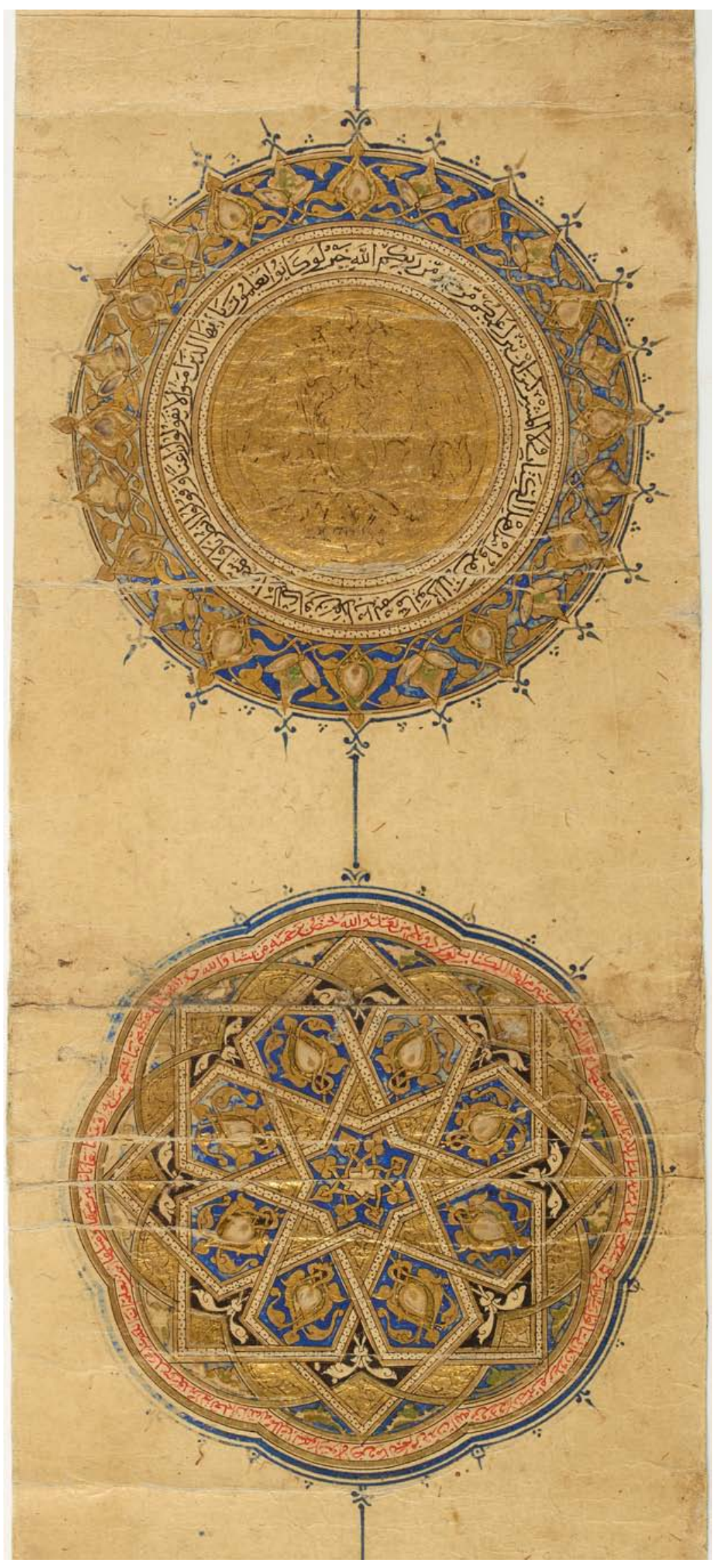

ABB. 30

Paris, Bibliothèque Nationale de France, Arabe 6088 (vgl. nach Anm. 22 und 28): Zuerst rundes und darunter achtlappiges Medaillon. Beim Text in roter Tinte handelt es sich um Q 2:105b-109.

Tobias Nünlist - 9789004429154 


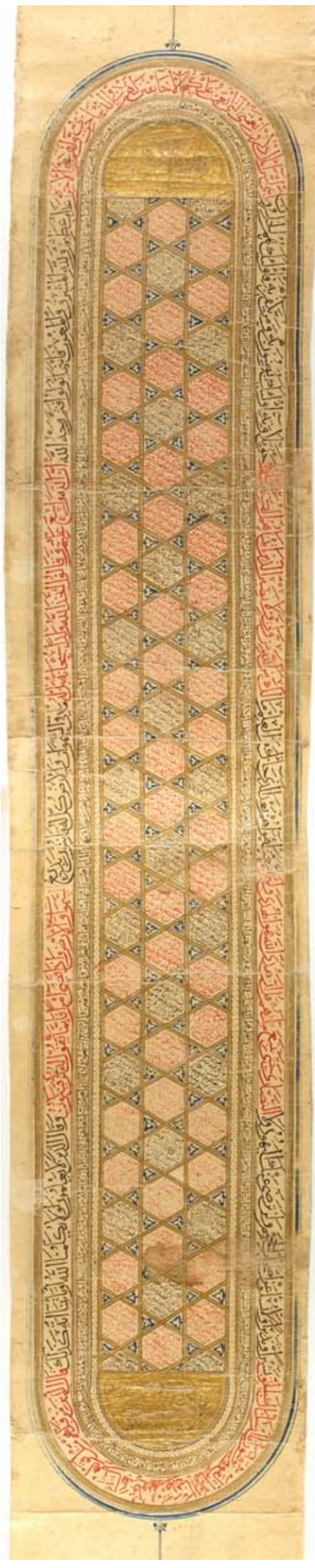

ABB. 31

Paris, Bibliothèque Nationale de France, Arabe 6 o88 (vgl. bei Anm. 29-32): Anfang eines Abschnitts in Federkastenform (oben und unten abgerundetes Rechteck von ca. $48 \mathrm{~cm}$ Länge). Im breiten Aussenband steht Q 2:114b-122; in Q 2:122 springt der Schreiber ins schwarze Innenband. Auch in den Sechsecken im Mittelstreifen steht Text aus dem Koran. Als Überschrift steht oben in weisser Tinte auf goldenem Hintergrund wa-li-[A]llāh al-asmä ; am Schluss dieses Abschnitt folgt als Unterschrift al-ḥusnā („Und Gott sind die Schönsten Namen“). 


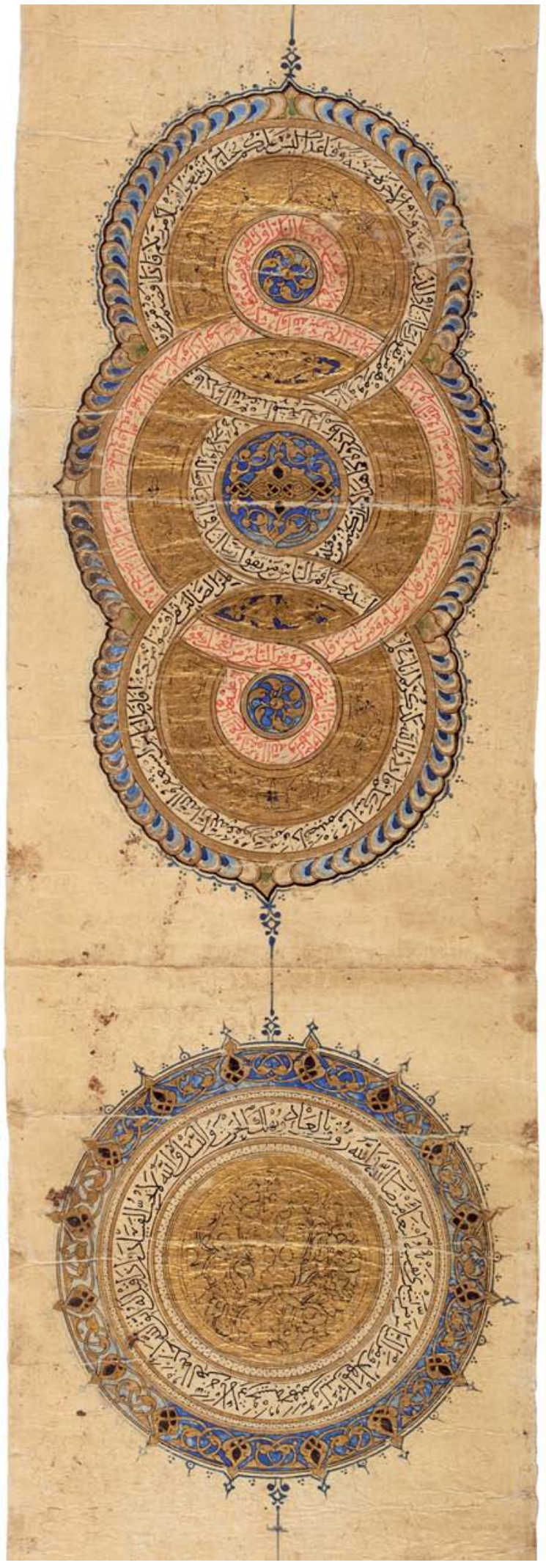

ABв. 32

Paris, Bibliothèque Nationale de France, Arabe 6088 (vgl. zwischen Anm. 32 und 33 und nach Anm. 36): Abschnitt mit Kreiselementen, die sich gegenseitig überschneiden. Im schwarzen Textband steht oben in der Mitte laysa aus Q 2:198. In Q 2:202 springt der Schreiber vom schwarzen Band ins Band mit rotem Text (erster Begriff: an-nār). 


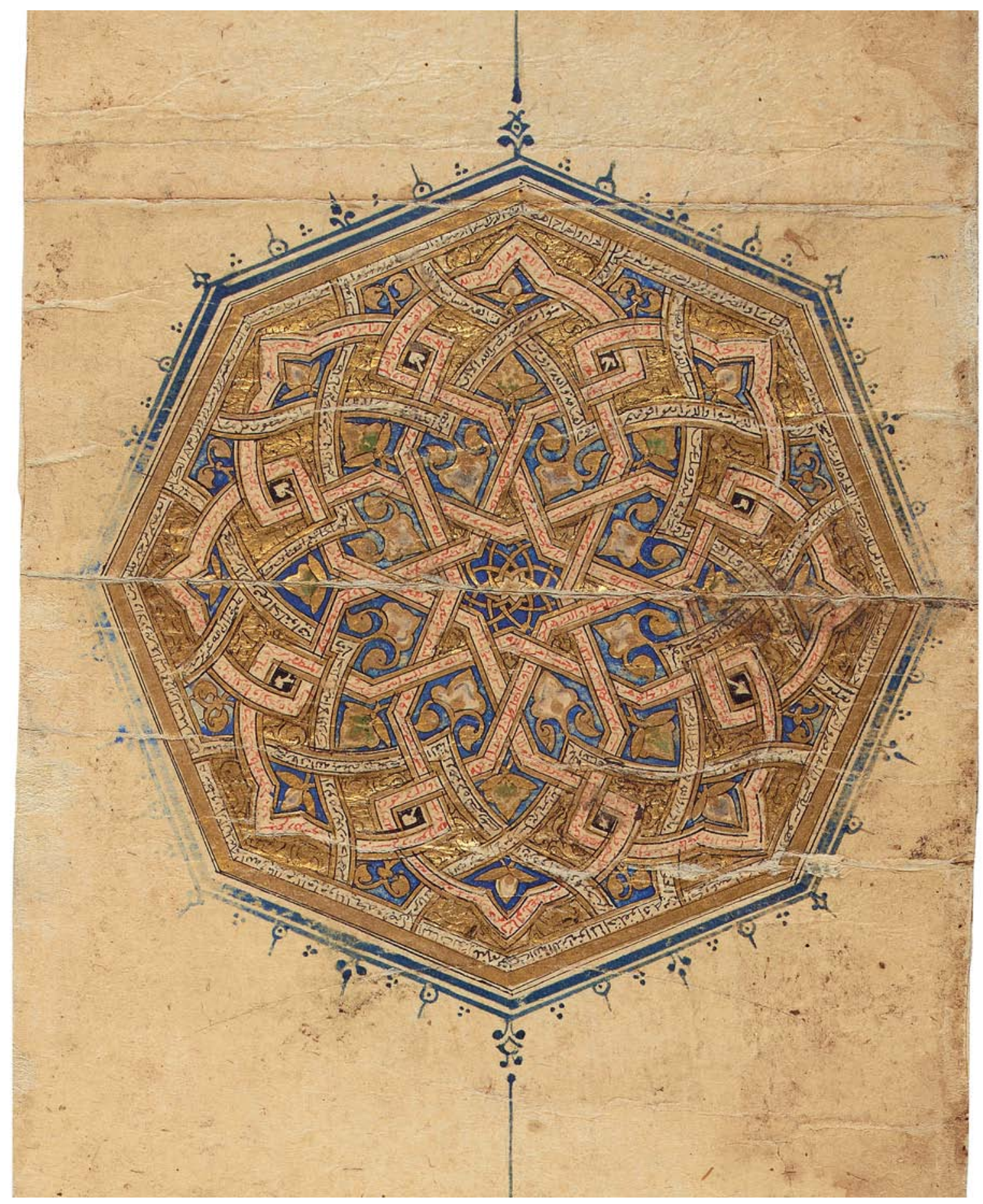

АВB. 33

Paris, Bibliothèque Nationale de France, Arabe 6088 (vgl. zwischen Anm. 32 und 33 und bei Anm. 38-40): Komplex aufgebaute achteckige Figur. In den Schriftbändern steht Q 2:208-224 (für die Einzelheiten beachte die Beschreibung). 


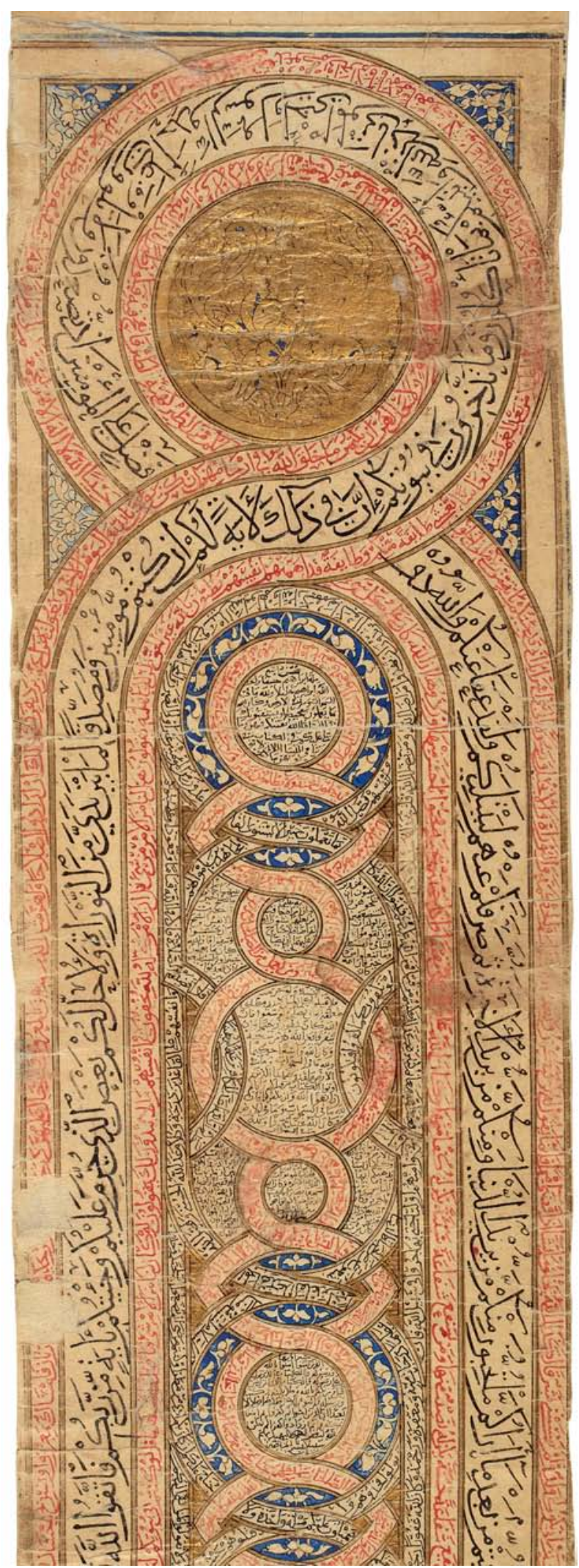

ABB. 34

Paris, Bibliothèque Nationale de France, Arabe $6 \circ 88$ (vgl. bei Anm. 43-59): Beginn von Teil II der Rolle, wo ein dreiteiliges Textband den Mittelstreifen umfährt. Die kopierten Textstellen werden in der Beschreibung bestimmt. 


\subsection{Dublin, Chester Beatty Library, Is 1624}

Das Dokument ist fragmentarisch erhalten (Anfang fehlt): ${ }^{1}$ Masse: $11.5^{\times 1126} \mathrm{~cm}(11.26 \mathrm{~m}$; Bibliotheksmessung). Verhältnismässig starkes Papier, das auf blauen und grünen Stoff aufgezogen ist. ${ }^{2}$ Die Rolle ist am Original untersucht worden. Die vorliegende Beschreibung stützt sich in erster Linie auf Abbildungsmaterial, das die Chester Beatty Library im Januar 2014 angefertigt hat (insgesamt 23 Photos, jeweils zwei pro Meter). ${ }^{3}$ Es stand zusätzlich eigenes Abbildungsmaterial zur Verfügung, sodass die Rolle lückenlos dokumentiert ist. ${ }^{4}$

Der Schreiber hat die Rolle in zwei Durchgängen angefertigt, wie aus zwei Kolophonen hervorgeht. Diese Feststellung bezieht sich allerdings nur auf den Inhalt des Mittelstreifens. Grundsätz-

1 Kurze Beschreibung in Arberry, Koran illuminated 29 (Nr. 97). Vgl. auch Nünlist, Devotion and protection: Amuletic scrolls dating from the 14th century.

Das Dokument wird in einem mit hellbraunem Leder überzogenen Behältnis mit Goldprägungen aufbewahrt; ähnlich gestaltetes Lederstück zum Schutz am Anfang der Rolle. Dieses Lederstück und das Behältnis sind jüngeren Datums (20. Jh.).

2 Vgl. Abb. 0.3 und 0.4 (beachte die Erklärungen in den beiden folgenden Anm.).

3 Abbildungsmaterial der Chester Beatty Library: Photos 1 und 2: $0-1$ Meter; Photos 3 und 4: 1-2 m; Photos 5 und 6: 2$3 \mathrm{~m}$; Photos 7 und 8: $3-4 \mathrm{~m}$; Photos 9 und 10: $4-5 \mathrm{~m}$; Photos 10 und 11: 5-6 m; Photos 13 und 14: 6-7 m; Photos 15 und 16: 7-8 m; Photos 17 und 18; 8-9 m; Photos 19 und 20: 9-10 m; Photos 21 und 22: 10-11 m; Photo 23: Schluss (die letzten $26 \mathrm{~cm}$ nach 11 Metern).

4 Die Verweise auf dieses zusätzliche Abbildungsmaterial sind wie folgt aufgebaut: 10.3 bezeichnet eine zusätzliche Abbildung nach der Aufnahme 10 der Chester Beatty Library. Sie befindet sich also in der ersten Hälfte des Abschnitts von Meter 9-10.

N.B.: Die Chester Beatty Library erstellte die im Abbildungsteil verwendeten Digitalisate der vollständigen Rolle erst 2019, als die vorliegende Untersuchung abgeschlossen war. Die hier in den Anmerkungen aufgeführten Stellenverweise beziehen sich auf im Lauf der Arbeit an diesem Belegstück in den Jahren 2014-2015 gemachte Aufnahmen; sie genügen professionellen Ansprüchen nicht (vgl. auch Einleitung zu Teil II, bei und mit Anm. 10). lich musste der Aufbau des Dokuments bereits am Anfang der Arbeit daran festgestanden haben. Der Schreiber hat bereits beim ersten Durchgang das dreiteilige Textband (Knotenband) entworfen und beschrieben, das die gesamte Rolle einfasst. Ein nicht fertiggestelltes Dokument aus dem Osmanischen Reich in der Universitätsbibliothek Leipzig (B. or. 322) legt dieses Vorgehen nahe. Auf diesem Vergleichsstück aus dem 16. oder 17. Jh. ist die Grundstruktur mit den Schriftbändern bereits vorgezeichnet. ${ }^{5}$ Während der Text auf den seitlichen Schriftbändern schon kopiert worden ist, ist der Mittelstreifen auf B. or. 322 noch weitgehend leer. Beim Anfertigen derartiger Dokumente dürfte also zuerst der Rahmen ausgeführt worden sein; erst danach wurde auch der Mittelstreifen beschrieben.

Die beiden Kolophone auf Is 1624 befinden sich an folgenden Stellen: Kolophon 1: Abb. 18, also zwischen Meter 8.5 und 9; Kolophon 2: ganz am Schluss des Dokuments, also nach Meter $11 .^{7}$

1. Kolophon (nach Ende der Abschrift von Q 114; ABB. 46):8 Datierung: Beginn der Abschrift am Anfang des Monats Ğumādā I 763 (beginnt am 26. Februar 1362); Ende der Abschrift am Samstag, den 27. Ğumādā l-āhira (23. April 1362); Ort der Abschrift: al-Qāhira l-mahrūsa; Schreiber: Muhammad b. Manșūr ‘Alī al-Ḥanafī al-Ḥusaynī alKahtāwī.

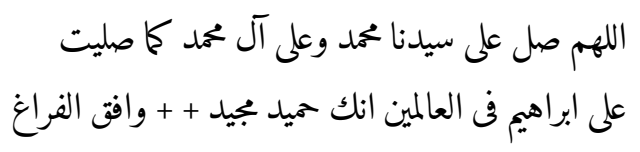

5 Vgl. https://www.islamic-manuscripts.net/receive/Isla mHSBook_islamhs_ooo11o6o (Stand: 10. Juli 2017); Fleischer, Catalogus $55^{2}$ (CCCLVI).

6 Abb. Is 1624.18 der Chester Beatty Library: ganz oben.

7 Abb. Is 1624.23 der Chester Beatty Library.

8 Abb. Is 1624.17.11-13 (eigene Aufnahmen).

9 Dieser Hinweis erlaubt einen Rückschluss darauf, wie lange die Abschrift eines solchen Dokuments dauerte (knapp zwei Monate). Die Angabe muss sich auf die Erstellung der Schriftbänder um die ganze Rolle und das Ausfüllen des Mittelstreifens im ersten Teil beziehen (bis Kolophon 1). Kolophon 1 befindet sich zwischen Meter 89 der Rolle. 


$$
\begin{aligned}
& \text { من كخابته على يد العبد الفقير الغريب }
\end{aligned}
$$

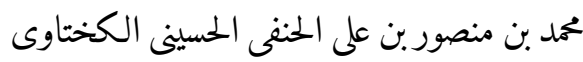

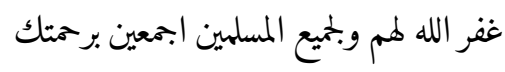

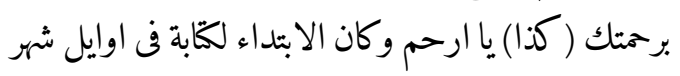

$$
\begin{aligned}
& \text { جمادى الاولى من شهور سنة }
\end{aligned}
$$

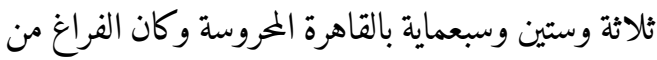

$$
\begin{aligned}
& \text { كابته نهار السبت } \\
& \text { السابع والعشرين من شهر بمادى الاخخه من شهور سنة } \\
& \text { تاريخه والحمد لله على توفيقه } \\
& \text { للتمامه ولا حول ولا قوة الا بالله العلى العظيم. }
\end{aligned}
$$

2. Kolophon (am Schluss der Rolle, auf die beiden letzten horizontal ausgerichteten mandelförmigen Figuren verteilt; АВВ. 50):10 Abschluss der Abschrift am Sonntag (zur Mittagszeit), den 15. Dū l-Higğğa 767/23. August 1366; Ort der Abschrift: Madīnat al-Qāhira l-maḥrūsa; Schreiber: erneut Muḥammad b. Manșūr b. 'Alī b. Muḥammad alḤanafì aš-Šarīf al-Ḥusaynī al-Kahtāwī.

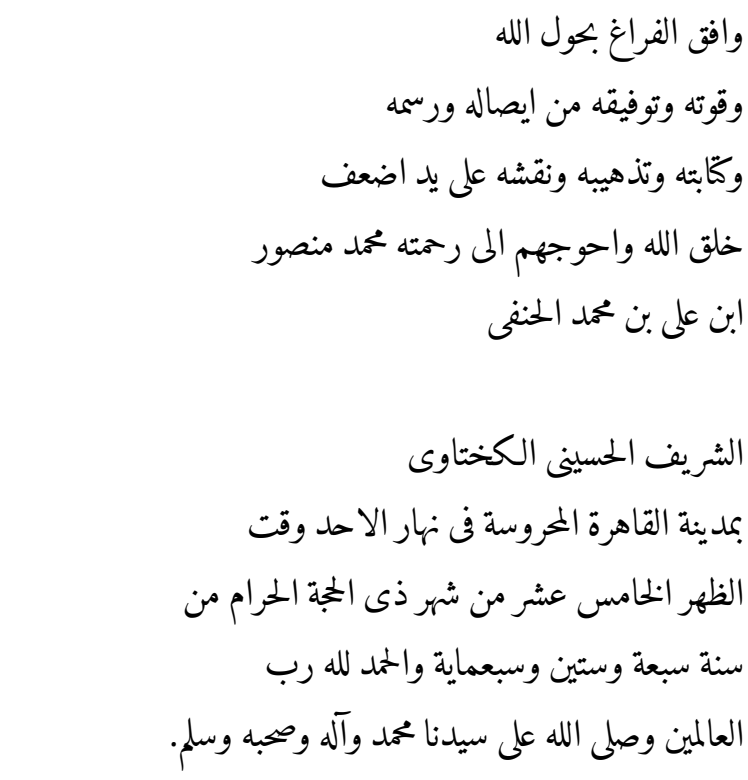

10 Aufnahme Chester Beatty: Is 1624.23; eigene Aufnahmen: Is $1624.22 .2-3$ und $8-11$.
Beim Lesen das unklar notierte 'ašr nach alhămis beachten; nur der 15. Tag dieses Monats ist ein Sonntag. Der 5. Dū l-Hiğğga entspräche einem Donnerstag. Zeile 2: wohl $\overline{\iota s ̣ a ̆ l}$ : Der zweite Rollenteil wurde vier Jahre später hinzugefügt.

Obwohl diese Angaben klar festhalten, dass die Abschrift in Kairo (al-Qāhira l-maḥrūsa) entstanden ist, wird auch dieses Belegstück mit einer Tradition in Verbindung gebracht, die in Ostanatolien, Nordmesopotamien und Nordwest-Iran gepflegt wurde. Ausschlaggebend für diese Zuordnung ist die Erwähnung der nisba al-Kahtāwī. Aus ihr lässt sich ableiten, dass der Schreiber einen Bezug zu Kahtā aufweist. Es handelt sich um eine zur Zeit der Mamluken wichtige Festung in SüdostAnatolien, ca. $80 \mathrm{~km}$ südlich von Malatya. ${ }^{11}$

Das Layout wird von einem Schriftband dominiert, das die ganze Rolle umfährt. Es ist zumeist dreiteilig. Es lassen sich aber auch Abschnitte feststellen, auf denen es nur ein- oder zweiteilig ist. Inhaltliche Überprüfungen legen nahe, dass nur ein einziger Teil des Schriftbands vom Anfang bis an den Schluss der Rolle durchläuft und wieder an deren Beginn zurückkehrt. Die weitere Beschreibung befasst sich in einem ersten Schritt mit diesem seitlichen Schriftband.

Am Anfang lässt sich im schmalen Band rechts aussen Text aus Q 2:76 erkennen (absteigend). ${ }^{12}$ Auf der linken Seite steht zuoberst im mittleren Band aufsteigend Q 2:127. Der Text umfährt das oberste Medaillon und steigt im mittleren Schriftband wieder ab. Auf der Höhe des obersten abgerundeten Rechtecks steht auf der rechten Seite Q 2:144. Text aus Q 2 steht auch ganz am Ende der Rolle im Bogen, der das letzte oben und unten abgerundete Rechteck umfährt. ${ }^{13}$ Im schmalen Innenband steht zuunterst der Schluss von Q 2:235. ${ }^{14}$ Direkt danach beginnt im schmalen Innenband auf der rechten Seite Q 2:236 (auf-

Vgl. zu dieser Zuordnung ausführlich bei Anm. 323-329.
Abb. Is 1624.1 und Is 1624.1.2.
Abb. Is 1624.22.3 und Is 1624.23.
Der Schluss von Q 2:235 lautet:

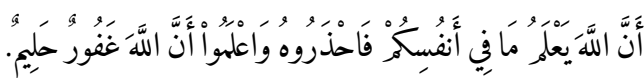


steigend). Q 2 endet mit Vers 286 im schmalen rechten Aussenband aufsteigend auf der Höhe des Rechtecks mit der Überschrift Sūrat al-Anfāl (Q 8) in einem goldenen Titelbalken. Unmittelbar danach beginnt Q 3 (Sūrat Āl Imrān) mit der basmala. $^{15}$

Bei der weiteren Beschreibung des Belegstücks drängt sich aufgrund seines komplexen Aufbaus ein abschnittsweises Vorgehen auf. Auf diesem Dokument dominieren Knoten. Sie werden durch Medaillons gebildet; es handelt sich wiederholt um eine Abfolge von mehreren Medaillons. Diese Knoten spielen bei der Einteilung in Abschnitte eine wichtige Rolle. Das bzw. die Schriftbänder umfahren diese Medaillons und wechseln dabei von der einen auf die andere Seite der Rolle. Die Haupteinteilung des Dokuments in Teil $\mathbf{I}^{16}$ und Teil II $^{17}$ wird durch die zwei Kolophone definiert. Die weitere Darstellung beschreibt den formalen Aufbau und den Inhalt der einzelnen Abschnitte weitgehend getrennt.

Teil I.1 (Grundstruktur): ${ }^{18}$ Dieser erste Abschnitt misst ca. ${ }^{163} \mathrm{~cm} .{ }^{19}$ Noch vor dem ersten Medaillon lässt sich ein Querbalken mit Text und Resten einer Verzierung erkennen. Zwischen den beiden Medaillons am Anfang und Ende dieses Teils wurden zwei Rechtecke eingefügt, die beide am Anfang und Ende abgerundet sind. Sie werden vom dreigliedrigen Schriftband eingefasst. Zwischen Rechteck 1 und 2 befindet sich kein Medaillon. Rechteck 1 ist deutlich länger als Rechteck 2 (Verhältnis ca. $2: 1$ ). Beim Übergang vom ersten zum zweiten Rechteck wechselt das Seitenband vom rechten zum linken Rand des Dokuments bzw. vice versa. Im Mittelstreifen der beiden Rechtecke wurde Text in schwarzer Schrift $(\dot{G} u b \bar{a} r)$

15 Abb. Is 1624.6 und Is 1624.6.4.

16 Teil I endet mit dem Kolophon 1; vgl. Abb. Is 1624.18.

17 Teil II beginnt direkt nach dem Kolophon von Teil I und endet am Schluss der Rolle (Abb. Is 1624.18-23).

18 Vgl. die Abb. Is 1624.1-3; Abb. Is 1624.4 gehört bereits zum Anfang von Teil I.2.

19 Eingeschlossen in diese Längenangabe sind: Medaillon am Anfang, die beiden abgerundeten Rechtecke und das Medaillon am Ende dieses ersten Abschnitts. auf horizontalen Zeilen kopiert. Die weiteren Ausführungen stellen Rechteck 1 (Teil I.1a) und Rechteck 2 (Teil I.1b) vor.

I.1a (detaillierter Aufbau und Inhalt; Ав B. 35): ${ }^{20}$ Unmittelbar vor dem ersten Medaillon lässt sich ein Zierbalken (Höhe ca. $3.5 \mathrm{~cm}$ ) mit Text erkennen. Die Verzierungen darin sind jetzt verderbt. Es lassen sich Überreste von blauer und goldener Farbe feststellen. In diesem Textbalken steht stark beschädigter Text in grossen Buchstaben. Die Stelle lässt sich entziffern als 'alayka $\left[. . .^{21}\right]$ șirātan mustaqiman. Der weitere Inhalt des Dokuments legt nahe, dass es sich um eine Stelle aus dem Koran handelt. Die soeben aufgeführte Abfolge von Ausdrücken kommt im Koran ein einziges Mal vor, nämlich am Ende von Q 48:2. Es ist zu vermuten, dass auf dem nicht mehr vorhandenen Teil der Rolle unmittelbar davor auch Q 48:1-2 gestanden hat. $^{22}$

Direkt unterhalb dieses Textbalkens folgt das erste grosse Medaillon. Zwischen dieses grosse Medaillon und das erste abgerundete Rechteck wurde ein kleines Medaillon (Aussendurchmesser $6.5 \mathrm{~cm}$ ) eingefügt. Im grossen Medaillon lässt sich in der oberen Hälfte Text auf blauem und goldenem Hintergrund erkennen. Die untere Hälfte wurde mit einem goldenen Rankenmuster mit Blüten auf blauem Hintergrund verziert. Dieser Kern des Medaillons wird von einem Zierband eingefasst, dessen Struktur kaum noch zu erkennen ist. Darum herum führt ein Schriftband von ca. $1 \mathrm{~cm}$ Breite mit Text in schwarzer Tinte. Dieses breite Schriftband läuft als innerstes Schriftband bis ans Ende des ersten Rechtecks durch und kehrt wieder zum obersten Medaillon zurück. Das erste Medaillon selbst wird zuäusserst von einem dreigliedrigen Band eingefasst. Dazwischen befindet sich ein

\footnotetext{
20 Vgl. Abb. Is 1624.1-2 und Is 1624.1.2-2.5.

21 Ein Ausdruck unleserlich.

22 Q 48:1-2 lautet (die auf der Rolle noch erkennbaren Ausdrücke am Schluss fett):

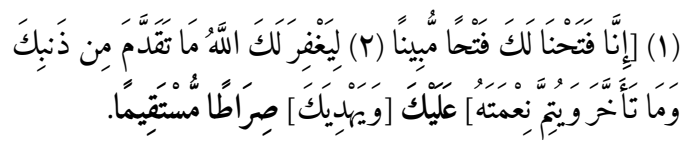


breites Zierband (Breite ca. $0.7 \mathrm{~cm}$; goldene Dreiecke auf blauem Grund). Es wird innen und aussen von einem schmalen Schriftband flankiert (Breite je ca. $0.4 \mathrm{~cm}$ ).

Der Text auf dem äussersten schmalen Schriftband ist am Anfang nicht mehr erkenntlich. Auf der Höhe des ersten Medaillons lässt sich darin aber auf der rechten Seite ein Teil von Q 2:76 erkennen; die Fortsetzung schliesst sich absteigend unmittelbar an. ${ }^{23}$ Aus dem Aufbau des Dokuments lässt sich ableiten, dass dieses Schriftband den Textbalken mit dem Schluss von Q 48:2 auf der linken Seite umfuhr. Text ist hier allerdings nur noch der Spur nach erkenntlich. Absteigend lässt sich der Text auf dem äussersten schmalen Schriftband trotz $\dot{G} u b \bar{a} r$-Schrift aber verfolgen. Am unteren Ende des ersten Rechtecks steht aussen der Übergang Q 2:85-86.24 Beim Übergang zum zweiten Rechteck wechselt das Band auf die linke Seite; der Schreiber setzt dort die Abschrift auf dem schmalen Innenband fort. Entlang des zweiten Rechtecks enthält dieses schmale Innenband (links) Q 2:87 ${ }^{25}$ bis Q 2:92. ${ }^{26}$ Auf den seitlichen Schriftbändern dieses Teils I lassen sich weitere Stellen aus Q 2 nachweisen. Ihre Identifizierung folgt später.

23 Q 2:76-78 lautet (die beiden ersten Wörter in Vers 76 jetzt nicht mehr erkenntlich):

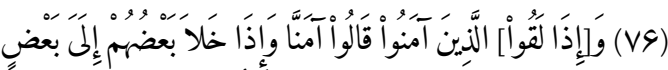

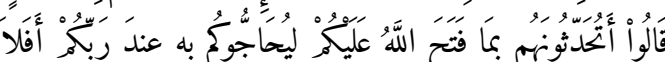

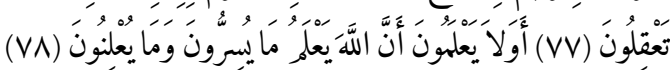

[Vers beginnt im äussersten Schriftband links auf der Höhe des ersten Rechtecks]

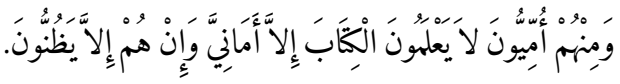

Q 2:92 (Schluss gerade vor dem Übergang ins Medaillon, das Teil I.1 abschliesst) lautet:

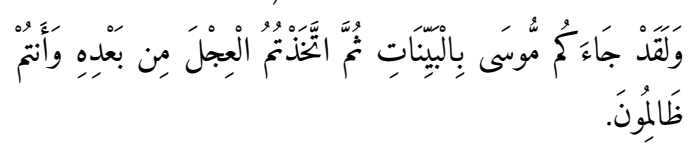

Die weiteren Ausführungen befassen sich mit dem Inhalt des Mittelstreifens zwischen den beiden Schriftbändern. ${ }^{27}$ In der oberen Hälfte des ersten Medaillons steht die Überschrift Min Āl Imrān (Titel von Q 3, Sūrat Āl Imrān). Dies lässt vermuten, dass auf dem diskutierten Abschnitt Stellen aus Q 3 enthalten sind. Auf der linken Seite lässt sich im schmalen Aussenband auf der Höhe des Rechtecks zuoberst der Schluss von Q 3:37 ${ }^{28}$ und der Beginn von Q 3:38 erkennen. ${ }^{29}$ Der Text von Q 3:38 steigt dem Schriftband entlang weiter nach oben und ist immer schlechter erkennbar. Auf dem schmalen Aussenband links dürfte zuletzt Q 3:40 gestanden haben. ${ }^{30}$

Auch im ersten Rechteck steht im Mittelstreifen auf horizontalen Linien Text aus Q 3. Vor dessen inhaltlicher Erfassung ist allerdings auf den Aufbau des Mittelstreifens in diesem Abschnitt (I.1a) hinzuweisen. Der Text ist hier in $\dot{G} u b \bar{a} r$ kopiert worden. Auf diesem „gubār-farbenen“ Hintergrund wurde an zwei Stellen Freiraum derart ausgespart, dass übergeordneter Text entsteht. Oben steht Li-llāh al-wā-hid; es folgt al-qahhār. Diese Aussage weist auf zwei Eigenschaften Gottes (al-wāhid: der Einzige; al-qahhār: der Siegreiche) hin.

Am Anfang und Schluss dieses Abschnitts fällt je eine Figur auf, die aus mehreren Teilen besteht, die sich sanduhrförmig ausdehnen und wieder verjüngen. Auf halber Länge dieses Mittelstreifens

27 Der Hintergrund dieses inneren Rechtecks wurde zumeist golden ausgefüllt. Darauf lassen sich Reste eines Blüten- und Rankenmusters erkennen, das mit schwarzer Tinte gezeichnet worden ist. Am oberen und unteren Ende zur Linken und Rechten jeweils ein Zierfeld mit blauem Hintergrund; darauf ein goldenes Blüten- und Rankenmuster. 
lässt sich eine Abfolge von Kreis-mandelförmiger Figur-Kreis erkennen. Davor und danach befindet sich je ein Rechteck. Sämtliche Figuren sind mit Text in schwarzem $\dot{G} u b \overline{a r}$ auf horizontalen Zeilen ausgefüllt. Zugleich werden sie links durch absteigenden und rechts durch aufsteigenden Text in $\dot{G} u b \bar{a} r$-Schrift in vertikaler Richtung eingefasst.

Da die Rolle am Anfang unvollständig erhalten ist, ist Q 3 hier nicht ganz vorhanden. Auf dem erhaltenen Teil des Dokuments lässt sich als nächste Stelle aus Q 3 erst wieder Q 3:154 erkennen; der Vers steht im Mittelstreifen auf der linken Seite senkrecht absteigend. ${ }^{31}$ Der Schreiber setzt die Abschrift entlang der linken Seite der Figuren im Mittelstreifen fort. Am Ende dieses ersten Rechtecks wechselt er auf die rechte Seite und steigt dort entlang der Figuren wieder nach oben. In der Mitte der obersten Ausbuchtung beginnt Q 3:179. Der Schreiber erreicht in diesem Vers das obere Ende des Rechtecks und springt jetzt auf die horizontalen Zeilen. Er setzt die Abschrift hier fort und steigt Zeile um Zeile nach unten. ${ }^{32}$ Q 4

31 Q 3:154 lautet (die 6 ersten Wörter des Verses fehlen an dieser Stelle):

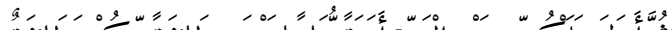

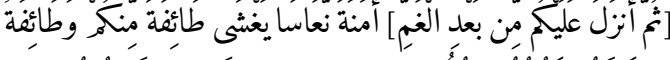

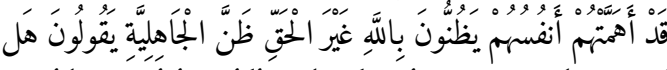

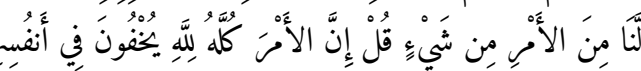

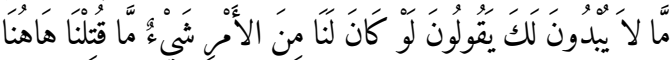

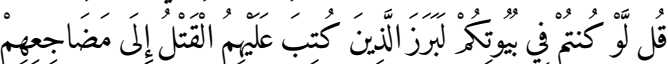

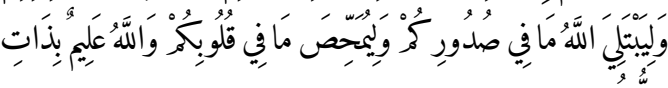
الصبلورون

32

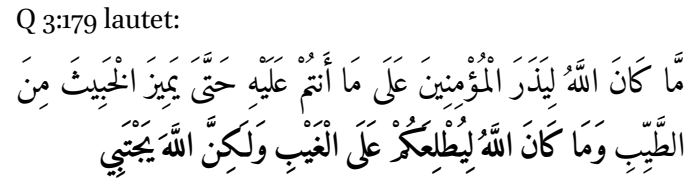

|| (Sprung auf die horizontalen Zeilen; fette Begriffe werden wiederholt)

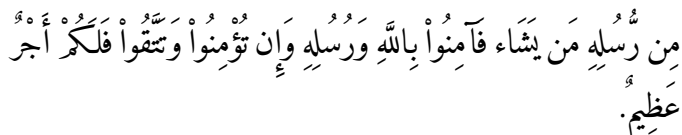

(Sürat an-Nis $\left.\bar{a}^{\prime}\right)$ beginnt in diesem Mittelstreifen kurz nach dem Ausdruck al-wāhid (weisse Stelle auf Hintergrund in $\dot{G} u b \bar{a} r$ ). Am Schluss dieses ersten Rechtecks steht im Mittelstreifen Q 4:104; im nächsten Rechteck folgt im Mittelstreifen in der obersten horizontal ausgerichteten mandelförmigen Figur Q 4:105. ${ }^{33}$

Aus diesen Ausführungen geht hervor, dass Q 3:40-153 auf der Rolle fehlt. Ausserdem lässt sich auf dem schmalen Aussenband rechts auf der Höhe des ersten Medaillons der Beginn von Q 2:76 erkennen. ${ }^{34}$ Auf dem erhaltenen Teil der Rolle fehlen somit auch Q 1 (Sūrat al-Fätiha, ganz) und Q 2:1-75. Diese Stellen nehmen in Druckausgaben 9 (Q 1:1-2:75) bzw. 18 Seiten (Q 3:40-153) ein. Es lässt sich nicht mehr feststellen, wie der verlorene Beginn der Rolle gestaltet war. Es kann aber davon ausgegangen werden, dass am Anfang des Dokuments $2-3 \mathrm{~m}$ verloren gingen.

I.1a: Interessant ist in diesem ersten Teil der Rolle aber v.a. der Text im breiten Schriftband, das die beiden Medaillons und das erste Rechteck umfährt. Es handelt sich im Gegensatz zu den restlichen Textelementen am Anfang nicht um Stellen aus dem Koran, sondern um ein Gebet. Es geht auf ein Prophetenwort (hadīt) zurück, das bereits bei Tirmidī ( $\left.\breve{G} \bar{a} m i^{i}\right)$ verzeichnet ist. ${ }^{35}$ Anfang und Schluss dieses Gebets befinden sich im grossen Medaillon. Die Stelle ist hier stark verwischt.

Dieses Gebet ist von grosser Bedeutung, da der Schreiber darin erwähnt, er habe diese hatma šarīfa, diese erhabene Abschrift des Korans, ${ }^{36}$ für

33 Abb. Is 1624.2.7.

34 Q 2:76 lautet:

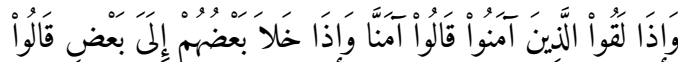

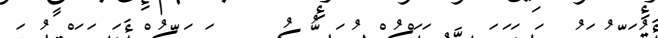

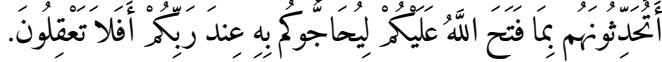

35 Vgl. http://library.islamweb.net/hadith/display_hbook. php?bk_no $=195 \&$ \&id $=3365 \&$ pid (Stand 23. November 2016). Weitere Fassungen finden sich in 18 zusätzlichen Quellen; eine Übersicht dazu findet sich in der angeführten Internetquelle unter dem Reiter Tahrïğ.

36 Der Ausdruck hatma lässt sich auch am Ende von Teil I, unmittelbar in Anschluss an den Kolophon, nachweisen 
einen gewissen Yalbuğ $\bar{a}^{37}$ hergestellt (ABB. 36). Er wünscht diesem Yalbugāa Sieg und Erfolg und ein glückseliges Leben, indem er die entsprechenden Wünsche aus dem hadīt konkret auf ihn überträgt. Im folgenden wird das Prophetenwort gemäss dem Wortlaut der in Anm. 35 angegebenen Quelle wiedergegeben. Beginn und Ende der auf der Rolle enthaltenen Stelle werden hervorgehoben:

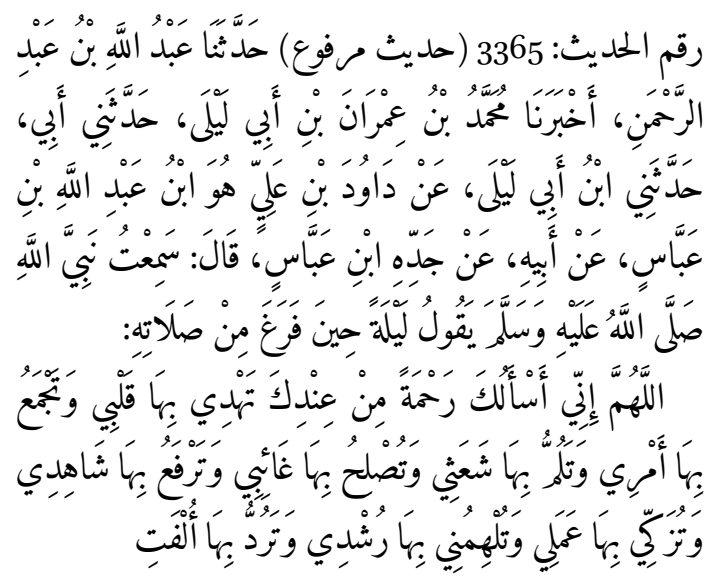

Ab hier ist der Text auf der Rolle klar erkenntlich:

(vgl. Abb. Is.1624.17.13). Hier steht in einem Zierfeld als Abschluss zu Teil I tammat al-hatma al-karima. Der Begriff hatma bezeichnet eine vollständige Rezitation des Korans.

Dieser Yalbugāa (siehe auch direkt hiernach bei Anm. 46) wird auf der Rolle ein zweites Mal erwähnt (siehe Abschnitt I.5, Anm. 111). Beide Stellen enthalten keine Namenszusätze, die eine eindeutige Identifizierung zulassen. Da es sich bei dieser Rolle aber um ein sehr wertvolles Exemplar handelt, muss es sich bei ihm um eine Person aus dem Umfeld der herrschenden Eliten handeln. Diese Rolle wurde wahrscheinlich für Yalbugāā al-'Umarī (jetzt zumeist als Yalbugàa al-Hāșșakī bezeichnet) angefertigt, der in Kairo zwischen ca. 1358 und 1366 die Fäden der Macht in den Fingern hielt, da die Vertreter aus dem Herrscherhaus der Mamluken noch zu jung waren. Yalbugāa fiel im Dezember 1366 einem Attentat zum Opfer. Kahtāwī hatte die Arbeit am zweiten Durchgang des vorliegenden Dokuments am 23. August desselben Jahres abgeschlossen; vgl. zu den relevanten Zusammenhängen ausführlich unten bei Anm. 332-335 (Schlussfolgerungen).

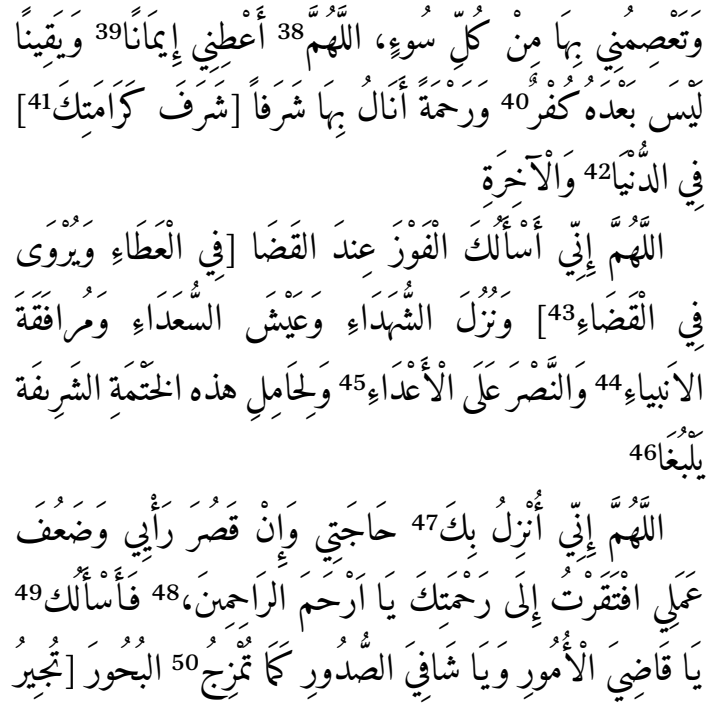

38 Dieses Allāhumma steht im breiten Schriftband rechts, wo das kleine Medaillon unterhalb des grossen Medaillons beginnt. Der Text verläuft im Schriftband weiter.

Auf der Rolle hier zusätzlich: Tirmidīi

46 Der Kopist erweitert hier den Hadīt aus der Sammlung Tirmidīis. Im Hadīt selbst bittet Muhammad Gott um Gewinn am Tag des Jüngsten Gerichts (al-fawz 'inda l-qaḍā), um den Rang von Märtyrern (nuzul aššuhadä'), um ein Leben unter den Glückseligen ('ayš assu'adā'), freundschaftlichen Umgang mit den Propheten (murāfaqat al-anbiya $\left.\bar{a}^{\prime}\right)$, Sieg über die Feinde (annașr 'ala $l$-a'd $\left.\bar{a}^{\prime}\right)$. Der Schreiber bezieht hier alle diese Wünsche auf Yalbugāā er wird auch als Träger dieser edlen Abschrift des Korans (al-ḩatma aš-šarīfa) bezeichnet.

47 So gemäss Tirmidīi; auf der Rolle verderbt.
Yã arhama ar-rāhimìn nur auf der Rolle.

Vgl. Abb. Is 1624.2.3.

Vokalisation unsicher. 


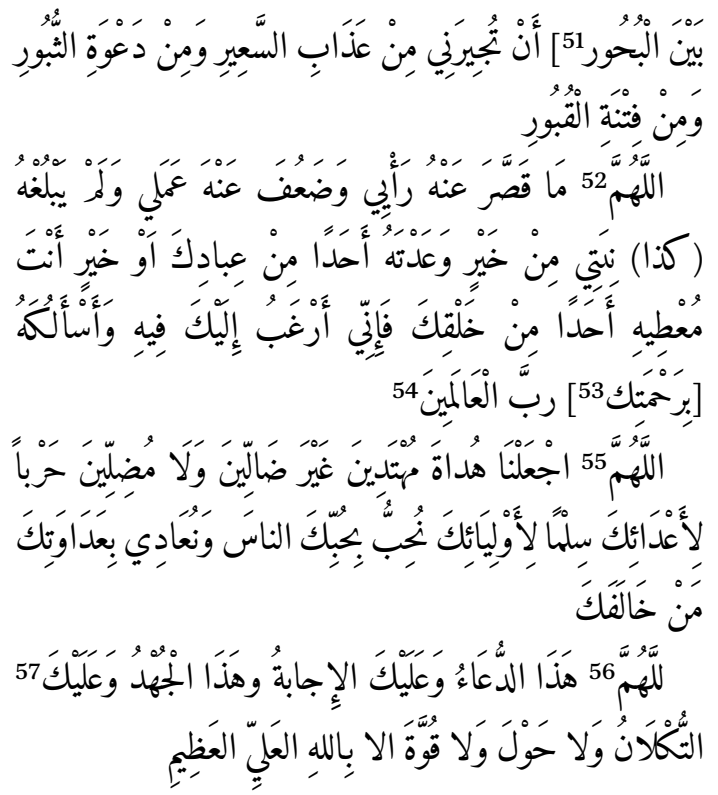

51 In eckigen Klammern: Wortlaut bei Tirmidī.

52 Vgl. Abb. Is 1624.2.5. Die Vorlage bei Tirmidī lautet hier:

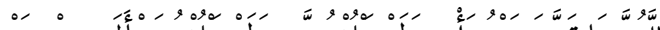

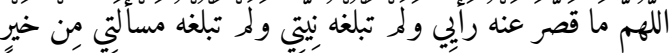

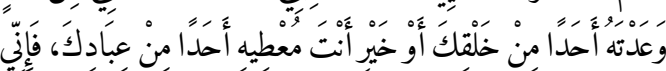

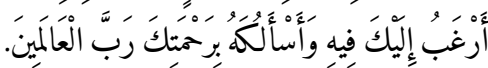

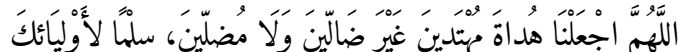

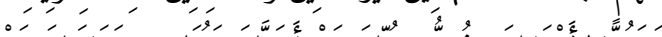

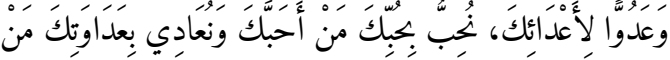

خَالَّكاك.

Wortlaut bei Tirmidī teilweise abweichend:

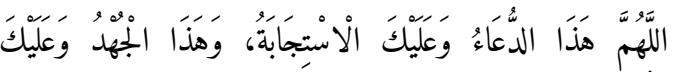

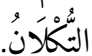

Vgl. Abb. Is 1624.2.3.

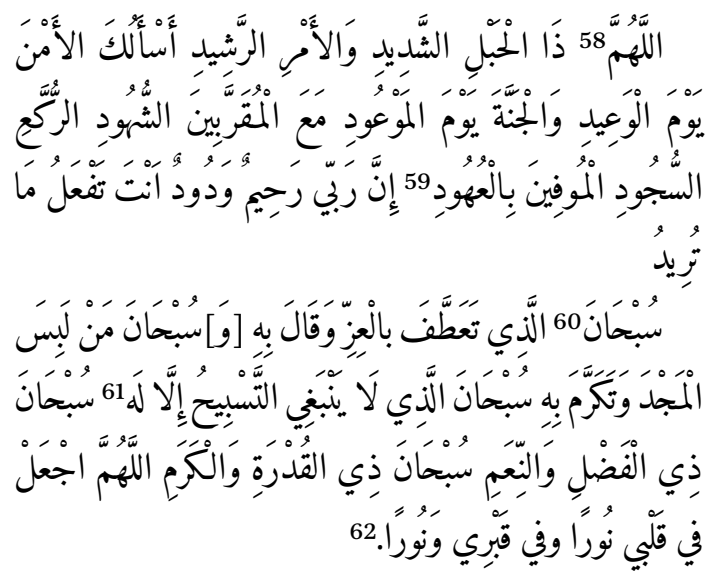

Der Schreiber nähert sich jetzt wieder dem Medaillon ganz am Anfang des erhaltenen Teils der Rolle, wo der Text zunehmend verblasst. Die folgende Fortsetzung findet sich nur bei Tirmidīi; zumindest ein Teil davon musste auf der Rolle aber noch vorhanden gewesen sein:

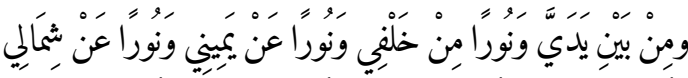

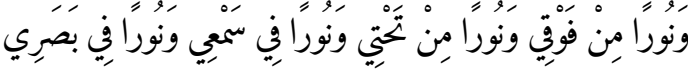

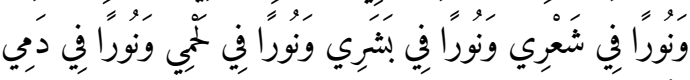

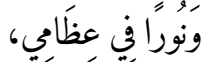

$5^{8}$ Die folgende Stelle fehlt in der Fassung bei Tirmidīi; sie lässt sich mit Abweichungen im Wortlaut aber belegen bei Ṭabarānī, al-Mư̆ğam al-awsaț, Hadịt Nr. 3821:

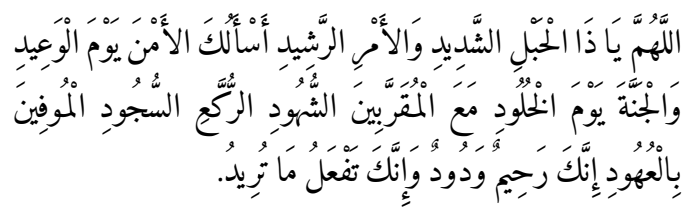

Vgl. http://library.islamweb.net/hadith/display_hbook. php?bk_no=475\&hid=3821\&pid=280641 (Stand 22. November 2016); Sulaymān b. Aḥmad b. Ayyūb al-Lahumī aț-Ṭabarānī, al-Mu'ğam al-awsaț. Qism at-taḥīiq bi Dār al-ḥaramayn, Abū Macād Țāriq b. 'Awaḍallāh b. Muhammad. Al-Qāhira, Dār al haramayn, 1415-1416 h.q./1995.

59 Vgl. Abb. Is 1624.2.2.

6o Diese Fortsetzung schliesst sich bei Ṭabarānī mit Abweichungen direkt an (vgl. Anm. 58); sie folgt bei Tirmidī mit grösserer Übereinstimmung im Wortlaut wenig später.

61 Vgl. Abb. Is 1624.1.4.

62 Ab hier lässt sich der Text nur noch der Spur nach entziffern. Das Schriftband geht jetzt ins kleine und danach ins grosse Medaillon über. 


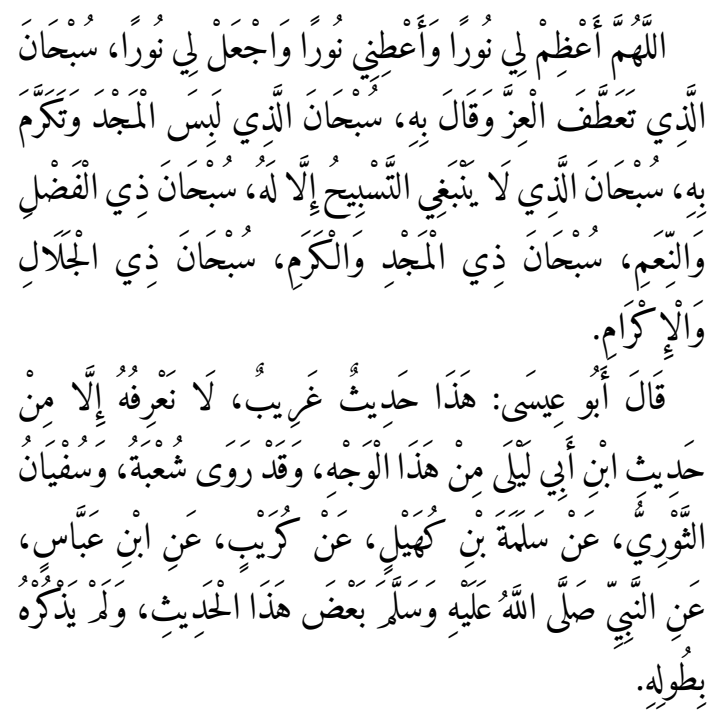

I.1b (AB B. 37): ${ }^{63}$ Die weiteren Ausführungen beschreiben das zweite an beiden Enden abgerundete Rechteck (Länge: $56.0 \mathrm{~cm}$ ). Die beiden Bögen oben und unten sind golden ausgefüllt. Im oberen Bogen lässt sich noch gut ein mit schwarzer Feder gezeichnetes Ziermuster (Blätter und Blüten) erkennen. Auch dieses zweite Rechteck wird auf der ganzen Länge von einem dreigliedrigen Band eingefasst. Die beiden äussern Bänder sind schmal und enthalten Text in $\dot{G} u b \bar{a} r$-Schrift (Stellen aus dem Koran). ${ }^{64}$ Sie fassen ein breiteres Zierband ein. Sein Hintergrund ist blau; darauf lässt sich eine goldene Zickzacklinie erkennen. Im Innern des Rechtecks lässt sich ein goldenes, schwarz strukturiertes Doppelband erkennen, das in regelmässigen Abständen Doppel- oder Dreifachknoten bildet.

Im Mittelstreifen dieses Rechtecks wurde Text in $\dot{G} u b \bar{a} r$-Schrift auf horizontalen Zeilen kopiert. Er ist in folgende Figuren eingefügt worden: Zuerst

63 Abb. Is 1624.3.1-3.3.

64 Beim Übergang vom 1. zum 2. Rechteck steht im schmalen Aussenband rechts (absteigend) der Übergang Q 2:85-86 (Fortsetzung als schmales Innenband links im 2. Rechteck). Ganz am Ende des 2. Rechtecks steht im schmalen Innenband Q 2:92 (Schluss, absteigend). Auf der Höhe der fünf Mandorlen am Ende des 2. Rechtecks steht Q 3:21-22 (schmales Innenband, rechts, aufsteigend). lässt sich eine Abfolge von fünf horizontal ausgerichteten mandelförmigen Figuren erkennen, die sich teilweise überschneiden. Nach der fünften Mandorla geht die Figur flaschenhalsartig in ein Rechteck über. Dieses Rechteck verjüngt sich unten erneut und geht in fünf weitere horizontal ausgerichtete mandelförmige Figuren über. In diesen Figuren wurde fortlaufender Text aus dem Koran kopiert. In der obersten Mandorla lässt sich der Schluss von Q 4:105 und der Beginn von Q 4:106 erkennen. ${ }^{65}$ In der untersten Mandorla folgt der Schlussvers von Q 4 (4:176). Die letzten drei Zeilen der Mandorla werden nach der Abschlussformel für die Rezitation einer Stelle aus dem Koran ${ }^{66}$ durch Eulogien ausgefüllt. In diesem Abschnitt ist auf einen goldenen Hizb-Vermerk in der zweiten Mandorla und einen ebenso goldenen $\breve{G} u z^{\prime}$-Vermerk im Rechteck in der Mitte hinzuweisen.

Abschnitt I.2 (AB B. 38): ${ }^{67}$ Die folgenden Ausführungen befassen sich mit einem Abschnitt von ca. $100 \mathrm{~cm}$ Länge, an dessen Anfang und Ende sich zwei auffällig gestaltete Medaillons befinden. Beide Medaillons füllen nahezu die ganze Breite (ca. $10 \mathrm{~cm})$ der Rolle aus. Zwischen diesen beiden Medaillons befinden sich zwei Rechtecke.

I.2a: Das erste Medaillon lässt sich je nach Blickwinkel unterschiedlich beschreiben. Es weist im Zentrum (Durchmesser ca. $7.0 \mathrm{~cm}$ ) goldene Verzierungen auf, deren Konturen durch schwarze Linien hervorgehoben werden. Grundsätzlich lässt sich ein Sechspass erkennen, dessen Lappen aussen einen blauen, mit goldenem Blattwerk versehenen

65 Q 4:105-106 lautet:

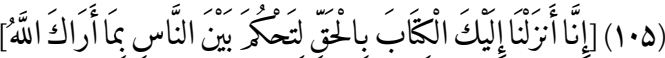

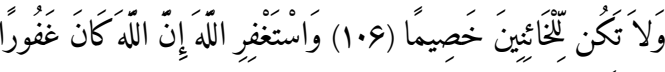
رحيماً.

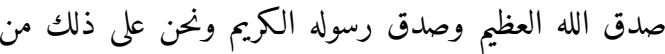
الشاهدين المؤمنين.

67 Diese Ausführungen beziehen sich auf die Abb. Is 1624.4.1-5.4. 
Hintergrund aufweisen. Die Kreislinien des Sechspasses laufen in der Mitte des Medaillons zusammen und bilden das Zentrum einer sechsblättrigen goldenen Blüte.

Ein dreigliedriges Band umfährt dieses Zentrum des Medaillons. Das mittlere Band ist breit und weist einen blauen Hintergrund auf, auf dem durch eine goldene Zickzacklinie Dreiecke entstehen. Dieses breite Zierband wird innen und aussen von je einem schmalen Schriftband mit Text in $\dot{G} u b \bar{a} r$ eingefasst. Es handelt sich um fortlaufenden Text aus dem Koran. Beim Übergang vom soeben beschriebenen Medaillon zum darunterliegenden abgerundeten Rechteck lassen sich folgende Stellen erkennen:

Absteigender Text: a. Am unteren Ende des Medaillons, Schriftband, rechts aussen: Beginn von Q 2:94; die Fortsetzung folgt im Rechteck darunter im Innenband links. b. Medaillon, Schriftband, rechts innen: Q 2:162 (Schluss); die Fortsetzung folgt im Rechteck darunter im Aussenband links. ${ }^{68}$

Aufsteigender Text: a. Am oberen Ende des Rechtecks steht auf dem Innenband Q 2:105 (Schluss) und der Anfang von Q 2:106. Beim Medaillon folgen auf dem linken Aussenband Q 2:107 und der Beginn von Q 2:108. b. Am oberen Ende des Rechtecks lässt sich auf dem Aussenband am unteren Ende des Medaillons der Übergang Q 3:19-2069 erkennen.

Beim Übergang zwischen Medaillon und Rechteck darüber lassen sich folgende Stellen erkennen: a. Im Aussenband links steht Q 2:108; dieser Vers wird auf dem rechten Aussenband beim Rechteck darüber fortgesetzt. b. In Übereinstimmung damit wechselt der Text im linken Innenband beim Medaillon ins rechte Innenband beim Rechteck darüber (Übergang Q 3:20-21).

Nach dem soeben beschriebenen Medaillon folgt darunter ein an beiden Enden abgerunde-

68 Deutlich erkennbar ist der Beginn von Q 2:163:

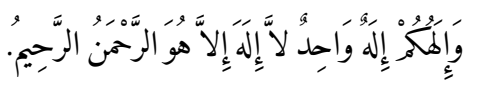

69 Der Schluss von Vers 3.19 lautet:

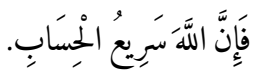

tes Rechteck. Das Innere des oberen und unteren Bogens diente dem Schreiber als Titelfeld. Im oberen Bogen lässt sich auf goldenem, mit durch schwarze Linien gebildeten Blüten verziertem Hintergrund in grosser weisser Schrift der Ausdruck Sūra ${ }^{70}$ erkennen. Im unteren Bogen steht auf blauem, mit einem goldenen Blatt- und Blütenmuster verziertem Hintergrund al-Mẩida. Sure al-Māida (Q 5) wurde im Innern dieses Rechtecks auf horizontalen Zeilen auch tatsächlich kopiert ( $\dot{G} u b \bar{a} r)$. Am Anfang lässt sich die Basmala und der Beginn von Q 5 erkennen. Der Abschnitt schliesst mit Q 5:120 (Schlussvers). ${ }^{71}$

In der Mitte dieses Rechtecks befindet sich eine horizontal ausgerichtete mandelförmige Figur. Darunter folgen drei sechsstrahlige Sterne. Über der mandelförmigen Figur lassen sich ebenso zwei solche Sterne erkennen. Zuoberst steht ein halber Stern, der unten einen bauchförmigen Abschluss aufweist. Diese oberste Figur ruft ähnliche Formen auf einer Liturgierolle aus christlichen Kontexten in Erinnerung, die aus dem Nahen Osten stammt und aus der zweiten Hälfte des 11. Jh. datiert. ${ }^{72}$ Die Zwischenräume zwischen die-

70 Verderbt.

71 Es wurde nicht überprüft, ob der Schreiber die ganze Sure kopierte oder einzelne Verse ausliess. Auslassungen von mehreren Versen lassen sich auf solchen Rollen wiederholt beobachten (vgl. auch Kapitel 4.8, vor Anm. 26 und bei Anm. 53-56; Rolle aus Basel).

72 Man vergleiche diese Figur, gerade auch ihre Bauchform, mit dem Frontispiz von Hagios Stavros 109 (Jerusalem, Bibliothek des Griechisch-orthodoxen Patriarchats); Abbildung in Bokotopulos, Byzantine illuminated manuscripts 96-123, v.a. 98f. (Fig. 44), 102 (Fig. 47). Abbildung auch in Maniaci und Orofino, Les 'rouleaux d'Exultet' 78 (Abb. 9); Grabar, Un rouleau liturgique constantinopolitain.

Die ähnliche Gestaltung dieser Figur auf Is 1624 und der beigebrachten Parallele auf Hagios Stavros mag auf den ersten Blick vernachlässigbar scheinen. Die Existenz von Dokumenten in Rollenform aus christlichen Kontexten verdient aber durchaus eingehendere Aufmerksamkeit. Diese Rollen waren in der christlichen Liturgie in Gebrauch. Es wird daran erinnert, dass auch die hier vorgestellten Dokumente aus dem islamischen Kulturraum viele Texte, gerade auch Gebete, enthalten. Sie wurden wahrscheinlich bei den frommen Zusammenkünf- 
sen Figuren und dem Rand des Mittelstreifens auf Is 1624 weisen zumeist einen blauen Hintergrund auf; er ist mit einem goldenen Blatt- und Blütenmuster verziert worden. Bei den Sternen sind diese Zwischenräume zumeist golden ausgefüllt und mit einem Muster versehen, das durch schwarze Linien gebildet wird.

I.2b (АВB. 39): Darunter schliesst sich das zweite Rechteck an (Länge ca. $32 \mathrm{~cm}$; mit Über- und Unterschrift); es wird auf seiner gesamten Länge von einem schmalen Textband in $\dot{G} u b \bar{a} r$-Schrift eingefasst. ${ }^{73}$ Dieses Schriftband ist hier nur einteilig, was speziell hervorzuheben ist. Am oberen und unteren Ende des Rechtecks lässt sich je ein halbes sechslappiges Medaillon erkennen (jeweils drei Lappen). Sein Hintergrund ist blau und mit vereinzelten goldenen Blättern und Blüten hinterlegt. Golden hinterlegt lässt sich auf diese beiden Felder verteilt in weisser Schrift der Titel von Q 6 erkennen (Sūrat al-An'ām). ${ }^{74} \mathrm{Q} 6$ wurde in diesem Rechteck in $\dot{G} u b \bar{a} r$-Schrift auch tatsächlich kopiert. Die Zeilen sind in der Längsrichtung des Rechtecks und somit der Rolle ausgerichtet. Es lassen sich 33 Zeilen erkennen; die Breite des Rechtecks misst an dieser Stelle $7.2 \mathrm{~cm}$. Die Höhe einer Zeile beträgt damit etwas mehr als $2 \mathrm{~mm}$. Oben rechts steht die Basmala und der Beginn von Q 6 . Unten links folgt Q 6:111. ${ }^{75}$

Der Kopist hat in diesem Abschnitt Freiraum derart ausgespart, dass ein übergeordneter Text entsteht. Es handelt sich um die šahāda (Lā ilāha illā Allāh Muhammad rasūl Allāh). Diese Technik lässt sich später auf Belegstücken aus dem

ten von den Mitgliedern von Männerbünden rezitiert. Vgl. zu diesen Liturgierollen u.a.: Maniaci, The liturgical scroll between Orient and Occident; Gerstel, Liturgical scrolls in the Byzantine Sanctuary.

73 Es handelt sich um Stellen aus dem Koran; am Ende des Rechtecks stehen die beiden folgenden Stellen: Schriftband rechts absteigend: Q 2:171; Schriftband links aufsteigend: Q 3:11 (Abb. Is 1624.5.1).

74 Vgl. Abb. Is 1624.4.5 und 5.4.

75 Die Fortsetzung von Q 6:111 im Medaillon darunter. Es wurde nicht überprüft, ob der Text von Q 6:1-111 lückenlos kopiert wurde. iranischen Kulturraum mehrfach beobachten und wurde darauf noch viel raffinierter ausgeführt. ${ }^{76}$ Diese formale Kontinuität über mehrere Jahrhunderte hinweg sei hier hervorgehoben. Sie lässt sich auch dahingehend erklären, dass sich die hier untersuchten Rollen in eine Tradition einordnen lassen, die sich über mehrere Jahrhunderte hinweg fortsetzte und - wenn auch nicht auf identische so doch auf ähnliche Grundhaltungen der jeweiligen Hersteller schliessen lässt.

Am Ende dieses Rechtecks ist die Abschrift von Q 6 mit Vers 111 nicht abgeschlossen. Die Fortsetzung der Abschrift (Q 6:111) folgt im Medaillon unmittelbar darunter, das die ganze Breite des Schriftspiegels ausfüllt. Es wurde als sechsteiliger Sonnenwirbel gestaltet (АВВ. 40). ${ }^{77}$ Die einzelnen Teile des Wirbels werden durch blau-goldene Bänder gebildet. Im Innern dieser sechs Teile wurde Text in $\dot{G} u b \bar{a} r$-Schrift kopiert, wobei auf einen Abschnitt in schwarzer ein solcher in roter Tinte folgt. Im schwarzen Teil oben in der Mitte lässt sich die Fortsetzung von Q 6:111 und auch Q 6:114 erkennen. Der Kopist setzt die Abschrift von Q 6 in den einzelnen Abschnitten des Sonnenwirbels im Gegenuhrzeigersinn fort. ${ }^{78}$ Am Schluss erreicht er den sechsten Abschnitt des Wirbels (rote Tinte). Hier lässt sich zuinnerst Q 6:165 erkennen, wobei die letzten Wörter aus Platzmangel weggelassen wurden. ${ }^{79}$ Dieses Medaillon mit dem Sonnenwirbel wird übrigens vom schmalen

76 Man beachte dazu u.a. folgende Vergleichstücke: Chester Beatty Library, Is 1623 (Kapitel 5.3); Paris, BNF, Arabe 5102 (Kapitel 5.4). Siehe auch hier unten bei Anm. 142144.

77 Man vergleiche damit einen zwölf-fächrigen Wirbel in der Kuppel des Heiligtums von Šāh Ni'matullāh Walī in Māhān (bei Kerman, Iran); siehe: http://archnet.org/ sites/1637/media_contents/42355 (Stand 22. November 2016).

78 Es wurde nicht überprüft, ob die Abschrift lückenlos ist. 79 Q 6:165 lautet (Schluss in eckigen Klammern fehlt):

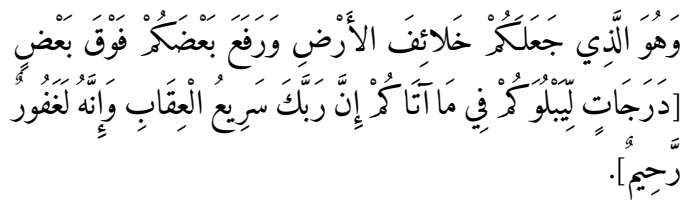


Schriftband (auch hier nur einteilig) eingefasst, das die Abschrift von Stellen aus dem Koran in diesem Aussenband fortsetzt. 80

Abschnitt I.3: ${ }^{81}$ Die folgenden Ausführungen befassen sich mit dem Abschnitt zwischen dem vorangehenden sechs-fächrigen Sonnenwirbel ${ }^{82}$ und einem zwölflappigen Medaillon mit Text in $\dot{G} u b \overline{a r} .{ }^{83}$ Zwischen diesen beiden Figuren befindet sich ein an beiden Enden abgerundetes Rechteck von ca. $65 \mathrm{~cm}$ Länge. Von besonderem Interesse ist in diesem Abschnitt der Inhalt des breiten Textbands, das dieses Rechteck umfährt. Ausserdem umfährt ein schmales Textband diesen Abschnitt auf beiden Seiten entlang des Rollenrands. Dieses schmale Textband ist Teil jener Einfassung, die die gesamte Rolle umfährt. Im unteren Teil dieses Rechtecks lässt sich etwas unterhalb des horizontalen goldenen Balkens mit dem Titel von Q 8 (Sūrat al-Anfäl) auf dem linken schmalen Aussenband (Text aufsteigend) der Schluss von Q 2 (Vers 286) und der Anfang von Q 3 (Sūrat Āl Imrān) erkennen. Ihr Titel ist golden hervorgehoben; danach steht die Basmala. Auf der gegenüberliegenden Seite steht im schmalen Schriftband (rechts, absteigend) auf dieser Höhe Q 2:177.84

8o Im vorwärtslaufenden Schriftband steht links (absteigend) Q 2:172 (Übergang zum Medaillon markiert):

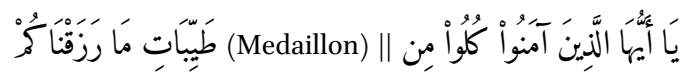

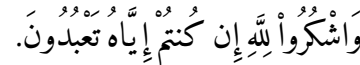

Im aufsteigenden Schriftband lässt sich auf der rechten Seite des Medaillons der Beginn von Q 3:8 erkennen; Q 3:8 lautet:

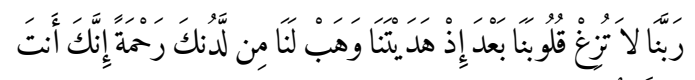

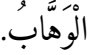

81 Abb. Is 1624.5.5-6.5.

82 Abb. Is 1624.5.4.

83 Abb. Is 1624.6.5. Dieses zwölflappige Medaillon wird erst in Abschnitt I.4 beschrieben (nach Anm. 95).

84 Die Abschrift von Q 2 weist danach eine Lücke auf. Klar erkenntlich ist in diesem schmalen Seitenband gegen den Schluss des Rechtecks wieder Vers 2:183.
Der Mittelstreifen wird im Innern auf seiner gesamten Länge von einem goldenen Flechtband eingefasst, dessen Konturen mit schwarzer Feder hervorgehoben werden. Vereinzelt wurden kleine blaue Zierfelder in dieses Flechtband eingestreut. Der Mittelstreifen selbst weist eine Breite von ca. $5.0 \mathrm{~cm}$ auf. Er wird auf halber Länge durch ein sechslappiges Medaillon in zwei ähnlich lange, aber unterschiedlich gestaltete Abschnitte aufgeteilt.

Im oberen Bogen des abgerundeten Rechtecks lässt sich ein Titelfeld mit blauem Hintergrund und vereinzelten goldenen Zierelementen (Blätter) erkennen. Golden hinterlegt steht hier in grosser weisser Schrift Sürat al-A'rā $f\left(Q_{7}\right) \cdot{ }^{85}$ Abschnitt a. weist im Mittelstreifen eine dreiteilige Gliederung auf. Das Schriftfeld nimmt am oberen und unteren Ende die ganze Breite des Mittelstreifens ein. Es verjüngt sich zur Mitte hin zu einem schmalen Hals, dehnt sich aber sogleich wieder aus. Die entstehende Figur erinnert an eine dreiteilige Sanduhr. Die seitlichen Felder weisen zuerst einen goldenen Hintergrund auf und sind mit einem Muster mit Blättern und Blüten versehen (ausgeführt mit schwarzer Feder). Die beiden nächsten Seitenfelder haben einen blauen Hintergrund und weisen goldene Verzierungen auf (Blätter und Blüten). Dieser Abschnitt wird unten durch ein halbes sechslappiges Medaillon (3 Lappen) abgeschlossen. Er ist mit goldenen Verzierungen versehen; sein Muster (Blätter und Blüten) wurde mit schwarzer Feder gezeichnet. b. Es schliesst sich darauf ein sechslappiges Medaillon an, das golden eingefasst ist und im Innern Text in $\dot{G} u b \bar{a} r-$ Schrift enthält. Die seitlichen Freiräume weisen einen blauen Hintergrund auf und sind mit goldenen Verzierungen (Blüte und Blätter) versehen. Danach folgt Abschnitt c., der auf horizontalen Zeilen Text in $\dot{G} u b \bar{a} r$-Schrift enthält. Er wird oben durch einen dreiteiligen Bogen abgeschlossen und erinnert somit an einen Mihrāb. Dieser Abschnitt

85 Q 7 beginnt unmittelbar darunter im Mittelstreifen in $\dot{G} u b \bar{a} r-$ Schrift. 
wird durch einen goldenen Titelbalken unterbrochen. Darauf steht in weisser Schrift Sūrat al-Anfāl (Q 8). ${ }^{86}$

Vorliegend interessiert aber v.a. der Text im breiten Schriftband, das dieses Rechteck auf seiner gesamten Länge einfasst; er beginnt oben in der Mitte mit der Basmala. Es handelt sich um ein Gebet mit Anrufungen Gottes. Ganz am Schluss steht eine Eulogie, die mit einer Lobpreisung Muhammads beginnt.

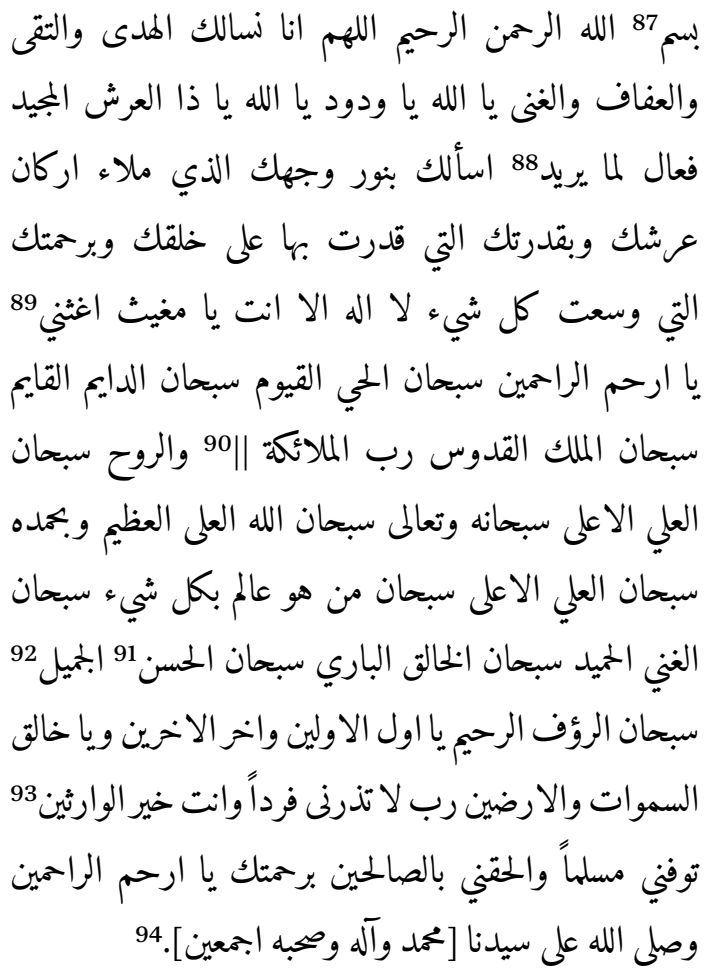

86 Q 8 beginnt unmittelbar darunter im Mittelstreifen in Gubār-Schrift.

87 Abb. Is $1624 \cdot 5 \cdot 5$.

88 Abb. Is 1624.6.1.

89 Abb. Is 1624.6.4.

9o Übergang in den Bogen am Ende des abgerundeten Rechtecks; danach Text auf der rechten Seite rückwärtslaufend aufsteigend.

91 Oder الحسن (Entzifferung wahrscheinlich).

92 Abb. Is 1624.6.1.

93 Abb. Is 1624.5.5.

94 Mit grosser Wahrscheinlichkeit stand hier die in eckigen Klammern angefügte Eulogie; sie lässt sich mit Mühe erkennen.
Abschnitt I.4 (АB B. 41): ${ }^{95}$ Am Anfang dieses Abschnitts befindet sich ein zwölflappiges Medaillon; es wird von einem einteiligen schmalen Schriftband umfahren. Im Innern dieses Medaillons wurde Text in $\dot{G} u b \bar{a} r$ auf horizontalen Zeilen notiert. Nach einem an beiden Enden abgerundeten Rechteck (Länge $58 \mathrm{~cm}$ ) folgt das nächste Medaillon mit Text auf horizontalen Zeilen in schwarzem $\dot{G} u b \bar{a} r$. Auch es wird von einem einteiligen schmalen Schriftband umfahren.

Die folgende Übersicht beschreibt das Rechteck und seine einzelnen Teile näher: Das an beiden Enden abgerundete Rechteck wird zusätzlich von einem breiten Schriftband umfahren. Im oberen Bogen des Rechtecks befindet sich ein Zierfeld mit goldenem Hintergrund und einem mit schwarzer Feder gezeichneten Muster (Blätter und Blüten); hier auch Reste einer blauen Verzierung. In diesem Bogen steht der Titel von Q 9 (Sürat at-Tawba) ${ }^{96}$ in grossen weissen Buchstaben. Nach etwas mehr als der Hälfte dieses Rechtecks folgt im Mittelstreifen ein horizontaler Titelbalken mit blauem Hintergrund und goldenen Blättern. Darin Titel in weisser Schrift, die golden hinterlegt ist (Sürat Yūnus: Q 10). Der Bogen am Schluss des Rechtecks weist einen blauen Hintergrund auf und wurde mit goldenen Verzierungen (Blätter, Blüten) versehen. Darin in weisser Schrift (golden hinterlegt) der Titel Sürat Hüd (Q 11).

Im Mittelstreifen dieses Rechtecks wurde der Text des Korans auf horizontalen Linien in $\dot{G} u b \bar{a} r-$ Schrift kopiert. Das Rechteck wird durch den blauen Titelbalken von Q 10 (Sūrat Yünus) in zwei Abschnitte aufgeteilt. Im ersten Abschnitt lassen sich sechs auf der Spitze stehende Quadrate erkennen, die durch goldene Linien gebildet werden und untereinander verbunden sind. Zusätzlich wurden drei horizontal ausgerichtete mandelförmige Figuren eingefügt, die ebenso durch goldene Linien gebildet werden. Die gesamte Breite des Mittelstreifens $($ ca. $5.5 \mathrm{~cm})$ ist mit Text ausgefüllt (fortlau-

95 Abb. Is 1624.6.5-8.1.

96 Sūratat-Tawba; sie beginnt im Mittelstreifen unmittelbar darunter. 
fender Korantext). Nach dem blauen Titelbalken folgen drei weitere auf der Spitze stehende Quadrate und zuletzt ein halbes Quadrat. In den zum Rand des Mittelstreifens hin entstehenden Dreiecken lassen sich Verzierungen erkennen. Der Hintergrund von Dreieck 1 und 3 (jeweils links und rechts) ist golden. Darauf lassen sich die Reste von mit schwarzer Feder ausgeführten Verzierungen erkennen (Blüten und Blätter). Der Hintergrund von Dreieck 2 (links und rechts) ist blau und weist eine goldene Verzierung auf (Blüte und Blätter).

Auch in diesem Abschnitt wurde im breiten Schriftband ein Gebet notiert; es thematisiert in erster Linie das bedingungslose Vertrauen in Gott (tawakkul):97

$$
\begin{aligned}
& \text { بسم } 98 \text { الله الرحمن الرحيم فاذا عزمتَ فتوكل على الله ان } \\
& \text { الله يحب المتوكلين } 99 \text { فن ذا الذي ينصركم من بعده } 100 \text { وعلى } \\
& \text { الله فليتوكل المؤمنين (كذا)101 وسع ربنا كل شي علماً } 102 \\
& \text { على الله توكلنا ربنا افتح بيننا وبين قومنا بالحق ||103 وانت } \\
& \text { خير الوارثين } 104 \text { واذا توليت عليهم آياته زادتهم ايماناً وعلى } \\
& \text { ربهم يتوكلون105 ومن يتوكل على الله فان الله وزيز حكيم } 106 \\
& \text { وتوكل على الله فان الله سميع عليم } 107 \text { فان تولوا فقل حسبي الله } \\
& \text { لا اله الا هو عليه توكلت وهو رب العرش العظيم. } 108
\end{aligned}
$$

Abschnitt I.5: ${ }^{109}$ Der nächste Abschnitt wird von einem breiten Schriftband eingerahmt. Es fasst

\footnotetext{
97 Zum Konzept des tawakkul vgl. Kapitel 3.1 (bei Anm. 138) und Kapitel 3.2 (Anm. 259 und bei Anm. 285).

98 Is 1624.7.2: Die basmala steht in der Mitte; Text danach im Schriftband links, absteigend.

99 Vgl. Q 3:159 (Schluss).

100 Abb. Is 1624.7.4.

101 Q 3:16oa.

102 Abb. Is 1624.7.5.

103 Übergang in den Bogen am Ende des Rechtecks.

104 Vgl. Q 7:89, wo letztes Wort al-fätihìn.

105 Vgl. Q 8:2.

106 Abb. Is 1624.7.4: Schriftband rechts, rückwärtslaufend; vgl. Q 8:49 (Schluss).

107 Abb. Is 1624.7.2; vgl. Q 8:61.

108 Vgl. Q 9:129.

109 Abb. Is 1624.8.2-9.5.
}

zwei Rechtecke ein und umfährt zuletzt ein Medaillon. Auch am Anfang dieses Abschnitts befindet sich ein Medaillon; es enthält Text in schwarzem $\dot{G} u b \bar{a} r$ auf horizontalen Zeilen. Auf der Höhe dieses oberen Medaillons lässt sich im schmalen Aussenband rechts Q 2:282 erkennen. ${ }^{110}$

I.5a: Die Länge des ersten an beiden Enden abgerundeten Rechtecks misst ca. $38 \mathrm{~cm}$. Es enthält im Innern 11 horizontal ausgerichtete mandelförmige Figuren mit Text aus dem Koran in $\dot{G} u b \bar{a} r-$ Schrift. Zwischen dem breiten Schriftband aussen und den mandelförmigen Figuren verläuft ein goldenes Flechtband, dessen Muster schwarz strukturiert ist. Im Bogen am oberen Ende des Rechtecks befindet sich ein Titelfeld mit blauem Hintergrund und golden hinterlegten Stellen in grosser, weisser Schrift (Sūrat Yūsuf: Q 12). Am Ende dieses ersten Rechtecks wechselt das Schriftband die Seite und geht

[I.5b] in ein zweites an beiden Enden abgerundetes Rechteck (Länge ca. $38 \mathrm{~cm}$ ) darunter über. Es weist im Bogen am Anfang und am Schluss ein Titelfeld mit goldenem Hintergrund auf. Darauf steht in grosser, weisser Schrift a. Sürat ar-Ra'd (Q 13) und b. Sürat an-Naḥl (Q 16). Der Mittelstreifen in diesem zweiten Rechteck wird durch drei senkrecht stehende mandelförmige Figuren von gleicher Höhe dominiert (mit Text aus dem Koran in $\dot{G} u b \bar{a} r$-Schrift). Die mandelförmigen Figuren sind untereinander durch horizontal ausgerichtete Zwickel mit Text in $\dot{G} u b \bar{a} r$ verbunden. Diese Figuren (Mandorlen und Zwickel) werden durch schmale, goldene Bänder eingefasst. Der Hintergrund des Felds mit der obersten und untersten mandelförmigen Figur ist blau; er wurde mit einem Muster aus goldenen Blättern und Blüten verziert. Der Hintergrund der mittleren mandelförmigen Figur ist golden. Es lassen sich Reste einer mit schwarzer Feder ausgeführten Verzierung (Blüten und Blätter) und vereinzelte blaue Farbtupfer erkennen.

110 Abb. Is 1624.8.1. 
Zuunterst folgt ein Medaillon, das nahezu die gesamte Breite der Rolle einnimmt (Durchmesser ca. $10 \mathrm{~cm})$. Das breite Schriftband umfährt dieses Medaillon und geht dabei vom vorwärtslaufenden ins rückwärtslaufende Schriftband über. Die folgende Übersicht befasst sich mit dem Inhalt des breiten Schriftbands, das beide Rechtecke zusammen umfährt. Die Länge dieses Abschnitts misst insgesamt etwa $84 \mathrm{~cm}$. Beim Text in diesem Abschnitt handelt es sich um ein weiteres Gebet. Der Text ist von besonderer Bedeutung, da der Schreiber hier den Namen des bereits bekannten Yalbugāa ein zweites Mal erwähnt. ${ }^{111}$ Dieser Name befindet sich im breiten Schriftband (links), das das Medaillon am Schluss dieses Abschnitts umfährt.

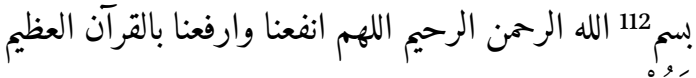

$$
\begin{aligned}
& \text { وتب علينا به انك انت التواب الرحيم يا جواد يا حليم اللهم } \\
& \text { اجعل القران ربيعا لقلوبنا وجلاء احزاننا وذهاب همومنا }
\end{aligned}
$$

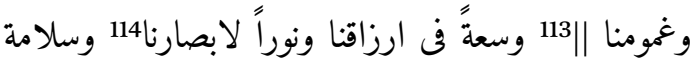

$$
\begin{aligned}
& \text { لديننا ودنيانا وتؤنس به لوحشتناو وترحم به لغربتنا فاءذا توفيتنا }
\end{aligned}
$$

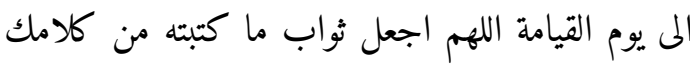

$$
\begin{aligned}
& \text { العظيم في صحيفة عبدك وفقيرك يلبغا ||115 اللهم اجعله في } \\
& \text { امنك وحرزك وحفظك يا خير الحافظين وانصره على من } \\
& \text { يعاديه يا خير الناصرين ||116 اللهم يا الله يا رباه يا سيداه يا وحريا }
\end{aligned}
$$

$111 \mathrm{Zu}$ ihm bereits oben Teil I.1a bei Anm. 37 und 46. Zu seiner Einordnung siehe v.a. unten bei Anm. 332-335 (Schlussfolgerungen).

112 Abb. Is 1624.8.2-8.5. Beginn in der Mitte des breiten Schriftbands; Fortsetzung auf der linken Seite absteigend.

113 Hier stossen das erste und das zweite Rechteck aufeinander; das Schriftband wechselt auf die rechte Seite der Rolle.

Abb. Is 1624.9.2: Schriftband rechts, vorwärtslaufend.

Abb. Is 1624.9.5: ab hier umfährt das Schriftband das Medaillon und geht in den rückwärtslaufenden Abschnitt über.

116 Abb. Is 1624.9.5: ab hier Übergang in das rückwärtslaufende Schriftband auf der linken Seite.

$$
\begin{aligned}
& \text { مولاه ||117 يا غاية رغبتاه اسالك بنبيك محمد وآله ان تحفظه } 118 \\
& \text { بعينك التي لا تُنام واكنفه بكنفك التي لايرّام من بلاء }
\end{aligned}
$$

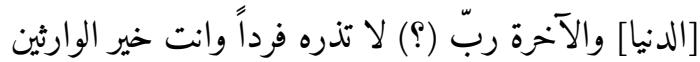

$$
\begin{aligned}
& \text { |119 اللهم من اراد كَيْدَهُ فككه ومن اراد غلبته فاغلبه اللهم } \\
& \text { اغفر لناولوالديناومن علمنا وبلميع المسلمين والمسلمات الاحياء } \\
& \text { مهم والاموات انك قريب بجيب الدعوات برحمتك يا ارحم } \\
& \text { الراحمين وصلى الله على سيدنا محمد وآله اجمعين. }
\end{aligned}
$$

Abschnitt I.6: Die weiteren Ausführungen befassen sich mit Aufbau und Inhalt eines Abschnitts von ca. $180 \mathrm{~cm}$ Länge. Dieser Abschnitt weist kein breites Textband mit Gebetstext auf, wie dies auf dem vorliegenden Dokument sonst häufig der Fall ist. ${ }^{120}$ Vielmehr wird dieser Teil, zumindest in seinem Hauptabschnitt, seitlich nur je von einem schmalen Textband eingefasst. Dieser Teil der Rolle lässt sich in drei Abschnitte gliedern:

A. Zuerst lässt sich ein Abschnitt mit vier zwölflappigen Medaillons erkennen (Länge ca. 39 cm; АВB. 42). Dieser Abschnitt hängt im Mittelstreifen noch mit dem vorangehenden runden Medaillon zusammen, wo die Abschrift von Q 16 beginnt (mit dem Titelfeld unmittelbar darüber: Sūrat an-Nahll).

B. Es folgt ein langer Abschnitt mit Text in $\dot{G} u b \overline{a r}$, der in der Rollenrichtung verläuft (АВВ. 43). Auf diesem Hintergrund in mikroskopischer Schrift sind Freiräume derart ausgespart, dass ein übergeordneter Text entsteht. Die Länge dieses Abschnitts beträgt ca. $120 \mathrm{~cm}$ (inkl. den beiden fünflappigen Zierfeldern mit Überbzw. Unterschrift).

117 Abb. Is 1624.9.2: Band links, rückwärtslaufend.

118 Text liest: تحفطه.

119 Abb. Is 1624.9.2 und 8.4: Übergangsstelle, wo die beiden abgerundeten Rechtecke aufeinandertreffen; das Schriftband wechselt von der linken auf die rechte Seite der Rolle (rückwärtslaufend).

120 Dies war im Abschnitt davor der Fall (vgl. Abb. Is 1624.8.2-9.5: Band breit) und wird auch wieder im unmittelbar anschliessenden Abschnitt so sein (vgl. Abb. Is 1624.13.3-14.2: Band breit). 
C. Dieser Teil der Rolle wird durch zwei weitere zwölflappige Medaillons abgeschlossen (Länge ca. $19.5 \mathrm{~cm}$, mit den Verzierungen vor und nach den beiden Medaillons).

A. Die Länge dieses ersten Abschnitts misst ca. $39 \mathrm{~cm}$ (АВB. 42). ${ }^{121}$ Inhaltlich ist der Text in $\dot{G} u b \bar{a} r$-Schrift auf den horizontalen Zeilen im Mittelstreifen noch mit dem vorangehenden Teil der Rolle verknüpft. Dort befand sich ein letztes rundes Medaillon, das von einem breiten Textband umfahren wird. Unmittelbar darüber steht im unteren Bogen eines an beiden Enden abgerundeten Rechtecks auf goldenem Hintergrund in weissen Buchstaben Sūrat an-Naḥl (Q 16). Die Abschrift von Q 16 beginnt mit der Basmala im runden Medaillon mit dem breiten Schriftband. Sie wird in den beiden zwölflappigen Medaillons darunter fortgesetzt. Die weiteren Ausführungen stellen die Gestaltung dieses Abschnitts mit den vier zwölflappigen Medaillons vor:

Die drei unteren Medaillons sind identisch gestaltet. Das oberste Medaillon ist abweichend aufgebaut. Auch es weist aber zwölf Lappen auf. Die Lappen des ersten Medaillons werden innen jedoch nicht von einem Kreis abgeschlossen. Vielmehr verlaufen hier zwölf nach innen gewölbte Kreisbögen, die gegenüber den zwölf äusseren Lappen versetzt sind. Das zwischen den Abgrenzungen der zwölf Lappen aussen und den zwölf Bögen innen entstehende Band weist zwölf Spitzen auf und ist zumeist golden ausgefüllt. Auf dem goldenen Hintergrund lassen sich schwarze Striche erkennen, die Blätter und Blüten darstellen. Im Zentrum von zehn Lappen lässt sich wenig blaue Farbe erkennen. Die beiden Lappen rechts und links sind mit einer goldenen Blüte auf blauem Hintergrund verziert.

Die drei anschliessenden Medaillons werden innen einfach durch einen Ring abgeschlossen, der das Textfeld einfasst. In diesen drei Medaillons wurden zehn Lappen golden ausgefüllt. Sie weisen ein mit schwarzer Feder gezeichnetes Blütenmus-

121 Abb. Is 1624.9.5 und 10.1-4. ter mit wenigen blauen Einsprengseln auf. Auch in diesen drei Medaillons weisen die Lappen am linken und rechten Rand jeweils einen blauen Hintergrund auf und sind mit einer goldenen Verzierung (Blatt, Blüte) versehen.

Die Leerräume zwischen Schriftspiegel und den vier Medaillons sind auf diesem Abschnitt der Rolle blau ausgefüllt und mit goldenen Verzierungen (Blätter, Blüten) versehen.

Beachtung verlangen auf diesem Abschnitt ausserdem die in der Rollenrichtung verlaufenden schmalen Schriftbänder. In einem ersten Schritt stehen jene beiden Schriftbänder im Vordergrund, die eine Fortsetzung der beiden seitlichen Bänder auf den Abschnitten davor und danach darstellen. Auf der Höhe des goldenen Felds mit dem Titel von Q 16 (Sürat an-Naḥl) befindet sich auf der linken Seite ein schmales, absteigendes Schriftband. Auf der Höhe des erwähnten Titelfeldes endet Q 2:196 und beginnt Q 2:197. ${ }^{122}$ Der Schreiber umfährt das obere runde Medaillon und setzt beim Übergang zum ersten zwölflappigen Medaillon die Abschrift fort, wobei er von der rechten Seite auf die linke Seite der Rolle wechselt. Er folgt dabei immer der Logik des Layouts der Rolle. Auf der Höhe des nächsten Abschnitts (mit Text in Gubār in Rollenrichtung) steht ein goldenes Titelfeld mit dem Text Sūrat al-Kahf (Q 18). Unmittelbar davor umfährt der Schreiber im schmalen Textband das letzte zwölflappige Medaillon. Er wechselt dabei von der rechten Seite der Rolle auf die linke. Er erreicht auf der Höhe des erwähnten Titelfelds beim Übergang ins schmale Band am linken Rand der Rolle $\mathrm{Q}$ 2:207.23

Auch auf der gegenüberliegenden Seite, also am rechten Rand der Rolle, ist ein schmales Textband

122 Die Übergangsstelle Q 2:196-197 ist klar erkenntlich und lautet:

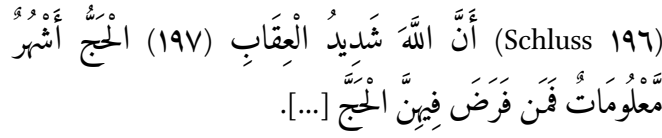

123 Q 2:206-207 lautet:

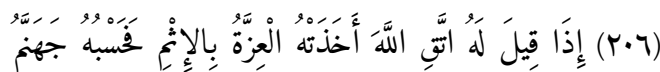


vorhanden. Der Text darin verläuft aufsteigend. In diesem seitlichen Schriftband stehen auf der Höhe des Titelfeldes zu Sürat al-Kahf Stellen aus Q 2:266. Der Schreiber folgt auch hier dem Verlauf dieses Bandes und kopiert den Text aufsteigend. Auf der Höhe des untersten Medaillons geht dieses aufsteigende Schriftband ins Rolleninnere über und umfährt die Lappen des untersten Medaillons; es wechselt dabei auf die linke Seite der Rolle und ins zweitunterste Medaillon. Beim Übergang ins Rolleninnere steht auf der rechten Seite der Schluss von $Q$ 2:266 und der Beginn von 2:267. ${ }^{124}$ Der Kopist folgt danach weiterhin dem Verlauf dieses schmalen Bands. Er umfährt zuletzt von links kommend das oberste zwölflappige Medaillon, erreicht den rechten Rollenrand und setzt die Abschrift nach innen fort. Unmittelbar vor dem Übergang zum darüberliegende Medaillon mit dem breiten Textband lassen sich der Schluss von Q 2:271 und der Anfang von Q 2:272 erkennen. ${ }^{125}$

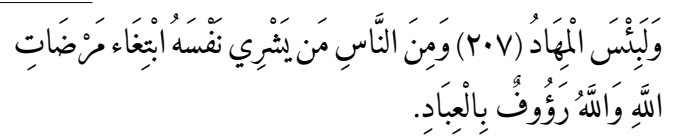

Q 2:206 beginnt im schmalen Band über dem Titelfeld von Q 18 (Sürat al-Kahf). Der Übergang zu Q 2:207 steht an der Stelle, wo das Schriftband den linken Rand der Rolle erreicht.

Die Übergangsstelle lautet:

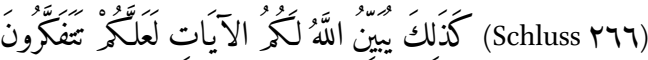

unterstes Medaillon, Schriftband wechselt auf der Y YV)

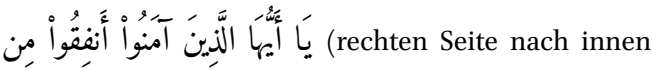

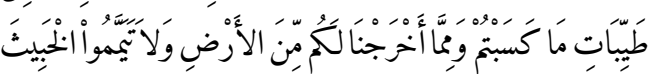

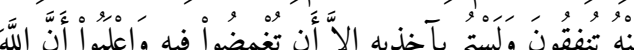

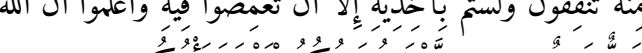

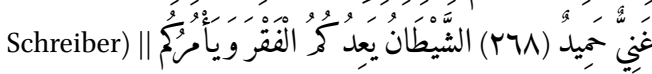
erreicht auf der Höhe des zweituntersten Medaillons (im schmalen Textband die linke Seite

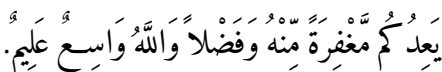

Diese Übergangsstelle lautet (Q 2:271 Schluss und Q 2:272 Anfang):

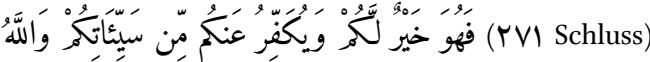

Aus dieser Übersicht geht hervor, dass die Abschrift von Teilen von Q 2 im absteigenden bzw. aufsteigenden Schriftband diesen Abschnitt umfährt. Zur Verwirrung trägt nun bei, dass sich auf dem diskutierten Abschnitt zwei weitere schmale Bänder beobachten lassen, die beide Text in absteigender Richtung enthalten. Ein Schriftband beginnt als Aussenband auf der Höhe des obersten zwölflappigen Medaillons am rechten Rollenrand. Das zweite Schriftband beginnt auf der linken Seite der Rolle und umfährt die Lappen des obersten bzw. des zweitobersten Medaillons und wechselt dabei vom linken zum rechten Rollenrand. Auch diese beiden Schriftbänder mit absteigendem Text werden fortgesetzt; sie enden auf der Höhe des Feldes mit dem Titel von Q 18 (Sūrat al-Kahf). Die einzelnen Schriftbänder überschneiden sich mehrfach. Der Kopist respektiert aber den Verlauf der Textbänder stets strikt. Er wiederholt in diesen beiden zusätzlichen Bändern in absteigender Richtung übrigens einfach Q 112 (Sūrat al-Ihlāṣ). ${ }^{126}$

Nach diesen Hinweisen zu Aufbau und Inhalt der schmalen Textbänder bleibt in diesem Abschnitt noch der Inhalt des in den vier zwölflappigen Medaillons kopierten Texts in $\dot{G} u b \bar{a} r$-Schrift zu bestimmen. Noch vor dem eigentlichen Beginn dieses Abschnitts steht in einem goldenen Feld der Titel von Q 16 (Sürat an-Naḥl). Sie beginnt im Medaillon, das von einem breiten Schriftband umfahren wird. Der Schreiber springt am Ende dieses Medaillons ins oberste zwölflappige Medaillon und setzt die Abschrift von Q 16 auf horizontalen Zeilen fort. Im zweiten zwölflappigen Medaillon lässt sich eine mandelförmige Figur mit hellblauem Hintergrund und Text in goldener Farbe erkennen. Hier steht der Titel von Q 17 (Sūrat alIsra $)$ und der Beginn dieser Sure. Am Schluss die-

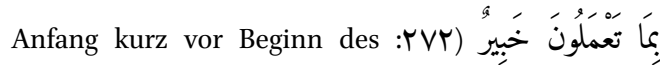
(Medaillons mit dem breiten Schriftband

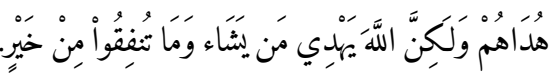

126 Vergleiche für Wiederholungen von Q $112 \mathrm{im}$ schmalen Textband auch bei Anm. 221, 307-311, 337. 
ses Medaillons steht Q 17:6 (Ende) und das erste Wort aus Q 17:7.

Im nächsten Medaillon wurde der Text nicht auf horizontalen Zeilen kopiert. Der Kopist springt hier vielmehr in die Mitte des Kreises und setzt dort die Abschrift fort, indem er nach und nach nach aussen vordringt. Der Text ist im Zentrum des Kreises derart stark verderbt, dass er sich nicht mehr erkennen lässt. Auf den äusseren Zeilen ist der Text aber noch klar lesbar. Während hier eigentlich sämtliche Linien schwarz sind, ist die drittäusserste Zeile rot. Am Schluss erreicht der Schreiber zuäusserst Q 17:42. Der Kopist hat hier einen letzten Teil der äussersten Zeile nicht mit Text gefüllt. Er springt vielmehr in Vers 17.42 ins nächste Medaillon und setzt die Abschrift von Q 17:42 dort auf den horizontalen Zeilen fort. ${ }^{127}$ Zuunterst in diesem letzten zwölflappigen Medaillon wechselt der Kopist von den horizontalen Zeilen auf eine Zeile, die das Medaillon innen im Uhrzeigersinn umfährt (zuunterst steht Q 17:110). Die Abschrift von Q 17 endet oben nach dem zweiten ${ }^{128}$ Lappen des Medaillons. Der Kopist hat den verbleibenden Platz auf dieser Kreiszeile mutmasslich mit Anrufungen Gottes ausgefüllt; sie lassen sich nicht mehr lückenlos erkennen. Es wurde nicht überprüft, ob der Schreiber den Text von 17:43110 vollständig kopiert oder allenfalls Stellen übersprungen hat.

B. Nach diesen vier zwölflappigen Medaillons beginnt der Hauptabschnitt dieses Teils der Rolle (АВв. 43). ${ }^{129}$ Er ist ca. $120 \mathrm{~cm}$ lang und enthält Text in $\dot{G} u b \bar{a} r$-Schrift, der auf parallel zur Rollenrichtung ausgerichteten Zeilen angeordnet ist. Die Breite des Schriftspiegels misst ca. $7.5 \mathrm{~cm}$. Der

127 Q 17:42 lautet (die Übergangsstelle vom 3. zum 4. Medaillon ist mit || markiert):

(Text in der äussersten Zeile; er steht auf dem Kopf $₹ \uparrow$ )

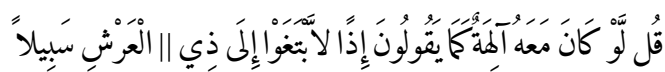

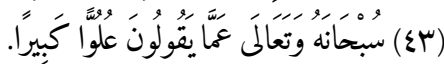

128 Vom obersten Lappen in der Vertikalen des Medaillons aus gezählt.

129 Abb. Is 1624.10.4-12.4.
Kopist hat auf diese Breite 35 Zeilen Text verteilt. ${ }^{130}$ Dieses lange Rechteck wird durch ein goldenes Band mit einem schwarz strukturierten Flechtmuster eingefasst (Breite ca. $1 \mathrm{~cm}$ ). Auf diesem goldenen Band lassen sich in regelmässigen Abständen Vierecke mit blauem Hintergrund und einer goldenen Verzierung (Blatt, Blüte) feststellen. Diesem langen Rechteck ist je ein halbes zehnlappiges Medaillon vor- bzw. nachgestellt (je fünf Lappen). Der Hintergrund des halben Medaillons am Anfang ist golden. Darauf lassen sich Reste einer schwarzen Verzierung und blauer Farbe (Blätter?) erkennen. Hier steht als Überschrift (weiss) Min Sūrat al-Kahf. Am andern Ende des Rechtecks ${ }^{131}$ folgt als Gegenstück dazu das zweite halbe zehnlappige Medaillon (blauer Hintergrund, goldene Verzierungen in der Form von Blättern und Blüten). Darin steht in weissen Buchstaben als Unterschrift ilā l-Qāf. Diese Über- bzw. Unterschriften lassen erwarten, dass im Rechteck selbst der Text von Q 18 (al-Kahf $)^{132}$ bis Q 50 (al-Qāf) kopiert worden ist. Eine Überprüfung ergibt, dass in diesem Rechteck auf der ersten Zeile in der Tat Q 18:1 steht. ${ }^{133}$ Am Ende dieses Rechtecks ${ }^{134}$ lässt sich auf der obersten Zeile Q 18:83f. erkennen.135 Der Schreiber schliesst die Abschrift von Q 18 auf der zweitobersten Zeile ca. $19 \mathrm{~cm}$ vor dem Ende des Rechtecks ab. Hier steht in grösseren goldenen, schwarz eingefassten Buchstaben die Überschrift Sūrat Maryam (Q 19). Die Überschriften der weiteren Suren in diesem Rechteck wurden identisch ausgeführt. Sie fallen jedenfalls bei einem genaueren Blick auf diesen Abschnitt auf. Bei einer Überprüfung ergab sich, dass dieses Rechteck Q 18-

130 Gezählt zwischen alif und lām des Artikels von assamawāt am Anfang dieses Feldes: إن في خلق السموات.

Abb. Is 1624.13.1.

Q 18: Die Siebenschläfer.

Abb. Is 1624.11.3.

Abb. Is 1624.11.10 und 13.1.

Q 18:83-84 lauten (Vers 83 ist klar erkenntlich, ab Beginn von Vers 84 ist der Text stark verblasst):

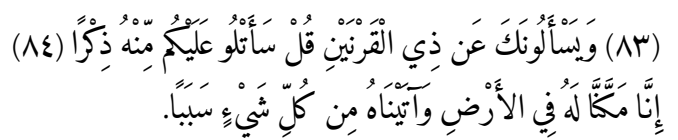


49 enthält. Es wurde nicht kontrolliert, ob die Abschrift lückenlos ist. Der Text von Q 5o (Sürat $Q \bar{a} f$ ) folgt erst im anschliessenden Medaillon und ist nicht im Rechteck selbst enthalten. ${ }^{136}$ Abgesehen vom Titel von Q 46 (Sürat al-Aḥqāf) sind aber sämtliche weiteren Titel zwischen $Q 19$ und 49 nachweisbar. Der Titel von Q 46 fehlt, da er unmittelbar unterhalb des Titels von Q 41 (Fuṣșilat) zu liegen gekommen wäre, was der Kopist offensichtlich aus ästhetischen Gründen vermeiden wollte. Der Text von Q 46 aber ist vorhanden. ${ }^{137}$ Der Schreiber hat jedoch Q 49 nicht gänzlich abgeschlossen. Das Ende von Q 49 steht unterhalb des grossen Ausdrucks yatafakkarūna. ${ }^{138}$

Nach diesem modifizierten Abschluss von Q 49 beginnt ein Gebet mit Allāhumma. ${ }^{139}$ Es verläuft auf der zweituntersten Zeile bis beinahe ans Ende des Rechtecks. Diese zweitunterste Zeile wird kurz vor dem Ende des Rechtecks zur untersten Zeile. Sie endet mit einer Folge von Zeichen, die in ähnlicher Form von den Sieben Siegeln Salomons bekannt sind. ${ }^{140}$ Der Gebetstext und dieser Text auf der zusätzlich eingeschobenen untersten Zeile liessen sich nicht mit Sicherheit entziffern. Es handelt sich um sehr kleines $\dot{G} u b \bar{a} r$ (Höhe etwas mehr als $1 \mathrm{~mm}) \cdot{ }^{141}$ Es stehen hier aber oft Anrufungen Gottes und Ausschnitte aus Q 112.

In diesem Rechteck ist jedoch ein weiteres Element mühelos erkennbar: Der Kopist hat hier bei der Abschrift von Q 18-49 Stellen derart ausgespart, dass auf dem "gubār-farbenen" Hintergrund ein übergeordneter Text entsteht. Es handelt sich um Q 3:190-191. ${ }^{142}$ Dieses Vorgehen liess sich auf

136 Vgl. bei Anm. 146.

137 Abb. Is 1624.11.3: am Anfang des Rechtecks, $\dot{G} u b \bar{a} r$-Text, vierte Zeile von unten.

138 Hier lässt sich auf der zweituntersten Zeile Q 49:15 erkennen, danach der modifizierte Schlussvers von Q 49 (Vers 18); Verse 16-17 fehlen.

139 Abb. Is 1624.11.8.

140 Abb. Is 1624.11.10.

141 Abb. Is 1624.11.6-10.

142 Abb. Is 1624.11.3 und 12.2-4; Q 3:19o-191 lautet (Text in eckigen Klammern fehlt auf dem Dokument):

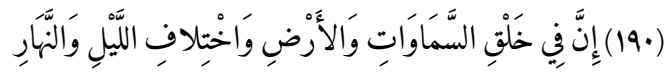

keinem weiteren Belegstück aus dem 14. Jh. feststellen. Es lässt sich aber gerade auf Dokumenten belegen, die im 18. und im 19. Jh. in Iran entstanden sind. ${ }^{143}$ Es lässt sich ausserdem auf Is 1623 nachweisen (datiert 1578). ${ }^{144}$ Unter den aus dem 14. Jh. erhaltenen Belegstücken allerdings ist diese Gestaltung isoliert.

C. Unmittelbar nach dem soeben diskutierten Rechteck folgen als Abschluss dieses bzw. als Überleitung zum nächsten Teil der Rolle zwei weitere zwölflappige Medaillons. ${ }^{145}$ Die Leerräume zwischen diesen Medaillons und dem Schriftspiegel sind golden ausgefüllt und weisen ein schwarzes Muster auf (Blätter, Blüten); vereinzelt sind Stellen mit blauer Farbe erhalten geblieben. Der Hintergrund der zwölf Lappen der beiden Medaillons ist blau; darauf wurden erneut goldene Verzierungen (Blätter, Blüten) angebracht. In den Medaillons selbst wurde Text (Koran) auf horizontalen Zeilen kopiert. ${ }^{146}$ Im ersten Medaillon steht Q 5o (Sürat $Q \bar{a} f)$. Ihr Titel steht bereits im halben Medaillon (fünf Lappen), das das vorangehende Rechteck unten abschliesst. In diesem ersten Medaillon selbst beginnt Q $5^{1}$ (Sūrat a $\left.\underline{d}-\underline{D} \bar{a} r i y \bar{a} t\right)$, deren Titel golden hervorgehoben ist. In der unteren Hälfte des nächsten Medaillons folgen der Titel und der Text von Q 52 (at-Tür). Der Schreiber setzt die Abschrift im nächsten Medaillon fort, das eigentlich bereits zum folgenden Abschnitt der Rolle zählt. ${ }^{147}$

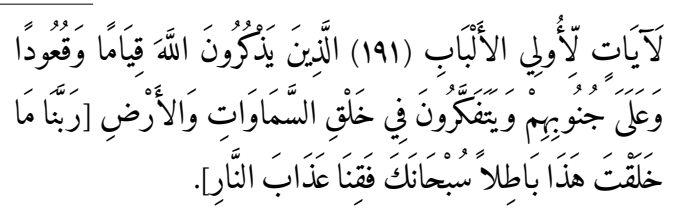

Vgl. dazu Kapitel 5.3 (Is 1623, Chester Beatty Library); Kapitel 5.4 (Arabe 5102, Paris, BNF); Kapitel 5.5 (Is 1621 und 1622, Chester Beatty Library). Vgl. die Beschreibung in Kapitel 5.3. Vgl. aber auch hier bei Anm. 76 .

Die Schriftrichtung verläuft hier also nicht mehr parallel zur Rollenrichtung, sondern ist um $90^{\circ}$ gedreht worden. 
Dieser nächste Abschnitt wird mit einem Titelfeld eingeleitet; darin steht auf blauem Hintergrund Sürat an-Nağm (Q 53). Sie beginnt allerdings erst auf der sechsten Zeile des darunter liegenden Medaillons, wo sich die basmala erkennen lässt. Da beim Betrachten der Eindruck entstand, dass die einzelnen Suren nicht vollständig kopiert worden sind, wurde dies bei Q 53 genauer überprüft. Es liess sich feststellen, dass Q 53:1-26 vorhanden ist. Der Kopist liess dann aber die Verse $27-58$ aus und setzte die Abschrift erst wieder mit den letzten Versen dieser Sure (Q 53:59-62) fort. Es ist zu vermuten, dass der Schreiber auch bei andern Gelegenheiten immer wieder Korantext wegliess. Für ihn war das Respektieren der Form wichtiger als das getreue Abschreiben der islamischen Offenbarung. Aus naheliegenden Gründen konnte aber nicht überall überprüft werden, ob die Abschrift der einzelnen Suren lückenlos ist. Der Kopist setzt die Abschrift des Korans im Mittelstreifen ab hier fort, bis er den ersten Kolophon erreicht. Davor lässt sich am Schluss Q 114 erkennen; davor stehen die weiteren Suren am Ende des Korans. ${ }^{148}$

Nach diesen Ausführungen zur Gestaltung des Mittelstreifens sind einige Bemerkungen zu den schmalen Textbändern hinzuzufügen, die auch hier dem Rollenrand entlang verlaufen bzw. die soeben beschriebenen Medaillons in Abschnitt C umfahren. Diese schmalen Seitenbänder enthalten zumeist Text aus Q 2. Es lassen sich in der Regel zwei solche schmalen Bänder feststellen; eines auf der linken, das andere auf der rechten Seite.

Auf mehreren Abschnitten sind aber plötzlich vier schmale Bänder vorhanden. Dies trifft auch auf den soeben vorgestellten Abschnitt $\mathrm{C}$ zu. Beim Titelfeld von Q 53 (an-Nağm) $)^{149}$ beginnt auf der rechten Seite der Rolle ein schmales Band, das aufsteigend Q 112 (al-Ihlāss) wiederholt. Dieses Band endet auf der linken Seite auf der Höhe des Titelfelds mit dem Text Sūrat al-Qāf. Beim Titelfeld von Q 53 beginnt auf der linken Seite zugleich ein weiteres aufsteigendes Schriftband mit Q 2:26o. Dieses

148 Abb. Is 1624.17.10.

149 Abb. Is 1624.13.3.
Schriftband umfährt aufsteigend die Medaillons und setzt sich im darüberliegenden Abschnitt als rechtes Aussenband fort. Dort steht der Beginn von Q 2:263. Ausserdem steigt auf der Höhe des Titels von Q 53 auf der rechten Seite ein schmales Schriftband mit Q 2:274-277 empor. Es bricht auf der Höhe des Titelfelds von Sūrat al-Qāf auf der rechten Seite ohne Fortsetzung ab. ${ }^{150}$ Zugleich steigt auf der Höhe des Titels Sūrat al-Qāf auf der linken Seite ein schmales Band ab, das dann die darunterliegenden Medaillons umfährt und erneut die linke Seite der Rolle erreicht. Es setzt sich dort als schmales Band auf der linken Seite fort. Dieses absteigende Band enthält in diesem Abschnitt Q 2:212-215.

Der Kopist dürfte beabsichtigt haben, in diesen schmalen Schriftbändern den beiden Längsseiten der Rolle entlang Q 2 als Ganzes zu kopieren. Der Aufbau dieses schmalen Seitenbands mit der Abschrift von Q 2 liess sich aber gerade im vorliegenden Abschnitt nicht abschliessend rekonstruieren; sein Aufbau ist hier ausgesprochen komplex. Auch ist der Text in diesen Aussenbändern oft verderbt, was seine Entzifferung erschwert. Wer aber genügend Zeit hat, dürfte grundsätzlich in der Lage sein, den Verlauf dieser schmalen Aussenbänder auch in diesem Abschnitt nachzuvollziehen.

Abschnitt I.7: Dieser Abschnitt besteht aus einem Rechteck (Länge ca. 6 o cm, inkl. Über- und Unterschrift), das von einem breiten Textband umfahren wird. ${ }^{151}$ Entlang der beiden Längsseiten der Rolle zusätzlich ein schmales Band mit Text aus Q 2. ${ }^{152}$ Im Innern des Rechtecks lassen sich folgende Figuren erkennen: 2 Kreise - ein oben und unten abgerundetes Rechteck - drei Kreise. Diese Figuren sind alle mit Text in $\dot{G} u b \bar{a} r$ auf horizontalen Zeilen ausgefüllt und enthalten Korantext. Vor diesem Rechteck selbst lässt sich ein hal-

\footnotetext{
150 Wobei ganz am Schluss ein Auszug aus Q 2:274 steht.

$15^{1}$ Abb. Is 1624.13.3-14.3.

$15^{2}$ Am Ende dieses Rechtecks steht im schmalen Textband auf der linken Seite Q 2:217b (absteigend). Auf der gegenüberliegenden Seite lässt sich Q 2:268 erkennen (schmales Textband, rechts, aufsteigend).
} 
bes Medaillon (mit fünf Lappen) ${ }^{153}$ mit der Überschrift Sūrat Wa-n-nağm (Q 53 ${ }^{154}$ ) erkennen. In den soeben erwähnten Figuren im Rechteck selbst wurden die Überschriften der einzelnen Suren golden hervorgehoben. Es lassen sich die Überschriften und der Text von Q 54 (oberster Kreis) bis Q 66 (Sūrat at-Tahrìm; letzter Kreis) erkennen. Der Abschnitt mit dem Rechteck wird unten von einem halben Medaillon (mit fünf Lappen) abgeschlossen.

Die weitere Übersicht stellt den Text im breiten Schriftband vor, das das Rechteck umfährt:

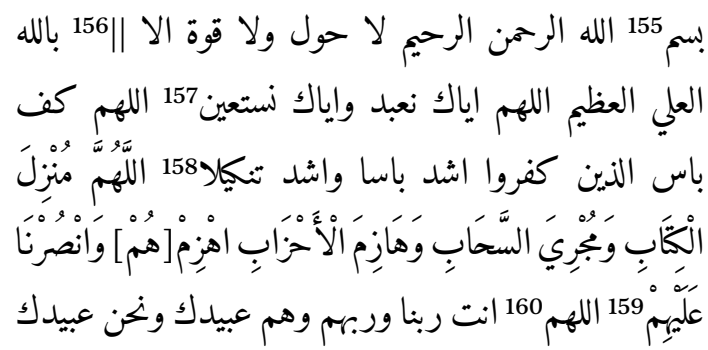

153 Dieses halbe Medaillon (vgl. Abb. Is 1624.13.3) weist einen blauen Hintergrund auf. In den Ausbuchtungen der fünf Bögen lassen sich golden ausgeführte Blätter und Blüten erkennen. Darunter steht auf goldenem Hintergrund in grossen, weissen Buchstaben Sūrat Wan-Nağm.

Text von $\mathrm{Q} 53$ beginnt erst auf der 6. Zeile im Medaillon darunter; für die Einzelheiten siehe zwischen Anm. 147-148. Waagrechtes Schriftband unterhalb des Titelfeldes mit der Überschrift Sūrat Wa-n-Nağm.

${ }_{15} 6$ Übergang ins absteigende Schriftband auf der linken Seite.

157 Vgl. dazu Q 1:5.

$15^{8}$ Anspielung auf Q 4:84; wo Wortlaut allerdings abweichend:

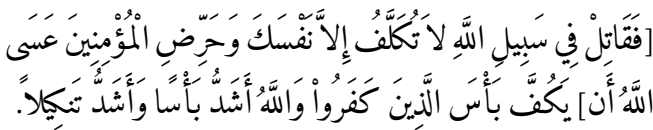

Oktober 2017):

$$
\begin{aligned}
& \text { ونواصينا ونواصيهم بيدك فاهزهه وانصرنا عليهم الله اكبر الله }
\end{aligned}
$$

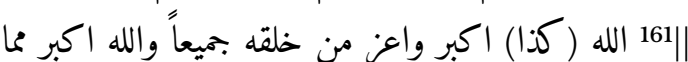

$$
\begin{aligned}
& \text { اخاف ||162 واحذر واعوذ بالله الذى لا اله الا هو الممسك له }
\end{aligned}
$$

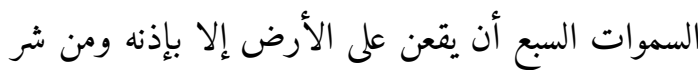

$$
\begin{aligned}
& \text { عبيدك وجنودهم وأشياعهم واتباعهم من الجن والأنس الس } \\
& \text { اللهم انا نعوذ بك } 163 \text { ان يفرط علينا احد من خلقك وان يطنى } \\
& \text { اللهم كن لي جاراً من شرهم جل ثناؤك ووز جارك وتبارك } \\
& \text { اسمك ولا إله غيرك يا الله. } 164
\end{aligned}
$$

Abschnitt I.8: In diesem Abschnitt fällt ein Rechteck auf (Länge ca. $55 \mathrm{~cm}$, inkl. Über- und Unterschrift; ABB. 44), ${ }^{165}$ in dessen Innern Text in $\dot{G} u b \bar{a} r-$ Schrift entlang eines Gitters kopiert wurde. ${ }^{166}$ Vor diesem Rechteck befindet sich ein zwölflappiges Medaillon, das die gesamte Rollenbreite einfasst. ${ }^{167}$ Nach dem Rechteck mit dem Gitter schliessen sich 3 weitere zwölflappige Medaillons an. In all diesen Figuren wurde der fortlaufende Korantext in $\dot{G} u b \bar{a} r$ kopiert.

Die folgenden Bemerkungen beschreiben den Aufbau des Rechtecks, um das ein breites und ein schmales Textband herumführen. In diesem Rechteck wurde Text aus dem Koran in $\dot{G} u b \bar{a} r-$ Schrift entlang eines Gitters notiert. Vor bzw. nach diesem Rechteck befindet sich je ein halbes Medaillon (fünf Lappen) mit golden ausgefülltem Hintergrund. Darauf lassen sich Reste einer mit schwarzer Feder ausgeführten Verzierung erkennen. Auf diese zwei Figuren verteilt steht in gros-

161 Übergang in das waagrechte Schriftband unten.

162 Übergang in das aufsteigende Schriftband am rechten Rand. Der Text ab hier liess sich nachweisen unter http://www.islamguiden.com/hisnulmuslim/o37 .htm (Stand 12. Juli 2017); als Quellenverweis wird dort

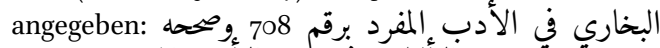
الألباني وفي صحيح الأدب المئ المفرد برقم :546.

$B i$-ka: Ausdruck über der Zeille nachträglich ergänzt.

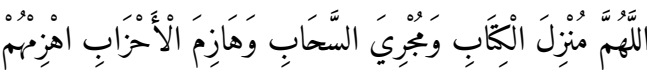

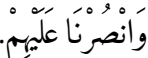

Der Text kehrt damit an den Anfang des Schriftbands in diesem Abschnitt zurück.

Abb. Is 1624.15.1-16.2.

Abb. Is 1624.15.4-5.

Abb. Is 1624.15.1. 
sen weissen Buchstaben als Über- bzw. Unterschrift zum Rechteck من سورة الحاقة || الم النباً (von Sure 69 bis Sure 78). Der Text dieser Suren ist entlang des Gitters kopiert worden, wobei sich allerdings verschiedentlich Auslassungen feststellen lassen. ${ }^{168}$

Ein Schriftband (Breite ca. $0.9 \mathrm{~cm}$ ) mit Text in schwarzer Tinte führt im Gegenuhrzeigersinn um dieses Rechteck herum. Der Inhalt dieses Schriftbands lautet:

$$
\begin{aligned}
& \text { بسم } 169 \text { الله الرحمن الرحيم يا عماد من لا عماد ||170 له ويا ذخخ } \\
& \text { من لا ذخرله ويا سند من لا سند له ويا حرز من لا حرز له } \\
& \text { يا وز الضعفاء ويا كنز الفقرا يا عظيم الرجا يا منقذ الغرقا يا }
\end{aligned}
$$

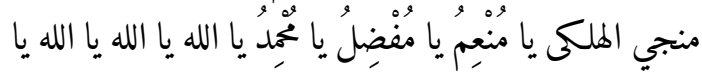

$$
\begin{aligned}
& \text { الله يا رحمن يا رحيم انت الذي سبد لك سواد الليل وضوء } \\
& \text { الهار وحفيف ||171 الشجر ودوى الماء وشعاع الشمس و وله }
\end{aligned}
$$

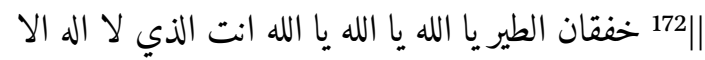

$$
\begin{aligned}
& \text { انت وحدك لا شريك لك اغثني يا غياث المستغيثين اسالك }
\end{aligned}
$$

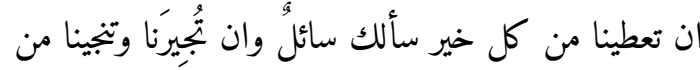

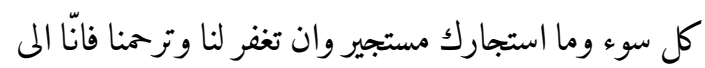

$$
\begin{aligned}
& \text { رحمتك فقرايا ارحم الراحمين. }
\end{aligned}
$$

Nāṣir Makārim Šīrāzī führt einen Text weitgehend identischen Inhalts in seiner Zusammenstellung von Gebeten auf, die unter dem Titel al-Mafätīh al-ğadìda veröffentlicht worden ist. Er führt dieses Gebet auf 'Alī b. Abī Ṭālib zurück. Wer es rezitiere, dessen Sorgen lasse Allāh abnehmen. ${ }^{173}$ Der Anfang des Gebets lässt sich auch in al-Ğawšan

168 Vgl. die Abb. Is 1624.15.4-5

169 Text waagrecht.

170 Beginn absteigendes Schriftband links.

171 Übergang ins waagrechte Schriftband am unteren Ende des Rechtecks.

172 Übergang ins aufsteigende Schriftband rechts.

173 Nāṣir Makārim Šīrāzī, al-Mafātīḥ al-ğadīda 774. Qum, Dār an-Našr al-Imām 'Alī b. Abī Țālib; vgl. http://lib .eshia.ir/10279/1/774 (Stand 19. November 2016). Šīrāzì (geb. 1926) ist ein schiitischer Ayatollah. al-kabìr nachweisen. ${ }^{174}$ Kaf'amī erwähnt es modifiziert überdies in den Mafātīh al-ğinān. ${ }^{175}$ Es lässt sich, mit gelegentlichen Abweichungen im Wortlaut, ausserdem im Internet nachweisen und wird als $D u^{\prime} \bar{a}^{\prime}$ al-fağr [ba'd aš-šidda] bezeichnet. ${ }^{176}$

Abschnitt I.9 (АВB. 45): Die folgenden Ausführungen stellen in einem ersten Schritt den Inhalt des Mittelstreifens vor, der Teil I der Rolle abschliesst und mit Kolophon 1 endet. Sie machen bereits bei dieser Gelegenheit auf das breite Band mit Gebetstext aufmerksam, das hier noch im Teil I beginnt und nahezu bis ans Ende der Rolle (also Teil II) hindurchläuft und von dort wieder bis zum letzten Medaillon in Teil I emporsteigt, wo es begonnen hatte. Anhand dieses Textbands, das sich über Teil I und I I erstreckt, lässt sich aufzeigen, dass der Schreiber auch den Text in diesem breiten Band und im schmalen Band unmittelbar daneben bereits im ersten Durchgang geschrieben hat. Er hat nur den Inhalt im Mittelstreifen von Teil II (Beginn nach Kolophon 1) im zweiten Durchgang ergänzt.

Am Ende von Teil I steht im Mittelstreifen selbst der Schluss der Abschrift des Korans. ${ }^{177}$ Am Anfang der zu diskutierenden Stelle befindet sich hier ein Medaillon, das vom breiten Textband umfahren wird. Darunter schliessen sich zwei an beiden Enden abgerundete Rechtecke an. Sie werden von einem Medaillon mit blauem Hintergrund voneinander getrennt. Diese beiden Rechtecke enthalten in schwarzem $\dot{G} u b \bar{a} r$ auf horizonta-

174 Vgl. al-Kaf'amī, al-Balad al-amin 402-411; hier relevant S. 404 unten; vgl. http://lib.eshia.ir/71565/1/404 (Stand 24. Oktober 2017). Siehe auch al-Kaf'amī, al-Balad alamīn. Qaddama la-hū wa-'allaqa 'alay-hi 'Alā' ad-Dīn al-A'lamī. Bayrūt, Mu’assasat al-A'lamī li-l-Mațbūāàt, 1418/1997. Darin S. 547 (Abschnitt 28).

175 Vgl. dazu die Angabe unter http://ahlolbait.com/doa/11

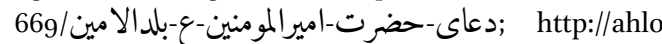
داى-حضرت-اميرالمومنين-ع-مفاتيح / Ibait.com/doa/1451) الجنان - (Stand 19. November 2016).

176 Vgl. z.B. http://islam.ahram.org.eg/NewsQ/2035.aspx; http://mchkae.com/vb/showthread.php?t=108; http:// forum.kooora.com/f.aspx?t=9455261 (Stand 19. November 2016).

177 Vgl. Abb. Is 1624.17.1-10. 
len Zeilen den Schluss der Abschrift des Korans. Im oberen Bogen des ersten Rechtecks steht auf goldenem Hintergrund in weisser Schrift der Titel zu Q 84 (Sūrat al-Inšiqāq). Im Rechteck selbst werden auch die weiteren Surentitel hervorgehoben. Im Medaillon mit blauem Hintergrund zwischen den beiden Rechtecken steht der Titel von Q 9o (Sūrat al-Balad). Im Rechteck danach folgt der restliche Korantext bis Q 114. Da die Suren am Schluss der islamischen Offenbarung kurz sind, folgen hier auch die Überschriften immer rascher aufeinander. Am Schluss steht im Mittelstreifen Kolophon 1. ${ }^{178}$ Der Mittelstreifen wird hier mit einem Halbbogen abgeschlossen, in dem auf blauem Hintergrund steht: Tammat al-hatma alkarima (Авв. 46). ${ }^{179}$

Die weiteren Ausführungen befassen sich mit dem Text (Gebet) im breiten seitlichen Schriftband (Breite ca. $1.1 \mathrm{~cm}$ ), das einen bedeutenden Teil am Ende der Rolle umfährt. ${ }^{180}$ Dieses breite Schriftband wird innen und aussen von je einem schmalen Schriftband (Breite je ca. $0.4 \mathrm{~cm}$ ) mit Text aus dem Koran flankiert. Der Text im breiten Schriftband beginnt auf der rechten Seite des bereits erwähnten Medaillons am Ende von Teil I (ca. $71 \mathrm{~cm}$ vor Kolophon 1). ${ }^{181}$ Das breite Schriftband läuft nahezu bis ans Ende des Dokuments durch. Kurz vor dem Schluss der Rolle umfährt es ein zweites Medaillon und wechselt dabei die Seite der Rolle. Am Schluss folgt ein kürzeres Rechteck, das an beiden Enden abgerundet ist (Länge ca. $26 \mathrm{~cm}$ ). Das breite Schriftband umfährt auch dieses Rechteck und steigt dann auf der

178 Siehe dazu bereits oben nach Anm. 9.

179 Siehe dazu bei Anm. 211-214.

180 Die Ausführungen beziehen sich auf die Stellen zwischen Abb. Is 1624.16-23, die von der Chester Beatty Library vom Dokument angefertigt worden sind. Zusätzliches eigenes Abbildungsmaterial dokumentiert den Schlussteil des Dokuments lückenlos.

Dieses erste Medaillon (nach Abb. Is 1624.17) weist goldene Verzierungen auf. Es handelt sich um Blätter oder Blüten auf blauem Hintergrund. Sie sind untereinander durch schwarz eingefasste goldene Linien verbunden, die in der Mitte ein auf der Spitze stehendes Viereck mit neun Zellen bilden.
Gegenseite wieder in Richtung Rollenanfang nach oben. Es wechselt in diesem Abschnitt ausserdem ein Mal ohne Umfahren eines Medaillons die Seite der Rolle. Dies geschieht auf der Höhe eines Medaillons im Mittelstreifen der Rolle. Darin lässt sich auf goldenem Hintergrund in weisser Schrift der Text erkennen: Li-l imām al-Ġazzāli rahma. ${ }^{182}$

Der Text im breiten Schriftband ist frommen Inhalts. Es handelt sich um Auszüge aus unterschiedlichen Gebeten. ${ }^{183}$ Der Text appelliert im ersten Abschnitt an frühere Propheten (АВB. 45):184

$$
\begin{aligned}
& \text { بسم الله الرحمن الرحيم اللهم اني اسالك يا الله يا رحمن يا رحيم } \\
& \text { باءسمك العظيم وبنور وجهك الكريك يا الله يا حي يا قيوميا ذا } \\
& \text { الجلالة والاكرام ||185 و.بكق اسمك الذى دعاك به آدم عليه } \\
& \text { السلام فغفرت له زلته و.كق اسمك الذي دعاك به يونس } \\
& \text { عليه السلام فنجيته من بطن الحوت ||186 واسالك باسمك } \\
& \text { الذى صيرت به النار على ابراهيم برداً وسلاماً واسالك باسمك فيك اليك } \\
& \text { الذي فلقت البحر لموسى بن عمران وقومه واسالك باسمك } \\
& \text { الذي دعاك به موسى وهارون على فرعون وقومه فاستجبت بـت بهريت } \\
& \text { لمما ||187 واسالك باسمك الذي خلقت به عيسى ابن مريم } \\
& \text { وايدته بروح القُدس واسالك باسمك الذي ملّكت [واسيّرّت } \\
& \text { لسليمان ابن داود عليهما السلام الريح والجن والانس والطير لعري } \\
& \text { فهم يوزَعَونَ }
\end{aligned}
$$

182 „Für den Imām al-Ġazzālī Erbarmen“. Die Stelle befindet sich nach Abb. Is 1624.19.

183 Abb. Is 1624.17.2; die weiteren Ausführungen stützen sich auf zusätzliches Abbildungsmaterial des Dokuments im Besitz des Verfassers; die Stelle im breiten Schriftband ist somit lückenlos dokumentiert. Der Text beginnt mit der basmala beim Medaillon auf der rechten Seite im breiten Schriftband.

184 Die Namen der folgenden Propheten werden erwähnt: Ādam, Yūnus, Ibrāhīm, Mūsā, Hārūn, '̄̃sā, Sulaymān.

185 Übergang ins langgezogene Rechteck; breites Schriftband rechts, Text vorwärtslaufend; Abb. Is 1624.17.

186 Abb. Is 1624.17.8 und 17.10.

187 Abb. Is 1624.18 und 18.2 . 
|| واسالك 188 بما في صحف ابراهيم وزبور داود وتورية موسى وانجيل عيسى وفرقان محمد صلى الله عليه وعلى آله وصحبه اجمعين و.بكق الايات السبع والسبع المثانى والقران العظيم و.بحرمة العيدين ويوم عرفة ويوم || الاثنين ويوم الخميس ||189 والجمعة و.بحرمة شهر رمضان الذي انزل فيه القران و.بحرمة ليلة القدر التي هي خير من الف شهر

و.بحرمة جبريل وميكئيل واسرافيل ووزرايل صلوات ||190 الله عليهم اجمعين وبحرمة حملة العرش الذين يسبحون

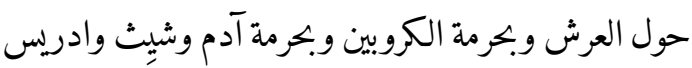
ونوح وابراهيم واسمعيل واسحق ||191 ويعقوب ويوسف وموسى وهارون وداود وسليمان واليسع وذى الكفل وغزير وصالح وهود والياس وطالوت ||192 وذى النون وايوب

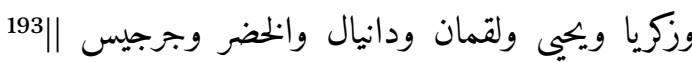

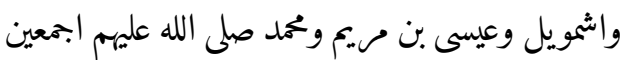
وباسم الذي وضعت على ||194 عين الشمس فاطمانت

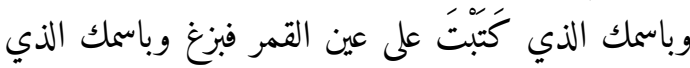
وضعت على الكواكب ||195 فربخت وعلى العيون ففجرت

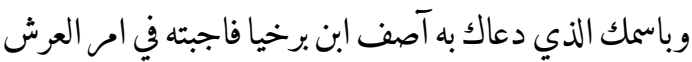

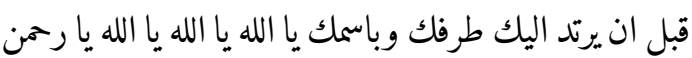

$$
\text { يا رحمن يا رحمن يا رحيم || }
$$

188 Abb. Is 1624.19 und 19.3.

189 Hier wechselt das vorwärtslaufende Schriftband von der rechten auf die linke Seite der Rolle. Im Mittelstreifen befindet sich das Medaillon mit dem goldenen Hintergrund; darin steht in weisser Schrift Li-l-imäm alGazzālè rahma (vgl. Anm. 182). Für den weiteren Text vgl. Abb. Is 1624.20.3 (sowie Abb. 20 und 21). Abb. Is 1624.20.8 (und Abb. 20).

Abb. Is 1624.21.2 (und Abb. 21).

Abb. Is 1624.21.8.

Abb. Is 1624.21.10.

Abb. Is 1624.21.11.

Abb. Is 1624.22, 22.2 und 22.6; hier umfährt der Text das nächste Medaillon und geht danach ins kurze Rechteck am Ende der Rolle über, das an beiden Enden abgerundet ist. Die Länge des Rechtecks misst ca. $26 \mathrm{~cm}$.

Der Schreiber befindet sich jetzt zuunterst im abge-
(Übergang ins rückwärtslaufende Schriftband) يا [جبار يا منان يا ديان يا امان197] يا غفران يا سبحان يا سلطان يا مستعان يا بديع السموات والارض يا عالم الغيب والشهادة يا ذا الجلال والاكرام ||198 يا جبار السموات لمعول والا وض

انت الرب وانا العبد انت المالك وانا المملوك انت العزيز

وانا ذليل انت الغني وانا الفقير انت المي وانا الميت انت

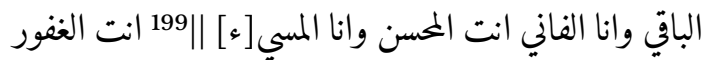
وانا المذنب انت الرحيم وانا الخاطي انت الخالق وانا الخخلوق انت القوي وانا الضعيف ||200 انت المعطي وانا السائل انت

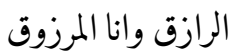

كم من مذنب قد غفرته وكم من مسيئ قد تجاوزت عنه

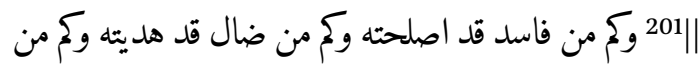

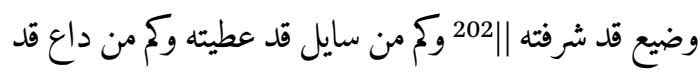
اجبته

انا العبد الضعيف الخاطي المذنب ||203 الجاني وانت المي واله ابائي في الدنيا والآخرة اغفر لي وارحمني واغفر لابائي وامهاتي واصحابي واخواني ولحامل هذه الختمه الكريمه يا الله يا الله يا الله يا حى يا قيوم يا ذا الجلال ولي والاكرام يا حليم يا عظيم يا ززيز يا حكيم ||204 رب لا تذرنى فردا وانت خير

rundeten Rechteck. Das Schriftband wechselt hier von der linken auf die rechte Seite der Rolle und läuft aufsteigend zurück. Im Schlussbogen des Rechtecks sind einige Ausdrücke (ca. fünf Wörter) kaum mehr zu erkennen.

Diese Übergangsstelle ganz am Schluss ist stark verderbt; Entzifferung nicht gesichert.

198 Das Schriftband umfährt hier das Medaillon; vgl. Abb. Is 1624.22 und die Fortsetzung auf Abb. 21.11. Abb. Is 1624.21.10 (Schriftband rückwärtslaufend). Abb. Is 1624.21.8 (Schriftband rückwärtslaufend). Abb. Is 1624.21.2 und 21 (Schriftband rückwärtslaufend). Abb. Is 1624.20.8 (Schriftband rückwärtslaufend).

Abb. Is 1624.20 und 20.3 (Schriftband rückwärtslaufend).

204 Abb. Is 1624.19, sowie Abb. 19.3 und 19.4. Hier wechselt das rückwärtslaufende Schriftband von der rechten auf 


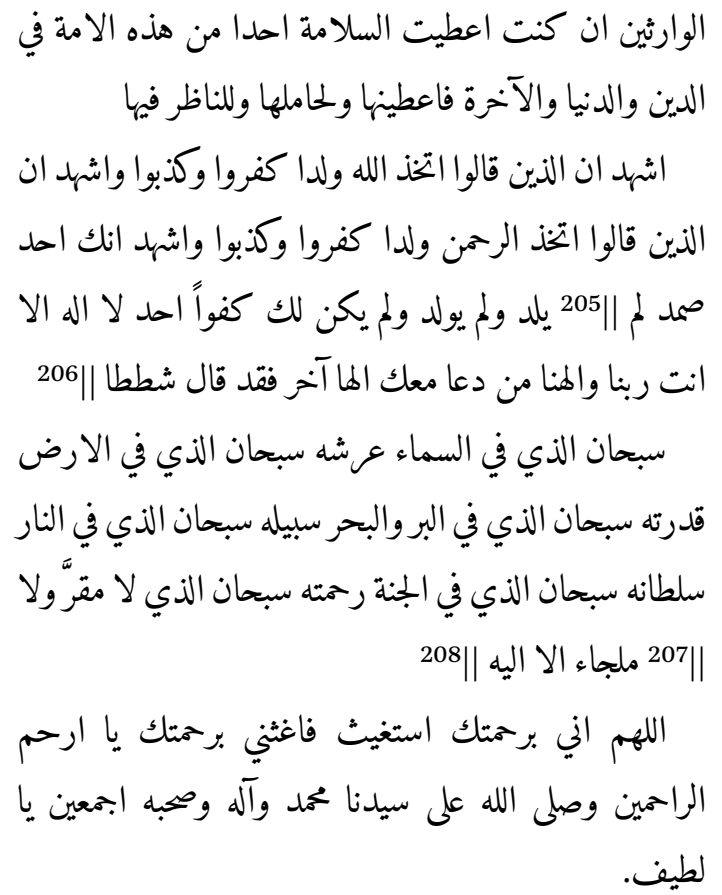

Teil II der Rolle (Länge: $237 \mathrm{~cm}$; Beginn der Messung direkt nach Kolophon 1):

Der Kopist hat die vorliegende Rolle - wie bereits aufgezeigt - in zwei Durchgängen in den Jahren 1362 und 1366 angefertigt. Dies geht aus den beiden Kolophonen eindeutig hervor. ${ }^{209}$ Der Schreiber dürfte aber das Grundmuster bereits im Jahr 1362 bis an den Schluss der Rolle entworfen haben. Das Gebet im breiten Schriftband ${ }^{210}$ beginnt bereits in Teil I der Rolle und umfährt dann

die linke Seite der Rolle; hier ist aber kein Medaillon vorhanden.

Man beachte, dass der Schreiber an dieser Stelle zwei Mal auf den Träger (hâamil) der Rolle aufmerksam macht und auf jene Personen, die sich diese Rollen bzw. diese Abschrift des Korans anschauen (an-nāzir fi-hā). Er bittet Gott um Vergebung für sie. Auch möge Gott ihnen Wohlergehen (saläma) schenken.

Abb. Is 1624.18, sowie Abb. 18.1 und 18.2 (Schriftband rückwärtslaufend). Hier Anspielungen auf Q 112.
Abb. Is 1624.17.10 (Schriftband rückwärtslaufend).

Abb. Is 1624.17.8 (Schriftband rückwärtslaufend).

Abb. Is 1624.17 sowie Abb. 17.2 und 17.3 (Schriftband rückwärtslaufend).

Vgl. zu diesen beiden Kolphonen nach Anm. 9 bzw. 10.

Vgl. dazu bei Anm. 180-208. eigentlich den gesamten im zweiten Durchgang angefertigten Abschnitt. Der Schreiber hat diesen Gebetstext im breiten Schriftband wohl schon im Jahr 1362 niedergeschrieben. Er hätte demnach im Jahr 1366 im zweiten Durchgang nur noch den Mittelstreifen ausgefüllt.

Auch inhaltliche Argumente sprechen für diese Sichtweise. Im ersten Teil der Rolle stehen in jenen Teilen des Mittelstreifens mit Text ausschliesslich Stellen aus dem Koran in $\dot{G} u b a \bar{r}$. Am Ende von Teil I stehen im Mittelstreifen die letzten Suren aus dem Koran. Auch steht im Bogen unmittelbar unterhalb des Kolophons zum ersten Teil Tammat al-hatma al-karima. ${ }^{211}$ Dies weist darauf hin, dass die Abschrift des Korans abgeschlossen ist. ${ }^{212} \mathrm{Im}$ Mittelstreifen des zweiten Teils der Rolle werden keine weiteren Suren mehr kopiert (АBB. 46).

Die weiteren Ausführungen stellen Aufbau und Inhalt dieses Mittelstreifens in Teil II der Rolle vor. ${ }^{213}$ Er lässt sich in drei grössere Abschnitte einteilen (II.1-3).

Abschnitt II.1 (АBB. 47): ${ }^{214}$ Unmittelbar nach dem Vermerk Tammat al-hatma al-karima beginnt der erste Abschnitt von Teil II. Er ist ca. $70.5 \mathrm{~cm}$ lang. Am Schluss befindet sich ein Medaillon, in dem in grosser weisser Schrift auf goldenem Hintergrund steht Li-l-Imām al-Ġazzālì raḥma. Davor lassen sich sieben Zellenquadrate erkennen, die alle von einem goldenen Flechtband umrahmt werden. Diesen Quadraten ist ein Titelbalken mit blauem Hintergrund und vereinzelten goldenen Verzierungen vorangestellt. In den Einträgen werden die sieben Quadrate als wafq bezeichnet und mit den sieben Planeten in Verbindung gebracht: ${ }^{215}$ a. Wafq aš-šams: $6 \times 6$ Zellen,

211 Abb. Is 1624.18.1.

212 Als hatma wird eine vollständige Rezitation der islamischen Offenbarung bezeichnet; vgl. Melchert und Afsaruddin, Reciters of the Qurān, in EQ. Darin wird der Begriff hatma kurz erwähnt. Anzumerken ist, dass die Abschrift des Korans auf der vorliegenden Rolle nicht vollständig ist.

213 Abb. Is 1624.18-23.

214 Abb. Is 1624.18.1-19.4.

215 Bei einem wafq handelt es sich um ein Zellenquadrat; 
nicht magisch; dieses Zellenquadrat ist der Sonne (šams) zugeordnet; ${ }^{216}$ b. Li-z-zuhal: $7 \times 7$ Zellen, nicht magisch; es ist dem Saturn (zuhal) zugeordnet; c. Li-l-mirrih : $7 \times 7$ Zellen, nicht magisch; es ist dem Mars (mirrīh) zugeordnet; d. Li-z-zuhara:217 $7 \times 7$ Zellen; die ersten beiden Zeilen sind teilweise verderbt, es lassen sich nicht mehr alle Ziffern erkennen. Dieses Quadrat ist der Venus (zuhara) zugeordnet; e. Li-l-'uțārid: $4 \times 4$ Zellen, magisch, die Summe beträgt 34; dieses Quadrat ist dem Merkur ('uțārid) zugewiesen; f. Qamar: ${ }^{218} 4 \times 4$ Zellen, magisch, die Summe beträgt 34; dieses Quadrat ist dem Mond (qamar) zugewiesen; g. Li-l-muštarī: Buchstabenquadrat $(6 \times 6$ Zellen); dieses Quadrat ist dem Jupiter (muštarī) zugewiesen. ${ }^{219}$ Dieser Abschnitt wird durch eine Unterschrift (tammat $a l-a w f \bar{q} q)$ abgeschlossen. Darauf folgt das bereits erwähnte Medaillon mit der Inschrift Li-l-Imām Ġazzālì raḥma (ABB. 48).

Beim soeben angeführten Medaillon mit der Erwähnung Ġazzālīs (gest. 1111) 220 beginnt ein schmales Schriftband. Es umfährt dieses Medaillon im Gegenuhrzeigersinn und wird am rechten Rollenrand als Aussenband fortgesetzt. Der Text darin folgt dem Verlauf dieses schmalen Bands und umfährt ganz am Schluss des Dokuments ein zwölflappiges Medaillon; danach steigt der Schreiber wieder nach oben und erreicht im linken Aussenband erneut das Medaillon mit der Erwähnung Ġazzālīs. In diesem Schriftband, es erstreckt sich

es kann ein Zahlen- oder Buchstabenquadrat sein. Es gibt auch magische Quadrate; darin ist die Summe der Zahlen in allen Horizontalen, Vertikalen und den beiden Hauptdiagonalen identisch; siehe Sesiano, Wafk, in $E I^{2}$.

216 Abb. Is 1624.18.2.

217 Abb. Is 1624.19.2.

218 Abb. Is 1624.19.3.

219 Die Buchstaben stehen hier allenfalls für Zahlen (Abğad-System); siehe dazu Canaan, Decipherment $147 \mathrm{f}$.

Wohl Abū Hāmid al-Ǵazzālī, der Religionsgelehrte, der sich aber auch gemässigten Formen der Mystik gegenüber offen zeigte. Siehe zu ihm Knysh, Islamic mysticism 140-149: „The maturity of Sufi science: alGhazālī“. Es ist eher unwahrscheinlich, dass hier sein Bruder Aḥmad-i Ġazzālī (gest. 1126) gemeint ist. über eine Länge von ca. $172 \mathrm{~cm}$ zu beiden Seiten der Rolle, wird unablässig Q 112 in mikroskopischer Schrift wiederholt. Die kurze Q 112 (Sūrat al-Ihlāṣ) betont die Einheit und Einzigartigkeit Allāhs; sie hält ausserdem fest, dass Gott weder gezeugt hat noch gezeugt worden ist. Dies wird gemeinhin als Kritik am Christentum interpretiert. Diese Sure fasst somit gewissermassen die Quintessenz des islamischen Glaubens zusammen. ${ }^{221}$ Diese unablässige Wiederholung eines einzelnen Texts erinnert an die in der islamischen Mystik gepflegten Dikr-Übungen. ${ }^{222}$

Unmittelbar unterhalb des Ǵazzālī-Medaillons wechselt ausserdem ein weiteres, zuvor auf der rechten Seite der Rolle absteigendes schmales Schriftband ins Innere des nächsten Abschnitts (II.2) und wird dort auf der linken Seite fortgesetzt. An dieser Übergangsstelle lässt sich absteigend Q 2:228 erkennen. ${ }^{223}$ Die Abschrift von Q 2 folgt dann diesem Schriftband bis an den Schluss des Dokuments (ohne Umfahrung des zwölflappigen Medaillons). Zurück beim $\dot{G} a z z a \bar{l} l \bar{\imath}$-Medaillon steht auf der gegenüberliegenden Seite Q 2:249 ( $L \bar{a}$ țāqata la-nā al-yawm bi-Ğālūt wa-ğunūdi-h̄̄).

Abschnitt II.2: ${ }^{224}$ Nach dem Wafq-Teil schliesst sich ein nächster Abschnitt von ca. $122 \mathrm{~cm}$ Länge an. Dieser Abschnitt ist in ein Rechteck eingepasst, das oben und unten abgerundet ist. Die folgende Beschreibung befasst sich mit Aufbau und Inhalt

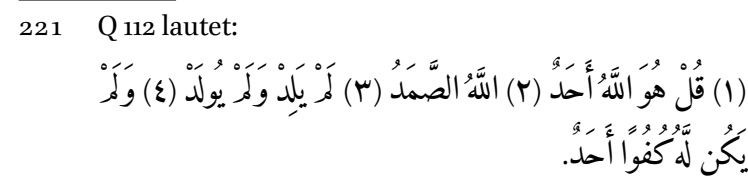

Zur Bedeutung der Repetition bestimmter Texte bei den Dikr-Übungen vgl. Kapitel 3.4.2.

223

Q 2:227-228 lautet:

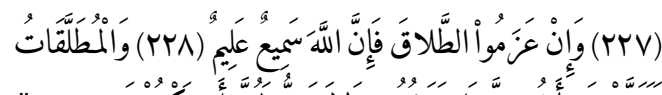

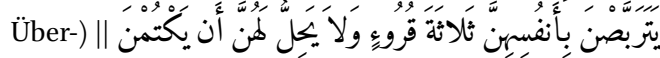

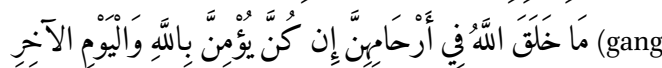
و

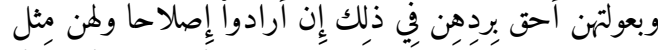

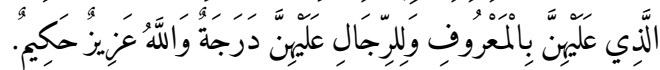


des Mittelstreifens. In der Mitte dieses Abschnitts lässt sich ein kleineres an beiden Enden abgerundetes Rechteck (Länge ca. $16 \mathrm{~cm}$ ) erkennen, in dem Text steht. Davor und danach befinden sich je sieben Kreise mit Text in schwarzer Schrift. Diese 15 Abschnitte werden durch einen Titelbalken bzw. einen Balken mit einer Unterschrift voneinander getrennt. Sämtliche Titelbalken enthalten den Begriff hiğăa und bringen damit zum Ausdruck, dass es sich beim folgenden Text um ein Schutzgebet handelt. ${ }^{225}$ Die einzelnen Abschnitte sind dem Propheten Muhammad, den vier rechtgeleiteten Kalifen (darunter auch 'Alī, der 1. Imam der Schiiten) und danach Hasan (2. Imam der Schiiten), Ḥusayn (3. Imam der Schiiten) und Ğa far aṣ-Ṣāiq

225 Unter einem hiǧāa versteht man im vorliegenden Kontext ein Schutzgebet. Beachte dazu u.a. Kazimirski, Dictionnaire, s.v. hiğāa $b$ : „10. Charme, talisman, moyen d'enchantement (du nombre de ceux que la religion ne condamme pas, comme p. ex. le Coran regardé comme le moyen le plus puissant pour détourner le mal)." Lane, Lexicon, s.v. hiğāa (II, 516a): „A thing that veils, conceals, hides, covers, or protects $[. .$.$] - Hence,$ in the present day, $\dagger \mathrm{A}$ written charm or amulett; generally worn in a case (called bayt hiğăb) suspended, on the right side, by a string passing over the left shoulder, or on some other part of the person." Der Begriff hiğāb in dieser Bedeutung ist nicht verzeichnet bei Padwick, Muslim devotions. Index. Siehe ausserdem Eintrag تفاوت حز و تعويذ و حجاب" unter

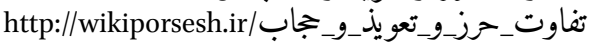
(Stand 10. November 2017):

تعريف حجاب: ججاب نيز كل به معناى يوشش است، به جيزى كفته مىشود كل بين دو بيز حائل مىشود و مانع برخورد آن دو با هم مىشود. از إن رو؛ به حرزيا دعايى كم براى هيى دفع آفت يا جشم زخم بر خود آويزند نيز ججاب كفته مىشود. هرجند كه اين جند كلمه (حرز، تعويذ، ججاب) در اصل معنا با يككيكر تفاوت دارند ولى در معناى اصطلاحى تقريبا به يك معنا ومترادف با هم هستند؛ يعنى حز، تعويذ و حجاب، در منابع روايى و در كتب ادعيه، به دعاهايى اطلاق مىشود كم

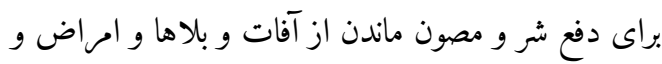

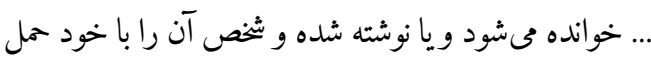

(6. Imam der Schiiten) gewidmet. Im einzelnen handelt es sich um folgende Teile:

II.2.1 (ABB. 48):226 Muhammad: Hiǧāb annabiyy / șallā Allāhu 'alayhi [wa-sallam]. ${ }^{227} \mathrm{Da}-$ nach schliesst sich im Kreis folgender Text in normal grosser Schrift an (Höhe der Zeilen ca. $0.7 \mathrm{~cm}$ ):

$$
\begin{aligned}
& \text { إسم الله الرحمن الرحيم |228 الحمد لله رب العالمين الرحمن } \\
& \text { الرحيم || مالك يوم الدين اياك نعبد واياك نستعين اهدنا || }
\end{aligned}
$$

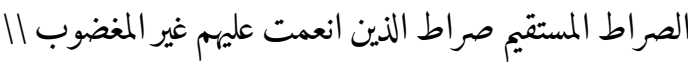

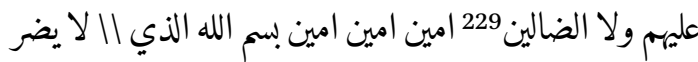

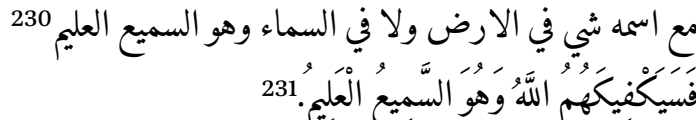

Fortsetzung nach blauem Balken mit Eulogie auf Muhammad im nächsten Medaillon:

$$
\begin{aligned}
& \text { حسبي الله لا اله الا هو عليه | توكلت وهو رب العرش العظيم } \\
& \text { || اعوذ بكلمات الله التامات كلها من شر || ما خلق وذراء }
\end{aligned}
$$

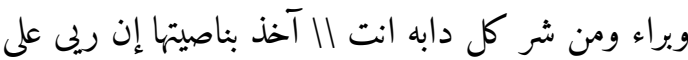

$$
\begin{aligned}
& \text { صراط مستقيم } 232 \text { ولا || حول ولا قوة الا بالله العلي العظيم } \\
& \text { || ولا حول ولا قوة الا بالله العلي || العظيم. }
\end{aligned}
$$

226 Abb. Is 1624.19.7 und 20.3.

227 Dies als Über- bzw. Unterschrift vor bzw. nach dem ersten Kreis.

228 Die Markierung // zeigt den Zeilenwechsel an.

229 Der Text bis hier: Sūrat al-Fātiḥa (Q 1).

230 Dieser Abschnitt lässt sich auf lib.e-shia.ir in 98 Werken nachweisen. Darunter auch in Ibn 'Asākir, Ta'rīh Madinat Dimašq vi, 149 دار الفكر للطباعة والنشر والتوزيع; vgl. http://lib.eshia.ir/22014/6/149, Stand 23. November 2016). Diese Stelle stammt nicht aus dem Koran. Der Text lässt sich überdies bei Mağlisī, Bihāar al-anwār, nachweisen (http://lib.eshia.ir/110o8/95/8). Aus Q 2:137.

Eine Anspielung auf Q 11:56, die Stelle lautet:

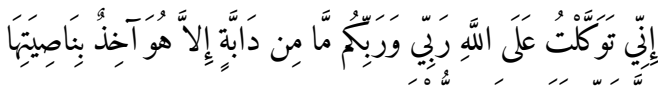

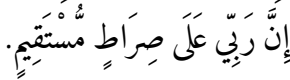

Man vergleiche aber auch: Muslim, Șahịh, Hadīt Nr. 4888 (http://library.islamweb.net/hadith/display_hboo 
II.2.2: ${ }^{233}$ Abū Bakr (1. rechtgeleiteter Kalif; starb $13 / 634):^{234}$ Es folgen zwei Kreise mit folgender Überschrift und Eulogie, die auf zwei Titelbalken mit blauem Hintergrund verteilt sind: Hiǧăa Abì Bakr / radiya Allāhu 'an-hū. Der obere Kreis (Durchmesser ca. $5.5 \mathrm{~cm}$ ) enthält auf zehn Zeilen ausschliesslich Wiederholungen der basmala. Es schliesst sich ein zweites Medaillon an:

k.php?bk_no $=158 \&$ hid $=4888 \&$ pid $=108355 ;$ Stand 23 . November 2016):

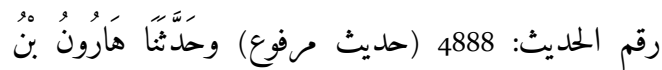

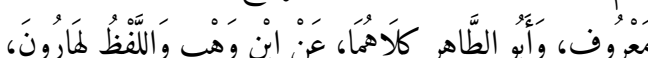

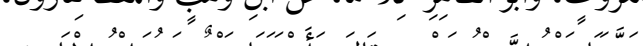

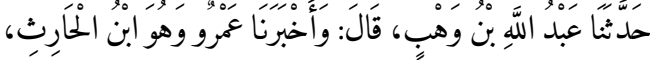

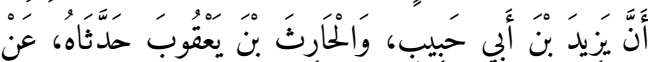

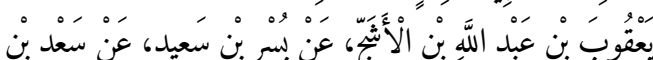

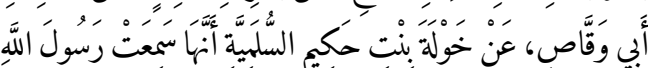

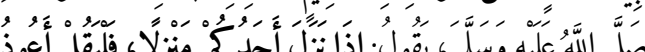

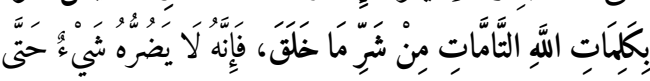

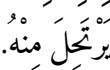

Siehe ausserdem Ibn Māğa, Șahīh, Hadīt Nr. 3871 (http:// library.islamweb.net/hadith/display_hbook.ph p?bk_no=173\&hid=3871\&pid=111967; Stand 23. November 2016):

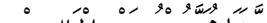

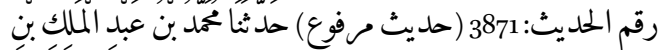

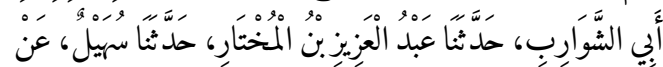

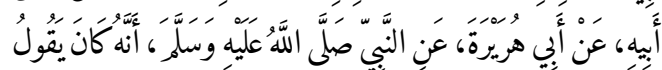

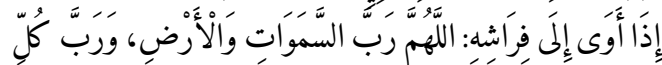

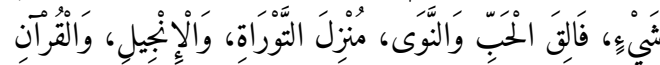

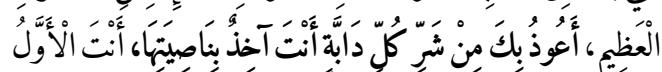

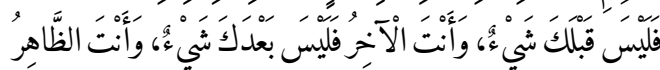

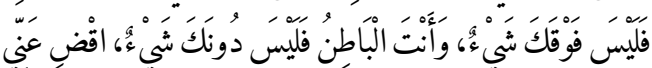

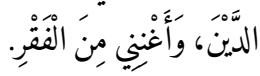

Für weitere Belege beachte lib.eshia.ir.

Abb. Is 1624.20 .3 .

Vgl. zu ihm Athamina, Abū Bakr, in $E I^{3}$.

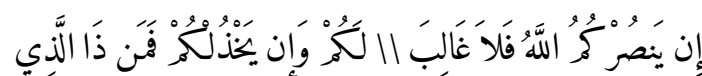

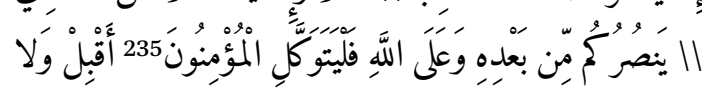

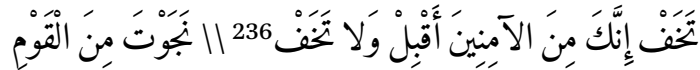

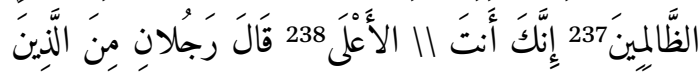

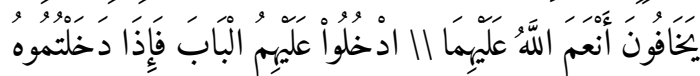

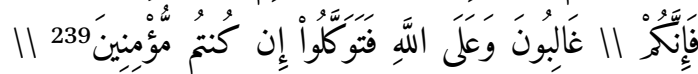

$$
\text { [وصلى الله على سيدنا محمد وسلم].240] }
$$

II.2.3: ${ }^{241}$ 'Umar (gest. 23/644): ${ }^{242}$ Titelbalken mit goldenem Hintergrund und weissem Eintrag auf einer einzigen Zeile: Hiğāb Umar radiya Allāhu 'an-hū:

$$
\text { || |اكت الله الرحمن الرحيم || قالوا سبحانك لا علم لنا الا ما علمتنا }
$$

235 Q 3:16o; Zeilen 1-3 im Medaillon bzw. Kreis.

236 Aus Q 28:31 (Schluss, mit Wiederholung):

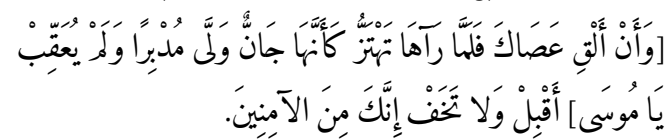

Aus Q 28:25 (Schluss):

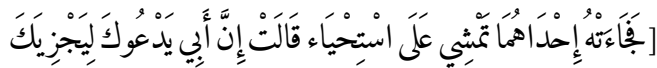

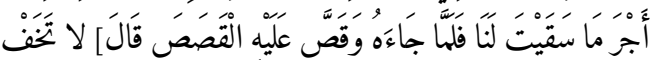

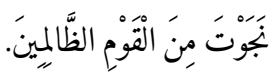

Aus Q 20:68; auch diese Stelle richtet sich an Moses:

$$
\text { قَلْنا لا تَخَفْ إِنَّكَ أَنَتَ الأَعْلَ. }
$$

239

240

241

242
Q 5:23.

Diese Eulogie lässt sich nur noch schwer entziffern. Abb. Is 1624.20.6-8.

$\mathrm{Zu}$ 'Umar, dem zweiten rechtgeleiteten Kalifen, vgl. Levi della Vida und Bonner, 'Umar (I) b. Al-Khațțāb, in $E I^{2}$.

Q 2:32:

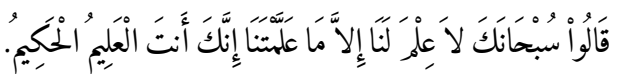

Aus Q 2:116. Der hier fehlende Anfang hält fest, dass sich Gott einen Sohn genommen habe; allerdings würden sich Gott alle unterwerfen (qānitūn): 
ولا تهلكا بعذابك 245 ربنا اتنا في الدنيا حسنة وفى || الآخرة

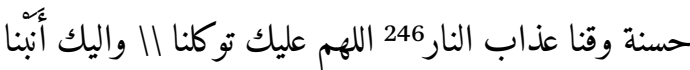
واليك المصير 247 ولا حول ولا قوة الا با ال لله العلي العظيم وصلى الله على الله (كذا) على || سيدنا محمد وآله وصحبه

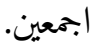

II.2.4: ${ }^{248}$ 'Uțān (starb 35/655):249 Zwei Balken mit goldenem Hintergrund und folgenden Einträgen in weisser Schrift: Hiğăb Uțmān // radiya Allāh 'an-hū.

بسم الله الرمن الرحيم || ثم افيضوا من حيث افاض

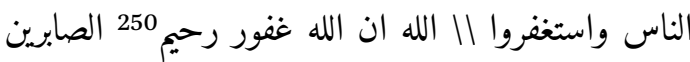

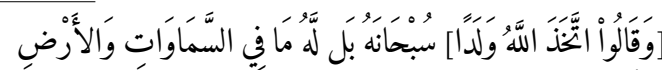

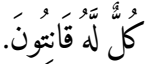

Vgl. dazu das Prophetenwort bei Tirmidīi, Ǧāmi', Hadīt Nr. 3396 (http://library.islamweb.net/hadith/display_h book.php?bk_no=195\&hid=3396\&pid $=>$ und die Parallelstellen unter dem Reiter Tahrïg. Stand 27. September 2017):

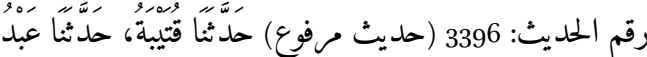

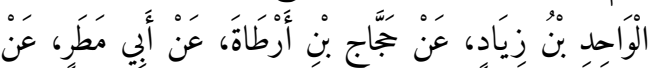

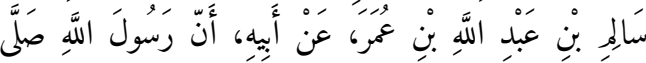

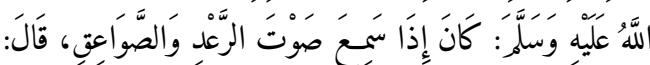

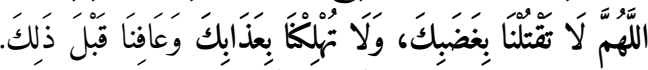

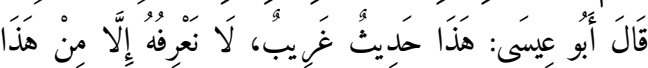

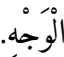

Q 2:201:

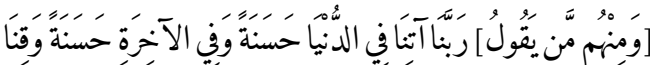

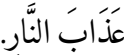

Schluss von Q 60:4.

Abb. Is 1624.20.8; dieser Abschnitt umfasst zwei Kreise. Zu 'Uțān b. 'Affān, dem dritten rechtgeleiteten Kalifen, vgl. Levi della Vida und Khoury, 'Uthmān b. 'Affān, in $E I^{2}$.

250 Q 2:199.

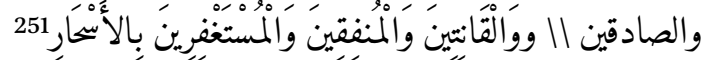

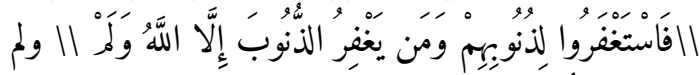

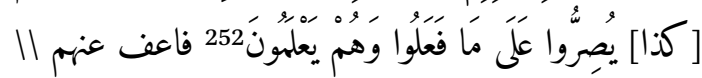

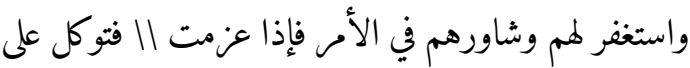
الله إن الله يحب المتوكلين 253 || ولو انهم اذ ظلموا انفسهم ||| || جاءوك فاستغفروا الله || واستغفر لمم الرسول لوجدوال الله || توابا رحيما255 قلنا يا نار كوني برداً وسلاماً على الى الى ابراهيم 256 || وارادوا به كيدا إفعلناهم الاخسرين 257 الآن خفف |ل الله عنكم وعلم أن فيك ضعفا258 الله نور السموات

251 Q 3:17:

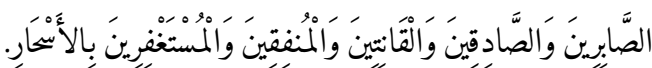

252

Q 3:135:

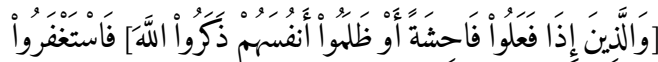

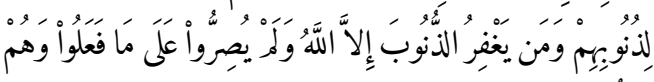

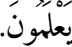

253 Q 3:159, zweiter Teil:

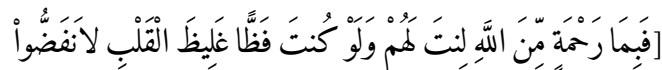

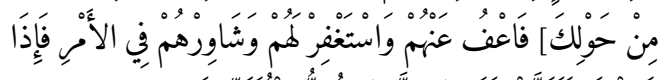

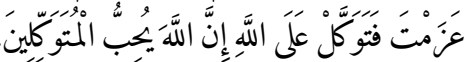

Hier Übergang in den nächsten Kreis. Bei der Stelle handelt es sich um ein Zitat aus Q 4:64:

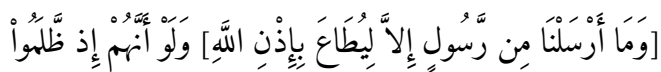

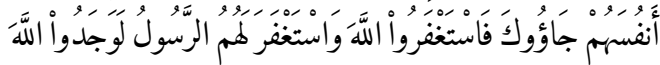
توَّابًا رََّحيمًا.

Schluss von Q 4:64.

256 Q 21:69. Anspielung auf Ibrāhīm, der von Nimrod ins Feuer geworfen wurde; Gott liess es für ihn kühl sein; vgl dazu Bocian, Lexikon der biblischen Personen 18; Busse, Abraham, in $\mathrm{EI}^{3}$; Schützinger, Abraham-NimrodLegende.

Beginn von Q 8:66:

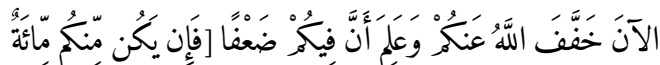

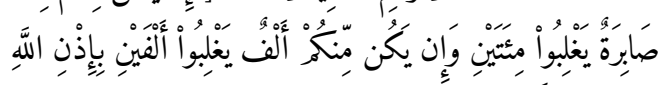
وَاللَّهُ مَعَ الصَّابرِينَ]. 


$$
\begin{aligned}
& \text { والارض || مثل نوره كمكاة فيها مصباح259 حسبي الله لا } \\
& \text { اله الا هو || عليه توكلت وهو رب العرش العظيم ولا || حول } \\
& \text { ولا قوة الا بالله العلي العظيم || وصلى الله على سيدنا محمد واله } \\
& \text { اجمعين. }
\end{aligned}
$$

II.2.5 (A B B. 49): 260 'Alī:261 Hiğāa 'Alī // radiya Allāh 'an-hü. Dieser Abschnitt befindet sich in der Mitte des hier diskutierten Teils der Rolle (II.2) und nimmt darin eine dominierende Stellung ein. Sie dürfte die grosse Verehrung für 'Alī zum Ausdruck bringen. Diese Hervorhebung 'Alīs wäre auch für die Bestimmung jener Umfelder relevant, in denen diese Rolle entstanden ist. 'Alī nimmt in diesem Abschnitt eine Scharnierstellung zwischen den drei ersten rechtgeleiteten Kalifen der Muslime und den schiitischen Imamen ein, von denen danach ebenso drei Vertreter, nämlich Hasan, Husayn und Ğa'far aș-Ṣādiq, ${ }^{262}$ angeführt werden. 'Alī selbst zählt dabei zu beiden Gruppen, nämlich zu den vier rechtgeleiteten Kalifen, deren letzter er ist. Er ist aber zugleich der erste Imam der Schiiten.

Der 'Alī gewidmete Abschnitt setzt sich aus zwei Teilen zusammen. Es handelt sich um a. ein an beiden Enden abgerundetes Rechteck (Länge ca. $18 \mathrm{~cm}$, inkl. Titelbalken) und b. einen Kreis (Länge ca. $6.5 \mathrm{~cm}$, inkl. Titelbalken). Vor dem Rechteck und dem Kreis befindet sich jeweils ein goldener Titelbalken mit Text in weisser Schrift (Hiğăb Alì //radiya Allāh 'an-hū). Dieser Abschnitt misst insgesamt ca. $25 \mathrm{~cm}$.

$$
\begin{aligned}
& \text { |263 بسم الله الرحمن الرحيم || اللهم يا رب لك الحمد ولك } \\
& \text { الشكر || اذ هديتنى وقويتنى على اداء الفريضة || وانت القديم } \\
& \text { وهذه سنة جديده اسالك فيها العصمة || ه من الشيطان }
\end{aligned}
$$

259 Aus Q 24:35 (Lichtvers).

26o Abb. 1624.20.5 und 21.3.

261 'Alī ist der vierte rechtgeleitete Kalif der Muslime und der erste Imam der Schiiten; er starb 40/661; vgl. zu ihm Gleave, 'Alī b. Abī Țālib, in $E I^{3}$.

262 2., 3. und 6. Imam der Schiiten; vgl. zu ihnen unten bei der Diskussion der ihnen gewidmeten Abschnitte.

263 Die Zeilen werden hier in Fünferschritten numeriert.
الرجيم والسلطان العظيم المجبر على || المساكين واسالك العون على هذه النفس الامارة || بالسوء والاستغال (؟) بما يقربني

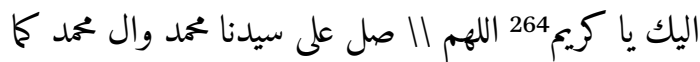
صليت على ابراهيم || انك حميد مجيد اللهم اني اشهدك واشهد

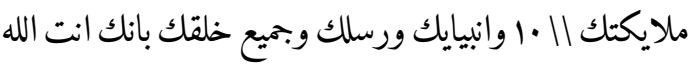
الواحد || الفرد الصمد الذي لم يلد ولم يولد ولم يكن له كفوا

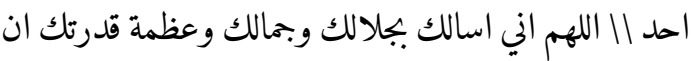
تكن (؟) 265 لي || معينا وناصرا وانيساً (؟) يا الله يا الله يا الله وعله

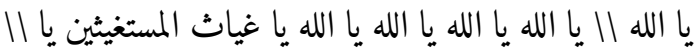

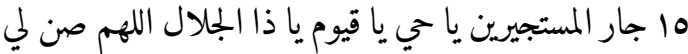

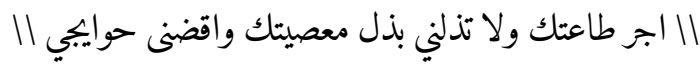

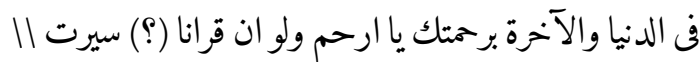

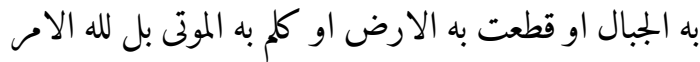

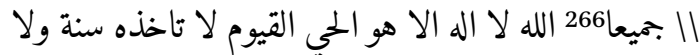

264 Es handelt sich um ein Gebet um Segen und Schutz, das zum Jahresanfang rezitiert wird (sana ğadīda). Ein ähnliches Gebet liess sich nachweisen bei Muhammad Kibrīt Ḥusaynī Madanī (gest. 1070 h.q.), al-Ǧawāhir attamina fi mahāāin al-madaniyya 184. Bayrūt, Dār alKutub al-ilmiyya, ohne Jahr.

شهر المحرم و هو أول السنه القمريه، أقسم الله تعالى به في خطابه و افتتح به سوره من كتابه فقال والفجر وليال عشر قبل الفجر هو المحرم لأنه هفر العام و ليال عشر هي لياليه بل لآليه و من أدعيته اللهم إنك أنت الأبدي القديع و هذه سنه جديده أسألك فيها العصمه من الشيطان و أوليائه و العون على هذه النفس الأماره بالسوء والاشتغال بمايقربني إليك زلفي يا ذا الجلال و الإكرام.

Auf der Rolle eigentlich يكن.

Aus Q 13:31:

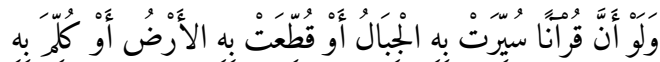

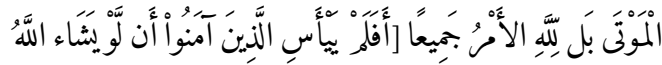

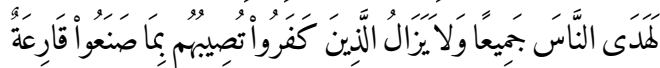

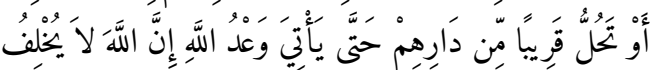

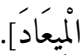


II • نوم له ما وفي السموات وما في الارض من ذا الذى

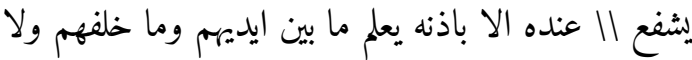
يحيطون || بشيء من علمه الا بما شاء وسع كرسيه السموات والارض || ولا يؤده حفظهما فهو العلى العظيم 267 لاًَإكْرَاهَ

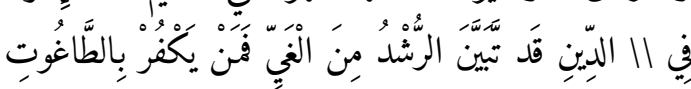

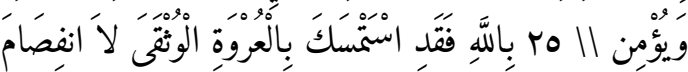

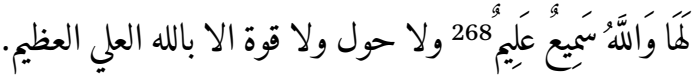
Es schliessen sich Zeichen an ${ }^{269}$ سيدنا محمد واله وصحبه اجمعين. Es folgt eine Zeile mit 271.Zeichen

Hier folgt nach dem Balken mit goldenem Hintergrund und dem Text radiya Allāh 'an-hū der Übergang in den Kreis darunter: Hier zuerst vier Zeilen mit Einzelbuchstaben; Entzifferung nicht gänzlich gesichert:

ن ن ن ن ن الن ن ن ن ل ل ل ل ل ل ل || و و و وو وو

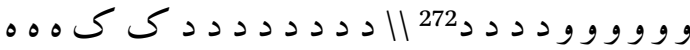

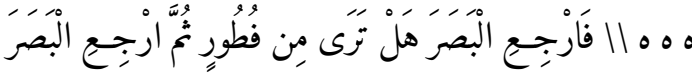

$267 \quad$ Q 2:255 (Thronvers):

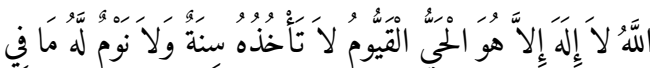

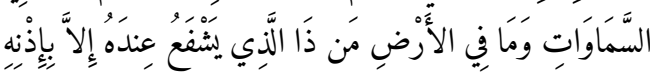

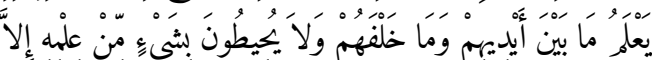

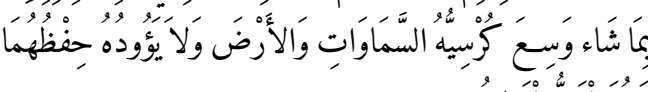

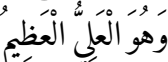

268 Q 2:256.

269 Siehe Abb. Is 1624.21.2 (am Ende des abgerundeten Rechtecks). Siehe dazu Canaan, Decipherment $169 \mathrm{f}$ (mit Fig. 3oa); Winkler, Siegel und Charaktere 114-119. Die letzten beiden Ausdrücke sind verschnörkelt geschrieben; sie passen gut zur Abfolge von Zeichen davor und danach.

Siehe dazu Abb. Is 1624.21.2: ن ن ا اlllllll.

272 Dies auf einer Zeile; bis etwa zum 10. Zeichen handelt es sich klar um den Buchstaben wāw, dann fliessender Übergang zu dāl. Bei den vier letzten Zeichen handelt es sich um ein dāl.

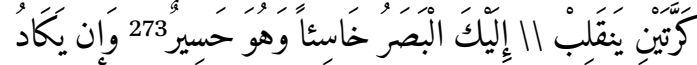

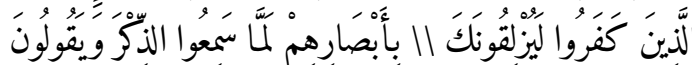

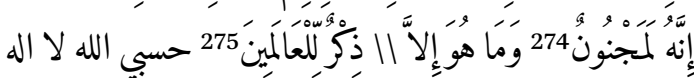

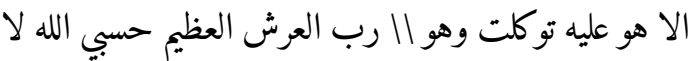
اله الا هو عليه توكلت || وهو رب العرش العظيم فصلى الله

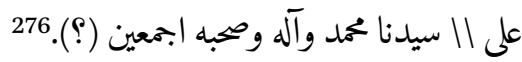

II.2.6: ${ }^{277}$ Hasan:278 Hier gehören erneut zwei Kreise zusammen. Ihnen geht jeweils ein goldener Balken mit folgendem Text in weisser Schrift voraus: Hiǧāb al-Hasan // radiya Allāhu 'an-hū:

$$
\begin{aligned}
& \text { بسم الله الرممن الرحيم || يا لطيف لطفاً باهل السموات } \\
& \text { والارض II الطف بنا في قضايك وبلايك سبحان بك الك الكان } \\
& \text { الابدي || الابد سبحان الواحد الاحد سبحان الذي رفع } \\
& \text { السموات || بغير عمد } 280 \text { المتفرد [ما له] صاحبة ولا ولد الد الد } \\
& \text { سبحان الذي || لم يلد ولم يولد ولم يكن له كفوا احد } 281 \\
& \text { سبحان الله ملء (؟)282 || الميزان ومنتهى لعلم وزنة العرش }
\end{aligned}
$$

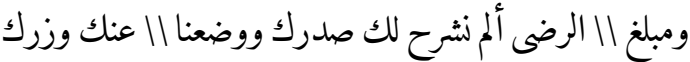

273 Vgl. Q 67:3-4 (Auszug):

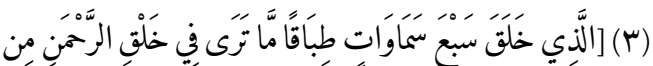

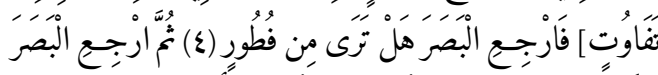

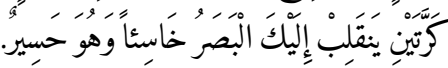

Beginn von Q 68:52.

Q 68:51-52 (die beiden Schlussverse ganz).

Die letzten Wörter dicht gedrängt geschrieben und nur noch zu erraten.

Abb. Is 1624.21.8.

Hasan: der zweite Imam der Schiiten, 'Alīs Sohn; vgl. zu ihm Veccia Vaglieri, (al-) Hasan b. 'Alī b. Abī Ṭālib, in $E I^{2}$. $B i-k a$ : durchgestrichen.

Anspielung auf Q 13:2:

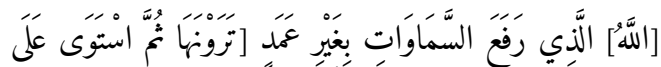

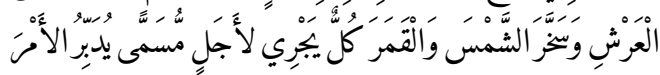

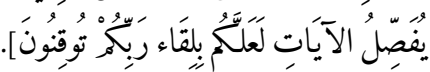

Aus Q 1.

Dieser Ausdruck ist stark verderbt. 
الذي أنقض ظهرك283 ورفعنا284 لك ذكرك فان مع || العسر يسرا ان مع العسر يسرا فاذا || فرغت فانصب والم ربك فارغب285 [... هم]286 يا || الله يا بديع السموات والارض كن لي ناصرا ومعينا || في جميع الشدايد واحفظنى من بليات الدنياوية || والاخروية انك [على] كل شي قدير فسيكفيكهم

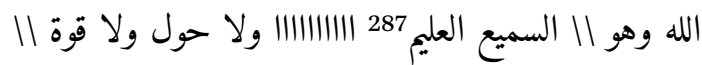
الا بالله العلي العظيم وصلى الله على سيدنا محمد واله || وصحبه

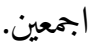

II.2.7: ${ }^{288}$ Husayn (starb 61/68o): ${ }^{289}$ Es folgt der Hiğāb Husayn, dessen Text auf zwei Kreise verteilt ist. Vor beiden Kreisen ein goldener Titelbalken mit dem Titel in weisser Schrift: Hiǧăb al-Husayn // radiya Allāh 'an-hū.

بسم الله الرمن الرحيم || اللهم اني اسالك واتوجه اليك | عليك 290 بنبيك || وحبيك محمد صلى الله عليه وسلم بنبى

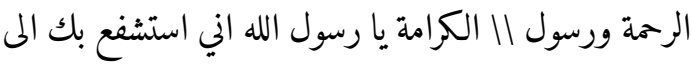
ربي || في قضاء حاجتي هذه اللهم شفعني في نفسي وشفع

283 Zuletzt Q 94:1-3:

$$
\text { أَنَضَضَ ظَهْرَكَ. }
$$

284 Ab diesem Ausdruck: zweiter Kreis dieses Hiğă $b$ Gebets; es handelt sich um die restlichen Verse von Q 94, also 94:4-8 (vgl. vorangehende Anm.):

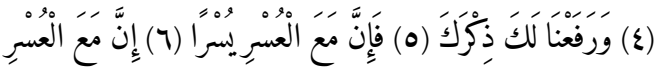

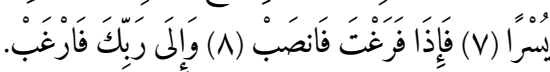

285 Schluss von Q 94:8.

286 Ein Ausdruck unleserlich.

287 Aus Q 2:137:

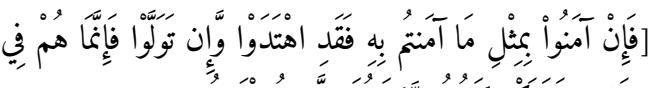

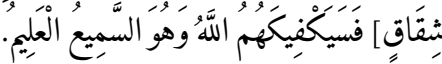

288 Abb. Is 1624.21.10.

289 Ḥusayn ist der dritte Imam der Schiiten; vgl. zu ihm Haider, al-Ḥusayn b. 'Alī b. Abī Ṭālib, in $E I^{3}$.

Korrektur im Original.
نبيك || في واقض حاجتي بفضلك ورأفتك ورممتك يا ارحم

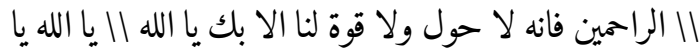
الله يا الله يا الله يا الله 291

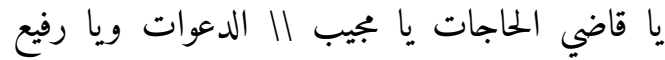
الدرجات يا غياث || المستغيثين ويا جار المستجيرين عز المات المات جارك وجل || ثناوك وتقدست اسماؤك اللهم ربنا وانت الهنا || وانت مصورنا وانت مالكا وانت سلطاننا فانه || لا حول ولا قوة لنا الا بك كن له في شدتي صاحبا وفي الا لحدي

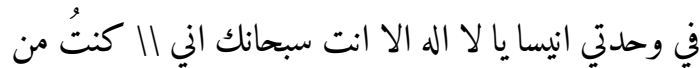

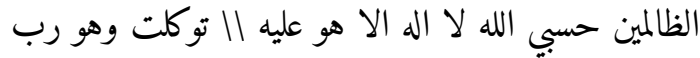

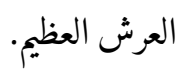

II.2.8:292 Ğa far aș-Ṣādiq (starb 148/765):293 Es folgt der Hiğăb Ğafar // aș-Ṣādiq // radiya Allāh 'an$h \bar{u}$. Dieses Hiğăb-Gebet ist auf zwei Kreise verteilt. Titel und Eulogie sind auf zwei goldene Balken und auf den Bogen am Ende des Rechtecks verteilt. Das Gebet besteht aus einer Auswahl von Versen aus Q 6. ${ }^{294}$

بسم الله الرمن الرحيم ل| الحمد لله الذي خلق السموات

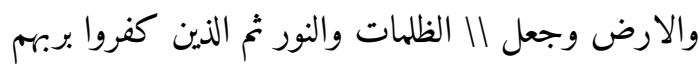

291 Hier folgt der Übergang zum nächsten Kreis; zuvor der Balken mit dem Text radìa Allāhu 'an-hū.

292 Abb. Is 1624.21.11.

293 Bei Ğa far aș-Ṣādiq handelt es sich um den 6. Imam der Schiiten; vgl. zu ihm Hodgson, Dja far aṣ-Ṣādiḳ, in $E I^{2}$.

294 Q 6:1-5: lautet:

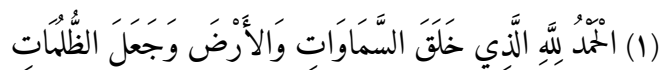

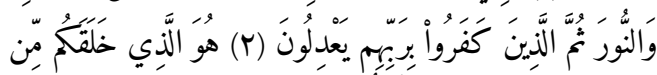

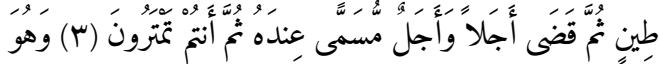

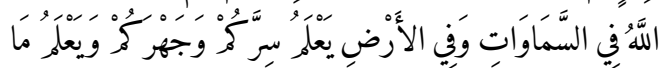

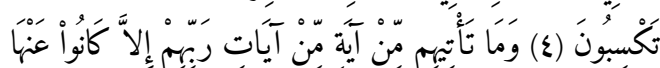

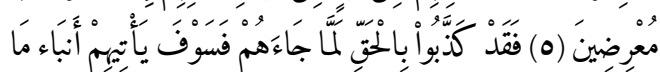

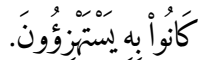


يعدلون295 || هو الذي خلقكم من طين ثم قضى اجلا واجل || مسمى عنده ثم انتم تمترون296 وهو الله في السموات || في موني

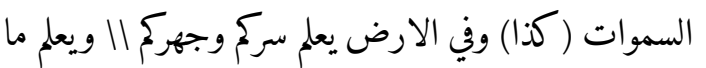
تكسبون297 وما تاتيهم من اية || من آيات ||| 298

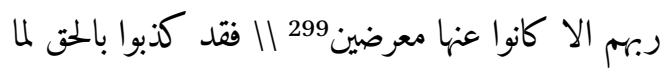
جاءهم فسوف || ياتيهم انباء ما كانوا به يستهزءون300 قل بهن

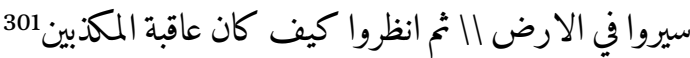

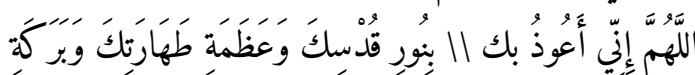

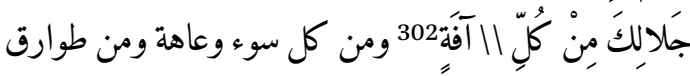
الليل والهار || الا طارقاً يطرق منك بخير يا رممن الدنيا

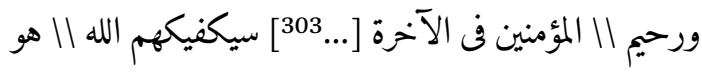
السميع العليم.304

Abschnitt II.3 (ABB. 50): ${ }^{305}$ Nach dem Muhammad, den vier rechtgeleiteten Kalifen und den Imamen Hasan, Husayn und Ğa'far aṣ-Ṣādiq gewidmeten Abschnitt folgt auf der Rolle ein letztes, an beiden Enden abgerundetes Rechteck von ca. $25 \mathrm{~cm}$ Länge. Ihm geht ein Medaillon voraus, das im Innern üppige goldene Verzierungen

$\begin{array}{ll}295 & \text { Q 6:1. } \\ 296 & \text { Q 6:2. } \\ 297 & \text { Q 6:3. } \\ 298 & \text { Hier Übergang zum zweiten Kreis; im Balken steht } a s ̣-~ \\ & \text { Ṣādiq. } \\ 299 & \text { Q 6:4. } \\ 300 & \text { Q 6:5. } \\ 301 & \text { Q 6:11: } \\ & \\ & \end{array}$

302 Die Stelle lässt sich nachweisen in einem hadīt, der bei Bayhaqī verzeichnet ist: http://library.islamweb.net/ hadith/display_hbook.php?bk_no=679\&hid=105\&pid= (Stand 27. September 2017); mit Parallelstellen unter dem Reiter Tahrīğ. Vgl. dazu die Druckausgabe: alBayhaqī, Ahmad b. Al-Husayn (994-1066), Bayān hața' man ahța'a 'alā šššâfict. Bayrūt, Mu’assasat ar-Risāla, 1983. Diese Druckausgabe ist in Genf (Bibliothèque de Genève) vorhanden; sie wurde nicht eingesehen.

Ein Wort unleserlich.

304 Schluss von Q 2:137.

305 Abb. Is 1624.22.1-23.1. aufweist (Blüten- und Blattwerk). Sie füllen das Medaillon nahezu vollständig aus; sein blauer Hintergrund ist nur noch an wenigen Stellen sichtbar. Sowohl das Medaillon als auch das anschliessende Rechteck werden vom dreiteiligen Schriftband umfahren. Sein Mittelstreifen ist am breitesten; darin lässt sich das bereits zuvor erfasste Gebet erkennen (es beginnt noch am Schluss von Teil I). ${ }^{306}$ Auf dem schmalen Aussenband wurde - wie bereits erwähnt - Q 112 zahllose Male kopiert. ${ }^{307}$ Der Kopist benötigte auf diesem schmalen Band ca. $6 \mathrm{~cm}$, um die Sūrat al-Ihlās einmal zu kopieren. ${ }^{308}$ In diesem letzen Rechteck steht zuunterst auf dem schmalen Innenband Q 2; deren Abschrift bereits am Anfang der Rolle begonnen hatte. ${ }^{309}$ Der Kopist steigt auf der linken Seite nach unten, geht in den Bogen über und steigt auf der rechten Seite wieder nach oben. Die Schrift ist zuunterst stark verblasst; es lassen sich aber Stellen aus Q 2:235 erkennen. ${ }^{310}$ Es ist bei dieser Gelegenheit zu ergänzen, dass das Aussenband mit Q 112 ganz am Schluss der Rolle noch ein letztes zwöfllappiges Medaillon umfährt, das später beschrieben wird. ${ }^{311}$

Die weiteren Ausführungen befassen sich mit Aufbau und Inhalt des Mittelstreifens dieses letzten Abschnitts (Rechteck). Hier lassen sich neun horizontal ausgerichtete mandelförmige Figuren erkennen. Die fünfte Mandorla in der Mitte ist etwas kleiner als jene vier davor und danach.

306 Vgl. zu diesem Gebet bei Anm. 18o-208.

307 Vgl. dazu bereits oben bei Anm. 220-222.

308 Dieses schmale Aussenband setzt sich nach oben fort und erstreckt sich über einen Abschnitt am Ende der Rolle, der ca. $172 \mathrm{~cm}$ misst. Da das Band mit Q 112 wieder ans Ende der Rolle zurückkommt, wurde diese Sure auf einer Länge von ca. $344 \mathrm{~cm}$ kopiert. Dieses Band folgt dem vorgegebenen Layout und wechselt somit auch nach innen; vgl. auch bei Anm. 220-222. Vgl. dazu oben bei Anm. 12-15.

Q 2:235 beginnt im linken Innenband auf der Höhe der dritten Mandorla im Mittelstreifen; sie endet unmittelbar nach dem Bogen, wo der Text wieder parallel zum Rollenrand verläuft (zwischen unterster und zweitunterster Mandorla). Q 2:236 endet auf der Höhe der dritten Mandorla von oben.

311 Vgl. II.4 (nach Anm. 320). 
Die vier grösseren Mandorlen oben und unten werden paarweise in drei sich überschneidende Kreise zusammengefasst. Die Freiräume zwischen den Mandorlen und dem Rand des Rechtecks sind entweder golden ausgefüllt ${ }^{312}$ oder weisen einen blauen Hintergrund mit goldenem Blattwerk auf. ${ }^{313}$ Die weitere Übersicht befasst sich mit dem Inhalt dieses Abschnitts:

II.3.1 (oberste Mandorla): $: 314$

$$
\begin{aligned}
& \text { بسم الله الرحمن الرحيم قل هو الله || احد الله الصمد لم يلد } \\
& \text { ولم يولد ولم يكن له كفوا احد315 || قل اعوذ برب الفلق من } \\
& \text { شر ما خلق ومن شر غاسق || اذا وقب ومن شر النفاثات فى } \\
& \text { العقد ومن شر || حاسد اذا حسد } 316 \text { سبحان }
\end{aligned}
$$

II.3.2. (2. Mandorla):

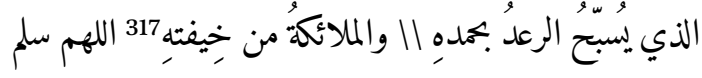

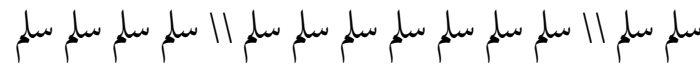

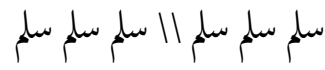

II.3.3. (3. Mandorla):

يا سالميا مؤمن يا مهيمن || يا عزيزيا جباريا متكبريا خالق يا

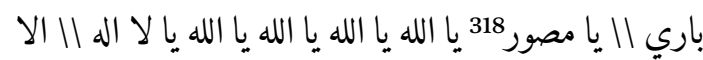

$$
\text { انت اني كنت من الظالمينع ع || ف ف ف ف }
$$

312 Es lassen sich Reste einer mit schwarzer Feder ausgeführten Verzierung (Blüten, Blätter) erkennen; diese Gestaltung zwischen den Mandorlen 1-2, 3-4, 6-7, 8-9. So in den restlichen Zwischenräumen.

314 Abb. Is 1624.22.1 und 22.3.

315 Dies ist Q 112 (al-Ihlāṣs).

316 Dies ist Q 113 (al-Falaq).

317 Anfang von Q 13:13 (Sürat ar-Ra'd):

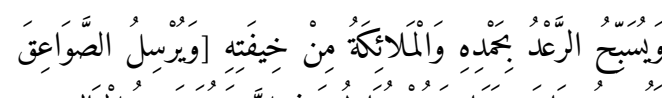

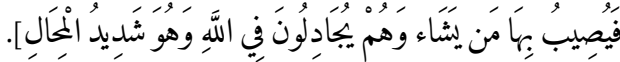

Dieser Versteil lässt sich in Gebeten vielfach belegen.

318 Es handelt sich hier also um Anrufungen Gottes bei ausgewählten seiner Schönen Namen.

319 Allenfalls handelt es sich um ein nūn. Die Bedeutung dieser Buchstaben liess sich nicht klären.
II.3.4 (4. Mandorla):

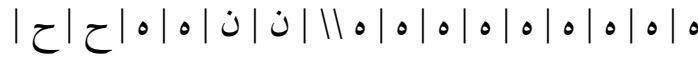

$$
\begin{aligned}
& \text { ح يا هيا شراهيا (؟) ل| ادونا اصباووت ال شداى (؟) الوهيم } \\
& \text { اللهم با-رك || لنا فيما اعطيتنا وفيما رزقتنا خيرا منها ووفقنا } \\
& \text { لشكره ويسر }
\end{aligned}
$$

II.3.5 (5. Mandorla):

علينا حسابنا (؟) الله اني |لا اشرك به شياً (؟) الله الله الله اي (؟) لا شريك || لك بالله نومن وبالله نعوذ (؟) وبالله العظيم

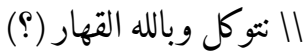

II.3.6 (6. Mandorla):

$$
\begin{aligned}
& \text { القوي نستعين اللهم اياك || نعبد واياك نستعين ربي اشرخ لي } \\
& \text { صدري |ا ويسر لي امري اللهم اني اني [ كذا] وتوكلت عليك } \\
& \text { والجأت ظهري اليك وفوضت تدبر (؟) اموري || [اليك] } \\
& \text { واربطني (؟) في لطفك ورحتك ورك الك }
\end{aligned}
$$

II.3.7 (7. Mandorla):

$$
\begin{aligned}
& \text { وكرمك خيرا [فمن ذا الذي] || يحيها اللهم صل على سيدنا محمد } \\
& \text { وعلى (؟) ال || محمد كما صليت وسلمت على ابراهيم انك حميد } \\
& \text { || ججيد ولا حول ولا قوة الا بالله العلي || العظيم. }
\end{aligned}
$$

II.3.8-9 (8. und 9. Mandorla): In diesen beiden Mandorlen folgt der zweite Kolophon, der bereits separat erfasst worden ist. ${ }^{320}$

Abschnitt II.4 (AB B. 51): Ganz am Schluss der Rolle befindet sich ein letztes Medaillon. Es weist zwölf Lappen auf und wird vom Schriftband mit der Abschrift von Q 112 umfahren. Die Lappen selbst sind golden ausgefüllt und wurden mit einem Muster (Blätter, Blüten) in schwarzer Tinte verziert; vereinzelt lassen sich Reste blauer Farbe erkennen. Unmittelbar nach den zwölf Lappen folgt nach innen ein Ring von ca. $0.9 \mathrm{~cm}$ Breite.

320 Vgl. dazu nach Anm. 10. 
Er war ursprünglich blau und mit einer goldenen Zickzacklinie verziert, durch die Dreiecke entstanden. Die blaue Farbe fehlt jetzt zumeist. Die Fläche im Innern des Medaillons (Durchmesser ca. $5.5 \mathrm{~cm}$ ) ist golden ausgefüllt. Darauf steht Text in weisser Schrift auf vier (?) Zeilen. Die Stelle ist allerdings derart stark verderbt, dass sie sich nicht sinnvoll entschlüsseln liess. Man meint, am Schluss links 'izz Allāh zu erkennen.

Schlussfolgerung: Is 1624 ist in mehrfacher Hinsicht von besonderem Interesse. Es lässt sich dank zwei Kolophonen klar datieren und muss in zwei Durchgängen 1362 und 1366 entstanden sein. ${ }^{321}$ Kolophon 1 hält zusätzlich fest, dass der Schreiber zwischen Anfang des Monats Ğumādā I 763 (beginnt am 26. Februar 1362) und dem Samstag, den 27. Ğumādā II 763 (23. April 1362), mit den Arbeiten am ersten Durchgang des Dokuments beschäftigt war. ${ }^{322}$ Das Erstellen des ersten Teils der Rolle nahm somit knapp zwei Monate in Anspruch.

Beide Kolophone halten auch unmissverständlich fest, dass das Dokument in Kairo (al-Qāhira l-mahrūsa) entstanden ist. Dieser Hinweis auf den Entstehungsort des Belegstücks soll hier auch in keiner Weise hinterfragt werden. Dennoch wird auch diese Rolle mit einer Tradition in Verbindung gebracht, die in erster Linie aus dem Städtedreieck mit den Eckpunkten Konya-Tabriz-Bagdad bekannt ist. Diese regionale Zuweisung stützt sich auf den Namen des Kopisten, insbesondere seine nisba al-Kahtāwī. Dieser Name wird in den beiden Kolophonen aufgeführt und lautet Muhammad b. Manșūr b. 'Alī al-Ḥanafī al-Husaynī al-Kahtāwī. Dem Namen lässt sich entnehmen, dass diese Person dem hanafitischen Ritus angehörte und eine Abstammung von Husayn beanspruchte. Eine Person exakt dieses Namens liess sich anderweitig bis anhin nicht belegen.

\footnotetext{
321 Ende der Arbeit am zweiten Durchgang: 5. Dū l-Ḥiğğa 767 (Sonntag, den 23. Aug. 1366).

322 Vgl. dazu die Erfassung der Kolophone oben bei Anm. 9
} und 10.
Aus der nisba al-Kahtāwī lässt sich ableiten, dass derSchreiber aus Kahtā stammt oder sich über längere Zeit dort aufgehalten hatte. Kahtā befindet sich etwa $80 \mathrm{~km}$ südlich von Malatya in Südostanatolien. ${ }^{323}$ Hier befand sich eine Festung, die den Mamluken am Ende des 13. Jh. als wichtiger Stützpunkt im Kampf gegen die Mongolen diente. Später wechselte Kahtā (modern Kahta) wiederholt zwischen den Mamluken und den Āq Quyunlū hin und her. Der Ort verlor seine Bedeutung mit der Ausdehnung des Osmanischen Reichs in Richtung Osten. Auch G. Le Strange macht gestützt auf Abu l-Fidā' auf den Ort aufmerksam. ${ }^{324}$

Die Ruinen dieser einst bedeutenden Festung sind bis heute erhalten und befinden sich in der Nähe des Dorfs Kocahisar (Eski Kahta) nördlich des modernen Orts Kahta (Provinz Adiyaman). ${ }^{325}$ Diese Festung ist heute als Yeni Kale („Neue Festung“) bekannt. Man unterscheidet sie von der Eski Kale („Alte Festung“) in Arsameia am Nymphäus auf der gegenüberliegenden Flussseite gerade in der Nähe, wo sich eine als hierothesion bekannte Kultstätte befindet. ${ }^{326}$ Wir befinden uns in der in der Antike als Kommagene bekannten Region am Oberlauf des Euphrats, deren Landschaft sich seit dem Bau des Atatürk-Stausees in den 199oerJahren stark verändert hat. ${ }^{327}$ Bei der Hauptstadt dieser Region handelt es sich um Samosata, das bei

323 Vgl. Cahen, Kakhtā, in $E I^{2}$; Raphael, Muslim fortresses 113 und 115 .

324 Le Strange, Palestine under the Moslems 475: „This place [Kahtā], in the extreme north of Syria, is a very highbuilt castle, and quite impregnable. It has gardens and a river, and lies 2 days east of Malatyah. It is one of the fortresses of Islam, of the north frontier, and lies about a march north, and somewhat west of Hisn Mansûr.“

325 Die weiteren Ausführungen stützen sich auf Wagner, Gottkönige am Euphrat; Brijder, Nemrud Dağı; Artikel „Arsameia“, in Wikipedia: https://en.wikipedia.org/ wiki/Arsameia und http://turkisharchaeonews.net/obj ect/yeni-kale-fortress-eski-kahta (Stand beide 25. Januar 2018).

Siehe den Situationsplan bei Brijder, Nemrud Dă̆ı 133 (Fig. 155).

327 Für einen Überblick siehe Wagner, Gottkönige am Euphrat 8f. (Abb. 1) und 45 (Abb. 3o); Brijder, Nemrud Dă̆ı 38-51 („I.1: Commagene: Some topography“). 
der Eröffnung des Stausees überflutet wurde. Ganz in der Nähe liegt sodann auch der Berg Nemrud (Nemrud Dağı), wo sich ein eindrückliches weiteres Grabheiligtum (hierothesion) befindet. Diese Anlage geht auf Antiochus I. Theos zurück, der sich dort offensichtlich als Gottheit verehren liess. Dieser Antiochus I. (reg. 69 bis ca. 36. v. Chr.) war der bedeutendste Herrscher aus der Dynastie der Orontiden im späthellenistischen Königreich Kommagene, das sich damals an der Grenze zwischen dem sich rasch nach Osten ausdehnenden Römischen Reich und dem Reich der Parther befand.

In der für unsere Belange wichtigen Festung Yeni Kale liessen sich Inschriften nachweisen, die Sultān Qalāwūn (regierte 1279-129o), al-Ašraf Halīl (1290-1293) und an-Nāṣir Muhammad (1293-1341) erwähnen. ${ }^{328}$ Es liess sich allerdings aufzeigen, dass Qarā Sunqur, der Gouverneur von Aleppo, eine ältere Festung hier bereits 1286 einnehmen konnte. Unser Kahtāwī dürfte diese Gegend und ihre verschiedenen vorislamischen und islamischen Stätten gut gekannt haben.

In der Mamluken-Festung gab es auch einen Taubenschlag. Offensichtlich benutzte Sulțān Qalāwūn im Vorfeld der Schlacht von Homs gern auch Brieftauben zur Kommunikation, um die Truppenbewegungen der feindlichen Mongolen $\mathrm{zu}$ verfolgen. ${ }^{329}$ In der Brieftaubenpost übrigens wurde oft die $\dot{G} u b \bar{a} r$-Schrift verwendet, galt es doch, möglichst viel Informationen auf geringem Raum unterzubringen. F. Taeschner zeigte nun auf, dass das Züchten von Brieftauben in den FutuwwaKreisen eine besonders beliebte Beschäftigung war. ${ }^{330}$ An-Nāṣir li-Dīn Allāh habe auch angeordnet, dass sämtliche Brieftauben in seinem Reich

328 Für Abbildungen der Yeni Kale siehe Brijder, Nemrud Dă̆ı 48 (Fig. 26), ebenso 265, 297; beachte auch http:// turkisharchaeonews.net/object/yeni-kale-fortress-eski -kahta (Stand 25. Januar 2018).

Artikel „Arsameia“, in Wikipedia: https://en.wikipedia .org/wiki/Arsameia (Stand 25. Januar 2018).

330 Siehe dazu auch Frembgen und Rollier, Wrestlers, pigeon fanciers, and kite flyers 49-9o (Kapitel „The everyday pleasures of flying pigeons“). umgebracht und durch Tiere aus seiner eigenen Zucht ersetzt würden. ${ }^{331}$ Der Kalif versuchte wohl auch mit dieser Massnahme, sich die FutuwwaBünde gefügig zu machen. Es ist übrigens auch sehr gut möglich, dass die Herrscher in ihrem Gefolge Spezialisten hatten, die in der Lage waren, die in der Brieftaubenpost gebräuchliche $\dot{G} u b \bar{a} r-$ Schrift nicht nur zu schreiben, sondern auch wieder zu entziffern. Derartige Spezialisten dürften oft im Umfeld von Futuwwa-Bünden oder mystischen Bruderschaften rekrutiert worden sein. Sie dürften ihre besonderen Fähigkeiten also im Sinn einer l'art pour l'art einerseits bei der Herstellung von Rollen von der hier untersuchten Art eingesetzt haben. Sie stellten ihr ausserordentliches Können den Machthabern anderseits aber auch für viel praktischere Belange im Nachrichtendienst und in der Spionage zur Verfügung.

Diese Yeni Kale diente also den Mamluken als wichtiger Stützpunkt, um die Grenze ihres Reichs gegen Einfälle aus dem Norden zu schützen. Diese Angaben legen nahe, dass der Kopist neben seinen mutmasslichen Affiliationen in Mystik oder Futuwwa - sie kommen gerade auch in den zahlreichen Gebeten auf der Rolle zum Ausdruck - in irgendeiner Form mit kriegerischen Auseinandersetzungen in Verbindung gestanden hatte.

Dieser Bezug zur Festung Kahtā ruft eine Bemerkung auf dem Belegstück aus Kopenhagen in Erinnerung (Cod. Arab. 53, hier Kapitel 4.4). Sie hält fest, dass die Rolle aus Kopenhagen ihren Träger im Kampf gegen Araber, Perser, Türken, Kiptschaken, Tataren (also Mongolen), Byzanti-

331 Taeschner, Zünfte und Bruderschaften 66 (siehe auch Index bei F. Taeschner, s.v. „Brieftauben“, S. 658): „In diesem Jahr (590/1194) vergoss der Kalif das Blut der Brieftauben; er liess sie erdrosseln und löschte ihre Spuren aus. Dann hielt er sich an die Jungen, deren Eltern man erdrosselt hatte, und liess sie aufziehen und an die Wallfahrtsstätte (mašhad) senden, um sie nach Baghdad (zurück)fliegen zu lassen. Er übertrug ihre Leitung dem Ober-Kadi Ibn an-Naǧğāāī und dem Jūsuf al-'Uqāb, dem Oberhaupt der fitjān. Er teilte sie in zwölf Klassen nach dem Namen der Imame." (S. 66; aus Sibṭ b. al-Ğawzī, Mir'āt az-zamān). Siehe ausserdem Kapitel 3.2, Anm. 216. 
ner und Armenier schütze. Eine wichtige Aufgabe von Angehörigen der Futuwwa-Bünde bestand darin, die islamische Welt vor dem Eindringen von Ungläubigen zu bewahren. Dies ist gemeinhin als ğihād, als heiliger Krieg, bekannt. Die bisherigen Beobachtungen legen nahe, dass derartige Rollen von Angehörigen dieser mystisch orientierten Futuwwa-Bünde als Schutzmittel geschätzt wurden. Sie dürften sie bei ihren Kampfeinsätzen mitgeführt haben. Aufgrund der hohen Qualität der beigezogenen Belegstücke, müssen wir sie mit gesellschaftlichen Eliten in Verbindung bringen. Diese Angaben legen nahe, dass der Kopist von Is 1624 in irgendeiner Form mit kriegerischen Auseinandersetzungen in Verbindung gestanden hat. Es kann auch gut sein, dass er die Arbeiten an seiner Rolle erst vier Jahre später abschliessen konnte, da er von Kairo erneut nach Kahtā oder an einen andern Ort an der Nordgrenze des Mamlukenreichs gesandt worden war, bedrohten doch immer wieder Angreifer aus dem Norden die islamische Welt.

Is 1624 ist nun auch von besonderem Interesse, da diese Rolle mehrere Gebete enthält. An zwei Stellen integriert der Schreiber den Namen des Trägers, für den die Rolle bestimmt war, in den fortlaufenden Gebetstext. Der Kopist erwähnt darin einen gewissen Yalbugàa und bezeichnet ihn als Träger dieser edlen Abschrift des Korans („lihāamili hāḍihi al-ḩatma aš-šarīfa Yalbugāa“ bzw. „Allāhumma ağcal țawāba mā katabtu-hū min kalāmi-ka al-'azīm fì șahīfati 'abdi-ka wa-faqīri-ka Yalbuḡāa). ${ }^{332}$ Der Name dieses Yalbug̀ā - er tönt so gar nicht arabisch - wird an beiden Stellen nicht näher präzisiert.

Bei diesem Yalbuġā könnte es sich um Yalbug̀ā al-Ḩāșșakī handeln. ${ }^{333}$ Dieser Yalbug̉ā war zwar

332 Vgl. dazu oben Abschnitt I.1a bei Anm. 37, 46 und Anm. 111 .

Yalbugāa wird hier bis zum Beweis des Gegenteils mit Yalbug̣ā al-Hāasșakī identifiziert. Zur Kontextualisierung dieses Yalbugàa wird hier auf zwei Aufsätze von J. van Steenbergen verwiesen: van Steenbergen, The Amir Yalbughā al-Khāșșaki, und ders., On the brink of a new era? Die weiteren Ausführungen stützen sich aber v.a. nicht selbst ein Mamluken-Sultan. Er war allerdings jene Person, die zwischen ca. 1358 und 1366 in Kairo die Fäden der Macht in den Fingern hielt. Dieser Yalbugàa sprang bei der Durchsetzung seiner Interessen mit seinen Gegnern nicht immer zimperlich um. Er war an die Macht gekommen, nachdem er Sulțān Hasan 763/1362 umgebracht und dessen Herrschaft ein Ende gesetzt hatte. ${ }^{334}$ Yal-

auf verschiedene Einträge in der Encyclopaedia of Islam $\left(E I^{2}\right)$ : Holt, Sha'bān, 2. al-Malik al-Ashraf, in $E I^{2}$ : „Owing to Sha'bān's youth (he was born in $754 / 1353^{-1354}$ ), a series of high Mamlūk amīrs held power in the early years of his reign. Yalbughā al-'Umarī [now usually referred to as al-Khāșșakī] and Ṭaybughā al-Ṭawīl, originally Mamlūks of al-Nāṣir Ḥasan [q.v.], at first shared the regency, until Ṭaybughā was ousted in Djumādā II 767/March 1366, when Yalbughā assumed sole power. In the meantime, a Crusading expedition under King Peter I of Cyprus briefly occupied Alexandria (Muharram 767 /October 1365), but withdrew as Yalbughā and the sultan advanced to relieve the city."

Für Quellenangaben verweist Holt auf Ibn Hağar al-'Askalānī, ad-Durar al-kāmina, 2. Aufl., Haydarābād 1972-1976: Einträge zu Šacbān, II.342-343 (Nr. 1936); Ṭaybuḡā al-Ṭawīl, II.395-396 (Nr. 259); Yalbug̣āa al-'Umarī, VI.208-210 (Nr. 2565).

334 Vgl. dazu Wansbrough, Ḥasan, al-Malik al-Nāșir Nāṣir al-Dīn Abu 'l-Ma'alī, 19th Mamlūk Sultan of Egypt, in the line known to contemporary chroniclers as Dawlat al-Turk, in $E I^{2}$ : „Finally Hasan's second and last reign was brought to an end by one of his own ambitious mamlūks, Yalbughā, who murdered the Sultan in the Citadel while he, having got word of the conspiracy, was arranging an escape to Syria in bedouin dress, on 12 D Djumādā I 763/9 March 1362.“

Siehe überdies Holt, al-Nāṣir, 3. al-Nāșir Ḥasan (748-752/1347-1351, 755-762/1354-1361), in $E I^{2}$ : „Growing resentment between the sultan and his own Mamlūk, Yalbughā al-'Umarī [al-Khāșșakī], led to an armed clash in which Hasan was defeated. He was captured and put to death on 9 Djumādā I 762/17 March 1361 by Yalbughā, who installed Hâadjdjī's son, al-Manșūr Muhammad. Al-Nāșir Hasan left as his chief memorial his beautiful madrasa-mosque in Cairo."

Siehe auch Holt, Mamlūks, d. The ascendancy of the magnates (Schluss), in $E I^{2}$ : „The one sultan in this period who showed some promise of repeating the success of his father, al-Nāșir Muhammad, was al-Nāṣir Hasan. Eleven years old when he was first raised to the throne after the killing of his brother and predecessor (Ramaḍān 748/December 1347), he was deposed in favour of another brother in Djumādā II 
bugàa wurde wegen seines rücksichtslosen Strebens nach Macht allerdings einige Jahre später auch selbst gestürzt (Ermordung: Dezember 1366). ${ }^{335}$ Kahtāwī hatte die Arbeit am zweiten Durchgang

752/August 1351. Restored in Shawwāl 755/October 1354, he succeeded in ridding himself of the kingmaker and regent, Șarghatmush al-Nāṣirī, in Ramaḍān 759/August 1358. He then promoted his own mamlūks, chief among them being Yalbughā al-'Umarī [al-Khāșṣakī] , and tried to create a power-base of a new kind by conferring high amīrates and provincial governorships on awläd al-nās [q.v.], i.e. descendants of the mamlūks, a socially privileged group who nevertheless did not normally form part of the military and ruling establishment. This experiment inevitably aroused the mistrust of the mamlūks, and an opposition faction appeared, headed (against the traditions of mamlūk loyalty to the founder of the household) by Yalbughā al-'Umarī [alKhāșșakī]. The sultan was defeated, captured, and put to death (Djumādā I 762/March 1361). Yalbughāa acted as regent until his own overthrow and death in Rabī' II 768/December 1366. Sixteen years later, Barkūụ b. Anaș [q.v.], a Circassian nurtured in his military household, the Yalbughāwiyya, deposed the last Kalāwūnid and usurped the sultanate."

Beachte ausserdem Haarmann, Mișr, 5 . The Mamlūk period 1250-1517, in $E I^{2}$ : „The key positions in the realm were in non-Mamlūk hands. Yet sultan Hasan thus jeopardised the whole Mamlūk system. It should be seen in this context that Yalbughā al-'Umarī [alKhāṣṣakī], one of Hasan's favourites, killed his own master, breaking a hitherto carefully-protected taboo. Under Yalbughā's effective rule (his regency lasted until 768/1366, when sultan al-Ashraf Sha'bān, with the support of discontented Mamlūks, took a vigorous hand in politics himself) the (re-) Mamlūkisation of state and military was to make rapid progress. Hasan is best known for the magnificent madrasa beneath the Cairo citadel, one of the most lavish monuments of Mamluk architecture."

Siehe nochmals Holt, Sha'bān, in $E I^{2}$ : „2. al-Malik alAshraf, Mamlūk sultan (grandson of al-Nāșir Muhammad b. Kalāwūn [q.v.]), who succeeded his cousin, al-Manșūr Muhammad, when the latter was deposed on 15 Shacbān 764/3o May 1363. Owing to Shacbān's youth (he was born in 754/1353-1354), a series of high Mamlūk amīrs held power in the early years of his reign. Yalbughā al-'Umarī [al-Ḳhāșșakī] and Ṭaybughā al-Ṭawīl, originally Mamlūks of al-Nāṣir Ḥasan [q.v.], at first shared the regency, until Ṭaybughā was ousted in Djumādā II 767/March 1366, when Yalbughā assumed sole power. In the meantime, a Crusading expedition under King Peter I of Cyprus briefly occupied des Dokuments am 23. August desselben Jahres abgeschlossen. So blieben Yalbugàa doch noch drei Monate Zeit, um sich des Anblicks der fertigen Rolle zu erfreuen.

Es fällt auch auf, dass Kaḩtāwīs Ergänzung des Dokuments aus dem Jahr 1366 (2. Durchgang) einen viel individuelleren Charakter aufweist als Teil I. In diesem zweiten Abschnitt lassen sich die acht Hiğāb-Gebete nachweisen, die Muhammad, den drei ersten rechtgeleiteten Kalifen (Abū Bakr, 'Umar, 'Uțmān), 'Alī b. Abī Ṭālib (4. rechtgeleiteter Kalif und 1. Imam der Schiiten), Hasan, Ḥusayn und Ğacfar aṣ-Ṣādiq (2., 3. und 6. Imam der Schiiten) gewidmet sind. Diese Zusammenstellung kombiniert aus der Sunna bzw. aus der Schia bekannte Personen mit einer Selbstverständlichkeit, wie sie zu jener Zeit in Futuwwa-Kreisen oder mystisch orientierten Gruppierungen weit verbreitet war. Sie steht auch für jenes Phänomen, das M.G.S. Hodgson als Alid loyalty bezeichnet hatte und im 14. Jh. in der islamischen Welt weit verbreitet war. ${ }^{336}$

Bezüge zu mystisch orientierten Gruppierungen (țariqa, futuwwa), werden bei diesem Exemplar auch in Betracht gezogen, da es an zwei Stellen auffällig lange Wiederholungen von Q 112 (Sūrat al-Ihlāṣs) enthält. Diese Wiederholungen rufen die von Mystikern gepflegten Dikr-Übungen in Erinnerung. ${ }^{337}$ Auch sei daran erinnert, dass der erste Teil der Rolle eine zwar nicht vollständige, aber doch sehr umfassende Abschrift von Stellen aus dem Koran enthält und am Schluss als hatma bezeich-

Alexandria (Muharram 767 / October 1365), but withdrew as Yalbughà and the sultan advanced to relieve the city. The regent thereupon set on foot the construction of a war-fleet for, he asserted, a counter-offensive. An appeal from the king of Dongola [q.v.] for aid against his usurping nephew led to the organisation of an expeditionary force (Rabī' I 767/December 1365), and action against Arab tribesmen who were ravaging the Aswān frontier-region. In Rabīi II 768/December 1366 Shacbān, resenting Yalbughā's domination, colluded with the regent's mutinous Mamlūks to overthrow him.“ Vgl. Kapitel 3.3: „Alid loyalty“.

337 Vgl. dazu Kapitel 3.4.2. 
net wird. ${ }^{338}$ Der Begriff hatma dient zur Bezeichnung einer in der Regel vollständigen Rezitation des Korans. Er unterstreicht die auditive Dimension dieser Dokumente in Rollenform. Er erinnert an jene Gesänge frommer Texte, die die Angehörigen von Männerbünden mutmasslich bei ihren Zusammenkünften gepflegt hatten.

In diesem zweiten Abschnitt der Rolle fallen sodann die sieben Zellenquadrate (wafq) auf, die den einzelnen Planeten gewidmet sind. Man ist versucht, darin eine Reminiszenz an eine früher gerade auch im Nahen Osten gepflegte Verehrung der Planetengottheiten zu sehen. Auch die Sabäer von Harrān verehrten diese Planeten in ihrem Kult. Šahrastānī bezeichnet eine Untergruppe dieser Sabäer von Ḥarrān als Așhāb al-Hayākil, „die Leute der Tempel“. Diese Bezeichnung ruft zwei weitere Belegstücke aus jener Zeit in Erinnerung (Kopenhagen Cod. Arab. 53, Basel M III 173), ${ }^{339}$ auf denen sich ebenso ein siebenteiliges Gebet nachweisen lässt. Seine einzelnen Abschnitte werden als haykal bezeichnet. Auf dem vorliegenden Belegstück (Is 1624) werden diese sieben den Planeten gewidmeten Abschnitte allerdings nicht als haykal, sondern als wafq (Zellenquadrate) bezeichnet. Diese Quadrate enthalten auch Zahlen und keinen Gebetstext, wie dies auf den beiden soeben angeführten Parallelstücken der Fall ist. Dennoch lassen sich innere Abhängigkeiten zwischen den angeführten Exemplaren nicht in Abrede stellen.

Von Bedeutung ist auch, dass sich bereits auf dem vorliegenden Belegstück eine Technik beobachten lässt, die später - ab dem 16. Jh. - in persischen und persisch beeinflussten Kontexten zur Vollendung gebracht wird. Es handelt sich darum, auf dem Hintergrund in $\dot{G} u b \bar{a} r$-Schrift Stellen derart auszusparen, dass ein übergeordneter Text entsteht. Die Tatsache, dass sich dieselbe Technik 200 oder 300 Jahre später weiterhin, allerdings besser ausgebildet, nachweisen lässt, unterstreicht, dass sich die vorliegend untersuchten Dokumente

338 Vgl. bei Anm. 212.

339 Vgl. Kapitel 4.4 (bei und mit Anm. 82-89) und Kapitel 4.8 (bei Anm. 471-472). in eine längerfristige Entwicklung einordnen lassen. Die verschiedenen Exemplare dürften auch in Umfeldern entstanden sein, in denen ähnliche Grundauffassungen geteilt wurden.

Auf diesem Dokument lassen sich ganz vereinzelt auch Elemente feststellen, wie sie auch aus der islamischen Magie im engeren Sinn bekannt sind. ${ }^{340}$ Sie nehmen allerdings eine derart untergeordnete Stellung ein, dass es nicht angezeigt ist, das Belegstück Is 1624 als Ganzes aus der islamischen Magie heraus zu erklären. Auch fällt auf, dass der Schreiber im zweiten Durchgang, also gut versteckt am Schluss bzw. im Innern der Rolle, mehrfach Elemente kopiert hat, die seine individuelle Haltung zum Ausdruck bringen. Im ersten Teil des Dokuments dominierte jedoch die Abschrift des Korans (hatma), die durch einige Gebete ergänzt wurde. Der Schreiber entfernt sich am Schluss des Dokuments in seinem persönlich geprägten Nachtrag deutlicher von Positionen, die sich problemlos mit dem normativen Islam in Verbindung bringen lassen. In diesem Schlussteil lässt sich mehrfach eine heterodox gefärbte Einstellung des Kopisten erkennen.
340 Vgl. dazu bei Anm. 140 und Abschnitt II.3.4 (4. Mandorla), nach Anm. 319 (arabischer Text). 

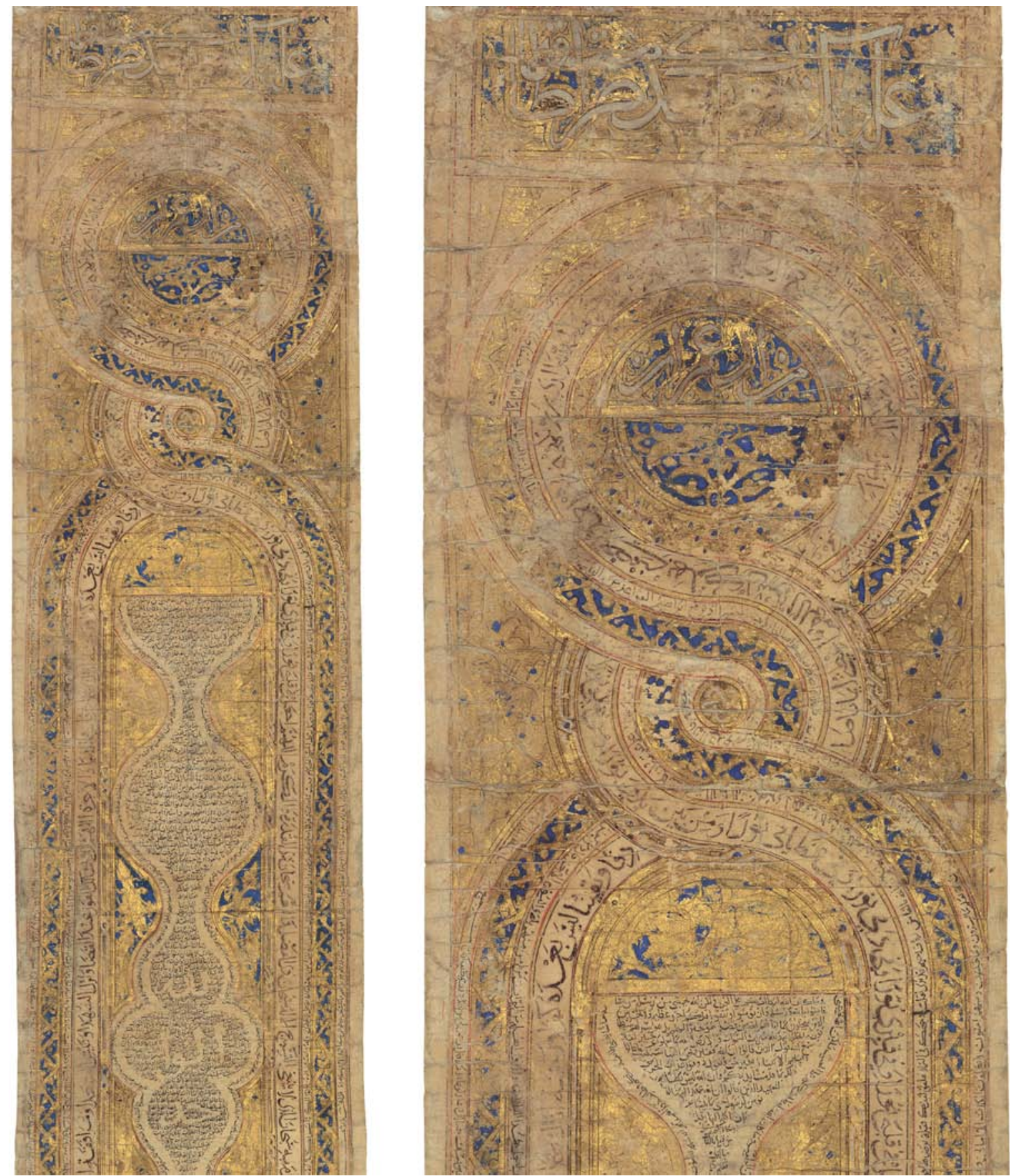

ABB. 35

Dublin, Chester Beatty Library, Is 1624 (vgl. bei Anm. 20-31): Beginn des erhaltenen Teils der Rolle. Im horizontalen Textbalken am Anfang lassen sich Teile von Q 48:1-2 erkennen. Im breiten Textband um die Figuren herum steht ein Gebet (vgl. nach Anm. 35). In den beiden schmalen Textbändern steht Text aus dem Koran. Dies ist ebenso in der Figur mit Text in $\dot{G} u b \bar{a} r$-Schrift auf horizontalen Zeilen der Fall, wo am Anfang Text aus Q 3:179 steht. (C) THE TRUSTEES OF THE CHESTER BEATTY LIBRARY, DUBLIN (CHESTER BEATTY, DUBLIN. CC BY-NC 4.0) 


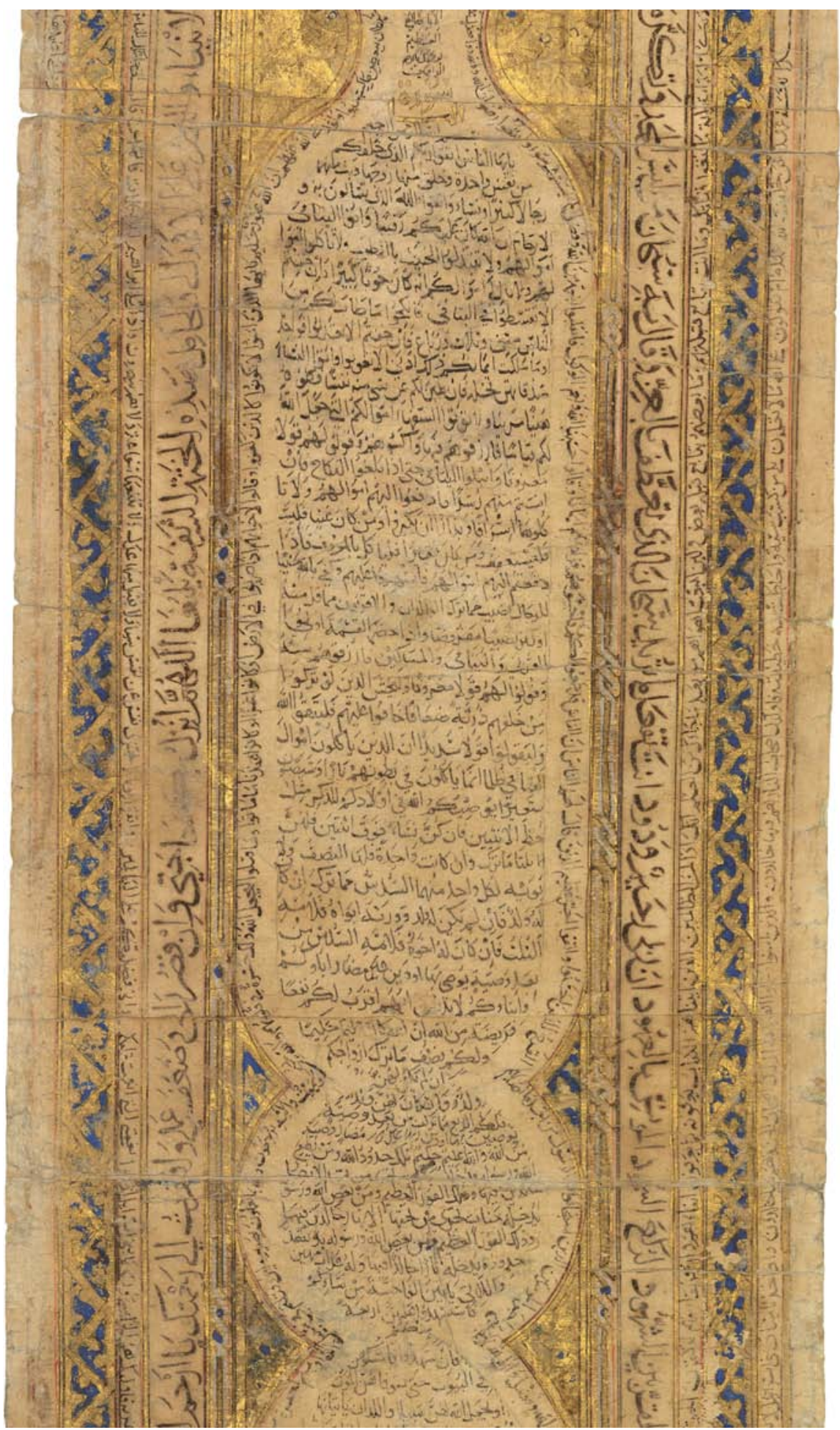

ABB. 36

Dublin, Chester Beatty Library, Is 1624 (vgl. bei Anm. 37): Im breiten Textband links lässt sich der Name Yalbugāa erkennen. Es ist der Name des ersten Besitzers der Rolle.

(C) THE TRUSTEES OF THE CHESTER BEATTY LIBRARY, DUBLIN (CHESTER BEATTY, DUBLIN. CC BY-NC 4.0) 


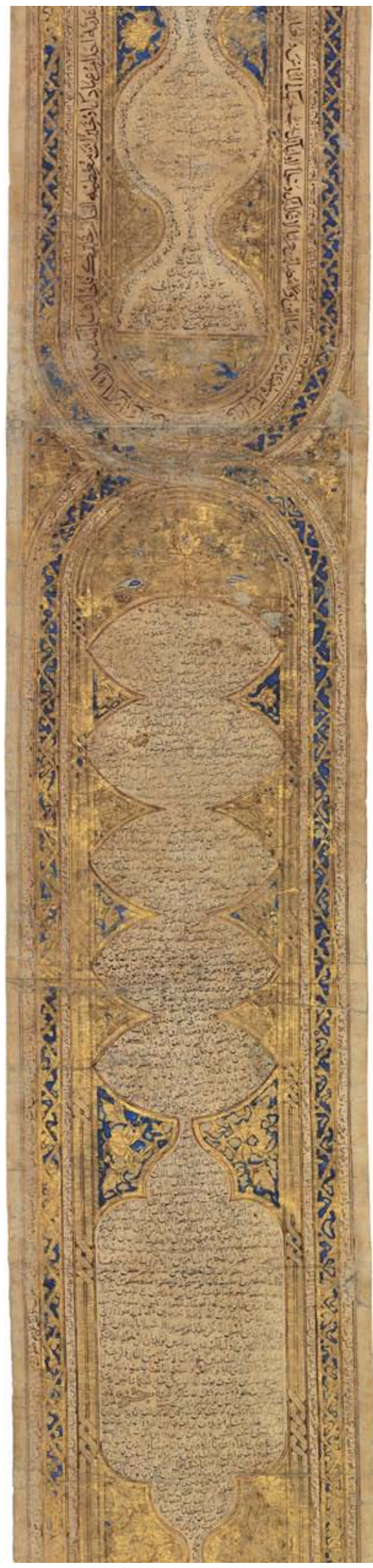

ABB. 37

Dublin, Chester Beatty Library, Is 1624 (vgl. bei Anm. 63): Beginn eines an beiden Enden abgerundeten Rechtecks (Länge ca. $56.0 \mathrm{~cm}$ ). Am Anfang lässt sich eine Abfolge von fünf horizontal ausgerichteten, mandelförmigen Figuren erkennen. Auf der ersten Zeile steht der Übergang Q 4:105-106.

(C) THE TRUSTEES OF THE CHESTER BEATTY LIBRARY, DUBLIN (CHESTER BEATTY, DUBLIN. CC BY-NC 4.0) 


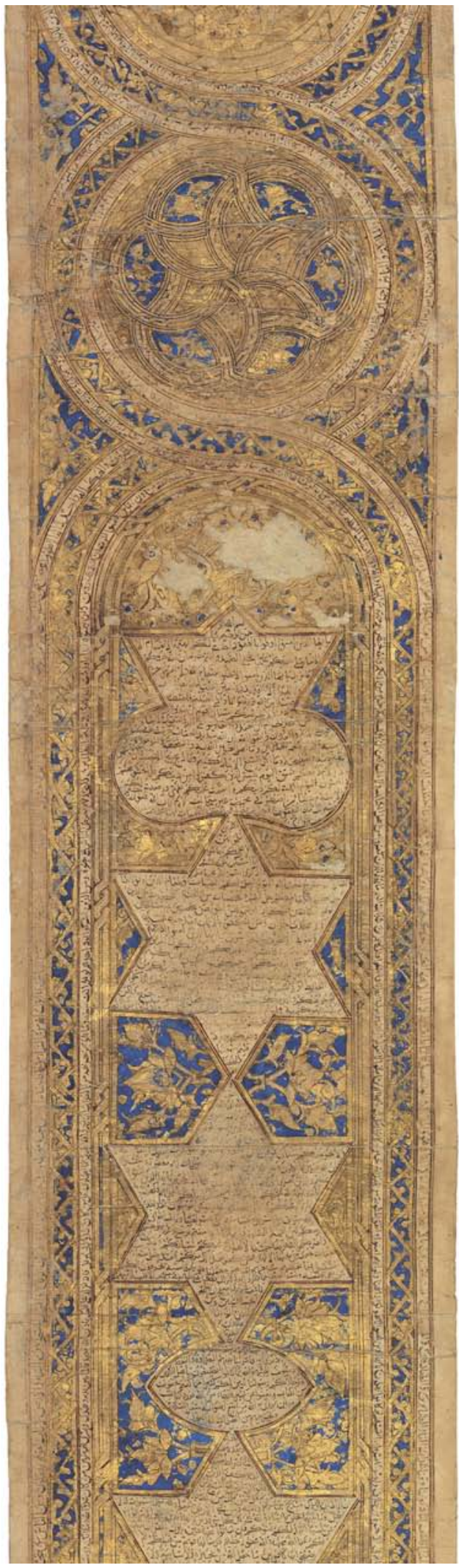

ABB. 38

Dublin, Chester Beatty Library, Is 1624 (vgl. bei Anm. 67): Beginn eines Abschnitts von ca. $100 \mathrm{~cm}$ Länge. Am Anfang ein Medaillon, das die ganze Breite der Rolle ausfüllt. Darunter beginnt ein an beiden Enden abgerundetes Rechteck. In der ersten Figur im Mittelstreifen steht in $\dot{G} u b \bar{a} r$-Schrift der Beginn von Q 5. Der Titel im Zierfeld darüber ist jetzt stark verderbt ( $a$ l-Mẩida). Man beachte auch die Ausführungen zu den Figuren in diesem Mittelstreifen in und bei Anm. 72.

(C) THE TRUSTEES OF THE CHESTER BEATTY LIBRARY, DUBLIN (CHESTER BEATTY, DUBLIN. CC BY-NC 4.0) 


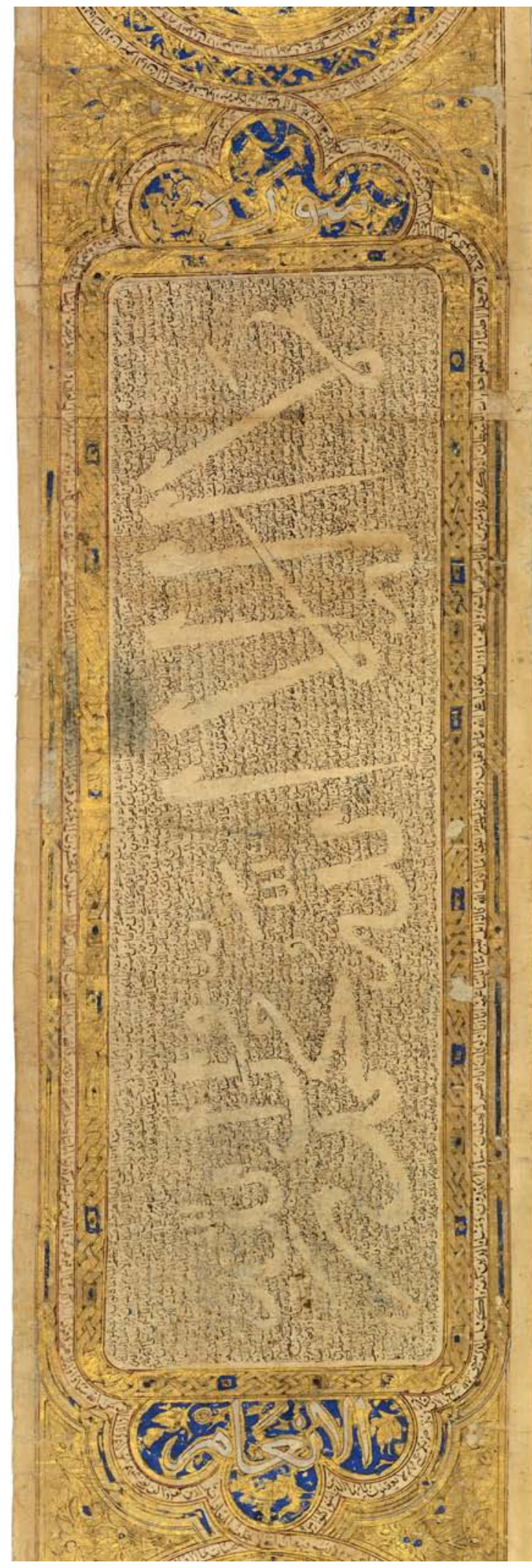

ABB. 39

Dublin, Chester Beatty Library, Is 1624 (vgl. bei Anm. 7376): Rechteck von ca. $32 \mathrm{~cm}$ Länge. Im Rechteck steht in Gubār-Schrift Q 6:1-111. Der Text wurde auf 33 Zeilen in Rollenrichtung kopiert (Breite des Rechtecks: 7.2 cm). Der Schreiber hat auf diesem $\dot{g} u b \bar{a} r$-farbenen Hintergrund Freiräume derart ausgespart, dass die šahāda entsteht ( $L \bar{a}$ ilāha illā Allāh, Muḥammad rasūl Allāh).

(C) THE TRUSTEES OF THE CHESTER BEATTY LIBRARY, DUBLIN (CHESTER BEATTY, DUBLIN. CC BY-NC 4.0) 


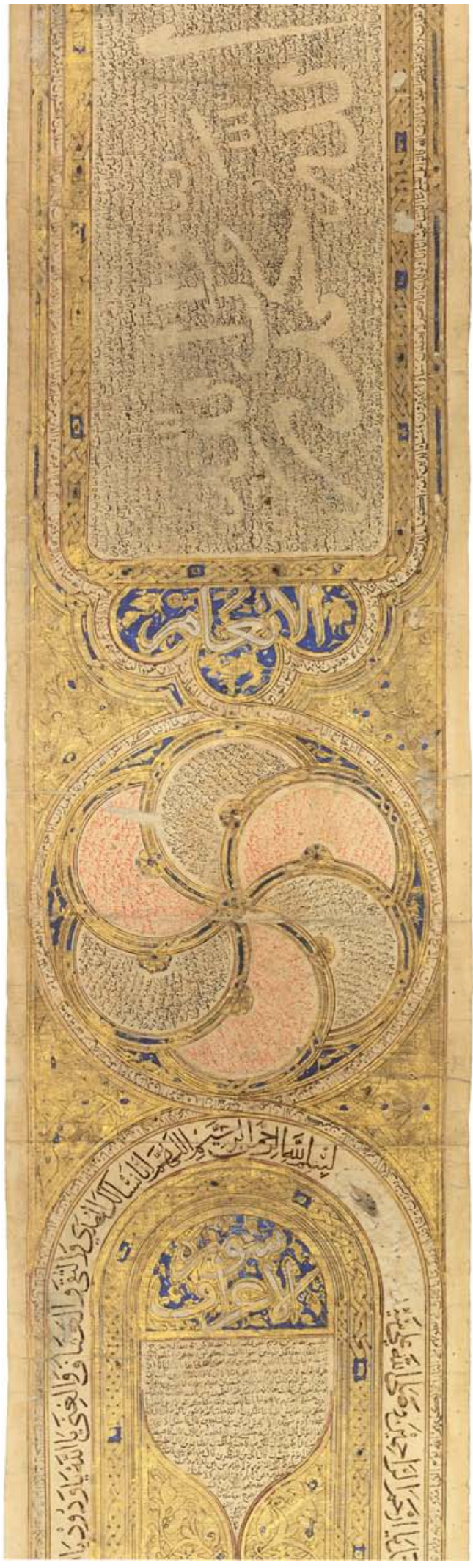

ABB. 40

Dublin, Chester Beatty Library, Is 1624 (vgl. bei Anm. 77):

Sechsfächriger Sonnenwirbel mit der Fortsetzung von Q 6 (Verse 111165). Eine ähnliche Verzierung lässt sich im Schrein von Šāh Ni‘matullāh in Māhān (bei Kirman, Iran) nachweisen. (C) THE TRUSTEES OF THE CHESTER BEATTY LIBRARY, DUBLIN (CHESTER BEATTY, DUBLIN. CC BY-NC 4.0) 


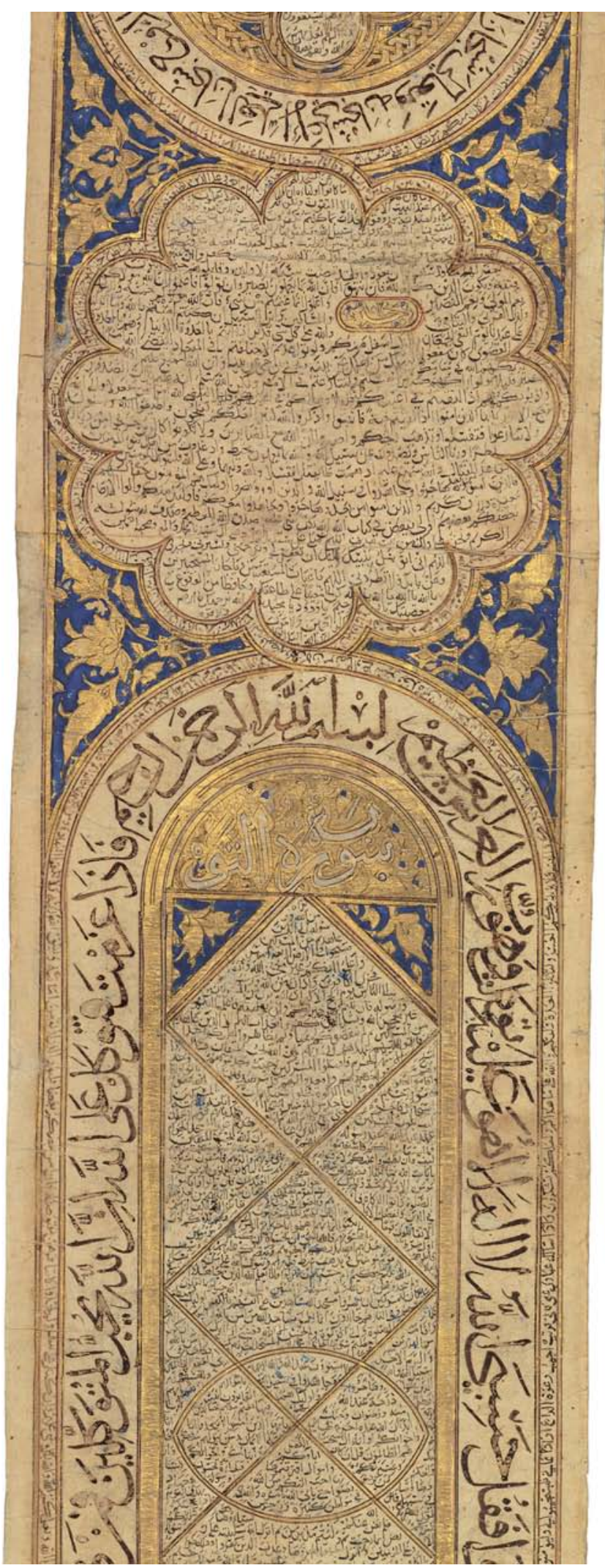

ABB. 41

Dublin, Chester Beatty Library, Is 1624 (vgl. bei Anm. 95-108): Beginn eines Abschnitts mit einem zwölflappigen Medaillon und einem an beiden Enden abgerundeten Rechteck. Im Mittelstreifen des Rechtecks wurden Q 9-11 kopiert. Ganz am Anfang steht in $\dot{G} u b \bar{a} r$-Schrift Q 9:1. Im Titelfeld darüber steht in weisser Schrift auf weissem Grund: Min Sūrat at-Tawba [ilā Sūrat Hūd, dies als Unterschrift]. Im breiten Textband steht ein Gebet, das das Konzept des tawakkul thematisiert.

(C) THE TRUSTEES OF THE CHESTER BEATTY LIBRARY, DUBLIN (CHESTER BEATTY, DUBLIN. CC BY-NC 4.0) 


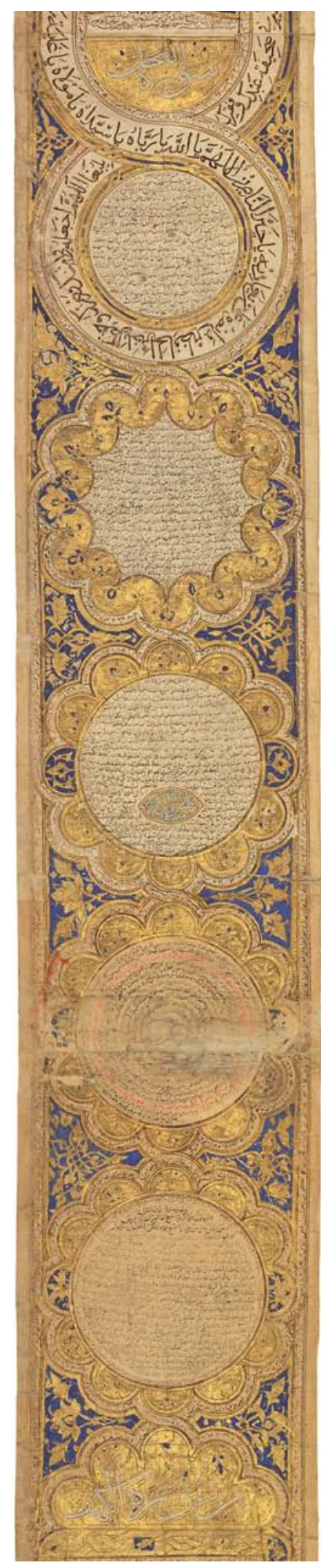

ABB. 42

Dublin, Chester Beatty Library, Is 1624 (vgl. nach Anm. 120, Buchstaben A und nach Anm. 121): Abschnitt mit fünf Medaillons

(C) THE TRUStees of THE CHESTER BEATTy Library, DUblin (CHESTER BeAtTy, DUBLIN. CC BY-NC 4.0) 


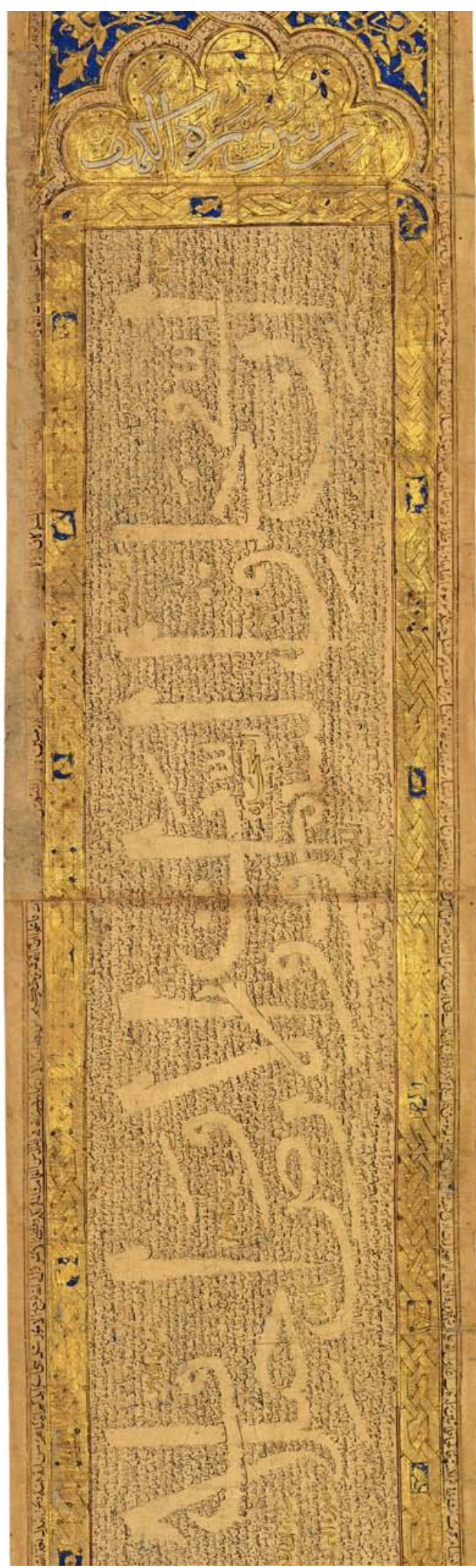

ABB. 43

Dublin, Chester Beatty Library, Is 1624 (vgl. nach Anm. 120, Buchstaben B und nach Anm. 129): Abschnitt von ca. $120 \mathrm{~cm}$ Länge. Der Text in $\dot{G} u b \bar{a} r$-Schrift wurde in Rollenrichtung auf 35 Zeilen kopiert (Breite des Schriftspiegels: ca. 7.5 cm). Der Schreiber kopierte hier in $\dot{G} u b \bar{a} r$-Schrift Q 18-49. Auf diesem $\dot{g} u b \bar{r} r$-farbenen Hintergrund entsteht durch das Aussparen von enstprechenden Freiräumen der Text von Q 3:19o-191.

(C) THE TRUSTEES OF THE CHESTER BEATTY LIBRARY, DUBLIN (CHESTER BEATTY, DUBLIN. CC BY-NC 4.0) 


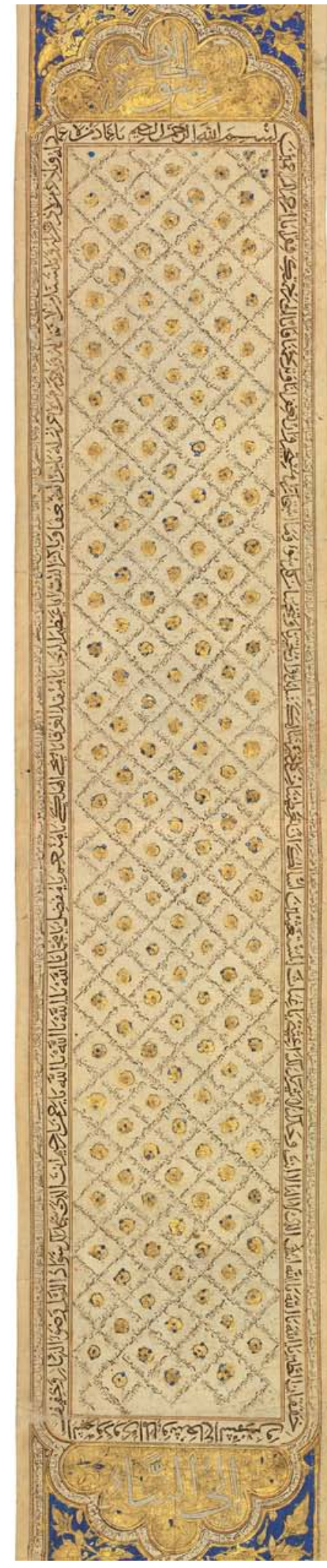

ABB. 44

Dublin, Chester Beatty Library, Is 1624 (vgl. nach Anm. 165): Abschnitt mit einem Rechteck von ca. $55 \mathrm{~cm}$ Länge, in dem Korantext in $\dot{G} u b \bar{a} r$-Schrift entlang den Stäben eines Gitters kopiert worden ist. Gemäss Über- bzw. Unterschrift (weisse Schrift auf goldenem Hintergrund) wurden hier Q 69-78 kopiert. Überprüfungen ergaben, dass der Schreiber verschiedentlich Stellen ausliess. Im breiten Schriftband steht ein Gebet.

(C) THE TRUSTEES OF THE CHESTER BEATTY LIBRARY, DUBLIN (CHESTER BEATTY, DUBLIN. CC BY-NC 4.0) 


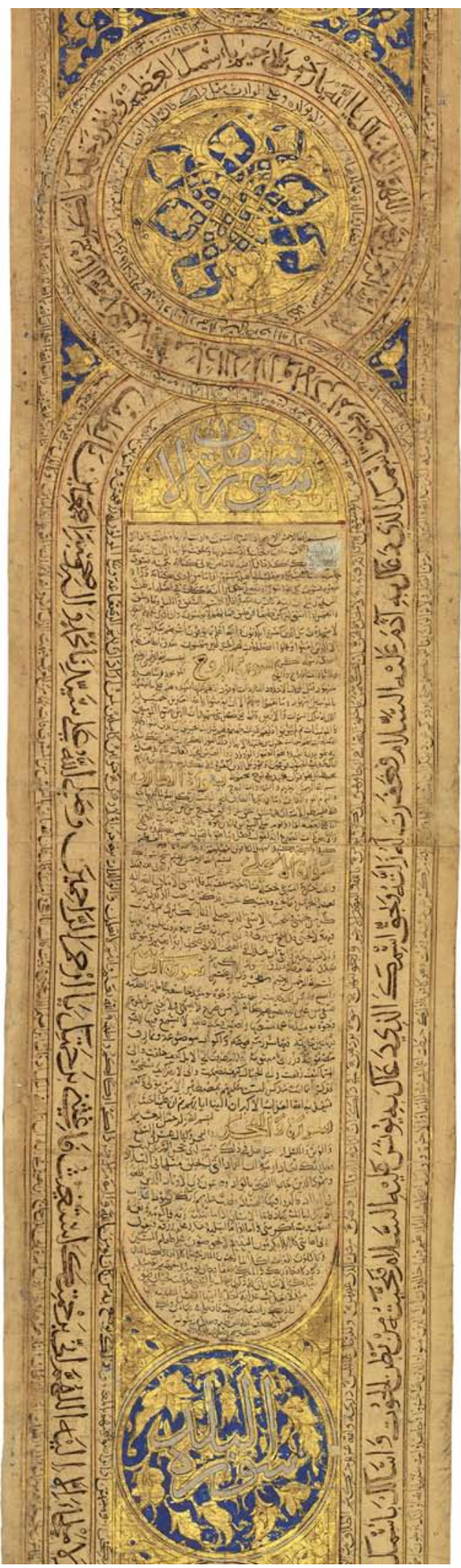

ABB. 45

Dublin, Chester Beatty Library, Is 1624 (vgl. nach Anm. 176 und 183): Beginn des letzten Abschnitts, in dessen Mittelstreifen Korantext kopiert worden ist (Q 84-114). Im breiten Textband steht ein Gebet (vgl. bei Anm. 183).

(C) THE TRUSTEES OF THE CHESTER BEATTY LIBRARY, DUBLIN (CHESTER BEATTY, DUBLIN. CC BY-NC 4.0) 

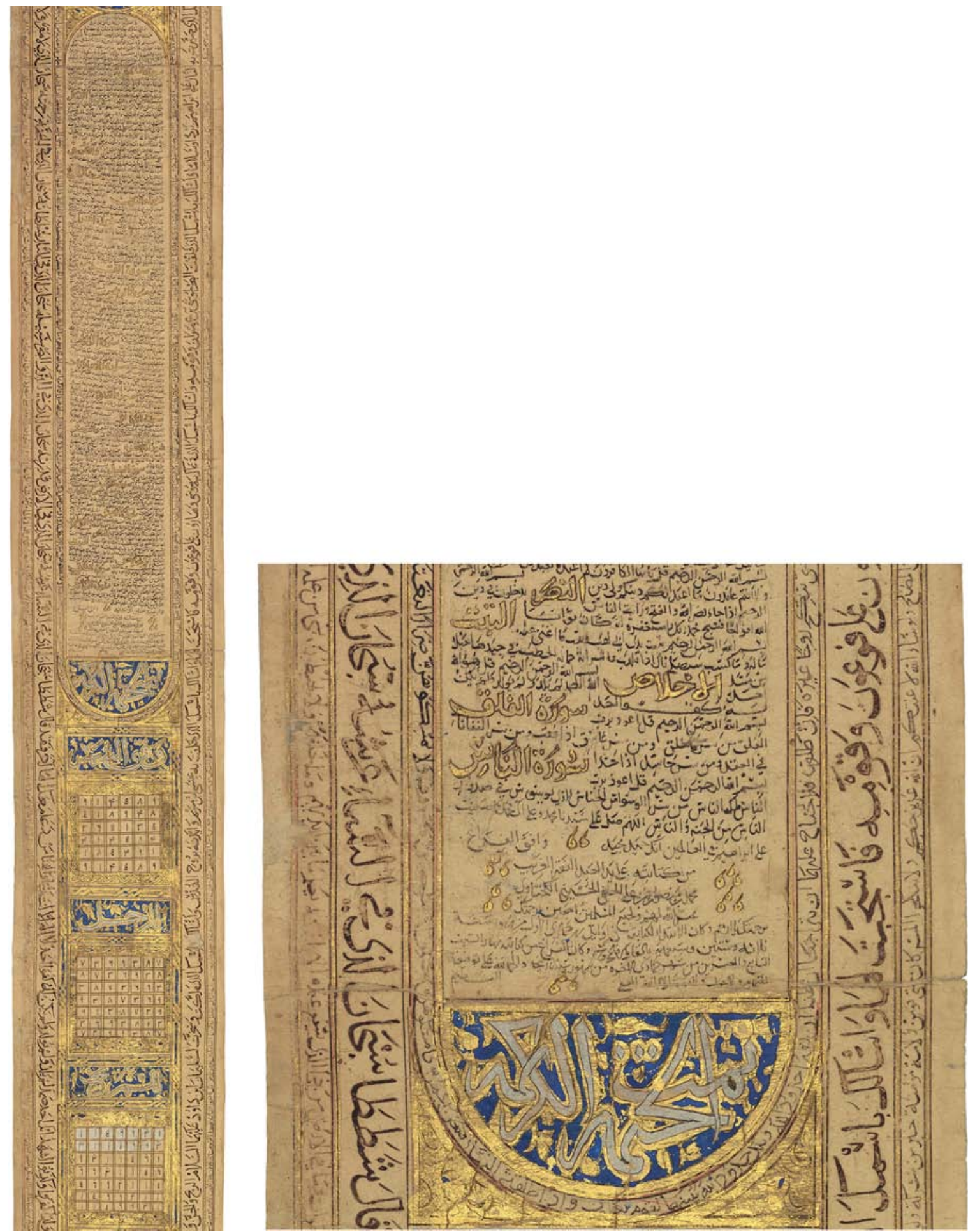

ABB. 46

Dublin, Chester Beatty Library, Is 1624 (vgl. bei Anm. 9, 179 und 211): Abschluss von Teil I bzw.

Beginn von Teil II der Rolle (links). Am Ende von Teil I steht auch der Kolophon dazu (rechts). (C) THE TRUSTEes of THE CHESTER BEATTy LibRARY, DUblin (CHESTER BEATTy, DUBLIN. CC BY-NC 4.0) 


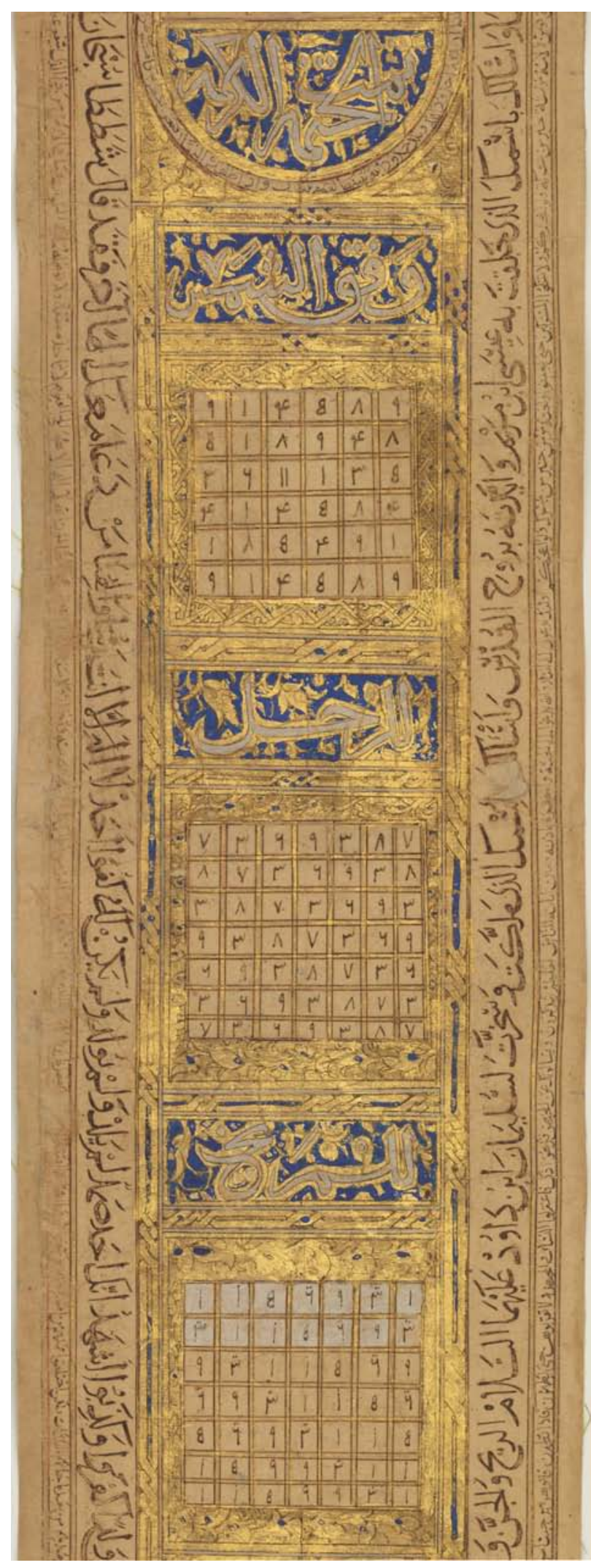

ABB. 47

Dublin, Chester Beatty Library, Is 1624 (vgl. nach Anm. 214): Teil II der Rolle enthält individuellere Elemente. Hier beginnt ein Abschnitt mit insgesamt 7 Zellenquadraten, die den einzelnen Planeten zugeordnet werden.

(C) THE TRUSTEES OF THE CHESTER BEATTY LIBRARY, DUBLIN (CHESTER BEATTY, DUBLIN. CC BY-NC 4.0) 


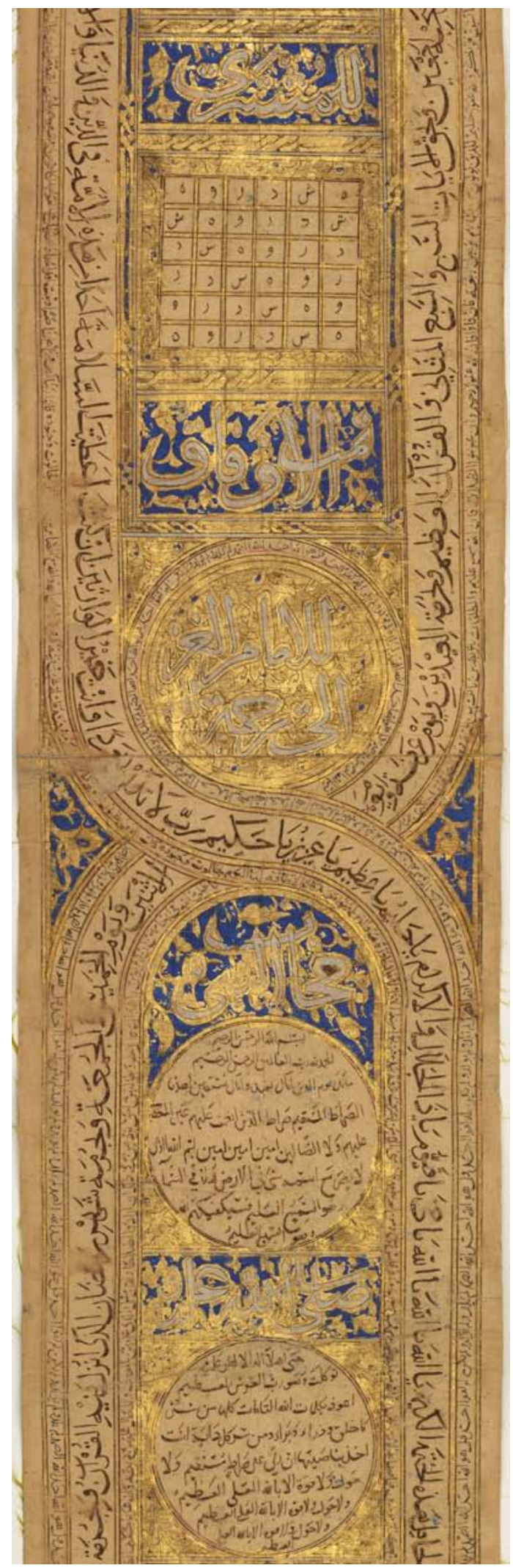

ABB. 48

Dublin, Chester Beatty Library, Is 1624: Schluss des Abschnitts mit den Zellenquadraten, die den sieben Planeten zugeordnet sind. Im goldenen Medaillon steht Li-l-imām al-Ġazzāli rahma (vgl. bei Anm. 182 und 214-222). Danach folgt im Mittelstreifen ein Abschnitt mit einem Schutzgebet, das an den Propheten Muhammad appelliert (Hiğāb an-nabī; vgl. nach Anm. 226). Beim Text in grosser Schrift im Seitenband handelt es sich um ein Gebet.

(C) THE TRUSTEES OF THE CHESTER BEATTY LibRARY, DUBLIN (CHESTER BEATTY, DUBLIN. CC BY-NC 4.0) 


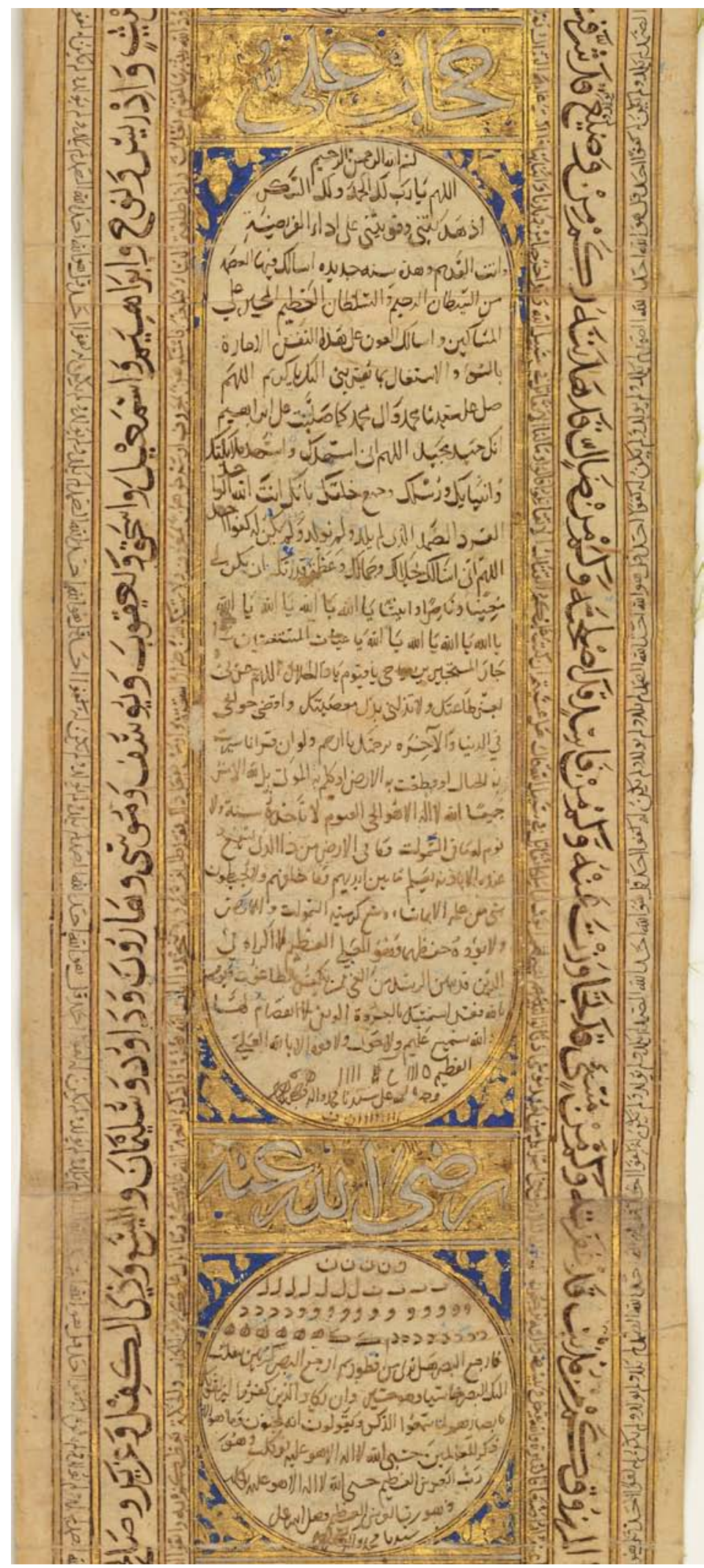

ABB. 49

Dublin, Chester Beatty Library, Is 1624 (vgl. nach Anm. 26o): Abschnitt mit einem Schutzgebet, das an 'Alī b. Abī Tālib appelliert (Hiǧāb 'Alī). Man beachte die Abfolge von Zeichen am Ende des abgerundeten Rechtecks.

(C) THE TRUSTEES OF THE CHESTER BEATTY LIBRARY, DUBLIN (CHESTER BEATTY, DUBLIN. CC BY-NC 4.0) 


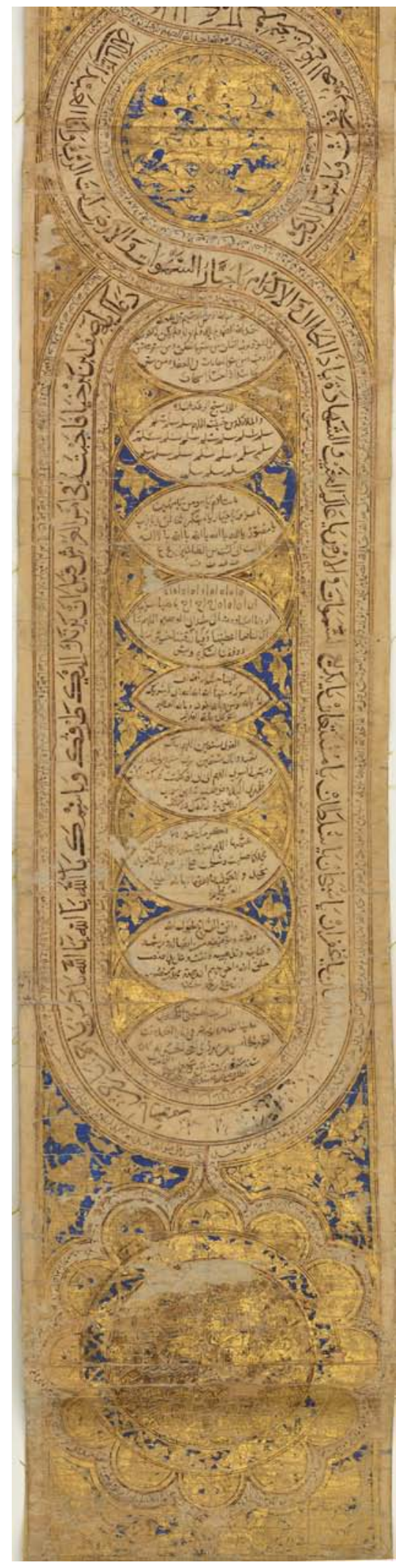

ABB. 50

Dublin, Chester Beatty Library, Is 1624 (vgl. nach Anm. 305): Das letzte an beiden Enden abgerundete Rechteck auf der Rolle. In den beiden letzten horizontal ausgerichteten Figuren am Schluss steht der Kolophon zu Teil II der Rolle. Beim Text im breiten Schriftband handelt es sich um das Gebet, das schon in Teil I beginnt. Im äussersten Schriftband wiederholt der Schreiber Q 112 in $\dot{G} u b \bar{a} r$-Schrift.

(C) THE TRUSTEES OF THE CHESTER BEATTY LIBRARY, DUBLIN (CHESTER BEATTY, DUBLIN. CC BY-NC 4.0) 


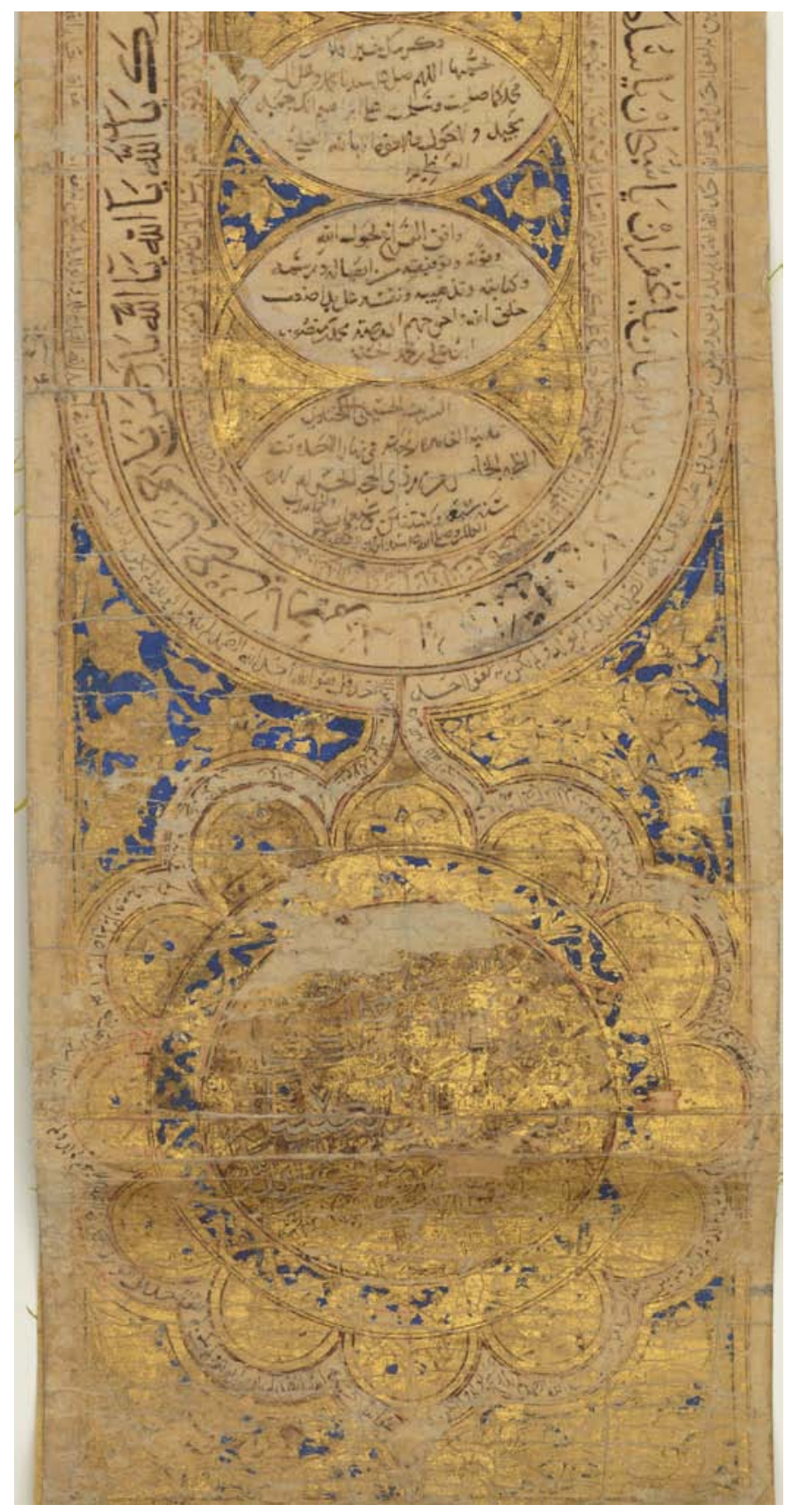

ABB. 51

Dublin, Chester Beatty Library, Is 1624 (vgl. bei Anm. 10 und nach Anm. 320): Letztes Medaillon ganz am Schluss der Rolle. Es wird vom Schriftband umfahren, in dem der Schreiber Q 112 (Sūrat al-Ihlāṣ) wiederholt. Im Innern des Medaillons Text in weisser Schrift auf goldenem Hintergrund. Dieser Text ist derart stark verderbt, dass er sich nicht sinnvoll entschlüsseln liess. Oberhalb dieses Medaillons zwei mandelförmige Elemente, die den Kolophon zu Teil II enthalten. (C) THE TRUSTEES OF THE CHESTER BEATTY LIBRARY, DUBLIN (CHESTER BEATTY, DUBLIN. CC BY-NC 4.0) 


\subsection{Dublin, Chester Beatty Library, Is 1625}

Masse $\quad 10.5 \times 1128 \mathrm{~cm} \quad(11.28 \mathrm{~m} ; \quad$ Bibliotheksmessung). ${ }^{1}$ Das Dokument ist fragmentarisch erhalten; Anfang fehlt: Q 1 und ein grosser Teil von Q 2 sind nicht mehr vorhanden. Am Anfang wurde ausserdem ein Teil (Länge: $9.0 \mathrm{~cm}$ ) abgetrennt; er enthält den Text unmittelbar vor dem Rest der Rolle. Ausserdem fehlt auf dem Dokument Q 48.2 Auch bei Q 37 lassen sich Unregelmässigkeiten feststellen. ${ }^{3}$ Abschrift des Korans mit zahlreichen Stellen in unterschiedlichen Zierschriften.

Im Gegensatz zu den weiteren, in diesem Kapitel untersuchten Rollen weist das vorliegende Belegstück keine Medaillons oder Knoten auf, die von einem Schriftband umfahren werden. Auch

1 Dieses Belegstück wurde am Original untersucht. Für die Beschreibung des Dokuments stand Abbildungsmaterial zur Verfügung, das von der Chester Beatty Library 2014 angefertigt worden ist. Es ist aber unvollständig. Zusätzliche eigene Photos füllen die entsprechenden Lücken; die Rolle war somit vollständig dokumentiert. Die Chester Beatty Library erstellte jeweils zwei Abbildungen pro Meter; die eigenen Photos ordnen sich in diese Zählung ergänzend ein. Die folgenden Angaben gestatten eine grobe Zuordnung der einzelnen Photos zu den entsprechenden Stellen auf dem Dokument. Bei den Angaben werden die Photos mit Dezimalstellen numeriert (z.B. 6.1, 6.2, 6.3); diese Aufnahmen beziehen sich auf den 6. (sechsten) Meter der Rolle. 6.1 bezeichnet die von der Chester Beatty angefertigten Abbildungen; 6.2-x bezieht sich auf eigenes Abbildungsmaterial. Folgende Übersicht gestattet eine Zuordnung zu den einzelnen Abschnitten der Rolle: o-1 Meter: Photos 1 und 2; 1-2 Meter: Photos 3 und 4; 23 Meter: Photos 5 und 6; 3-4 Meter: Photos 7 und 8; 4-5 Meter: Photos 9 und 10; 5-6 Meter: Photos 11 und 12; 6-7 Meter: Photos 13 und 14; 7-8 Meter: Photos 15 und 16; 89 Meter: Photos 17 und 18; 9-10 Meter: Photos 19 und 20; 10-11 Meter: Photos 21 und 22; am Schluss $28 \mathrm{~cm}$ : Photo 23.

N.B.: Die Chester Beatty Library erstellte die im Abbildungsteil verwendeten Digitalisate der vollständigen Rolle erst 2019, als die vorliegende Untersuchung abgeschlossen war. Die hier in den Anmerkungen aufgeführten Stellenverweise beziehen sich auf im Lauf der Arbeit an diesem Belegstück in den Jahren 2014-2015 gemachte Aufnahmen; sie genügen professionellen Ansprüchen nicht (vgl. auch Einleitung zu Teil II, bei und mit Anm. 10).

2 Vgl. dazu unten bei Anm. 105-108.

3 Vgl. dazu ausführlicher unten bei Anm. 94-97. dieses Dokument wird aber auf seiner gesamten Länge von einem Schriftband eingefasst; seine Breite beträgt knapp $1.5 \mathrm{~cm}$. Auch am Schluss wird die Rolle durch dieses Schriftband abgeschlossen. Da der ursprüngliche Anfang des Belegstücks fehlt, muss dessen Gestaltung offen bleiben. Beim Beschreibstoff handelt es sich um starkes Papier, das auf ein grünes textiles Gewebe aufgezogen worden ist.

Das vorliegende Belegstück ist nicht datiert; es dürfte mit grosser Wahrscheinlichkeit aus dem 14. Jh. (Ende) stammen. Die von A.J. Arberry mit der Beschreibung des Dokuments im Abschnitt mit den mamlukischen Dokumenten zumindest suggerierte Einordnung in diesen zeitlichen und geographischen Kontext wird hier nicht übernommen. ${ }^{4}$ Auf diesem Exemplar lassen sich mehrfach Gestaltungsmittel feststellen, die ansonsten aus Zentralasien bekannt sind. Diese geographische Zuordnung stützt sich u. a. auf Abschnitte in Zierschrift, auf denen die Buchstaben durch mehrere parallele Linien gebildet werden (АВ В. 53, 57, 62 und 64). Ein vergleichbares Vorgehen lässt sich auf der Innenseite des Eingangs zum Āq SarāyPalast in Šahr-i Sabz (Usbekistan) beobachten, dessen Bau von Timur (reg. 1370-1405) 1380 angeordnet worden war. ${ }^{5}$ Auch lassen sich einzelne Stellen in geometrisierendem Kūfî feststellen. ${ }^{6}$ Die Gestaltung ganzer Gebäudefassaden in Schachbrett-Kūfī ist im 14. Jh. gerade in Zentralasien und Iran gut belegt. ${ }^{7}$

4 Vgl. die kurze Beschreibung in Arberry, Koran illuminated 30 (Nr. 98, mit Abb. auf Tafel 42).

5 Beachte dazu Abb. 1.1, 6.1 und 12.4 der Rolle. Man vergleiche dies mit den Abbildungen vom Āq Sarāy-Palast in Šahr-i Sabz unter http://archnet.org/sites/2481/media _contents/1573 (Stand 29. September 2016). Vgl. zu diesen kunsthistorischen Vergleichen auch Anm. 14 und bei Anm. 61.

6 Vgl. Abb. 13.1.

7 Vgl. 1. Qāḍīzāda-Rūmī-Mausoleum in Samarkand (errichtet um 1425): https://archnet.org/sites/2911 und https:// archnet.org/sites/2911/media_contents/149o

(Stand 29. September 2017). 2. Mīr Čāqmāq-Moschee in Yazd: Golombek und Wilber, Timurid architecture I, 421423 (Nr. 226A, R. Holod) und II, Abb. 450-46o, v.a. Abb. 45o, Pläne $145^{-147}$; 3. Ardabil, Grabturm Šayh Șafĩ ud-Dīns 
Auf den beiden Schriftbändern (АВ B. 52) auf der linken und rechten Seite des Dokuments wird Q 112 (Sūrat al-Ihlās ) wiederholt. Der Text wurde auf beiden Seiten in absteigender Richtung kopiert. Die Abschriften von Q 112 verlaufen dabei links und rechts nur am Anfang nahezu parallel zueinander. Je weiter sich der Kopist vom Anfang der Rolle entfernt, desto grösser werden die Abweichungen. ${ }^{8}$ Diese beiden Bänder sind je ca. $1.5 \mathrm{~cm}$ breit. Der Text von Q 112 wurde in grossem goldenem Nash kopiert. Die Leerräume zwischen den Wörtern und den Rändern des Schriftbands wurden mit goldenen Bändern ausgefüllt. Die Abschrift von Q 112 ist jeweils etwa $25 \mathrm{~cm}$ lang; danach wird der Text einfach wiederholt. Tropfenförmige, golden eingefasste Trennzeichen mit blauem Hintergrund und einem Punkt in der Mitte markieren Anfang und Ende der einzelnen Einheiten.

Diese beiden seitlichen Schriftbänder mit Q 112 fassen einen Mittelstreifen ein, dessen Breite ca. $7 \cdot 3 \mathrm{~cm}$ beträgt. Darin ist auf horizontalen Linien $^{9}$ der Text des Korans in zumeist schwarzem $\dot{G} u b \overline{a r}$ kopiert worden. Horizontal angeordnete Titelbalken enthalten die Überschriften der einzelnen Suren. Auf dem Hintergrund mit dem mikroskopischen Text sind einzelne Sätze in unterschiedlichen Zierschriften notiert worden. Sie werden in den weiteren Ausführungen vorgestellt.

Im ersten Titelbalken (АВB. $\left.\mathbf{5}^{\mathbf{2}-\mathbf{5 3}}\right)^{10}$ (Höhe $3 \mathrm{~cm}$ ) lässt sich in goldener Schrift (stilisiertes $K \bar{u} f \bar{\imath})$ in einer blauen, mit vereinzelten Blüten ausgefüllten federkastenförmigen ${ }^{11}$ Kartusche der

(errichtet 1345, also vor den Timuriden): https://archnet .org/sites/1595/media_contents/40812 (Stand 29. September 2017). Siehe dazu auch Kapitel 4.9 (Anm. 6).

8 Zuletzt (Abb. 23.1) umfährt das rechts absteigende Schriftband das Ende der Rolle und steigt links wieder nach oben. Dort stossen die Schlussbegriffe von Q 112 auf das links absteigende Schriftband.

9 Diese Linien verlaufen also nicht in Rollenrichtung, sondern sind dazu um $90^{\circ}$ gedreht.

10 Abb. 1.3.

11 Federkastenförmig: Die Figur lässt sich auch als ein auf beiden Seiten abgerundetes Rechteck beschreiben.
Titel von Q 3 (Sürat Āl Imrān) erkennen. Q 3 beginnt unmittelbar darunter in $\dot{G} u b \bar{a} r$-Schrift mit der Basmala. Darüber steht der Schlussvers von Q 2 (Q 2:286). Auf dem Fragment davor lässt sich absteigend in grosser goldener Schrift der Begriff [ar]-Rahīm erkennen.12 Q 3 scheint vollständig kopiert worden zu sein; jedenfalls steht auf der letzten Zeile vor dem Titelbalken von Q 4 Q 3:200 (Schlussvers). Der Abschnitt mit Q 3 ist $42 \mathrm{~cm}$ lang (inkl. vorangestellter Titelbalken) und mit Text in kleinem $\dot{G} u b \overline{a r}$ ausgefüllt (5 Zeilen auf ca. $1 \mathrm{~cm})$.

Die Besonderheit dieses Belegstücks besteht darin, dass auf seinem Mittelstreifen mit dem Korantext ausgewählte Texte in unterschiedlichen, oft nur schwer zu entziffernden Zierschriften notiert worden sind. Die an der Herstellung beteiligten Kopisten waren darauf erpicht, möglichst komplexe Darstellungen zu ersinnen. Der Betrachter sieht sich beim Entziffern oft mit eigentlichen Rätseln konfrontiert. Diese Stellen in Zierschrift dürften bei der Anfertigung zuerst ausgeführt worden sein; erst danach wurde der Hintergrund mit dem fortlaufenden Text aus dem Koran in $\dot{G} u b \bar{a} r$ ergänzt.

Im Abschnitt mit Q 3 wurde als übergeordneter Text auf dem Hintergrund in $\dot{G} u b \overline{a r}$ Q 56:77-79 kopiert. ${ }^{13}$ Dabei kamen zwei verschiedene Gestaltungsarten zum Einsatz: a. Der Abschnitt Innahū la-Qurān karīm fì erscheint als Leerraum auf dem Hintergrund in $\dot{G} u b \bar{a} r$-Schrift und füllt in

12 Unmittelbar oberhalb des Titelbalkens steht Q 2:286 (Schlussvers von Q 2). Das jetzt abgetrennte Stück muss sich unmittelbar davor angeschlossen haben, wie sich anhand der horizontal liegenden, tropfenförmigen Verzierung feststellen lässt. Da die Schrift hier sehr klein und stark verderbt ist, liess sich nicht ermitteln, mit welcher Koranstelle dieses Fragment einsetzt.

13 Q 56:77-79 lautet:

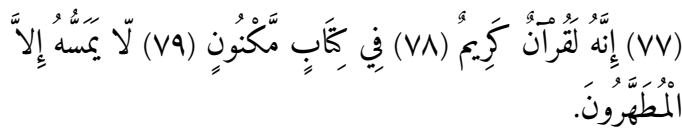

Vgl. Abb. 1.3 und 1.1 (in dieser Reihenfolge); auch Abb. 1.12.2. 
absteigender Richtung die ganze Breite des Mittelstreifens aus. Vokalisation und Punktierung wurden in Form von goldenen Zeichen hinzugefügt. In diesem Abschnitt werden die grossen Buchstaben durch Text in roter $\dot{G} u b \bar{a} r$-Schrift hervorgehoben. Diese rote Schrift ist allerdings derart stark verblasst, dass sie sich kaum noch entziffern lässt. Der Künstler ändert danach sein Vorgehen für die Abschrift der Fortsetzung Kitāb maknūn lā yamussu-hū illā l-muțahharūn. In dieser Stelle werden die Buchstaben durch drei parallel zueinander verlaufende rote Striche gebildet. Auch hier lassen sich goldene Vokalisationszeichen und Punktierungen erkennen; sie werden zum Teil rot hervorgehoben. Der Begriff maknūn und das nūn in al-muțahharūn stehen auf dem Kopf und verlaufen nicht in derSchriftrichtung des restlichen Texts des Zitats von Q 56:77-79.

Es sind diese Stellen mit Zierschrift, deren Buchstaben durch drei Striche gebildet werden, die eine Zuordnung dieses Dokuments in zentralasiatische Kontexte nahelegen. Ein vergleichbares Vorgehen lässt sich u. a. auf der Innenseite des Eingangs zum Āq Sarāy-Palast in Šahr-i Sabz (Usbekistan) nachweisen. ${ }^{14}$

Direkt in Anschluss an Q 3 folgt der zweite Titelbalken mit der Überschrift von Q 4 (an-Nisä); goldene Schrift auf blauem Grund). ${ }^{15}$ Länge dieses Abschnitts ca. $35 \mathrm{~cm} .{ }^{16}$ Der Text von Q 4 ist auf horizontalen Zeilen in schwarzer $\dot{G} u b \bar{a} r$-Schrift notiert. ${ }^{17}$ Auf diesem Hintergrund aus schwarzer $\dot{G} u b \bar{a} r$-Schrift lassen sich Stellen in rotem $\dot{G} u b \bar{a} r$

14 Vgl. dazu bereits oben bei Anm. 5; beachte auch Abb. 1.1, 6.1 und 12.4 der Rolle. Man vergleiche dies mit den Abbildungen vom Āq Sarāy-Palast in Šahr-i Sabz unter http://archnet.org/sites/2481/media_contents/1573 (Stand 29. September 2016). Diese kunsthistorischen Vergleiche werden später präzisiert; vgl. unten bei Anm. 61 .

Diese Längenangaben umfassen jeweils den Querbalken mit dem Surentitel und das anschliessende Rechteck mit der Abschrift der jeweiligen Sure.

17 Der Text beginnt mit der basmala von Q 4; auf der letzten Zeile dieses Abschnitts lassen sich die letzten Wörter aus Q 4 (Schlussvers 176) erkennen. erkennen. Diese Stellen in roter Schrift enthalten im ersten Teil des Abschnitts Q 56:80:18

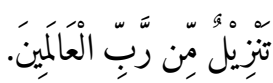

Auch hier Punktierungen und Vokalisationen in goldener Farbe. Auf den letzten zwei Fünfteln dieses Abschnitts bilden diese Stellen in rotem $\dot{G} u b \bar{a} r$ keinen Text mehr, sondern eine Figur. Es muss offen bleiben, ob diese Figur eine besondere Bedeutung hat oder ihr einfach Zierfunktion zukommt. ${ }^{19}$ Im Gegensatz zu den Stellen in schwarzem $\dot{G} u b \bar{a} r$, die auf horizontalen Linien angeordnet sind, orientiert sich der Text in rotem $\dot{G} u b \bar{a} r$ an der Ausrichtung der Begriffe in Q 56:80 oder den Figuren in den letzten beiden Fünfteln dieses Abschnitts. Der Text in rotem $\dot{G} u b \bar{a} r$ ist somit gegenüber dem schwarzen Text zumeist um $90^{\circ}$ versetzt bzw. folgt den Ausrichtungen der Figuren. Es war bis anhin nicht möglich, diesen Text in rotem $\dot{G} u b a \bar{r} r$ selbst zu entziffern, ist er doch oft verblasst. ${ }^{20}$ Am Schluss dieses Abschnitts folgt zur Verzierung eine horizontal ausgerichtete tropfenförmige Figur.

3. Querbalken mit der Überschirft Sūrat alMã̄ida (Q5) in goldener Schrift auf blauem Hintergrund. ${ }^{21}$ Länge dieses Abschnitts: $30.5 \mathrm{~cm}$. Zuerst lässt sich ein Abschnitt mit 15 horizontalen Zeilen in $\dot{G} u b \bar{a} r$-Schrift erkennen. ${ }^{22}$ Es handelt sich um Q 5:1-8. ${ }^{23}$ Danach folgt ein Abschnitt (Länge ca. $12.5 \mathrm{~cm})$ mit $8 \times 14$ goldenen Punkten. In diesem Abschnitt steht Text in rotem und schwarzem $\dot{G} u b \bar{a} r$, der sich anhand des Abbildungsmaterials allerdings kaum noch entziffern lässt. Die gol-

\footnotetext{
18 Abb. 2.2.

19 Interpretationen dieser Figur sind einstweilen gescheitert. Es ist nicht auszuschliessen, dass der Künstler ganz konkrete Vorstellungen umzusetzen versuchte.

20 Eine Entzifferung dürfte anhand von scans mit einer höheren Auflösung als die zur Verfügung stehenden grundsätzlich machbar sein.

21 Abb. 2.5-6.

22 Hier 16 Zeilen auf eine Höhe von ca. $3.5 \mathrm{~cm}$; dies ergibt inkl. Zeilenabstand eine Höhe von ca. $2 \mathrm{~mm}$ pro Zeile.

2315 Zeilen schwarz, letzte Zeile rot. Übergang Q 15:7-8 am Schluss der letzen (15.) schwarzen Zeile.
} 
denen Punkte werden jeweils durch je eine horizontal bzw. vertikal verlaufende Zeile mit Text in rotem $\dot{G} u b \bar{a} r$ voneinander getrennt. Sie bilden ein Gitter mit $8 \times 14$ Zellen. In jeder Zelle befindet sich der bereits erwähnte goldene Punkt. Diese goldenen Punkte werden von schwarzem Text eingefasst. Der Kopist dürfte diese Punkte jeweils auf einer im Zickzack verlaufenden Zeile zuerst oberhalb und dann unterhalb umfahren haben. Soweit ersichtlich enthält der soeben beschriebene Abschnitt einfach Stellen aus Q 5, die sich an Q 5:8 anschliessen. Jedenfalls folgen nach dem Gitter erneut horizontale Zeilen. Hier lassen sich am Anfang Q 5:67-69 erkennen (Text in schwarzem $\dot{G} u b \bar{a} r$ ). Auf jeweils 6 Zeilen in schwarzer Schrift folgen zwei Zeilen in roter Schrift (an zwei Stellen stark verblasst). Goldene Punkte trennen die einzelnen Verse voneinander. Am Ende dieses Abschnitts steht der Schlussvers von Q 5 (Vers 120). Es wurde nicht überprüft, ob der Text lückenlos kopiert wurde; dies liegt allerdings nahe.

4. Querbalken (AB B. 54): ${ }^{24}$ Sūratal-Añ̄m (Q 6). Länge dieses Abschnitts: ca. $30 \mathrm{~cm}$. Der Titel steht in ursprünglich wohl goldenem, jetzt grünlich verfärbtem Kūfı in einem Titelbalken mit blauem Hintergrund. Ein dritter Ausdruck im Balken ist stark verderbt. Es handelt sich wohl um den Vermerk makkiyya; er weist somit auf Mekka als Offenbarungsort dieser Sure hin. Q 6 beginnt im Mittelstreifen unmittelbar darunter mit der basmala in schwarzem Gubār. Am Ende dieses Abschnitts steht in schwarzem $\dot{G} u b \bar{a} r$ Q 7:24. Q 6:165 (Schlussvers) steht bereits acht Zeilen vor dem Schluss dieses Rechtecks.

Beim Betrachten fällt aber v.a. der in grosser Zierschrift in Rollenrichtung angebrachte Text auf. Es handelt sich um einen Auszug aus Q 6:73; er lautet:

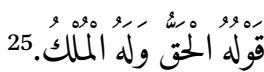

24 Abb. 3.1-2.

25 Übersetzung Bobzin Koran: „Sein Wort ist die Wahrheit. Sein ist die Herrschaft.“
Dieser Text erscheint als Leerraum auf dem „gubār-farbenen“ Hintergrund. Die Buchstaben werden ausserdem durch Text in dunkelrotem $\dot{G} u b \bar{r} r$ eingefasst und somit hervorgehoben. Dieser dunkelrote Text folgt der Ausrichtung der grossen Buchstaben. Er kann durchaus auf dem Kopf stehen. Es lassen sich ausserdem goldene Punktierungen und Vokalsiationszeichen feststellen; sie gehören zum grossen Text. Zusätzlich Verzierungen (Blattranken?); sie sind durch Text in hellrotem $\dot{G} u b \bar{a} r$ ausgefüllt, der aber häufig stark verblasst ist und sich kaum noch entziffern lässt. Dieser Text in hellrotem $\dot{G} u b \bar{a} r$ wurde in diesen Verzierungen zumeist in Rollenrichtung angebracht.

5. Querbalken (АВB. 55): ${ }^{26}$ al-A'rāf makkiyya (Q 7). Länge dieses Rechtecks: ca. $28 \mathrm{~cm}$. Der Titel steht in Zierkūfì in einem Titelbalken mit blauem Hintergrund und vereinzelten roten Zierelementen. Im Rechteck selbst wurde der Text von Q 7 in schwarzem $\dot{G} u b \bar{a} r$ auf horizontalen Zeilen kopiert. Zuunterst steht Q 7:206 (Schlussvers). In diesem Abschnitt fallen ausserdem weitere Zierelemente auf:

a. Am Anfang des Abschnitts: ein horizontal liegender, golden eingefasster Ziertropfen mit blauem Hintergrund und einem goldenen Blatt im Innern.

b. Im Zentrum dieses Abschnitts steht erneut Text in grosser Zierschrift. Die Buchstaben entstehen durch Aussparungen auf dem Hintergrund in schwarzem $\dot{G} u b \bar{a} r$. Diese grossen Buchstaben sind mehrfach ineinander verschlungen und ihrerseits mit Text in rotem $\dot{G} u b \bar{r} r$ ausgefüllt, das aber oft stark verblasst ist. In Übereinstimmung mit dem Vorgehen des Schreibers auf den andern Abschnitten dieser Rolle ist zu erwarten, dass es sich beim grossen Text um eine Stelle aus $\mathrm{Q}_{7}$ handelt. Im Vordergrund steht ein Auszug aus Q 7:40.27 Der

\footnotetext{
26 Abb. 4.1-2.

27 Q 7:40 lautet:

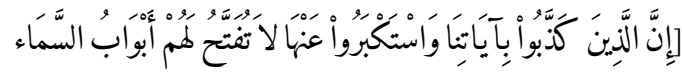


Begriff hattā lässt sich auf diesem Abschnitt klar erkennen. Die Verbindung zwischen $h \bar{a}^{3}$ und $t \bar{a}$ bildet eine horizontale Linie, die die ganze Figur durchmisst. Am Ende der Figur steht das $t \bar{a}$; das $\check{s} a d d a$ und die beiden Punkte des $t \bar{a}^{\prime}$ bereits am Anfang der Figur (golden). Das alif maqșūra am Schluss von hattā holt dann deutlich nach rechts aus. Identifizieren lässt sich überdies der Begriff al-hiyāt; er steht links oben (Buchstaben zumeist rot ausgefüllt). Links oben wahrscheinlich auch die Präposition $f i$. Auch der Ausdruck al-ğamal (Kamel) lässt sich in diesem Vexierbild erkennen, ebenso das Verb yaliǧa.

c. Im untersten Drittel dieses Abschnitts befindet sich ein Zierkreis mit mehreren konzentrisch angeordneten Ringen. In der Mitte dieses Medaillons ein Kreis mit blauem Hintergrund und einem goldenen Zierelement. Nach aussen hin folgen zwei weitere goldene Ringe, die durch einen Leerraum voneinander getrennt werden. Zuäusserst umfahren drei konzentrisch angeordnete Zeilen mit Text in $\dot{G} u b \overline{a r}$ (rot-schwarz-rot) diese Figur. Der Text liess sich bis anhin nicht entziffern. ${ }^{28}$

6. Querbalken: ${ }^{29}$ Sūrat al-Anfäl makkiyya (sic, gemäss Ausgabe D. Masson: madaniyya). Es handelt sich also um Q 8. Diese Überschrift steht in weissem $K \bar{u} f \imath$ auf einem blauen Hintergrund, der mit goldenen Verzierungen versehen ist. Länge dieses Abschnitts: ca. $15.8 \mathrm{~cm}$. Der Surentext wurde auf horizontalen Linien in gut leserlichem schwarzem $\dot{G} u b a \bar{r}$ kopiert; goldene Verstrenner. Im Zentrum dieses Abschnitts steht ein horizontal ausgerichteter Ziertropfen, in dessen Innern sich ein kleinerer Tropfen mit goldener Verzierung und einem blauen Innenfeld befindet. Dieser Tropfen

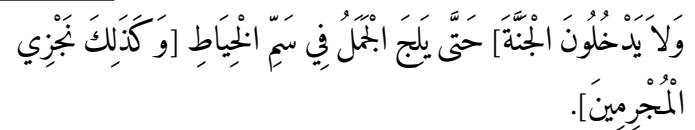

Die Stellen in eckigen Klammern fehlen in diesem grossen Text.

28 Abb. 4.4.

29 Abb. 4.5 ist mit Text in rotem $\dot{G} u b \bar{a} r$ weitgehend ausgefüllt. Zwei Zeilen in hellrotem, oft stark verblasstem $\dot{G} u b \bar{a} r$ greifen die Tropfenform auf und grenzen eine im Innern liegende Fläche ab, die mit Text in dunkelrotem $\dot{G} u b \bar{a} r$ ausgefüllt ist. Auf diesem dunkelroten $\dot{G} u b \bar{a} r$-Hintergrund sparte der Schreiber Leerräume aus. Sie bilden zusammen Text (Schluss von Q 8:49, wo das Gottvertrauen thematisiert wird). ${ }^{30}$

7. Querbalken (AB B. 56):31 Sūrat Barāt (Q 9; üblicher Titel: Sūrat at-Tawba). Diese Überschrift in goldenem $K \bar{u} f \iota$ in einem Titelbalken mit blauem Hintergrund. Länge dieses Abschnitts: ca. $40 \mathrm{~cm}$. Der Abschnitt weist grundsätzlich einen Hintergrund in roter $\dot{G} u b \bar{a} r$-Schrift auf. Dieser Text in mikroskopischer Schrift auf horizontalen Zeilen. Q 9 ist die einzige Sure, die ohne basmala beginnt. Die ersten Wörter dieser Sure hätten wohl besonders gestaltet werden sollen. Allerdings sieht es danach aus, dass die Arbeit an dieser Stelle nicht abgeschlossen wurde. Die Begriffe Barāatun min Allāh wa-rasūli-hı̄ wurden in ähnlicher Schrift ausgeführt wie Q 112 auf den Seitenbändern. Allerdings dürfte hier die Vergoldung vergessen worden sein; allenfalls wurde ein Fehler in der Abschrift zu einem späteren Zeitpunkt ausgebessert. Ganz am Schluss dieses Abschnitts der Schlussvers von Q 9 (Vers 129) in rotem $\dot{G} u b \bar{a} r$.

In diesem Abschnitt fallen aber v.a. Text und Verzierungen in blauer Farbe auf. Beim Text in blauem Zierkufi handelt es sich um den Schlussteil von Q 9:129 (Schlussvers von Q 9). Der Text wurde vorwärtslaufend und rückwärtslaufend kopiert. Die Oberlängen der Buchstaben (v.a. von alif und lām) sind ineinander verschlungen. ${ }^{32}$ In diesem Abschnitt fallen zusätzliche blaue Verzierungen

30 Q 8:49 lautet (der Text in eckigen Klammern fehlt im Tropfen):

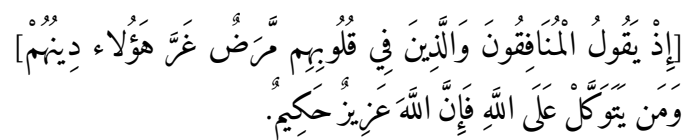

31 Abb. 5.1-3.

32 Q 9:129 lautet (die Stelle mit dem Wechsel von der vorwärtslaufenden auf die rückwärtslaufende Zeile ist durch || markiert): 
auf (eine blaue tropfenförmige Verzierung am Schluss und blaue Blätter und Ranken). Ausserdem lassen sich goldene šaddas und Vokalisationszeichen feststellen.

8. Querbalken (ABB. 57): ${ }^{33}$ Sūrat Yūnus (Q 10): Dieser Abschnitt misst ca. $41 \mathrm{~cm}$. Am Anfang ein Titelbalken mit blauem Hintergrund; darauf steht in goldenem Küfi Sūrat Yūnus. Der Surentext wurde in diesem Abschnitt wahrscheinlich vollständig in schwarzem $\dot{G} u b a \bar{r}$ kopiert und bildet dessen Hintergrund. Jedenfalls lässt sich am Anfang der Beginn der Sure und am Ende deren Schlussvers (10.109) erkennen. ${ }^{34}$ Mutmasslich hat der Schreiber aber bei der Anfertigung des Dokuments zuerst den grossen Text kopiert, dessen Buchstaben durch $2-5$ parallel zueinander verlaufende rote Striche gebildet werden. Bei dieser hervorgehobenen Stelle handelt es sich um Q 10:62. ${ }^{35}$ Gerade im mittleren Drittel dieses Abschnitts hat der Künstler zusätzliche Zierelemente in zumeist blauer Farbe hinzugefügt (Blüten, Blätter, Vokalisations- und weitere Hilfszeichen). Diese Zierelemente sind wiederholt golden eingefasst oder weisen golden ausgefüllte Stellen auf.

9. Querbalken: ${ }^{36}$ Sūrat Hūd (Q 11). Länge: ca. $32.3 \mathrm{~cm}$. Goldener Titelbalken mit einem Flechtband, das in der Mitte eine Kartusche mit blauem Hintergrund und dem Titel in weissem $K \bar{u} f \iota$ einfasst. Auf der rechten und linken Seite der Kartusche bildet das Flechtband unter Umfahrung eins Kreises gewissermassen einen Knoten. Q 11 wurde in rotem $\dot{G} u b \bar{a} r$ auf horizontal ausge-

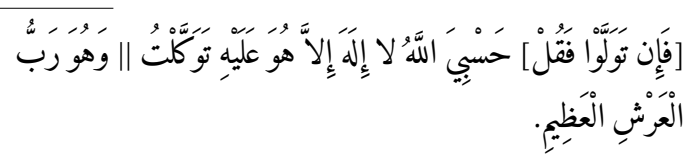

33 Abb. 6.1-3.

34 Keine Überprüfung der Abschrift auf ihre Vollständigkeit hin.

35 Q 106:2 lautet:

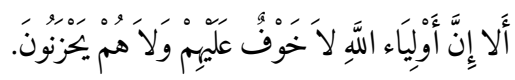

Der Vers ist also der im Hintergrund kopierten Sure entnommen.

Abb. 6.5-7. richteten Zeilen kopiert. Am Ende des Abschnitts lässt sich in roter Schrift Q 11:123 (Schlussvers) erkennen. Auch auf diesem Abschnitt wurde ein Vers durch besondere Gestaltung hervorgehoben (Schluss von Q 11:88). ${ }^{37}$ Abgesehen von den beiden letzten Begriffen (wa-ilay-hi unību) entsteht der Auszug aus diesem Vers durch Buchstaben, in denen weiterer Text in schwarzem $\dot{G} u b \bar{a} r$ kopiert worden ist. Während der Anfang des gross kopierten Ausschnitts aus Q 11:88 in grossem Nash vorwärts läuft, hat der Schreiber die beiden letzten Begriffe in goldenem, unpunktiertem Zierkufi rückwärtslaufend notiert. Diese beiden Begriffe stehen also auf dem Kopf.

Der Text in schwarzem $\dot{G} u b \bar{a} r$ liess sich nicht mit hinreichender Sicherheit entziffern. Grundsätzlich ist auch hier Text aus Q 11 selbst zu erwarten. Es lässt sich jedoch nicht ausschliessen, dass es sich allenfalls um Gebetstext handelt. Die Zeilen mit Text in schwarzem $\dot{G} u b \bar{a} r$ folgen dem Verlauf der grossen Buchstaben; ihre Richtung ändert sich dementsprechend mehrfach.

Auch in diesem Abschnitt lassen sich wiederholt Verzierungen feststellen. Bei den zumeist golden eingefassten Zeichen in roter Farbe handelt es sich um Punktierungen, Vokalisationen und weitere Hilfszeichen (šadda). Zudem lockern blaue, oft golden eingefasste Zierelemente (Blätter, Blüten) diesen Abschnitt auf.

10. Querbalken (Ав B. 58): ${ }^{38}$ Yūsuf (Q 12). Länge $30.6 \mathrm{~cm}$. Titel in einer Kartusche mit blauem Hintergrund in goldenem Küfi. Auch hier bildet eine Abschrift von Q 12 in schwarzem $\dot{G} u b a \bar{r}$ den Hintergrund des Abschnitts. Am Anfang sind der Beginn von Q 12 und am Ende deren Schlussvers (Q 12:111) festzustellen. Es ist nicht ausgeschlossen, dass auf diesem Abschnitt Q 12 vollständig kopiert ist, allerdings wurde die Abschrift nicht auf ihre Lückenlosigkeit hin überprüft.

37 Q 11:88 lautet:

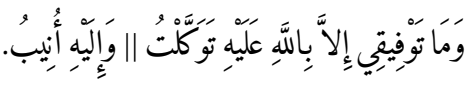

38 Abb. 7.1-2. 
Bei den beiden Stellen in grosser roter, als Kü $\iota \grave{\imath}$ einzustufender Schrift handelt es sich um Hervorhebungen aus Q 12 selbst. Bei der in der Rollenrichtung verlaufenden ersten Stelle handelt es sich um den Schluss von Q 12:64. ${ }^{39}$ Am Ende dieses Abschnitts steht auf einer horizontal ausgerichteten Zeile in etwas kleinerem roten $K u ̈ f \imath$ der Schluss von Q 12:76. ${ }^{40}$ Abgesehen von diesen beiden Stellen in rotem $K \bar{u} f \imath$ tragen weitere Elemente zur Verzierung dieses Abschnitts bei. Die Zeichen für Punktierungen und Vokalisationen wurden hier zumeist blau ausgeführt und golden eingefasst. Ausserdem fällt die Gestaltung des alif im Begriff arham auf, weist es doch auf etwa halber Höhe zu beiden Seiten je einen Halbkreis auf, in dessen Zentrum sich ein Punkt befindet. Darüber wurden links und rechts zwei blaue Kreuze (?) mit einer goldenen Blüte in der Mitte angebracht.

11. Querbalken: ${ }^{41}$ Sürat ar-Ra'd (Q 13); eher kurzer Abschnitt (14.2 cm). Die Überschrift wurde in rotem, golden eingefasstem Kü $f \imath$ auf blauem, mit weissen Bändern verziertem Hintergrund kopiert. Auch in diesem Abschnitt lassen sich Stellen in schwarzem und rotem $\dot{G} u b \bar{a} r$ erkennen. Der schwarze Text auf horizontalen Linien. Am Anfang steht der Beginn und am Ende der Schlussvers von Sūrat ar-Ra'd (Q 13:43). Auf der Höhe der fünftobersten Zeile beginnt ein Rechteck, das durch eine Zeile in rotem $\dot{G} u b \bar{a} r$ gebildet wird. In seinen Ecken je eine goldene Blüte. Ausserdem verlaufen in diesem Rechteck weitere Zeilen mit Text in rotem $\dot{G} u b \overline{a r}$ in geschwungenen Bögen. ${ }^{42}$ Im Zen-

39 Der kopierte Text lautet:

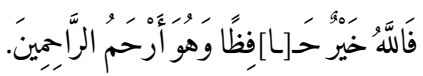

Der Schreiber dürfte das alif in hăfizan bewusst ausgelassen haben, da es die Gestaltung an dieser Stelle gestört hätte.

Der kopierte Ausschnitt aus Q 12:76 lautet:

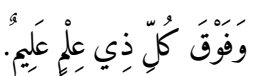

41 Abb. 7.2.

42 Soweit ersichtlich handelt es sich auch bei diesem Text in rotem $\dot{G} u b \bar{a} r$ um eine Abschrift aus Q 13. Jedenfalls trum steht ein Vierpass, dessen vertikale Lappen grösser sind als die beiden horizontalen Lappen. Im Zentrum des Rechtecks laufen von der linken bzw. rechten Seite zwei Kreisbögen aufeinander zu. Oben und unten wurden in golden eingefasster, jetzt grüner Schrift zwei Ausdrücke in grösserem $K u ̈ f \imath$ notiert. In oranger Schrift stehen zwei weitere Begriffe auf der linken und rechten Seite dieses Rechtecks. Die Entzifferung ist mit Schwierigkeiten verbunden. Im Vordergrund stehen Auszüge aus Q 13:2.43 Mit Sicherheit erkennen lässt sich allerdings nur der Ausdruck wa-l-qamar (orange, links). Zuoberst (grün) dürfte Allāh zu lesen sein. Rechts (orange) stünde al-'arš. Der untere Begriff (grün) ist verderbt; es könnte sich um das Verb istawā handeln.

12. Querbalken (АВ B. 59): ${ }^{44}$ Sürat Ibrāhìm makkiyya (Q 14). Länge dieses Abschnitts: ca. $19.0 \mathrm{~cm}$. Der Titel der Sure wurde auf blauem Hintergrund in ursprünglich wohl goldenem, jetzt aber weissem Küfı notiert. Im Abschnitt mit dem Korantext selbst wurde Q 14 in rotem $\dot{G} u b \bar{a} r$ auf horizontalen Zeilen notiert. Am Anfang steht Q 14:1, am Ende des Abschnitts lässt sich Q 14:52 erkennen. Ins Auge sticht auf diesem Abschnitt aber v. a. grosser Text in Zierkufi, dessen Buchstaben zumeist durch schwarze Doppellinien gebildet werden. Beim kopierten Text handelt es sich um den Schluss von Q 14:12. Der Text verläuft zuerst absteigend. Der letzte Begriff (al-mutawwakilūn) jedoch verläuft auf der gegenüberliegenden Seite aufsteigend. Gerade die Buchstaben mit Oberlängen sind

lässt sich in der auf der rechten Seite des Rechtecks aufsteigenden Linie am Schluss Q 13:20 (nach dem goldenen Verstrenner) und davor Q 13:19 erkennen; Q 13:20 lautet:

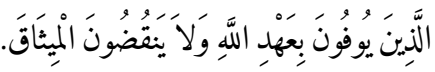

43

Q 13:2 lautet:

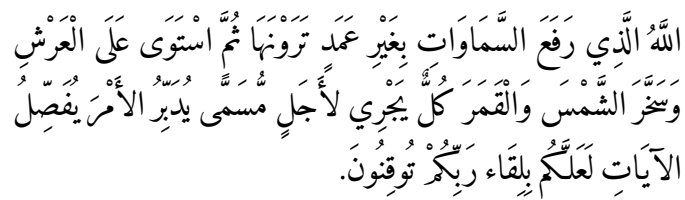


ineinander verzahnt. ${ }^{45}$ In diesem Abschnitt fallen ausserdem verschiedene Zierelemente auf. Dazu zählt eine Blüte mit blauen und goldenen Blättern sowie roten und orangen Stellen.

13. Querbalken: ${ }^{46}$ Sūrat al-Hiğr makkiyya (Q 15). Die Überschrift wurde in goldener Schrift auf blauem Hintergrund notiert. Länge dieses Abschnitts: ca. $15 \mathrm{~cm}$. Auch hier Text in schwarzem $\dot{G} u b \bar{a} r$ auf horizontalen Zeilen (4 Zeilen auf eine Höhe von knapp $1 \mathrm{~cm})$. In diesem Abschnitt lässt sich ein Rechteck erkennen, in dem geschwungene Zierlinien Bögen bilden. Sie lassen ein geometrisches Muster erkennen, das mit jenem im Abschnitt mit Q 13 ( ar-Ra'd) übereinstimmt. ${ }^{47} \mathrm{Im}$ oberen und unteren Zierfeld mit blauem Hintergrund steht Text in jetzt weissem Zierkufi. Im oberen Feld steht وَاعبد ربكَ رَّكَ (Q 15:99, Anfang). Im unteحتى ren Feld steht der zweite Teil dieses Verses

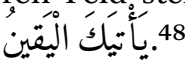

14. Querbalken: ${ }^{49}$ Sūrat an-Nahl (Q 16). Länge: $24.3 \mathrm{~cm}$. Die Überschrift der Sure steht in jetzt weissem Küf $\imath$ auf einem blauen, mit goldenem Rankenmuster versehenen Hintergrund. In diesem Abschnitt ist Text in schwarzem $\dot{G} u b \bar{a} r$ auf horizontalen Zeilen notiert worden. Am Anfang des Abschnitts steht Q 16:1; am Schluss lässt sich Q 16:128 (Schlussvers) erkennen. Der Kopist dürfte zuerst den grossen Text in roten Buchstaben geschrieben haben. Die Buchstaben werden durch zwei parallel zueinander verlaufende Striche gebildet. Dieses Vorgehen ähnelt der Gestal-

45 Q 14:12 (Schluss) lautet:

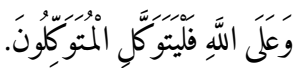

46 Abb. 8.1.

47 Vgl. nach Anm. 41.

48 Q 15:99 lautet:

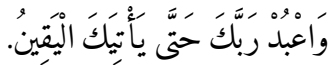

Der Text im oberen Feld ist klar lesbar. Im unteren Feld steht der Begriff hattā auf der unteren Zeile; unmittelbar danach folgt $y a^{\prime}$-[tiya-ka]; tiya-ka allerdings erst in der Zeile darüber. Auf der oberen Zeile am Schluss al-yaqin (gestaucht)

Abb. 8.3-5. tung, die sich bereits in den Abschnitten mit Q 3 und 8 beobachten liess. ${ }^{50}$ Eine lange rote Doppellinie (stark verlängerte Schlusslänge des alif maqșūra am Schluss von 'alā) trennt hier zwei gegenläufige Linien mit grossem rotem Text. Bei der kopierten Stelle handelt es sich um eine vollständige Abschrift von Q 16:42. ${ }^{51}$ Dieser Text war mit ursprünglich blauen und golden umrahmten Punktierungen und Vokalisationszeichen versehen.

15. Querbalken (ABB. 6o):52 Sūrat Subhāna (Q 17; üblicherweise unter dem Namen al-Isrā bekannt). Länge: ca. $16.2 \mathrm{~cm}$. Die Überschrift steht in weissem, golden eingefasstem Küf $\iota$ auf blauem Hintergrund. Im anschliessenden Textfeld wurde als Hintergrund Q 17 auf horizontalen Linien in rotem $\dot{G} u b \overline{a r}$ kopiert. Q 17 ist auf diesem Abschnitt wohl vollständig enthalten. Die beiden letzten Zeilen sind dicht ineinander gedrängt und kaum mehr zu lesen. Am Schluss der drittletzten Zeile in rotem $\dot{G} u b a \bar{r}$ steht Q 17:103. In diesem Abschnitt sticht v.a. die Abschrift der ersten Hälfte von Q 17:84 hervor. ${ }^{53}$ Diese Stelle ist in goldener Schrift kopiert worden. Die Stelle steht einmal absteigend und dann gegenläufig aufsteigend in diesem Rechteck. Die Oberlängen von alif und lām der beiden gegenläufigen Zeilen sind miteinander verbunden. Der grosse Text ist mit goldenen Markierungen punktiert und vokalisiert. Auf der vertikalen Mittelachse lassen sich zudem sieben goldene Blüten mit blauen Zierpunkten erkennen.

16. Querbalken: ${ }^{54}$ Sürat al-Kahf (Q 18). Länge: $29.5 \mathrm{~cm}$. Der Titel steht in weissen, golden hinterlegten Buchstaben $(K \bar{u} f i)$ in einem Querbal-

50 Vgl. dazu nach Anm. 13 und 29 .

51 Q 16:42 lautet (die Markierung || kennzeichnet den Richtungswechsel):

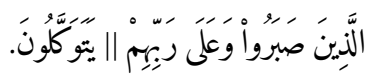

Abb. 9.1-2.

Q 17:84 lautet:

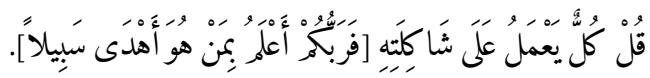

Der Text in eckigen Klammern wurde nicht kopiert.

Abb. 9.3. 
ken mit blauem Hintergrund. Der Text von Q 18 selbst ist hier erneut in schwarzem $\dot{G} u b \bar{a} r$ auf horizontalen Zeilen kopiert worden. Am Anfang dieses Abschnitts steht Q 18:1, am Schluss Q 18:110 (Schlussvers). Es wurde nicht überprüft, ob diese Abschrift lückenlos ist. Auf dem „gubār-farbenen“ Hintergrund sind Leerräume derart ausgespart, dass übergeordneter Text entsteht. Es handelt sich um einen Auszug aus Q 18:38.55 Goldene Elemente dienen als Punktierungen, Vokalisierungen und Verzierungen. Das goldene Tanwin-Zeichen von ahadan ganz am Schluss fällt besonders auf. Ausserdem fallen zwei blaue, golden eingefasste Zierelemente am Anfang und am Schluss dieses Rechtecks auf.

17. Querbalken (ABB. 61): ${ }^{56}$ Sūrat Maryam (Q 19). Länge: $19.3 \mathrm{~cm}$. Im Titelfeld in einer Kartusche die Überschrift Maryam und ursprünglich wohl goldene Verzierungen. Die Stelle ist durch Kupferfrass verderbt. In diesem Rechteck selbst steht der Text von Q 19 auf horizontalen Zeilen in rotem $\dot{G} u b \bar{a} r$. Am Anfang Q 19:1, am Ende des Rechtecks Q 19:97-98 (letzter Vers allenfalls gekürzt). ${ }^{57}$ In diesem Abschnitt fällt v.a. der grosse Text in goldenem Zierkufi auf: Buchstabenfolge $K \bar{a} f-h \bar{a}^{\prime}-y \bar{a}^{\prime}-{ }^{\prime} a y n-s ̦ \bar{a} d$ aus Q 19:1. Derartige Abfolgen von Buchstaben stehen am Anfang bestimmter Suren; ihre Bedeutung ist nicht wirklich geklärt. ${ }^{58}$ Besonders auffällig ist die Gestaltung des $k \bar{a} f$ mit seiner stark nach rechts ausholenden Oberlänge. Die Leerräume in den Buchstaben $h \bar{a}$, 'ayn und șād sind blau ausgefüllt. Alle Buchstaben weisen einen weissen Kern auf. Im Hintergrund: goldene Girlanden mit farbigen (roten, blauen) Verzierungen; sie bilden zwei Wirbel. Derartige Girlanden lassen sich auf Bauten aus der

55 Q 18:38 lautet:

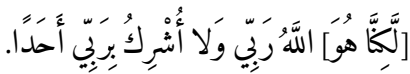

56 Abb. 10.1

57 Der Text wurde in sehr kleinem $\dot{G} u b \bar{r} r$ notiert und lässt sich nur noch schlecht entziffern.

$5^{8}$ Vgl. dazu u.a. Michot, Ibn Taymiyya on astrology 316 (Anm. 126).
Timuridenzeit nachweisen, ${ }^{59}$ sind aber teilweise auch aus Ägypten bekannt. ${ }^{60}$

Es sei jedoch daran erinnert, dass die weiteren Gestaltungsmittel auf diesem Belegstück eine Zuschreibung zu einem spät-ilkhanidischen oder früh-timuridischen Kontext nahelegen. Dazu gehört die Art der Abschrift von Q 112 auf den beiden Seitenbändern. Die Bildung von Buchstaben durch mehrere, parallel zueinander verlaufende Linien lässt sich - wie erwähnt - ansatzweise ebenso am Âq Sarāy-Palast in Šahr-i sabz beobachten, dessen Bau von Timur 1380 angeordnet worden ist. ${ }^{61}$

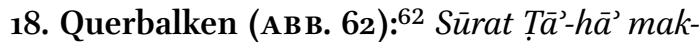
kiyya (Q 20). Länge: $22.4 \mathrm{~cm}$. Der Titel der Sure in rotem, golden eingefasstem Küf $\iota$ in einem Titelfeld mit blauem Hintergrund. Hier auch ein jetzt weisses Zierband. Der Surentext selbst in schwarzer $\dot{G} u b \bar{a} r$-Schrift auf horizontalen Zeilen. Die Abschrift beginnt mit Vers 1 und endet mit dem Schlussvers (Vers 135). Es wurde nicht überprüft, ob der Text lückenlos kopiert wurde. In diesem Abschnitt sticht in erster Linie der Text in grosser Schrift hervor. Es handelt sich um Q 20:1-2. ${ }^{63}$

59 Vgl. dazu z.B. Eingangsportal zum Gūr-i Amīr-Komplex (Samarkand, ca. 1400-1404), abgebildet in Lentz und Lowry, Timur and the princely vision 154; auch Abb. 76 (S. 213: Abb. der Fassade eines Mausoleums für eine Schwester Timurs, Samarkand, ca. 1400). Siehe ebenso das Frontispiz zu einer Koranhandschrift aus Iran (ca. 1400-1450) in Lentz und Lowry, Timur and the princely vision $76 \mathrm{f}$. (Abb. 19).

6o Für ein Beispiel aus dem mamlukischen Ägypten siehe Behrens-Abouseif, Islamic architecture in Cairo 127 (Abb. 9o): aus der Sulțān Hasan-Moschee (erbaut 13561361; S. 122-128); und S. 148 (Abb. 108): aus der Moschee des Qāḍi Abū Bakr b. Muzhir, erbaut 1479-148o. Siehe auch Meinecke, Mamlukische Architektur, Bd. I, Tafel 82c: Kairo, Madrasa des an-Nāṣir Ḥasan (mit Bd. II, Nr. 19B/13).

61 Vgl. dazu http://archnet.org/sites/2481/media_content s/1575 (Stand 6. Dezember 2016); Lentz und Lowry, Timur and the princely vision 43 (Abb.12). Siehe für diese Gestaltung auch die direkt anschliessende Sure.

62 Abb. 10.2.

63 Q 20:1-2 lautet:

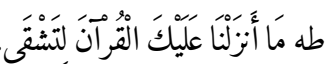


Der erste Begriff besteht aus den beiden Buchstaben $t \bar{a}^{\prime}-h \bar{a}^{\prime}(\mathrm{Q} 20: 1)$. Diese beiden Buchstaben sind blau ausgefüllt und golden eingefasst; sie sind mit einzelnen blauen Blatt- und Blütenelementen verziert. Die Abschrift von Q 20:2 wurde abweichend ausgeführt: die Buchstaben werden durch drei parallel zueinander verlaufende rote Linien gebildet. Punktierungen als rote Doppelkreise; v.a. unterhalb dieses zweiten Verses: blaue Blätter und Blüten zur Verzierung.

19. Querbalken: ${ }^{64}$ al-Anbiyā' Sūra makkiyya (sic; Q 21); Länge: $18 \mathrm{~cm}$. Überschrift in goldenem $K \bar{f} f \grave{\imath}$ auf blauem, mit einem weissen Zierband versehenem Hintergrund. Im Rechteck darunter Q 21 in roter $\dot{G} u b \bar{a} r$-Schrift auf horizontalen Zeilen. Am Anfang Vers 1; am Schluss lassen sich Teile von Q 21:112 erkennen (Schlussvers). Es wurde nicht überprüft, ob der Surentext lückenlos kopiert ist. Auch hier stellt der hervorgehobene Text das wichtige Gestaltungselement dar. Er entsteht durch Aussparungen auf dem $\dot{g} u b \bar{a}$-farbenen, hier roten, Hintergrund. Diese grossen Buchstaben erinnern z.T. an kufische Schrift. Dieser grosse Text (Q 21:107 ${ }^{65}$ ) wurde gegenläufig kopiert; die beiden auf- bzw. absteigenden Zeilen sind durch die Oberlängen von alif und lām ineinander verzahnt.

2o. Querbalken: ${ }^{66}$ Sürat al-Hağğ (Q 22). Länge: $16 \mathrm{~cm}$. Überschrift in weissem Kū $f \grave{\imath}$ auf blauem Hintergrund, der zusätzlich mit goldenen Ranken verziert ist. Im Rechteck darunter der Text von Q 22 in schwarzem $\dot{G} u b \bar{a} r$ auf horizontalen Zeilen. Im schwarzen $\dot{G} u b \bar{a} r$-Text steht am Anfang Q 22:1, auf der letzten Zeile Q 22:78 (Schlussvers). Es wurde nicht überprüft, ob die Abschrift des Surentexts lückenlos ist. Auf diesem Hintergrund in schwarzem $\dot{G} u b \bar{a} r$ lassen sich zwei Zierelemente erkennen: a. ein Rankenmuster, das durch zwei

\footnotetext{
64 Abb. 10.3 .

65 Q 21:107 lautet:
}

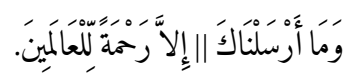

Die Markierung || kennzeichnet den Übergang vom vorwärts- in den rückwärtslaufenden Text.

66

Abb. 10.4.
Kreise bzw. Wirbel gebildet wird. Die Linien dieses Rankenmusters werden durch Text in orangem $\dot{G} u b \bar{a} r^{67}$ gebildet. Die Stellen sind häufig verblasst; die Auflösung des zur Verfügung stehenden Abbildungsmaterials lässt eine Entzifferung kaum noch zu. In dieses wirbelförmige Rankenmuster wurden blaue Sprenkel mit goldenem Innern eingestreut. b. Am Schluss des Rechtecks steht in grösserer Schrift (Nash) eine Textstelle, die sich am Ende von Q 22:40 und 22:74 nachweisen lässt. ${ }^{68}$ Dieser Text wird aus einer Abschrift von Stellen in orangem $\dot{G} u b a \bar{r}$ gebildet. Es fallen einzelne blaue Hilfszeichen (Vokalisierung, Punktierung) auf.

21. Querbalken (Ав B. 63):69 Sürat al-Mu'minūn (Q 23). Länge: ca.16.o cm. DerTitel in jetzt weissem Küfı im Titelbalken mit blauem Hintergrund und einem goldenen Rankenmuster. Im Rechteck darunter auf horizontalen Zeilen Text in weinrotem und orangem $\dot{G} u b a \bar{r}$. Am Anfang der Beginn von Q 23:1 in weinroter Schrift; am Ende des Abschnitts liess sich der Text nicht mit Sicherheit entziffern. Am Schluss der siebtuntersten Zeile lässt sich das Ende von Q 23:107 (az-žālimūn) erkennen. Ganz am Ende des Abschnitts steht aber Text, der nicht aus Q 23 selbst stammen dürfte. ${ }^{70}$

In diesem Abschnitt fällt insbesondere ein schwarzes Rechteck auf, in das ebenso schwarze Linien eingepasst worden sind. Diese Linien bilden einen Text in geometrisierendem Küft. Man meint, in diesem Rechteck u.a. den Begriff almu'minūn zu erkennen, der als Titel dieser Sure dient und auch in Vers 1 vorkommt. Allerdings ist die Entzifferung dieser Stelle in geometrisierendem Küfı̈ nicht gesichert. Auch in den Leerräumen zwischen diesen schwarzen Linien wurde Text aus Q 23 auf horizontalen Zeilen in oranger $\dot{G} u b \bar{a} r-$ Schrift kopiert.

67 Die Farbe des Textes unterscheidet sich vom weinroten $\dot{G} u b a \bar{r}$ im Abschnitt mit Q 21 davor.

68 Der zitierte Text lautet (vgl. Q 22:40 und 74, Schluss):

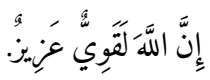

69 Abb. 11.1-2.

$70 \quad$ Q 23 hat 118 Verse. 
22. Querbalken: ${ }^{71}$ Sūrat an-Nūr (der Begriff nūr weitgehend unleserlich; Q 24). Der Titel in goldenem $K \bar{u} f \iota$ in einem Balken mit blauem Hintergrund. Länge: ca. $12.6 \mathrm{~cm}$. In diesem Abschnitt fehlt ein übergeordneter Text. Der Schreiber hat hier den Text auf horizontalen Zeilen abwechselnd in orangem und schwarzem $\dot{G} u b \bar{a} r$ kopiert. Die Stellen in gleicher Farbe bilden jeweils Quadrate. Das Rechteck enthält $6 \times 9^{72}$ solche Quadrate; zuunterst eine Zeile in schwarzem $\dot{G} u b \bar{a} r$. Der Kopist scheint beim Schreiben Quadrat um Quadrat auf der gleichen Höhe im Rechteck ausgefüllt zu haben. Die einzelnen Quadrate messen ca. $1 \times 1 \mathrm{~cm}$ und enthalten Text auf jeweils sechs Zeilen. Auf der letzten Zeile in schwarzem $\dot{G} u b \bar{a} r$ : Q 24:64 (Schlussvers). Goldene Punkte als Verstrenner.

23. Querbalken: ${ }^{73}$ Sūrat al-Furqān (Q 25). Länge: $20.2 \mathrm{~cm}$. Der Titel in weissem, golden eingefasstem Küfı auf blauem Hintergrund im Querbalken. Am Anfang des Rechtecks: Vers 1; am Ende: Vers 77 (Schlussvers). Es wurde nicht überprüft, ob der Text dieser Sure lückenlos kopiert worden ist. Der Text der Sure auf horizontalen Zeilen in weinrotem $\dot{G} u b \bar{a} r$. Dieser Abschnitt wird aber v.a. durch grossen Text in schwarzer Schrift auf diesem Hintergrund in weinrotem $\dot{G} u b \bar{a} r$ dominiert. Es handelt sich um den Schluss von Q 25:2. ${ }^{74}$ Der Text beginnt auf der unteren Zeile in schwarzem Nash. Die Buchstaben werden im Grund durch drei parallel zueinander verlaufende schwarze Linien gebildet. Es lässt sich in den Buchstaben aber auch ein schwarzes Flechtmuster feststellen. Beim Sprung auf die obere Zeile wechselt der Schreiber von Nash zu Küfì. Die Buchstaben werden hier durch schwarze Doppellinien gebildet. In diesem Abschnitt fallen ausserdem blaue Zierelemente

71 Abb. 12.2.

72 Breite $\times$ Höhe.

73 Abb. 12.1.

74 Der grosse Text aus Q 25:2 lautet:

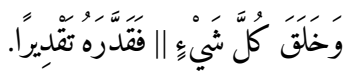

Die Markierung || kennzeichnet den Zeilenumbruch. auf: Blüten sowie Vokalisierungen und Punktierungen zum grossen Text.

24. Querbalken: ${ }^{75}$ Sūrat aš-Šúarā' (Q 26$)$. Länge: $15.6 \mathrm{~cm}$. Titel in weissem, schwarz eingefasstem $K \bar{u} f \iota$ auf goldenem Hintergrund, vereinzelt blaue Blätter zur Verzierung. Im Rechteck darunter hat der Schreiber einen grossen Teil des Texts derSure in schwarzem $\dot{G} u b \bar{a} r$ auf horizontalen Zeilen notiert. Am Anfang des Rechtecks Vers 1; am Ende Vers 227 (Schlussvers). Auf der letzten Zeile: Leerraum abwechselnd mit blauen und goldenen Punkten ausgefüllt. Am Anfang des Rechtecks steht die Buchstabenfolge Tă ${ }^{2}-\sin$-mìm (Q 26:1). Im Rechteck selbst fallen Stellen in orangem $\dot{G} u b \bar{a} r$ und weinrotem Küfı auf. Diese beiden Stellen bilden übergeordneten Text; es handelt sich um eine Abschrift von Q 26:217-218. ${ }^{76}$ Q 26:217 wird durch Stellen in orangem $\dot{G} u b \bar{a} r$ gebildet, die übergeordnete Buchstaben entstehen lassen. Der in diesen Buchstaben kopierte $\dot{G} u b \bar{a} r$-Text folgt dem Verlauf der grossen Buchstaben. Nach dem Begriff 'alā aus Vers 217 wechselt der Schreiber die Richtung. Der zuerst vorwärtlaufende Text steigt jetzt auf der gegenüberliegenden Seite wieder nach oben. Die Oberlängen der Buchstaben sind ineinander verstrickt. Der danach anschliessende Vers Q 26:218 wurde in weinrotem Küfı kopiert. Die Buchstaben werden zumeist durch weinrote, parallel zueinander verlaufende Doppellinien gebildet.

25. Querbalken (АвB. 64): ${ }^{77}$ Sürat an-Naml (Q 27). Länge: $24.0 \mathrm{~cm}$. Titel in goldenem $K \bar{u} f \imath$ in einer Kartusche mit blauem Hintergrund. Diese Kartusche wird durch ein punktiertes Zierband eingefasst. Im Rechteck darunter folgt der Text der Sure in rotem $\dot{G} u b \bar{a} r$ auf horizontalen Zeilen. Am Anfang des Abschnitts: Q 27:1. Die Buch-

75 Abb. 12.3.

76 Q 26:217-218 lautet:

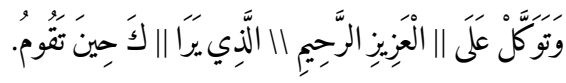

Die Markierung \| kennzeichnet den Wechsel von Nash (Stellen in orangem $\dot{G} u b \bar{a} r$ ) zu weinrotem Küfi. Die Markierung || steht für den Übergang vom vorwärts- in den rückwärtslaufenden Text.

Abb. 12.4. 
stabenfolge $T \bar{a}^{3}-\sin$ wurde in grossen goldenen Buchstaben hervorgehoben. Auf der letzten Zeile steht Q 27:93 (Schlussvers). Auf diesem Hintergrund in rotem $\dot{G} u b \bar{a} r$ fallen v.a. weinrote Verzierungen auf, die einen übergeordneten Text in Zierkufi bilden; es handelt sich um die Basmala (Bismi $[A]$ llāhi r-raḥmān ar-rậìm). Die Buchstaben werden durch drei parallel zueinander verlaufende Linien gebildet. Die einzelnen Begriffe der Basmala sind zusammenhängend notiert worden. Beachtenswert ist die stilisierte Gestaltung der beiden Begriffe ar-rahmān und ar-rahīm am Schluss der Zeile. Unterhalb dieser Zeile ein Zierband mit blauen und goldenen Ranken. Über dem Begriff bism ein Tropfenmedaillon, das golden umrandet, weinrot eingefasst und im Innern blau und golden ausgefüllt ist. Von diesem Tropfen führen mehrere blaue, oft golden eingefasste Verzierungen weg. Ob dieses Element in Anlehnung an den Titel der Sure (an-Naml: Die Ameise) eine Ameise darstellt, lässt sich zwar nicht beweisen, ist aber naheliegend. Über den beiden Begriffen ar-Rahmmān und ar-Rahim zwei weitere blau-goldene Zierelemente.

26. Querbalken (Авв. 65):78 Sūrat al-Qișas (Q 28). Länge: $21 \mathrm{~cm}$. Titel in braun-rotem, golden umrahmtem Küfı auf blauem Hintergrund, der zudem mit weissen Zierbändern versehen ist. Im Rechteck selbst steht der Surentext in schwarzem $\dot{G} u b \bar{r} r$ auf horizontalen Zeilen. Am Anfang Vers 1; am Ende des Rechtecks steht Q 28:88 (Schlussvers). Auf diesem Abschnitt fallen zwei rote Verzierungen auf, die wohl Text in geometrisierendem Küfı̀ enthalten. Die Buchstaben des oberen Zierelements sind breiter und rot. Im unteren Zierelement sind die Buchstaben schmaler. Zwischen diesen beiden Zierelementen befindet sich eine goldene Blüte, die mit blauen und braunroten Punkten versehen worden ist. Diese beiden Stellen konnten bis anhin nicht entschlüsselt werden. Sie müssen mit grosser Wahrscheinlichkeit Text aus Q 28 enthalten, handhabt der Kopist dies doch auf den meisten andern Feldern auch so.

78 Abb. 13.1-2.
Da die Suren im Koran zumeist nach ihrer absteigenden Länge angeordnet sind, werden die einzelnen Abschnitte zunehmend kürzer. Der Kopist verzichtet deshalb mehr und mehr darauf, in die einzelnen Textfelder auch weiterhin grossen Text in Zierschrift einzufügen. Ab hier deshalb zunehmend kein grosser Text.

27. Querbalken: ${ }^{79}$ Sūrat al-'Ankabūt (Q 29, hier goldener Hintergrund). Länge: $10.8 \mathrm{~cm}$. Der Titel in weissem $K \bar{u} f \iota$ auf goldenem Hintergrund mit vereinzelten blauen Zierpunkten. In diesem Abschnitt fehlt grosser Text. Der Schreiber hat einfach den Text von Q 29 in schwarzem $\dot{G} u b \bar{a} r$ auf horizontalen Zeilen kopiert. Am Anfang steht Q 29:1; am Ende ist Q 29:69 (Schlussvers) zu erkennen. Es wurde nicht überprüft, ob die Abschrift lückenlos ist.

28. Querbalken: ${ }^{80}$ Sūrat ar-Rūm (Q 30). Länge: $9.5 \mathrm{~cm}$. Der Titel in jetzt weissem Kü $f \imath$ auf blauem Hintergrund, der vereinzelt mit goldenen Bändern versehen ist. Im Textfeld darunter folgt Q 30:1-6o (6o: Schlussvers) in weinrotem $\dot{G} u b \bar{r} r$ auf horizontalen Zeilen. Am Schluss allerdings steht der Text in abwechselnd weinrotem und orangem $\dot{G} u b \bar{a} r$ in 6×3 Quadraten. Ganz zuunterst steht Q 30:6o. Kein grosser Text in diesem Abschnitt.

29. Querbalken:81 [Luqmān]; Q 31. In diesem Abschnitt von ca. $7.5 \mathrm{~cm}$ Länge wurde in schwarzem $\dot{G} u b \bar{a} r$ auf horizontalen Zeilen der Text von Q 31:1-34 (34: Schlussvers) kopiert. Der Titel in weissem $K \bar{u} f \imath$ auf blauem, mit goldenen Verzierungen versehenem Hintergrund lautet allerdings al'Ankabūt (Titel von Q 29). Q 31 ist jedoch zumeist unter dem Titel Luqmān bekannt. Die Entzifferung des jetzigen Titels ist derart klar, dass hier ein Fehler des Kopisten vorliegen muss.

3o. Querbalken:82 Sūratas-Sağda (Q 32$)$. In diesem Abschnitt (Länge ca. $6.9 \mathrm{~cm}$ ) wurde Q 32:1-30 (Schlussvers) in weinrotem $\dot{G} u b \bar{a} r$ auf horizontalen Zeilen kopiert. Der Titel in weissem Zierkufi im

\footnotetext{
79 Abb. 13.1.

8 o Abb. 13.3.

81 Abb. $13 \cdot 3$.

82 Abb. 13.3 und 14.1.
} 
Querbalken. Goldene Verstrenner. Auf der Mittelachse eine golden umrandete Scheibe mit blauem Hintergrund und goldenem Blattmuster. Ein übergeordneter grosser Ziertext fehlt.

31. Querbalken:83 al-Ahzāb (Q 33). Länge: $25.2 \mathrm{~cm}$. Die Überschrift in goldenem Küf $\iota$ auf blauem Hintergrund mit roten Einsprengseln; sie ist jetzt nicht mehr eindeutig lesbar. Der Text wurde in schwarzem $\dot{G} u b \bar{a} r$ auf horizontalen Zeilen kopiert. Er ist auf der ersten Zeile stark verblasst. Am Ende dieses Abschnitts lässt sich Q 33:73 (Schlussvers) erkennen. Auf diesem Abschnitt fällt aber v. a. übergeordneter Text auf, der durch Aussparungen auf dem ${ }_{n} \dot{g} u b \bar{a} r$-farbenen" Hintergrund entsteht. Bei diesem grossen Text handelt es sich um Q 33:45. ${ }^{84}$ Der Vers wurde anfänglich vorwärtslaufend kopiert; die Fortsetzung verläuft aber in der Gegenrichtung aufsteigend (rückwärts). Die Oberlängen der beiden gegenläufigen Zeilen sind ineinander verstrickt. Der Schlussausdruck wanadieran ganz im Innern wurde aufsteigend kopiert. Die Buchstabenfolge nad ist durch einen goldenen Balken im Innern gekennzeichnet. Neben goldenen Punktierungen lassen sich wiederholt florale Verlängerungen der Buchstaben erkennen.

32. Querbalken: ${ }^{85}$ Sürat Saba' makkiyya (Q 34). Länge: ca. $9.2 \mathrm{~cm}$. Der Text von Q 112 auf dem rechten Seitenband ist hier nur in gekürzter Form kopiert worden. ${ }^{86}$ Überschrift in goldenem Küfi auf blauem Hintergrund. Der Text von Q 34 wurde auch in diesem Abschnitt in $\dot{G} u b \bar{a} r$-Schrift kopiert (weinrote, orange und schwarze Tinte). Stellen in gleicher Farbe wurden jeweils in der From von Quadraten und Rechtecken angeordnet. Im Zentrum dieses Abschnitts befindet sich ein Quadrat mit Text in weinrotem $\dot{G} u b \bar{a}$. Auffällig ist an dieser Stelle ein blaues Element, das an die klecksartigen

83 Abb. 14.4-5.

84 Q 33:45 lautet:

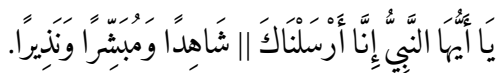

Die Markierung || kennzeichnet den Übergang vom vorwärts- zum rückwärtslaufenden Text.

85 Abb. 15.2 .

86 Es steht hier nur Q 112:1-2; Verse 3-4 fehlen.
Figuren erinnert, wie sie aus dem Rorschach-Test bekannt sind. Es dürfte sich um ein Wort handeln. Es steht jedenfalls fest, dass es sich bei den goldenen Elementen in kufischer Schrift in den vier Ecken dieses Abschnitts um einen Auszug aus Q 34:21 handelt. ${ }^{87}$ Beim klecksartigen blauen Element im Zentrum muss es sich um den Begriff hafiz am Schluss dieses Verses handeln. Zwischen diesen Elementen in kufischer Schrift befindet sich je ein kleines goldenes Quadrat mit einem blauen Tupfer oder Quadrat mit weissem Punkt in der Mitte. Die zuvor erwähnten Stellen in $\dot{G} u b \bar{a} r$ Schrift in unterschiedlichen Farben werden auch durch leere Balken voneinander getrennt. Bei den Stellen in $\dot{G} u b \bar{a} r$-Schrift dürfte es sich stets um Text aus Q 34 handeln. ${ }^{88}$ Der Schreiber hat den Text hier nicht ausschliesslich auf horizontalen Zeilen kopiert. Wiederholt lassen sich Zeilen erkennen, auf denen der Text vertikal notiert ist. Vereinzelt steht der Text auf dem Kopf. Rechts oben steht unterhalb der Basmala Q 34.1. In der linken unteren Ecke steht zuletzt Text in weinrotem $\dot{G} u b \bar{a} r$. Hier steht auf der drittuntersten Zeile der Beginn von Q 34.53. Die beiden letzten Begriffe dieses Verses stehen am Schluss der viertuntersten Zeile; der Kopist springt hier also nach oben. ${ }^{89}$ Der letzte Vers der Q (34.54) liess sich noch nicht mit Sicherheit identifizieren. Es ist aber davon auszugehen, dass auch dieser Vers hier kopiert worden ist.

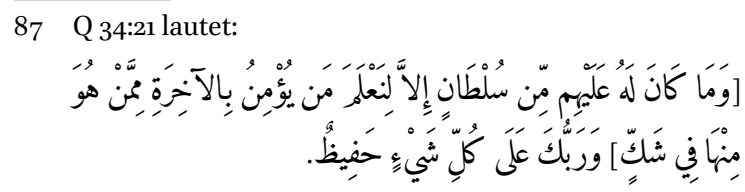

Der Text in eckigen Klammern hier nicht in grossem Kufi hervorgehoben.

88 Die zur Verfügung stehenden scans sind zwar von sehr guter Qualität. Für das sichere Bestimmen der hier kopierten Stellen in besonders kleinem $\dot{G} u b \bar{a} r$ wären aber professionell erstellte Digitalisate mit einer noch höheren Auflösung erforderlich.

89 Q 34:53 lautet:

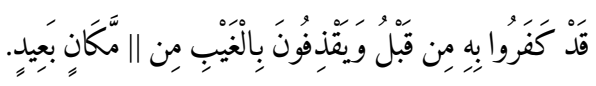

Die Markierung || kennzeichnet die Stelle, wo der Kopist am Schluss der drittuntersten Zeile ans Ende der viertuntersten Zeile springt. 
33. Querbalken: ${ }^{90}$ Sürat Fāțir (Q 35). Länge: ca. $11.8 \mathrm{~cm}$. Überschrift in goldenem $K u ̈ f \imath$ auf blauem Hintergrund mit roten Einsprengseln. ${ }^{91}$ In diesem Abschnitt wurde Text mit schwarzer Tinte in $\dot{G} u b \bar{a} r$-Schrift kopiert und derart angeordnet, dass ein übergeordneter Text in Schachbrett-Küfì entsteht. Im Zentrum ein schmaler, senkrecht ausgerichteter Balken mit schwarzem Hintergrund, auf dem sich goldene und jetzt hellblaue Querstriche erkennen lassen. Es liess sich nicht klären ob diese Elemente einen Text bilden. Um diesen senkrechten Balken herum führen 3 (oben 4) Zeilen mit Text in schwarzem $\dot{G} u b a \bar{r}$. Aussen zusätzliche Stellen in $\dot{G} u b \bar{a} r$-Schrift, die einen übergeordneten Text bilden. Beim Entziffern ist wohl unten zu beginnen, wo sich horizontal der Begriff al-hamd erkennen lässt. Links aufsteigend steht mit grosser Wahrscheinlichkeit li-[A]llāh. Oben horizontal dürfte allad̄̄ zu lesen sein. ${ }^{92}$ Diese Abfolge stünde in Q 35:1, wo sich dann fātîir anschliesst. Es ist nicht ausgeschlossen, diesen Begriff im rechts absteigenden Ausdruck zu erkennen. Allerdings kann die Entzifferung dieses letzten Begriffs nicht restlos überzeugen. Der Text in $\dot{G} u b a \bar{r}$-Schrift in diesen grossen Begriffen in Schachtbrett-Kūfì dürfte eine Abschrift von Q 35 enthalten. Der Schreiber ändert in den einzelnen Buchstaben immer wieder die Richtung. Einzelne Stellen sind horizontal ausgerichtet, andere senkrecht. Der Text steht auch mehrfach auf dem Kopf; er verläuft ausserdem sowohl aufsteigend als auch absteigend. Es konnte nicht restlos geklärt werden, von welchen Grundsätzen sich der Kopist bei der Abschrift leiten liess. So liess sich z.B. die Basmala dieser Sure nicht nachweisen; auch sie dürfte aber in diesem Abschnitt enthalten sein.

34. Querbalken (Aв B. 66): ${ }^{93}$ Sūrat $Y \bar{a}-\sin (\mathrm{Q} 36)$. Länge: $9.8 \mathrm{~cm}$. Der Titel von Sure $Y \bar{a}$-sin steht in roter, golden umrahmter Schrift auf blauem Hin-

$90 \quad$ Abb. 15.2 .

91 Im Titel fällt die Gestaltung des Buchstabens țầ' in Fāțir auf; sie erinnert stark an ein $k \bar{a} f$.

92 Alif-lām wären dabei wider Erwarten miteinander verbunden.

93 Abb. 15.1. tergrund. Der Hintergrund dieses Abschnitts wird durch Text in weinrotem $\dot{G} u b \bar{a} r$ gebildet, der auf zumeist horizontalen Linien angeordnet ist. Wahrscheinlich ist der Text von Q 36 hier nur zum Teil kopiert worden, stehen die Länge der Sure und jene des vorliegenden Abschnitts doch in keinem vernünftigen Verhältnis. In diesem Abschnitt dominiert eine aufwendig ausgeführte Verzierung. Es handelt sich um die Buchstabenfolge $Y \bar{a}$-sìn, die dieser Sure den Namen gibt und sie auch eröffnet (vgl. Q 36:1). Dieser Ausdruck steht senkrecht ausgerichtet in grossen goldenen Buchstaben in diesem Abschnitt; die Buchstaben werden durch schmale weisse Linien im Innern strukturiert. Um diese Buchstabenfolge herum zusätzliche Verzierungen in blauer, goldener und vereinzelt roter Farbe (Blätter, Blüten, vereinzelt Ranken). Unten ein horizontal ausgerichtetes Medaillon in Tropfenform.

35. Querbalken: ${ }^{94}$ aṣ-Ṣāfāt (Q 37). Länge: $9.8 \mathrm{~cm}$. Der Titel von Q 37 (aș-Ṣâāat) lässt sich in weinrotem, golden eingefasstem Kü $\imath \iota$ auf blauem, mit vereinzelten weissen Ranken versehenen Titelbalken klar erkennen. Im Mittelstreifen darunter folgen 8 horizontale Zeilen mit Text in schwarzem $\dot{G} u b \bar{a} r$. Danach ändert die Gestaltung unerwartet: Es schliesst sich ein Abschnitt an, in dem diagonale Linien mit Text in schwarzem $\dot{G} u b \bar{a} r$ ein Gitter bilden. Die Maschen dieses Gitters wurden mit Text in weinrotem $\dot{G} u b \bar{a} r$ auf horizontalen Zeilen ausgefüllt.

Da der Text im Mittelstreifen in nur schwer zu entzifferndem $\dot{G} u b \bar{a} r$ notiert worden ist, fällt die Unregelmässigkeit nicht bereits im ersten Moment auf. Ein Kontrollblick auf die beiden Seitenbänder macht aber deutlich, dass hier etwas nicht stimmt. قل هd [?] كفوا احد. قل هو حد الله قال هل Abschnitt der Rolle verloren gegangen. Es wurde offensichtlich der Versuch unternommen, diesen Verlust zu vertuschen, indem man die verbliebe-

94 Abb. 15.1-3.

95 Unmittelbar zuvor geht eine Einheit mit der Abschrift von Q 112 zu Ende. 
nen Teile wieder sorgfältig zusammenfügte. Auch ein Blick auf den nächsten Querbalken bestätigt dies. Dort steht nämlich Sūrat Fuṣillat, der Titel von Q 41. Unmittelbar über diesem Querbalken lässt sich eine weitere Bruchstelle erkennen: Der goldene Streifen zur Abgrenzung des Seitenbands ist gerade auf der rechten Seite klar unterbrochen.

Am Anfang dieses Abschnitts stehen unterhalb des Querbalkens mit dem Titel die Anfangsverse von Q 37 (aș-Ṣāfāt). ${ }^{96}$ Bei den Stellen, die im anschliessenden Abschnitt mit dem Gittermuster kopiert worden sind, handelt es sich soweit ersichtlich jedoch um Passagen aus Q 40. Auch diese Beobachtungen bestätigen, dass hier ein bedeutender Abschnitt der Rolle verloren gegangen ist. DerVerlust betrifft Q 38 und 39 (jeweils ganz), Q 37 (zu grossen Teilen) und Q 40 (teilweise). Allfällige Erklärungen für diesen Verlust folgen später. ${ }^{97}$

36. Querbalken: ${ }^{98}$ Sūrat Fușșilat (Q 41). Länge: $9.5 \mathrm{~cm}$. Nach diesen Unregelmässigkeiten folgt der Abschnitt mit Q 41. Der Titel in goldenem Küfı auf blauem Hintergrund mit roten Einsprengseln. Im Abschnitt darunter der Text von Q 41 in schwarzem $\dot{G} u b \bar{a} r$ auf horizontalen Zeilen. Am Anfang die Basmala; unmittelbar darunter steht in grosser goldener Schrift die Buchstabenfolge $h \bar{a}^{3}$-mìm (Q 41:1). Zuunterst links steht Q 41:54 (Schlussvers). Der Schreiber hat in diesem Abschnitt Stellen leer gelassen, die jetzt winkelförmige Figuren bilden. Auf den ersten Blick erinnert diese Gestaltung an Stellen in Schachbrett-Kūfì. Die gewählte Gestaltung dient hier aber wohl ausschliesslich der Verzierung. Ein Text liess sich darin nicht erkennen.

37. Querbalken: ${ }^{99}$ Sūrat aš-Šūrā (Q 42). Länge: $7.8 \mathrm{~cm}$. Titel in goldenem, jetzt stark verderbtem $K \bar{u} f \imath$ auf blauem Hintergrund. Am Anfang steht in grosser, goldener Schrift die Buchstabenfolge

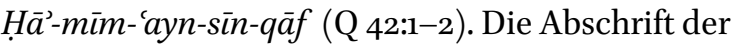
Sure beginnt mit der Basmala; sie endet unten links in rotem $\dot{G} u b \overline{a r}$ mit Q 42:48. Der Schluss

96 Da die Stelle verderbt ist, lassen sich die Einzelheiten nur noch schwer erkennen.

97 Vgl. unten bei Anm. 107-108.

98 Abb. 15.3.

99 Abb. 15.4.
(Q 42:49-53) fehlt. Der Schreiber kopierte den Text in rotem und schwarzem $\dot{G} u b \bar{a} r$. Während der Wechsel der Farben oben und unten ein Winkelmuster entstehen lässt, lässt sich in einem Mittelband eine bogenförmige Anordnung erkennen. Diese Gestaltung dürfte ausschliesslich zur Verzierung dienen und bildet wohl keinen Text.

38. Querbalken:100 Sūrat az-Zuhruf (Q 43). Länge: $8.2 \mathrm{~cm}$. Titel in jetzt weissem Zierkūfî im Querbalken mit blauem Hintergrund und goldenen Ranken. Im Abschnitt darunter Q 43 in schwarzem und weinrotem $\dot{G} u b \bar{a}$. Unterhalb der Basmala steht in grosser goldener Schrift die Buchstabenfolge $H \bar{a}^{3}$-mim (Q 43:1). Der Schluss der Sure liess sich aufgrund des sehr kleinen $\dot{G} u b \bar{a} r$ nicht mit Sicherheit lokalisieren. Der Schreiber hat den Text zumeist in abwechselnd schwarzen und weinroten Rechtecken angeordnet, die zwei oder drei Zeilen umfassen. Dadurch entsteht ein Rastermuster. Durch Aussparungen entstehen v.a. auf der linken Seite mit einem goldenen Punkt verzierte Quadrätchen.

39. Querbalken: ${ }^{101}$ Sūrat ad-Duhāon (Q 44). Länge: $6.0 \mathrm{~cm}$. Titel in weissem Küfı auf einem jetzt schwarzen, mit goldenen Ranken verzierten Hintergrund. Im Rechteck darunter wurde der Surentext in rotem $\dot{G} u b \bar{a} r$ kopiert. Am Anfang in grosser goldener Schrift die Buchstabenfolge $H \bar{a}^{\prime}$ mim (übereinander angeordnet) aus Q 44:1. In der untersten Zeile steht Q 44:57. Beim Ausdruck ganz am Schluss dürfte es sich um yatadakkarūna (letztes Wort Q 44:58) handeln. Der Schlussvers (44.59) liess sich nicht lokalisieren. Der Schreiber hat in diesem Abschnitt Leerraum derart ausgespart, dass übergeordneter Text entsteht. Es handelt sich um Q 44:49. ${ }^{102}$

40. Querbalken:103 Sūrat al-Ğātiya (Q 45). Länge: $5.8 \mathrm{~cm}$ (links); $6.5 \mathrm{~cm}$ (rechts). Titel in gol-

\footnotetext{
100 Abb. 15.4.

101 Abb. 16.1-2.

102 Q 44:49 lautet:

103 Abb. 16.1-2.
} 
dener Schrift auf schwarzem Hintergrund, der zur Verzierung mit weissen Ranken versehen ist. Im Abschnitt darunter folgt der Text von Q 45 in schwarzem $\dot{G} u b \bar{a} r$ auf horizontalen Zeilen. Unterhalb der Basmala wurde die Buchstabenfolge $H \bar{a}^{3}-\operatorname{mim}(\mathrm{Q} 45: 1)$ in grosser goldener Schrift hervorgehoben. Goldene Punkte als Verstrenner. Links unten steht Q 45:37 (Schlussvers). In diesem Abschnitt lassen sich Hinweise auf leichte Beschädigungen feststellen, wie sich anhand von Bruchstellen in den Zierleisten rechts (oben) und links (unten) erkennen lässt; dies erklärt auch die abweichenden Längen des Abschnitts auf der linken bzw. rechten Seite. Der Text im Mittelstreifen ist durch diese Beschädigung leicht gestaucht, dürfte aber vollständig sein.

41. Querbalken: ${ }^{104}$ Sūrat al-Aḥqāf (Q 46). Länge: ca. $7 \cdot 7 \mathrm{~cm}$. Titel in goldenem, jetzt häufig grün verfärbtem $K \bar{u} f \imath$ auf einem blauen Hintergrund mit roten Einsprengseln. Im Abschnitt darunter der Surentext in weinrotem $\dot{G} u b \bar{a} r$ auf horizontalen Zeilen. Unterhalb der Basmala wurde die Buchstabenfolge $H \bar{a}^{\prime}-$ mim $(\mathrm{Q}$ 46:1) in grosser goldener Schrift hervorgehoben. Am Schluss lässt sich unten links Q 46:35 (Schlussvers) erkennen.

42. Querbalken (Ав B. 67): ${ }^{105}$ Sūrat Muhammad (hier der alternative Titel al-Qitāl, Q 47). Diese Überschrift in weissem Küfı auf blauem, mit goldenen Ranken verziertem Hintergrund. Die Länge dieses Abschnitts bis zum nächsten Querbalken beträgt ca. $9.7 \mathrm{~cm}$.

In diesem Abschnitt lassen sich Unregelmässigkeiten feststellen. Dies geht aus den Bruchstellen im Text im Mittelstreifen und in den Zierleisten der Seitenbänder auf der linken und rechten Seite hervor. Im Mittelstreifen selbst wurde durchgehend Text in schwarzem $\dot{G} u b \bar{a} r$ kopiert. Die Schrift im unteren Drittel unterscheidet sich allerdings deutlich von jener darüber. Der Wechsel stimmt mit den Bruchstellen in den beiden Seitenbändern überein. Eine Überprüfung ergab, dass im oberen

104 Abb. 16.1-2.

105 Abb. 16.3
Teil Q 47:1-37/38106 kopiert worden ist. Q 47 steht somit vollständig auf der Rolle.

Unmittelbar darunter ändert die Schrift. Am Anfang lässt sich rechts eine Basmala erkennen. Der sonst übliche Titelbalken davor fehlt jedoch. ${ }^{107}$ Überprüfungen ergaben, dass danach der Text von Q 49 (Q 49:1-18) vollständig kopiert worden ist.

Aus diesen Beobachtungen geht hervor, dass auf dieser Rolle Q 48 (al-Fath) ganz fehlt. Der Umstand, dass Q 47 und 49 davor und danach aber auf der Rolle vollständig enthalten sind, weist darauf hin, dass Q 48 an dieser Stelle bewusst herausgeschnitten worden ist. Indem man auch das Titelfeld von Q 49 heraustrennte, versuchte man wohl, diese Unregelmässigkeit derart zu vertuschen, dass sie nicht auf den ersten Blick erkenntlich ist. Es sei darauf hingewiesen, dass Q 48 (alFath) bei Initiationszeremonien in mystisch orientierten Gruppierungen (Sufi-Orden, Futuwwa- und Ahi-Gruppierungen) eine besondere Rolle spielt. Es stellt sich damit die Frage, ob der jetzt fehlende Abschnitt mit Q 48 und ihren im Rahmen von Initiationszermemonien besonders wichtigen Versen am Anfang (Q 48:1-3) allenfalls Hinweise auf jene Person enthalten hatte, für die die Rolle bestimmt war. ${ }^{108}$

43. Querbalken:109 Sūrat [al-Qāf] makkiyya (Q 50): Länge: ca. $5 \cdot 5 \mathrm{~cm}$. Titel in goldenem Küfi in einem Querbalken mit blauem Hintergrund. Der Name der Sure ist hier nicht mehr erkenntlich. Der Buchstaben $q \bar{a} f$ steht aber gross und blau eingefasst im Abschnitt darunter. Der Surentext selbst in weinrotem $\dot{G} u b \bar{a} r$ auf horizontalen Zeilen. Der Abschnitt ist rechts oben verderbt. Text aber ab Q 50:2b klar erkennbar. Auf der letzten Zeile steht unten links Q 50:45 (Schlussvers). In einer blau und golden umrahmten Figur in der

\footnotetext{
106 Die letzte Zeile ist verderbt.

107 Der Titel von Q 49 lautet al-Huğurāt.

$108 \mathrm{Zu}$ diesen Initiationszeremonien vgl. Kapitel 3.4.3. Zur Fragen siehe auch Nünlist, Devotion and protection: Amuletic scrolls dating from the 14 th century, 505-510. 109 Abb. 16.3.
} 
Mitte des Abschnitts wurde Text in schwarzem $\dot{G} u b a \bar{r}$ kopiert. Dieser Text liess sich nicht mit Gewissheit bestimmen. Es dürfte sich aber um Korantext handeln.

44. Querbalken:110 Sūrat ad-Dāriyāt (Q 51). Länge: $5.1 \mathrm{~cm}$. Titel in goldenem Küfi im Querbalken mit blauem Hintergrund. Im dazugehörenden Abschnitt darunter wurde der Text von Q 51:1-6o in schwarzem $\dot{G} u b \bar{a} r$ auf horizontalen Zeilen wohl vollständig kopiert. ${ }^{111}$ Goldene Punkte als Verstrenner.

45. Querbalken:12 Sūrat aț-Ṭūr (Q 52). Länge: $5.3 \mathrm{~cm}$. Titel in weisser Schrift in einem Querbalken mit goldenem Hintergrund und blauen Einsprengseln; er lässt sich kaum erkennen. Allerdings steht im Abschnitt klar leserlich der Text von Q 52:1-49. Es wurde nicht überprüft, ob die Abschrift lückenlos ist.

46. Querbalken:113 Sūrat wa-n-Nağm (Q 53). Länge: $7.7 \mathrm{~cm}$. Titel in goldenem $K \bar{u} f \imath$ auf blauem Hintergrund mit weissen Ranken. Im Abschnitt darunter wurde der Surentext (Q 53:1-62) $)^{114}$ in rotem $\dot{G} u b \bar{a} r$ auf horizontalen Zeilen kopiert. Goldene Punkte als Verstrenner. In diesem Abschnitt fällt ein Medaillon auf, das durch zwei voneinander getrennte goldene Ringe eingefasst wird. Im Innern auf blauem, mit vereinzelten goldenen Verzierungen versehenem Hintergrund in weissem Küfi: Wa-n-nağm (Q 53:1).

47. Querbalken:115 Sūrat al-Qamar (Q 54): Länge: $5 \cdot 5 \mathrm{~cm}$. Titel in rotem, golden eingefasstem $K \bar{u} f \iota$ im Querbalken mit blauem Hintergrund, der zur Verzierung mit goldenen Ranken versehen ist. Im Abschnitt darunter Q 54:1-55 ${ }^{116}$ in schwarzem $\dot{G} u b a \bar{r}$ auf horizontalen Zeilen. Goldene Punkte als

\footnotetext{
110 Abb. 16.3-4.

111 Die Abschrift wurde nicht auf ihre Vollständigkeit hin überprüft.

112 Abb. 16.4.

113 Abb. 16.4.

114 Die Abschrift wurde nicht auf ihre Vollständigkeit hin überprüft.

115 Abb. 16.4.

116 Die Abschrift wurde nicht auf ihre Vollständigkeit hin überprüft.
}

Verstrenner. Der Text ist verschiedentlich verderbt. Kein übergeordneter Text in diesem Abschnitt.

48. Querbalken:117 Sūrat ar-Raḥmān (Q 55). Länge: $8.2 \mathrm{~cm}$. Titel der Sure in goldenem Küfı auf blauem Hintergrund im Querbalken. Der Surentext selbst im Abschnitt darunter in weinrotem $\dot{G} u b \bar{a} r$ auf horizontalen Zeilen. Am Anfang lässt sich Q 55:1 und auf der letzten Zeile Q 55:78 (Schlussvers) erkennen. ${ }^{118}$ Auf diesem Hintergrund dominiert in grosser blauer, golden eingefasster Schrift der Ausdruck ar-Raḥmān. Ausserdem fallen goldene Ranken auf. In der linken Ecke ein zusätzliches Zierelement.

49. Querbalken:119 Sūrat al-Wāqia (Q 56): Länge: $6.4 \mathrm{~cm}$. Überschrift in weissem $K \bar{u} f \grave{\imath}$ auf blauem, mit goldenen Ranken versehenem Hintergrund. Der Surentext (Q 56:1-96) ${ }^{120}$ im dazugehörenden Abschnitt darunter in schwarzem $\dot{G} u b \bar{r} r$ auf horizontalen Zeilen. Goldene Punkte als Verstrenner. Kein übergeordneter Text in diesem Abschnitt.

50. Querbalken:121 Sūrat al-Hadīd (Q 57): Länge: $47.2 \mathrm{~cm}$. Titel in weissem $K \bar{u} f \imath$ auf blauem, mit goldenen Ranken versehenem Hintergrund. Ausgebesserte Beschädigung im linken Seitenband. In diesem Abschnitt wurde als Hintergrund Text in weinrotem $\dot{G} u b \bar{a} r$ kopiert. Dieser Text, es handelt sich wohl um eine Abschrift von Q 57, ist oft aber nur noch schlecht erkenntlich. Er ist gerade am Anfang stark verblasst. Auf der letzten Zeile lässt sich aber der Beginn von Q 57:29 (Schlussvers) erkennen. Ob der Text von Q 57 in rotem $\dot{G} u b \bar{a} r$ hier vollständig kopiert wurde, wurde im einzelnen nicht überprüft; dies ist allerdings zu vermuten.

Der $\dot{G} u b \bar{a} r$-Text wird in diesem Abschnitt vielfach durch übergeordneten grossen Text und zusätzliche Zierelemente unterbrochen. Diese

\footnotetext{
117 Abb. 17.1-2.

118 Die Abschrift wurde nicht auf ihre Vollständigkeit hin überprüft.

119 Abb. 17.2.

120 Die Abschrift wurde nicht auf ihre Vollständigkeit hin überprüft.

121 Abb. 17.2-18.3.
} 
zusätzlichen Zierelemente füllen die meisten Leerstellen in diesem Abschnitt aus und erinnern an das aus der klassischen Antike bekannte Prinzip, jeglichen freien Raum auszufüllen (horror vacui).

Der übergeordnete Text wurde in grossen goldenen Buchstaben kopiert und verläuft in der Rollenrichtung absteigend. Er lässt sich nicht an sämtlichen Stellen zweifelsfrei entziffern. Es handelt sich aber soweit ersichtlich um eine Abschrift von Q 57:3:

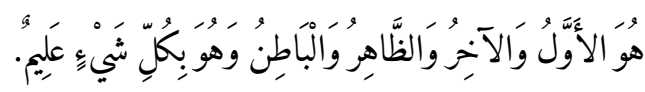

Bei einem Blick auf diesen Abschnitt fallen ausserdem die zahlreichen blauen und auch roten Zierelemente auf, die sich als Blätter und Blüten interpretieren lassen. Dieser Abschnitt hinterlässt beim Betrachten einen komplexen Eindruck. Es ist, als ob man einen Dschungel oder Urwald vor sich hätte. Die Oberlängen der Buchstaben würden dabei die Stämme der Bäume und die blauen und roten Verzierungen deren Blätter und Blüten darstellen.

Nach dem vorangehenden Abschnitt mit der Abschrift von Q 57:3 als grosser Text folgen die weiteren Suren (Q 58-66). Dieser Abschnitt misst insgesamt $41.2 \mathrm{~cm}$. Die Gestaltung dieser Abschnitte ist weitgehend identisch. Ein grosser Text fehlt. Der Titel der jeweiligen Sure wird in kufischer Schrift in einem Querbalken notiert. Der Text der einzelnen Suren wurde danach in $\dot{G} u b \bar{a} r$-Schrift auf horizontalen Zeilen kopiert (zumeist schwarz, vereinzelt rot). Dieser Abschnitt wird hier nur summarisch vorgestellt:

51. Querbalken:122 Sūrat al-Muğādala (Q 58). Schwarzes $\dot{G u b a ̄ r}$. 52. Querbalken:123 Sūrat alHašr (in goldenem Kūfı auf blauem Hintergrund; Q 59), schwarzes Gubār. 53. Querbalken: ${ }^{124}$ Sūrat al-Mumtahina (Q 6o). Surentext in rotem Gubār. 54. Querbalken:125 Sūrat aș-Ṣaff (Q 61, Titelbalken

\footnotetext{
122 Abb. 18.4.

123 Abb. 18.4.

124 Abb. 18.4.

125 Abb. 18.4.
}

mit rotem Hintergrund). Surentext in schwarzem $\dot{G} u b \bar{a} r$. 55. Querbalken:126 Sūrat al-Ğum'a (Q 62), Surentext in schwarzem $\dot{G} u b \overline{a r} .5^{6}$. Querbalken:127 Überschrift Sūrat at-Tajāābun. Dies ist der Titel von Q 64. Beim anschliessend in schwarzem $\dot{G} u b \bar{a} r$ kopierten Text handelt es sich aber um Q 63, die ja eigentlich hierhin gehört. 57. Querbalken:128 Überschrift Sūrat al-Munāfiqūn (Q 63). Beim anschliessend in schwarzem und rotem $\dot{G} u b \bar{a} r$ kopierten Text handelt es sich aber um jenen von Q 64, der hier auch zu erwarten ist. Diese erneuten Unregelmässigkeiten in den Titelbalken dürften darauf hinweisen, dass die Überschriften durch eine andere Person angefertigt wurden als die Abschrift des Surentexts in $\dot{G} u b \bar{a} r$. Man beachte, dass bereits der Titel al-'Ankabūt irrtümlich an zwei Stellen steht. ${ }^{129}$ 58. Querbalken:130 Sūrat aț-Ṭalāq makkiyya (Q 65); Abschrift in rotem und schwarzem $\dot{G} u b \bar{a} r$ auf horizontalen Zeilen. 59. Querbalken:131 Sürat at-Tahrim makkiyya (Q 66).

6o. Querbalken (AвB. 68):132 Sūrat al-Mulk (Q 67). Der Abschnitt mit Q 67 weist wieder eine besondere Gestaltung auf. Seine Länge beträgt $9.4 \mathrm{~cm}$. Titel in goldenem, jetzt teilweise grün verfärbtem Küfı auf blauem Hintergrund mit goldenen, weiss eingefassten Einsprengseln. Im dazugehörenden Abschnitt darunter wurde der Surentext in rotem $\dot{G} u b \bar{a} r$ auf horizontalen Zeilen kopiert. Am Ende des Abschnitts Q 67:30 (Schlussvers). Auf der ersten horizontalen Zeile steht am Anfang die Basmala und danach Q 67:1b. Der Anfang dieses Verses (Q 67:1a) fehlt zwar auf dieser ersten Zeile, er wurde in diesem Abschnitt aber dennoch kopiert. Er steht prominent in vertikaler, zuerst absteigender, dann aufsteigender Richtung, in grossen, an Küfı erinnernden Zierbuchstaben. Dieser Anfang von Q 67:1 lautet:

\begin{tabular}{ll}
\hline 126 & Abb. 18.5 \\
127 & Abb. 18.5 \\
128 & Abb. 18.5 \\
129 & Vgl. dazu oben nach Anm. 79. \\
130 & Abb. 18.5 \\
131 & Abb. 18.6 und 19.1. \\
132 & Abb. 19.1-2.
\end{tabular}




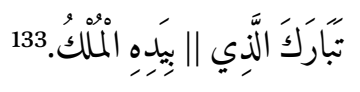

Die Ausführung in gegenläufiger, zuerst ab-, dann aufsteigender Schriftrichtung, führt dazu, dass die Oberlängen der Buchstaben ineinander verzahnt sind. Dies trifft gerade auf die beiden Begriffe ALLad̄i und AL-mulk zu. Alif und lām werden hier als drei parallel zueinander verlaufende goldene Balken dargestellt. In der oberen Hälfte dieses Abschnitts wurden die Buchstaben rot eingefasst und erscheinen in kufischer Schrift als Aussparungen auf dem Hintergrund in $\dot{G} u b \bar{a} r$. Am Schluss des Abschnitts lässt sich horizontal ausgerichtet ein Vogel (?) erkennen (goldener Schnabel, goldenes Auge, goldener Flügel). Das Wechselspiel zwischen Aussparungen und Stellen in $\dot{G} u b \bar{a} r$-Schrift akzentuiert diese Figur. Sie scheint zugleich den Buchstaben $y \bar{a}^{\prime}$ im Ausdruck allad̄i darzustellen. Verschiedene goldene Punkte in diesem Abschnitt dienen einerseits der Verzierung, anderseits als Punktierungen der Buchstaben.

Es fällt auf, dass der Betrachter beim Auflösen der Stellen in grosser Schrift auf diesem Belegstück oft vor einer Art Vexierbild steht. Erst nach und nach wird deutlich, auf welche Art der Hersteller des Dokuments vorging. Verschiedentlich liessen sich diese Stellen in Vexierschrift nicht auflösen. Im vorliegenden Abschnitt liess sich bis anhin nicht klären, was es mit der Darstellung des Vogels auf sich hat. Es könnte sich um eine Anspielung auf Q 67:19 handeln, wo der Begriff at-tayr (Vogel, auch Kollektivum) vorkommt. ${ }^{134}$ Der Vers spielt auf die Allmacht Gottes (al-mulk, vgl. den Titel der vorliegenden Sure) an, der die Vögel beim Fliegen in der Luft hält, ohne sie abstürzen zu lassen. Es kann aber gut sein, dass sich mit dieser Abbildung eines Vogels zusätzliche Vorstellungen verbinden,

133 Die Markierung || kennzeichnet die Stelle, wo der vorwärtslaufende in den rückwärtslaufenden Text übergeht.

Q 67:19 lautet:

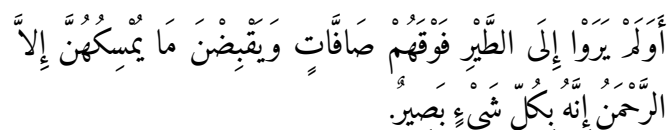

die sich nicht klären liessen. In einem islamischen Kontext, zumal auf einer Abschrift des Korans, verdient die Abbildung eines Lebewesens aber Beachtung. Die islamische Dogmatik kritisiert das Darstellen von Lebewesen bekanntlich, sei der Künstler doch nicht in der Lage, diesen Tieren auch Leben einzuhauchen. Dies sei das ausschliessliche Privileg des Schöpfergottes Allāh. ${ }^{135}$ Immerhin hat der Künstler den Vogel im vorliegenden Bild gut versteckt. Auf Belegstücken aus dem 18. oder 19. Jh. und dem iranischen Kulturraum werden Vögel (Pfauen) viel deutlicher dargestellt. ${ }^{136}$

Die Anordnung der Suren nach absteigender Länge führt dazu, dass die Abschnitte des Korans gegen den Schluss kürzer werden. Dies lässt sich auch auf dem vorliegenden Belegstück feststellen. Die kurzen Abschnitte eignen sich nur noch schlecht, um darin übergeordneten Text unterzubringen. Die Rolle wird damit eintöniger, wurde der Text in der Folge doch einfach in schwarzem oder vereinzelt rotem $\dot{G} u b \bar{a} r$ auf horizontalen Zeilen kopiert. Der Hersteller des vorliegenden Belegstücks wirkt einer allfälligen Eintönigkeit allerdings entgegen, indem er die Titelbalken aufwendiger gestaltet. Sie sind jetzt tendentiell aufmerksamer ausgeführt als am Anfang der Rolle. Die weitere Beschreibung beschränkt sich auf das Hervorheben der wichtigsten Eckpunkte. Die Art der Abschrift ist von Q 68 bis und mit Q 96 weitgehend identisch; sie ändert erst wieder mit Q 97. Die Länge des Abschnitts mit den Q 68-96 beträgt ca. $96 \mathrm{~cm}$ :

61. Querbalken: ${ }^{137}$ Sūrat Nūn (Q 68; die Sure ist üblicherweise unter dem Titel Sūrat al-Qalām bekannt). Der Buchstaben nūn steht einerseits im Titelfeld; er wird aber auch auf der ersten Zeile des Texts golden hervorgehoben. Auf der letzten Zeile

\footnotetext{
135 Vgl. zu dieser Debatte: Naef, Bilder und Bilderverbot 1132 (zur Ausgangslage: „Die heiligen Schriften und ihre klassischen Interpretationen“).

136 Eine Rolle mit der Darstellung von Vögeln befindet sich im Privatbesitz von Prof. Dr. J.W. Frembgen (München), der das Exemplar dem Verfasser bei einem Treffen im Mai 2014 in Basel gezeigt hatte. 
des Abschnitts wurde der Buchstaben kāf (im Begriff dikr aus dem Schlussvers, Q 68:52) derart stark gedehnt, dass er einen grossen Teil der Zeile ausfüllt. 62. Querbalken:138 Sūrat al-Hāqa (Q 69). 63. Querbalken:139 Sūrat Sāill (?) (Q 70). Die Sure ist üblicherweise unter dem Titel al-Mírāğ bekannt; der anschliessend kopierte Text entspricht jenem von Q 70. 64. Querbalken:140 Sūrat Nūh (Q 71), rote Tinte auf blauem Grund. 65. Querbalken:141 Sūrat al-Ğinn (Q 72). 66. Querbalken:142 Sūrat alMuzammil (Q 73). Q 73:1-2 wurde hier in grosser goldener Schrift notiert:

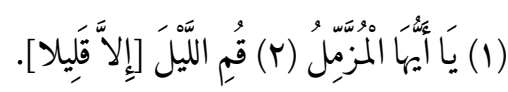

Der restliche Text der Sure in rotem $\dot{G} u b \bar{a} r$ auf horizontalen Zeilen (goldene Verstrenner). 67. Querbalken:143 Sürat al-Mudattirir (Q 74, Querbalken mit rotem Hintergrund). 68. Querbalken:144 Sūrat al-Qiyāma (Q 75). 69. Querbalken:145 Sūrat alInsān (Q 76). 7o. Querbalken:146 Sūrat al-Mursalāt (Q 77). 71. Querbalken:147 Titel unklar, da verderbt; übliche Benennung: Sūrat an-Naba' (Q 78). Der Text stimmt mit Q 78 überein. 72. Querbalken:148 Sūrat an-Nāzicāt (Q 79). 73. Querbalken:149 Q 8o; Titel verderbt (Schrift auf goldenem Hintergrund). Er müsste lauten: Sūrat 'Abasa. Der Text stimmt mit Q 8o überein; stellenweise verderbt. 74. Querbalken:150 Takwir (Q 81, Rand des Querbalkens abweichend gestaltet). 75. Querbalken: ${ }^{151}$ Sürat al-Infițār (Q 82). 76. Querbalken:152

$\begin{array}{ll}138 & \text { Abb. 19.2 und 20.2. } \\ 139 & \text { Abb. 2O.2. } \\ 140 & \text { Abb. 2O.1-2. } \\ 141 & \text { Abb. 20.2. } \\ 142 & \text { Abb. 20.2. } \\ 143 & \text { Abb. 20.2. } \\ 144 & \text { Abb. 2O.1 und 3. } \\ 145 & \text { Abb. 20.3. } \\ 146 & \text { Abb. 20.3. } \\ 147 & \text { Abb. 20.3. } \\ 148 & \text { Abb. 20.3. } \\ 149 & \text { Abb. 20.3. } \\ 150 & \text { Abb. 20.3 (Titel) und 21.2 (Surentext). } \\ 151 & \text { Abb. 21.2. } \\ 152 & \text { Abb. 21.2. }\end{array}$

Sūrat al-Muțaffifin (Q 83).77. Querbalken:153 Sūrat al-Inšiqāq (Q 84, Titel teilweise unleserlich, verderbt, Textverlust). 78. Querbalken:154 Sūrat alBurūğ (Q 85; rotes $\dot{G} u b \overline{a r}$; Schlussverse in grossem goldenem Nash: 85:20-22):

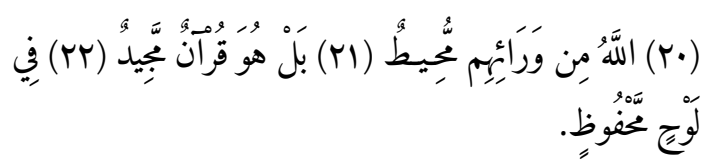

79. Querbalken:155 Sūrat aț-Tāriq (Q 86). 8o. Querbalken:156 Sūrat Sabbih (Q 87: üblicherweise Sūrat al-Alā; Titel rot auf blauem Grund). 81. Querbalken: ${ }^{157}$ Sūrat al-Ġāšiya (Q 88). 82. Querbalken:158 Sūrat al-Fağr (Q 89). 83. Querbalken:159 Sūrat alBalad makkiyya (Q 90). 84. Querbalken:160 Sūrat aš-Šams wa-duhāa-hā (Q 91). 85. Querbalken:161 Sūratwa-l-Layl (Q 92). 86. Querbalken: ${ }^{162}$ Sürat aḍDuhāa makkiyya (Q 93). 87. Querbalken:163 Sūrat Alam našrah (Q 94; Titel in weisser Schrift auf goldenem Hintergrund). 88. Querbalken: ${ }^{164}$ Sūrat Wat-Tin makkiyya (Q 95). 89. Querbalken:165 Sūrat al'Alaq (Q 96).

Hier endet der Abschnitt mit Q 68-96, deren Abschrift stets ähnlich gestaltet wurde. Die Länge des folgenden Abschnitts mit Q 97-99 beträgt $15.3 \mathrm{~cm}$.

9o. Querbalken (ABв. 69):166 Sūrat al-Qadr (Q 97; Text in grossen goldenen Buchstaben kopiert; Nash). 91. Querbalken:167 Sūrat Lam yakun (Q 98, im allgemeinen als al-Bayyina bekannt).

\footnotetext{
153 Abb. 21.2.

154 Abb. 21.2.

155 Abb. 21.2.

156 Abb. 21.2.

157 Abb. 21.2.

$15^{8}$ Abb. 21.2 (Titel) und 21.1 (Titel und Text zusammen).

159 Abb. 21.1 (sic).

16o Abb. 21.1.

161 Abb. 21.1.

162 Abb. 21.1.

163 Abb. 21.1.

164 Abb. 21.1.

165 Abb. 21.1 und 22.2 (Text der Sure nicht vollständig photographiert).

166 Abb. 22.2.

167 Abb. 22.2.
} 
Der Text hier wieder in schwarzem $\dot{G} u b \bar{a} r$ auf horizontalen Zeilen. 92. Querbalken:168 Sūrat azZalzala (Q 99). Text in grossen goldenen Buchstaben (Nash, Basmala aber in rotem $\dot{G} u b \bar{r}$ oben in der Mitte).

Ab Q 100 oder auch bereits zuvor sind die einzelnen Abschnitte des Korans aufgrund von deren Anordnung gemäss abnehmender Länge nun derart kurz, dass sie bei einer Abschrift in $\dot{G} u b \bar{a} r$ nur noch eine, höchstens zwei Zeilen beanspruchen würden. Der Schreiber hat Q 99 deshalb in grossen goldenen Buchstaben kopiert. Danach aber folgt ein Abschnitt mit vier Querbalken (also Querbalken 93-96), in dem die Suren in 3 Spalten angeordnet worden sind (АВв. 69). ${ }^{169}$ Die Länge dieses Abschnitts beträgt $19 \mathrm{~cm}$. Die dreiteiligen Querbalken und die anschliessende Abschrift der einzelnen Suren bilden jeweils Quadrate von nahezu identischer Grösse. Dieser Abschnitt umfasst also $3 \times 8$ Quadrate. In den dreiteiligen Querbalken wurden die Titel der einzelnen Suren in ähnlicher Gestaltung wie zuvor angeführt. Für die einzelnen Suren steht jetzt einfach nur noch ein Drittel der Breite des Mittelstreifens zur Verfügung. Der Surentext wurde in den jeweils dazugehörenden Quadraten darunter in $\dot{G} u b \bar{a} r$-Schrift kopiert, wobei der Text in den beiden äusseren Spalten rot, in der Mittelspalte aber schwarz ist. Auf der untersten Ebene steht der Text in den beiden Aussenspalten teils in grosser goldener Schrift und teils in rotem $\dot{G} u b \overline{a r}$. Der Abschnitt enthält im einzelnen die folgenden Suren:

93. Querbalken (dreiteilig): a. Q 100: al-Ādiyāt, Titel in weissem $K \bar{u} f \imath$ in Medaillon mit goldenem Hintergrund; b. Q 101: al-Qāríya; c. Q 102: Alhākum (üblicher Name: at-Takātur). 94. Querbalken (dreiteilig): a. Q 103: al-Așr; b. Q 103: al-Așr, die hier somit wiederholt wird (Spalte a: rotes $\dot{G} u b \bar{a} r$; Spalte b: schwarzes $\dot{G} u b \overline{a r}$ ); c. Q 104: al-Humaza. 95. Querbalken (dreiteilig): a. Q 105: al-Fïl; b. Q 106:

168 Abb. 22.2.

169 Abb. 22.1, 3 und 4.
Qurayš; c. Q 107: [al-Mā̄ūn?]. ${ }^{170}$ 96. Querbalken (dreiteilig): a. Q 108: al-Kawtar; der Text wurde hier abwechselnd auf einer Zeile in grosser Schrift (golden) und kleiner Schrift (rotes $\dot{G} u b \bar{a} r$ ) kopiert, insgesamt sechs Zeilen; Q 1og: al-Kāfirūn, Abschrift in schwarzem $\dot{G} u b \bar{a} r$ auf sechs Zeilen; c. Q 110: anNașr, Abschrift auf fünf Zeilen: zuerst drei Zeilen grosse goldene Schrift, danach zwei Zeilen rotes $\dot{G} u b a \bar{r}$.

Nach diesem Abschnitt kehrt der Schreiber wieder zur vorherigen Gestaltung zurück. Nach einem Querbalken folgt jeweils die Abschrift der entsprechenden Sure. Die Länge dieses nächsten Abschnitts beträgt $18.3 \mathrm{~cm}$ (Q 111-114): 97. Querbalken:171 Sūrat al-Masad (Q 111), Titel hier Sūrat Lahab in goldener Schrift. Abschrift der Sure auf drei horizontalen Zeilen in rotem $\dot{G} u b \bar{a} r$, erste Zeile Basmala. 98. Querbalken:172 Q 112, Titel jetzt verloren; Text der Sure auf zwei Zeilen in grossem goldenem Nash, darüber Basmala in rotem Gubār. 99. Querbalken:173 Sūrat al-Falaq (Q 113). Text auf drei Zeilen in grossem goldenem Nash. Darüber Basmala in rotem $\dot{G} u b \bar{a} r$. 10o. Querbalken: Q 114 (Sūrat an-Nās makkiyya). Text auf vier Zeilen in grossem goldenem Nash. Darüber Basmala in rotem $\dot{G} u b \bar{a}$. Rote Schraffierungen zum Ausfüllen der Leerräume zwischen den Zeilen

101. Querbalken (AB B. 70): 174 Überschrift: dunkelrote Tinte auf blauem Grund: Awfāq; der Abschnitt mit diesen awfāq schliesst sich sogleich an. Länge: $19.8 \mathrm{~cm}$. Der Abschnitt enthält $20 \times 50$ Zellen, die durch feine rote Doppellinien voneinander getrennt werden. Die Schnittstellen der Linien wurden zum Teil mit goldenen Punkten markiert. Die anfängliche Vermutung, dass diese goldenen Punkte Text bilden, liess sich nicht erhärten. Im Zellenrechteck selbst sind bei weitem nicht

\footnotetext{
170 Hier alternativer Titel, der sich nicht entziffern liess beim kopierten Text handelt es sich aber um jenen von Q 107.

171 Abb. 22.5.

172 Abb. 22.5

173 Abb. 22.5

174 Abb. 23.1-3.
} 
alle Zellen beschrieben. In den beschriebenen Zellen sind die Zeichen oft stark verblasst. An drei Stellen lassen sich Zeichen erkennen, die zu einem späteren Zeitpunkt mit schwarzer Tinte nachgeschrieben worden sind. In diesem Rechteck lassen sich acht verschiedene Einheiten mit Zeichen erkennen:

a. Zuoberst lässt sich eine Stelle feststellen, deren mit jeweils einem Buchstaben in schwarzer Tinte beschriebene Zellen ein Dreieck bilden, dessen Spitze nach unten weist. ${ }^{175}$ Die Buchstaben in diesen Zellen sind oft verderbt oder verblichen.

b. und c. Auf der linken und rechten Seite lassen sich danach zwei Zahlenquadrate erkennen; sie werden durch $4 \times 4$ Zellen gebildet, die mit Ziffern beschrieben sind. Es handelt sich nicht um magische Quadrate. ${ }^{176}$ Diese Quadrate entstehen durch die beschriebenen Zellen; sie weisen keinen Rahmen auf.

d. Unterhalb der beiden Zahlenquadrate schliesst sich ein Abschnitt mit $11 \times 14$ Zellen an. In diesem Abschnitt selbst befindet sich unten ein Quadrat mit $5 \times 5$ Zellen, die mit schwarzen Buchstaben und Ziffern beschrieben sind. Links davon schliesst sich eine Spalte mit Zellen an, die jeweils drei schwarze Punkte enthalten. Diese Einheit mit den schwarz beschriebenen Zellen befindet sich im Rechteck mit den $11 \times 14$ Zellen; diese restlichen Zellen sind mit jeweils einem Buchstaben in roter Tinte beschrieben. Es liess sich nicht bestimmen, ob diese Einzelbuchstaben einen Text bilden. Es könnte auch sein, dass die Buchstaben für Ziffern stehen, wie dies aus dem

175 Unten schliessen sich $3 \times 3$ Zellen an, die wohl ebenso beschrieben waren, jetzt aber stark verderbt sind.

176 Die Summe in den einzelnen Spalten ergibt zwar häufig, aber nicht immer, 2o. In magischen Quadraten müsste diese Summe stets identisch sein. Es fällt auf, dass die Zellen in der Hauptdiagonalen von rechts oben nach links unten stets die Ziffer 2 enthalten. Dies trifft auch auf die weiteren Zahlenquadrate in diesem Abschnitt zu (vgl. unten Buchstaben f. und g.).
Abğad-System bekannt ist. ${ }^{177}$ Ihr Sinn liess sich nicht ermitteln.

e. In der unteren Hälfte dieses Rechtecks folgt ein Abschnitt mit $12 \times 8$ Zellen, die zumeist Einzelbuchstaben in schwarzer Schrift enthalten. Es ist zu vermuten, dass sie einen Text bilden, der sich aber nicht bestimmen liess. Die oberste Zeile ist durch Verlust des Beschreibstoffs teilweise verderbt.

f. und g. ${ }^{179}$ Links und rechts schliessen sich hier zwei weitere Quadrate mit $4 \times 4$ Zellen an. Viele Ziffern scheinen zu einem späteren Zeitpunkt mit schwarzer Tinte neu geschrieben worden zu sein.

h. Zuunterst scheint sich ein letztes Quadrat mit $4 \times 4$ Zellen befunden zu haben, die mit Ziffern beschrieben waren. Die Stelle ist jetzt stark verderbt.

Die Interpretation dieses Abschnitts mit den beschriebenen Zellen muss offen bleiben. Es kann darauf hingewiesen werden, dass Zellenquadrate (wafq) aus der magischen Literatur bekannt sind. Ein Abschnitt mit wafq befindet sich auch auf Is 1624 (Chester Beatty Library). ${ }^{180}$

102. Querbalken: ${ }^{181}$ Die Rolle wird von einem Zierbalken (goldene Bänder auf blauem Hintergrund) abgeschlossen, der keinen Text enthält. Ein Kolophon scheint auf der Rolle zu fehlen. Ganz zuunterst wird das Dokument vom Rahmen abgeschlossen, in dem Q 112 wiederholt wird.

Schlussbemerkungen: Wie einleitend erwähnt dürfte das vorliegende Belegstück um 1400 (Ende 14. Jh., Anfang 15. Jh.) in zentralasiatischen Kontexten entstanden sein. Diese zeitliche und geographische Zuordnung stützt sich in erster Linie auf jene Stellen in Zierschrift, in denen die Buchstaben durch mehrere, parallel zueinander verlaufende Linien gebildet werden. Dieses Vorgehen lässt sich in modifizierter Form am Āq Sarāy-Palast in Šahr-i

\footnotetext{
177 Vgl. zum Abğad-System Canaan, Decipherment 147 f.; Weil und Colin, Abdjad, in $E I^{2}$.

179 Siehe auch Anm. 175f., Zahlenquadrat magisch.

180 Vgl. dazu Kapitel 4.6 bei Anm. 215.

181 Abb. 23.1-3.
} 
Sabz (Usbekistan) beobachten, dessen Bau 1380 von Timur in Auftrag gegeben worden ist. ${ }^{182}$

Auf diesem Belegstück fallen zwei Gestaltungsmittel auf: Es handelt sich einerseits um den Einsatz von winzigem $\dot{G} u b \overline{a r}$ bei der Abschrift des Korans. Sie verlangte dem Kopisten bei seiner Arbeit höchste Konzentration ab. Dies ruft die in mystischen Kreisen gepflegten Dikr-Übungen in Erinnerung, bei denen der Ausübende seine Gedanken ausschliesslich auf Gott ausrichtet. Anderseits enthält das vorliegende Dokument zahlreiche Abschnitte, in denen auf dem "gंubārfarbenen“ Hintergrund ausgewählte Passagen aus dem Koran in komplexen und immer wieder andern Zierschriften angeordnet worden sind. Die Gestaltung dieser Abschnitte ruft oft Vexierbilder in Erinnerung, die der Betrachter nur nach langem Rätseln entziffern kann. Es ist in vielen Fällen gelungen, diese Stellen aufzulösen. Andere Abschnitte harren weiterhin ihrer Klärung; dies trifft gerade auf die Stellen mit Text in geometrisierendem Küfı zu. Dieses Dokument verlangt also auch vom Betrachter einen hohen Grad an Konzentration, wie er aus den bereits angeführten Dikr-Übungen („Gottgedenken“) in mystischen Kontexten bekannt ist.

182 Vgl. dazu oben bei Anm. 5, 14 und 61. 

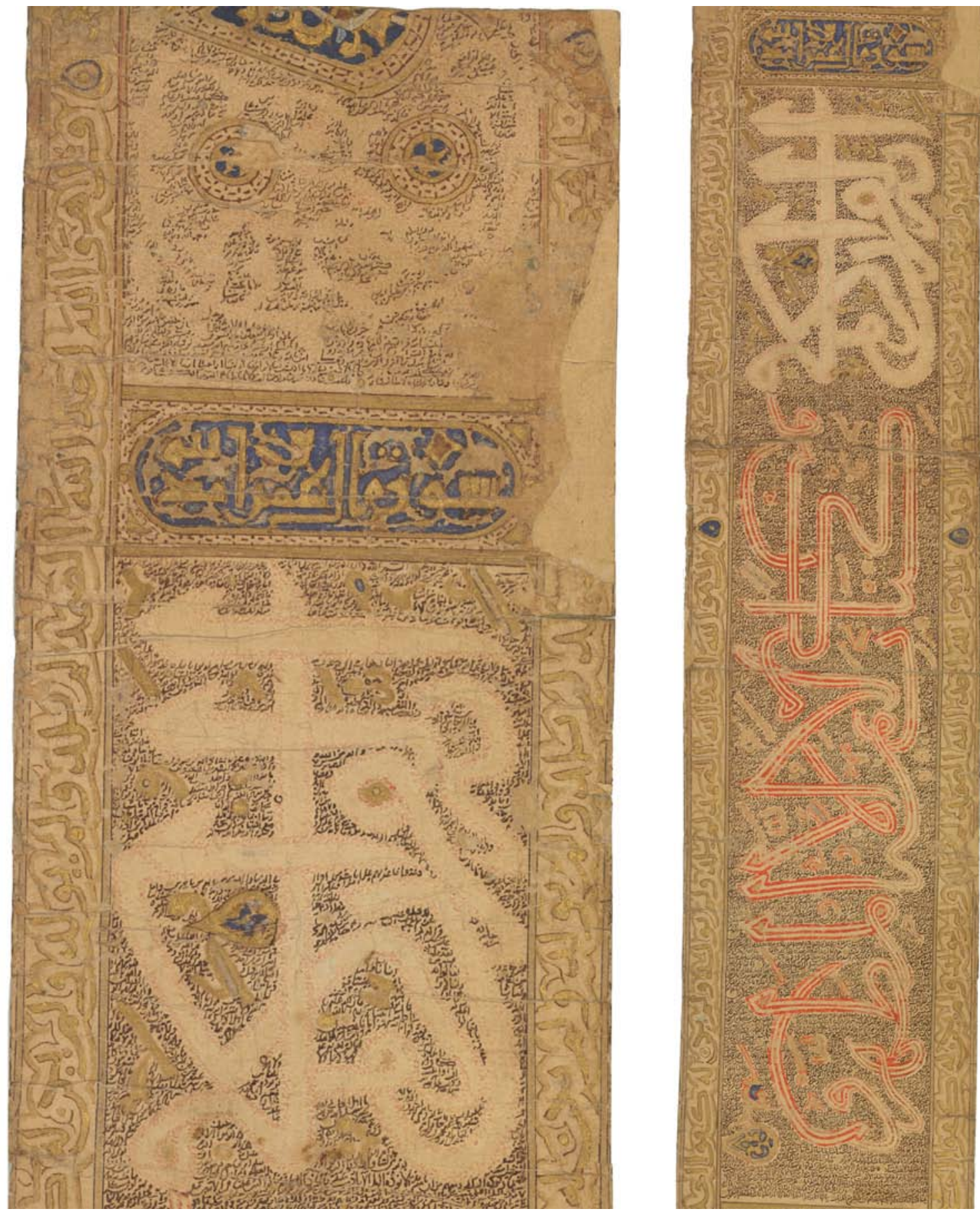

Aвв. 52-53 Dublin, Chester Beatty Library, Is 1625 (vgl. bei Anm. 5, 7-14): Anfang des erhaltenen Teils der Rolle. Auf den beiden Seitenleisten wurde Q 112 (Sürat al-Ihlāṣ) kopiert; der Schreiber hält dies bis zum Ende des Dokuments durch. Auf dem „g்bār-farbenen“ Hintergrund lässt sich in grosser Schrift Q 56:77-79 erkennen. Beim als Hintergrund kopierten Text handelt es sich um Q 3 (Sürat Āl Imrān; im Titelbalken notiert).

(C) THE TRUSTEES OF THE CHESTER BEATTY LibRARY, DUBLIN (CHESTER BEATty, DUBLIN. CC BY-NC 4.0) 


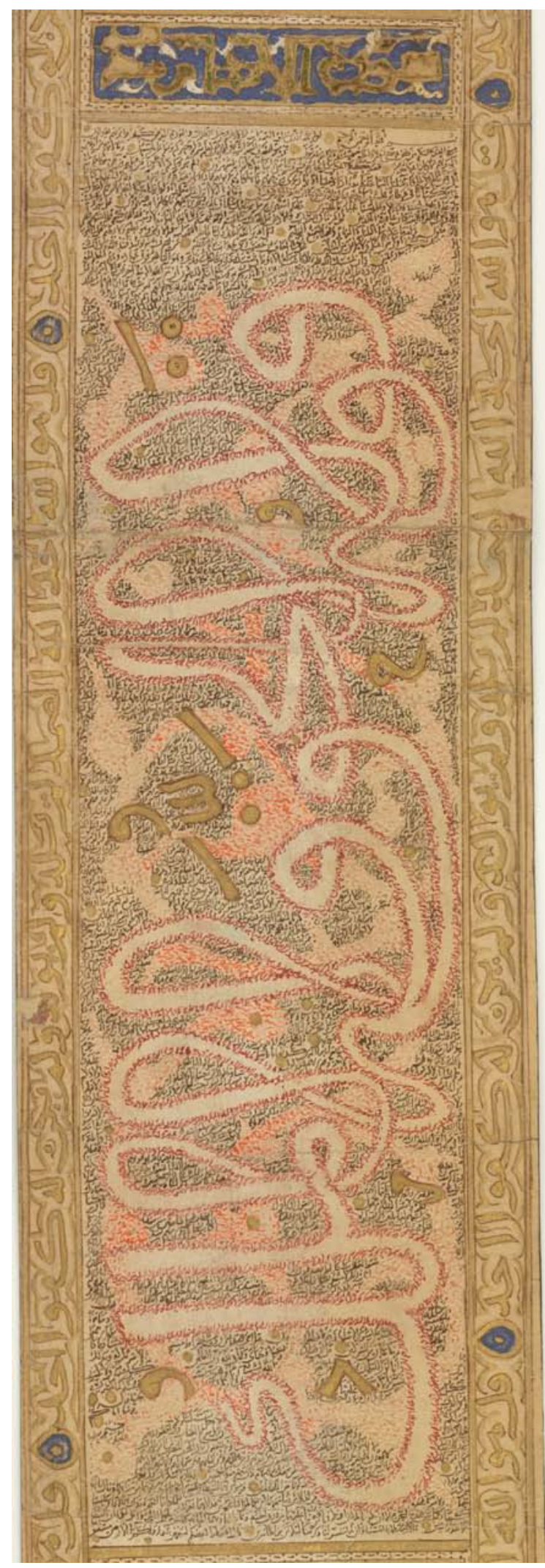

ABB. 54

Dublin, Chester Beatty Library, Is 1625 (vgl. bei Anm. 24): Auf dem „gubār-farbenen“ Hintergrund steht Q 6 (Sūrat al-Anām, Überschrift im Titelbalken). Beim grossen Text handelt es sich um einen Auszug aus Q 6:73 (Qawlu-hū al-haqq, wa-lahū almulk).

(C) THE TRUSTEES OF THE CHESTER BEATTY LIBRARY, DUBLIN (CHESTER BEATTY, DUBLIN. CC BY-NC 4.0) 


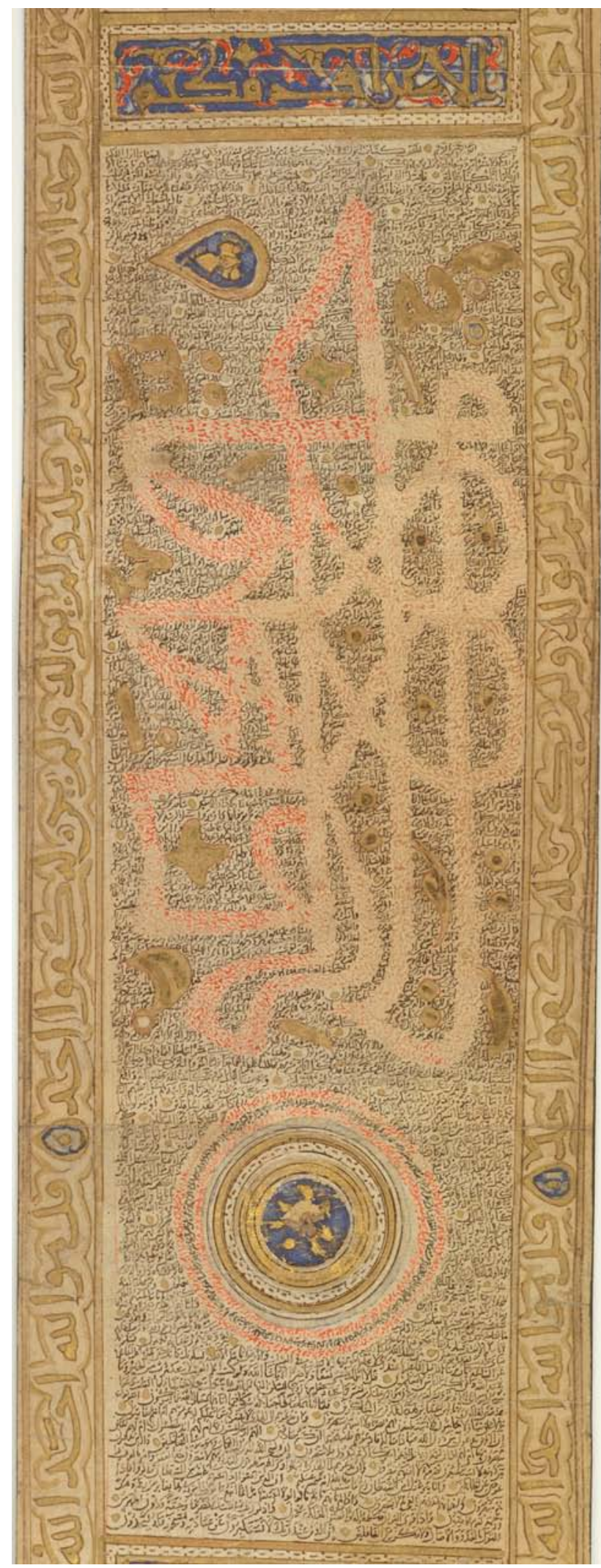

ABB. 55

Dublin, Chester Beatty Library, Is 1625 (vgl. bei Anm. 26): Abschnitt mit der Abschrift von Q 7 (al$\left.A^{\prime} r a \bar{f}\right)$. Die Entzifferung des grossen Texts auf dem " $\dot{g} u b a \bar{r}$-farbenen" Hintergrund ist nicht gänzlich gesichert. Es dürfte sich um einen Auszug aus Q 7:40 handeln (für die Einzelheiten siehe die Beschreibung bei Anm. 27).

(C) THE TRUSTEES OF THE CHESTER BEATTY LIBRARY, DUBLIN (CHESTER BEATTY, DUBLIN. CC BY-NC 4.0) 


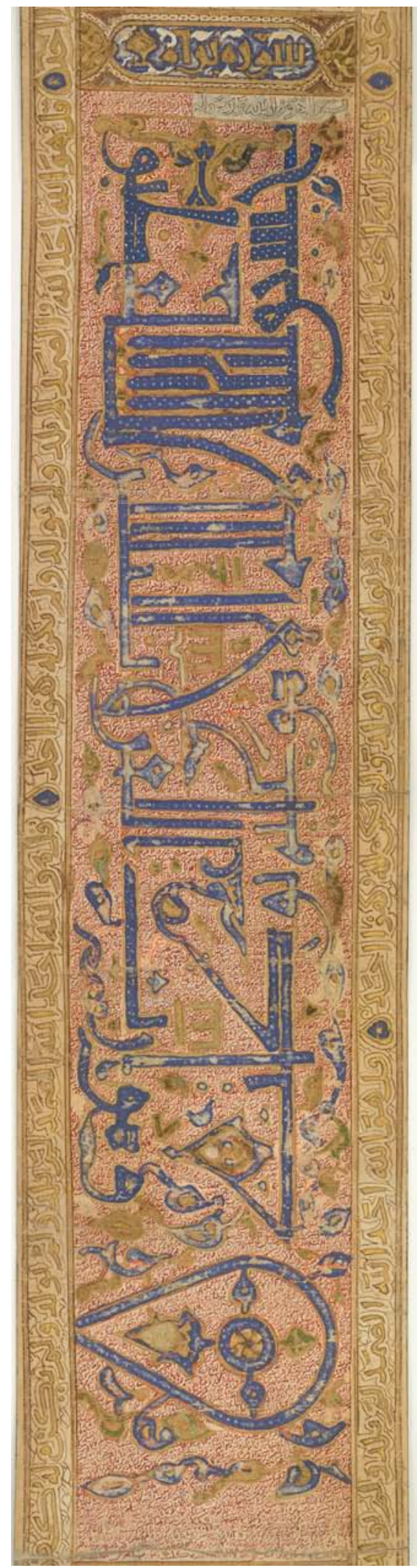

ABB. 56

Dublin, Chester Beatty Library, Is 1625 (vgl. bei Anm. 31): Abschnitt von ca. $40 \mathrm{~cm}$ Länge. Q 9 wurde hier auf dem „gubār-farbenen“ Hintergrund in roter Tinte kopiert; Überschrift von Q 9 auch im Titelbalken. In grosser

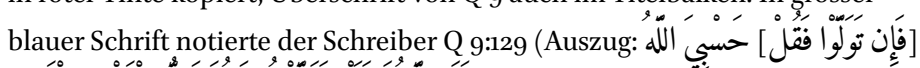

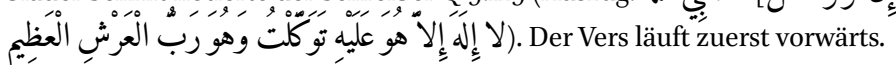
Der Kopist wechselt die Schriftrichtung zwischen tawakkaltu und wa-huwa. (C) THE TRUSTEES OF THE CHESTER BEATTY LIBRARY, DUBLIN (CHESTER BEATTY, DUBLIN. CC BY-NC 4.0) 


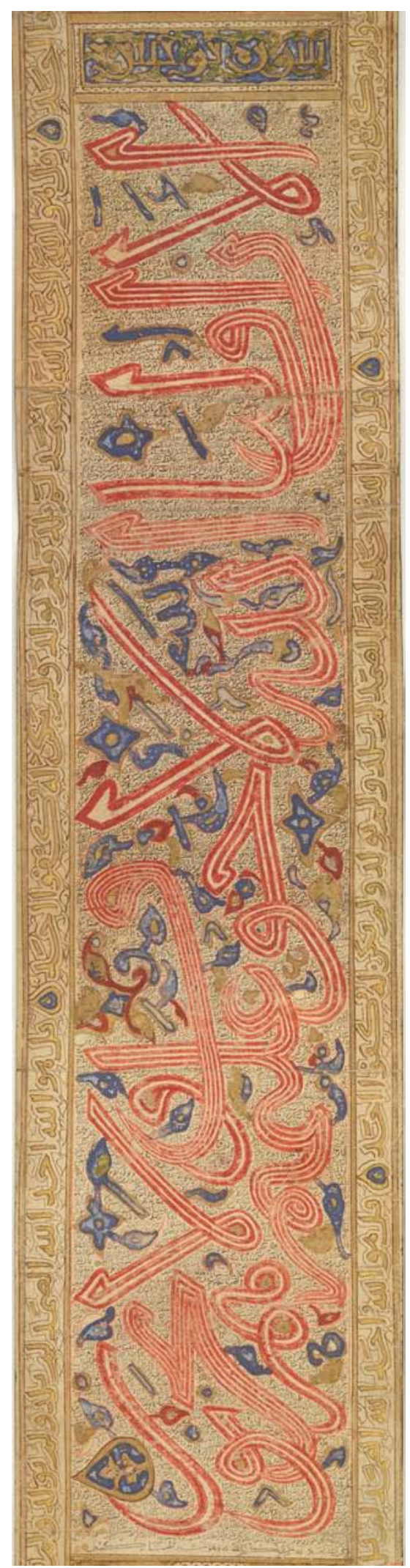

ABB. 57

Dublin, Chester Beatty Library, Is 1625 (vgl. bei Anm. 33): Abschnitt von ca. $41 \mathrm{~cm}$ Länge mit der Abschrift von Q 10 (Sūrat Yūnus) in $\dot{G} u b \bar{a} r$-Schrift.

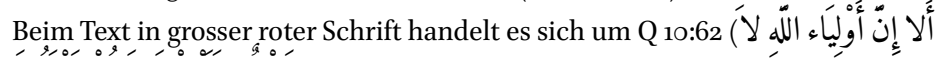

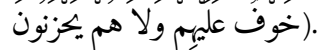

(C) THE TRUSTEES OF THE CHESTER BEATTY LIBRARY, DUBLIN (CHESTER BEATTY, DUBLIN. CC BY-NC 4.0) 


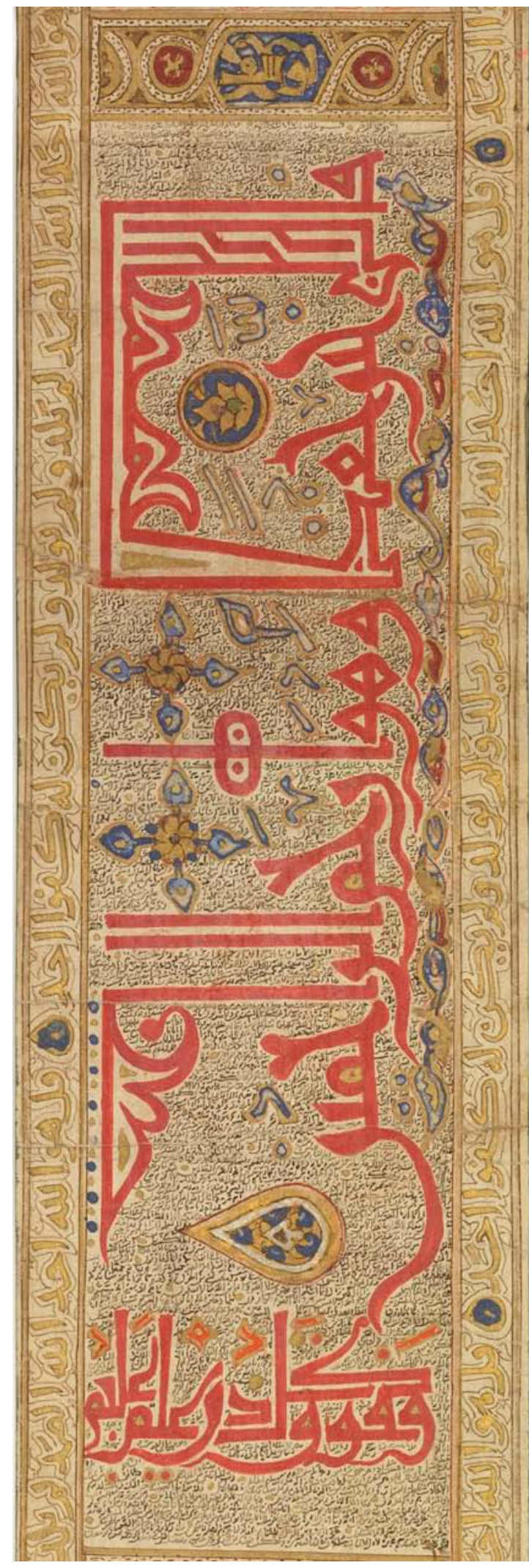

ABB. 58

Dublin, Chester Beatty Library, Is 1625 (vgl. bei Anm. 38): Abschnitt von $30.6 \mathrm{~cm}$ Länge. Abschrift von Q 12 (Sūrat Yūsuf)

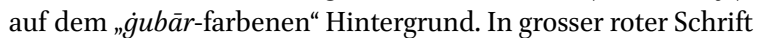
Q 12:64: Fa-Allāhu hayrun h $[\bar{a}]$ fizan wa-huwa arham ar-rāḥimīn. In horizontaler Ausrichtung am Schluss in roter Tinte Q 12:76 (Auszug): Wa-fawqa kulli dì 'ilmin 'alìm. (C) THE TRUSTEES OF THE CHESTER BEATTY LIBRARY, DUBLIN (CHESTER BEATTY, DUBLIN. CC BY-NC 4.0) 


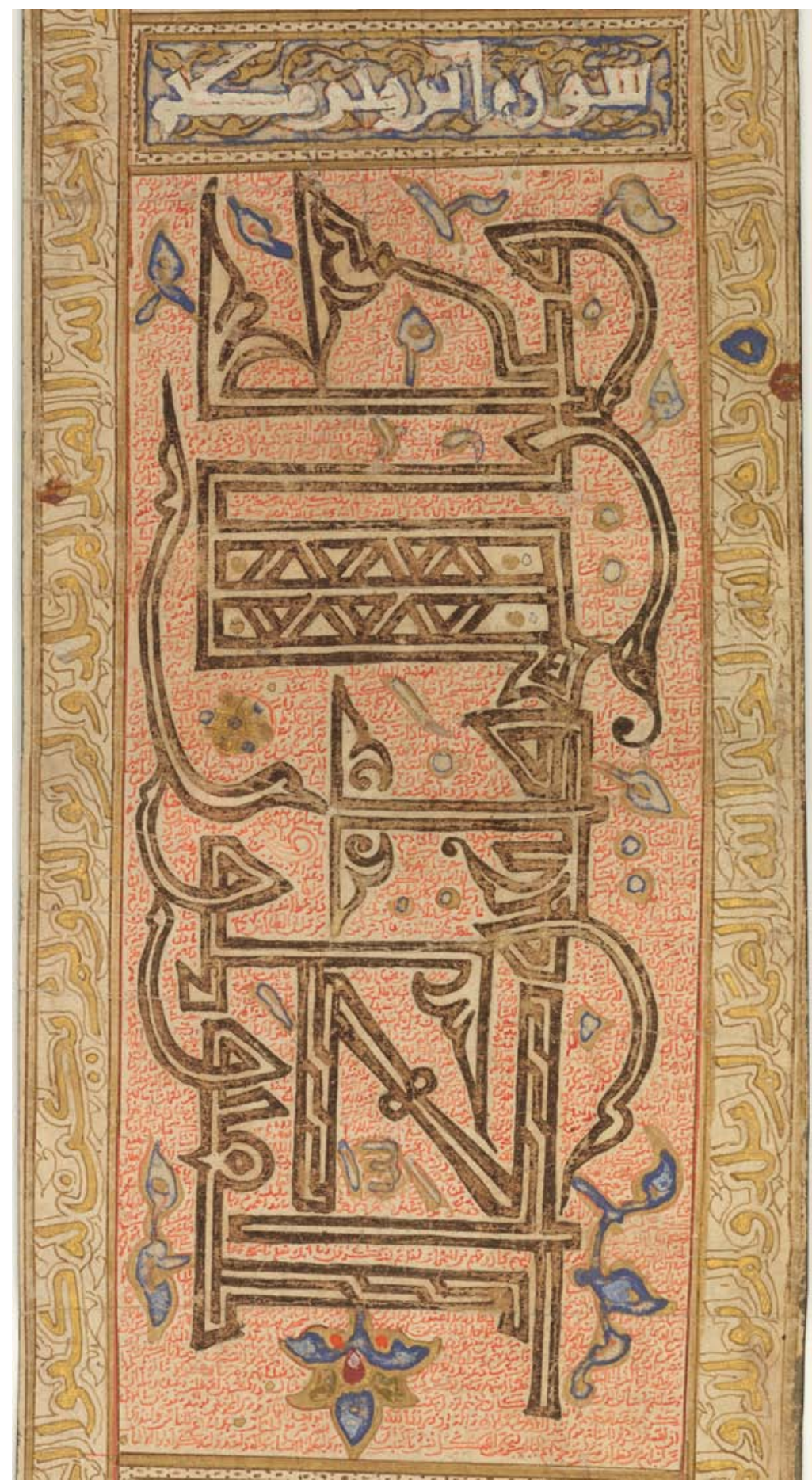

ABB. 59

Dublin, Chester Beatty Library, Is 1625 (vgl. bei Anm. 44): Abschnitt von ca. $19.0 \mathrm{~cm}$ Länge mit der Abschrift von Q 14 (Sürat Ibrāhìm) in rotem $\dot{G} u b \bar{a} r$. In grosser schwarzer Zierschrift hervorgehoben wurde Q 14:12 (Schluss): Wa-áāa [A]llāh fa-l-yatawakkali l-mutawakkilūna.

(C) THE TRUSTEES OF THE CHESTER BEATTY LIBRARY, DUBLIN (CHESTER BEATTY, DUBLIN. CC BY-NC 4.0) 


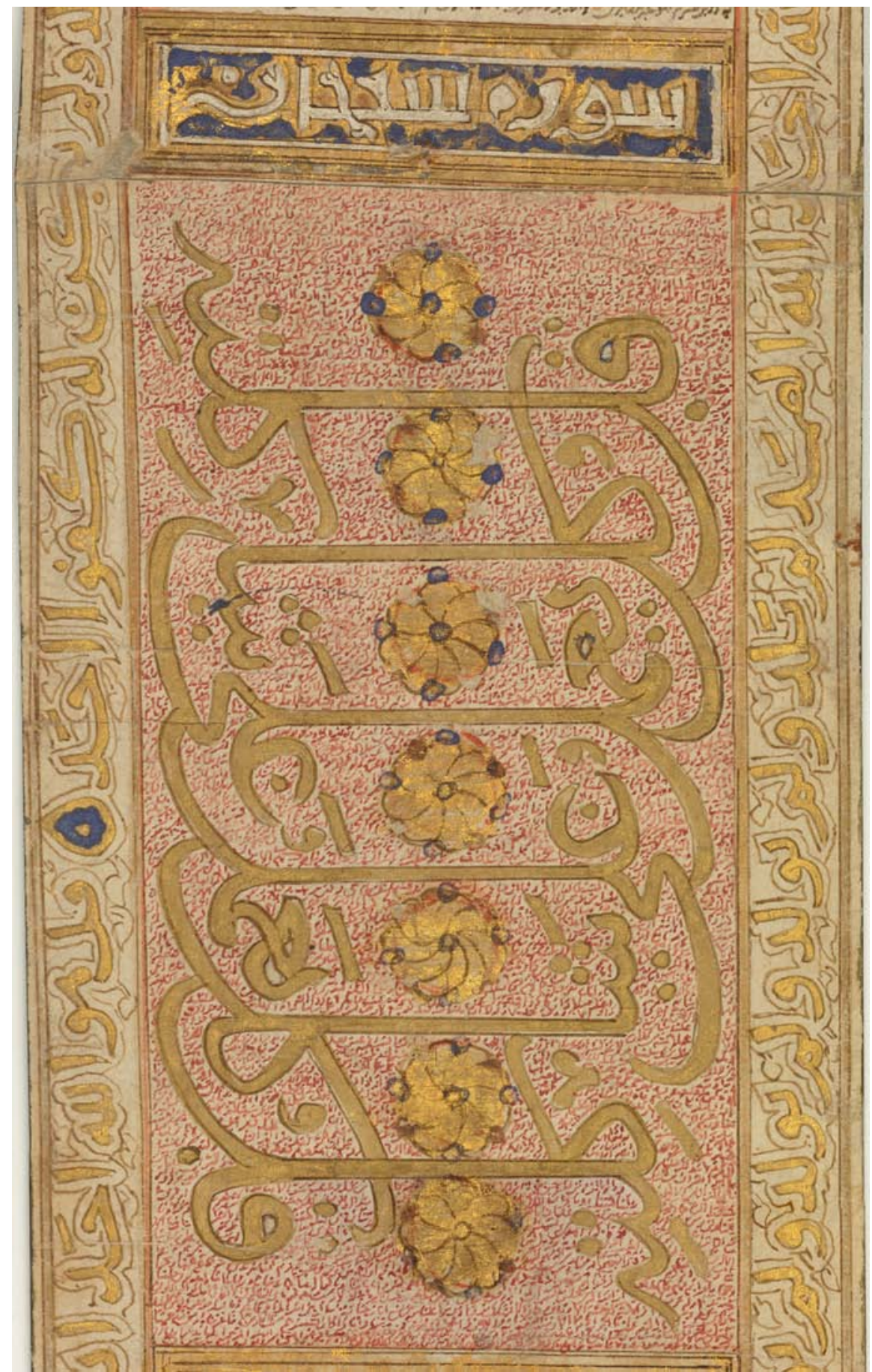

Авв. 60 Dublin, Chester Beatty Library, Is 1625 (vgl. bei Anm. 52): Abschnitt von ca. $16.2 \mathrm{~cm}$ Länge mit der Abschrift von Q 17 (hier Sūrat Subhāna). In grosser goldener Schrift wurde Q 17:84 (erste Hälfte) hervorgehoben. Der Text verläuft zuerst absteigend, dann auf der Gegenseite aufsteigend: Qul kullun ya'malu 'alā šākilati-hī (identischer Text absteigend und aufsteigend).

(C) THE TRUSTEES OF THE CHESTER BEATTY LIBRARY, DUBLIN (CHESTER BEATTY, DUBLIN. CC BY-NC 4.0) 


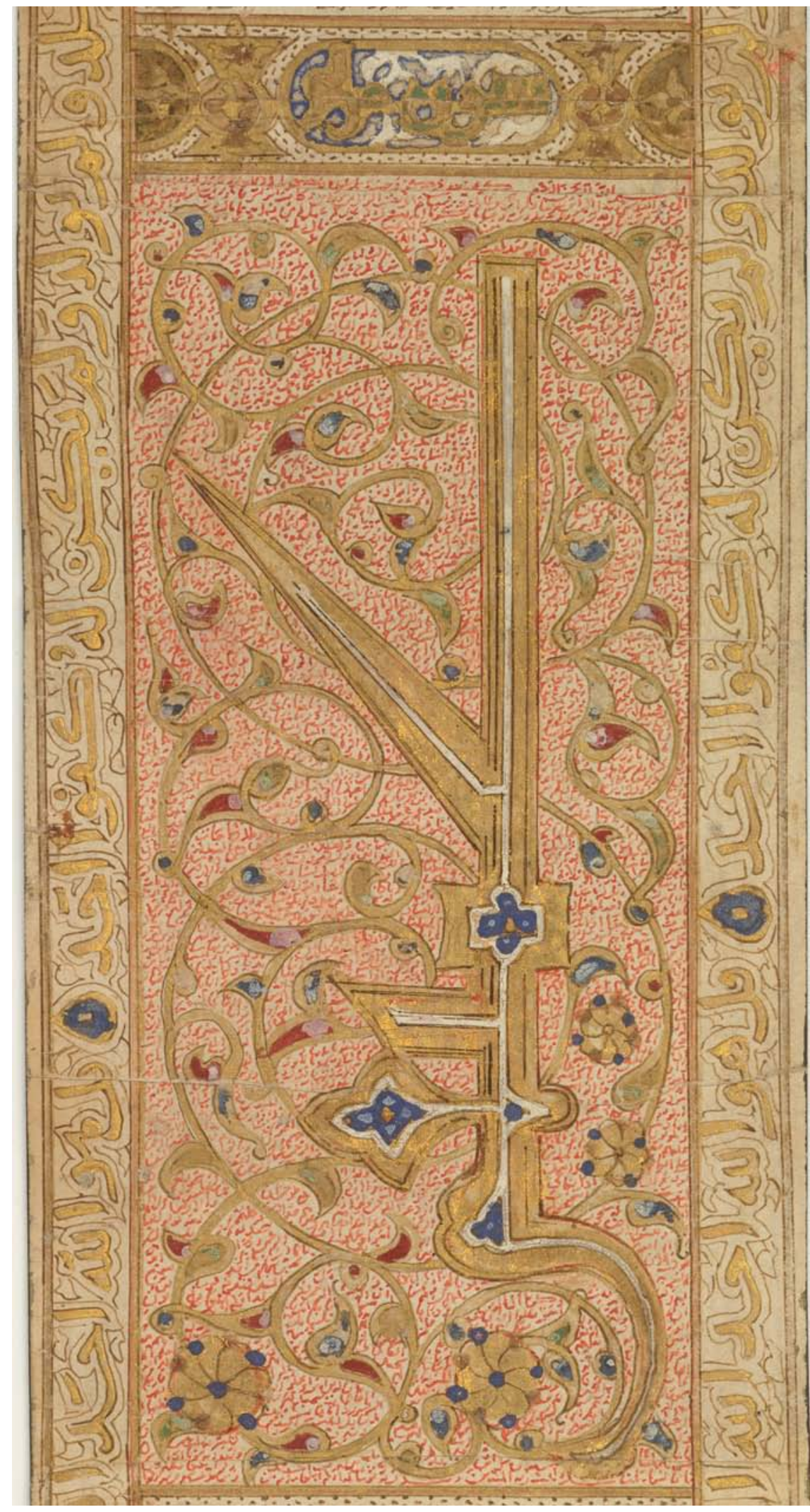

ABB. 61

Dublin, Chester Beatty Library, Is 1625 (vgl. bei Anm. 56): Abschnitt mit Q 19 (Sūrat Maryam). Die Länge des Abschnitts misst ca. $19.3 \mathrm{~cm}$. Golden hervorgehoben wurde die Buchstabenfolge Kăf-häyā'- 'ayn-șād aus Q 19:1. (C) THE TRUSTEES OF THE CHESTER BEATTY LIBRARY, DUBLIN (CHESTER BEATTY, DUBLIN. CC BY-NC 4.0) 


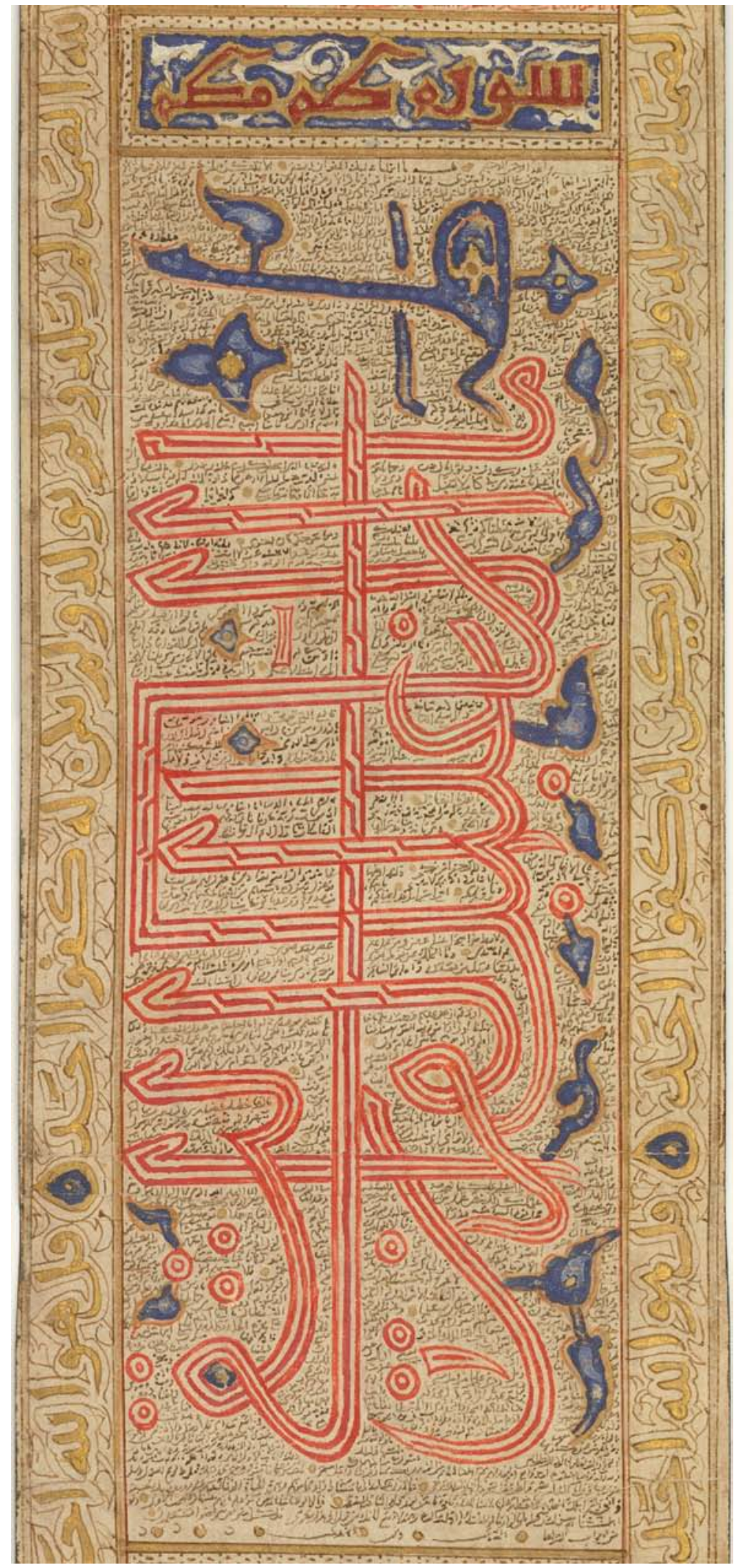

ABB. 62

Dublin, Chester Beatty Library, Is 1625 (vgl. bei Anm. 62): Abschnitt von ca. 22.4 cm Länge mit der Abschrift von Q 20 (Sūrat Țā-hā) in $\dot{G} u b \bar{a} r$-Schrift. In grosser Schrift hervorgehoben wurde Q 20:1-2: Țāhā (danach rot), mā anzalnā 'alay-ka al-Qurāna li-tašqā.

(C) THE TRUSTEES OF THE CHESTER BEATTY LIBRARY, DUBLIN (CHESTER BEATTY, DUBLIN. CC BY-NC 4.0) 


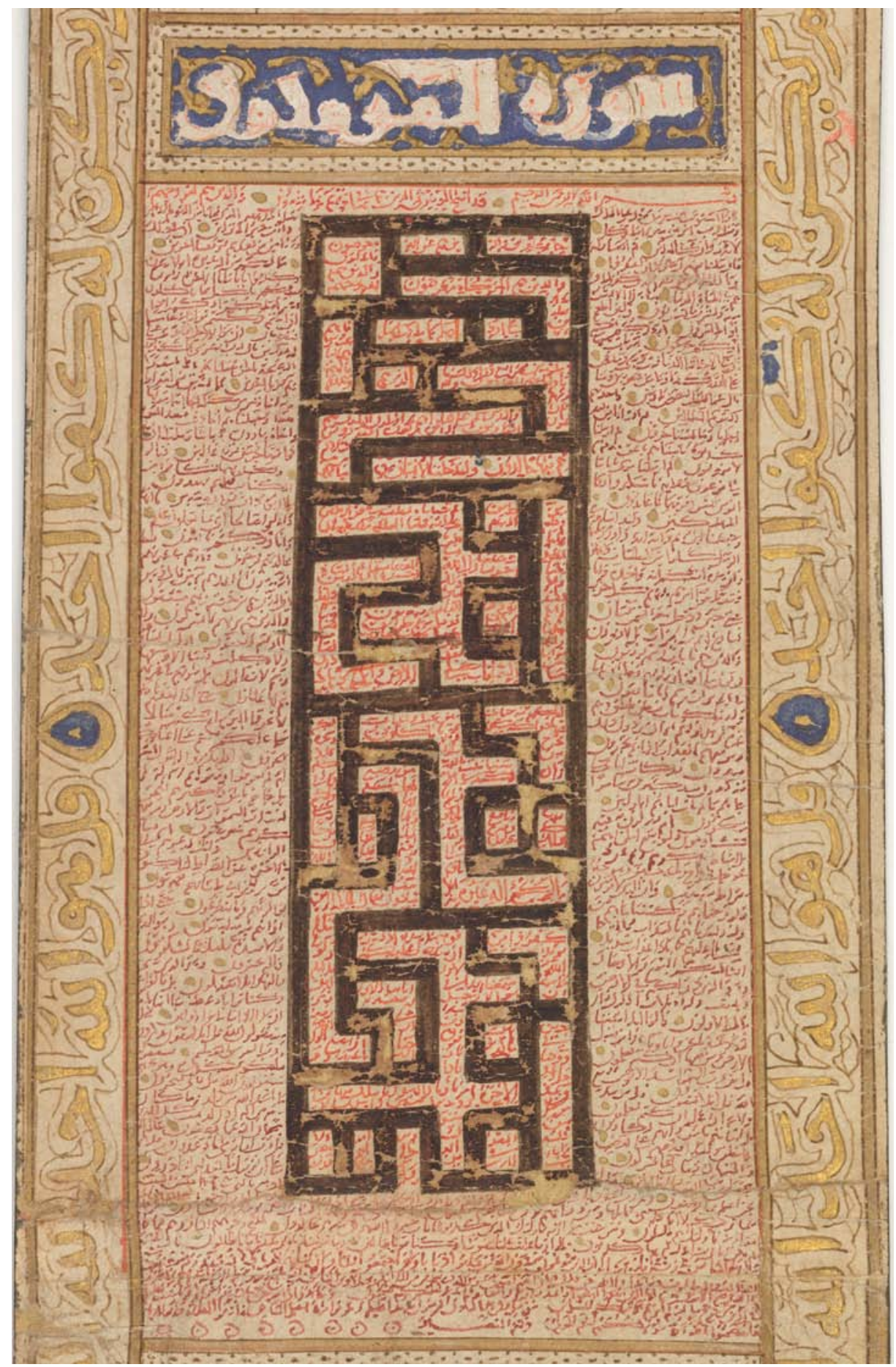

Авв. 63 Dublin, Chester Beatty Library, Is 1625 (vgl. bei Anm. 69): Abschnitt von ca. 16.o cm Länge. Im Hintergrund wurde Q 23 (Sūrat al-Müminūn) in rotem Ġubār notiert. Beim schwarzen "Gitter" muss es sich um Text handeln; er liess sich nicht mit Sicherheit entziffern.

(C) THE TRUSTEES OF THE CHESTER BEATTY LIBRARY, DUBLIN (CHESTER BEATTY, DUBLIN. CC BY-NC 4.0) 


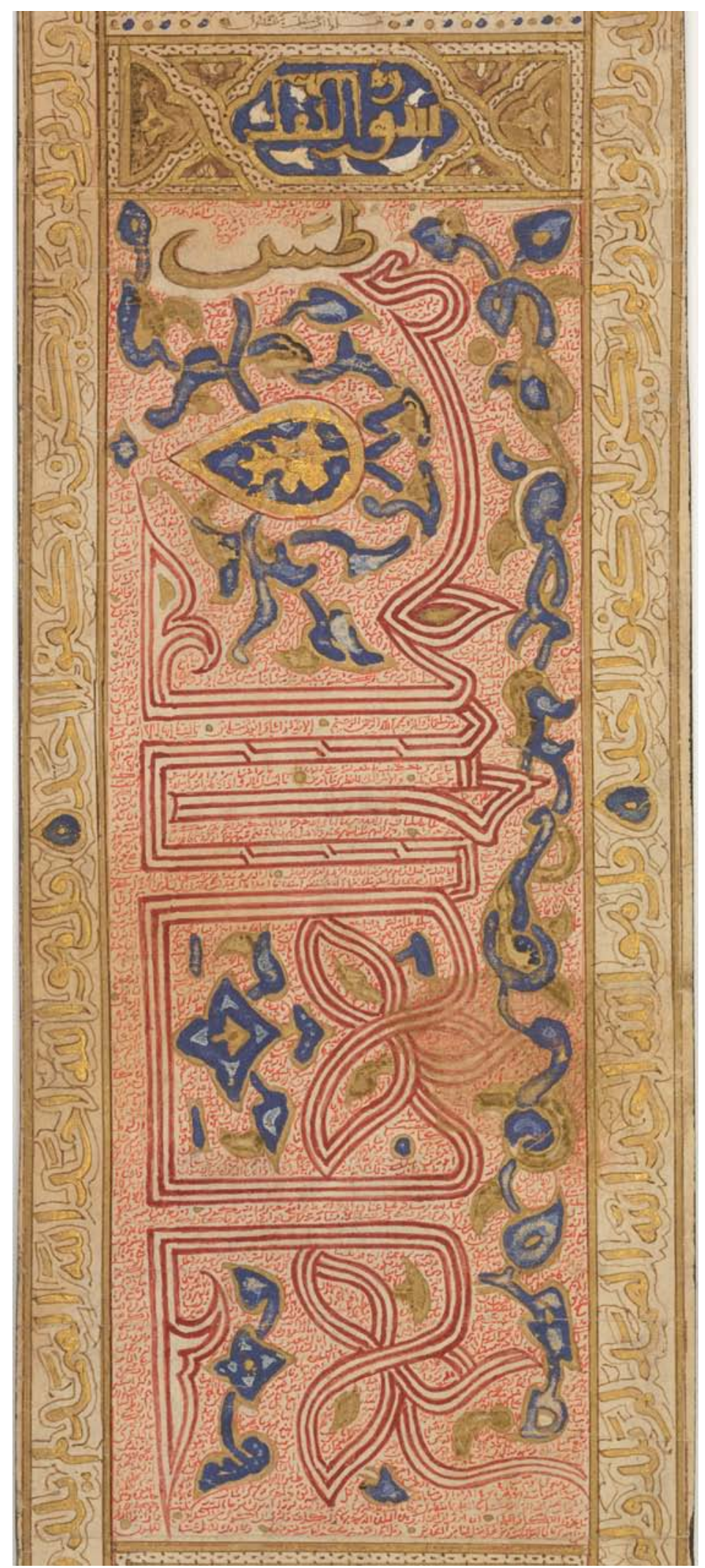

ABB. 64

Dublin, Chester Beatty Library, Is 1625 (vgl. bei Anm. 77): Abschnitt von ca. $24.0 \mathrm{~cm}$ Länge. Im Hintergrund wurde Q 27 (Sūrat an-Naml, Die Ameise) kopiert. Allenfalls stellt das blaue Zierelement (Tropfen mit nach links weisender Spitze) eine Ameise dar. In grosser roter Schrift wurde die Basmala notiert.

(C) THE TRUSTEES OF THE CHESTER BEATTY LIBRARY, DUBLIN (CHESTER BEATTY, DUBLIN. CC BY-NC 4.0) 


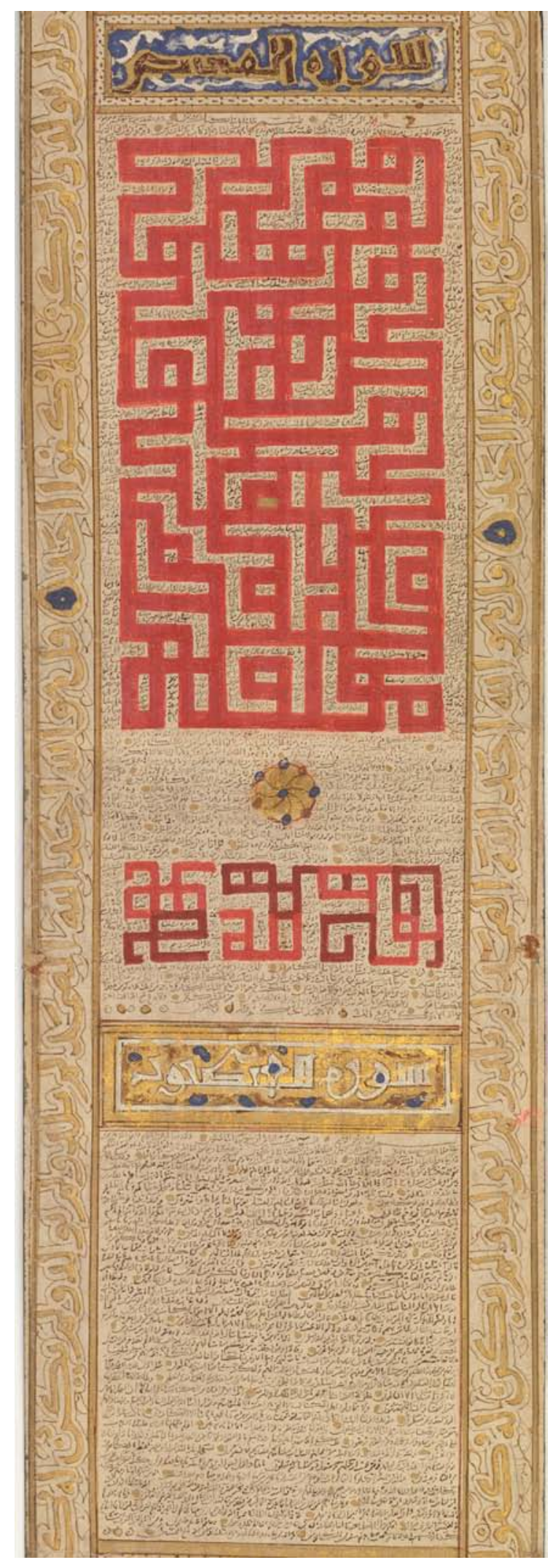

ABB. 65

Dublin, Chester Beatty Library, Is 1625 (vgl. bei Anm. 78): Abschnitt von $21 \mathrm{~cm}$ Länge mit der Abschrift von Q 28 (Sūrat al-Qișaș). Die grosse rote Figur enthält wohl Text, der sich aber nicht bestimmen liess. In $\dot{G} u b \bar{a} r$-Schrift folgt darauf Q 29.

(C) THE TRUSTEES OF THE CHESTER BEATTY LIBRARY, DUBLIN (CHESTER BEATTY, DUBLIN. CC BY-NC 4.0) 


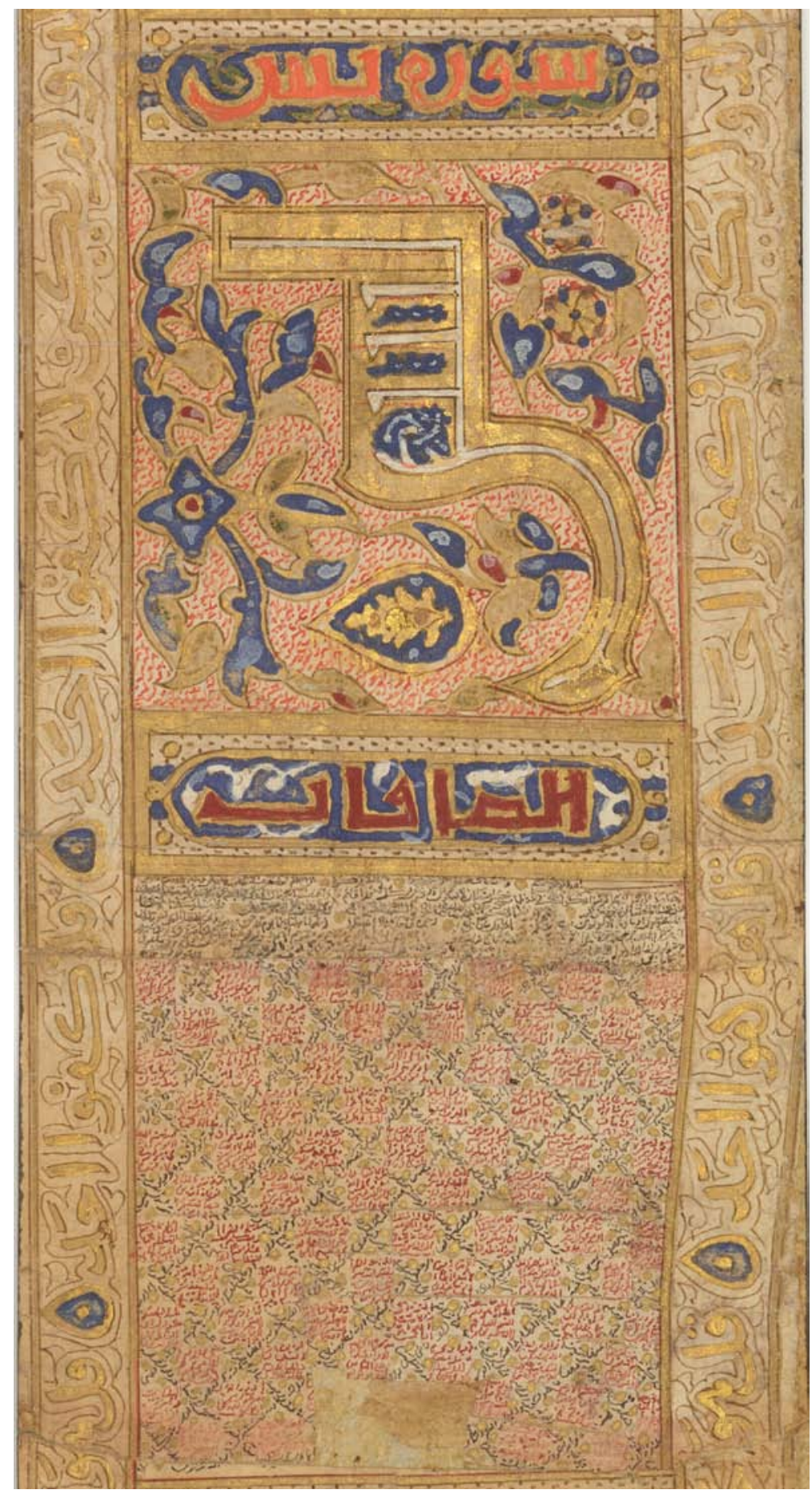

ABB. 66

Dublin, Chester Beatty Library, Is 1625 (vgl. bei Anm. 93): Abschnitt von $9.8 \mathrm{~cm}$ Länge mit Q 36 (Sūrat Yā-sīn). Ihr Titel wird auch in einer aufwendigen Verzierung hervorgehoben. Da der Abschnitt relativ kurz ist, ist Q 36 auf dem roten „gubār-farbenen“ Hintergrund wohl nur teilweise kopiert worden. Es schliesst sich darauf Q 37 an. In den beiden Seitenleisten mit der Abschrift von Q 112 lässt sich gut erkennen, dass hier zu einem späteren Zeitpunkt ein Abschnitt der Rolle entfernt wurde (vgl. bei Anm. 94-97). (C) THE TRUSTEES OF THE CHESTER BEATTY LIBRARY, DUBLIN (CHESTER BEATTY, DUBLIN. CC BY-NC 4.0) 


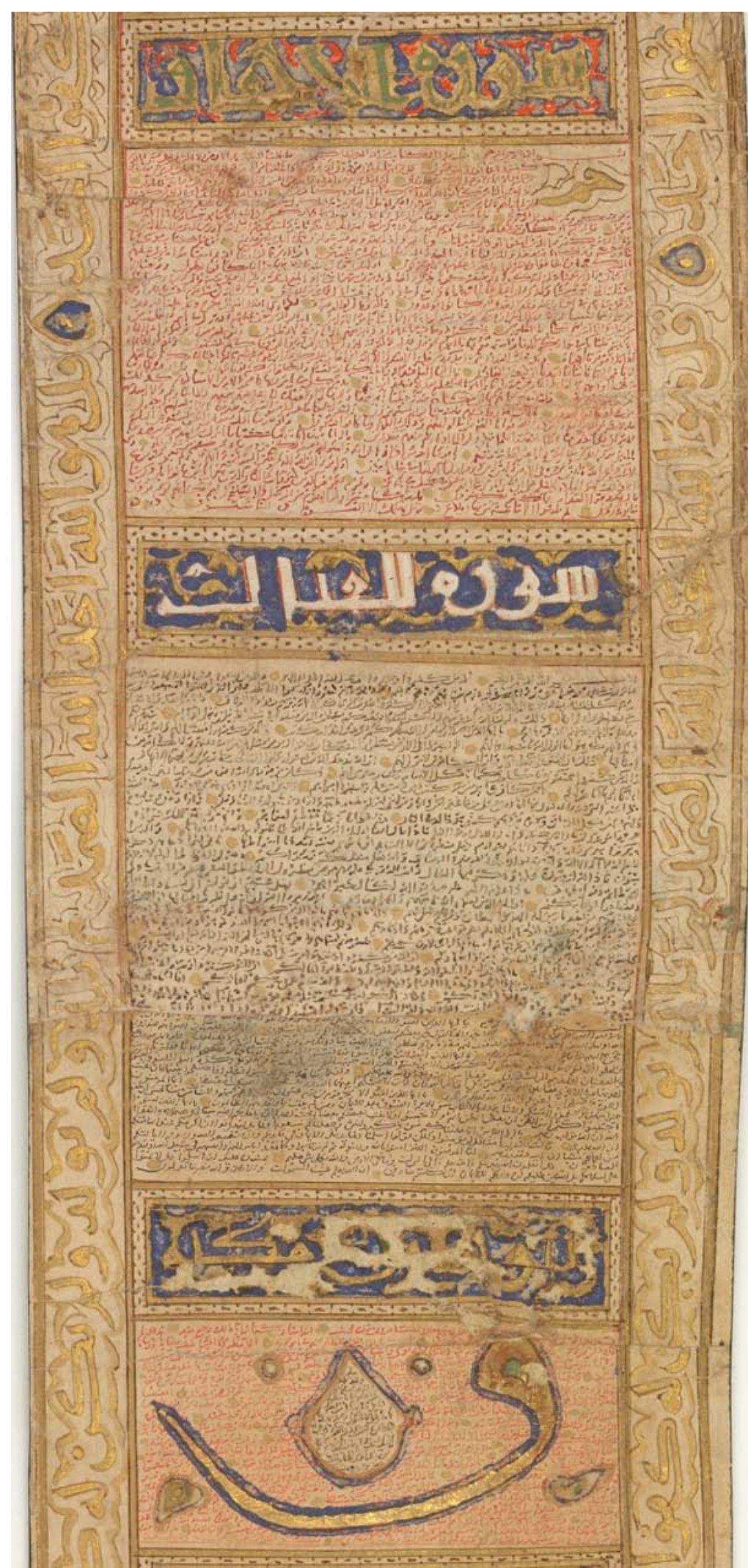

ABB. 67

Dublin, Chester Beatty Library, Is 1625 (vgl. bei Anm. 105-108): Fehlstelle bei Q 47-49. Hier wurde zu einem späteren Zeitpunkt ein längerer Abschnitt der Rolle mit der Abschrift von Q 48 (al-Fath) wohl absichtlich entfernt. Für die Einzelheiten vgl. die Beschreibung.

(C) THE TRUSTEES OF THE CHESTER BEATTY LIBRARY, DUBLIN (CHESTER BEATTY, DUBLIN. CC BY-NC 4.0) 


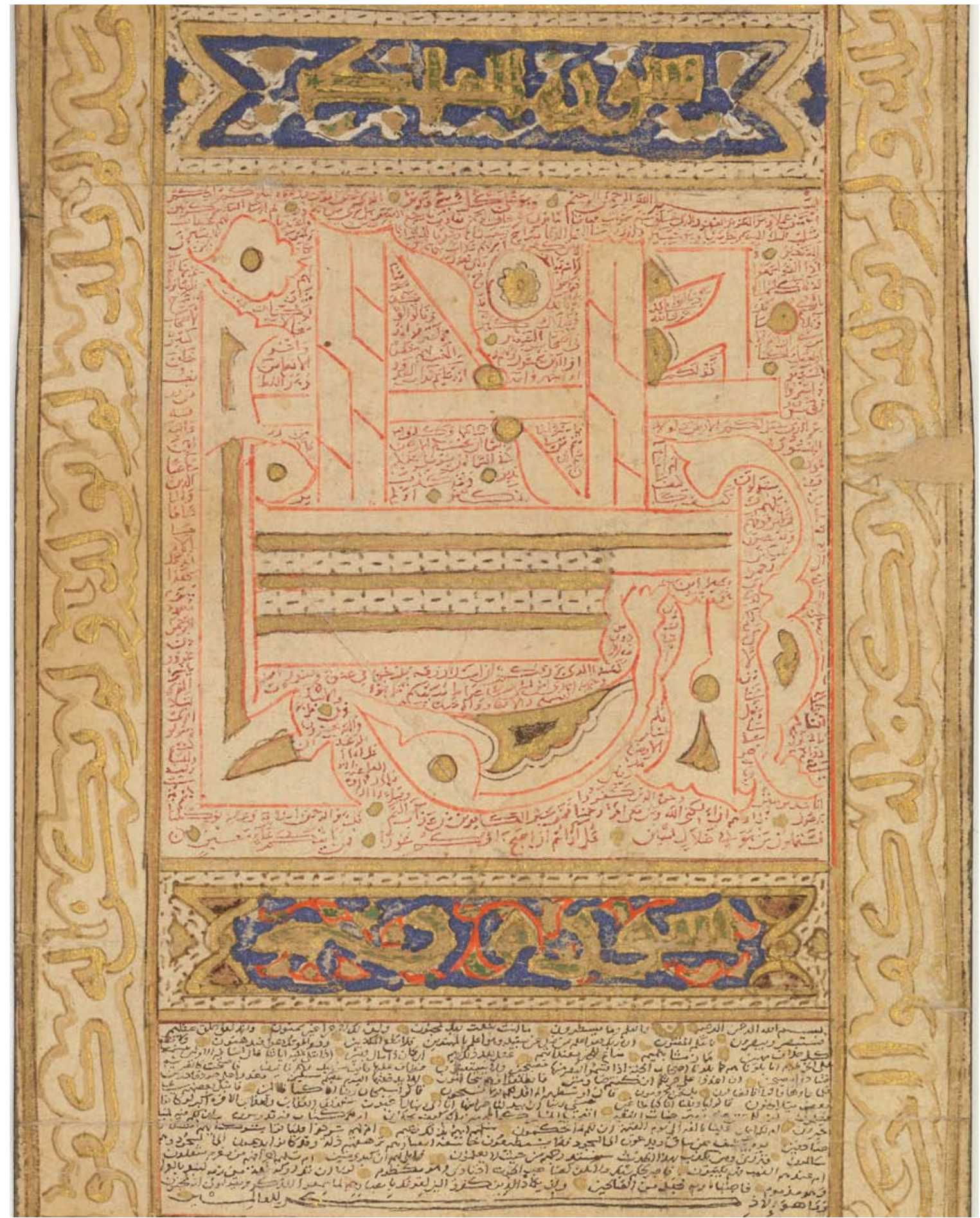

ABB. 68

Dublin, Chester Beatty Library, Is 1625 (vgl. bei Anm. 132-136): Abschrift von Q 67 (Sürat alMulk); Abschnitt von ca. 9.4 cm Länge. Hervorgehoben wurde Tabāraka allad̄i bi-yadi-hì al-mulk (Anfang von Q 67:1). Man meint, in dieser Stelle auch die Abbildung eines Vogels zu erkennen (unten, horizontal ausgerichtet, für die Einzelheiten siehe die Beschreibung). (C) THE TRUSTEES OF THE CHESTER BEATTY LIBRARY, DUBLIN (CHESTER BEATTY, DUBLIN. CC BY-NC 4.0) 


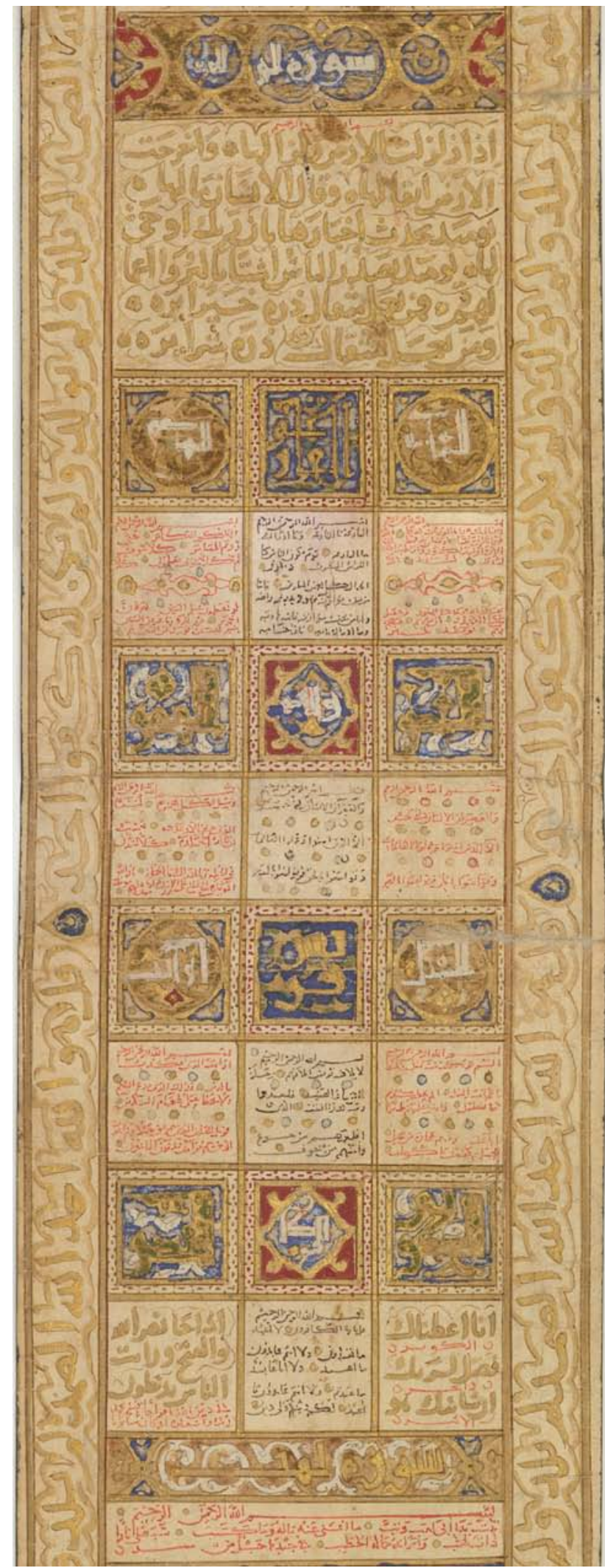

АВB. 69

Dublin, Chester Beatty Library, Is 1625 (vgl. nach Anm. 166): Da die Suren gegen das Ende des Korans immer kürzer werden, ändert der Schreiber sein Vorgehen. Hier werden Q 100-110 in drei Spalten notiert (siehe für die Einzelheiten die Beschreibung). Davor Q 99 (Sūrat az-Zalzala) in grossen goldenen Buchstaben. Danach Q 111 (Sürat al-Masad). (C) THE TRUSTEES OF THE CHESTER BEATTY LIBRARY, DUBLIN (CHESTER BEATTY, DUBLIN. CC BY-NC 4.0) 


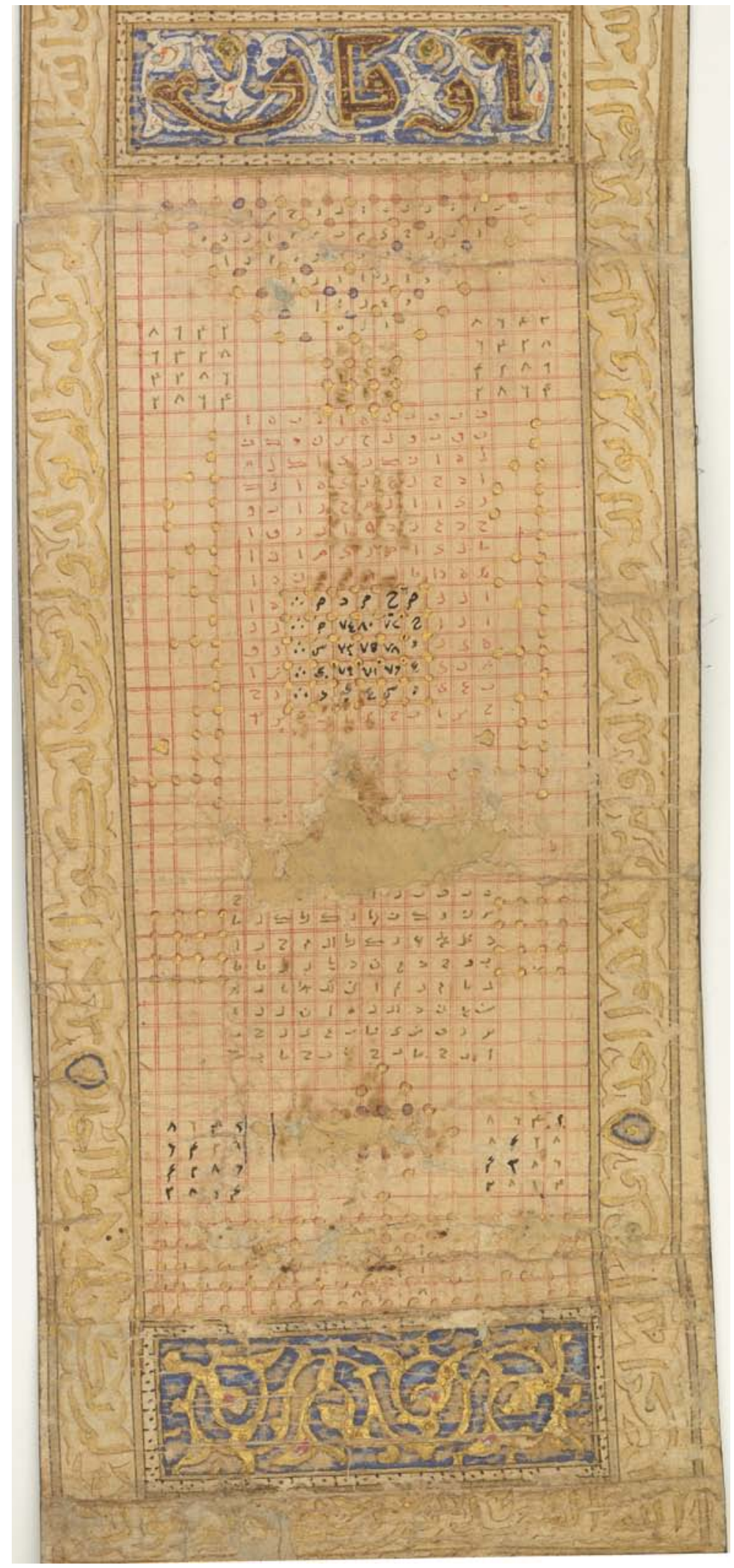

ABB. 70

Dublin, Chester Beatty Library, Is 1625 (vgl. bei Anm. 174-180): Abschluss der Rolle; Abschnitt von ca. $19.8 \mathrm{~cm}$ Länge. In Übereinstimmung mit seiner Überschrift enthält der Abschnitt Zellenquadrate. Siehe für die Einzelheiten die Beschreibung. (C) THE TRUSTEES OF THE CHESTER BEATTY LIBRARY, DUBLIN (CHESTER BEATTY, DUBLIN. CC BY-NC 4.0) 
Universitätsbibliothek Basel, M III 173: ${ }^{1}$ 12.5× $890 \mathrm{~cm}$, unvollständig erhalten; Anfang und Ende fehlen. Die ursprüngliche Länge der Rolle kann ohne weiteres $12 \mathrm{~m}$ betragen haben. Aus dem Vorbesitz von Prof. Dr. Fritz Meier, die näheren Umstände ihres Erwerbs sind nicht geklärt. ${ }^{2}$

Das Belegstück dürfte um $1400^{3}$ in einem mamlukisch beeinflussten Umfeld entstanden sein. Es könnte in Syrien, Westiran oder Ostanatolien von einem Schreiber mit iranischem Hintergrund angefertigt worden sein, wie sich aufgrund der Schrift vermuten lässt. Eine präzisere Einordnung ist wegen der hohen Mobilität der Schreiber und der fertigen Rollen vorläufig nicht möglich. Da das Dokument fragmentarisch erhalten ist, fehlt ein Kolophon mit allenfalls klärenden Angaben. Die zeitliche und geographische Einordnung ergibt sich deshalb v.a. aufgrund von kodikologischen und kunsthistorischen Vergleichen.

Dieses Belegstück stellt das komplexeste Dokument im Korpus dar, das dieser Arbeit zugrundeliegt. Der Schreiber kopierte zahlreiche Passagen in einem besonders kleinen $\dot{G} u b \bar{a} r$ und ordnete diese Stellen in unterschiedlichen geometrischen Figuren an. Die kopierten Stellen weisen oft vom Kopisten beabsichtigte Brüche in der

1 Vgl. die kodikologische Beschreibung von Schubert und Würsch, Arabische Handschriften 243-246 (Nr. 101). Die Rolle ist zur Restaurierung vorgesehen. Abbildungsmaterial der gesamten Rolle ist zugänglich unter: http://dx .doi.org/10.7891/e-manuscripta-16628 (Stand 28. September 2016); siehe auch: http://www.e-manuscripta.ch/bau/ content/pageview/837968 (Stand 17. Dezember 2016; die weiteren Verweise auf diese Quelle jeweils ohne Datumsangabe).

Man vergleiche mit diesem Belegstück unbedingt SHM 11998-Y.4O aus dem Sadberk Hanım Museum; beschrieben in Tanınd, Harmony I, 200-203 (Nr. 39; Katalog erschienen während der Drucklegung der vorliegenden Studie).

2 Mündliche Information von Dr. G. Schubert (Universitäsbibliothek Basel), die F. Meiers Nachlass am besten kennt.

3 Die Datierung ins 11.-12. Jh./17.-18. Jh. durch Schubert und Würsch, Arabische Handschriften 244, wird nicht übernommen.
Wortfolge innerhalb eines Satzes auf. ${ }^{4}$ Der arabische Text weist häufig Fehler auf. Dies lässt darauf schliessen, dass der Schreiber nicht arabischer Muttersprache war; er dürfte aus Iran stammen. Die folgende Übersicht ist als Anfang zu verstehen, der zur weiteren Auseinandersetzung mit diesem Exemplar anregen soll. Es ist vorläufig nicht möglich, dieses Dokument abschliessend zu erklären.

Das vorliegende Belegstück ist dem Knotentyp zuzuweisen und vertritt diesen in besonders ausgeprägter Weise. Es wird auf seiner gesamten Länge von einem dreiteiligen Schriftband eingefasst (Breite insgesamt ca. $3.0 \mathrm{~cm}$ ), das auf der einen Seite der Rolle vorwärts, auf der andern Seite rückwärts läuft. Das Mittelband ist am breitesten (ca. $1.7 \mathrm{~cm}$ ) und enthält Text in zumeist grosser Schrift (Nash). Die Seitenbänder zur Linken und Rechten sind deutlich schmaler (ca. o.65 cm). Der Schreiber wechselt aber wiederholt auch im breiten Mittelband zu Gubār. Er ordnet den Text dabei in unterschiedlichen geometrischen Figuren an (Tropfen, mandelförmige Figuren, Vierecke etc.). Auch in den beiden schmalen seitlichen Schriftbändern (innen und aussen) wurde der Text in $\dot{G} u b \bar{a} r$ kopiert. Die Schriftrichtung in den jeweils zusammengehörenden drei Bändern ist identisch. In diesem dreiteiligen Schriftband wurde soweit ersichtlich ausschliesslich Text aus dem Koran kopiert.

Dieses dreiteilige Schriftband umfährt unter Bildung von Knoten unterschiedliche geometrische Figuren. Am häufigsten lässt sich an diesen Stellen mit Knoten die Abfolge kleines-grosses-kleines Medaillon beobachten. Das grosse Medaillon in der Mitte füllt die gesamte Breite des Schriftspiegels aus. ${ }^{5}$ An diese Abfolge schliesst sich jeweils ein Viereck an, das ebenso vom dreiteiligen Schriftband eingefasst wird. Bei diesen Vierecken han-

\footnotetext{
4 So springt der Schreiber beim Kopieren wiederholt zwischen einzelnen Zeilen hin und her; er beginnt die Abschrift beispielsweise auf der unteren Zeile, springt für den nächsten Ausdruck nach oben, fährt auf der unteren Zeile weiter etc.

5 Die Rolle weist auf beiden Seiten einen schmalen Streifen (Breite je ca. $0.4 \mathrm{~cm}$ ) auf, der leer ist.
} 
delt es sich zumeist um Rechtecke. Sie sind oft an beiden Enden abgerundet und somit federkastenförmig. Am Anfang der Rolle handelt es sich bei diesen Vierecken aber wiederholt um Quadrate. An diesen Stellen tritt das Knotenmuster des Dokuments besonders ausgeprägt in Erscheinung. Am Schluss des erhaltenen Teils der Rolle befindet sich ein langes Rechteck; es ist am oberen Ende abgerundet. Diese geometrischen Figuren fassen einen Mittelstreifen ein, der einerseits Verzierungen, anderseits Textelemente enthält. Diese Textelemente sind oft derart angeordnet, dass auch sie zur Verzierung des Dokuments beitragen.

Die Inhalte der Texte in den dreiteiligen Seitenbändern und jener im Mittelstreifen sind voneinander unabhängig. Diese Unabhängigkeit kommt auch darin zum Ausdruck, dass der Text in den dreiteiligen Schriftbändern in der Rollenrichtung, also sozusagen vertikal, kopiert worden ist. ${ }^{6}$ Die Textelemente im Mittelstreifen allerdings sind grundsätzlich auf horizontalen Linien notiert worden, sofern sie nicht in besonderen Figuren angeordnet sind. Diese inhaltliche Unabhängigkeit der Texte in den dreiteiligen Seitenbändern bzw. im Mittelstreifen erfordert auch bei der Auseinandersetzung mit dem vorliegenden Belegstück einen doppelten Zugang:

I. Die weiteren Ausführungen befassen sich in einem ersten Schritt mit Inhalt und Gestaltung der Seitenbänder mit Text aus dem Koran. Die Abschrift ist in der Regel fortlaufend; es lassen sich allerdings wiederholt Auslassungen feststellen.

II. Gestaltung und Inhalt des zwischen den beiden dreiteiligen Schriftbändern eingeschlossenen Mittelstreifens werden in einem zweiten Teil erfasst. Auch hier lassen sich vielfach Stellen aus dem Koran nachweisen. Allerdings dominieren hier Texte aus weiteren Quellengattungen, v. a. aus Gebetssammlungen. Dieser zweite Teil trägt wegen seiner oft aufwendi-

6 Auf der einen Seite vor-, auf der andern rückwärtslaufend. gen Gestaltung massgeblich zur ästhetischen Wirkung und dem individuellen Charakter des Dokuments bei. Er erlaubt auch Rückschlüsse auf die ideologischen Auffassungen, denen sich sein Hersteller und seine Träger verpflichtet fühlten.

\section{Inhalt und Gestaltung der dreiteiligen Schriftbänder}

Am Anfang der Rolle enthalten nur die dreiteiligen Schriftbänder Textelemente; im Innern der Medaillons befinden sich ausschliesslich Verzierungen. Bei den kopierten Textstellen (in schwarzer Tinte) handelt es sich um Stellen aus dem Koran. Da das Dokument am Anfang fragmentarisch erhalten ist, beginnen sie mitten im jeweiligen Vers (АВВ. 71).

Im vorwärtslaufenden dreiteiligen Textband lassen sich oben rechts folgende Stellen erkennen: ${ }^{7}$ a. (Mittelstreifen, grosse Schrift): $\mathrm{Q} 2: 34{ }^{8}$ b. im schmalen Schriftband rechts aussen steht Q 44:41. ${ }^{9}$ c. im schmalen Textband rechts innen steht Q 32:11. ${ }^{10}$ Auf der gegenüberliegenden linken Seite bricht das rückwärtslaufende Schriftband ab. Hier bzw. im aufsteigenden Band auf der rechten Seite unmittelbar darunter lassen sich folgende Koranstellen identifizieren: a. Mittelstreifen, grosse Schrift: Q 23:28, Vers beginnt auf der linken Seite des unteren kleinen Medaillons. ${ }^{11}$

7 Abb. 2 der Rolle unter http://www.e-manuscripta.ch/ bau/content/pageview/837969.

8 Q 2:34 lautet:

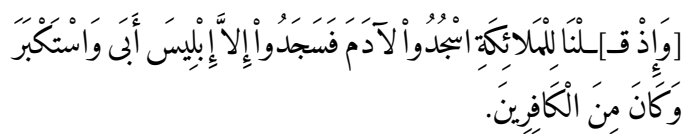

9 Q 44:41 lautet:

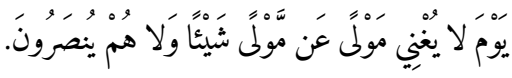

Danach Verstrenner (golden).

Q 32:11. lautet:

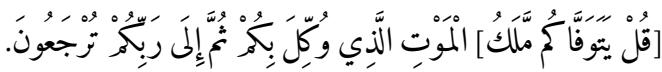

Danach Verstrenner (golden).

11 Q 23:28 lautet: 
b. Schmales aufsteigendes Schriftband links aussen bzw. im vorangehenden Abschnitt dieses Bandes: Q 104:9 (Schlussvers). ${ }^{12}$ Unmittelbar danach müsste nach einem Leerraum Q 105 beginnen; diese Sure fehlt aber, da das Dokument am Anfang fragmentarisch erhalten ist. c. Auf der linken Seite endet das aufsteigende schmale Schriftband innen mit Q 43:49; der Vers beginnt nach einem Trennzeichen auf der rechten Seite des grossen Medaillons darunter. $^{13}$

Bei der ersten nachweisbaren Stelle handelt es sich um Q 2:34, bei der letzten um Q 104:9. Somit fehlen auf dem Dokument die ganze Sure 1 ( (Q 1) und Q 2:1-33. Auch fehlt der Schluss der islamischen Offenbarung (Q 105-114). Bei den andern Textbändern ist ebenso Surentext verloren gegangen. Es lässt sich nicht abschätzen, wie lange der verlorene Teil gewesen war. Es könnte sich ohne weiteres um 2-3 $\mathrm{m}$ handeln.

Die beiden dreiteiligen Schriftbänder laufen unter Umfahrung von unterschiedlichen geometrischen Figuren bis ganz an den Schluss des Dokuments durch. Am Ende lassen sich in den einzelnen Teilen der beiden Schriftbänder die folgenden Koranstellen erkennen:14

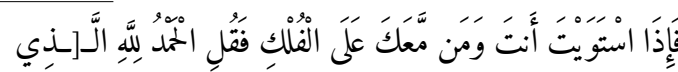

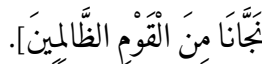

12 Q 104 beginnt im schmalen äusseren Textband auf der linken Seite des unteren kleinen Medaillons mit der Basmala. Sie endet mit Vers 104.9 (Schlussvers) im schmalen Innenband am oberen Ende des grossen Medaillons. Q 104 lautet:

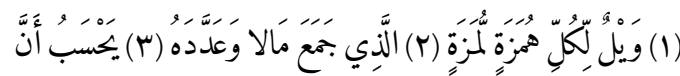

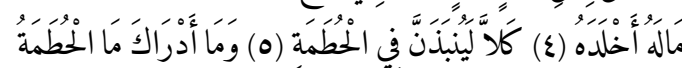

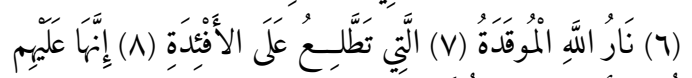

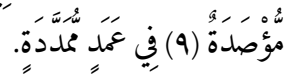

13 Q 43:49 lautet:

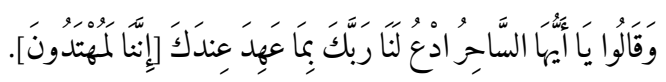

14 Abb. 12 der Rolle unter http://www.e-manuscripta.ch/ bau/content/pageview/837979.
Linkes Schriftband, absteigend: a. Im breiten Schriftband steht links am Schluss Q 2:245. ${ }^{15} \mathrm{~b}$. Im schmalen Schriftband links aussen steht zuletzt Q 40:30. ${ }^{16}$ c. Im schmalen Textband links innen steht am Schluss Q 55:70-71. ${ }^{17}$ Auf der rechten Seite lassen sich am Schluss im aufsteigenden Schriftband folgende Stellen erkennen (jeweils aufsteigend): a. Im breiten Schriftband steht Q 6:20.18 b. Im schmalen Schriftband rechts aussen steht Q 40:82. ${ }^{19}$ c. Im schmalen Schriftband innen steht am Schluss Q 68:51. ${ }^{20}$

Aus dem allgemeinen Aufbau der Rolle ist $\mathrm{zu}$ schliessen, dass das vorwärts- und das rückwärtslaufende dreiteilige Schriftband am Schluss miteinander verbunden waren. Die Gestaltung dieses Übergangs lässt sich allerdings nicht rekonstruieren. Es fällt auf, dass es sich bei der letzten Stelle

15 Q 2:245 lautet:

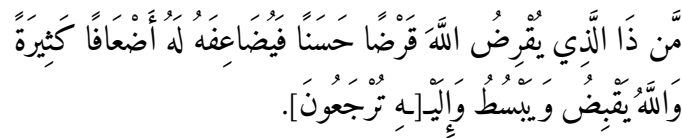

16 Q 40:29-3o lautet:

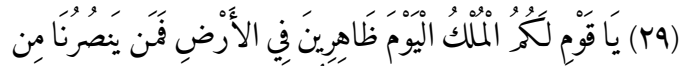

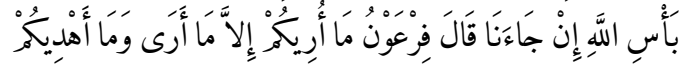

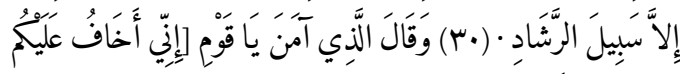

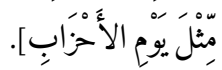

Q 55:70-71 lautet:

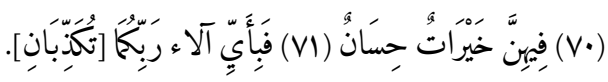

18 Q 6:20 lautet:

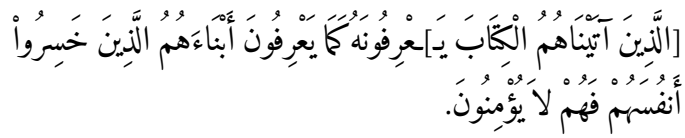

19 Q 40:82 lautet:

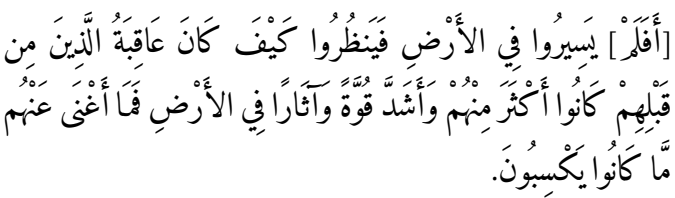

20

Q 68:51-52 (Schlussvers) lautet:

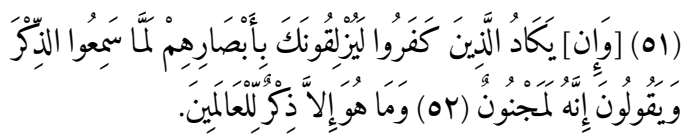


im breiten Schriftband links absteigend um Q 2:245 handelt. Im aufsteigenden Schriftband rechts steht als erste Stelle Q 6:20. Ebenso miteinander verbunden gewesen sein mussten die beiden Aussenbänder, die beide Stellen aus Q 40 enthalten (links absteigend: Q 40:30; rechts aufsteigend: Q 40:82).

Diese Beobachtungen lassen darauf schliessen, dass Q 40:31-81 auf dem jetzt fehlenden Schlussteil vollständig kopiert worden war. Aufgrund der beträchtlichen Länge des Abschnitts zwischen $\mathrm{Q}$ 2:245 und Q 6:20 ist aber auszuschliessen, dass auch der fehlende Abschnitt zwischen Q 2:245 und Q 6:20 auf dem Dokument enthalten war. Wahrscheinlicher ist, dass der Kopist Q 3-5 hier ganz ausliess. Nur der Rest von Q 2 (Verse 246-286) und der Anfang von Q 6 (Verse 1-19) dürften in diesem verlorenen Teil des breiten Schriftbands gestanden haben. Auch im schmalen Innenband dürfte der Kopist einen bedeutenden Teil zwischen Q 55:70 und Q 68:51 ausgelassen haben.

Nach diesen Hinweisen zum Inhalt der beiden dreiteiligen Schriftbänder am Anfang und Schluss gehen die weiteren Ausführungen diesen Seitenbändern anhand von ausgewählten Details ausführlicher nach. Die folgende Darstellung beginnt am Anfang des Dokuments:

Der Kopist hat zwischen den einzelnen Suren stets einen Abstand eingehalten. Dies lässt sich am Anfang gut aufzeigen (АВB. 72). ${ }^{21}$ Neben dem Titelfeld für den 2. Haykal (al-Haykal at-tān̄ì $)^{22}$ endet auf der rechten Seite im schmalen Schriftband innen Q 103. Q 104 beginnt erst nach einem Zwischenraum im schmalen Schriftband links aussen neben dem kleinen Medaillon. Auch am unteren Ende dieses Rechtecks mit den beiden mandelförmigen Figuren lassen sich in den beiden schmalen Schriftbändern (ab- bzw. aufsteigend) die Übergänge zwischen Ende und Anfang von zwei Suren erkennen. Das Vorgehen des Kopisten lässt sich ebenso anhand der Stelle beim Anfang

21 Abb. 2 der Rolle unter http://www.e-manuscripta.ch/ bau/content/pageview/837969.

22 Abschnitt mit den beiden senkrecht übereinander angeordneten mandelförmigen Figuren. der Abschrift des 3. Haykal bzw. in der Abfolge von drei Medaillons unmittelbar davor aufzeigen. ${ }^{23}$ Hier lässt sich im schmalen Schriftband (rechts innen) am Rand des grossen Medaillons der Übergang zwischen Q 99:8 und Q 100:1 erkennen; Q 100 beginnt nach einem Freiraum mit der Basmala.

Der Surentext im breiten Schriftband wurde nicht durchgehend in grossem Nash notiert. Vor dem Beginn des Abschnitts mit dem 3. Haykal (АВв. 74) befindet sich eine Abfolge von drei untereinander verbundenen Medaillons (kleinesgrosses-kleines Medaillon). Der Schreiber hat hier den Text in $\dot{G} u b \bar{a} r$-Schrift kopiert und diesen auf zwei Zeilen in Tropfenform angeordnet. Diese Tropfen laufen oben spitz zu. Beim kopierten Text handelt es sich weiterhin um Abschriften der entsprechenden Auszüge aus dem Koran. Der Surentext ist in diesen Tropfen oft versetzt angeordnet. Der Schreiber notiert die Sätze nicht fortlaufend auf der jeweiligen Zeile, sondern springt wiederholt zwischen der inneren und äusseren Zeile hin und her.

Direkt neben dem Titelbalken mit der Überschrift für den 3. Haykal lässt sich ein Tropfen erkennen, der aus nur einer Zeile Text in $\dot{G} u b a \bar{r}$ gebildet wird. ${ }^{24}$ Er enthält den Beginn von Q 23 (Q 23:1-3). Der Schreiber setzt die Abschrift von Q 23 im aufsteigenden breiten Schriftband fort; er notiert den Surentext weiterhin in $\dot{G} u b \bar{r} r$ in Tropfen. Er wechselt erst wieder an jener Stelle zu grossem Nash, wo er den Abschnitt mit dem neunzelligen goldenen Quadrat erreicht. Hier steht im aufsteigenden breiten Schriftband der Übergang Q 23:25-26.25 Die Stelle verdient besondere Erwähnung, da vor dem einzeiligen Tropfen mit dem Beginn von Q 23 (direkt rechts neben dem Titelfeld

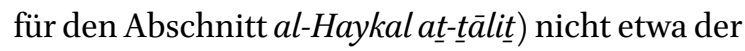

23 Abb. 3 der Rolle unter http://www.e-manuscripta.ch/ bau/content/pageview/837970.

24 Abb. 3 der Rolle unter http://www.e-manuscripta.ch/ bau/content/pageview/837970.

25 Q 23:25-26 lautet:

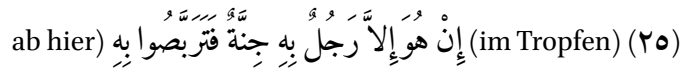

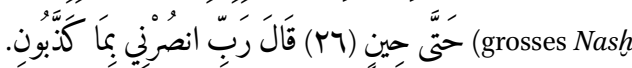


Schluss von Q 22 steht (А В B. 74). Im Tropfen darunter steht vielmehr der Schluss von Q 18 (Verse 109c110). Im dritten Tropfen darunter steht im breiten Band rechts Q 18:107-109. Zweierlei ist dabei $\mathrm{zu}$ beachten: a. In den beiden Tropfen mit dem Schluss von Q 18 notiert der Schreiber den Korantext nicht fortlaufend auf einer Zeile; er springt vielmehr unablässig zwischen innerer und äusserer Zeile hin und her. Beim Entziffern ist die korrekte Textfolge richtiggehend zu rekonstruieren. b. Anderseits fällt auf, dass Q 19-22 an dieser Stelle fehlen. Dies ist ein weiterer Hinweis darauf, dass der Koran auf dieser Rolle nicht vollständig enthalten ist. Eine weitere Lücke liess sich bereits am Schluss des Dokuments feststellen, wo der Kopist mutmasslich Q 3-5 gänzlich ausgelassen hatte. ${ }^{26}$

Der Kopist kehrt nach dem Abschluss des 3 . Haykal bei der Abschrift des Korans von der $\dot{G} u b a \bar{r} r-$ Schrift in den Tropfen auch im breiten Mittelband wieder zu grossem Nash zurück. Unmittelbar oberhalb des Medaillons mit der Inschrift al-Mulk li[A]llāh befindet sich allerdings ein Quadrat. Hier notiert der Schreiber den Korantext im breiten Mittelband erneut in $\dot{G} u b \bar{a} r$-Schrift. Er ordnet ihn hier aber auf vier diagonal ausgerichteten Zeilen in auf der Spitze stehenden Quadraten an. ${ }^{27}$

Auf der Höhe des Medaillons mit der Inschrift al-Mulk li-[A]llāh (Авв. 75) lassen sich im dreiteiligen Schriftband u.a. die folgenden Stellen erkennen: ${ }^{28}$ a. breites Band rechts, aufsteigend: Q 18:60;29 schmales Schriftband, rechts innen: Q 96:1 (Beginn mit Basmala nach einem Zwischenraum); c. Im breiten Schriftband, absteigend steht sodann Q 2:83. ${ }^{30}$ Unterhalb des grossen Medaillons mit der Inschrift al-Mulk li-[A]llāh steht im brei-

26 Vgl. dazu oben zwischen Anm. 20 und 21.

27 Abb. 3 (Ende) der Rolle unter http://www.e-manuscrip ta.ch/bau/content/pageview/83797o.

28 Abb. 3 der Rolle unter http://www.e-manuscripta.ch/ bau/content/pageview/83797o.

29

Q 18:6o lautet:

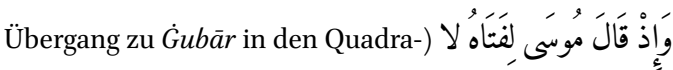
(ten 30

Diese Übersicht zeigt auf, dass im breiten absteigenden ten Schriftband (aufsteigend) Q 18:59; der Schreiber wechselt hier von $\dot{G} u b a \bar{r}$-Schrift im Text, der in kleinen Quadraten angeordnet ist, zu grossem Nash. ${ }^{31}$ Zugleich lässt sich auf dem äussersten Schriftband rechts im Rahmen des Abschnitts mit der Überschrift al-Haykal ar-rābic der Übergang zwischen Q 42:53 (Schlussvers) und Q 43:1 erkennen. Q 43 beginnt im schmalen aufsteigenden Schriftband innen direkt neben dem kleinen Medaillon oberhalb des Balkens mit dem Titel alHaykal ar-rābi. ${ }^{32}$

Im Abschnitt mit dem goldenen Gitter (АВВ. 76), der mutmasslich ursprünglich die Schönen Namen Gottes enthalten hatte, ${ }^{33}$ lassen sich u. a. die folgenden Koranstellen erkennen: ${ }^{34}$ a. Im absteigenden breiten Schriftband steht Q 2:106f.; ${ }^{35}$ b. im aufsteigenden breiten Schriftband steht am oberen Ende des Rechtecks mit dem goldenen Gitter der Beginn von Q 18:29;36 c. in der rechten oberen Ecke des goldenen Gitters lässt sich

Schriftband Q 2 kopiert wurde; enthalten sind die Verse Q 2:34-245. Der hier kopierte Vers (Q 2:83) lautet:

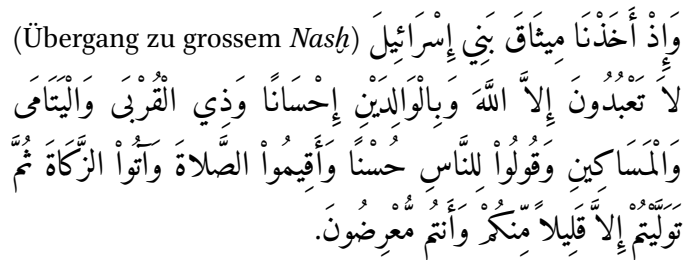

Q 18:59 lautet:

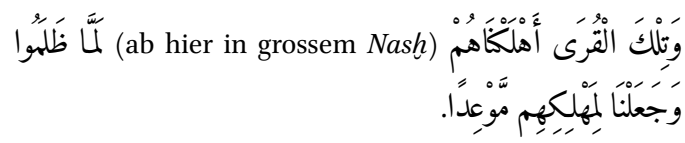

Abb. 3 der Rolle (Schluss) unter http://www.e-manuscri pta.ch/bau/content/pageview/83797o.

33 Vgl. zu diesem Abschnitt unten nach Anm. 203.

34 Abb. 5 der Rolle (Anfang) unter http://www.e-manuscri pta.ch/bau/content/pageview/837972.

35

Q:106f. lautet:

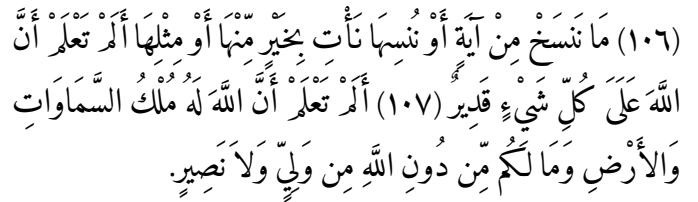

36 Q 18:29 lautet:

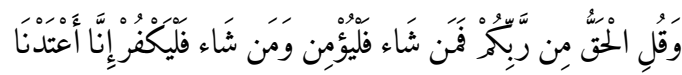


im schmalen aufsteigenden Schriftband (innen) der Übergang zwischen zwei Suren erkennen. Es handelt sich um den Schluss von Q $91^{37}$ und den Anfang von Q 92. ${ }^{38}$

Oberhalb des Abschnitts mit dem 5. Haykal befindet sich ein Medaillon mit dem Text Subhāana Allāh (Авв. 77) ${ }^{39} \mathrm{Im}$ breiten Textband, das dieses Medaillon umfährt, hat der Schreiber den Text in grossem Nash kopiert. Beim Übergang zum Abschnitt mit dem 5. Haykal wechselt er zu Gubār Schrift und ordnet den Text in Rauten an, die durch zwei Zeilen Text gebildet werden. Sie sind innen mit einem goldenen Zierpunkt versehen. Auf der Höhe des Medaillons mit der Inschrift Subhāna Alläh bzw. etwas darunter lassen sich u. a. die folgenden Stellen identifizieren: ${ }^{40}$ a. Breites Textband, absteigend: Q 2:109; ${ }^{41} \mathrm{~b}$. breites Textband aufsteigend: Q 18:28.42

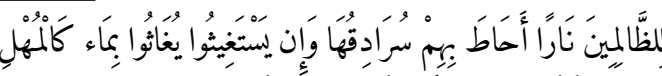

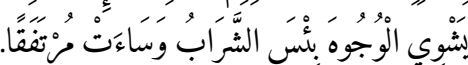

Q 91:13-15 lautet:

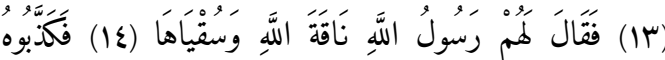

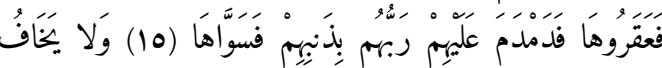

عُقَِّاهَا.

38 Q 92:1 lautet (im äussern schmalen Schriftband, aufsteigend, links neben dem kleinen Medaillon):

$$
\text { بسم الله الرحمن الرحيم (1) وَالليَّلِ إِذَا بغْشَى. }
$$

Abb. 5 der Rolle unter http://www.e-manuscripta.ch/ bau/content/pageview/837972; vgl. zu diesem Medaillon unten bei Anm. 205.

Q 18:28 lautet:

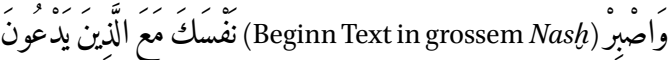

Beim Beginn des Abschnitts mit dem 6. Haykal (АВB. 79) lassen sich in den seitlichen Schriftbändern u.a. folgende Stellen erkennen:43 a. Breites Schriftband, absteigend: Q 2:126;44 im breiten aufsteigenden Schriftband steht Q 18:5. ${ }^{45}$

Vor dem Beginn des Abschnitts mit dem 7. Haykal befindet sich eine Abfolge von drei Medaillons (kleines-grosses-kleines Medaillon). ${ }^{46}$ Der Schreiber hat den Text in den breiten Textbändern um diese Medaillons herum erneut in $\dot{G} u b \bar{a} r-$ Schrift notiert und den Text in Tropfen angeordnet. Im Rechteck darüber steht der Text im breiten Mittelband wieder in grossem Nash. Hier lassen sich u. a. folgende Stellen erkennen: a. breites Schriftband absteigend (zuerst grosses Nash: Q 2:129);47 b. breites Textband aufsteigend: hier beginnt Q 18 (al-Kahf) mit der Basmala; c. Parallel zum Beginn von Q 18 lässt sich auf dem schmalen Schriftband

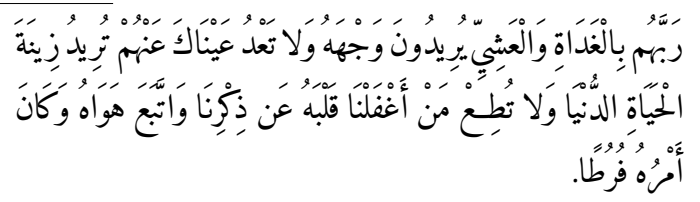

43 Abb. 6 der Rolle (Anfang) unter http://www.e-manuscri pta.ch/bau/content/pageview/837973.

44 Q 2:126 lautet:

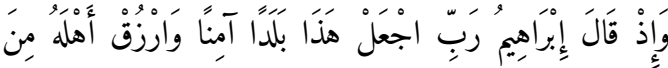

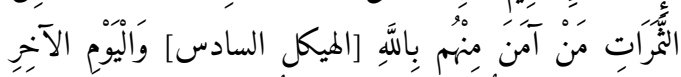

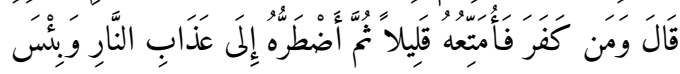

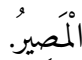

Q 18:5 lautet:

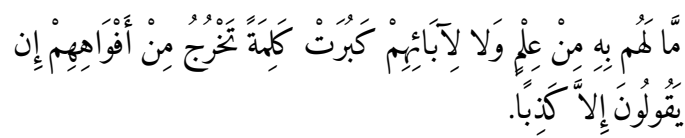

Abb. 7 der Rolle (Anfang) unter http://www.e-manuscri pta.ch/bau/content/pageview/837974.

47 Q 2:129 lautet:

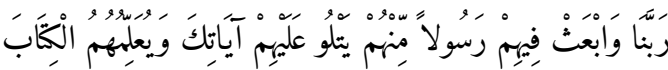

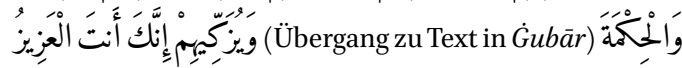
الخِكَيمَ. 
rechts innen der Schluss von Q $87^{48}$ erkennen. Nach einer kurzen Lücke beginnt darüber Q 88 mit der Basmala. ${ }^{49}$ Die Stelle vor Q 18 im breiten Schriftband aufsteigend soll im folgenden näher untersucht werden:

Im Tropfen unmittelbar vor der Basmala von Q 18 würde man grundsätzlich den Schluss von Q 17 erwarten. In der Tat steht hier allerdings der Schluss von Q 6. Beim Zurückverfolgen des Schriftbands lässt sich vor dem Beginn von Q 18 (mit der Basmala) ein grosses Medaillon mit Verzierung erkennen. ${ }^{50}$ Auf der Höhe dieses grossen Medaillons lassen sich im breiten Schriftband rechts drei Tropfen mit nach oben gerichteter Spitze feststellen; sie enthalten Text in $\dot{G} u b \overline{a r}$. Im untersten dieser drei Tropfen stehen am Schluss der inneren Zeile aufsteigend die drei ersten Wörter aus Q 6:161. ${ }^{51}$ Der Kopist setzt die Abschrift dieses Verses im nächsten Tropfen darüber auf der äusseren Zeile an der Spitze fort; er umfährt diesen Tropfen im Gegenuhrzeigersinn. Zurück an der Spitze dieses Tropfens springt er von der äusseren auf die innere Zeile des Tropfens. Darauf springt der Kopist erneut in den nächsten Tropfen unmittelbar darüber und setzt die Abschrift des Schlusses von Q 6 darin fort, indem er erneut an der Spitze des Tropfens auf der äusseren Zeile beginnt.

48 Der Schluss von Q 87 lautet:

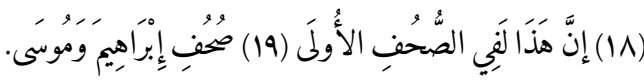

49 Der Beginn von Q 88 lautet:

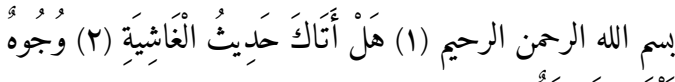

$$
\begin{aligned}
& \text { يَومئَل خَاشعَة. }
\end{aligned}
$$

50 Vgl. die Beschreibung dieses Medaillons unten nach Anm. 248.

51 Q 6:161 lautet:

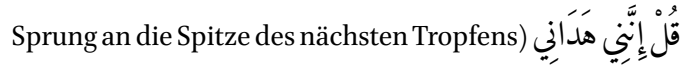
darüber; Fortsetzung an der Spitze auf der äusseren

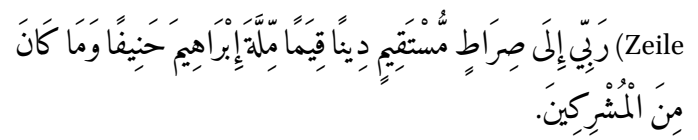

Im Tropfen unmittelbar vor der Basmala zu Q 18 steht dann Q 6:165 (Schlussvers).52 Der Schreiber beginnt auch hier an der Spitze des Tropfens und notiert den Text absteigend. Er vervollständigt diesen Tropfen durch die Abschrift von Q 112. Danach folgt die Basmala zu Q 18 in grosser Schrift. Die Abschrift des Textes der Schlussverse von Q 6 erfolgt jeweils fortlaufend zuerst auf der äusseren, dann auf der inneren Zeile der einzelnen Tropfen.

Die soeben vorgenommene Beschreibung zeigt auf, dass auf den Schluss von Q 6, nach dem Einschub von Q 112, Q 18 folgt. Die Suren 7-17 fehlen an dieser Stelle. Der Einschub von Q 112 erklärt sich einzig damit, dass der Kopist Q 18 nicht mitten in diesem letzten Tropfen beginnen wollte. Er zog es vor, diese Sure in grosser Schrift neu zu beginnen. Die kurze Q 112 schien ihm offensichtlich am geeignetsten, den Tropfen davor abzuschliessen. Dieser Tropfen wird übrigens aus nur einer Zeile gebildet. Der Kopist springt am Schluss von Q 112 im Innern von der Spitze des Tropfens an dessen unteres Ende.

Die vorangehenden Ausführungen zeigen auf, dass in den seitlichen Schriftbändern auf der vorliegenden Rolle nicht der gesamte Korantext kopiert worden ist. Die Lücke zwischen Q 6 und 18 ist beträchtlich. Auch ist bereits auf die Lücken mit den fehlenden Q 3-5 und Q 19-22 hingewiesen worden. ${ }^{53}$ Eine nächste Lücke lässt sich auf der Rolle nur wenig später feststellen: Vor dem Abschnitt mit der Du'a'’ mubārak befindet sich eine Abfolge von drei Medaillons (АВ В. 80); das mittlere davon (gross) weist eine aufwendig gestal-

\footnotetext{
52 Q 6:165 lautet:

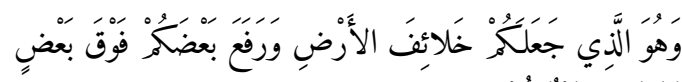

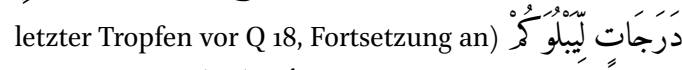

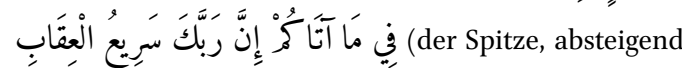

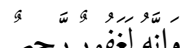

Vgl. oben zwischen Anm. 20 und 21 und vor Anm. 26.
} 
tete Verzierung auf. ${ }^{54}$ Direkt oberhalb dieses grossen Medaillons lässt sich im schmalen Schriftband rechts aussen absteigend ein Leerraum erkennen. Vor diesem Leerraum steht Q 46:35 (Schlussvers). ${ }^{55}$ Nach dem Leerraum beginnt Q 48 mit der Basmala. ${ }^{56}$ Die eigentlich zu erwartende Q 47 fehlt an dieser Stelle. Es lässt sich natürlich nicht ausschliessen, dass Q 47 an einer andern Stelle auf der Rolle doch enthalten ist. Dies ist allerdings eher unwahrscheinlich. Der Text in diesen Schriftbändern wurde jedoch nicht auf seiner gesamten Länge überprüft, wäre dies doch mit einem unverhältnismässigen Aufwand verbunden gewesen.

Am Ende des Abschnitts mit der Du'ǟ mubārak schliesst sich erneut eine Serie von drei Medaillons an. Das mittlere davon enthält einen sechsstrahligen Stern. ${ }^{57}$ a. Vor diesem Stern steht im breiten absteigenden Schriftband Q 2:169. ${ }^{58} \mathrm{~b}$. Im breiten Band aufsteigend steht Q 6:129. ${ }^{59} \mathrm{c}$. Im schmalen aufsteigenden Schriftband lässt sich rechts aussen

54 Abb. 7 der Rolle unter http://www.e-manuscripta.ch/ bau/content/pageview/837974; vgl. die Beschreibung dieses Medaillons unten nach Anm. 267.

55 Q 46:35 lautet:

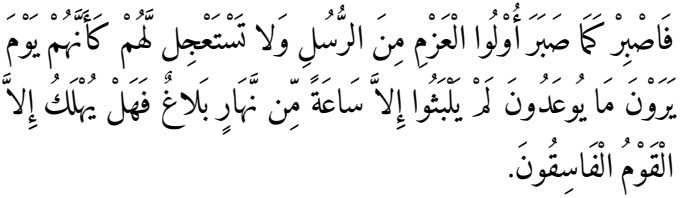

56 Q 48:1-2 lautet:

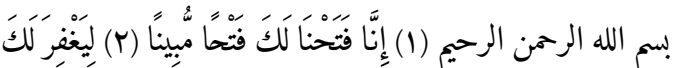

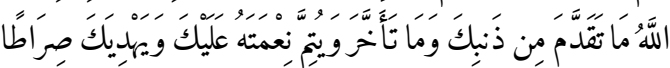

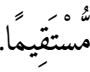

57 Abb. 8 der Rolle (Anfang) unter http://www.e-manu scripta.ch/bau/content/pageview/837975; vgl. die Beschreibung dieses sechsstrahligen Sterns unten nach Anm. 279 .

58 Q 2:169 lautet:

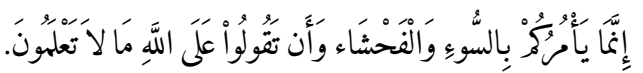

59 Q 6:129 lautet:

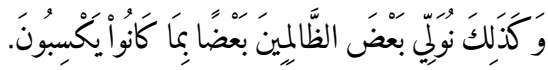

der Beginn von Q 42 erkennen (mit Basmala). ${ }^{60}$ Davor endet Q 41:54 (Schlussvers). ${ }^{61}$

Entlang des Abschnitts mit der Du'ā' Ibrāhìm b. Adham hat der Kopist den Text aus dem Koran in den breiten Teilen der Schriftbänder weiterhin in grossem Nash notiert. ${ }^{62}$ Er ändert dieses Vorgehen aber beim Übergang zur nächsten Abfolge von drei untereinander verbundenen Medaillons und behält es bis zum Abschnitt mit der Überschrift Faḍ Āyat (sic) al-Hars bei. ${ }^{63}$ Er notiert den Text im breiten Mittelband hier in $\dot{G} u b a \bar{r}$; die Abschrift ist in mandelförmigen Figuren angeordnet, die durch Text auf zwei Zeilen gebildet werden. Beim Übergang zwischen dem Text in grossem Nash zu den mandelförmigen Figuren lässt sich im breiten absteigenden Schriftband Q 2:171-172 erkennen. ${ }^{64} \mathrm{Im}$ breiten aufsteigenden Schriftband steht Q 6:128.65

6o Q 42:1-3 lautet:

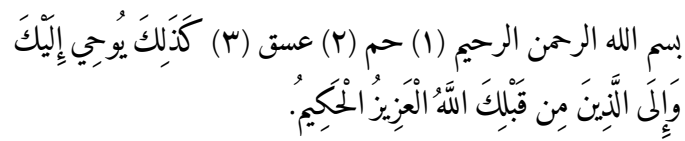

61 Q 41:54 lautet:

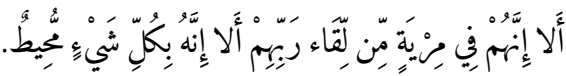

62 Abb. 8 der Rolle unter http://www.e-manuscripta.ch/ bau/content/pageview/837975; Beginn nach dem Medaillon mit dem sechsstrahligen Stern.

63 Abb. 8 der Rolle (Schluss) unter http://www.e-manuscri pta.ch/bau/content/pageview/837975 und Abb. 9 (Anfang) unter http://www.e-manuscripta.ch/bau/cont ent/pageview/837976; vgl. die Beschreibung der $D u^{i} \bar{a}^{3}$ Ibrāhìm b. Adham unten nach Anm. 284.

64 Q 2:171-172 lautet (Der Kopist notiert den Text in der ersten Mandel zuerst auf der äussern Zeile fortlaufend; danach wechselt er auf die innere Zeile):

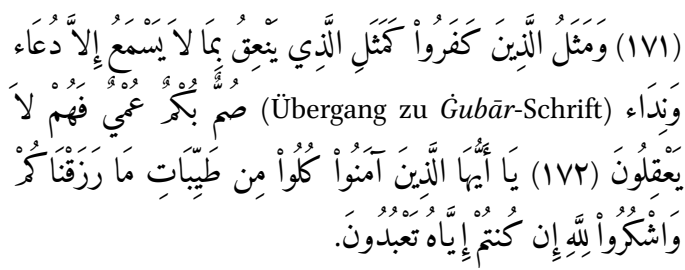

65 Q 6:128 lautet:

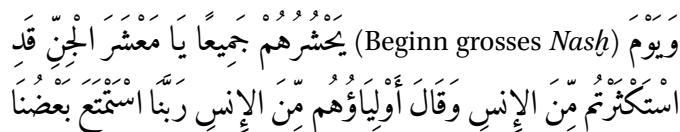


Es lohnt sich, an dieser Stelle einen Blick auf das Vorgehen des Kopisten in der mandelförmigen Figur mit Text in $\dot{G} u b \bar{a} r$ unmittelbar vor dem Übergang zu grossem Nash zu werfen (vor Q 6:128). Es handelt sich um die mandelförmige Figur im breiten Schriftband rechts neben dem grossen Medaillon ${ }^{66}$ mit der Verzierung auf blauem Hintergrund bzw. in der Figur unmittelbar davor: ${ }^{67}$ Der Kopist notiert die vier ersten Wörter von Q 6:125 in dieser unteren Figur auf der inneren Zeile links absteigend. Er springt dann in die obere mandelförmige Figur und setzt die Abschrift von Q 6:125 auf der äusseren Zeile aufsteigend fort. An der oberen Spitze der mandelförmigen Figur angekommen springt er wieder zurück nach unten. Er kopiert den Rest von Q 6:125 auf der innern aufsteigenden Zeile der mandelförmigen Figur. Q 6:125 endet an der oberen Spitze dieser Figur. ${ }^{68}$ Q 6:126 folgt auf der äusseren Zeile der mandelförmigen Figur links absteigend. ${ }^{69}$ Die beiden letzten Wörter auf dieser Zeile (La-hum dār) gehören bereits zu Q 6:127; dieser Vers wird auf der innern Zeile der mandelförmigen Figur links absteigend fortgesetzt. $^{70}$ Das letzte Wort auf dieser innern abstei-

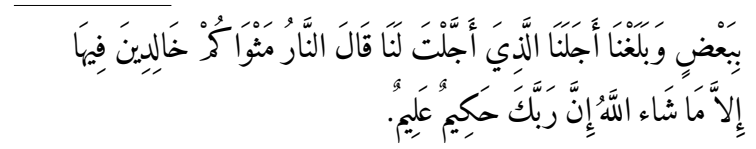

66 Bzw. rechts oberhalb des Medaillons.

67 Abb. 8 der Rolle (Schluss) unter http://www.e-manuscri pta.ch/bau/content/pageview/837975.

68 Q 6:125 lautet:

(untere Mandel, innere Zeile links absteigend, Schluss)

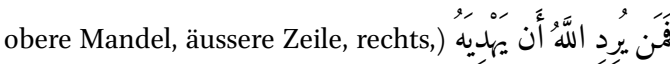

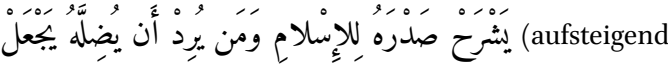

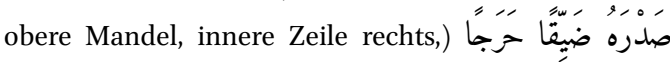

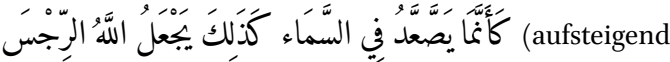

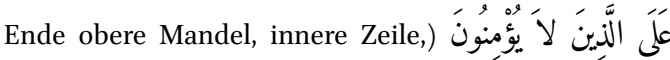
.(rechts, aufsteigend

69 Q 6:126 lautet:

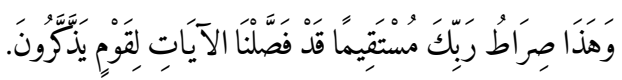

Q 6:127 lautet: genden Zeile der mandelförmigen Figur gehört schon zu Q 6:128; nach dessen ersten Begriff (wayawma) setzt der Kopist die Abschrift in grossem Nash fort. ${ }^{71}$ Die Gestaltung dieser mandelförmigen Figuren ist von Interesse, da sie aufzeigt, dass der Schreiber beim Ausfüllen derartiger Elemente mit Stellen in $\dot{G} u b \bar{a} r$-Schrift den Text immer wieder nach andern Kriterien anordnete. ${ }^{72}$

Am Schluss des Abschnitts mit der Du'äà Ibrāhim b. Adham ${ }^{73}$ lässt sich im schmalen, aufsteigenden Schriftband rechts innen der Beginn von Q 74 (mit Basmala) erkennen. ${ }^{74}$ Unmittelbar davor endet vor einem Leerraum Q $73 \cdot{ }^{75}$

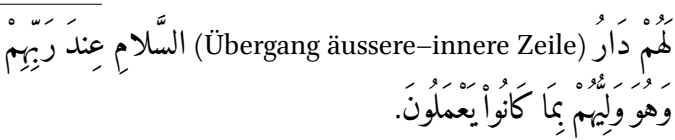

71

Q 6:128 lautet:

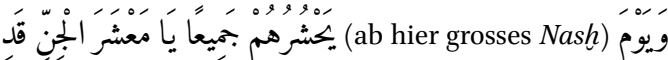

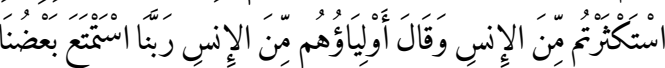

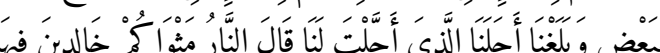

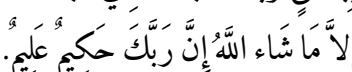

72 Man beachte zum Vorgehen des Kopisten in diesen Stellen auch die Ausführungen im Abschnitt zwischen Anm. 23 und 24.

73 Abb. 8 der Rolle unter http://www.e-manuscripta.ch/ bau/content/pageview/837975.

74 Q 74:1-3 lautet:

فَكَّبَه

75 Q 73:20 (Schlussvers) lautet:

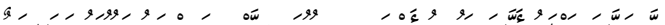

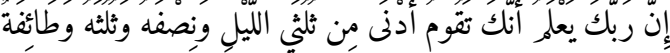

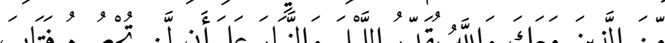

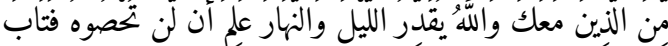

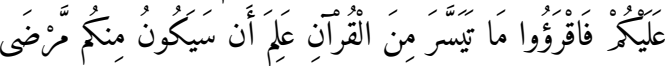

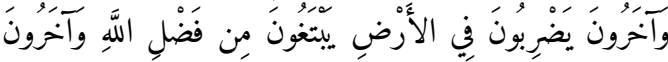

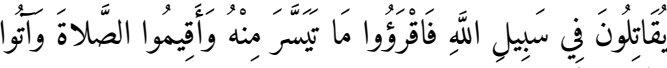

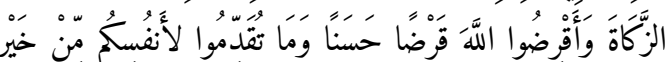

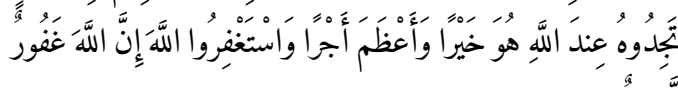
رحت, 
Beim Beginn des Abschnitts mit der Überschrift Faḍ Āyat (sic) al-Hars wechselt der Schreiber im breiten Mittelband wieder von der Anordnung des Texts in mandelförmigen Figuren zu grossem Nash bzw. vice versa in aufsteigender Richtung. ${ }^{76}$ Hier lassen sich die beiden folgenden Stellen erkennen: Im absteigenden Schriftband steht in grossem Nash Q 2:207. ${ }^{77}$ Im aufsteigenden breiten Schriftband steht Q 6:82-83. ${ }^{78}$

Kurz vor dem Beginn des Abschnitts mit der Überschrift Li-Ğalb ar-rizq ändert der Kopist sein Vorgehen bei der Gestaltung des breiten Teils des Schriftbands erneut: ${ }^{79}$ Er wechselt von grossem Nash zu Gubār (bzw. vice versa) und ordnet den Text in langgestreckten Sechsecken an, die aus zwei Zeilen Text in $\dot{G} u b \bar{r} r$ gebildet werden. Diese Figuren sind innen leer. ${ }^{80}$ Beim Übergang zu den Stellen in $\dot{G} u b \bar{a} r$ lassen sich im breiten Schriftband die folgenden Stellen erkennen: a. Links absteigend: Übergang Q 2:211-212; ${ }^{81} \mathrm{~b}$. rechts aufsteigend:

76 Abb. 9 der Rolle unter http://www.e-manuscripta.ch/ bau/content/pageview/837976.

77 Q 2:207 lautet:

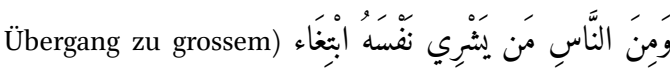

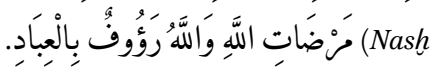

78 Q 6:82-83 lautet:

(AT)

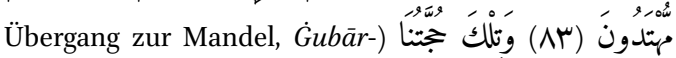
(Schrift

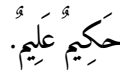

Abb. 11 der Rolle (Anfang) unter http://www.e-manuscri pta.ch/bau/content/pageview/837978.

8o Die oberste Figur ist ganz mit Text in $\dot{G} u b \bar{a} r$-Schrift ausgefüllt.

81 Q 2:211-212 lautet:

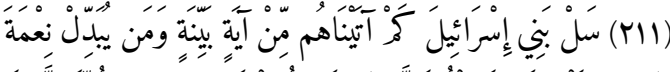

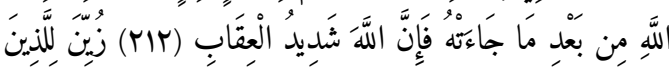

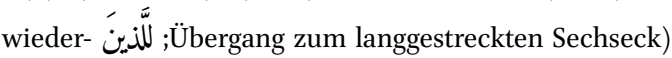

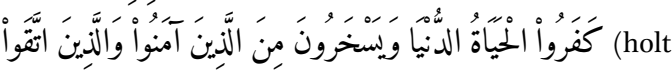

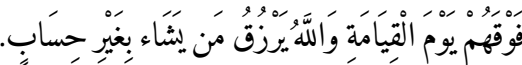

Q 6:79; ${ }^{82}$ c. Auf der Höhe des Titelfelds mit der Überschrift $L i$-Ğalb ar-rizq (АВв. 83) lässt sich im schmalen Innenband der Beginn von Q 55 erkennen. ${ }^{83}$ Unmittelbar davor endet Q 48:29 (Schlussvers) ${ }^{84}$ Hier liess der Kopist also erneut mehrere Suren (Q 49-54) aus. ${ }^{85}$

Kurz vor dem Anfang des Abschnitts mit dem Titel Li-ramy an-nuššā $b^{86}$ ändert der Schreiber sein Vorgehen im breiten Mittelband erneut (Ав B. 84). Es handelt sich um die Stelle, wo sich im Mittelstreifen zwei Bögen mit Pfeilen erkennen lassen. ${ }^{87}$ Hier wechselt der Schreiber von der Anordnung des Texts in $\dot{G} u b \bar{a} r$ in langgestreckten Sechsecken zu einer solchen in kleinen, auf der Spitze stehenden Quadraten. Die Zeilen in diesen Quadraten verlaufen diagonal. Im absteigenden Schriftband (hier links) steht beim Übergang von den langgestreckten Sechsecken zu den Quadraten Q 2:222-223. Q 2:222 steht im letzten langgestreckten Sechseck. Der Kopist hat die Abfolge der Wörter bei der Abschrift mehrfach aufgebrochen und komplex angeordnet. Im ersten Quadrat darunter steht Q 2:223. ${ }^{88}$ Auf der gegenüber-

82 Q 6:79 lautet:

(إنّي (Text zuinnerst im langgestreckten Sechseck)

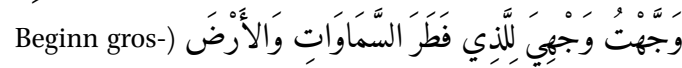

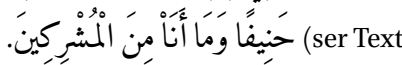

83 Q 55:1-3 lautet:

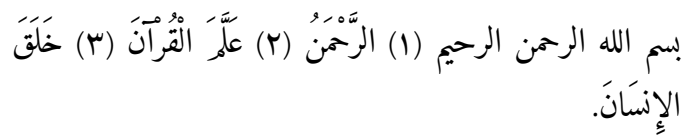

84 Das Ende des langen Schlussverses von Q 48:29 lautet:

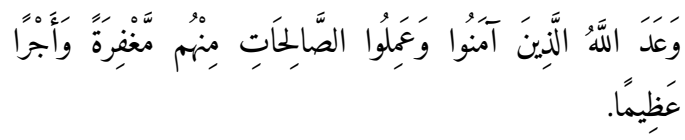

85 Diese Suren liessen sich an keiner andern Stelle auf der Rolle nachweisen.

86 Vgl. immer noch Abb. 11. Siehe die Beschreibung dieses Abschnitts unten nach Anm. 400.

87 Abb. 11 der Rolle (Anfang) unter http://www.e-manuscri pta.ch/bau/content/pageview/837978.

88 Q 2:223 lautet (die letzten beiden Wörter dieses Verses stehen im nächsten Quadrat darunter): 
liegenden Seite (rechts aufsteigend) befindet sich der Übergang Q 6:58-59. ${ }^{89}$ Ausserdem lässt sich an dieser Stelle im schmalen Schriftband, rechts innen, direkt oberhalb des Titelbalkens mit der Überschrift Li-Ramy an-nuššāb der Beginn von Q 70 erkennen. ${ }^{90}$ Davor endet Q 69. ${ }^{91}$ Der Schreiber ordnet den Text im breiten Textband $14 \mathrm{Mal}$ in auf der Spitze stehenden Quadraten an; dann wechselt er wieder zu den langgestreckten Sechsecken.

Kurz unterhalb des Titelbalkens mit der Überschrift Du'ä’ li-kull šay ${ }^{\prime 2}$ wechselt der Kopist im breiten Seitenband nach den langgestreckten Sechsecken zurück zur Abschrift in grossem Nash. Hier steht links absteigend Q 2:242-243. ${ }^{93}$ Auf der

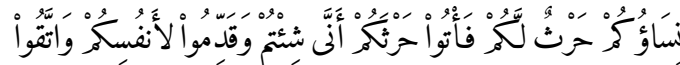

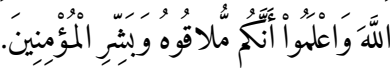

89 Q 6:58-59 lautet (Der Schreiber hat den Text in den Quadraten sozusagen auf dem Kopf kopiert):

Schluss des zweiten Quadrats vor dem langge-) (०^)

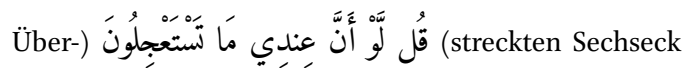

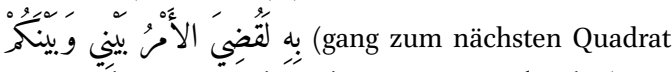

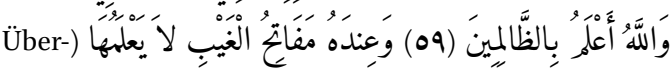
(gang zum langgestreckten Sechseck

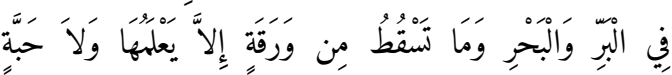

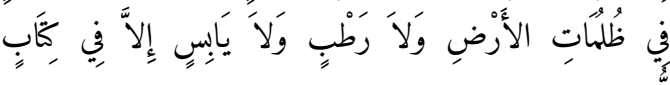

90 Q 70:1-3 lautet:

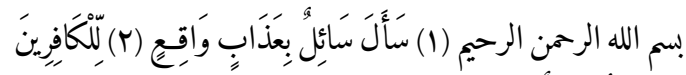

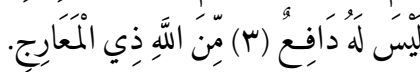

91 Q 69:51-52 (Schlussvers) lautet:

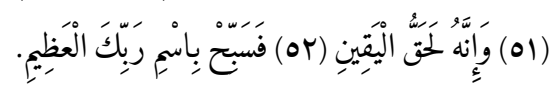

Immer noch auf Abb. 11; vgl. http://www.e-manuscripta .ch/bau/content/pageview/837978; vgl. die Beschreibung dazu unten bei Anm. 441.

93 Q 2:242-243 lautet (das erste Wort von Vers 242 in $\dot{G} u b \bar{a} r-$ Schrift im langgestreckten Sechseck davor): gegenüberliegenden Seite steht im rechten Schriftband aufsteigend Q 6:24-25. ${ }^{94}$

Im Rahmen dieser Übersicht über Inhalt und Gestaltung der dreiteiligen Seitenbänder gilt es auf eine letzte Auffälligkeit hinzuweisen: Auf der Höhe des Titelbalkens mit der Überschrift Tahlīl al-Qur'ān wa-l-ism al-a'zam ${ }^{95}$ lässt sich am rechten Rand der Rolle ausserhalb des Schriftspiegels eine Bemerkung erkennen, die sich nicht entziffern liess. Hier steht im schmalen Aussenband rechts (aufsteigend) der Beginn von Q 41. ${ }^{96}$ Davor endet Q 40. ${ }^{97}$ Die Stellen in den beiden dreiteiligen Schriftbändern ganz am Schluss dieses Belegstücks wurden bereits oben zusammengestellt. ${ }^{98}$

94 Q 6:24-25 lautet:

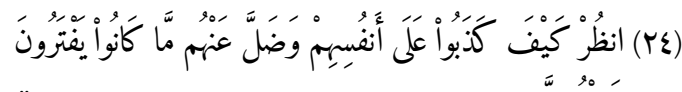

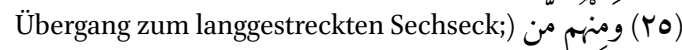
(Text in kleinem Gubār

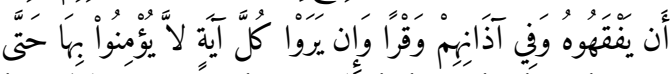

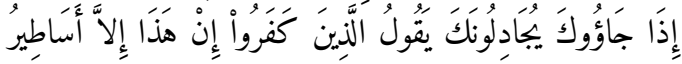
الأَوَّلَّنَ.

95 Abb. 12 der Rolle unter http://www.e-manuscripta.ch/ bau/content/pageview/837979; vgl. die Beschreibung zu diesem Abschnitt unten bei Anm. 466.

96 Q 41:1-3 lautet:

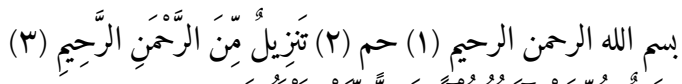

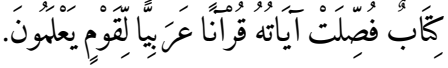

97 Q 40:85 (Schlussvers) lautet:

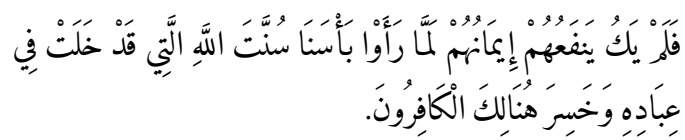

Vgl. dazu oben bei Anm. 14. 


\section{Inhalt und Gestaltung des Mittelstrei-} fens $^{99}$

1. Abfolge von drei Medaillons (АВв. 71): ${ }^{100}$ Der erhaltene Teil der Rolle beginnt mit einer Abfolge von drei Medaillons (klein-gross-klein), wobei vom obersten kleinen Medaillon nur der untere Teil erhalten geblieben ist. Das grosse Medaillon in der Mitte und das kleine Medaillon darunter sind vollständig vorhanden. Diese Medaillons werden vom dreiteiligen Schriftband umfahren. Darunter schliesst sich das erste Rechteck an; auch es wird vom dreiteiligen Schriftband eingefasst.

Die Medaillons sind mit Verzierungen ausgefüllt, bei denen grosszügig goldene Farbe eingesetzt wurde. Sie weisen im Innern keinerlei textliche Elemente auf. Die Verzierungen werden durch feine schwarze Linien strukturiert. Im unteren (kleinen) Medaillon lässt sich als zentrales Motiv ein Muster mit Blättern und einer Blüte erkennen. ${ }^{101}$ Im mittleren (grossen) Medaillon dominieren goldene Verzierungen. An vier Stellen wurden sie auf rotem Hintergrund angebracht. Es lassen sich auch spärliche Reste blauer Farbe erkennen. Dieses mittlere Medaillon enthält ebenso pflanzliche Ornamente, die durch schwarze Linien hervorgehoben werden. Sie wurden in unterschiedliche geometrische Figuren eingepasst. Es lassen sich vier dreilappige Figuren erkennen, die vertikal und horizontal ausgerichtet sind. Ihre Spitzen sind innen durch geschwungene Doppelbögen miteinander verbunden. Sie lassen im Zentrum ein Achteck mit nach innen geschwungenen Seitenlinien entstehen.

Auch die Überschrift zum ersten Rechteck unmittelbar nach diesen Medaillons macht deutlich, dass es am Anfang des Dokuments zu Verlusten gekommen ist. Sie lautet al-Haykal at-tān̄ì,

99 Die folgende Darstellung macht hier in knappen Hinweisen erneut auch auf den Inhalt der Seitenbänder aufmerksam; diese Wiederholungen sollen das Identifizieren der entsprechenden Stellen erleichtern.

1 oo Abb. 2 unter http://www.e-manuscripta.ch/bau/conten t/pageview/837969.

101 Das obere kleine Medaillon dürfte identisch ausgefüllt gewesen sein, ist jetzt aber verloren. also der „Zweite Haykal“. ${ }^{102}$ Aus dieser Bezeichnung geht hervor, dass auf dem jetzt verlorenen Abschnitt ein erster Haykal gestanden haben muss. Es folgen weitere Abschnitte mit der Überschrift Haykal. Beim letzten handelt es sich um den Siebten Haykal. ${ }^{103}$ Diese Haykal-Abschnitte enthalten Schutzgebete, wie noch aufzuzeigen ist. ${ }^{104}$

Der Abschnitt mit der Überschrift al-Haykal attâāī weist eine auffällige Gestaltung auf (АВВ. 72). Es handelt sich grundsätzlich um ein Rechteck von ca. $28 \mathrm{~cm}$ Länge, das zwischen zwei Abfolgen von drei Medaillons (kleines-grosses-kleines Medaillon) eingepasst worden ist. Das Rechteck wird vom vorwärts- bzw. rückwärtslaufenden dreiteiligen Schriftband mit Korantext eingefasst. ${ }^{105}$ Die Überschrift selbst steht in weisser, von schwarzen Linien eingefasster Schrift auf goldenem Hintergrund. Darunter beginnt der Text in steilem Nash (schwarze Tinte); am Anfang und am Schluss des Rechtecks steht der Text in normaler Schriftgrösse auf drei bzw. vier horizontalen Zeilen (mit goldenen Trennpunkten). Dazwischen befinden sich zwei in der Vertikalen ausgerichtete mandelförmige Figuren. Sie werden durch Text in $\dot{G} u b \bar{a} r-$ Schrift gebildet (jeweils fünf Zeilen) und weisen

102 Abb. 3 der Rolle unter http://www.e-manuscripta.ch/ bau/content/pageview/837969.

103 Abb. 8 der Rolle unter http://www.e-manuscripta.ch/ bau/content/pageview/837974.

$104 \mathrm{Zu}$ weiteren Bedeutungen des Begriffs Haykal beachte die Ausführungen bei Anm. 471-472 und Kapitel 4.4 (bei und mit Anm. 82-89).

105 In diesen Schriftbändern wurde jeweils der vorangehende bzw. anschliessende Text jener Stellen aus dem Koran kopiert, die auf den entsprechenden Bändern ganz am Anfang der Rolle identifiziert worden sind. Es fällt auf, dass der Schreiber zwischen den einzelnen Suren jeweils einen Abstand einfügt und die nächste Sure erst danach mit der Basmala einleitet. So lässt sich im schmalen inneren Textband rechts (aufsteigend) zuerst Q 102 erkennen; danach folgt Q 103 (mit Basmala). Im breiten Schriftband (absteigend) steht oberhalb des Titelfelds zum 2. Haykal der Beginn von Q 2:35:

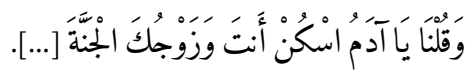

Im schmalen Innenband links (absteigend) lässt sich sodann der Übergang von Q 44 zu Q 45 erkennen. 
im Innern einen Leerraum mit einem Zierelement auf. An der Stelle, wo die beiden Mandeln aufeinanderstossen, lässt sich links und rechts ein tropfenförmiges Zierelement erkennen. Es wird durch jeweils drei Zeilen Text in $\dot{G} u b \bar{a} r$-Schrift gebildet. Die zur Linken und Rechten der beiden mandelförmigen Figuren verbleibenden Freiräume werden durch Verzierungen (goldene Ranken bzw. Girlanden mit blauen Blüten) ausgefüllt.

a. Der Text dieses al-Haykal at-tāâñ ist zuerst in normal grossem Nash kopiert worden; er lautet:106

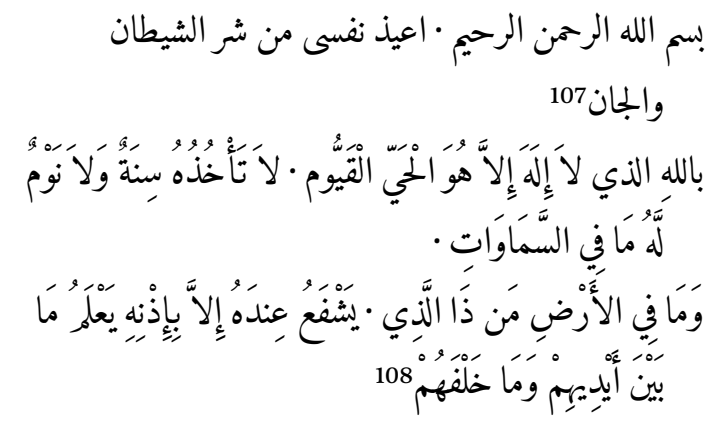

b. Jetzt springt der Schreiber in die obere mandelförmige Figur und setzt die Abschrift auf der linken äusseren Zeile (absteigend) in $\dot{G} u b \bar{a} r$ fort:

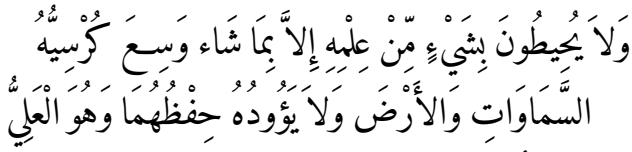

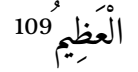

$$
\begin{aligned}
& \text { اعيذ نفسي بالله الذي لا اله الا هو عالم الغيب والشهادة هو } \\
& \text { الرحمن الرحيم واعيذ نفسي بالله الذي لا |||110 }
\end{aligned}
$$

106 Abb. 3 der Rolle unter http://www.e-manuscripta.ch/ bau/content/pageview/837969.

107 Bei den Haykal-Gebeten handelt es sich um Schutzgebete. Sie beginnen zumeist mit der Aussage $U^{\top} \underline{i} \underline{d} u$ nafsi $\min$ (Ich nehme Zuflucht vor).

108 Q 2:255a (Thronvers).

$109 \mathrm{Q}$ 2:255b (Fortsetzung, Schluss). Die letzten Wörter des Verses auf der zweitäussersten Zeile.

110 Hier endet die äusserste Zeile (absteigend) der oberen mandelförmigen Figur. Der Schreiber setzt den Satz auf der äussersten Zeile auf der gegenüberliegenden Seite (aufsteigend) fort.

$$
\begin{aligned}
& \text { اله الا هو الملك القدوس السلام المومن المهيمن سبحان الله } \\
& \text { عما يشركون واعيذ نفسي بلله الذي لا اله الا هو الخالق } \\
& \text { الباري المصور له الاسما ( كذا) الحسنى |||111 } \\
& \text { فسبح له (؟) ما في السموات والارض وهو العزيز الحكيم } \\
& \text { واعيذ نفسي بالله الاحد الصمد الذي لميلد ولميولد ولم } \\
& \text { يكن له كفو|112 احد } 113 \text { واعيذ نفسي بالله من شر ما خلق } \\
& \text { ومن شر غاست اذا ||114 } \\
& \text { وقب ومن شر النفاثات في العقد ومن شر حاسد اذا } \\
& \text { [ح][سد } 115 \text { واعيذ نفسي بالله من شر الوسواس الخناس } \\
& \text { الذي يوسوس في صدور الناس من الجنة والناس } 116 \\
& \text { واعيذ نفسي بالله مالك الملك |||117 }
\end{aligned}
$$

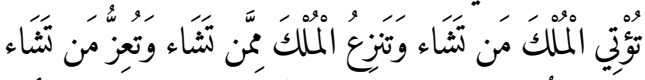

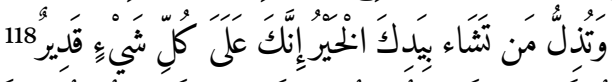

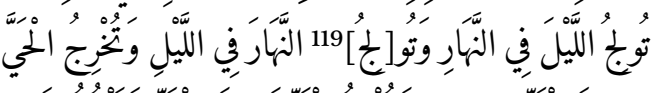

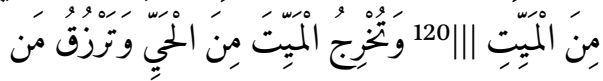

111 Hier erreicht der Schreiber die obere Spitze der oberen mandelförmigen Figur. Er setzt die Abschrift auf der gegenüberliegenden Seite auf der zweiten Zeile von aussen (absteigend) fort.

Beschädigung im Papier; Ausdruck verderbt.

Aus Q 112 (Beginn angepasst an die Einleitung $u^{\imath} \underline{\imath} \underline{d u}$ ). Hier erreicht der Schreiber auf der zweitäussersten Zeile (absteigend) die untere Spitze der oberen mandelförmigen Figur. Er setzt die Abschrift auf der gegenüberliegenden Seite auf der zweitäussersten Zeile (aufsteigend) fort.

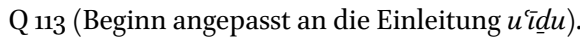
Q 114 (Beginn angepasst an die Einleitung $u \iota \underline{\imath} d u$ ).

117 Zeile (aufsteigend) die obere Spitze der oberen mandelförmigen Figur. Er setzt die Abschrift auf der gegenüberliegenden Seite auf der drittäussersten Zeile (absteigend) fort. Q 3:26 (Beginn angepasst an die Einleitung $u^{\imath} \underline{\imath} \underline{d} u$ ). Verderbt; Bruch im Papier.

Hier erreicht der Schreiber auf der drittäussersten Zeile (absteigend) die untere Spitze der oberen mandelförmigen Figur. Er setzt die Abschrift auf der gegenüberliegenden Seite auf der drittäussersten Zeile (aufsteigend) fort. 


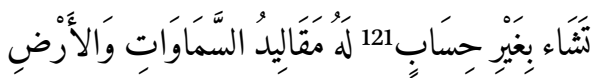

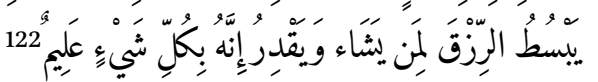

$$
\begin{aligned}
& \text { اعيذ نفسي بالله العلي (؟) |||123 العظيم وباسمايه الرحيم } \\
& \text { الكريك } 124
\end{aligned}
$$

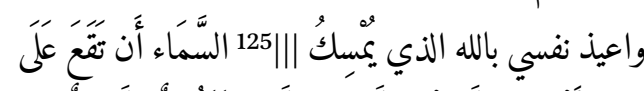

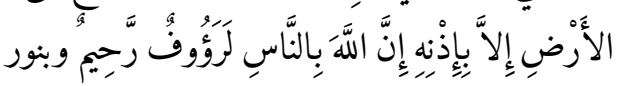

$$
\begin{aligned}
& 126[\ldots] \text { وجهd }
\end{aligned}
$$

Es schliesst sich darauf die zweite mandelförmige Figur an. Der Text beginnt erneut links aussen, absteigend. Er ist dann Zeile um Zeil nach innen fortschreitend zu lesen.

$$
\begin{aligned}
& \text { ا. 127 [...] وبالاسم الذي اصلح (؟) به امور الاولين } \\
& \text { والآخرين من المسلمين نار [...]128 واحرسني من شر كل } \\
& \text { جبار عنيد وشيطان مريد الله حززنا وحارسنا وناصرنا } \\
& \text { وكافينا129 }
\end{aligned}
$$

$121 Q_{3: 27}$ (ganz, hier fertig).

$122 \mathrm{Q}$ 42:12.

123 Hier erreicht der Schreiber auf der drittäussersten Zeile (aufsteigend) die obere Spitze der oberen mandelförmigen Figur. Er setzt die Abschrift auf der gegenüberliegenden Seite auf der vierten Zeile von aussen bzw. der zweiten von innen (absteigend) fort.

124 Der Text auf dieser vierten Zeile liess sich nicht restlos entziffern. Diese Zeile (ab- und aufsteigend) enthält aber zumeist Anrufungen Gottes bei seinen Schönen Namen und auch beim Umm al-Kitāb.

125 Ab hier auf der innersten Zeile, absteigend. Es handelt sich um Q 22:78b:

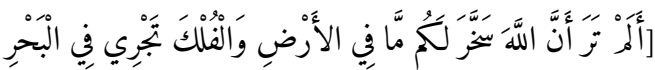

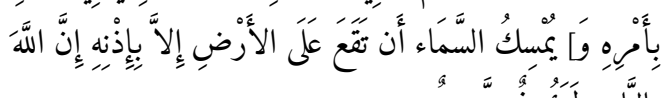

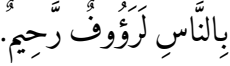

Hier Bruch im Papier, der das Entziffern erschwert. Erste Zeile von aussen, nach links absteigend.

Ein Begriff kaum leserlich.
Der Text erreicht hier die untere Spitze der mandelförmigen Figur; er verläuft danach auf der gegenüberliegenden Seite rechts aussen aufsteigend.

$$
\begin{aligned}
& \text { وهو مواسينا (؟) ومولانا وهو حسبنا ونعم الوكيل لا شريك } \\
& \text { له ولا معز لمن اذل ولا مذل لمن اعز وهو الواحد القهار } \\
& \text { ولا حول ولا قوة الا بالله العلي العظيم حسبنا الله } \\
& \text { ب.130 ونعم الوكيل وصلى الله على سيدنا محمد وآله وصحبه }
\end{aligned}
$$

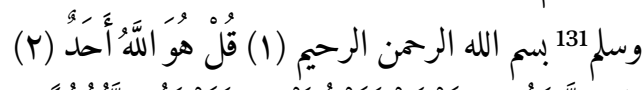

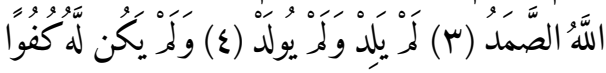

$$
\begin{aligned}
& \text { أَحَ's }
\end{aligned}
$$

Der Schreiber füllt danach diese zweite mandelförmige Figur mit weiteren Abschriften von Q 112 aus. ${ }^{132}$ Zwischen den beiden soeben erfassten Figuren befinden sich zwei tropfenförmige Verzierungen, die aus Stellen in $\dot{G} u b \bar{a} r$-Schrift gebildet werden. Sie sind im Innern mit einem goldenen Zierpunkt versehen. Der darin enthaltene Text liess sich nicht vollständig entziffern.

c. Unterhalb der zweiten mandelförmigen Figur folgt wieder Text in normaler Grösse; er schliesst dieses Rechteck ab:

$$
\begin{aligned}
& \text { يولد } 133 \text { ولم يكن له كفواً احد · بسم الله الرحمن الرحيم •قُلْ }
\end{aligned}
$$

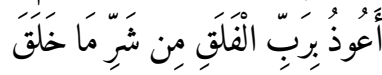

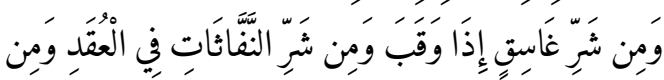

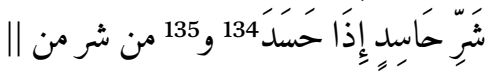

$$
\begin{aligned}
& \text { يسرق السمع والابصار بالله الواحد القهار بالف لا حول }
\end{aligned}
$$

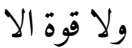

130 Hier beginnt an der oberen Spitze der mandelförmigen Figur die zweite Zeile von aussen, links absteigend.

$131 \mathrm{Q}$ 112. Ab hier füllt der Schreiber den Rest der mandelförmigen Figur mit Abschriften von Q 112 aus (stets mit Basmala). Die letzte Abschrift zuinnerst ist nicht vollständig (Abbruch nach Vers 3a), der Vers wird aber im Text in grossem Nash auf der obersten horizontalen Zeile am Schluss fortgesetzt (vgl. übernächste Anm.). Vgl. vorangehende Anm.

Dies der Schluss von Q 112; der Anfang steht in der zweiten mandelförmigen Figur auf der innersten Zeile, links absteigend. Q 113 .

135 Diese Erweiterung zu Q 113 fehlt in der Kairiner Fassung des Korans. 


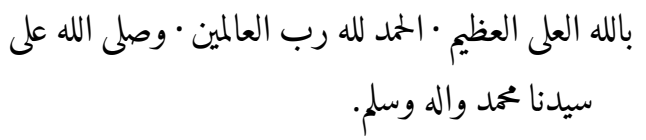

Hier endet der Abschnitt mit dem 2. Haykal. Es ist darauf hinzuweisen, dass die beiden mandelförmigen Figuren darin beim Betrachten den Anschein erwecken, es handle sich um ein Augenpaar. Dies ist zumindest der Fall, wenn man die Rolle quer hinlegt. Dieses Augenpaar legt unterschiedliche Assoziationen nahe:

a. Es könnte einerseits als Schutz vor dem Bösen Blick (al-'Ayn) verstanden werden. Der (neidische) Blick des Fremden wird in der gesamten islamischen Welt gefürchtet. ${ }^{136}$ Schutzmittel gegen den Bösen Blick aber enthalten zumeist nur die Abbildung eines einzelnen Auges. ${ }^{137}$ Es kann aber dennoch nicht gänzlich ausgeschlossen werden, dass auch dieses Augenpaar gegen den Bösen Blick schützen soll. Eine allenfalls als Abbildung eines einzelnen Auges zu interpretierende Verzierung findet sich auf einem Belegstück, das in der vorliegenden Arbeit nicht näher untersucht wird, da dazu keine lückenlose Dokumentation vorliegt. ${ }^{138}$

b. Nicht a priori von der Hand zu weisen ist allerdings eine zweite Interpretation dieses Abschnitts. F. Taeschner und H. Thorning haben in ihren Untersuchungen zum Schrifttum der Futuwwaund $A h \bar{\imath}$-Bünde wiederholt auf die Bedeutung des

136 Zum Bösen Blick (arabisch: al-'ayn; persisch: čašm$i$ bad, čašm-zahm) besteht sowohl aus allgemeiner als auch aus islamwissenschaftlicher Perspektive eine breite Literatur: Šakūrzāda und Omidsalar, Cašmzakm, in EIr; Marçais, al-'Ayn, in $E I^{2}$; Elworthy, The evil eye; Maloney, The evil eye; Seligmann, Der böse Blick. Auf einem jüdischen Amulett lässt sich ein weitgehend identisch gestaltetes Auge nachweisen (siehe die Abbildung in Vukosavović, Angels and demons 57).

137 Für entsprechende Abbildungen vgl. z.B. Kriss und Kriss-Heinrich, Amulette, Zauberformeln und Beschwörungen 10-12 (mit Tafel 14), auch ihr Index s.v. „Auge, Augen-Amulett" (235).

138 Vgl. dazu die Abbildung in Islamic calligraphy - Calligraphie Islamique 98f. (Nr. 22; Katalog zur Ausstellung im Musée d'Art et d'Histoire, Genève, 1988); siehe ebenso Alsaleh, Licit magic 349 (Figur 34: Anfang der Rolle LNS 25 MS aus der Dār al-Ātār al-Islāmiyya, Kuwait).
Blicks des Vorstehers einer solchen Vereinigung junger Männer hingewiesen. Der Vorsteher dieser Gruppierungen habe das Verhalten der ihm unterstellten Jünglinge stets mit strengem Blick kontrolliert und ihr Fehlverhalten sanktioniert. ${ }^{139}$ Wenn die beiden mandelförmigen Figuren im vorliegenden Abschnitt tatsächlich ein Augenpaar darstellen sollten, lässt sich diese zweite Interpretation des Abschnitts nicht a priori von der Hand weisen.

Die beiden soeben vorgeschlagenen Interpretationen kranken allerdings daran, dass der in diesem Abschnitt kopierte Text weder die eine noch die andere Sichtweise stützt. Allerdings dürften es die Hersteller derartiger Dokumente durchaus begrüsst, und wohl auch beabsichtigt, haben, dass deren Betrachter mit ihnen ganz unterschiedliche Vorstellungen in Verbindung brachten.

Die vorliegende Rolle muss ursprünglich sieben als Haykal bezeichnete Abschnitte enthalten haben; deren erster jetzt aber verloren ist. Zwischen dem 2. und 3. Haykal folgt ein Übergangsteil. Erst danach schliesst sich der 3. Haykal an. ${ }^{140}$ Der Übergang besteht aus folgenden Figuren, die alle vom dreiteiligen Schriftband eingefasst werden. Die Länge der folgenden drei Teile zusammen misst ca. $34 \mathrm{~cm}:{ }^{141}$ A. Abfolge von drei Medaillons (kleines-grosses-kleines Medaillon). B. Quadrat, das im Innern mit einer Verzierung versehen ist. C. Abfolge von drei Medaillons (kleines-grosseskleines Medaillon).

A. Um die ersten drei Medaillons herum steht weiterhin Text aus dem Koran. Im Gegensatz zu andern Abschnitten der Rolle ${ }^{142}$ wurde der Text im

139 Thorning, Beiträge zur Kenntnis des islamischen Vereinswesens 241 (Nr. 37): die Seele des Lehrlings, auf der der Blick des Meisters ruht; auch 246 (Nr. 52): „[Frage:] Und wenn man zu Dir sagt: Nachdem Du Deinem Lehrmeister im Meidân der Ichtijârîja, den 'Ahl el-Futuwwa, genaht bist, was hat er Dir gegeben? - Antwort: Er hat mir das fehlerlose Gebet gegeben und mich mit seinem unwiderstehlichen Blick umfangen.

140 Abb. 2 der Rolle unter http://www.e-manuscripta.ch/ bau/content/pageview/837969.

141 Inkl. den beiden dreiteiligen Schriftbändern am Anfang und am Schluss.

142 Vgl. z. B. gerade anschliessend bei C. (nach Anm. 146). 
breiten Mittelband hier weiterhin in grossem Nash kopiert. Die beiden kleinen Medaillons oben und unten werden von einem goldenen Ring eingefasst und enthalten im Innern eine Verzierung (oben: floral). Wichtig ist das mittlere, grosse Medaillon in dieser Abfolge:

Es ${ }^{143}$ enthält im Innern Stellen in $\dot{G} u b \bar{a} r$, die bei genauem Hinsehen drei Mal den Namen 'Alī darstellen (АВв. 73). Die einzelnen Namenszüge sind in der Mitte miteinander verbunden. An der Stelle, wo die drei einzelnen Namenszüge in der Mitte aufeinandertreffen steht drei Mal der Ausdruck Allāh. So betrachtet würde die Figur implizit die Aussage enthalten 'Alī Allāh. Dies lässt sich als Nominalsatz verstehen, der bedeuten würde "Alī ist Allāh". ${ }^{144}$ Ein weiteres derartiges dreifaches 'Alī folgt vor dem Abschnitt mit dem 3. Haykal. ${ }^{145}$

Die einzelnen Teile dieses dreifachen 'Alīs setzen sich aus Abschriften von Q 2:255 und Q 112 bzw. aus Teilen davon zusammen. Im ersten dieser beiden Medaillons enthält der Begriff 'Alī rechts oben zuerst Q 2:255 (vollständig); im unteren Teil davon wurde Q 2:255 (Thronvers) unvollständig kopiert. Der Ausdruck Alī links oben besteht aus mehrfachen Abschriften von Q 112 (teils vollständig, teils unvollständig kopiert). Auch das dritte 'Alī unten in diesem Medaillon besteht aus Stellen aus Q 112. Einmal lässt sich der Text in der üblichen Wortfolge identifizieren. Ansonsten werden in diesem dritten Begriff 'Alī wiederholt Elemente aus Q 112 aufgegriffen; sie füllen den Namen aus.

B. Nach der soeben beschriebenen ersten Abfolge von drei untereinander verbundenen Medaillons schliesst sich ein Quadrat an, das vom dreifachen Schriftband eingefasst wird. Dieses Quadrat hat eine Seitenlänge von ca. $11.7 \mathrm{~cm}$ (aussen; inkl. Schriftbänder) bzw. $6 \mathrm{~cm}$ (innen). Es hat innen einen goldenen Rahmen und wird senkrecht und waagrecht durch je zwei dreifach geknickte gol-

143 Abb. 2 der Rolle unter http://www.e-manuscripta.ch/ bau/content/pageview/837969.

144 Vgl. zu diesen Zusammenhängen unten bei Anm. 479484 (Schlussfolgerungen); auch Kapitel 3.1, Abschnitt mit Anm. 117, und Kapitel 6, bei Anm. 150-153. dene Linien in $3 \times 3$ Zellen aufgeteilt. Der Hintergrund der Zelle in der Mitte ist golden. Die vier Zellen in den Ecken weisen einen blauen Hintergrund auf. ${ }^{146}$ Der Hintergrund der vier restlichen Zellen ist bräunlich-rot. Alle Zellen weisen eine goldene pflanzliche Verzierung auf, die schwarz konturiert ist.

C. Auf dieses Quadrat folgt eine nächste Serie von drei untereinander durch das dreiteilige Schriftband verbundenen Medaillons. Während der Text im breiten Mittelteil des Schriftbands bis anhin in grossem Nash kopiert worden war, wechselt der Schreiber jetzt zu $\dot{G} u b \bar{a}$-Schrift und ordnet den Text in Tropfen mit nach oben gerichteter Spitze an. Diese Tropfen werden aus zwei Zeilen Text in $\dot{G} u b \overline{a r}$ gebildet. Im Innern enthalten sie einen goldenen Zierpunkt. Beim kopierten Text handelt es sich weiterhin um eine Abschrift des Korans.

Auch in dieser zweiten Abfolge von drei Medaillons wurde im grössten Element der Name 'Alı̄ drei Mal auf einem Hintergrund in $\dot{G} u b \bar{a} r$ kopiert. ${ }^{147}$ Bei den $\dot{G} u b \bar{a} r$-Stellen handelt es sich erneut um Abschriften von Q 112 und Q 2:255. Der Text ist hier wiederholt versetzt, also nicht auf fortlaufenden Zeilen, kopiert worden. Der Schreiber bemühte sich offensichtlich darum, die durch die drei Ausdrücke 'Alī vorgegebenen Formen lückenlos auszufüllen. Es war für ihn nicht relevant, dass die Abschriften von Q 112 und Q 2:255 stets vollständig sind und der Text die Wortfolge im Koran respektiert.

Nach dem soeben vorgestellten Übergangsstück schliesst sich der 3. Haykal an. Auch er wird vom dreiteiligen Schriftband eingefasst.

al-Haykal at-taālit (ABB. 74): ${ }^{148}$ Erst jetzt folgt der Titelbalken mit der Überschrift al-Haykal altālitit:

146 Jetzt teilweise nicht mehr deutlich erkenntlich.

147 Abb. 2 der Rolle unter http://www.e-manuscripta.ch/ bau/content/pageview/837969.

148 Diese Überschrift in weisser, schwarz eingefasster Schrift auf einem goldenen Titelbalken; vgl. Abb. 3 der Rolle unter http://www.e-manuscripta.ch/bau/conten t/pageview/83797o. 
|149 بسم الله الرحمن الرحيم •اعيذ نفسى من شر ماهو كاين بالليل والنهار

بالله الذى خلق السموات العلى • الرمن على العرش

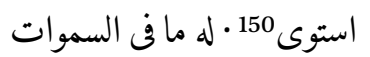

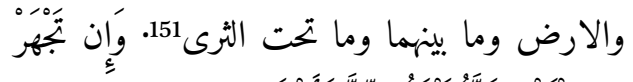

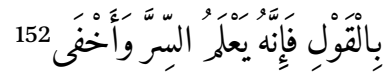

الله لا اله الا هو له الاسما الحسنى 153 . واعيذ نفسى بالله

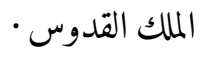

السلام المومن المهيمن العزيز الجبار المتكبر سبحان الله

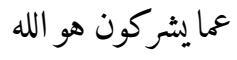

الخالق البارى المصور له الاسما الحسنى يسبح له ما في اله

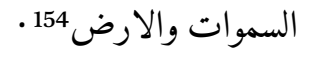

وهو العزيز الحكيم · واعيذ نفسى بالله العظيم من كل

$$
\text { شيطان مريد }
$$

وجبار عنيد · ومن شر كل ذى شر وكل ذى مخلب

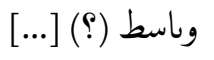

بالوصيد · ومن شر كل ذى ساحر وساحره • وساكن

$$
\text { وساكنه }
$$

• ا في البر والبحر والآكام والآجام ومن يولع بالفراش

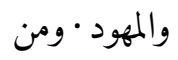

شر كل انسى ناقض العهود · ومن شر كل جنى وجنية

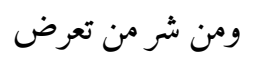

الاجساد · ومن شر من يسرق السمع والابصار

$$
\text { ويوسوس فى الصدور }
$$

149 Bei den Ziffern am Zeilenanfang handelt es sich um die Zeilenzählung.

150 Q 20:5.

$151 \quad \mathrm{Q} 20: 6$.

$152 \quad \mathrm{Q} 20: 7$.

153 Q 20:8.

154 Q 59:24 (Schlussvers) lautet:

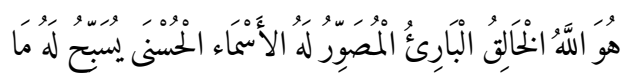

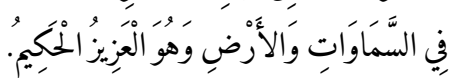

ومن اذا ذكر الله الذى لا اله الا هو ذاب كما يذوب

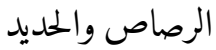

واعيذ نفسى برب جبرايل وميكايل واسرافيل

$$
\text { وغزرايل وحمله العرش والكرسى وابى وبري }
$$

10

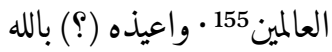

الذى اعطى التوريه لموسى بن عمران بطور سينا ومن علمه باخيه هارون عليهما

السلام وطرق له البحر وكان كل فرق كالطود

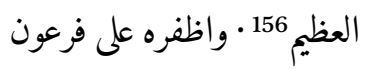

وجنوده واعيذه بالله الذي نجا باسمه الخليل عليه

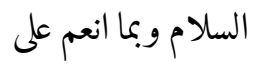

آل يعقوب عليه السلام وبالله العظيم المنان الذى سخر

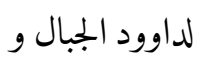

r.

$$
\text { واسلنا }
$$

له عين القطر ومن الجن 157 والانس (كذا) انه من سليمان وانه بسم الله الرمن الرحيم

155 Vgl. dazu Q 39:75 (Schlussvers), der lautet:

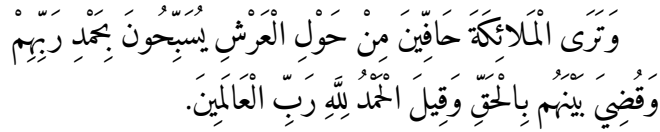

156 Vgl. dazu Q 26:63:

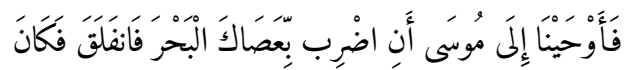

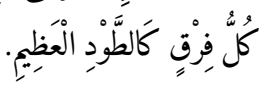

157 Q 34:12 lautet:

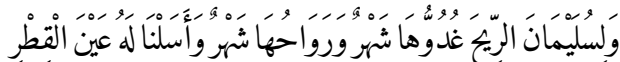

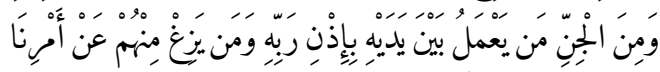

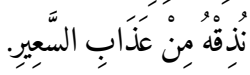

Wohl Fehler des Kopisten am Schluss bei wa-min alğinn wa-l-ins. 


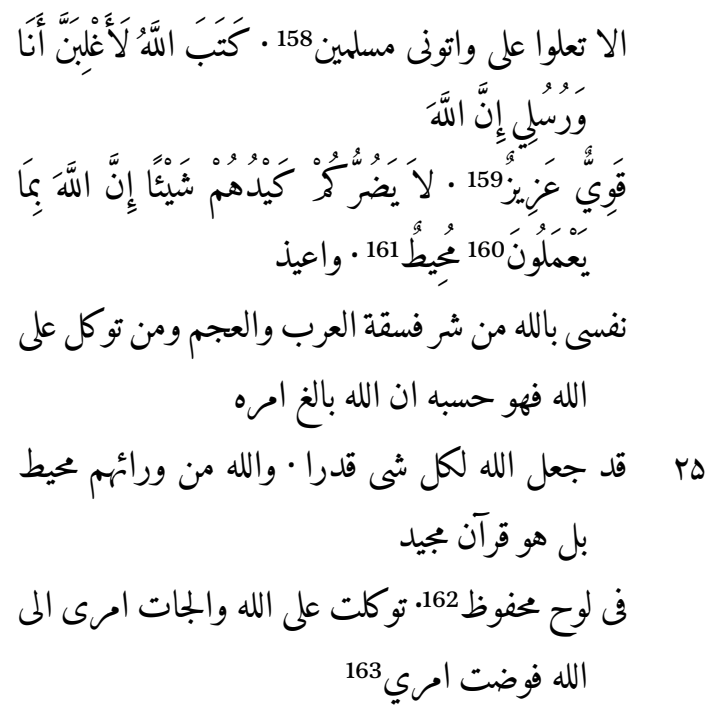

An dieser Stelle endet das Rechteck mit dem 3. Haykal. Es schliesst sich ein längerer Abschnitt an (Länge ca. $77 \mathrm{~cm}$ ), der im folgenden vorgestellt wird. Nach diesem Abschnitt folgt das Rechteck mit der Überschrift al-Haykal ar-rābic (4. Haykal). ${ }^{164}$ Der Abschnitt nach dem Rechteck mit dem 3. Haykal enthält die fünf folgenden Teile: ${ }^{165}$

A. Am Anfang befindet sich eine Abfolge von drei durch das dreiteilige Schriftband beidseitig eingefassten Medaillons (kleines-grosses-kleines Medaillon). Der Text im breiten Mittelband ist hier weiterhin in Tropfen notiert und in $\dot{G} u b \bar{a} r$ kopiert. Die beiden kleinen Medaillons oben und unten weisen eine einfache Verzierung auf; das grosse Medaillon ist hingegen aufwendig gestaltet: Im Zentrum des Medaillons treffen zwei Gruppen von Zierelementen aufeinander und bilden eine Art

\footnotetext{
$15^{8}$ Q 27:30-31.

159 Q 58:21.

16o Auf der Rolle an dieser Stelle تعملون.

161 Aus Q 3:120:

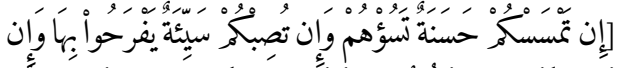

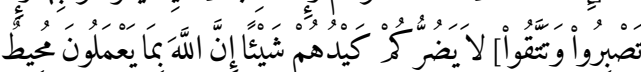

162 Q 85:20-22.

163 Der Kopist setzt die Abschrift dieses Texts unten bei Buchstaben D fort (vgl. bei Anm. 168).

164 Vgl. dazu unten bei Anm. 180.

165 Abb. 3 der Rolle unter http://www.e-manuscripta.ch/ bau/content/pageview/83797o.
}

sechsblättrige Blüte. Die erste Gruppe von Zierelementen ist weiss eingefasst und besteht aus drei Einzelteilen, die im Winkel von $120^{\circ}$ angeordnet sind. Sie weisen im Innern eine goldene Verzierung auf und sind schwarz ausgefüllt. Sie laufen gegen aussen spitz zu. Zwischen diesen drei Verzierungen wurde die zweite Gruppe von drei Zierelementen eingefügt. Sie werden golden eingefasst, sind rot ausgefüllt und im Innern mit einem grünen Blatt (?) versehen. Das oberste Element ist vertikal ausgerichtet; die beiden andern sind in einem Winkel von jeweils $120^{\circ}$ zur Linken bzw. Rechten angeordnet.

B. Es schliesst sich ein erstes Quadrat an, das vom dreiteiligen Schriftband eingefasst wird. Der Schreiber wechselt hier im Mittelband wieder von den Tropfen in $\dot{G} u b \bar{a} r$-Schrift zu grossem Nash. Im Innern dieses Rechtecks ist Text in Figuren angeordnet, die durch Stellen in $\dot{G} u b \bar{a} r$ gebildet werden. Einerseits lässt sich eine ellipsenartige, nahezu kreisrunde Figur erkennen. Darin befindet sich eine $x$-förmige Figur.

Beim im Quadrat kopierten Text handelt es sich um Abschriften von Q 2:255 und Q 112 bzw. teilweise Auszügen daraus. ${ }^{166}$ Dem Text lässt sich am Anfang gut folgen. Der Schreiber beginnt auf der äussersten Zeile oben in der Mitte und steigt nach links ab. Zuunterst angekommen wechselt er auf die äusserste Zeile rechts und steigt nach oben: Es handelt sich um Q 2:255. Danach schliesst sich auf halber Höhe im aufsteigenden Ellipsenbogen Q 112 an; die Sure endet an der oberen Spitze auf der äussersten Zeile. Auch bei den weiteren in diesem Quadrat kopierten Stellen handelt es sich um Abschriften von Q 112 und Q 2:255. Die Wortfolgen in diesen weiteren Abschriften sind aber mehrfach versetzt und stehen nicht einfach auf einer regelmässig angeordneten Zeile. Auch die Textstellen in der x-förmigen Figur in der Mitte des Quadrats bestehen aus Abschriften von Q 112 und Q 2:255.

C. Nach diesem Quadrat schliesst sich eine weitere Abfolge von drei Medaillons an (gross-

166 Abb. 3 der Rolle unter http://www.e-manuscripta.ch/ bau/content/pageview/837970. 
klein-gross). Die Verzierung im grossen Medaillon in der Mitte ist am aufwendigsten ausgeführt. Das Medaillon wird innen von zwei goldenen Ringen eingefasst. Der Hintergrund zuinnerst ist blau. Darauf lässt sich eine stilisierte Blüte erkennen (zumeist golden). Der Text aus dem Koran im breiten Teil des Mittelbands um diese Abfolge von Medaillons herum wurde weiterhin in grossem Nash kopiert. Der Schreiber ändert sein Vorgehen erst beim Übergang zum direkt anschliessenden Quadrat.

D. Hier kopiert der Schreiber den Text aus dem Koran auch im breiten Teil des Mittelbands erneut in $\dot{G} u b \bar{a} r$-Schrift. Er ordnet den Text in Gruppen zu vier kurzen Zeilen an, die zusammen ein Quadrat bilden. Diese kurzen Zeilen sind gegenüber der Rolle um $45^{\circ}$ geneigt. Das grosse Quadrat selbst weist im Innern eine Gestaltung auf, die mit jener in Abschnitt B übereinstimmt. Die Figuren darin werden durch Stellen in $\dot{G} u b \bar{a} r$-Schrift gebildet. Die folgende Zusammenstellung erfasst den darin kopierten Text. Festzuhalten ist, dass hier der Schluss des 3. Haykals folgt: ${ }^{167}$

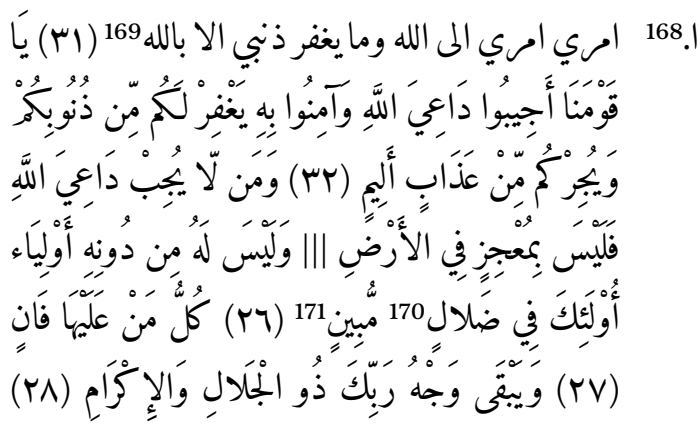

167 Abb. 3 der Rolle unter http://www.e-manuscripta.ch/ bau/content/pageview/83797o.

168 Dies ist die Fortsetzung des Textes aus dem Rechteck mit der Überschrift al-Haykal aț-tālit (vgl. oben nach Anm. 163). Der Text beginnt oben in der Mitte in der ellipsenartigen Figur und steigt darin auf der äussersten Zeile nach links unten ab. Zuunterst springt der Schreiber auf die rechte Seite und steigt dort auf der äussersten Zeile wieder empor.

169 So auf der Rolle.

170 Auf der Rolle ظلال

171 Q 46:31-32; die Markierung ||| kennzeichnet den Übergang auf die rechte Seite. Danach beginnt Q 55:26.

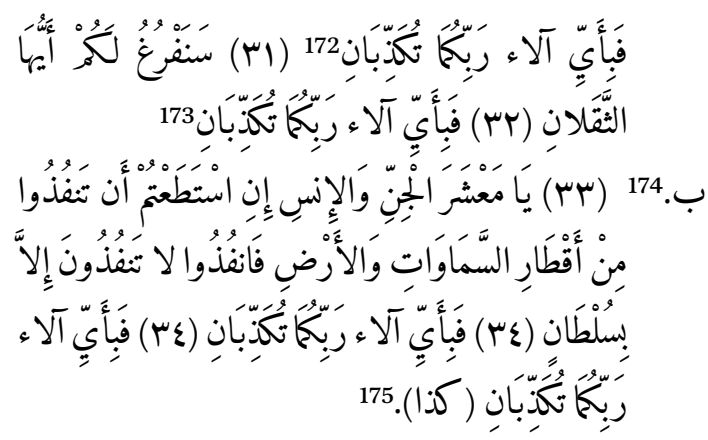

Der bedeutendste Abschnitt im von links oben absteigenden Ast der X-Figur besteht aus einer Abschrift von Q 2:255 (Thronvers). Die Wortfolge wurde mehrfach aufgebrochen. In diesem Ast liessen sich ausserdem die folgenden Stellen erkennen; die Wörter sind darin oft versetzt kopiert worden:

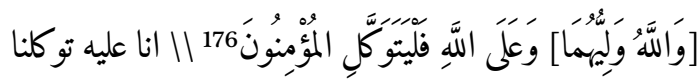

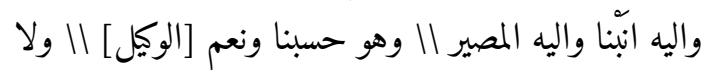

$$
\begin{aligned}
& \text { حول ولا قوة الا بالله العلي العظيم. }
\end{aligned}
$$

Auf dem rechts oben beginnenden Ast der X-Figur steht erneut Q 2:255. Der Text verläuft zuerst auf zwei Zeilen über die gesamte Länge dieses Asts der

172 Auf der Rolle fehlen die Verse 29-30:

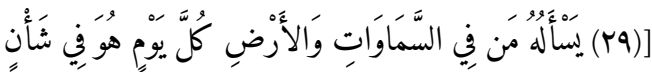

$$
\begin{aligned}
& \text { 范) }
\end{aligned}
$$

Der Kopist erreicht hier auf der rechten Seite auf der äussersten Zeile wieder den oberen Rahmen des Quadrats. Bei der kopierten Stelle handelt es sich um Q 55:26-32. Die Stelle ist teilweise stark verwischt; Verse 29-3o fehlen auf der Rolle. Auf der zweiten Zeile von aussen beginnt auf der linken Seite (absteigend) die Fortsetzung (Q 55:33).

174 Die Stelle beginnt auf der linken Seite auf der zweiten Zeile von aussen, absteigend; es handelt sich um Q 55:33-34 (mit Wiederholung von Vers 34). Der Text wird hier auf ganz kurzen Zeilen innen notiert und schreitet im Gegenuhrzeigersinn voran.

Die Stelle auf dem linken Ast der Ellipse liess sich nicht mit Sicherheit entziffern und identifizieren. Offen ist einstweilen ebenso ein bedeutender Teil des aufsteigenden Texts auf dem rechten Ast der Ellipse.

176 Aussage, im Koran mehrfach verzeichnet, z. B. Q 3:122. 
X-Figur; ${ }^{177}$ der Schluss des Verses dann nur in der oberen Hälfte dieses Asts. Der Rest des Asts der XFigur unten links enthält Q 112 (zuerst vollständig, dann Auszug). Wenn sich auch nicht sämtliche Stellen in diesem Quadrat identifizieren liessen, zeigt sich doch erneut, dass der Schreiber in erster Linie Stellen aus dem Koran auswählte.

E. Nach dem soeben beschriebenen Viereck schliesst sich eine weitere Serie von drei untereinander verbundenen Medaillons an. ${ }^{178}$ Der Text im breiten Teil des dreiteiligen Textbands wurde in diesem Abschnitt erneut in grossem Nash notiert. Der Schreiber kehrt am Anfang des Abschnitts mit dem 4. Haykal zur Gestaltung in geneigten Quadraten mit Text in $\dot{G} u b \bar{a} r$ zurück. Auch hier wurde wieder das Innere des grossen Medaillons in der Mitte besonders aufwendig gestaltet (blauer Hintergrund mit kreisförmig angeordnetem Rankenmuster). Im Medaillon ausserdem eine Figur, deren vier horizontal bzw. vertikal angeordneten Seitenlinien durch drei Kreissegmente gebildet werden. Im Innern dieses Medaillons steht in goldenem Zierkufi der Text al-Mulk li-[A]lläh (Ав B. 75). ${ }^{179}$ Danach folgt der Abschnitt mit dem 4. Haykal.

4. Haykal: al-Haykal ar-rābic in weisser Schrift in einem goldenen Titelbalken mit teilweise blauem Hintergrund. Im Rechteck darunter steht der folgende Gebetstext: ${ }^{180}$

$$
\text { بالله بـ الله الرحمن الرحيم • اعيذ نفسى من كل سو وبلا }
$$

177 Der Schreiber überspringt am Kreuzpunkt der beiden Äste den von links oben absteigenden Ast.

178 Abb. 3 der Rolle unter http://www.e-manuscripta.ch/ bau/content/pageview/837970 (direkt beim Beginn des 4. Haykal).

179 „Die Macht ist Gottes.

180 Abb. 4 der Rolle unter http://www.e-manuscripta.ch/ bau/content/pageview/837971. Ein Text mit weitgehend demselben Wortlaut liess sich nachweisen unter https://www.facebook.com/permalink.php?story_fbid $=1455540211363543 \&$ \&id=1419617271622504 (Stand 18 . Oktober 2018). Auch bei diesem Text handelt es sich um al-Haykal ar-rābi'; er ist für den Mittwoch (al-yawm arrābic) bestimmt.

$$
\begin{aligned}
& \text { الذى لا اله الا هو عالم الغيب والشهاده هو الرحمن } \\
& \text { الرحيم •واعيذ نفسى }
\end{aligned}
$$

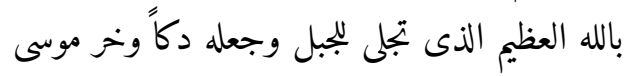

$$
\begin{aligned}
& \text { صعقا1811 • من شر كلم المك } \\
& \text { غول وغوله · ومن شر كل ساحر وساحره · وماكر } \\
& \text { وماكره } \\
& \text { ها م وجنى وجنيه · ومن شر ابليس واتباعه واشياعه ومن } \\
& \text { شر كل جبار عنيد } \\
& \text { وسحار عليم · ومن شر الشيطان ومن شر كل دابه انت } \\
& \text { آخذ بناصيتها ان ربى } \\
& \text { على سراط مستقيم 182. واعيذه بالله الكبير المتعال • } \\
& \text { رب الملايكه الثمانية } \\
& \text { والعرش الذى لا يتحرك وبالاسم الاعظم الذى هو }
\end{aligned}
$$

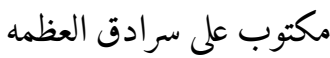

$$
\begin{aligned}
& \text { وباسمك الاعظم الاعظم (كذا) الاعلى وباسمايك } \\
& \text { الحسنى وبكتى آهيا شراهيا [ادونايب183] }
\end{aligned}
$$

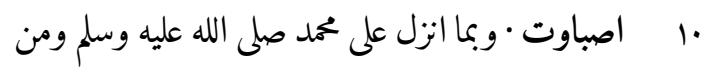

$$
\begin{aligned}
& \text { شر الشيطان الرجيم } \\
& \text { ومن اولاتهم وهمزاتهم وخيلهم ورحلهم وشرورهم } \\
& \text { واماتهم واستفرازهم } 184
\end{aligned}
$$

(n)




$$
\begin{aligned}
& \text { وغرورهم وفردهم وبمعهم وريكهم ونفحهم ونفهم } \\
& \text { ومن شر كل ساكن } \\
& \text { في الهواء والسهل والجبل ومن هوفى ظلهات البر والبحر } \\
& \text { وعبده النيران والعيون }
\end{aligned}
$$

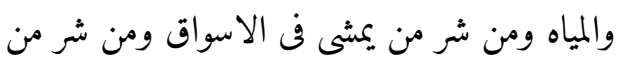

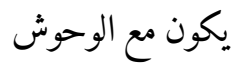

$$
\begin{aligned}
& \text { 1ه والدواب والسباع ومن شر ساكن الخراب والعمران } \\
& \text { والآكام والآجام } \\
& \text { ومن يوسوس في صدور الناس من الجنة والناس } \\
& \text { ويعمل الخطايا بسم الله } \\
& \text { الكريم الاكرم •بسم الله الكبير الاكبر •بسم الله العلى }
\end{aligned}
$$

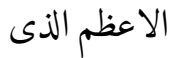

$$
\begin{aligned}
& \text { هو مكتوب على سرادق عرشه القايم الرفيع الذى } \\
& \text { شداداً لا يعصون الله ما امرهم ويفعلون ما يؤمرون · } \\
& \text { وكلف } \\
& \text { r. } \\
& \text { الذى يميت } \\
& \text { به الاحياء] ويحى به الموتى وبالاسم الذى اشرقت به }
\end{aligned}
$$

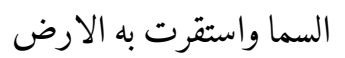

$$
\begin{aligned}
& \text { وكشفت به الطلام (الظلام) • وبالاسم الذى هو قايم } \\
& \text { به العرش الذى لا يتحرك }
\end{aligned}
$$

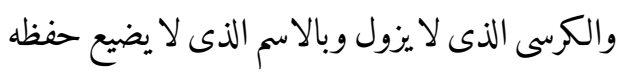

$$
\begin{aligned}
& \text { ولا يغلق باب } \\
& \text { رحمته · وبالاسما العظام · وبالعز186 الذي لا يرام }
\end{aligned}
$$

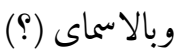

$$
\begin{aligned}
& \text { هr العليا • وبالنعما (؟) الذى لا تحصى · وباكرم الاسما } \\
& \text { الحسنى واوخمها }
\end{aligned}
$$

185 Lesevorschlag Dr. E. Badeen; auf der Rolle steht خلق. 186 Die Parallelstelle auf Facebook hat hier al-'arš.

$$
\begin{aligned}
& \text { واجزلها واسرعها بالاجابة وبالاسم المزون المكنون }
\end{aligned}
$$

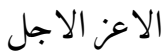

$$
\begin{aligned}
& \text { العلى الاعظم الذى تحبه وترضى عمن دعاك به وبكل }
\end{aligned}
$$

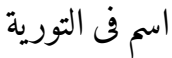

$$
\begin{aligned}
& \text { والانجيل والزبور والفرقان العظيم • وبكل اسم دعاك }
\end{aligned}
$$

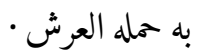

Hier endet das Rechteck mit dem Abschnitt alHaykal ar-rābic. Die Abschrift des vierten HaykalGebets ist allerdings noch nicht abgeschlossen. Dies zeigt ein Blick auf die angeführte Internetquelle. ${ }^{187}$ Die Stelle mit der Fortsetzung des Texts soll allerdings erst später ermittelt werden. Vorerst ist ein Blick auf den weiteren Aufbau der Rolle erforderlich:

Auf dem Dokument lassen sich vor dem nächsten Rechteck ${ }^{188}$ folgende Elemente erkennen, die jeweils beidseits von den beiden vorwärtsbzw. rückwärtslaufenden dreiteiligen Schriftbändern umfahren werden: A. Abfolge kleines-grosses-kleines Medaillon; B. Quadrat; C. Abfolge kleines-grosses-kleines Medaillon. In den vier kleinen Medaillons dominiert die Farbe Gold; es lässt sich darin jeweils eine mit schwarzer Tinte gezeichnete Blatt- und Blütenform erkennen. Die Aussenkanten des Quadrats (B.) messen $12 \mathrm{~cm}$; im Innern messen die Kanten ca. 6.3 cm. Im Quadrat (B.) lassen sich mehrere Figuren erkennen, die durch schwarze Doppellinien auf einem goldenen Streifen gebildet werden. Es handelt sich einerseits um einen Vierpass; anderseits lassen sich vier leicht nach innen geknickte Doppellinien erkennen, die in der Mitte eine Figur mit vier nach aussen und vier nach innen gerichteten Spitzen entstehen lassen. Die einzelnen Felder in dieser Figur sind mit unterschiedlichen Ornamenten ausgefüllt.

\footnotetext{
187 Vgl. Anm. 18o bzw. https://www.facebook.com/permali nk.php?story_fbid=1455540211363543\&id $=141961727162$ 2504 (Stand 22. Dezember 2016).

188 Es enthält ein goldenes Gitter; vgl. dazu bei Anm. 203.
} 
Für die Fortsetzung des Textes relevant sind allerdings die beiden grossen Medaillons vor (A.) bzw. nach (C.) dem soeben beschriebenen Quadrat. Ihr Innendurchmesser beträgt ca. $6.0 \mathrm{~cm}$. In diesen Medaillons lassen sich sechs mandelförmige Figuren erkennen, deren Spitzen in der Mitte aufeinander stossen. Zwei mandelförmige Figuren sind vertikal ausgerichtet, die andern vier links bzw. rechts davon regelmässig verteilt. Diese Figuren bilden eine sechsblättrige Blüte. Sie enthalten Text in $\dot{G} u b \bar{a} r$-Schrift (zumeist vier Zeilen). Die sechs Zwischenräume zwischen den Figuren sind mit Verzierungen ausgefüllt, die Blätter nachahmen.

Bei den in den einzelnen mandelförmigen Figuren im oberen grossen Medaillon kopierten Stellen handelt es sich um die Fortsetzung des Texts des 4. Haykal. ${ }^{189}$ Der Text beginnt an der Spitze der oberen vertikal ausgerichteten mandelförmigen Figur auf der äussersten Zeile links (absteigend):

1. Mandelförmige Figur:

$$
\begin{aligned}
& \text { وملائكة عرشك في ارضك وسمائك وأصفيائك من خلقك } \\
& \text { من بني ||190 أو صديق أو شهيد [و]بحقهم عليك وبكق } \\
& \text { السائلين عليك والراغبين ||191 اليك أن تحفظني وتحرسني من } \\
& \text { شر كل جبار عنيد ||192 وشيطان مريد وعدو شديد (؟) قائم } \\
& \text { أو || }
\end{aligned}
$$

189 Abb. 4 der Rolle unter http://www.e-manuscripta.ch/ bau/content/pageview/837971. Im schmalen inneren Textband, das dieses Medaillon links umfährt lässt sich der Beginn von Q 46 erkennen (mit Basmala). Davor ist ein kurzer Abschnitt des Innenbands nicht beschrieben; bei der zuletzt kopierten Stelle davor handelt es sich um Q 45:37 (Schlussvers).

Die äusserste Zeile links (absteigend) erreicht hier das Zentrum der Rosette; die Fortsetzung des Texts folgt auf der äussersten Zeile rechts (aufsteigend).

191 Die äusserste Zeile rechts (aufsteigend) erreicht hier die Spitze der Rosette; die Fortsetzung des Texts folgt auf der innern Zeile rechts (absteigend).

Die innere Zeile rechts (absteigend) erreicht hier das Zentrum der Rosette; die Fortsetzung des Texts folgt auf der innern Zeile links (aufsteigend).

193 Die erste mandelförmige Figur in Gubār-Schrift ist jetzt vollständig; der Schreiber springt in die nächste
2. Mandelförmige Figur (im Gegenuhrzeigersinn betrachtet):

$$
\begin{aligned}
& \text { قاعد بناء [أ]و (؟) غواص وزوج وفرد194 وذكر وأنثى وما } \\
& \text { يخنى وما يظهر وما دارت عليه الشمس والقمر سبوح قدوس } \\
& \text { رب الملائكة [والروح أحزت بلله اللطيف الخبير الذي لا } \\
& \text { يأتي الباطل من بين يديه ولا من خلفه تنزيل من حكيم حميد } \\
& \text { بلله أحرزته لا سلطان لهم عليه ولا قوة إلا بلله العلي العظيم ألا }
\end{aligned}
$$

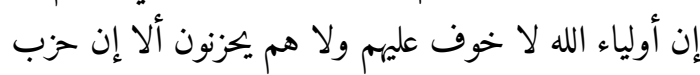

$$
\begin{aligned}
& \text { الله هم الغالبون الله حافظه وناصره ووليه وحسبنا الله ونعم } \\
& \text { الوكيل عليه توكلت وهو رب العرش العظيم }
\end{aligned}
$$

3. Mandelförmige Figur (im Gegenuhrzeigersinn): Die Entzifferung ist offen.

4. Mandelförmige Figur (im Gegenuhrzeigersinn; von innen nach aussen gelesen; es hat wiederholt Brüche in der Textfolge); der Anfang zuinnerst ist noch unklar.

$$
\begin{aligned}
& \text { لا خوف عليهم ولا هم يحزنون | هم المفلحون | الله ناصري } \\
& \text { وحافظي هو خير (؟) ولي | لا شريك له عليه توكلت. }
\end{aligned}
$$

5. Mandelförmige Figur (im Gegenuhrzeigersinn; der Text beginnt an der äusseren Spitze und verläuft dann auf geneigten kurzen Zeilen nach innen; vereinzelt lassen sich Abweichungen von diesem Grundsatz feststellen):

$$
\begin{aligned}
& \text { هو رب العرش العظيم ولا حول ولا قوة الا بالله الا بالله العلي }
\end{aligned}
$$

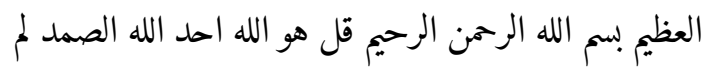

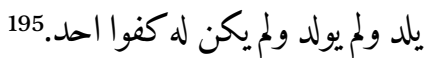

Figur links und setzt die Abschrift fort (Beginn an der äussern Spitze, äusserste Zeile links, zum Zentrum hin verlaufend).

194 Hier Abweichungen gegenüber Vorlage auf Facebook (vgl. Anm. 180); der Text in eckigen Klammern liess sich auf der Rolle nicht feststellen und stammt aus der angeführten Quelle.

195 Der Schreiber erreicht hier die innere Spitze der 5 . 
6. Mandelförmige Figur (im Gegenuhrzeigersinn): Der Text beginnt an der innern Spitze der mandelförmigen Figur mit der Basmala. Nach aussen hin schliesst sich auf kurzen Zeilen der Text von Q 112 an. Da Q 112 die Figur nicht ganz ausfüllt, wird zuäusserst folgende Ergänzung hinzugefügt:196

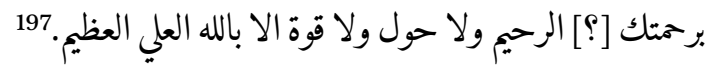

Nach dieser ersten Abfolge von drei Medaillons (A. ${ }^{198}$ ) schliesst sich das bereits beschriebene Viereck mit integriertem Vierpass an (Buchstaben B. oben $\left.{ }^{199}\right)$. Während im Innern dieses Vierecks kein Text enthalten ist, wurde in den dreiteiligen Schriftbändern darum herum weiterhin Korantext kopiert. Der Schreiber notierte auch den Text im breiten Schriftband um das Viereck herum in $\dot{G} u b \bar{a} r$.

Jetzt schliesst sich die zweite Abfolge von drei Medaillons an (C.). ${ }^{200}$ Das grosse Medaillon enthält auch hier sechs mandelförmige Figuren mit Stellen in $\dot{G} u b \bar{a} r .{ }^{201}$ Es handelt sich um den folgenden Text (die Figuren sind im Gegenuhrzeigersinn $\mathrm{zu}$ lesen $) \cdot{ }^{202}$

1. Mandelförmige Figur (in der Mitte oben): Zuoberst absteigend Q 112. Danach schliesst sich Q 2:255a an. 2. Mandelförmige Figur: Vers 255b; die Begriffe al-'alī al-'azìm am Versende werden wiederholt (in der Spitze der Figur). 3. Mandelförmige Figur: Im Zentrum beginnt Q 112. Auch im unte-

mandelförmigen Figur. Nach einer Einleitung besteht der Text aus einer Abschrift von Q 112.

196 Der Text ist teilweise verderbt.

197 Die Textfolge weist wiederholt Brüche auf und die Schriftrichtung wechselt; aber der Text ist vorhanden.

198 Vgl. bei Anm. 189.

199 Vgl. nach Anm. 188.

200 Vgl. vor Anm. 189.

201 Vgl. dazu die oben zusammengestellten Stellen in den mandelförmigen Figuren im Medaillon von $\mathrm{Ab}$ schnitt A. (nach Anm. 189).

202 Abb. 4 der Rolle unter http://www.e-manuscripta.ch/ bau/content/pageview/837971: mandelförmige Figur vor dem Gitter mit goldenem Hintergrund. ren Teil dieser Figur steht Q 112. 4. Mandelförmige Figur: Im Zentrum Q 112. Auch auf dem äussern Teil dieser Figur steht Q 112. Die beiden Abschriften werden durch eine zusätzliche Basmala voneinander getrennt. Eine weitere Basmala von der unteren Spitze her senkrecht aufsteigend. 5. Mandelförmige Figur: zwei Abschriften von Q 112. Ausserdem wurde die Basmala hinzugefügt, um die Figur auszufüllen. 6. Mandelförmige Figur: Abschrift von Q 2:255 (Teil).

Goldenes Gitter [mit den Schönen Namen Gottes $]^{203}$ (Авв. 76): Der nächste Abschnitt springt wegen der üppigen Verwendung von goldener Farbe ins Auge. Es handelt sich um ein Rechteck, das vom dreiteiligen Schriftband beidseits eingefasst wird. Es wird auch oben und unten von diesem dreiteiligen Schriftband umrahmt. In diesem Rechteck (Länge: ca. $37 \mathrm{~cm}$ ) lässt sich ein Gitter erkennen, das durch diagonal verlaufende, ursprünglich wohl weisse Linien gebildet wird. Die Maschen dieses Gitters haben nahezu Vierpassform und sind golden ausgefüllt. Es lassen sich $3 \times 21$ ganze Gittermaschen erkennen (horizontal $\times$ vertikal). Die Maschen zur Linken und Rechten, sowie oben und unten sind angeschnitten. Die angeschnittenen Maschen unten weisen einen roten Hintergrund auf und sind mit goldenen Blättern verziert. Zwischen diesen $3 \times 21$ grossen Maschen wurde jeweils eine Reihe mit vier kleineren Maschen eingefügt. In der obersten Reihe weisen diese vier kleineren Maschen einen roten Hintergrund auf und sind mit einer goldenen Verzierung (Blatt) versehen. Der Hintergrund der vier kleinen Maschen auf der nächsten Reihe ist blau; sie sind mit einer blattförmigen goldenen Verzierung versehen. Danach wechseln sich die Reihen von Maschen mit rotem bzw. blauem Hintergrund $\mathrm{ab}$.

Beim Betrachten dieses Abschnitts entsteht der Eindruck, er stelle ein Gitter dar. Derartige Gitter

\footnotetext{
203 Abb. 4 der Rolle unter http://www.e-manuscripta.ch/ bau/content/pageview/837971: Das Gitter befindet sich ganz am Schluss dieser Aufnahme.
} 
sind von Dokumenten in Rollenform aus andern zeitlichen und geographischen Kontexten bekannt und enthalten dort die Schönen Namen Gottes. ${ }^{204}$ Es ist davon auszugehen, dass ursprünglich auch das vorliegende Gitter die Schönen Namen Gottes enthielt. Dafür spricht einerseits die ähnliche Gestaltung. Anderseits lassen sich bei genauem Betrachten in verschiedenen Zellen (bzw. Gittermaschen) Überreste von textlichen Elementen erkennen. Am deutlichsten ist dies in der untersten Zelle der äussersten Spalte rechts der Fall. Hier lassen sich noch Spuren weisser Farbe erkennen, die zu Buchstaben gehören dürften. Auch in den beiden äussersten Zellen in der fünften Reihe von unten lassen sich, in diesem Fall bräunliche, Reste von Buchstaben erkennen.

Diese Beobachtungen legen nahe, dass auch in den restlichen Zellen ursprünglich Ausdrücke gestanden haben, bei denen es sich um einzelne der Schönen Namen Gottes handelt. Es ist bekannt, dass weisse Schrift auf goldenem Hintergrund nicht nur schwer zu entziffern ist. Vielmehr haften die Pigmente der weissen Farbe auf dem goldenen Hintergrund auch schlecht. Dies dürfte im vorliegenden Fall im Lauf der Jahrhunderte zu einem nahezu vollständigen Verlust der Textelemente in weisser Schrift geführt haben.

Medaillon Subhāna Allāh (Ав B. 77): ${ }^{205}$ Nach dem Rechteck mit dem goldenen Gitter schliesst sich eine weitere Abfolge von drei Medaillons an (Länge ca. $21 \mathrm{~cm}$ ). Das mittlere Medaillon ist am aufwendigsten gestaltet; es enthält die Inschrift Subhāna Allāh in goldenem Zierkufi. Der Begriff Al-lāh ist spiegelsymmetrisch angeordnet. Die Mittelachse wird durch eine senkrecht aufsteigende dreiteilige Verzierung markiert.

204 Vgl. u.a. folgende Parallelstücke: Zentralbibliothek, Zürich, Ms. or. 20; Badische Landesbibliothek, Karlsruhe, RA 204. Beachte zur Frage auch Kapitel 6, bei Anm. 87-9o und 9o-92.

205 Abb. 5 der Rolle unter http://www.e-manuscripta.ch/ bau/content/pageview/837972: Das Medaillon befindet sich nach dem goldenen Gitter.
5. Haykal: al-Haykal al-hāmis:206 Der allgemeine Aufbau der Rolle fusst auf dem Grundsatz, dass auf eine Abfolge von drei Medaillons erneut ein längerer Abschnitt folgt. Hier schliesst sich nach den Medaillons ein oben und unten abgerundetes Rechteck an (Länge ca. $40.8 \mathrm{~cm}$, inkl. Textbänder). Am oberen Ende dieses Abschnitts lässt sich beim Übergang nach dem kleinen Medaillon gut erkennen, dass für die Herstellung dieser Figuren eine Schablone benutzt wurde (Bruchstelle). Auf der Höhe des vorangehenden Medaillons mit dem Eintrag Subhāna Allāh lässt sich in der Mitte des breiten Schriftbands links der Beginn von Q 2:109 erkennen. Beim Übergang zum Abschnitt mit dem 5. Haykal setzt der Kopist die Abschrift auch im breiten Mittelband in $\dot{G} u b \bar{a} r-$ Schrift fort. Der Text ist hier in im Innern mit einem goldenen Zierpunkt versehenen Rauten auf zwei Zeilen angeordnet. ${ }^{207}$

In diesem Abschnitt fallen die folgenden gestalterischen Elemente auf: a. Im oberen Bogen steht die Überschrift al-Haykal al-hāmis. Zierelemente b., d. und f.: In diesem Abschnitt fallen drei mit einem goldenen Ring versehene Kreise auf; auf ihrem rötlich-braunen Hintergrund lassen sich goldene pflanzliche Verzierungen (Rispen mit Blättern) erkennen. c. und e. Auffälliger sind jedoch zwei aufrecht stehende Achtpässe zwischen den soeben beschriebenen drei Kreisen. In diesen beiden Achtpässen lassen sich zur Verzierung angebrachte Blätter erkennen, deren Ausführung an die Siyāh-Qalam-Technik erinnert. Sie enthalten je einen Ausdruck in goldenem Zierkufi. Im oberen Achtpass (c.) steht der Ausdruck al-'azim; es handelt sich um einen der Schönen

206 Abb. 5 der Rolle unter http://www.e-manuscripta.ch/ bau/content/pageview/837972: Das Medaillon befindet sich nach dem goldenen Gitter.

207 Q 2:109 lautet (die Markierung ||| kennzeichnet den Übergang zu den Rauten mit Text in $\dot{G} u b \bar{a} r$-Schrift):

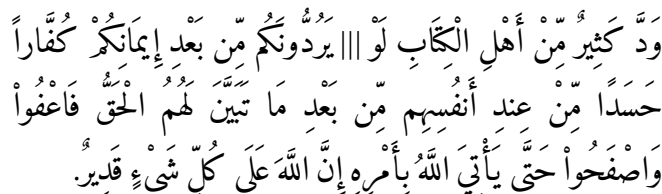


Namen Gottes. e. Im unteren Achtpass steht in identischer Ausführung der Begriff al-karim. Die auffällige Gestaltung des Buchstabens $k a \bar{f} f$ lässt eine Entstehung dieser Rolle am Ende des 14. oder am Anfang des 15. Jh. vermuten. ${ }^{208} \mathrm{~g}$. Im unteren Bogen lässt sich sodann die obere Hälfte eines Zehnpasses mit blauem Hintergrund erkennen.

Die Leerräume um die soeben beschriebenen Zierelemente (a.-g.) sind mit Text in $\dot{G} u b \bar{a} r$-Schrift ausgefüllt. Die Zierelemente geben häufig den Verlauf des Texts vor. Jedenfalls ist dieser Text oft nicht fortlaufend auf den Zeilen notiert worden. Die Wortfolge ist oft versetzt. Der kopierte Text dürfte dem Schreiber sehr geläufig gewesen sein. Er konnte daher die einzelnen Begriffe auf die leere Fläche in oft unregelmässiger Abfolge hinstreuen oder sozusagen hinspicken. Man muss sich wohl einen Schreiber in einem Zustand mystischer Entrückung (hāl) vorstellen, der einen ihm bestens vertrauten Text von sich gibt und die Wörter nach Belieben in die Leerräume hineinstreut. Die Anordnung des Textes hat etwas Zufälliges an sich. Sie erschwert oder verunmöglicht es für Aussenstehende, den Text an dieser Stelle zu rekonstruieren. Eine Rekonstruktion würde voraussetzen, dass es aufgrund von vereinzelten Hinweisen vorgängig gelänge, den Text zu identifizieren und darauf anhand der Vorlage die Begriffe im Teppich aus Wörtern in $\dot{G} u b \bar{a} r$-Schrift zu lokalisieren. Diese Identifikation war im vorliegenden Abschnitt vereinzelt möglich.

Es liessen sich folgende textliche Elemente lokalisieren: a. Zwischen dem Bogen mit der Überschrift al-Haykal al-hāmis und einer noch nicht erwähnten Verzierung (Blatt, dessen Ausführung ähnlich aus der Siyāh-Qalam-Technik bekannt ist) steht in grossem Nash: بسم الله الرحمن الرحيم وصلى الله والله b. Oberhalb des ersten Zierelements (Kreis mit goldenem Ring, rötlich-braunem

208 Auffällig ist die stark nach links ausholende Oberlänge des $k a \bar{f} s$. Eine ähnliche Gestaltung des $k a \bar{f} s$ fällt in den Anfangskartuschen mit blauem Hintergrund auf Arabe 6088 (BNF Paris) auf (vgl. Kapitel 4.5, bei Anm. 910). Arabe $6 \circ 88$ wurde aufgrund dieser auffälligen Gestaltung des kājs ins späte 14. Jh. datiert.
Hintergrund und goldenen Blättern zur Verzierung) steht der Beginn des Gebets, das hier alHaykal al-hāmis genannt wird. Der Text beginnt rechts aussen unterhalb des Bism aus der Basmala in grossem Nash und lautet (АВ В. 78):209

$$
\begin{aligned}
& \text { اعيذ210 نفسي بالله الذي [لا اله الا هو]211 الذي } \\
& \text { قامت السموات والارض بحكمه واهتدت } 212 \text { النجوم بامره } \\
& \text { وسيرت الجبال بامره213 يسجد له من } 214 \text { في السموات } \\
& \text { والارض طوعا وكرها وظلالمم بالغدو والاصال و [اعيذه } \\
& \text { [215 من شر [ما خلق وذرا وبرا من] طارق الليل والنهار } \\
& \text { الا طارقاً يطرق بخير [يا رحمن]216 واذا قرات القران جعلنا } \\
& \text { بينك وبين الذين لايؤمنون بالاخرة ججابا مستورا. }
\end{aligned}
$$

Der Text wurde auch in diesen einzelnen, farbig markierten Abschnitten nicht fortlaufend kopiert, sondern mehrfach versetzt angeordnet. Unterhalb des kurzen, diagonal verlaufenden Zierbalkens lässt sich auf der rechten Seite folgender, aus einer ومن 218.شر كل دابة أنت آخذ بناصيتها إن ربي على صراط مستقيم

209 Die Textfolge ist mehrfach unterbrochen. Sie liess sich aufgrund folgender Internetquelle rekonstruieren: https://ar-ar.facebook.com/KtabAlshryfHamdAlzrqany /posts/266253726835488 (Stand 3. Januar 2017).

210 Text orange markiert.

211 Text in eckigen Klammern fehlt auf der Rolle.

212 In der Internetquelle steht: وزهرت.

213 Text ab hier gelb markiert.

214

215

216

217

218 In der Internetquelle steht: ولله يسجد من.

Text ab hier grün markiert.

Text ab hier blau markiert.

Text rosarot markiert.

Es könnte sein, dass der Text einen Auszug aus folgender Quelle ist:

$$
\begin{aligned}
& \text { اللهم أنت ربي لا إله إلا أنت عليك توكلت وأنت رب العرش }
\end{aligned}
$$

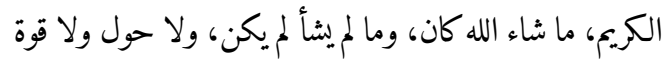

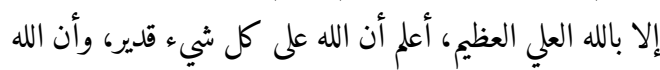

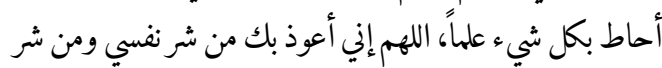

$$
\begin{aligned}
& \text { كل دابة أنت آخذ بناصيتها إن ربي على صراط مستقيم، من قالها }
\end{aligned}
$$


Diese Übersicht vermittelt einen Eindruck von der Komplexität des Aufbaus dieses Abschnitts. Wer den erheblichen Zeitaufwand zur Entzifferung nicht scheut, dürfte grundsätzlich in der Lage sein, auch zusätzliche Textelemente zu identifizieren. Es wird hier einfach festgehalten, dass es sich beim kopierten Text zumeist um Auszüge aus Gebeten und andern Texten frommen Inhalts handeln dürfte. Vielleicht sei noch auf ausgewählte Eigenheiten der Gestaltungen in diesem Abschnitt hingewiesen. Beim Achtpass mit dem Ausdruck al'ażìm (c.) umfährt der $\dot{G} u b \bar{a} r$-Text die Figur in konzentrischen Kreisen. Beim zweiten Achtpass mit dem Begriff al-karim (e.) ist der $\dot{G} u b \bar{a}$-Text auf kurzen horizontal ausgerichteten Linien notiert worden.

Von diesem zweiten Achtpass (e.) an abwärts besteht der Text in $\dot{G} u b \bar{a} r$-Schrift übrigens aus mehrfachen Abschriften von Q $112^{219}$ und Q 2:255 (Thronvers). ${ }^{220}$ Auch hier lässt sich aufzeigen, dass sich die Texte identifizieren lassen, wenn sie hinreichend bekannt sind. Es ist davon auszugehen, dass dem Kopisten des vorliegenden Belegstücks stets klar war, was er tat.

6. Haykal: al-Haykal as-sādis: ${ }^{221}$ Überschrift in weisser Schrift in einem Titelfeld am oberen Ende eines an beiden Enden abgerundeten Rechtecks mit Gebetstext. Dieses Rechteck wird beidseits vom üblichen dreiteiligen Schriftband eingefasst. Vor diesem Abschnitt eine Abfolge von drei Medaillons, die vom dreiteiligen Schriftband umfahren werden. Alle drei Medaillons weisen einen roten Hintergrund auf und werden innen von einem goldenen Ring eingefasst. Auf dem

$$
\begin{aligned}
& \text { في أول الههار لم تصبه مصيبة حتى يمسي، ومن قالها آخر النهار لم } \\
& \text { تصبه مصيبة حتى يصبح. }
\end{aligned}
$$

Vgl. http://fatwa.islamweb.net/fatwa/index.php?page= showfatwa\&Option=FatwaId\&Id=104155 (Stand 3. Januar 2017; vgl. auch Q 11:56).

Grün und orange markiert: Die Abschriften sind teilweise versetzt; auch steht der Text häufig auf dem Kopf.

Abb. 6 der Rolle unter http://www.e-manuscripta.ch/ bau/content/pageview/837973

roten Hintergrund wurden goldene pflanzliche Verzierungen angebracht; im mittleren Medaillon lässt sich eine Art Strauss in goldener Farbe erkennen. Der Text des 6. Haykal lautet:

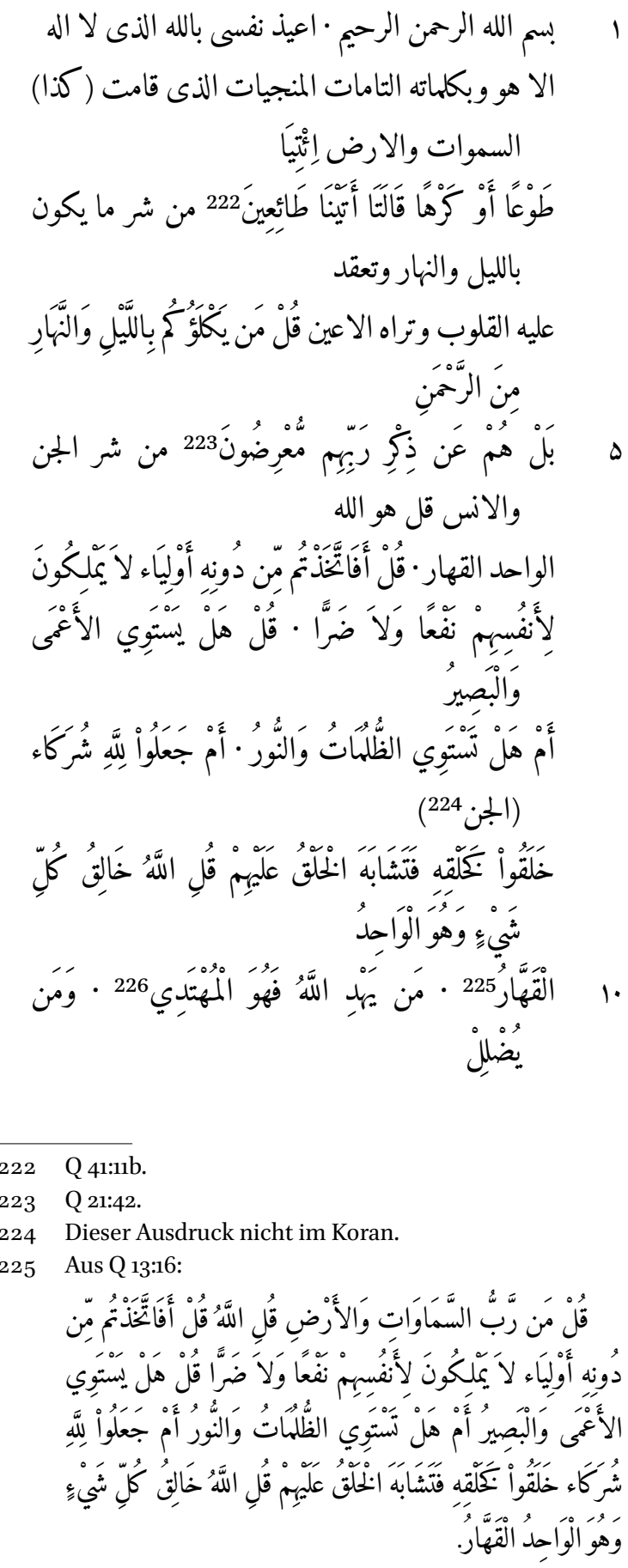

226 Leichte Abweichung im Text. 


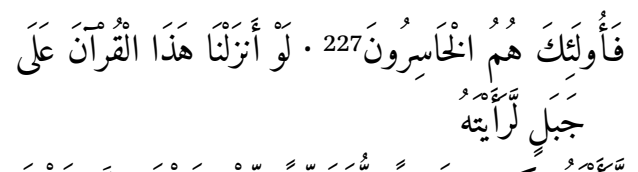

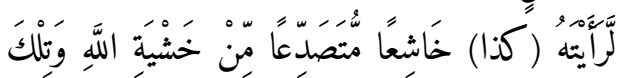

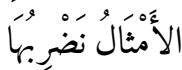

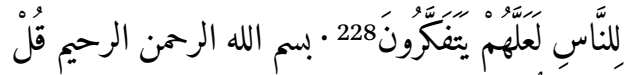

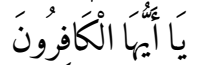

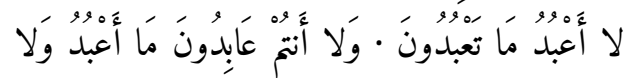

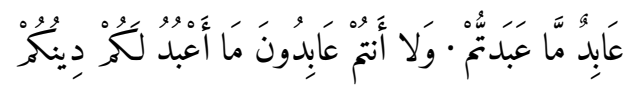
وَليَ

دِينِ 229 •بسم الله الرحمن الرحيم • قُلْ هوَ اللَّهُ

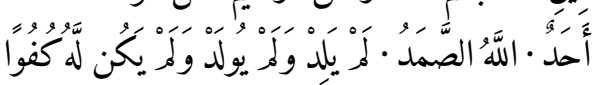

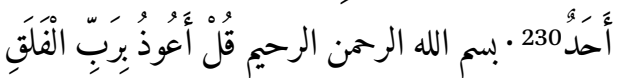

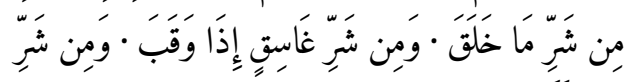
النَّاثًات

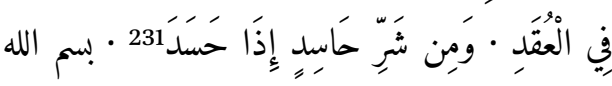
الرحمن الرحيم

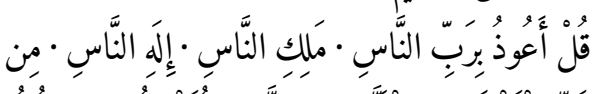

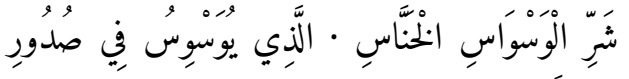
النَّاس آنس

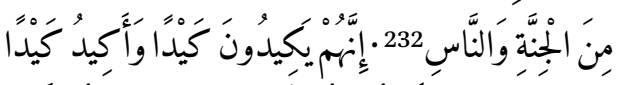

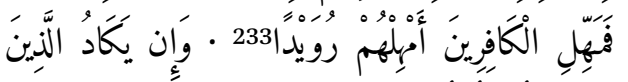

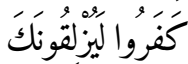

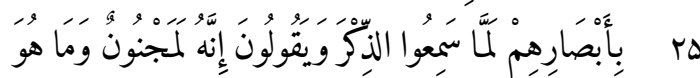

$\begin{array}{ll}227 & \text { Q 7:178. } \\ 228 & \text { Q 59:21. } \\ 229 & \text { Q 109 (ganz) } \\ 230 & \text { Q 112 (ganz). } \\ 231 & \text { Q 113 (ganz). } \\ 232 & \text { Q 114 (ganz). } \\ 233 & \text { Q 88:15-17. }\end{array}$

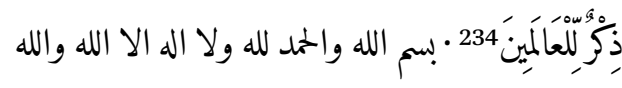

اكبر

اعتصمت بالله • وتوكلت على الله وما توفيقى الا بالله ·

وما النصر الا من عند الله · وما توفيقى الا بالله · ولا لاله

يصرف

السو الا الله فابكم من نعمة فن الله • وان الامر كله

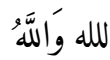

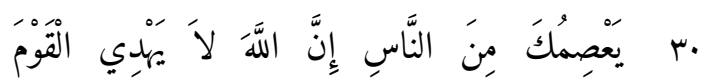

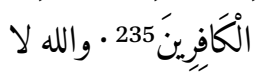

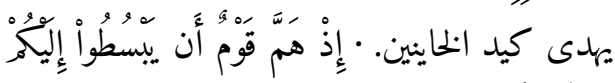
أبَديهن

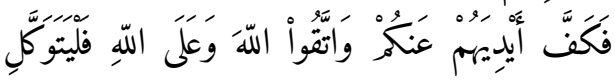

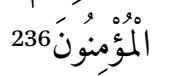

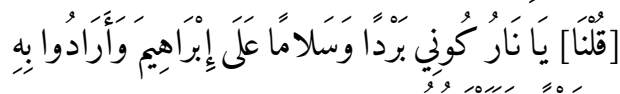

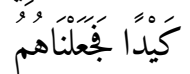

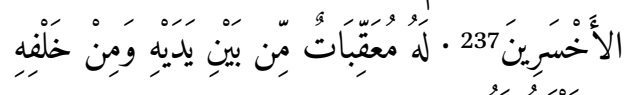

يحفظونه

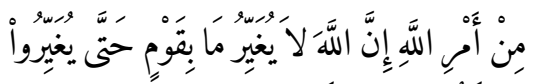

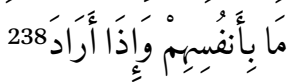

An dieser Stelle endet das an beiden Enden abgerundete Rechteck; es schliesst sich die auf diesem Dokument übliche Abfolge von drei Medaillons an, die vom dreigliedrigen Schriftband umfahren wird. Dieses Schriftband enthält weiterhin Abschriften des Korantexts. Die beiden kleinen

234 Q 68:51-52.

235 Q 5:67b; der ganze Vers lautet:

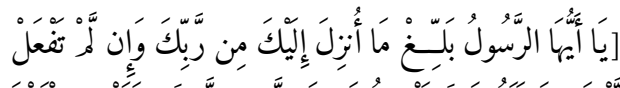

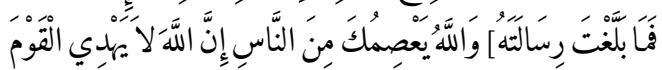
الْكَافرِين.

236 Q 5:11b.

237 21:69-70.

238 Q 13:11a (Fortsetzung im Mittelband darunter). 
Medaillons oben und unten weisen im Zentrum eine einfache pflanzliche Verzierung (golden) auf. Das Innere des grossen Medaillons in der Mitte ist aufwendiger verziert. Die Verzierung ist spiegelsymmetrisch aufgebaut.

Der Text des 6. Haykals war am Ende des vorangehenden Rechtecks nicht abgeschlossen. Seine Fortsetzung folgt vielmehr im nächsten, ebenso oben und unten abgerundeten Rechteck (Länge inkl. den dreiteiligen Schriftbändern ca. $33.0 \mathrm{~cm}$; Авв. 79). Der Text des Haykal-Gebets steht hier allerdings nicht mehr in grosser Schrift auf horizontalen Zeilen. Der Schreiber wechselt jetzt vielmehr zu $\dot{G} u b \bar{a} r$ und fügt den Text in speziell angeordnete Schriftbänder ein. Im folgenden wird versucht, den Text zumindest teilweise zu rekonstruieren. ${ }^{239}$

1. Der Schreiber setzt die Abschrift zuerst auf den horizontalen Zeilen in der Mitte fort (Stelle gelb markiert):

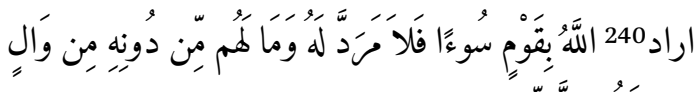

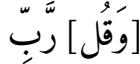

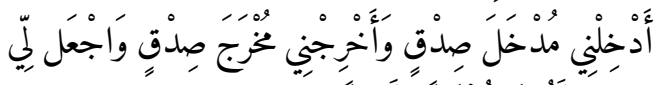

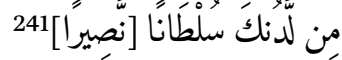

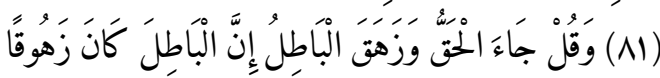

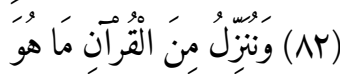

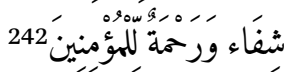

2. Orange markierte Stelle: Q 19:96:

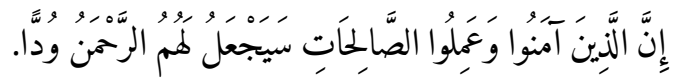

239 Abb. 6 der Rolle unter http://www.e-manuscripta.ch/ bau/content/pageview/837973.

240 Dies gewissermassen als Reklamant; das Verb arāda stand bereits am Ende des vorangehenden Rechtecks.

241 Q 17:80 (die beiden Wörter am Anfang und Schluss des Verses fehlen auf der Rolle). Es schliessen sich danach die weiteren Verse nach Q 17:80 an.

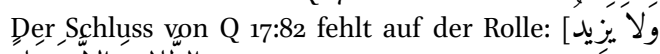
[الظّالمينَ إلاًّ خَسَار 3a. Grün markierte Stelle: Q 112. 3b. Grün markierte Stelle: Q 112; die Sure dürfte ganz kopiert sein; man beachte die unterschiedlichen Textrichtungen und die Brüche darin.

4. Blau markierte Stelle: Q 2:255 (Thronvers): a. (Stelle 1, oben rechts): man beachte die unterschiedlichen Textrichtungen. b. (Stelle 2, Text aufsteigend) beginnt unterhalb der obersten blau-goldenen Verzierung in der Zentralachse; endet oberhalb dieses Zierelements. Der Schreiber macht dazwischen einen Sprung zur Stelle mit der Fortsetzung. c. (Stelle 3, Text absteigend) beginnt auf der rechten Seite des Mittelstreifens und verläuft diagonal nach innen bis in die Mitte des Streifens.

5. Rosarot markierte Stelle: Q 16:108:

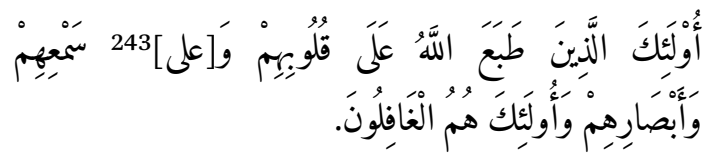

6. Violett markierte Stelle:244

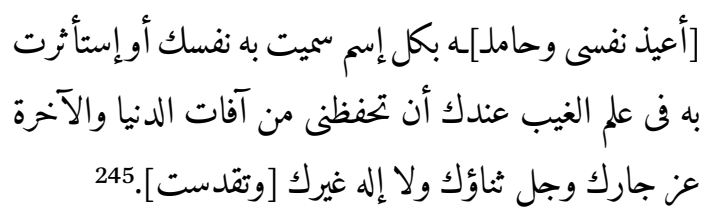

7. Grau markierte Stelle (Q 39:61):

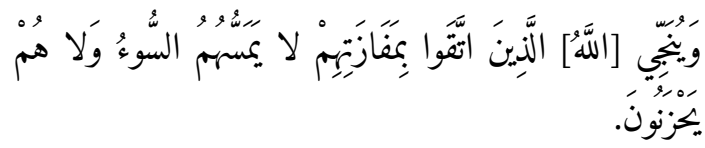

8. Die rot markierte Stelle $\left(\mathrm{Q}_{2: 25} \mathrm{ob}^{246}\right)$ liess sich auf der Rolle nicht vollständig entziffern:

\footnotetext{
243 'Alā auf der Rolle hier zusätzlich eingefügt.

244 Eine Stelle mit ähnlichem Wortlaut lässt sich nachweisen unter http://www.alfahl.net/Default.aspx?tabid=121 $\&$ ctl=ReadODefault\&mid $=448 \&$ ArticleId $=655 \quad$ (Stand 23. Dezember 2016). Davor drei Zeilen nicht entziffert.

245 Die beiden Stellen in eckigen Klammern fehlen auf der Rolle.

246 Q 2:25o, ganzer Vers, lautet:
} 
ربنَّا أَفْغْ عَلِينَا صَبرًا [...] وحسبنا الله ونعم الوكيل ولا حول

$$
\text { ولا قوة الا بالله العلي العظيم. }
$$

Nach dem Ende dieses oben und unten abgerundeten Rechtecks schliesst sich eine weitere Abfolge von drei untereinander verbundenen Medaillons an. ${ }^{247}$ Danach folgt der Abschnitt mit dem 7 . Haykal (al-Haykal as-sābi). ${ }^{248}$ Die Länge dieses Abschnitts mit den drei aufeinanderfolgenden Medaillons beträgt ca. $20.8 \mathrm{~cm}$ (inkl. den beiden dreiteiligen Schriftbändern oben und unten). Die beiden kleinen Medaillons sind einfach gestaltet. Das grosse Medaillon in der Mitte ist komplexer aufgebaut, weist allerdings keinerlei textliche Elemente auf. Im Zentrum lässt sich eine sechseckige Figur mit dunkelblauem Hintergrund erkennen. Die Ecken dieser Figur sind untereinander durch nach innen gewölbte Linien verbunden; sie führen zugleich an beiden Enden über die erwähnten Eckpunkte hinaus. Im Zentrum des Medaillons eine Verzierung mit goldenen Blättern und Ranken. Das Zentrum ist rot ausgefüllt.

Der Text im breiten Mittelband um diese Medaillons herum ist hier nicht, wie sonst üblich, in grossem Nash notiert worden. Er wurde ab hier vielmehr in Tropfen mit nach oben weisender Spitze eingefügt; sie werden durch Text in $\dot{G} u b \bar{r} r$ gebildet, der zumeist auf zwei Zeilen steht. Diese Gestaltung des Texts im breiten Mittelband als Tropfen wird entlang des ganzen Abschnitts mit dem 7. Haykal und der daran anschliessenden Abfolge von drei weiteren Medaillons beibehalten. Erst beim Übergang zum Abschnitt mit der Überschrift $D u^{\prime} \bar{a}$ m mubārak wechselt der Schreiber auch im Mittelband wieder zu grossem Nash. Der Text in

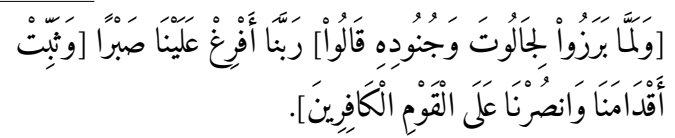

247 Abb. 7 der Rolle unter http://www.e-manuscripta.ch/ bau/content/pageview/837975.

248 Siehe dazu gerade anschliessend bei Anm. 253. den beiden schmalen Seitenbändern aber wurde stets in kleiner Schrift notiert. ${ }^{249}$

Beim Text in diesen Seitenbändern handelt es sich weiterhin um die Abschrift des Korans. Vor dem soeben beschriebenen grossen Medaillon in der Mitte, das um die Figur mit sechs untereinander verbundenen konkaven Linien aufgebaut ist, lassen sich u.a. folgende Stellen erkennen: Im breiten Schriftband links absteigend steht Q 2:129. Danach geht der Text in Q 2:129 in diesem Schriftband in die Tropfen über; die Stelle ist wie folgt angeordnet:

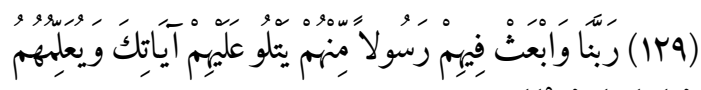

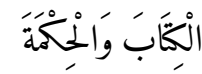

(Übergang zum 1. Tropfen, rechts neben dem oberen kleinen Medaillon)

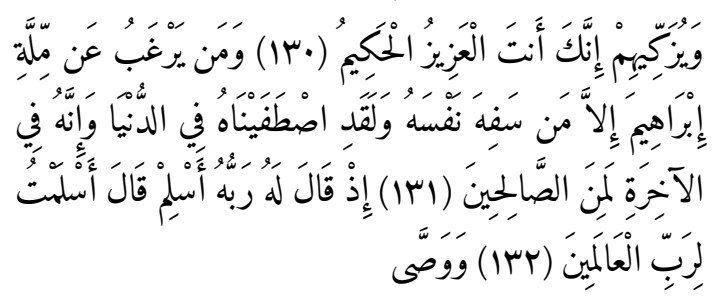

(Übergang zum 2. Tropfen mit nach rechts weisender Spitze)

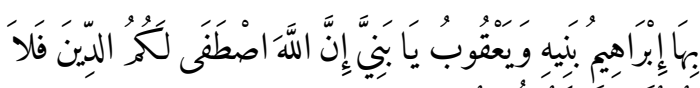

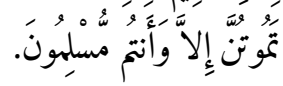

Im aufsteigenden Schriftband steht auf der Höhe des kleinen Medaillons der Beginn von Q 18 (Sūrat al-Kahf; Basmala klar erkenntlich). Im Tropfen unmittelbar darunter steht Q 6:165 (Schlussvers dieser Sure) und zum Ausfüllen Q 112. Q 7-17 fehlen an dieser Stelle. ${ }^{250}$ Im schmalen Band, das das obere Medaillon hier links aussen aufsteigend umfährt und dann ins darüberliegende Rechteck übergeht, lässt sich der Schluss von Q 87

249 Zur Du'â’’ mubārak siehe bei Anm. 271.

250 $\mathrm{Zu}$ dieser Lücke siehe bereits oben Abschnitt nach Anm. $5^{2}$. 
erkennen. ${ }^{251}$ Es schliesst sich danach ein kleiner Abschnitt ohne Text an; darauf beginnt Q 88 mit der Basmala. ${ }^{252}$

7. Haykal:al-Haykalas-sābi; dieser Titel in weisser Schrift auf goldenem Hintergrund im oberen Bogen, der das Rechteck mit dem folgenden Text abschliesst: ${ }^{253}$

$$
\begin{aligned}
& \text { | بسم الله الرحمن الرحيم • اعيذ نفسى بالله الحى القيوم } \\
& \text { ذى الجلال } \\
& \text { والاكرام · ذى البطش الحديد · والسلطان الرفيع · } \\
& \text { والقدره } \\
& \text { القاهره • والعزه الغالبه • له الجود والربا والرفعه والسناء } \\
& \text { الواحد الاحد · المتفرد بالوحد انيه · واعيذ نفسى بالله } \\
& \text { العزيز الجبار } \\
& \text { المتكبر له الاسما الحسنى لسبح له ما في السموات لهبار } \\
& \text { والارض وهو العزيز الحكيم }
\end{aligned}
$$$$
\text { من شر كل عين ناظره • والسن ناطقه • واذان سامعه }
$$$$
\text { وايد }
$$$$
\text { باطشه · وارجل ماشيه · وقلوب واعيه · وصدور }
$$$$
\text { خاويه }
$$$$
\text { فمن يستمع الآن نجد } 254 \text { له شهابا رصدا • واعيذه بالله }
$$$$
\text { الرحمن الرحيم }
$$

251 Schluss von Q 87 (Verse 15-19; die Stelle beginnt im schmalen Schriftband links aussen aufsteigend auf der Höhe des oberen kleinen Medaillons):

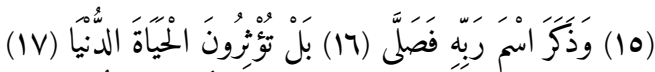

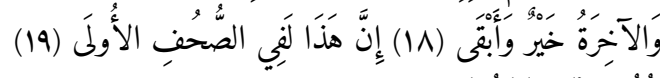

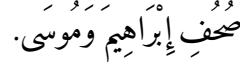

252 Der Beginn von Q 88 (Verse 1-2) lautet:

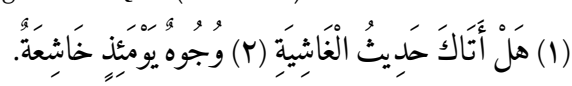

Abb. 7 der Rolle unter http://www.e-manuscripta.ch/ bau/content/pageview/837974.

Hier wohl nağid la-hū (1. Pers. Pl.). Die Stelle stammt

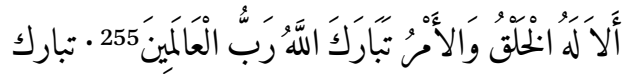

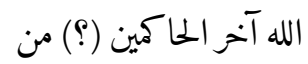

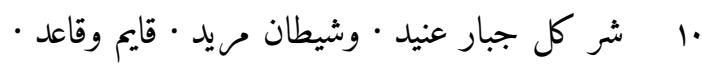

$$
\begin{aligned}
& \text { حاسد }
\end{aligned}
$$

وعاند · ونايم ويقظان • ادعوا ربكم تضرعا وخفية إنه

$$
\text { لا يحب }
$$

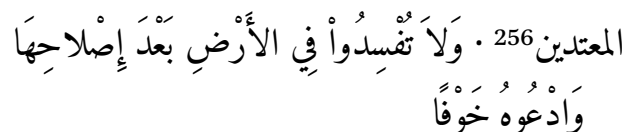

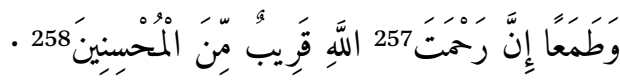

واعيذ نفسى برب عيسى عابس

و شهاب قابس • وماء] قارس • رددت العين المى لى

$$
\text { العين في كبده }
$$

1ه 10 259 يليق

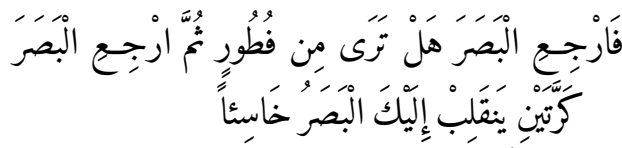

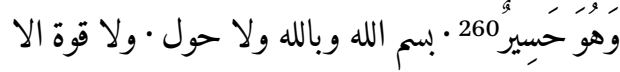<smiles>[13CH2][13CH2]</smiles>

شا الله كان • وما لم يشا لم يكن اشهد ان الله على كل

$$
\text { شى قدير · وان الله }
$$

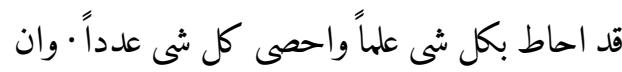

$$
\text { الله يبعث من في }
$$

aus Q 72:9; dort steht yağid la-hū (3. Pers. Sg.):

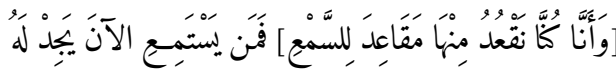

شَهَابَا رَََّدَا.

Ende Q 7:54.

Q 7:55.

So in den Druckausgaben des Korans; die Rolle liest hier مَّ.

$25^{8}$ Q 7:56.

259 Vgl. dazu https://ar-ar.facebook.com/AldktwrAlsydlany AlrwhanyZyadAlly/posts/154277741439355 (Stand 22. Dezember 2016).

260 


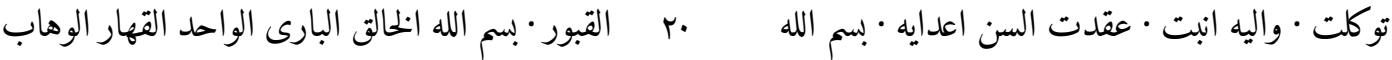

$$
\begin{aligned}
& \text { الفتاح العليم } \\
& \text { العظيم •اللهم اصرف عنى وعن صاحب هذه المياكل } \\
& \text { السبعه شر كل ذى } \\
& \text { شر ·وسحر كل ساحر ومكر كل ماكر ·وكيد كل كايد } \\
& \text { •وشر الجن } \\
& \text { والانس والشيطان الرجيم · واصرف عنى وعنه كل } \\
& \text { دايٍ وبليه وحمر وصداع } \\
& \text { ووجع وفزع • واكشف عنى كل هم وغم ووسواس ونم وضن } \\
& \text { وجنون انما صنعوا } \\
& \text { الذى لا يغلبه } \\
& \text { غالب · والله اعز من كل شى ظهرت قدرته · وتبين } \\
& \text { سلطان الله } \\
& \text { هـ ويبقى وجه الله ·.واذا جاء] وعد ربي جعله دكارًكان } \\
& \text { وعد ربي حقاً وجنا } 264 \\
& \text { وانزلنا من السما ماء ليطهركم به ويذهب عنكم رجز } \\
& \text { الشيطان وليربط } 265 \\
& \text { على قلوبهم ويثبت الاقدام اذيوحى ربك الم الملايكه } \\
& \text { انى معكم فثبتوا الذين آمنوا سالقى.266 }
\end{aligned}
$$$$
\text { ro r كيد ساحر ولا يفلح الساحر حيث اتى } 261 \text { • ويمكرون }
$$$$
\text { ومكر الله والله خير الماكرين } 262
$$

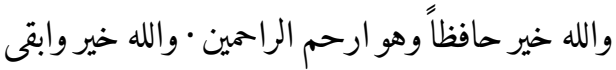$$
\text { وزمت عليكم }
$$$$
\text { بما زم به سليمان بن داوود عليهم (كذا) السلام • وبما }
$$$$
\text { غزم به موسى بن عمران عليه السلام }
$$$$
\text { بطور سينا على سحره فرعون • وباسما الله الجليلة المباركة عمدايه }
$$$$
\text { العظيمة وبالاسم }
$$$$
\text { الذى احيا به عيسى ابن مـيم عليه السلام الموتى • وابرأ }
$$

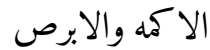

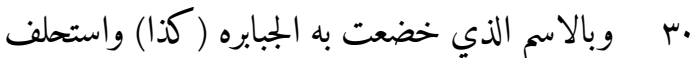$$
\text { الاخرين ان لا263 يقربوه ولا يفزعوه }
$$$$
\text { ولا يضروه من اليوم الم الدهر صاحب هذه المياكل }
$$$$
\text { السبعة في حرز الله - اله }
$$

وامان الله وحفظ الله •وجوار الله تعالى · بالله استعنت

$$
\text { وعليه }
$$

261 Vgl. Q 2o:69b:

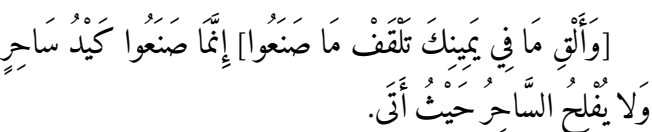

262 Vgl. Q 8:30 (Schluss).

$263 L \bar{a}$ : über der Zeile hinzugefügt.
Nach diesem Text und vor dem Beginn des Abschnitts mit der Überschrift Du'ā’ mubārak wird eine weitere Serie von untereinander verbundenen Medaillons eingeschoben. ${ }^{267}$ Die Länge dieser Abfolge von drei Medaillons misst ca. $21 \mathrm{~cm}$. Auch hier weisen die beiden kleinen Medaillons oben und unten eine einfache Verzierung auf. Das grosse Medaillon in der Mitte weist einen dunkelblauen Hintergrund auf. Seine Verzierungen erinnern an Blüten und sind achsialsymmetrisch angeordnet. Im Zentrum ein goldener Punkt. In der Senkrechten und der Waagrechten gehen aus diesem Zentrum heraus beidseits je eine innen blaue und

264 Vgl. Q 18:98:

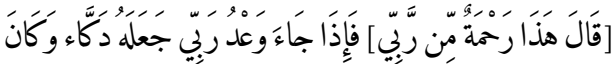

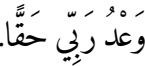

265 Vgl. Q 8:11:

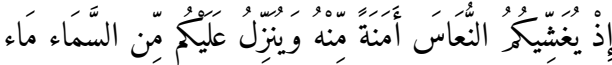

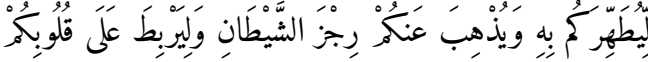

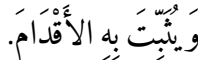

266 Vgl. Q 8:12a:

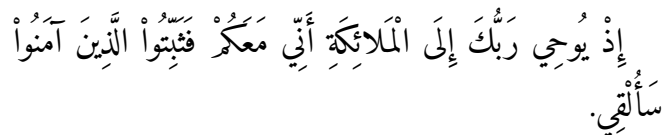

Abb. 7 der Rolle unter http://www.e-manuscripta.ch/ bau/content/pageview/837974. 
aussen rote, golden umrahmte Verzierung hervor. Zwischen diesen blau-roten Zierelementen wurde auf jeder Seite eine jetzt innen weisse golden umrahmte Figur hinzugefügt, die gegen aussen in einen Spitz mündet. In der Vertikalen und der Horizontalen zusätzlich vier identische, an Blüten erinnernde Verzierungen. Sie sind weiss umrahmt; ihr Hintergrund ist weinrot. Zwischen diesen vier weinroten Zierelementen lässt sich jeweils eine Figur erkennen, die aus goldenen Bögen bzw. Ranken besteht.

Der Text aus dem Koran im breiten Abschnitt des dreiteiligen Textbands ist hier weiterhin in Tropfen angeordnet. Sie werden durch zwei nebeneinander angeordnete Zeilen Text in $\dot{G} u b \bar{a} r-$ Schrift gebildet. Unmittelbar unterhalb des oberen kleinen Medaillons lässt sich im schmalen Innenband rechts ein Leerraum erkennen. ${ }^{268}$ Hier endet von oben absteigend Q 46 (Schlussvers: 46:35).269 Nach einem kleinen Abstand beginnt Q 48 (alFath). ${ }^{270}$ Es liess sich nicht klären, ob die an dieser Stelle zu erwartende Q 47 an einer andern Stelle auf der Rolle kopiert worden ist.

Du'ä’ mubārak (А в в. 80): ${ }^{271}$ Dieses Gebet („Gesegnetes Gebet") befindet sich in einem am oberen und unteren Ende abgerundeten Rechteck, das vom dreiteiligen Schriftband eingefasst wird. Der Text im breiten Mittelband wechselt hier von den

268 Also im oberen Medaillon der dreiteiligen Serie (kleines-grosses-kleines Medaillon) vor dem Abschnitt mit der Überschrift Du'ā' mubārak, das in W-Formen angeordnet ist; vgl. Abb. 7 der Rolle unter http://www.e -manuscripta.ch/bau/content/pageview/837974.

Der Schluss von Q 46 (Vers 46:35) lautet:

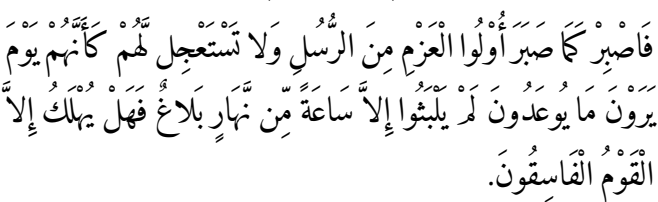

Q 48:1-2 lautet:

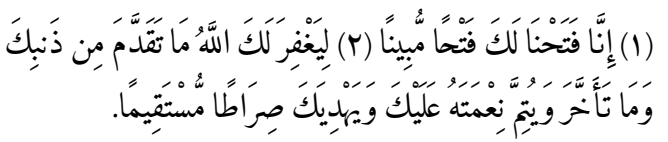

271 Abb. 7 der Rolle unter http://www.e-manuscripta.ch/ bau/content/pageview/837974. in Tropfen angeordneten Stellen in $\dot{G} u b a \bar{r}$ wieder zu grossem Nash (absteigendes Schriftband). ${ }^{272} \mathrm{Im}$ aufsteigenden Schriftband folgt der Übergang von grossem Nash zu Stellen in $\dot{G} u b \bar{a} r$-Schrift, die in Tropfen angeordnet sind. ${ }^{273}$

Die Länge dieses Rechtecks misst ca. 34 cm (inkl. dreiteiligem Schriftband oben und unten). Überschrift in weisser, schwarz eingefasster Schrift im oberen Bogen dieses Abschnitts. Der Text in diesem Abschnitt selbst wurde zuoberst und zuunterst auf je zwei horizontalen Zeilen in normal grossem Nash notiert (a. und c.). Dazwischen (b.) wurde der Text in $\dot{G} u b \bar{a} r$ notiert und in W-Formen eingepasst. Die oberste, mittlere und unterste WFormen enthalten je eine Zeile Text in grosser Schrift; der restliche Text in $\dot{G} u b \bar{a} r$. Zwischen den einzelnen W-Formen ist jeweils ein schmaler Streifen nicht beschrieben. Zuunterst lassen sich zur Linken und Rechten der letzten W-Form je ein Zwickel mit blauem Hintergrund und einer pflanzlichen Verzierung erkennen (Blüte: rot; Stiel, Blätter: golden). Die Leerräume zwischen den Hälsen der W-Formen sind oben mit zwei und unten mit einer angeschnittenen Raute ausgefüllt. Auch diese drei Figuren entstehen durch Text in $\dot{G} u b \bar{a} r$-Schrift.

272 Im breiten Teil des nach links absteigenden Schriftbands steht am Anfang Q 2:167-168 (der Anfang von Vers 167 im Tropfen davor, nur die beiden Schlusswörter gross; Übergang durch die Markierung ||| gekennzeichnet):

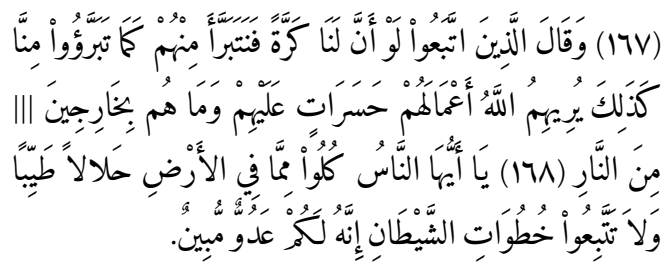

273 Hier lässt sich rechts aufsteigend Q 6:13o erkennen (Beginn am unteren Ende des Abschnitts mit den WFormen); der Übergang zur Stelle in Tropfenform ist durch die Markierung ||| gekennzeichnet:

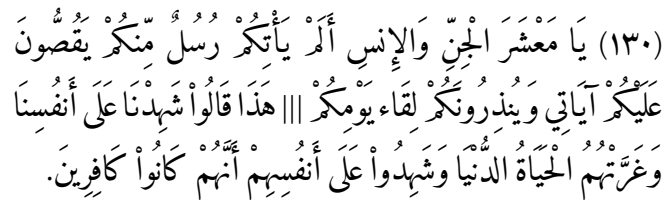


Inhalt a:

$$
\begin{aligned}
& \text { بسم الله الرحمن الرحيم •بسم الله باسمه المبتدا (كذا) رب }
\end{aligned}
$$

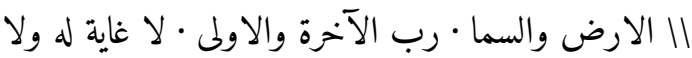

Inhalt b: In diesem Abschnitt sind drei Zeilen in grosser Schrift notiert worden; sie lassen sich entziffern. Der restliche Text in $\dot{G} u b \bar{a} r$ liess sich nicht durchgehend entschlüsseln. Die Stellen in grosser Schrift lauten (der Text folgt jeweils der WForm):

b.1:

$$
\begin{aligned}
& \text { لا مشبه له ولا شبيه له ولا حد له ولا حدود له ولا صاحبه } \\
& \text { له ولا ولد له ولا شريك له في الملك ولا وزير له. }
\end{aligned}
$$

b. $2: 274$

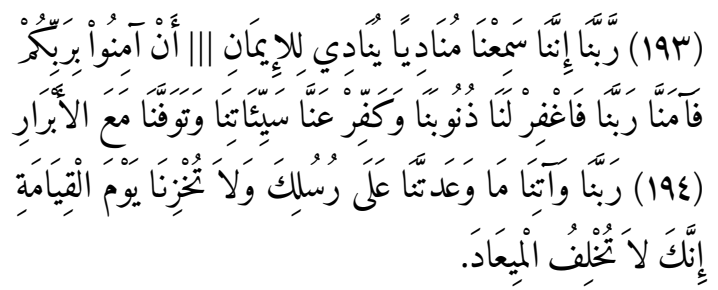

In dieser mittleren W-Form mit dem Zitat von Q 3:193-194 wurde eine Reihe weiterer Koranverse zusammengestellt, die mit der Anrufung Gottes mit rabba-nā beginnen. Die jeweiligen Verse wurden nicht ganz zitiert; sie beginnen erst mit rabba$n \bar{a}$. Folgende mit rabba-nā beginnenden Koranstellen liessen sich belegen (Aufzählung nicht vollständig): 2:25०; 2:285; 2:286; 3:9; 3:147; 3:193; 3:194; 3:53; 3:147; 3:191; 3:193; 3:194; ${ }^{275} 7: 126 ; 10: 85 ; 25: 65^{-}$ 66. Die Stelle zeigt exemplarisch die Schwierigkeit auf, den Inhalt dieser Rolle vollständig zu erfassen. Das Entziffern und Identifizieren der einzelnen Stellen erfordert sehr viel Zeit.

\footnotetext{
274 Q 3:193-194. Die Stelle beginnt links aussen in $\dot{G} u b \bar{a} r-$ Schrift oberhalb der Zeile in grosser Schrift. Der Wechsel zur Stelle in grosser Schrift ist durch ||| markiert.

b.3:

$$
\begin{aligned}
& \text { خلا فا للجاهلين وتكذيبا للملحدين وتصديقا لمرسلين واخلاصا } \\
& \text { لله رب العالمين الحمد لله خالق الخلق ورازقه ومصور العباد } \\
& \text { وصايغه ومعز الخلق ||| } 276 \text { ومذله. }
\end{aligned}
$$

Zwischen den beiden Schenkeln der untersten WForm lässt sich ein weiteres Element erkennen, das durch Text in $\dot{G} u b \bar{a} r$-Schrift gebildet wird und dessen Form an die Spitze einer Lanze erinnert (nach oben gerichtet). Goldener Zierpunkt im Innern der Figur. ${ }^{277}$ Abschrift des Thronverses; er beginnt mit vorangestellter Basmala an der Spitze und verläuft im Gegenuhrzeigersinn links absteigend. Nach Abschluss des ersten Durchgangs beginnt eine zweite Abschrift des Thronverses.

Inhalt c:

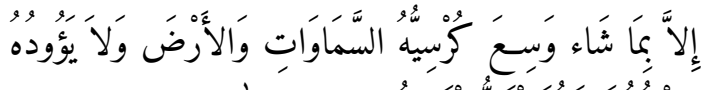

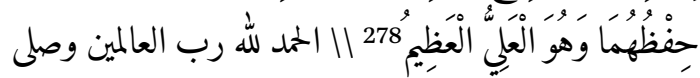

$$
\begin{aligned}
& \text { الله على سيدنا محمد واله وسلم تسليما كثيرا. }
\end{aligned}
$$

An diesen Abschnitt mit dem in W-Formen integrierten Text schliesst sich eine weitere Abfolge von drei Medaillons an (Länge ca. $21 \mathrm{~cm}) .{ }^{279}$ Das grosse Medaillon enthält einen vertikal ausgerichteten, sechsstrahligen Stern. Er wird durch weissliche, golden eingefasste Linien gebildet. Die Schnittpunkte der beiden Dreiecke wurden durch jetzt goldene Kreise markiert, ${ }^{280}$ die im Innern durch sechs blattartige Figuren in roter Farbe verziert werden. Auch das Innere dieses Sterns und

276 Hier endet die Stelle in grosser Schrift; Ausdruck mudill in $\dot{G} u b \bar{a} r$ auf der nächsten Zeile rechts.

277 Am oberen Ende dieses Abschnitts mit den W-Formen lassen sich zwei weitere identische Figuren erkennen, deren Spitzen allerdings nach unten weisen.

278 Schluss des Thronverses (Q 2:255). Der Anfang wohl in einer der W-Formen davor.

279 Abb. 8 der Rolle unter http://www.e-manuscripta.ch/ bau/content/pageview/837975.

280 Vereinzelte Überreste von dunkelblauer bzw. schwarzer Farbe. 
die Leerräume am Rand weisen einen rötlichbraunen Hintergrund auf und sind mit pflanzlichen Motiven (Blättern) in goldener Farbe verziert.

Sechsstrahlige Sterne spielen im islamischen Kulturraum häufig auf Salomon an. Auf dem vorliegenden Belegstück fehlt ein textliches Element (z.B. Überschrift), das diesen Bezug verdeutlichen würde. ${ }^{281}$ Auf andern Exemplaren, die später anzusetzen sind und aus osmanischen Kontexten stammen, wird dieser Bezug aber explizit hergestellt. ${ }^{282}$ Auf dem vorliegenden Belegstück dürfte der sechsstrahlige Stern implizit einen Bezug zu Salomon herstellen. Salomon gilt in der gesamten islamischen Welt als Beschützer wider alles Dämonische. Aus dieser Perspektive betrachtet würde die vorliegende Figur also an Salomons Schutzmächtigkeit appellieren und die allzeit drohenden Angriffe der ǧinn neutralisieren. ${ }^{283}$

Du'ä' Ibrāhìm b. Adham: ${ }^{284}$ Titel in weisser, golden eingefasster Schrift auf rotem Hintergrund im Bogen, der das Rechteck mit dem unten angeführten Gebetstext oben abschliesst. Das Gebet wird gemäss seiner Überschrift Ibrāhīm b. Ad hham ${ }^{285}$ zugeschrieben. Text in normal grossem Nash auf 39 horizontalen Zeilen: ${ }^{286}$

281 Vgl. dazu Winkler, Siegel und Charaktere 127-132; Canaan, Decipherment v. a. 170; Baer, Metalwork 126132 (Fig. 107-109). Siehe auch Meinecke, Restaurierung der Madrasa Tafel 15c. Die Madrasa des Amīr al-Ānūkī entstand wohl gegen 770/1368-1369 (op. cit. 29).

282 Vgl. dazu Zentralbibliothek Zürich, Ms. or. 20; München, Bayerische Staatsbibliothek, Cod. arab. 207.

283 Zu Salomons Rolle als Beschützer vor allem Dämonischen vgl. Nünlist, Dämonenglaube 405-522 (Kapitel 10: Salomon: Kämpfer wider alles Dämonische).

284 Abb. 8 der Rolle unter http://www.e-manuscripta.ch/ bau/content/pageview/837975.

285 Zu Ibrāhīm b. Aḍham (Mystiker aus Khorasan, gest. 16o/777) vgl. Knysh, Islamic mysticism 18-21; 32-34; Schimmel, Mystische Dimensionen 63-65 (Todesjahr hier 776 oder 79o); Renard, Dictionnary of Sufism 117 .

286 Abb. 8 der Rolle unter http://www.e-manuscripta.ch/ bau/content/pageview/837975.

$$
\begin{aligned}
& \text { دعا ابراهيم ابن ادهم } 287 \\
& \text { ا بـم الله الرحمن الرحيم ·بسم الله الحميد البميد (؟) • الرفيع } \\
& \text { الودود - (- مود } \\
& \text { الفعال في خلقه مايريد · اصبحت بالله مومناً · وبلقايه } \\
& \text { مصدقاً . } \\
& \text { وبحجته معترفاً ومن ذببي مستغفراً • ولربوبيه الله } \\
& \text { خاضعاً } \\
& \text { ولسوى الله في الاليه جاحداً • والى الله فقيراً . وعلى } \\
& \text { الله متوكلا } \\
& \text { ه والى الله منيباً · اشهد الله واشهد ملائكته وانبياوه } \\
& \text { (كذا) ورسله } \\
& \text { وممله عرشه ومن خلق ومن هو خالقه • بانه هو الله }
\end{aligned}
$$

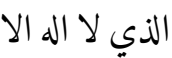

$$
\begin{aligned}
& \text { هو وحده لا شريك له وان محماً عبده ورسوله صلى له له } \\
& \text { الله عليه وسلم } \\
& \text { تسليماً · وان الجنة حق [وان النمان النار حق 288] والحوض } \\
& \text { حق والشفاعة حق ومنكراً } \\
& \text { ونكيراً حق ولقاوك (كذا) حق } 289 \text { ووعدك حق ومنك } \\
& \text { والساعة آتيه لا ريب فيها ولماول } \\
& \text { • ا وان الله يبعث من في القبور • [و[على ذلك احيا وعليه } \\
& \text { اموت · وعليه } \\
& \text { ابعث ان شاء الله • اللهم انت ربي لا رب ليه لي الا } \\
& \text { انت } 290 \text { خلقتني وانا عبدك وانا } \\
& \text { على عهدك ووعدك ما استطعت • اعوذ بك اللهم من } \\
& \text { شر ما صنعت } 291
\end{aligned}
$$

287 Adham: $\underline{d} \bar{a} l$ ist auf der Rolle nicht punktiert.

288 Text in eckiger Klammer nur unter https://hawa.univa

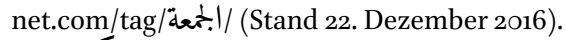

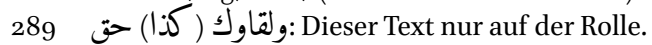

290 Diese Stelle lautet in der als Parallele beigezogenen

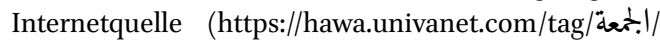
Stand 22. Dezember 2016): اللهم انت ربي لا اله الا انت//.

291 Auf der Höhe dieser Zeile Knick im Papier (mit Text- 


$$
\text { واعوذ بك اللهم)292 من شر كل ذي شر • اللهم اني }
$$

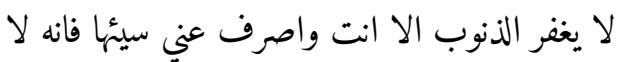

$$
\text { يصرف سئها الا انت }
$$

10 استغفرك

واتوب اليك • امنت اللهم بما ارسلت من رسول •

$$
\text { وامنت اللهم بما }
$$

انزلت من كّاب وصلى الله على [سيدنا293] محمد [النبي

الامي] و[على] اله وسلم [تسليما] كثيراً • خاتم

$$
\text { كلامي }
$$

ومفتاحه · وعلى انبيائه ورسله اجمعين [امين يا رب

$$
\text { العالمين] · اللهم اوردنا حوضه } 294
$$

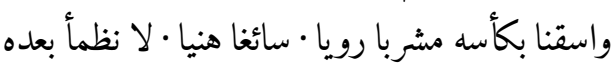

r.

$$
\text { مرتابين ولا مفتونين ولا مغضوب }
$$

علينا ولا ضالين • اللهم اعصمني من فتن الدنيا ووفتني

$$
\text { لما تحب وترضى }
$$

واصلح لي شأني كله وثبتني بالقول الثابت في الحياة

$$
\text { الدنيا وفي الاخرة }
$$

ولا تضلني وان كنت ظالما · سبحانك (سبحانك) يا

$$
\text { علي يا عظيم يا بار[ئ] يا رحيم }
$$

يا غزيز يا جبار · سبحان من سبحت له له الجبال

$$
\text { با كنافها }
$$

verlust); Rekonstruktion des Texts aber dank Internetquelle gesichert (vgl. vorangehende Anm.). Text in runden Klammern nur auf der Rolle.

Ausdrücke in eckigen Klammern nur in der Internetquelle.

294 Die Stelle lautet in der Internetquelle:اللهم اوردنا حوض عمل عاليه محمد صلى الله عليه وسلم.

295 Die Stelle lautet in der Internetquelle: سبحان من سبحت

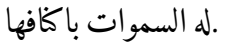

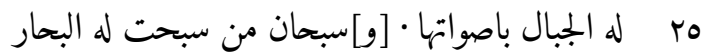
بامواجها .296 [و]سبحان من سبحت

له الحيتان بلغاتها • [و] سبحان من سبحت له النجوم في

$$
\text { السماء بابراقها297 • [و]سبحان }
$$

من سبحت له الشجر 298 باصولها ونضارتها [و[سبحان

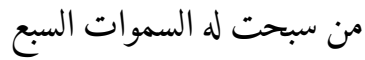

والارضون السبع ومن فيهن ومن عليهن 299 سبحانك

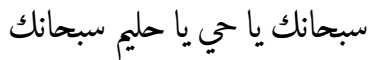

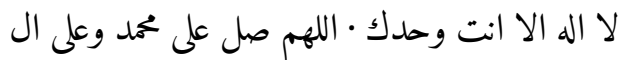

محمد صلاه تكون

r.

واجزه عنا ما هو اهله · واجزه افضل ما جازيت نبياً

$$
\text { عن امته }
$$

وصلى الله على جميع اخوانه من المومنين والنبيين

$$
\text { والصالحين يا ارحم الراحمين }
$$

اللهم اجعل فضايل صلواتك · وشرايف زكوتك

$$
\text { (كذا) • ونوامي بركاتك (ف) }
$$

ورافتك ورحمتك وتحيتك على سيد المرسلين ·وخاتم

$$
\text { النبيين وامام المتقين }
$$

هر ورسول العالمين · قايد الخير وفاتح البر وبي الرحمه وسيد

$$
\text { الازمنه }
$$

296 In der Internetquelle folgt hier: وسبحان من سبحت له الجبال باصدائها

297 In der Internetquelle steht hier: بابراجها

298 In der Internetquelle steht hier: الاشيجار.

299 Ab hier weicht der Text auf der Rolle zunehmend von jenem in der Internetquelle ab. Der Schluss lautet in der Internetquelle:

سبحان من سبح له كل شيء من مخلوقاته تباركت وتعاليت

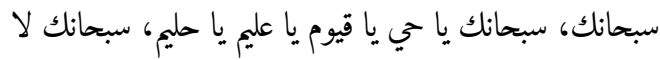

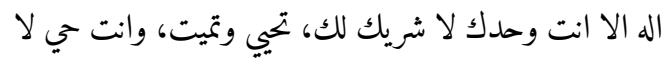

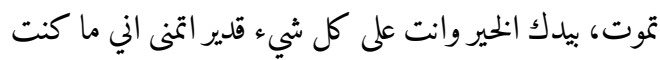

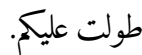




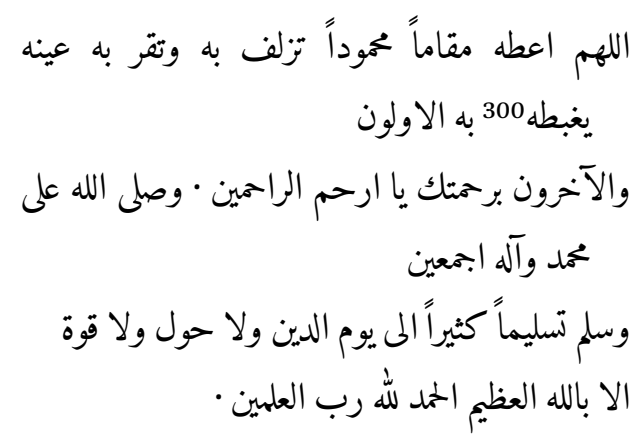

An dieses Gebet schliesst sich eine weitere Abfolge von drei unter einander verbundenen Medaillons an. ${ }^{301}$ Hier geht der Text in grossem Nash im breiten Mittelband des dreiteiligen Schriftbands in $\dot{G} u b \bar{a} r$ über, das in mandelförmigen Figuren angeordnet ist. Erst beim Abschnitt mit der Überschrift Faḍl Āyat (sic) al-ḥars kehrt der Schreiber im Mittelband wieder zu grossem Nash zurück. ${ }^{302}$ Die beiden kleinen Medaillons oben und unten sind auch hier einfach gestaltet. Das grosse Medaillon dazwischen ist komplexer aufgebaut. Im Zentrum lässt sich auf weinrotem, von weissen Linien eingefasstem Hintergrund ein fünfteiliges grünes Blatt erkennen, dessen Ränder ausfransen und golden hinterlegt sind. Zwischen Medaillonrand und der weinroten, von weissen Linien eingefassten Figur ist der Hintergrund blau und mit einem goldenen Blatt und Rankenmuster ausgefüllt. Vereinzelte Blätter sind rot. Danach schliesst sich die Du'ā' mubārak mustağāb an:

Du'ă’ mubārak mustağāb (АВ В. 81): 303 Überschrift im oberen Bogen eines an beiden Enden abgerundeten Rechtecks (Federkastenform; Länge ca. $34 \mathrm{~cm}$ ). Der Titel dieses Gebets bedeutet „Gesegnetes Gebet, das erhört wird (mustağā $b$ )“. ${ }^{304}$ Das

300 Auf der Rolle steht يغطبه.

301 Abb. 8 der Rolle unter http://www.e-manuscripta.ch/ bau/content/pageview/837975.

302 Abb. 9 der Rolle unter http://www.e-manuscripta.ch/ bau/content/pageview/837976.

303 Abb. 9 der Rolle unter http://www.e-manuscripta.ch/ bau/content/pageview/837976.

304 Der Ausdruck mustaǧā $b$ erinnert daran, dass gerade erfolgreiche Vorsteher von Derwischorden als mus tağ $\bar{a} b$ ad-du'ä' bezeichnet werden. Ihre Gebete zugunsten der Ratsuchenden werden von Gott erhört. Zum
Rechteck lässt sich in drei Abschnitte unterteilen: a. zuoberst stehen drei Zeilen Text in normal grossem Nash; sie sind horizontal ausgerichtet; b. im langen Teil in der Mitte wurde der Text in $\dot{G} u b \bar{r} r$ kopiert und ist in Figuren angeordnet. Es lassen sich drei ganze Spalten und zur Linken und Rechten je eine angeschnittene Spalte erkennen. In den ganzen Spalten ist der Text zumeist in Sechsecken angeordnet; ihre Ecken sind oft abgerundet. Es lassen sich aber auch sechsstrahlige Sterne erkennen. Diese Figuren werden aus drei Zeilen Text in $\dot{G} u b \bar{a} r$ gebildet. Die Leerräume in der Mitte der Figuren sind mit unterschiedlichen Zierelementen versehen (z.B. sechsblättrige goldene Blüten mit einem Punkt in der Mitte; oder goldene Zierpunkte mit einem roten Punkt im Zentrum). Seltener sind die golden eingefassten Kreise mit blauem Hintergrund. Sie fallen allerdings auf. Die beiden obersten Kreise mit blauem Hintergrund sind innen mit fünf Kreisen verziert (vier Kreise, die um einen fünften Kreis im Zentrum angeordnet sind). Die weiteren Kreise sind ebenso golden eingefasst und mit einem blauen Hintergrund versehen; darauf befindet sich ein golden eingefasstes Dreiblatt. Von dieser zweiten Art Kreise lassen sich insgesamt 9 Stück erkennen, die in Dreiergruppen angeordnet sind. Ebenso wie die beiden andern Kreise mit blauem Hintergrund verzieren auch sie jene Figuren aus $\dot{G} u b \bar{a} r$-Schrift, die als sechsstrahlige Sterne ausgebildet sind. c. Vor dem Abschluss dieses auch unten abgerundeten Rechtecks folgen nochmals acht Zeilen Text in normal grossem Nash.

Inhalt a:

$$
\begin{aligned}
& \text { بسم الله الرحمن الرحيم • الحمد لله رب العالمين الرحمن الرحيم } \\
& \text { || مالك يوم الدين · اياك نعبد واياك نستعين · اهدنا صراط } \\
& \text { المستقيم صراط || الذين انعمت عليهم غير المغضوب وعليهم } \\
& \text { ولضالين } 305 \text { آمين (كذا) بسم الله الرحمن الرحيم. }
\end{aligned}
$$

Konzept mustağāb ad-du'ç’ vgl. Kissling, Die islamischen Derwischorden 9; Schimmel, Mystische Dimensionen 23 .

305 Es handelt sich um die Fätiha (Q 1). Überraschend ist angesichts der Bekanntheit dieser Sure, die spezielle 
Inhalt b.: Der Text wurde in $\dot{G} u b \bar{a} r$ notiert und ist oft komplex angeordnet. Er liess sich deshalb nicht vollständig entziffern. Allerdings liessen sich doch wichtige Feststellungen machen: In der oberen Hälfte lassen sich vier Texteinheiten mit drei parallelen, im Zickzack verlaufenden und grundsätzlich horizontal ausgerichteten Zeilen erkennen. Die erste Einheit mit drei Zickzack-Zeilen befindet sich unmittelbar oberhalb der beiden obersten blauen Zierelemente (b.1). ${ }^{306}$ Darunter folgt die nächste Gruppe von drei im Zickzack verlaufenden Zeilen (b.2). Die dritte Gruppe von drei Zickzacklinien verläuft oberhalb der nächsten beiden blauen Zierpunkte (b.3). Es folgt eine letzte Gruppe von drei parallel verlaufenden Zickzacklinien (b.4).

In der oberen Hälfte dieses Abschnitts ist der restliche Text unabhängig von diesen horizontal ausgerichteten Gruppen mit Zickzacklinien angeordnet. In der unteren Hälfte folgen keine weiteren Gruppen mit Zickzacklinien. Der Text ist hier vielmehr um die weiteren Zierelemente herum gruppiert worden und verläuft in unterschiedlichen Richtungen. Dies erschwert das Bestimmen des Inhalts. Es war möglich, gerade den Text in den Gruppen mit drei parallelen Zeilen zu bestimmen: b.1 (АВB. 81):

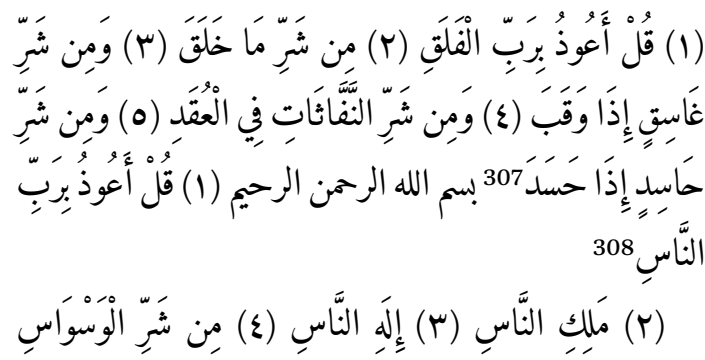

Schreibweise gerade der beiden letzten Wörter (der Text steht so auf der Rolle). Dies legt nahe, dass der Kopist nicht arabischer Muttersprache war.

306 Die beiden unteren Spitzen der dreifachen Zickzacklinie berühren die beiden obersten blauen Zierelemente von oben.

307 Q 113 (ganz, aber ohne Basmala); auf Авв. 81в orange markiert.

308 Hier Zeilenumbruch; Fortsetzung auf der nächsten Zickzacklinie rechts.

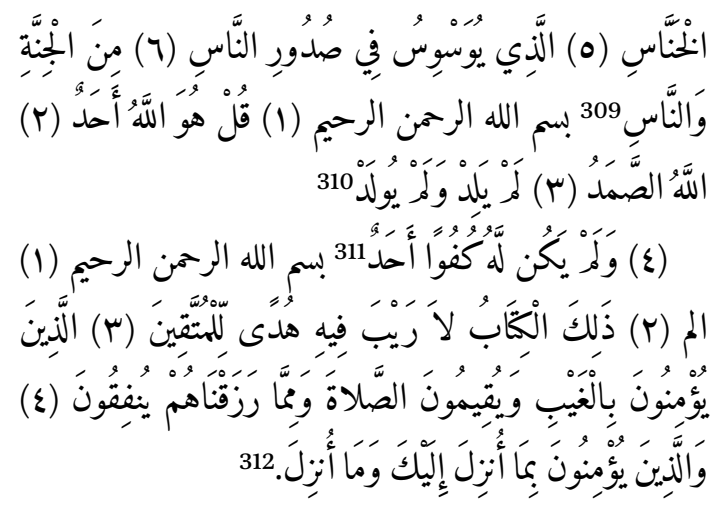

Hier endet die erste Gruppe mit drei zueinander gehörenden Zickzacklinien. Der Text von Q 2:4 wird in der nächsten Gruppe von Zickzacklinien fortgesetzt (b.2). Es ist gelungen, einzelne Textelemente in $\dot{G} u b \bar{a} r$-Schrift oberhalb dieser ersten Gruppe mit drei Zickzacklinien zu identifizieren:

Rechts aussen steht hier auf dem Kopf geschrie-

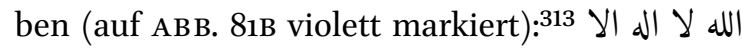

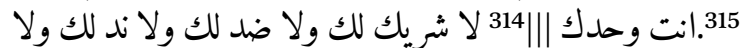

Links aussen liess sich oberhalb der obersten Gruppe von drei Zickzacklinien weiterer Text identifizieren. Die Stelle (Q 17:50-51) beginnt innen, steht zumindest am Anfang auf dem Kopf und steigt unter Änderung der Ausrichtung der Zeilen nach oben (auf Авв. 81в rosarot markiert): ${ }^{316}$

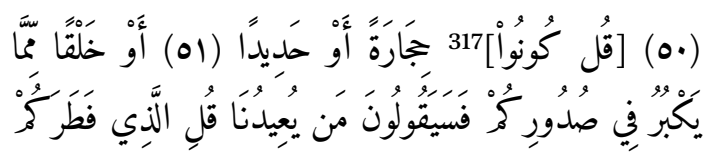

309 Q 114 ganz (auf Авв. 81в grün markiert); der Schluss befindet sich gerade nach der Spitze in der Mitte dieser Zickzacklinie.

Zeilenumbruch; Fortsetzung auf der nächsten Zickzacklinie rechts. Q 112 (vollständig); auf Ав в. 81в gelb markiert.

312 Q 2:1-4a (auf АBB. 81B blau markiert).

313 Der identifizierte Text beginnt rechts aussen bereits unterhalb der obersten Gruppe von drei Zickzacklinien. Hier Sprung und Fortsetzung oberhalb der Gruppe von drei Zickzacklinien. Der Text ist hier noch nicht zu Ende; er liess sich allerdings nicht mit Sicherheit entziffern.

316 Q 17:50-51.

317 Diese beiden Wörter liessen sich nicht lokalisieren. 


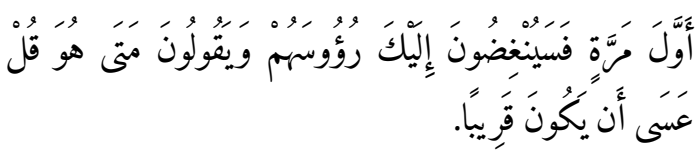

Nach dem Auszug aus Q17 (Verse 50-51) schliesst sich oberhalb der obersten Gruppe von drei Zeilen mit Text in Zickzack ganz links aussen absteigend folgende Koranstelle an. Einzelne Textteile werden beim Übergang in den zweiten, unterhalb der Zickzacklinie kopierten Abschnitt wiederholt: ${ }^{318}$

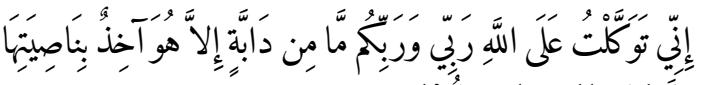

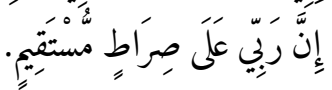

Der weitere Text unterhalb der obersten Gruppe von drei Zickzacklinien liess sich nicht mit Gewissheit identifizieren, da dessen Ausrichtung immer wieder ändert.

b.2: Nächste Gruppe von drei Zickzack-Zeilen: Hier folgt die Fortsetzung von Q 2:4; die erste Hälfte dieses Verses stand bereits in der ersten Gruppe von drei Zeilen, die im Zickzack verläuft:319

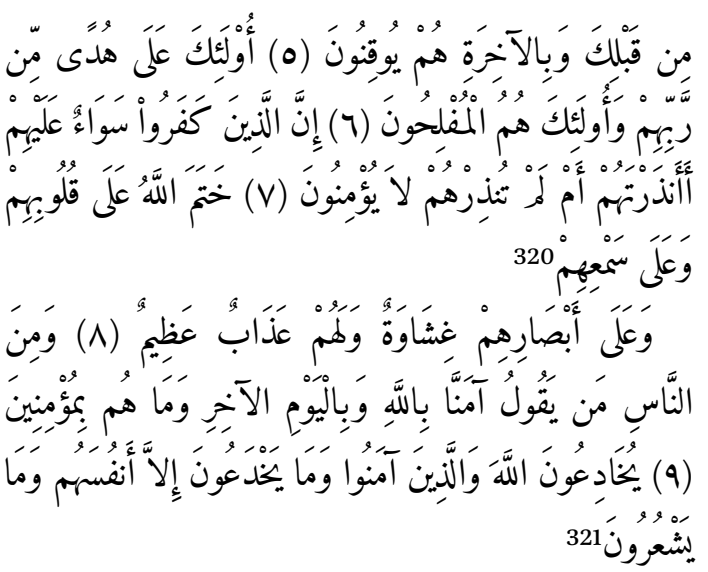

318 Q 11:56; erster Teil oberhalb, zweiter Teil unterhalb der Zickzacklinie; auf Авв. 81в türkisfarben markiert.

319 Vgl. zu diesem ersten Teil oben, nach Anm. 311: b.1; beim im folgenden kopierten Text handelt es sich um Q 2:4b10 (auf Авв. 81в blau markiert).

Zeilenumbruch; Fortsetzung auf der nächsten Zickzacklinie rechts.

321 Zeilenumbruch; Fortsetzung auf der nächsten Zickzacklinie rechts.

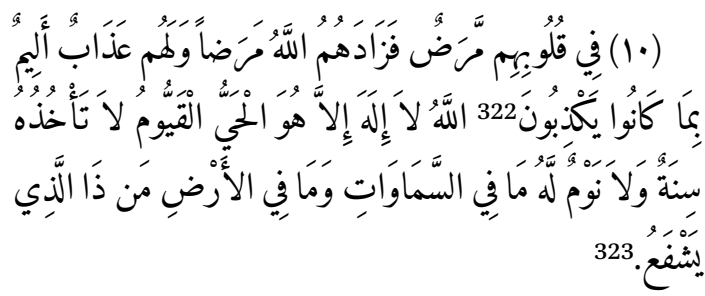

Zwischen den beiden Gruppen von drei Zickzacklinien b.2 und b.3 liessen sich weitere Textstellen identifizieren. Zur Linken des blauen Zierelements in der Mitte steht Q 36:65-67a (diagonal absteigend nach links aussen verlaufend; auf Авв. 81в orange markiert):

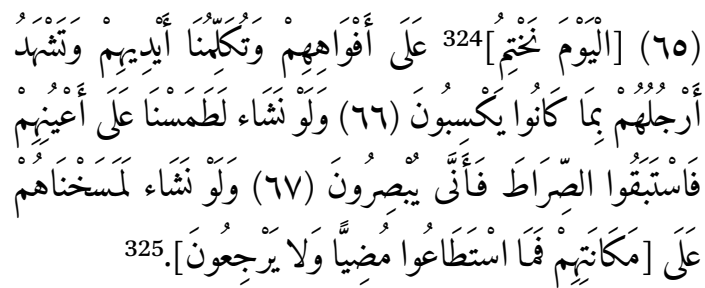

Links oberhalb dieses Auszugs aus Q 36 steht:

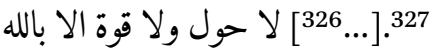

Links neben dem einzelnen blauen Zierelement steht ausserdem Q 5:23 (Auszug; auf АB B. 81B grün markiert):

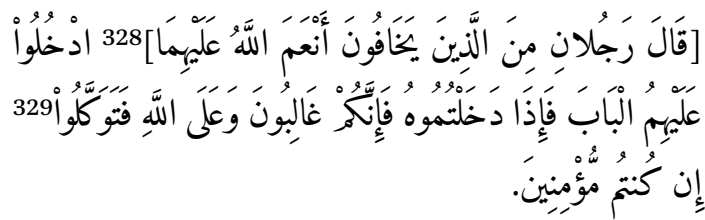

322 Hier endet das Zitat mit Q 2:10. Es schliesst sich auf dieser Zeile direkt Q 2:255 an (Thronvers; auf Aв B. 81B rot markiert).

323 Hier endet die zweite Gruppe von drei im Zickzack verlaufenden Zeilen; Q 2:255 (auf Авв. 81в rot markiert) wird in der dritten Gruppe von Zickzacklinien fortgesetzt (vgl. b.3). Diese beiden Ausdrücke liessen sich nicht lokalisieren. Der Schluss von Q 36:67 liess sich nicht lokalisieren. Drei Begriffe davor nicht entziffert.

327 Aufrecht stehend. Es schliessen sich zwei Zeilen an, die auf dem Kopf stehen; nicht entziffert.

328 Der Anfang von Q 5:23 liess sich nicht lokalisieren.

329 Die drei anschliessenden Begriffe unterhalb der drei folgenden Zickzack-Zeilen. 
b.3: In der dritten Gruppe von drei Zickzacklinien steht folgender Text:

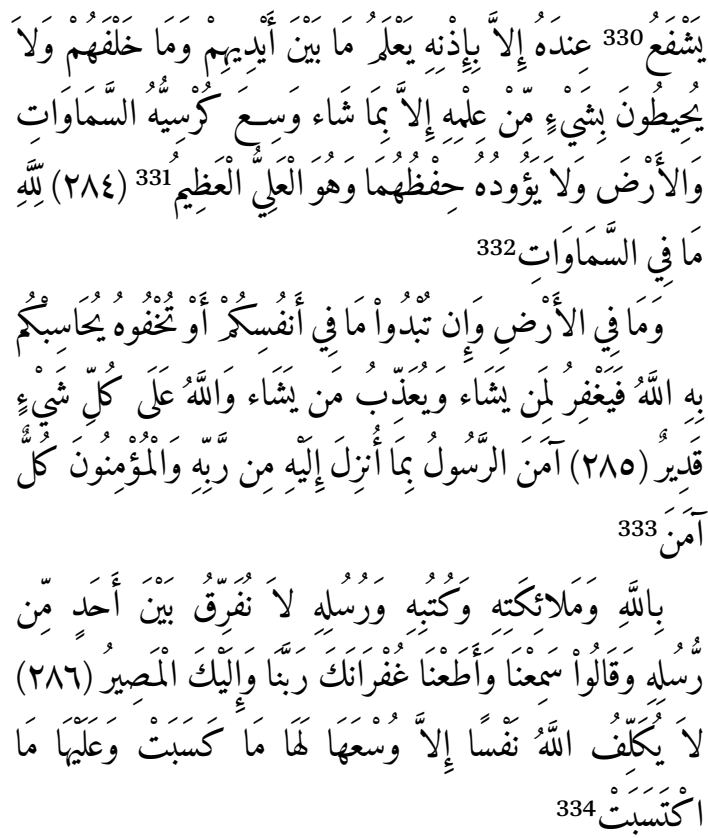

b.4:

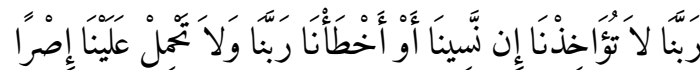

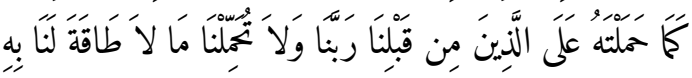

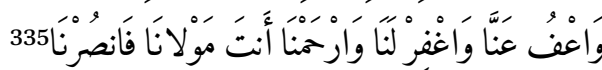

33 Fortsetzung der Abschrift von Q 2:255 (auf Авв. 81в rot markiert); der Begriff yašfáu wird wiederholt.

331 Ende Q 2:255 (auf Ав в. 81в rot markiert); der Text steht ganz links aussen auf der obersten Zeile dieser dritten Gruppe von Zickzacklinien. Unmittelbar danach schliesst sich eine Abschrift von Q 2:284-286 an (auf АВ В. 81B rosarot markiert).

332 Zeilenumbruch; Fortsetzung auf der nächsten Zickzacklinie rechts.

333 Zeilenumbruch; Fortsetzung auf der nächsten Zickzacklinie rechts.

Die Abschrift von Q 2:286 (auf Авв. 81в rosarot markiert) wird in der vierten Gruppe von drei Zickzacklinien fortgesetzt (vgl. gerade anschliessend bei b.4, bei Anm. 335).

335 Hier Zeilenumbruch; Fortsetzung auf der nächsten Zickzacklinie rechts.

$$
\text { ياهيا شراهيا. }
$$

Der weitere Text $(\dot{G} u b \bar{a} r)$ im zweiten Teil dieses Abschnitts verläuft in unterschiedlichen Richtungen; er ist um die einzelnen Zierelemente herum angeordnet. Mehrere Textelemente liessen sich identifizieren. Die folgenden Farbangaben beziehen sich auf die Markierungen auf Авв. 81в.

Gelbe Markierung (unterhalb der einzelnen Verzierung mit blauem Hintergrund in der Mitte): Q 112 (ohne Basmala), auf kurzen vertikalen Zeilen von rechts nach links kopiert; die letzten beiden Begriffe dann nach einem Sprung zurück auf der Zeile rechts aussen (АВВ. 81).

Graue Markierung: die Stelle befindet sich links aussen, unterhalb der zweituntersten Gruppe von zwei blauen Verzierungen; der Text verläuft diagonal nach links absteigend: Q 59:23. ${ }^{338}$

Violette Markierung: die Stelle befindet sich auf derselben Höhe wie die zuvor identifizierte Passage aus Q 59:23 mit der grauen Markierung; sie beginnt unterhalb des rechten Zierelements mit blauem Hintergrund: Q 61:14 (Schluss; violette Markierung). ${ }^{339}$

$336 \quad$ Hier endet Q 2:286.

337

338

Der Schluss dieser Stelle liess sich nicht entziffern.

Q 59:23 lautet (Begriffe in runden Klammern auf der Rolle hinzugefügt):

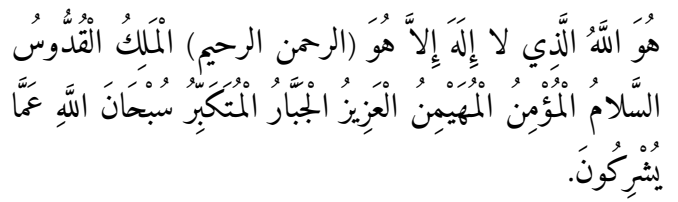

Q 61:14 lautet (auf der Rolle liess sich nur der Schluss lokalisieren):

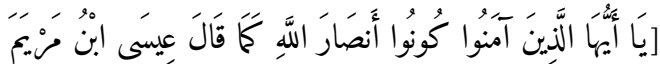

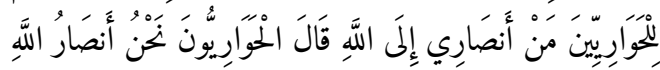

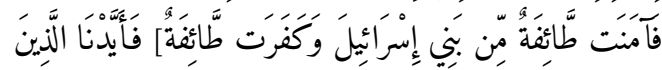

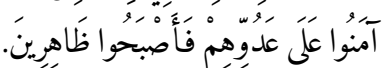


Gelbe Markierung (die Stelle schliesst direkt an den Auszug aus Q 61:14 an): Q 2:250 (Schluss) und Q 3:147 (Schluss). ${ }^{340}$

Türkisfarbene Markierung, in der Mitte, gerade unterhalb der letzten einzelnen Verzierung mit blauem Hintergrund: Q 11:55 (Schluss)-11:56. 341

Braune Markierung (die Stelle beginnt auf derselben Höhe wie Q 11:55-56, blau markiert, ganz rechts aussen; sie verläuft diagonal nach links unten); folgender Text liess sich entziffern: ولا

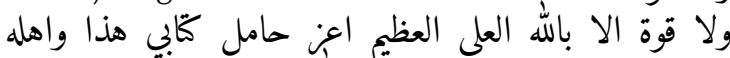

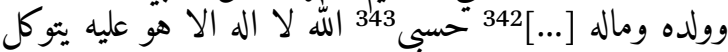

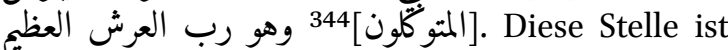
insofern relevant, als sie Gott bittet, den Träger dieses Schriftstücks, seine Familienangehörigen, Kinder und seinen Besitz zu erhöhen. Der Name des Trägers der Rolle wird hier allerdings nicht aufgeführt.

Dunkelblaue Markierung (Stelle direkt unterhalb der untersten blauen Verzierung, links): Q 68:1.345

Dunkelgrüne Markierung (Stelle in der Fortsetzung der Diagonalen links aussen): Q 53:1. ${ }^{346}$

340 Q 2:25o (Schluss) und 3:147 (Schluss; Anfang gegenüber Q 2:250 abweichend) lautet:

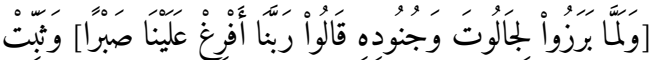

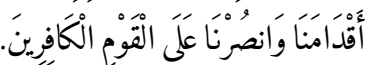

Q 11:55-56 lautet:

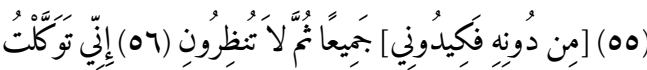

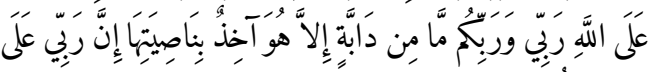

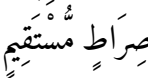

Fortsetzung bzw. Übergang zur nächsten Texteinheit unklar.

Dieser zweite Teil nach einem unklaren Übergang direkt zwischen den beiden untersten Verzierungen mit Blatt auf blauem Hintergrund.

Ausdruck fehlt auf der Rolle.

Q 68:1 lautet:

$$
\text { نَ وَالْقَلََ وَمَا يَسْطُوُونَ. }
$$

Direkt anschliessend allenfalls: والقران المجيد والطور (Entzifferung offen).

346 Q 53:1 lautet:
Es war zwar möglich, in diesem Abschnitt zahlreiche weitere Stellen zu entziffern. Die unregelmässige Anordnung dieser Textelemente in $\dot{G} u b \bar{a} r$ stellt aber eine grosse Herausforderung dar. Dem Kopisten dürfte aber stets klar gewesen sein, welche Stellen er kopierte. Bei den identifizierten Stellen handelt es sich häufig um Auszüge aus dem Koran; die Zitate beschränken sich zumeist auf ganz kurze Passagen. Auch sind immer wieder Anrufungen Gottes eingestreut. Ausserdem lassen sich weitere Elemente frommen Inhalts feststellen. Diese Übersicht legt nahe, dass der Kopist ein Netz oder einen Teppich anfertigte, der sich aus Passagen frommen Inhalts zusammensetzt. Wenn diese einzelnen Passagen auch keinen zusammenhängenden Text bilden, tragen sie doch zur Gestaltung und Schutzwirkung dieses Abschnitts bei. Das Einhalten der gestalterischen Erfordernisse, also das Ausfüllen des vorgegebenen Musters, ist in diesem Abschnitt, gegenüber einer inhaltlichen Stringenz von höherer Bedeutung. Diese Prävalenz gestalterischer gegenüber inhaltlichen Aspekten lässt sich auf den untersuchten Dokumenten in Rollenform immer wieder beobachten und wird deshalb hervorgehoben.

c. Der Text auf diesem Abschnitt mit der Überschrift Du'ā' mubārakmustağāb lässt sich erst wieder ganz am Schluss mit Leichtigkeit lesen. Diese sieben Zeilen wurden in normal grossem Nash kopiert:
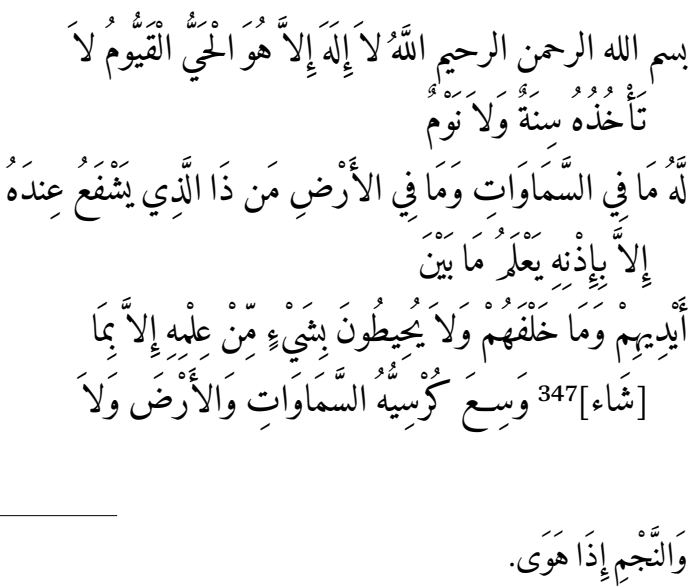

Davor eine kurze Zeile nicht mit Sicherheit lesbar. 347 


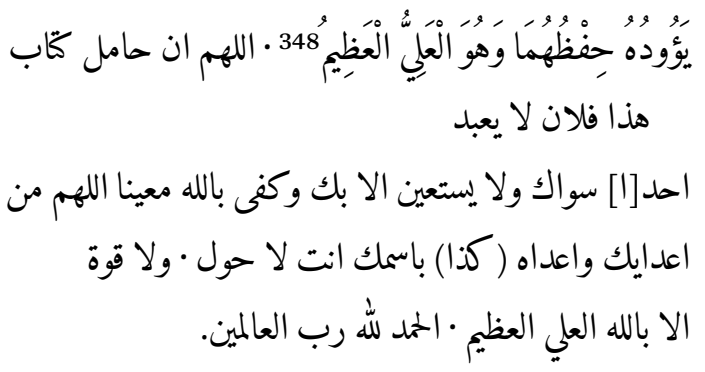

Fạ̣l Âyat (sic) al-hars ${ }^{349}$ („Vorzüge der Schutzverse ${ }^{\prime \prime} .{ }^{350}$ Titel in weisser Schrift im oberen Bogen eines an beiden Enden abgerundeten Rechtecks (Länge ca. $35.6 \mathrm{~cm}$; inkl. dreiteiliges Schriftband; unten der Titelbalken des nächsten Abschnitts). Im Rechteck lassen sich vier Abschnitte unterscheiden. Zumeist dominieren darin Figuren mit Stellen in $\dot{G} u b \bar{a} r$ :

a. Zuoberst steht eine horizontale Zeile mit Text

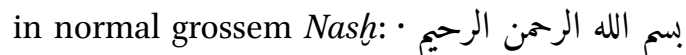
. وصلى الله على سيدنا محمد. Darauf schliessen sich die drei geometrisch angeordneten Abschnitte mit Stellen in $\dot{G} u b \bar{a} r$-Schrift an:

b. Ein Quadrat (Seitenlänge ca. $5.8 \mathrm{~cm}$ ), in dessen Ecken je eine nach der Ecke hin geöffnete Sichel eingepasst ist. Im Leerraum der Sichel eine sechsblättrige goldene Blüte. Die Leerräume zwischen den einzelnen Sicheln sind mit Text in $\dot{G} u b \bar{a} r$ ausgefüllt. Die Zeilen verlaufen hier parallel zu den jeweiligen Seitenlinien des Quadrats. Der Text verläuft links und rechts somit vertikal (ab- bzw. aufsteigend); unten steht er auf dem Kopf. Nur oben ist der Text normal ausgerichtet.

c. Langer Abschnitt (ca. $19.8 \mathrm{~cm}$ ) mit $4 \times 13$ auf der Spitze stehenden Quadraten, die durch jeweils fünf Zeilen Text in $\dot{G} u b \overline{a r}$ gebildet werden. In der Spalte rechts aussen sind die Zeilen in den Quadraten von rechts oben nach links unten

348 Q 2.255 (Thronvers).

349 Abb. 9 der Rolle unter http://www.e-manuscripta.ch/ bau/content/pageview/837976.

$35^{\circ} \mathrm{Zu}$ den Ayāt al-hars [wa-l-harz] siehe Canaan, Decipherment 131 (mit Anm. 39). Der Ausdruck àya steht auf der Rolle im Singular; es sind allerdings mehrere Schutzverse bekannt, die bei T. Canaan auch zusammengestellt sind. ausgerichtet. In den drei weiteren Spalten verläuft der Text von rechts unten nach links oben. Die Dreiecke entlang den Aussenkanten sind mit goldenen Zierpunkten mit einem roten Tupfer versehen. In den leeren Quadraten im Innern des Abschnitts: sechsblättrige goldene Blüte mit rotem Zierpunkt. Vor dem folgenden Abschnitt ein schmaler Zierbalken mit zwei Blattpaaren, deren Gestaltung an die Siyāh-Qalam-Technik erinnert.

d. Dieser Abschnitt ist wie b. gestaltet. Schrift etwas weniger sorgfältig als im Abschnitt b.

Zum Inhalt a:vgl. oben. ${ }^{351}$ Inhalt b: In diesem Quadrat mit den Sicheln wurden Q 2:255 (Thronvers) und Q 112 (Sūrat al-Ihlāṣ) mehrfach kopiert. Zwischen den beiden oberen Sicheln steht Q 2:255; im Zentrum zwischen den vier Sicheln schliesst sich Q 112 an. Auf der rechten Seite steht zwischen den beiden Sicheln Q 2:255 (Auszug). Zwischen den beiden unteren Sicheln und den beiden Sicheln auf der linken Seite stehen, jeweils von innen nach aussen geschrieben, Q 112 und Q 2:255 (Teil). Der restliche Text im Zentrum zwischen den vier Sicheln stammt aus Q 2:255 und ist mehrfach versetzt angeordnet.

Auch beim Text in den vier Sicheln selbst handelt es sich um Abschriften von Q 2:255 und Q 112. In der Sichel rechts oben beginnt Q 2:255 mit vorangestellter Basmala rechts oben; der Text fährt der äussern Linie entlang und endet auf der zweiten Linie von aussen. Danach schliesst sich Q 112 an. Es folgt den Linien der Sichel entlang eine weitere Abschrift von Q 2:255. In den drei weiteren Sicheln stehen dieselben Texte. Die zweite Stelle mit Q 2:255 im Innern der Sicheln ist hier allerdings mehrfach versetzt angeordnet und folgt zumeist nicht dem Verlauf der Zeilen.

Inhalt d: Das zweite Quadrat am Schluss dieses Rechtecks ist identisch aufgebaut wie sein Pendant am Anfang des Abschnitts (b). Auch hier wurden Q 2:255 und Q 112 kopiert. Zwischen den beiden oberen Sicheln steht in der Mitte absteigend Q 2:255. Zwischen den beiden unteren Sicheln

$35^{1}$ Nach Anm. 350. 
steht in der Mitte aufsteigend ebenso Q 2:255; der Text steht auf dem Kopf. Eine weitere Abschrift von Q 2:255 beginnt zwischen den beiden Sicheln auf der linken Seite und führt nach innen. Ganz in der Mitte steht die Basmala. Danach wird die Abschrift von Q 2:255 fortgesetzt. Auf der rechten Seite folgt Q 112 und am Schluss die Basmala. Auch in den vier Sicheln wurde Q 2:255 kopiert. Der Text folgt aussen den Zeilen entlang der Sichelform. Im Innern sind die Wörter jedoch mehrfach versetzt. Der Schreiber arbeitete hier weniger sorgfältig als im Quadrat am Anfang dieses Rechtecks (b).

Inhalt c: Auch im Abschnitt mit den $4 \times 13$ auf den Spitzen stehenden Quadraten wurde Q 2:255 und Q 112 kopiert. Der Schreiber beginnt in der äussersten Spalte rechts oben mit Q 2:255 (mit vorangestellter Basmala) und steigt in dieser Spalte Quadrat um Quadrat nach unten. Auf Q 2:255 folgt jeweils eine Abschrift von Q 112. In dieser Spalte steht im untersten Quadrat Q 112. Der Kopist springt danach in die oberste Reihe dieser Quadrate und setzt die Abschrift in der zweiten Spalte von rechts fort. Er notiert den Text hier auf den horizontalen Reihen, springt also von der zweiten in die dritte und dann in die vierte Spalte. Danach setzt er die Abschrift in der zweiten Reihe in der zweiten Spalte von rechts fort und steigt Reihe um Reihe nach unten. Auf eine Abschrift von Q 2:255 folgt jeweils Q 112. In der dritten und vierten Reihe von unten fehlt Q 112 jeweils zwischen zwei Stellen mit Q 2:255. Der Kopist schliesst mit zwei Abschriften von Q 112.

Du'ä’ Kunūz al-'arš al-'azīm („Gebet bei den Schätzen des gewaltigen Throns [Gottes“]): ${ }^{352}$ Titel in weisser Schrift in einem Balken mit goldenem und blauem Hintergrund. Text in normal grosser Schrift auf 47 horizontalen Zeilen:

$$
\text { دعا كنوز العرش العظيم }
$$$$
\text { لسم الله الرحمن الرحيم •روى عن النبى صلى الله عليه }
$$

$35^{2}$ Abb. 10 der Rolle unter http://www.e-manuscripta.ch/ bau/content/pageview/837977.

$$
\begin{aligned}
& \text { وسلم انه كان قاعداً بعد الضحر353 اذ نزل عليه جبريل } \\
& \text { عليه السلام فقال يرسول } \\
& \text { ربك يقريك (؟) السلام وقد اهدى اليك هديه من } \\
& \text { الفردوس الاعلى ثم ان جبريل }
\end{aligned}
$$$$
\text { قرا هذا الدعا وقال • يرسول }
$$$$
\text { واسمه }
$$$$
\text { ه كنوز العرش ما نزل على بنى قبلك ولا يعلم احد ثواب }
$$$$
\text { هذا الدعا الا الله فقال }
$$$$
\text { ولو كان جميع البحار مداداً والاشجار اقلاماً والملايكة }
$$<smiles>C1CC[As]C1</smiles>

والجن كخابا من اليوم المي يوم تقوم الساعه لعجزوا

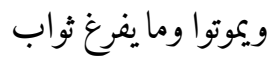

• هذا الدعا ومن قرا هذا الدعا في عمره مره يقوم من

$$
\text { قبره يوم القيمه ووجهه }
$$

مثل البدر ويتحيرون الخلايق من نور وجهه ويقولونه ونهون

$$
\text { فهذا ایى نبى }
$$

• ا من الانبيا فينادون الملايكه ما هذا بنى انما هو عبد من

عباد الله

$$
\begin{aligned}
& \text { تعالى قرا دعا كنوز العرش فُصل له بهذه المنزله } \\
& \text { وينادى المنادى تفتح }
\end{aligned}
$$

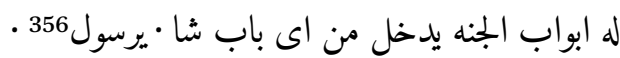

الله

$$
\begin{aligned}
& \text { من قرا هذا الدعا يكون يوم القيمه تحت ظل العرش · } \\
& \text { ويسهل الله عز وجل } \\
& \text { عليه الحساب · ويعطيه كَّابه بيمينه (؟) ويطهره من } \\
& \text { الذنوب والخطايا ثم يغفر }
\end{aligned}
$$

Wohl zu korrigieren in بعد الظهر زلأ. Für يا رسول الله

Siehe vorangehende Anm.

Hier klar ya-rasūl Allāh; siehe vorangehende Anm. 
من اهل بيته واقاربه سبعين نفراً •ويعبر على الصراط مثل البرق الخاطف

يا محمد من قرا هذا الدعا فرّ الله غمه وان كان مريضاً عافاه الله تعالى وان كان عليه دين قضاه الله تعالى وان طل (ضل) عن

$$
\text { طريق فى سفره هداه }
$$

الله الم الطريق · ومن قرا هذا الدعا بنيه صافيه صالحه فان الله

يقضى له كل حاجه في الدنيا والآخره ومن لا يعرف .

$$
\text { يقر المنية (؟) }
$$

ويعلّّه ومن يكون له حاجه دنياويه او اخرويه يصلى

$$
\text { اربع ركعات بنيه صافيه }
$$

ويقرافى الركعه الاولى سوره الفاتحه مره • وقل يا ايها

الكافرون

ثلث مرات وقل هو الله احد والمعوذتين ثلث مرات

$$
\text { وبعد السلام يقرا }
$$

هذا الدعا باخلاص ونام ويوضع الدعا على مخدته (؟) قضى الله تعالى حاجته

يرسول الله ومن قرا هذا الدعا بنيه صافيه كتب الله

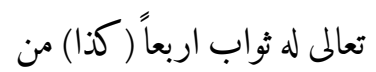

الانبيا واربع من الملايكه فاولمم من الانبيا انت يا محمد

$$
\text { وموسى وعيسى }
$$

وابرهيم عليهم السلام ومن الملايكه انا يرسول الله

$$
\text { وميكايل واسرافيل وعزرايل }
$$

ومن قرا هذا الدعا غفر الله ما تقدم من ذنبه وما تاخر

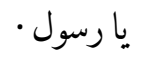

الله لا نعلم (كذا، يعلّم) هذا الدعا للمنافقين فانهم اذا

$$
\text { قراوه وطلبوا من للله حاجه ودخول }
$$

الجنه فان الله تعالم يقضيها ببركه هذا الدعا يا محمد من

$$
\text { قراه في عمره مره }
$$

r. م واحده فان الله ينصره في الجهاد والسفر والحظر

$$
\text { ويحفظه من كل بلاء }
$$

وان فزع من الشيطان · ومن علق عليه هذا الدعاثم

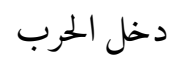

اعطاه الله تعالى قوه سبعين رجلا وظفره الله تعالى

$$
\text { باعدايه ·ومن }
$$

وقع فى يد ظالم او يكون مجبوسا يقرا هذا الدعا خاصه

خلصه الله تعالى

ومن كان به صرعا علق عليه بها يبرا باذن الله تعالى •

$$
\text { وان كان مريضا }
$$

او سقيما شفاه الله تعالى ببركم هذا الدعا • وان كان

$$
\text { غايبا رجع }
$$

الى وطنه سالماً وان شا الله تعالى طوّل عمره ومن لم

$$
\text { يعرف قدر هذا }
$$

الدعا فهو زنديق ويبرى الله تعالى عنه وال (؟) وبميع

ملايكته وقال •

امير المومنين على ابن ابى طالب كرم الله وجهه كنت

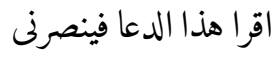

ro

الله تعالى على اعدائي وقال • النبى صلى الله عليه وسلم

$$
\text { مانزل }
$$

F.

$$
\text { يعرف قدر هذا }
$$

الدعا لان اسم الله تعالى الاعظم مكتوب فيه وقال

$$
\text { جبريل عليه السلام }
$$

$35^{8}$ Sufyān at-Tawrī, ein prominenter Gelehrter auf den Gebieten des Rechts, der sunna und des tafsìrs, lebte 97-161/716-778; siehe zu ihm Raddatz, Sufyān athThawrī, in $E I^{2}$. 


$$
\begin{aligned}
& \text { اذا اصاب احد من مصيبه من الجن يكتبه بمسك } \\
& \text { وزعفران ويغسله ويشرب ماءه } \\
& \text { يبرأ باذن الله تعالى ومن ابتلي بالجذام يعلق عليه هذا ونساء }
\end{aligned}
$$

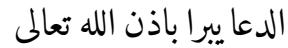

$$
\begin{aligned}
& \text { يا محد من قرا هذا الدعافى السنه مره واحده او فى شهر لهاتي } \\
& \text { مره واحده غفر الله } \\
& \text { تعالى له ذنوبه وقضى حوايجه ولو كانت مثل زبد البحر } \\
& \text { وعدد النجوم وقطر } \\
& \text { الامطار · ونبات الارض ولا يخرج من الجنه حتى ولى } \\
& \text { يرى مكانه في الجنه } \\
& \text { واذا دخل الجنه يكون تحت ظل العرش وهو } \\
& \text { هذا الدعا }
\end{aligned}
$$

Nach Zeile 47 endet das Rechteck mit der Überschrift Hāda d-Du'â' Kunūz al-'arš al-'azìm. Der soeben transkribierte Text enthält Hinweise zu den Umständen unter welchen das Gebet offenbart worden ist und gegen welche Schwierigkeiten es nützlich ist. Am Schluss dieses Rechtecks findet sich die Überleitung zum Gebet selbst mit dem Satz وهو هذا الدعا. Die beiden Begriffe Hāda d-du'a in weisser Schrift sind golden eingefasst und befinden sich in einem Balken, der teilweise einen roten Hintergrund aufweist. Aus dieser Überleitung geht hervor, dass der Text des Gebets erst im Abschnitt danach folgt (Länge ca. $35 \mathrm{~cm}$ ).

Dieses Gebet (АВВ. 82), es soll den Grössten Namen Gottes enthalten, wurde in $\dot{G} u b \bar{a} r$ notiert. Der Text wurde in eine Figur eingepasst, die durch ineinander verschlungene Textbahnen entsteht. Man kann darin auch zwei Serien von je fünf gegeneinander versetzten mandelförmigen Figuren erkennen. Die erste Serie von fünf Figuren wird durch die zweite Serie unterteilt. Der Hintergrund der Leerräume ist zumeist blau und mit pflanzlichen Verzierungen in goldener Farbe versehen. In den beiden Leerräumen zuoberst und zuunterst eine einfache Verzierung (Blätter), die an die Siyāh-Qalam-Technik erinnert. Dies trifft ebenso auf den Leerraum in der Mitte dieser Abfolge von sich überschneidenden mandelförmigen Figuren zu. Die Siyāh-Qalam-Technik wird mit dem 14. und 15. Jh. in Verbindung gebracht. ${ }^{359}$ Der Hintergrund der Leerräume zwischen dem rechteckigen Rahmen und den Schriftbändern im Innern ist blau. Darin pflanzliche Verzierungen, deren Stiele und Blätter goldig und deren Blüten rot sind (vereinzelt umgekehrt). Rote Farbe stellenweise verloren.

In diesen schlangenförmig angeordneten bzw. mandelförmigen Figuren bildenden Schriftbändern wurde der Gebetstext in $\dot{G} u b \bar{a} r$-Schrift angeordnet. Der Verlauf der Bänder gibt die Leserichtung vor. Innerhalb der Bänder ist der Text quer zu deren Verlauf auf kurzen Zeilen angeordnet. Nicht restlich klären liess sich die Frage, wo das Gebet beginnt. Gewiss ist, dass sich in der oberen rechten Ecke des Rechtecks eine Abweichung vom allgemeinen Vorgehen des Kopisten auf diesem Abschnitt feststellen lässt. Hier steht dem äussern Rand der obersten mandelförmigen Figur entlang absteigend Q 112; am Schluss der Stelle wird die Basmala wiederholt. Zur Linken des obersten Elements mit einer Verzierung in einer Art Siyāh Qalam-Technik lässt sich absteigend folgender Text erkennen: بسم الله الرحمن الرحيم الحمد لله رب المابن 年. ${ }^{360}$ Der Text des Gebets beginnt mutmasslich in der linken oberen Ecke und steigt dort zur Linken der Verzierung in einer Siyāh Qalam-ähnlichen Technik nach unten. Die erste Stelle lautet:

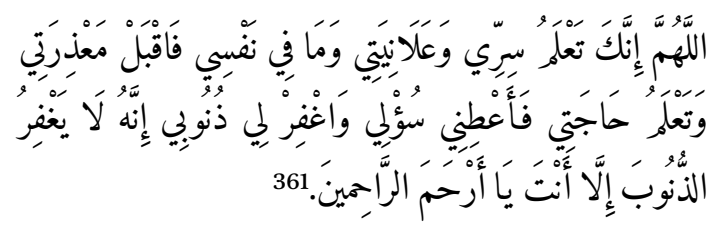

359 Zur Siyāh-Qalam-Technik siehe O'Kane, Siyah-Qalam, in EIr; vgl. auch vor Anm. 208 und 209.

36o Der Text dieses Gebets lässt sich mit Abweichungen nachweisen bei al-Kaf'amī al-Balad al-amīn wa-d-dir' al-hașin̄; Druckausgabe: al-Kaf'amī, al-Balad al-amin w-ad-dir' al-hașin 489-494 (Ausgabe Bayrūt, Mu’assasat al-Álamī li-l-Maṭbūāt, 1418/1997; Zürich, Abteilung Islamwissenschaft, PA II a 14). Siehe auch: http://lib.eshia.ir/71565/1/356 (S. 356-361; Stand 27 . Dezember 2016).

361 Vgl. dazu http://lib.eshia.ir/71565/1/357 (Stand 27. De- 
Sie schliesst sich unmittelbar an den auf der rechten Seite von unten aufsteigenden Text an, der auf dem Kopf steht. Es ist festzuhalten, dass der Gebetstext auf der Rolle mit jenem auf den beigebrachten Parallelstellen nicht gänzlich übereinstimmt. Das absteigende Schriftband dreht sich danach langsam nach rechts. Etwas unterhalb jener Stelle, wo ein weiteres, die oberste mandelförmige Figur durchschneidendes Schriftband von rechts oben absteigt, beginnt der Kopist, Allāh kraft des Inhalts der einzelnen Suren anzurufen. Die Stelle befindet sich knapp unterhalb eines Knicks im Papier und lautet:

$$
\begin{aligned}
& \text { واسألك بحق بسم الله الرحمن الرحيم عليك || عليك (كذا) }
\end{aligned}
$$

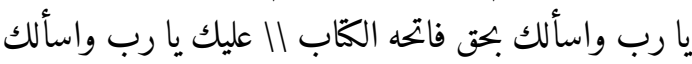

$$
\begin{aligned}
& \text { مق سوره البقره عليك [يا رب] }
\end{aligned}
$$

Danach ruft der Schreiber Allāh der Reihe nach bei allen weiteren Suren an und steigt dem Schriftband folgend nach und nach hinab. Er ist mit der Aufzählung der einzelnen Suren zuunterst allerdings nicht fertig. Er umfährt deshalb im Schriftband die unterste Verzierung, die an die SiyāhQalam-Technik erinnert. Der Text steigt danach auf dem Kopf wieder nach oben. Die Aufzählung der einzelnen Suren endet zwischen den beiden goldenen Verzierungen mit blauem Hintergrund beim oberen Abschluss der untersten mandelförmigen Figur; hier lässt sich zuletzt folgender Text erkennen:

$$
\begin{aligned}
& \text { واسألك بكق سورة الفلق عليك يا رب } \\
& \text { واسألك بسورة قل اعوذ برب الناس } \\
& \text { عليك يا رب واسألك بكق كل آية } \\
& \text { من القران عليك يا رب واسألك } \\
& \text { بكق سورة يونس } 362
\end{aligned}
$$

zember 2016) und Druckausgabe Bayrūt 1418/1997, S. 489 (Zeilen 17-19).

362 Der Rest dieser Zeile liess sich nicht entziffern. Der Kopist überspringt das absteigende Schriftband und fährt danach weiterhin aufsteigend fort.

$$
\begin{aligned}
& \text { يا رب363 واسألك بحق زبور داوود } \\
& \text { عليك يا رب واسألك بكق فرقان محد } \\
& \text { صلى الله عليه وسلم وعليهم اجمعين }
\end{aligned}
$$

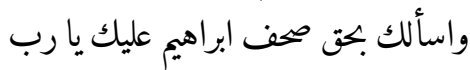

$$
\begin{aligned}
& \text { واسألك بحق موسى عليك يا رب واسألك } \\
& \text { بكق مايه الف نبي توارثوا قوى العرش } \\
& \text { اولمم آدم واخرهم محمد صلى الله عليه } \\
& \text { وسلم عليك يا رب واسألك بكق جبريل } \\
& \text { عليك يا رب واسألك بحق ميكاييل عليك } \\
& \text { يا رب واسألك بكق اسرافيل عليك } \\
& \text { يا رب واسألك بكق عزراييل عليك يا } \\
& \text { رب واسألك بحق حمله العرش عليك } \\
& \text { يا رب واسألك بكت الكروب عليك يا رب } \\
& \text { واسألك بكق العرش عليك يا رب [...] }
\end{aligned}
$$

Die hier auszugsweise festgehaltenen Passagen des Gebets zeigen, dass der Text rund um die Wendung واسألك بكق فلان عليك يا رب aufgebaut ist, die unablässig wiederholt wird. Es folgen später auch Abschnitte, in denen das Gebet Gott kraft jener Namen anruft, mit denen sich die vorislamischen Propheten an Allāh gewandt hatten. In diesem Abschnitt lässt sich immer wieder die Wendung erkennen واسالك بحق الاسم الذي دعاك به فلان. Dies ruft die Angabe in der Einleitung zu diesem Gebet in Erinnerung, wonach der Text auch den grössten Namen Gottes enthalten soll. Da der Text hier in mikroskopischer Schrift kopiert worden ist, ist eine lückenlose Entzifferung des Gebets mit erheblichen Schwierigkeiten verbunden. Bei einem Vergleich mit Druckausgaben des vorliegenden Gebets zeigt sich aber, dass sich auch der weitere Text auf der Rolle eng an die anderweitig belegten Fassungen hält. Der Vollständigkeit

363 Diese Entzifferung ist wahrscheinlich, aber nicht gesichert. 
halber soll hier eine weitere Stelle näher vorgestellt werden: ${ }^{364}$

$$
\begin{aligned}
& \text { اسالك بكق الاسم الذي دعاك به عيسى } \\
& \text { عليه السلام والخبر من الكتاب عليك يا رب ليك ليكي } \\
& \text { واسالك بحق الاسم الذي دعاك به محمد صلى الله عليه } \\
& \text { وسلم حين رفع قاب قوسين عليك يا رب }
\end{aligned}
$$

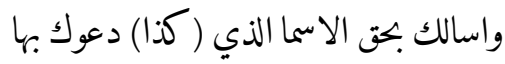

$$
\begin{aligned}
& \text { الانبيا عليهم السلام عليك يا رب اسالك } \\
& \text { بحق الاسم الذي دعاك [به] جميع الانبيا } \\
& \text { والمرسلين عليك يا رب واسالك بحق ليق } \\
& \text { الاسم الذي يرقيه (؟) السما بالاعماد يا رب }
\end{aligned}
$$

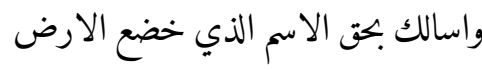

$$
\begin{aligned}
& \text { عليك يا رب365 }
\end{aligned}
$$

Der Text kehrt am Schluss, immer dem Schriftband folgend, zurück zur Stelle, wo das Gebet unmittelbar unterhalb des Titelfelds auch beginnt. Der aufsteigende Text steht weiterhin auf dem Kopf.

Kurz vor dem Schluss lässt sich in der Spitze der obersten mandelförmigen Figur deutlich folgende Stelle erkennen:

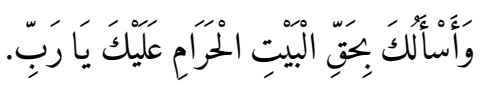

Die drei letzten Zeilen sind ineinander verschachtelt und liessen sich nicht mit Gewissheit entziffern. Der Schreiber beendet aber die Abschrift mit einer senkrecht absteigenden Zeile zur Linken der obersten Verzierung in einer Art Siyāh-QalamTechnik; sie lautet: بم الله الرحمن الرحيم الحمد لله رب لله

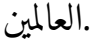

364 Diese Stelle steht auf dem Kopf; sie befindet sich in der obersten mandelförmigen Figur im aufsteigenden Schriftband rechts aussen. Vgl. Abb. 10 der Rolle unter http://www.e-manuscripta.ch/bau/content/pageview/ 837977 .

365 An dieser Stelle Knick im Papier; es bleibt noch ein halber Bogen bis zum Anfang dieses Abschnitts.
Das lückenlose Entziffern dieses Gebets war mit grossen Schwierigkeiten verbunden. Beim Betrachten und Entziffern dieser ineinander verschlungenen Schlangenlinien entsteht der Eindruck, dass man ein Gebet ohne Anfang und Ende vor sich hat, das man endlos weiterlesen kann. Dies ruft in Erinnerung, dass bei frommen Zusammenkünften Gebete oft bis zur Erschöpfung rezitiert werden (vgl. die Dikr-Rezitationen ${ }^{366}$ ).

Nach der Du'ẩ Kunūz al-'arš al-'ażìm folgen sieben weitere Abschnitte. Vier davon (I, II, III und VII in der anschliessenden Übersicht) versprechen dem Träger Nutzen in ganz spezifischen Situationen. Die drei weiteren Abschnitte (IV, V, VI) sollen offensichtlich allgemeiner von Nutzen sein, wie sich aus ihren Überschriften ableiten lässt: ${ }^{367}$ I. $L i$ Ğalb ar-rizq; II. Li-ramy an-nuššāb; III. Li-d-duhūl 'alā s-Sulțān; IV. Du'ấ' li-kull šay'; v. Du'â'-i Muhri nubuwwat; VI. Tahlīl al-Qur'ān wa-l-Ism al-äzam; vir. Du'ä'as-safar.

Auf der Rolle aus Kopenhagen (Cod. Arab. 53) lassen sich ebenso Abschnitte feststellen, die dem Träger der Rolle in ganz spezifischen Situationen Hilfe und Unterstützung versprechen. ${ }^{368}$ Es ist vorstellbar, dass gerade die Abschnitte für die spezifischen Situationen auf der Basler Rolle (Nr. I, II, III und VII in der Übersicht) die bisherige Zuordnung solcher Dokumente ins Umfeld der Magie begünstigt haben. In den Werken Būnīs oder Tilimsānīs finden sich jedenfalls Gebete und Anweisungen zur Herstellung von Schutzmitteln, die gerade für die zuvor angeführten Situationen von Nutzen sein sollen. ${ }^{369}$ Allerdings wird die detaillierte Analyse auch im Fall dieser sieben Abschnitte aufzeigen, dass sie zwar vereinzelt aus der islamischen Magie im engeren Sinn bekannte Elemente aufweisen. Zumeist handelt es sich aber auch beim Inhalt dieser sieben Abschnitte um Textelemente

366 Zu den Dikr-Übungen vgl. Kapitel 3.4.2 bei Anm. 463484 .

367 Abb. 11f. der Rolle unter http://www.e-manuscripta.ch/ bau/content/pageview/837978.

368 Vgl. Kapitel 4.4.

369 Vgl. z. B. Pielow, Quellen der Weisheit 144-149 und 16o166. 
frommen Inhalts (v.a. Koranzitate). Diese Beobachtung legt nahe, dass auch in diesen Fällen eine Erklärung aus der Magie heraus nicht im Vordergrund stehen darf. Die weiteren Ausführungen befassen sich mit den einzelnen Abschnitten:

I. Li-Ğalb ar-rizq (АВ В. 83): 370 Titel in weisser Schrift in einem goldenen Balken; Länge dieses Rechtecks: knapp 24cm (inkl. Titelbalken). Dieser Abschnitt dient der Sicherung des Lebensunterhalts, wie sich aus der Überschrift ableiten lässt. Im Abschnitt selbst lassen sich einerseits textliche Elemente erkennen. Anderseits fällt auf, dass diese Textstellen in unterschiedliche Figuren eingepasst worden sind. Sie werden häufig aus Textstellen in mikroskopischer Schrift gebildet. Bogen und Pfeil ganz am Schluss dieses Abschnitts gehören thematisch zum nächsten Teil der Rolle und werden erst dort behandelt. Der Abschnitt enthält die folgenden Hauptelemente:

a. Zuoberst: zwei horizontale Zeilen mit Text in normal grosser Schrift.

b. Eine erste auf der Spitze stehende Raute, die von fünf Zeilen Text eingefasst wird. Im Innern: eine achsialsymmetrisch aufgebaute pflanzliche Verzierung, deren Ausführung ähnlich aus der Siyāh Qalam-Technik bekannt ist; ihr Hintergrund ist rot schraffiert.

c. Zur Rechten und Linken dieser obersten Raute befinden sich zwei Tropfen mit nach innen gewandter Spitze; sie enthalten Text in $\dot{G} u b \bar{a} r-$ Schrift auf zwei Zeilen (goldener Zierpunkt mit rotem Tupfer). Oberhalb der beiden Tropfen eine goldene, sechsblättrige Blüte; darunter zwei Blüten mit sechs blauen Blättern, die von zusätzlichen goldenen Blättern voneinander getrennt werden.

d. Unterhalb der oberen Raute folgt eine zweite Raute (vgl. Beschreibung unter b.).

e. Die seitlichen Leerräume zwischen oberer und unterer Raute werden durch Textstellen in $\dot{G} u b \bar{a} r$ ausgefüllt. Sie bilden zwei achsialsym-

370 Abb. 11 der Rolle unter http://www.e-manuscripta.ch/ bau/content/pageview/837977. metrisch angeordnete Figuren, die an die Form der Schnäuze erinnern, wie sie von Männern aus dem Bektāšiyya-Orden getragen werden. ${ }^{371}$

f. Auch zuunterst in diesem Rechteck lassen sich zur Linken und Rechten zwei achsialsymmetrisch angeordnete Figuren erkennen, die durch Stellen in $\dot{G} u b \bar{a} r$ gebildet werden. Es könnte sein, dass diese Figuren den Namenszug 'Alı̀ gespiegelt enthalten.

Die weiteren Ausführungen stellen die Textelemente in diesen Verzierungen vor:

a. Zuoberst steht auf zwei horizontalen Zeilen nach der Basmala der Beginn des Thronverses (Q 2:255). Nach illā bi-idni-hī setzt der Kopist die Abschrift in der oberen Raute fort:

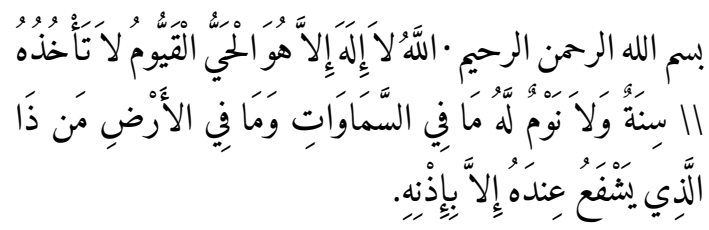

b. Obere Raute: 1. Zeile: Auf der äussersten, nach links absteigenden Zeile steht die Fortsetzung von Q 2:255. Der Text endet nach der ersten Ecke zur Linken mit den Ausdrücken huwa al-'alı̄ al'ažìm:

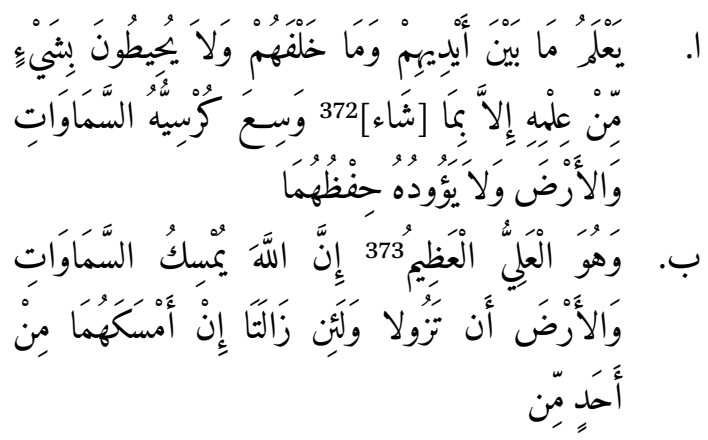

371 Vgl. dazu de Jong, Iconography, Plates 9, 12; aufrufbar unter http://www.islamicmanuscripts.info/reference/a rticles/Jong-1989-Iconography-MME4.PDF (Stand 19. Oktober 2017); vgl. auch bei Anm. 432.

372 Ausdruck fehlt auf der Rolle.

373 Ende Q 2:255 (Thronvers); danach Beginn Q 35:41. 


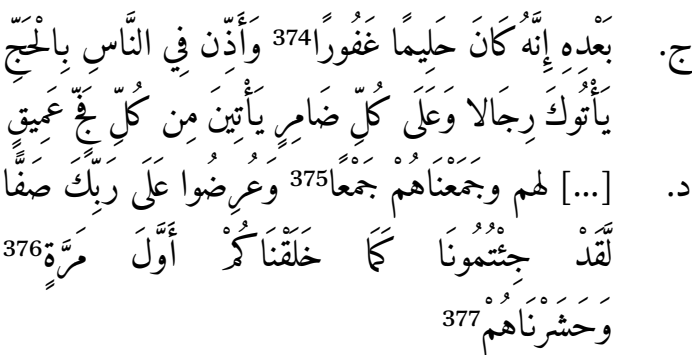

2. Zeile von aussen:

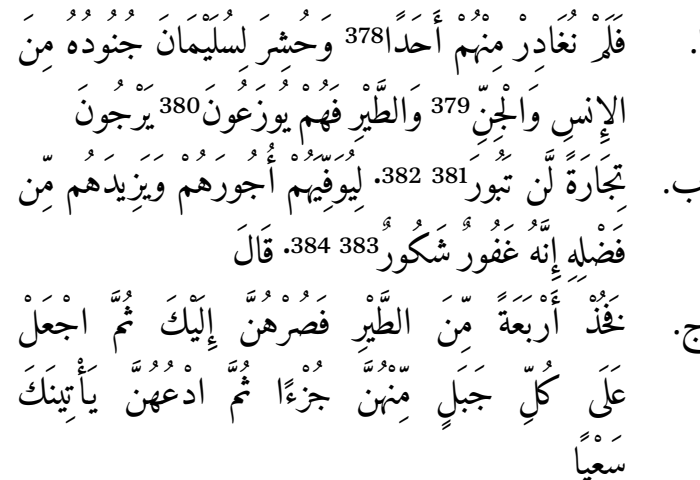

374 Schluss Q 35:41; danaç, , Beginn Q 22:27.

375 Aus Q 18:99: جمعناهم :جم:; danach folgt Q 18:48.

376 Schluss des Zitats aus Q 18:48; der eigentliche Schluss des Verses fehlt auf der Rolle:

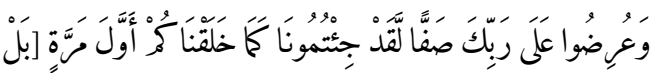

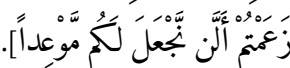

Auf der Rolle schliesst sich hier der Schluss von Q 18.47 (sic) an.

377 Q 18:47b; der Rest des Verses folgt auf der 2. Zeile von aussen, nach links absteigend.

378 Schluss Q 18:47b; es folgt Q 27:17.

379 Abweichung gegenüber Kairiner Ausgabe; vgl. folgende Anm.

380 Schluss Q 27:17; der Korantext liest:

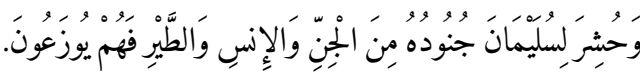

381 Dies der Schluss von Q 35:29; der ganze Vers lautet:

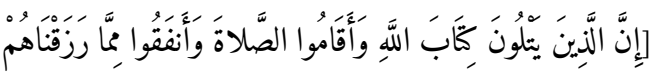

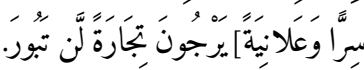

382 Drei rote Zierpunkte; danach Beginn Q 35:3o.

383 Schluss Q 35:30.

384 Drei rote Zierpunkte; danach Beginn Q 35.30; darauf ein Auszug aus Q 2:26ob.

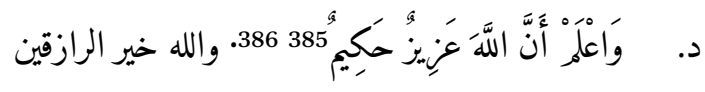

وصلى الله على محد الخختار 387

3. Zeile (grössere Schrift):

$$
\text { ب. }
$$

Die 4. und 5. (innerste) Zeile von aussen in dieser oberen Raute werden hier nicht erfasst.

Zu c.: vgl. nach Buchstaben d.: Bemerkungen zu c., e. und f. ${ }^{389}$

d. Die untere Raute enthält folgenden Text: 1 . Zeile von aussen (Beginn oben, Text nach links absteigend):

$$
\begin{aligned}
& \text { ا. اللهم احبس منطقتهم و[فدّ] انهم عن حامل كّابي هذا }
\end{aligned}
$$

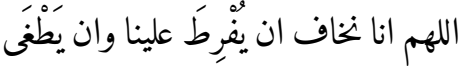

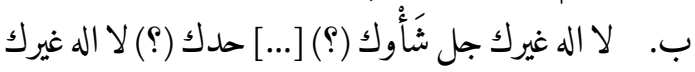

$$
\begin{aligned}
& \text { ولا احد سواك اعزني عليكم ايها الجن والشياطين } \\
& \text { ج. [...] الله [...] بكق هذه الاسما بسوسم } 390 \text { • حوسم · • }
\end{aligned}
$$

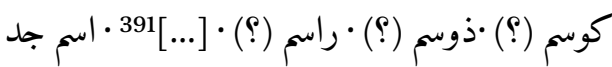

385 Q 2:26o lautet:

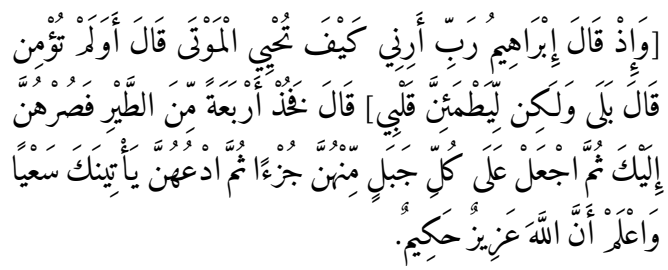

Drei rote Zierpunkte; danach Beginn Q 35:30; darauf ein Auszug aus Q 2.26ob.

Dieser Ausdruck in roter Schrift; er lässt sich nur schwer entziffern.

Dieser Ausdruck in roter Schrift.

Abschnitt vor Anm. 400.

Nach dem Namen: ein roter Punkt.

391

Unleserlich, da Knick im Papier. 


$$
\begin{aligned}
& \text { د. بجلب (؟) كاهن ابن كاهن يوكل [...] بعزه الله وقوته } \\
& \text { وجلاله يعقد السنتهم [...] }
\end{aligned}
$$

2. Zeile von aussen:

$$
[? \ldots] \quad . \quad .
$$

ب. اللهم اعيذ حامل [كتابي] هذا من كل شر وانصره على

$$
\text { من عاداه وناوأه اللهم من اراد به كيداً فكده [...] }
$$

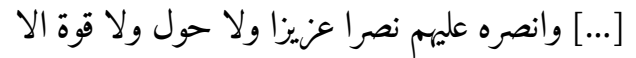

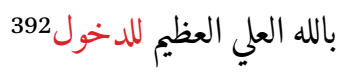

د. على الجائز بسم الله الرحمن الرحيم والنجم كل ما ردّ لمّيم

$$
\text { بقدرته وبركته وخضع كل ذي سطؤة }
$$

3. Zeile von aussen (grössere Schrift):

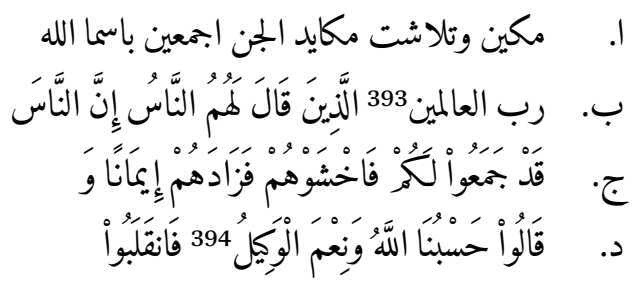

4. Zeile von aussen:

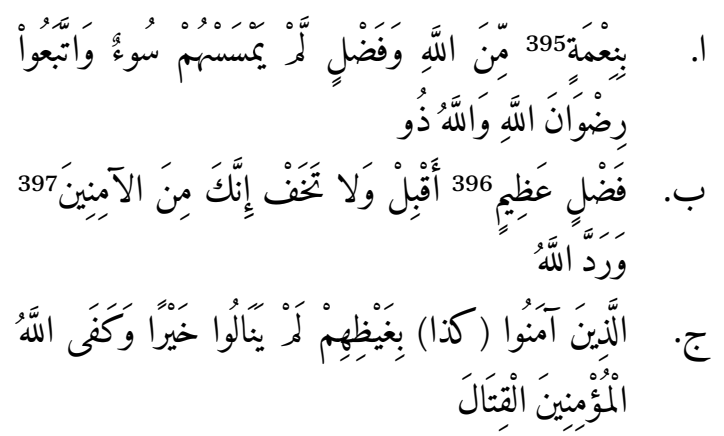

392 Dieser Ausdruck in roter Tinte.

393 Danach Beginn von Q 3:173 und später Q 3:174.

394 Schluss Q 3:173, Anfang Q 3:174.

395 Fortsetzung Q 3:174.

396 Schluss Q 3:174.

397 Schluss von Q 28:31:

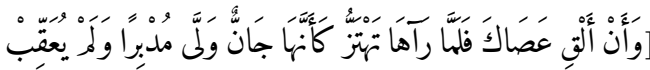

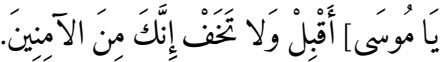

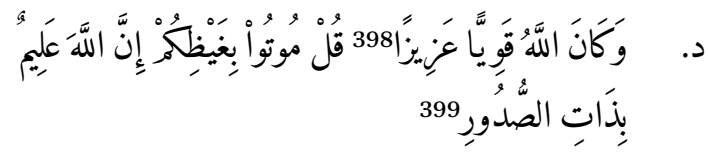

5. Zeile von aussen (innerste Zeile):

$$
\text { د. }
$$

Bemerkungen zu c., e. und f.: Die restlichen Figuren mit Stellen in $\dot{G} u b \bar{a} r$ enthalten Wiederholungen von Q 112: Die beiden Tropfen zuoberst: je vier Abschriften von Q 112; das erste Mal mit, danach ohne Basmala. Wiederholungen von Q 112 ebenfalls in den beiden spiegelsymmetrisch angeordneten Figuren zur Linken und Rechten zwischen den beiden Rauten. Auch die beiden Figuren zur Linken und Rechten gerade unterhalb der zweiten Raute bestehen aus Wiederholungen von Q 112.

II. Gemäss der Überschrift Li-ramy an-nušš $\bar{a} \boldsymbol{b}$ (Авв. 84) ${ }^{400}$ enthält der nächste Abschnitt Elemente, die Erfolg beim Schiessen mit Pfeil und Bogen verheissen. Oberhalb und unterhalb dieses Titelbalkens befindet sich je eine Abbildung von Pfeil und Bogen, in die Textelemente und Buchstaben integriert sind. Die beiden Bögen sind unterschiedlich ausgerichtet; sie zielen nach oben bzw. unten. Der obere Bogen ist in das Rechteck integriert, das zum Abschnitt mit der Überschrift $\mathrm{Li}^{-}$ Ğalb ar-rizq gehört. Diese doppelte Ausrichtung könnte bedeuten, dass der Abschnitt dem Träger Schutz nach allen Richtungen verleiht.

398 Q 33:25 mit Abänderung von kafarū in āmanū (Kopistenfehler?); der Vers lautet in der Kairiner Ausgabe:

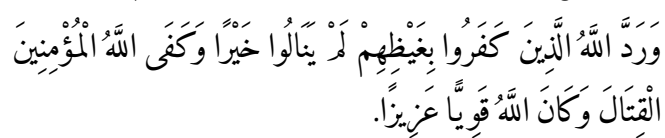

399 Q 3:119 (Schluss).

400 Abb. 11 der Rolle (Mitte) unter http://www.e-manuscri pta.ch/bau/content/pageview/837978. 
1. Die folgenden Ausführungen gehen in einem ersten Schritt auf die im Bogen enthaltenen Elemente ein; sie tun dies anhand des unteren Bogens, der sorgfältiger gestaltet wurde:

1.1 Zeile mit Einzelbuchstaben, unverbunden; ${ }^{401}$ sie sind entlang der Sehne des Bogens angeordnet: Auszug aus Q 8:17;402 die Stelle schreibt die Verantwortung für das Handeln des Schützen Allāh zu. Allāh allein ist für den Erfolg des Schützen verantwortlich. Der Vers entlastet den Schützen aber zugleich, wenn er durch sein Handeln Menschen tötet oder schwer verletzt.

Es schliesst sich eine Buchstabenfolge an (teilweise mit Trennpunkten zwischen den

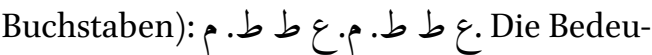
tung dieser Zeichen liess sich nicht ermitteln. Eine ähnliche Abfolge von Einzelbuchstaben zur Rechten und Linken des Pfeils (vgl. Ziffer 1.4 gerade anschliessend).

1.2 Dem Bogen entlang Auszug aus Q 17:1. ${ }^{403}$

1.3 Im Bogeninnern steht unterhalb der Sehne (horizontal): ولا حول ولا قوة || الا بالله العلى العظيم.

1.4 Im Bogeninnern steht zur Linken und Rechten des Pfeils (senkrecht) die Buchstabenfolge: (?) ( )

1.5 Zur Rechten und Linken des Pfeils, nahezu an dessen Spitze, stehen die beiden Buchstaben 'ayn und mim. Der rote Strich des Pfeils dazwischen könnte als alif interpretiert wer-

401 Zur Verwendung von unverbundenen Buchstaben vgl. Canaan, Decipherment 152. Das Notieren von Text in unverbundenen Buchstaben soll den Schutzcharakter eines Talismans erhöhen.

Q 8:17 lautet (der Text in eckigen Klammern fehlt auf der Rolle):

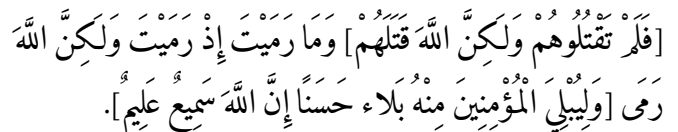

Q 17:1 lautet:

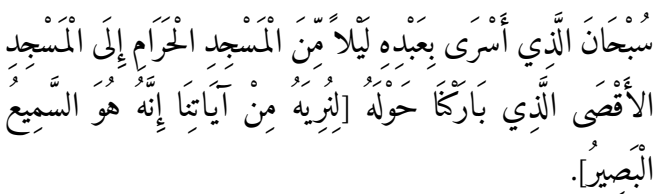

den. Diese Buchstaben könnten für Muḥammad (mìm), 'Alī ('ayn) und Allāh (alif) stehen. ${ }^{404}$

2. Unterhalb dieser Abbildung von Pfeil und Bogen lässt sich links und rechts ein identisches, aus Text in $\dot{G} u b \bar{a} r$-Schrift aufgebautes Zierelement erkennen. Beim Betrachten meint man wiederholt, dass diese Figuren einen konkreten Gegenstand darstellen: a. Die Figuren erinnern einerseits an die Standarten, die auch heute noch bei den 'ĀšūrāProzessionen mitgetragen werden; b. In der unteren Hälfte meint man, den Namen 'Alī zu erkennen, der spiegelsymmetrisch angebracht worden wäre. ${ }^{405}$ Diese Interpretationen sind einstweilen nicht gesichert.

Gewiss ist aber, dass diese beiden Figuren aus Abschriften von Q 112 (Sūrat al-Ihlāss, mit und ohne Basmala) in $\dot{G} u b \bar{a} r$-Schrift zusammengesetzt sind. Soweit ersichtlich ist der Text in der Figur rechts 14 Mal enthalten.

3. Obere Raute: Der Text beginnt mit den beiden roten Ausdrücken an der Spitze; er verläuft dann im Gegenuhrzeigersinn zuerst auf der äussersten Zeile. Zurück an der Spitze springt der Kopist auf die nächste Zeile nach innen:

(3.) 1. Zeile von aussen (Beginn mit den beiden roten Ausdrücken):

404 Vgl. zu dieser Interpretation Karamustafa, Extremist Shiites Ixf.: „Transcending this multi-denominalism is [the] common belief [of the members of these Ghulat sects] in the apotheosis of Ali (d. A.D.661) and in a trinity of God [Allah (T.N.)], Muhammad, and Ali (or, as among the Nusayris of Ali, Muhammad, and Salman al-Farisi).“ Diese Ǵulät-Gruppierungen werden S. IX unmittelbar vor der zitierten Stelle präzisiert. Es handelt sich um die Ahl-i Ḥaqq (bzw. 'Alī-Ilāhīs aus Iran). Im Iraq sind diese Kreise als Šabak, Bāğwān, Șārliyya, Kākāiiyya und Ibrāhimiyya bekannt. In Syrien wiederum handelt es sich um die Nuṣayrier (Alawiten). Und in der Türkei sind es die Bektāšīs, Qizilbāš (Alawiten), Tahtağīs und Çepnīs. Siehe zu den Implikationen dieser Auffassungen v. a. unten Abschnitt mit Anm. 481-483 („Schlussfolgerungen“).

Vgl. de Jong, Iconography, Plates 8, 12; aufrufbar unter http://www.islamicmanuscripts.info/reference/a rticles/Jong-1989-Iconography-MME4.PDF (Stand 19. Oktober 2017). 
ا. قبول رحت 406 بسم الله الرمن الرحيم الملك القدوس

السلام المومن المهيمن العزيز الجبار المتكبر سبحان الله

$$
\text { عما يشركون }
$$

ب. اللهم احبس عنى كيد كل ذى كيد 407 وشر كل ذى

شر وكل قلب قاسٍ لينه لى واعطفه كما اعطفت

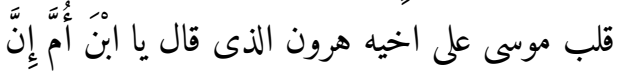

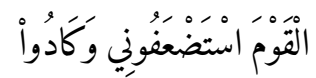

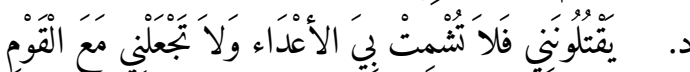

الظَّلمين 408 وسيكنى حامل كنّابى هذا وهو السميع

$$
\text { العليم.409 }
$$

(3.) 2. Zeile von aussen:

ا. العليم اهى 410 اهى اهى اهى اهى هوه هوه هوه هوه هوه

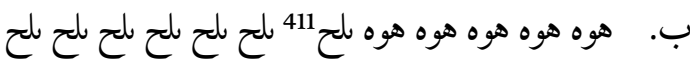

لح شفا شفا

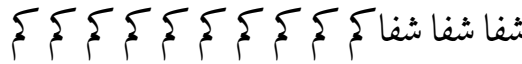

د. الم كم كميا من بيده مفاتح الغيب لا يعلمها الا هو 412

$$
\text { ويعلم ما في السموات }
$$

406 Man beachte die persische Syntax: Qawl-i rahmat.

407 Bruch im Papier.

408 Aus Q 7:150:

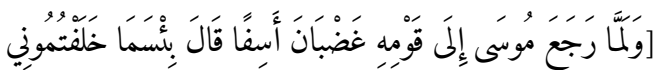

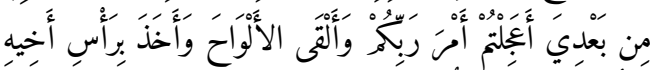

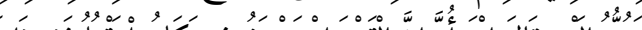

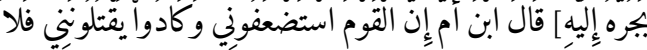

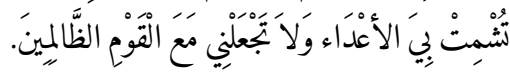

409 Letzter Ausdruck al-'alīm bereits auf der nächsten Zeile nach innen.

Die Entzifferung dieses Elements ist nicht gesichert.

Es folgt hier ein speziell geschriebener Begriff, der acht

Mal wiederholt wird; die Buchstaben hängen darin sozusagen übereinander.

412 Anlehnung an Q 6:59:
(3.) 3. Zeile von aussen:

$$
\text { د. }
$$

(3.) 4. Zeile von aussen (am Anfang ein Begriff rot):

ا. للهارب414 يكتب على ورقة وبخط يجب حمله بنفسك

ب. له [...] ويرجع باذن الله تعالى 415 بسم الله الرحمن

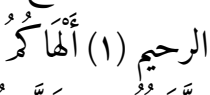

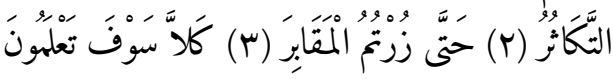
约

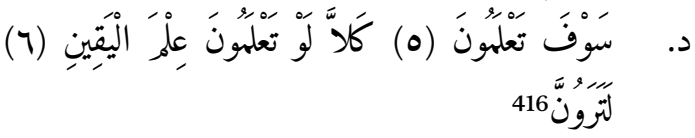

(3.) 5. Zeile von aussen, also innerste Zeile:

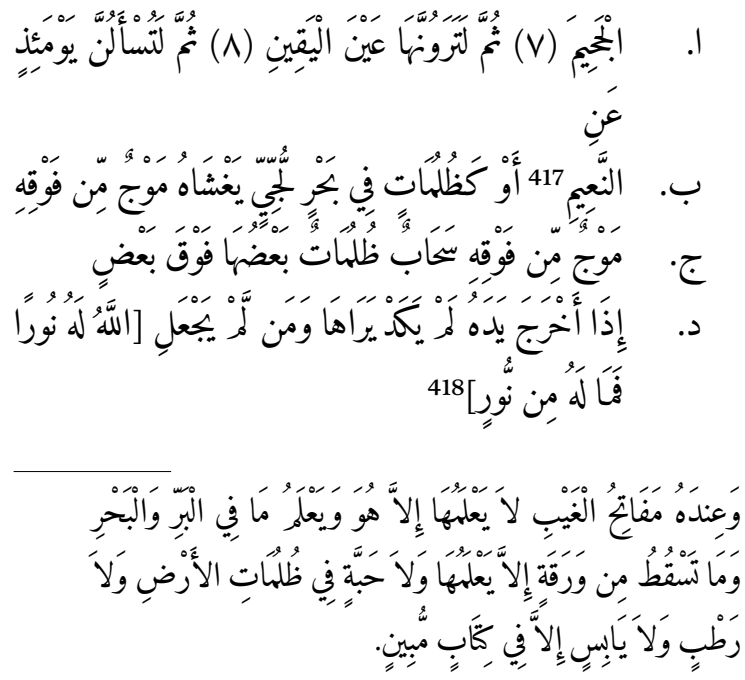

413 Allenfalls al-hakim.

414 Dieser Ausdruck in roter Tinte.

415 Es folgt eine vollständige Abschrift von Q 102.

416 Die Fortsetzung von Q 102 folgt auf der innersten Zeile.

417 Schluss von Q 102; danach beginnt eine Abschrift von Q 24:40.

418 Q 24:40; die letzten Begriffe (in eckigen Klammern) 
4. Untere Raute: Äusserste Zeile; Beginn in der oberen Spitze; der Text ist wiederholt unpunktiert:

(4.) 1. Zeile (äusserste Zeile):

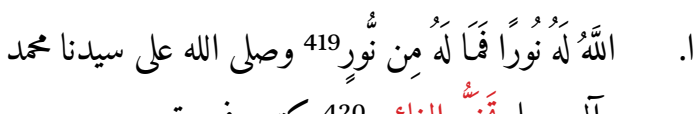

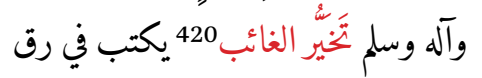

ب. غزال ويدفنه (؟) في موضع كامن [...] وهو اللهم ان

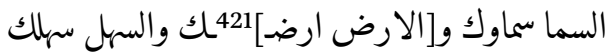

ج. والامر امرك وكل شي هو لك اللهم ضيق وسد [د؟ب]

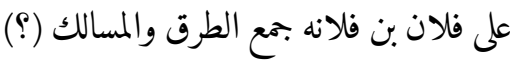

د. والبر والبحر والسهل والجبل (؟) وحيث ماتوجه حتى

يرجع المى اهله اللهم ضيق عليه الارض وسد (؟)

(4.) 2. Zeile von aussen, Beginn in der oberen Spitze:

ا. وجهه حتى لا يقدر [...] يطلب الا اهله يا اكبر (؟)

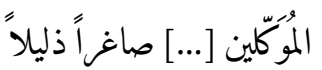

ب. ويضيقون عليك بِميع (؟) الطرق والمسالك وَجَعَلْنَا منن

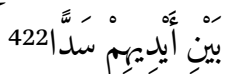

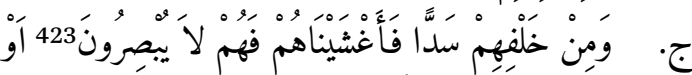

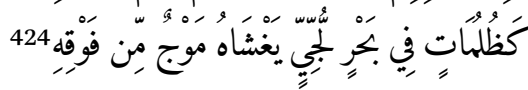

stehen erst in der nächsten Raute auf der äussersten Linie; siehe sogleich anschliessend bei Anm. 419.

419 Schluss Q 24:40 (Anfang in der oberen Raute, am Ende des innersten Umgangs).

Diese beiden Begriffe in roter Tinte.

Durch braunen Klecks nahezu gänzlich verdeckt.

Durch braunen Klecks nahezu gänzlich verdeckt.

Q 36:9 (ganz); der Vers lautet:

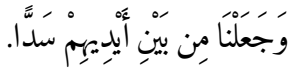

Q 24:40 (Anfang; der Schluss dieses Verses steht bereits an der Spitze dieser Raute auf der äussersten Zeile); der ganze Vers lautete:

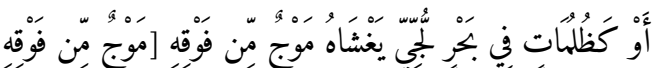

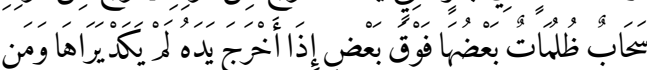

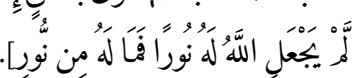

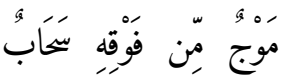

د. [...] والذي يريدها (؟)

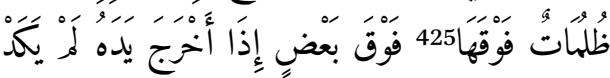

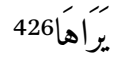

(4.) 3. Zeile (grössere Schrift):

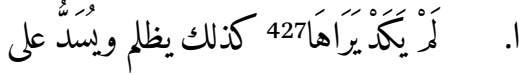

$$
\begin{aligned}
& \text { ب. فلان بن فلانه الف لا حول ولا قوه }
\end{aligned}
$$

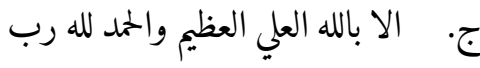

$$
\begin{aligned}
& \text { د. العالمين وصلى الله على محمد واله وسلم كثيرا }
\end{aligned}
$$

(4.) 4. Zeile:428

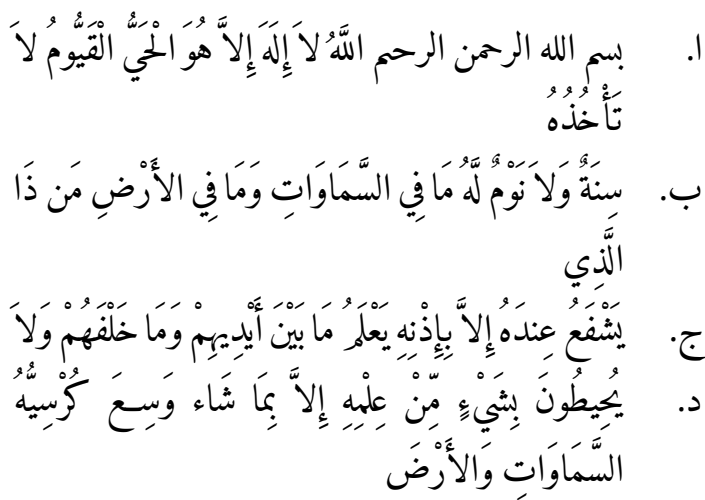

(4.) 5. Zeile (innerste Zeile):

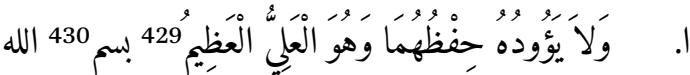

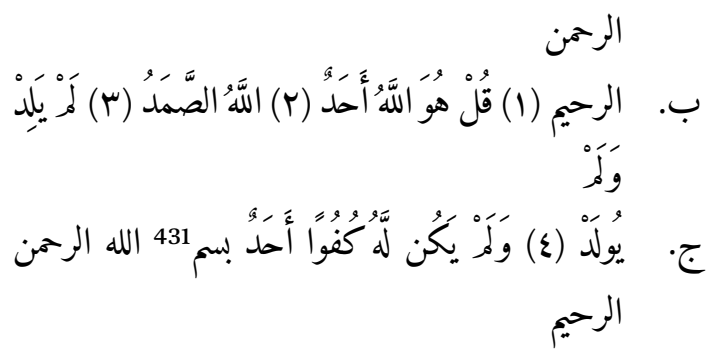

425 Weiterer Auszug aus Q 24:40; für den korrekten Wortlaut des Verses vgl. vorangehende Anm.

426 Abschluss auf der nächsten Zeile nach innen.

427 Abschluss des Auszuges aus Q 24:40.

428 Q 2:255 (Thronvers).

429 Ende Q 2:255.

430 Beginn Q 112, erste Abschrift.

431 Beginn Q 112, zweite Abschrift. 


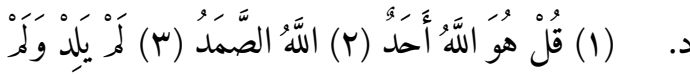

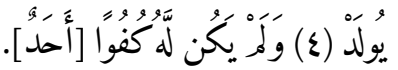

5. Zwischen den beiden Rauten befinden sich auch hier zu beiden Seiten Verzierungen, die aus Textstellen in $\dot{G} u b \bar{a} r$-Schrift zusammengesetzt sind. Ihre Gestaltung erinnert an die Schnäuze, wie sie von Bektāšīs gern getragen werden. Diese Interpretation ist allerdings offen. ${ }^{432}$ Fest steht aber, dass auch diese Figuren aus Abschriften von Q 112 (Sūrat al-Ihlāṣs) in $\dot{G} u b \bar{a} r$-Schrift zusammengesetzt sind.

6. Unterhalb der zweiten Raute lassen sich zur Linken und Rechten zwei weitere Zierelemente erkennen, die durch Stellen in $\dot{G} u b \overline{a r}$ gebildet werden. Es handelt sich um zwei tropfenförmige Figuren, deren Spitzen sich nach unten neigen und nach innen gerichtet sind. Auch hier wurde Q 112 mehrfach kopiert; in diesen beiden Figuren zumeist mit der Basmala.

7. Vor dem nächsten Abschnitt folgt eine Zeile mit sieben Zeichen. Sie erinnern an Brillenbuchstaben, wie sie aus der Magie bekannt sind. ${ }^{433}$

II I. Li-d-duhūl 'alà s-Sulțān (А В В. 85):434 Titel in weisser Schrift in goldenem Titelbalken mit Überresten einer schwarz konturierten pflanzlichen Verzierung. Länge des Rechtecks etwa $17 \mathrm{~cm}$ (inkl. Titelbalken). Dieser Abschnitt ist bei der Begegnung mit bzw. beim Eintreten bei einem Machthaber hilfreich (Li-d-duhūl 'alā s-Sultāan). Im Abschnitt lassen sich einerseits textliche Elemente erkennen. Anderseits fallen Folgen von Ziffern und Buchstaben, Brillenbuchstaben sowie an Buchstaben erinnernde Zeichen auf. Die folgenden Ausführungen sollen den Inhalt dieses Abschnitts möglichst genau festhalten. Die Leerräume in diesem Abschnitt sind mehrfach mit sechsblättrigen goldenen Blüten ausgefüllt:

432 Vgl. dazu bereits oben Anm. 371.

433 Vgl. dazu Canaan, Decipherment 169 (Fig. 29); Winkler, Siegel und Charaktere 150-167 („Die Brillenbuchstaben“, mit Abbildungen teils ähnlicher Figuren auf

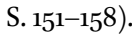

434 Abb. 11 der Rolle unter http://www.e-manuscripta.ch/ bau/content/pageview/837978.

$$
\text { تكتب (؟) هذه الاسما العظام وشرحها بطول • •وهذا }
$$

Es folgen fünf schwarze Linien; sie werden in der Mitte durch eine Blüte voneinander getrennt.

Die Zeilen 2 und 3 enthalten Ziffern und vereinzelt unverbundene Buchstaben ${ }^{436}$

$$
\begin{aligned}
& \text { قبول رحت } 437 \\
& \text { لسم الله الرحمن الرحيم حه (؟) Zeichen }
\end{aligned}
$$

Zeichen, die an Brillenbuchstaben erinnern.

2 Zeilen mit Ziffern und Buchstaben

(unterstrichen) $)^{438}$

3 Zeilen (ohne unmittelbar ersichtlichen Sinn)

$$
2 \text { Zeilen (teilweise lesbar) }{ }^{439}
$$$$
\text { Rechteck mit Zeichen }{ }^{440}
$$

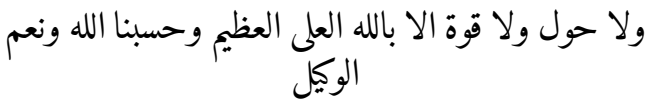

IV. Du'ä’ li-kull šay':441 Überschrift in weisser, schwarz eingefasster und golden umrahmter Schrift in einem Titelbalken mit rotem Hintergrund. Länge des Rechtecks danach: etwa $27.5 \mathrm{~cm}$ (inkl. Titelbalken). Aus der Überschrift lässt sich schliessen, dass dieser Abschnitt ein Gebet enthält, das für jegliche Angelegenheiten nützlich ist. Der Text ist zuerst auf acht horizontalen Zeilen in normal grosser Schrift kopiert (a.). Der Schreiber wechselt darauf zu mikroskopischer Schrift und notiert den Text in 15 mandelförmigen Figuren, die in drei Spalten angeordnet sind $(3 \times 5$ Mandeln $)$.

435 Es wird versucht, den oft unpunktierten Text möglichst unverändert zu übernehmen.

436 Zeilen 1, 4 und 5 (rechts) und Zeilen 1 und 4 (links, hier keine 5. Zeile) ohne Zeichen.

437 In roter Schrift; zur Rechten und Linken dieses Texts je eine Blüte.

438 Rechts und links davon je eine sechsblättrige goldene Blüte.

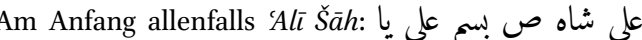
(؟) Diese Entzifferung ist ungesichert; es finden sich zusätzlich Zeichen, die sich nicht erklären lassen (z.T. Brillenbuchstaben); vgl. Abb. 11 der Rolle (link in Anm. 441). Rechts und links davon eine sechsblättrige goldene Blüte. .ch/bau/content/pageview/837978. 
Die Zwischenräume zwischen den mandelförmigen Figuren im Mittelstreifen werden durch insgesamt acht Rauten ausgefüllt, die ihrerseits Text in mikroskopischer Schrift enthalten. Die mandelförmigen Figuren in den vier Ecken des Rechtecks sind gänzlich mit Text ausgefüllt. Die restlichen mandelförmigen Figuren werden durch drei Zeilen Text in $\dot{G} u b \bar{a} r$-Schrift gebildet und sind im Innern mit einem goldenen Zierpunkt (z.T. mit rotem Tupfer) ausgefüllt. Die Zwischenräume zwischen den mandelförmigen Figuren dem linken und rechten Rand des Rechtecks entlang sind mit goldenen, sechsblättrigen Blüten ausgefüllt (b.). Die weitere Darstellung hält den Inhalt dieses Abschnitts möglichst genau fest:

a. Beginn des Gebets auf acht horizontalen Zeilen in normal grosser Schrift:

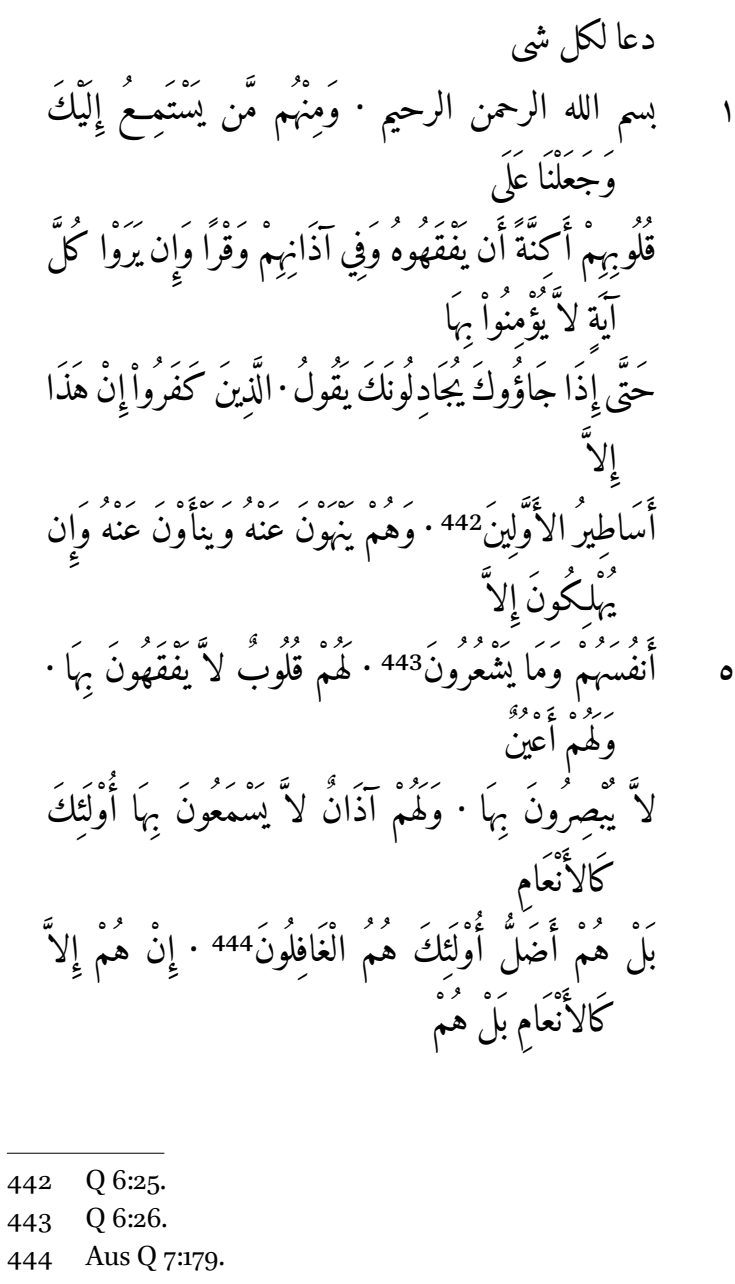

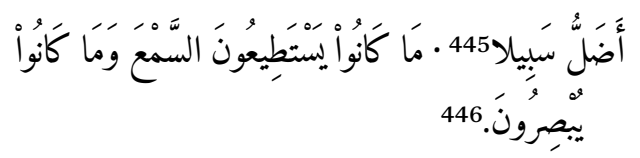

b. Danach folgt der $\dot{G} u b \bar{a} r$-Teil, in dem der Text zumeist in mandelförmigen Figuren angeordnet ist. Zwischen den beiden obersten Figuren befinden sich zwei Dreiecke mit nach unten gerichteter Spitze. Sie enthalten Q 16:108-109 in $\dot{G} u b \overline{a r} .447$ Im zweiten Dreieck steht am Anfang der zweiten Zeile Q 26:212. ${ }^{448}$ Am Schluss der zweiten Zeile beginnt Q 72:9b. ${ }^{449}$ Es lassen sich in den mandelförmigen Figuren auch Zitate zahlreicher weiterer Auszüge aus dem Koran erkennen; sie wurden nicht vollständig identifiziert. Erkennen lassen sich u.a.:

1. mandelförmige Figur, rechts aussen, ganz mit Text ausgefüllt: An der Spitze beginnt auf der äussersten Zeile nach links absteigend Q 10:42; es schliesst sich 10.43 an. ${ }^{450}$ Danach folgt

445 Aus Q 25:44.

446 Aus Q 11:20.

447 Schluss am Ende der obersten Zeile im linken Rechteck; Q 16:108-109 lautet:

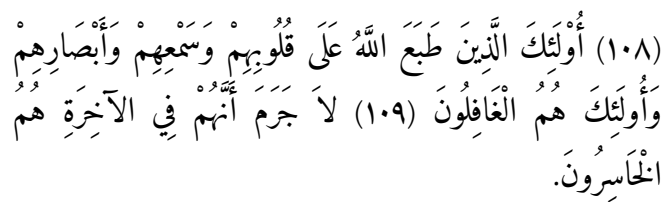

Q 26:212 lautet:

Der Text endet am Schluss dieses zweiten Dreiecks; Q 72.9 lautet:

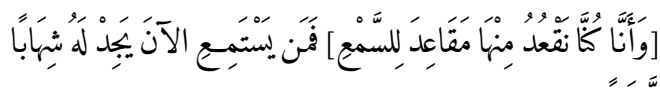

رصدَ" آنَا.

450

Q 10:42-43 lautet:

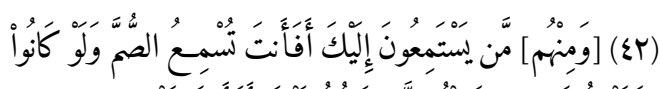

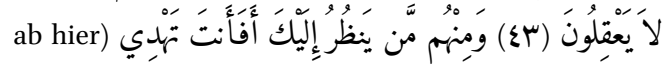

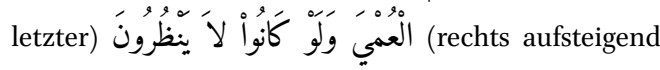
Begriff in Kairiner Ausgabe 
Q 8:22-23; Vers 23 beginnt auf der zweiten absteigenden Zeile (links) an der oberen Spitze der mandelförmigen Figur. ${ }^{451}$ Am Übergang der beiden äusseren Zeilen an der unteren Spitze der mandelförmigen Figur steht Q 74:50-51. ${ }^{452}$ Es schliesst sich auf der zweiten Zeile (rechts aufsteigend) Q 18:11 an; diese Stelle endet kurz vor der oberen Spitze der mandelförmigen Figur. ${ }^{453}$ Dort beginnt ganz am Schluss der zweiten Zeile (aussen rechts) Q 6:46; der Vers wird dann hauptsächlich auf der dritten Zeile kopiert (zuerst absteigend, dann aufsteigend). ${ }^{454}$ Zuinnerst ein Auszug aus Q 46:26.455

2. mandelförmige Figur, Mitte, im Innern mit einem goldenen Zierpunkt versehen: Auf der äussersten Zeile (rechts, aufsteigend) steht, an der unteren Spitze der mandelförmigen Figur beginnend, Q 63:3 (Auszug). ${ }^{456}$ In der Mitte

451 Q 8:22-23 lautet:

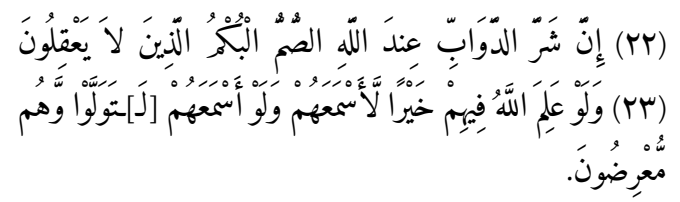

452 Q 74:50-51 lautet:

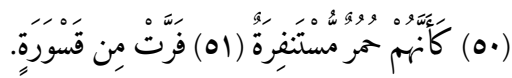

Q 6:46 lautet:

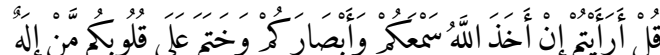

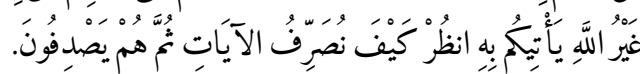

455 Q 46:26 lautet:

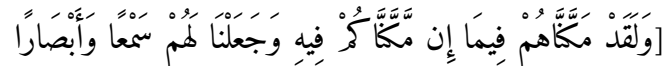

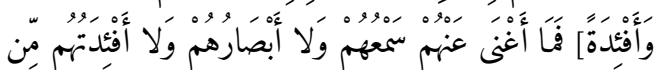

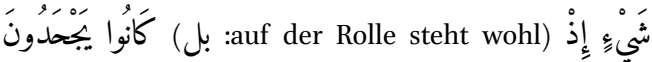

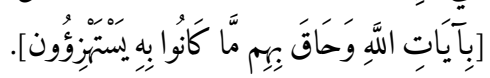

456 Ein Wort ganz zuunterst muss zu einer andern Stelle gehören; Q 63:3 lautet:

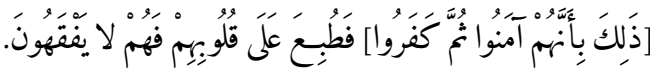

der zweiten Zeile (rechts, aufsteigend) beginnt das Zitat von Q 9:93b-94. ${ }^{457}$ Auf der zweiten Zeile (links, absteigend) steht danach Q 2:7.458 Auf der innersten Zeile (rechts, aufsteigend) schliesst sich 7.101 (Schluss) an. ${ }^{459}$ Anschliessend steht auf der innersten Zeile an der Spitze der mandelförmigen Figur Q 30:59 (zuerst auf-, dann absteigend). ${ }^{460}$ Ganz am Schluss schliesst sich zuinnerst mutmasslich ein Auszug aus Q 4:155 an. ${ }^{461}$

Die vorangehende Übersicht vermittelt einen Überblick über den Inhalt dieser Stellen in $\dot{G} u b \bar{a} r-$ Schrift. Es ist grundsätzlich möglich, diese Stellen $\mathrm{zu}$ lesen. Gerade wenn es sich um Zitate aus dem Koran handelt, lassen sie sich auch identifizieren.

457 Q 9:93-94 lautet:

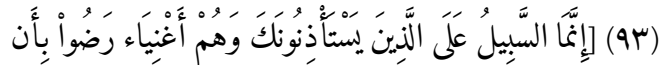

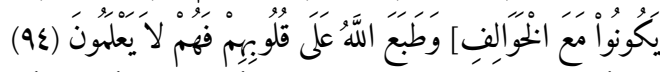

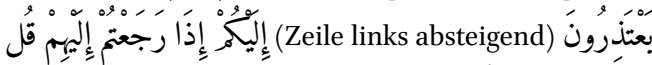

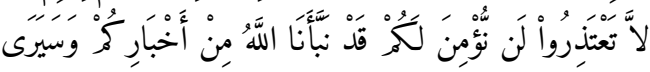
untere Spitze der Mandel, Übergang auf zweite Zeile,) (rechts, aufsteigend

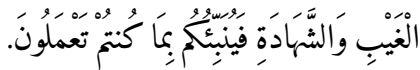

458 Q 2:7 lautet:

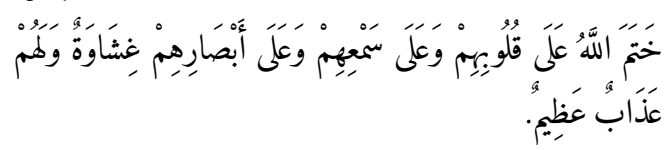

459 Q 7:101 lautet:

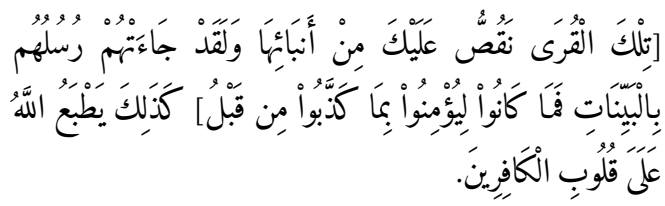

46o Q 30:59 lautet:

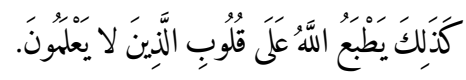

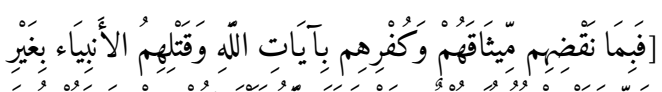

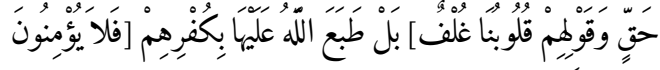

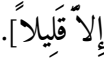


Allerdings ist das Bestimmen dieser Stellen mit einem erheblichen Zeitaufwand verbunden; dies verbietet es, diese Abschnitte durchgehend aufzuschlüsseln.

In diesem Abschnitt fällt zweierlei auf: a. Der Kopist ändert die Anordnung der kopierten Textpassagen innerhalb der verschiedenen mandelförmigen Figuren immer wieder. In der dritten mandelförmigen Figur auf der obersten Reihe wurde der Text dann auf der äussersten Zeile rechts absteigend kopiert; er steigt auf der linken Zeile aussen wieder nach oben. b. Anderseits werden die beiden analysierten mandelförmigen Figuren mit kurzen Zitaten aus dem Koran (zumeist 1-2 Verse) gefüllt, die inhaltlich zusammengehören. In der zweiten Figur stehen Verse im Vordergrund, die die Vorstellung enthalten, dass Gott die Herzen gewisser Menschen verschlossen habe; die Stellen enthalten immer wieder die Wendung: طبع الله على.

v. Du' $\mathfrak{a}^{\prime}-\boldsymbol{i}$ Muhr-i nubuwwat: ${ }^{462}$ Der Titel wurde hier ohne Artikel notiert und ist gemäss persischer Grammatik mit iḍa fa zu lesen. Dies ist ein weiterer Hinweis auf den mutmasslich persischen Hintergrund des vorliegenden Dokuments. Der Titel bedeutet "Gebet des Siegels der Prophetschaft“. Diese Überschrift steht in ursprünglich wohl weisser Schrift in einem goldenen Titelbalken. Er ist mit einem schwarz konturierten goldenen Rankenmuster versehen. Gerade im oberen Teil des Titelbalkens lassen sich Reste von blauer Farbe erkennen. Die Länge des zum Titel gehörenden Rechtecks beträgt etwa $33.7 \mathrm{~cm}$ (inkl. Titelbalken). Der Text ist zuerst auf fünf horizontalen Zeilen in normaler Grösse notiert (a.). Auch am Schluss dieses Abschnitts steht Text auf vier horizontalen Zeilen in normaler Grösse (c.).

Der Text dazwischen wurde in $\dot{G} u b \bar{a} r$-Schrift notiert und bildet ein Muster (b.): Zuoberst lässt sich eine Zeile in $\dot{G} u b \bar{a} r$-Schrift erkennen, die sich über die gesamte Breite des Mittelstreifens

462 Abb. 12 der Rolle unter http://www.e-manuscripta.ch/ bau/content/pageview/837979. erstreckt. Darunter bildet der Text vier Dreiecke, deren Spitzen nach unten weisen. Der Text danach greift die Zickzackbewegung der Dreiecke auf; die Zeilen verlaufen hier in der Regel parallel zu den Seitenlinien der Dreiecke. Es schliesst sich darauf ein Zierstreifen an, der ebenso im Zickzack verläuft. Er weist goldene Seitenlinien auf. Der Hintergrund der Felder in den nach oben und unten weisenden Spitzen ist blau und mit einer goldenen Verzierung versehen, die innen rot ausgefüllt ist. Die Felder in der Mitte dieses Zickzackbands weisen einen rötlichen Hintergrund auf und sind mit dunkelroten Zierpunkten versehen. Es folgt ein weiteres Zickzackband mit Text und darauf ein Zierband, das ebenso gestaltet ist wie das soeben beschriebene. Danach ein Abschnitt, in dem der Text in $\dot{G} u b \bar{a} r$-Schrift in unterschiedlicher Richtung in Rauten angeordnet ist. Die Zwischenräume zwischen den Rauten bilden ein Gitter. Oberhalb und unterhalb dieses Gitters ist der Text in $\dot{G} u b \bar{a} r$-Schrift in Zickzackbändern notiert. Gegen unten schliesst sich ein Zierstreifen an, der je vier nach oben und unten angeordnete grün ausgefüllte und golden umrandete Zierelemente in Blattform enthält. Die einzelnen Blätter sind untereinander durch goldene Linien verbunden. Bevor dieser Abschnitt mit Text auf horizontalen Zeilen endet, schliesst sich eine doppelte Abfolge von einem Zickzackband mit Text in $\dot{G} u b \overline{a r}$ und einem Zierband mit Spitzen mit blauem Hintergrund an. Der Abschnitt endet mit zwei Zeilen in $\dot{G} u b \bar{a} r$, die sich über die gesamte Breite des Mittelstreifens erstrecken. Zuletzt schliessen sich die vier Zeilen mit Text in normaler Grösse an (c.). Inhalt dieses Abschnitts; a.:

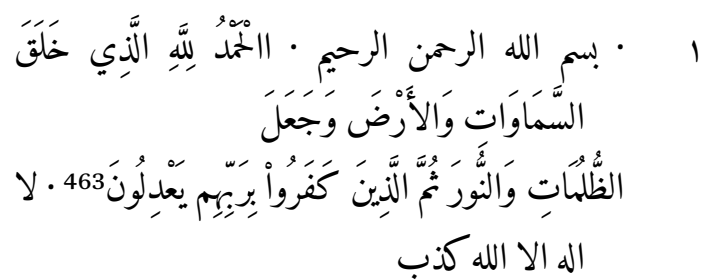

463 Q 6:1. 


$$
\begin{aligned}
& \text { العادلون بالله وضلّوا ضلالاًا } 464 \text { بعيداً · وخسروا } \\
& \text { خسراناً مبيناً واستوجبو[إل } \\
& \text { من الله عذابا اليما • هذا كّاب من الله السيد الصمد }
\end{aligned}
$$

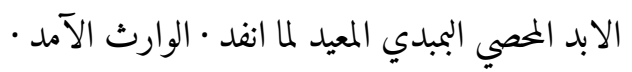

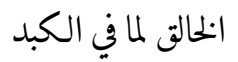

b. Der Schreiber wechselt hier nach einem kleinen Zwischenraum zu $\dot{G} u b \bar{a} r$-Schrift. Die Verwendung der mikroskopischen Schrift erschwert die vollständige Entzifferung dieses Abschnitts. Soweit ersichtlich handelt es sich bei den kopierten Stellen um Auszüge aus unterschiedlichen Gebeten. Der Schreiber ändert auch in in diesem Abschnitt in mikroskopischer Schrift die Schriftrichtung immer wieder. Die Ausrichtung der Figuren gibt den Verlauf der Zeilen vor. Zuerst steht eine Zeile mit waagrechtem Text; sie nimmt die gesamte Breite des Mittelstreifens ein und setzt den grossen Text unmittelbar davor fort (a.):

$$
\begin{aligned}
& \text { الطاهر (الظاهر؟) من الولد المجري (؟) لما وعد العزيزبلا عدد }
\end{aligned}
$$

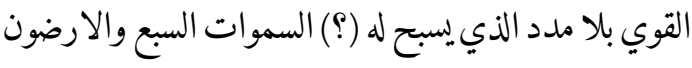

$$
\begin{aligned}
& \text { السبع وهو رب ||465 العرش العظيم ولا حول ولا قوة || الا }
\end{aligned}
$$

Im Abschnitt unterhalb des letzten Zierbands und vor den abschliessenden Zeilen mit horizontalem Text im Zickzackband und den Dreiecken darunter wurde Q 112 vielfach kopiert. Bevor der Kopist mit c. wieder zu grossem Nash übergeht, notierte er zwei Zeilen Text horizontal in kleinerer Schrift, die hier nicht erfasst werden.

c. Am Schluss des Abschnitts vier horizontale Zeilen Text in grosser Schrift:

$$
\begin{aligned}
& \text { اللهم صل على سيدنا محمد اولاً واخيرا ظاهراً وباطنا • اعتق }
\end{aligned}
$$

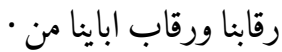

464 Auf der Rolle steht: طلالا

465 Der Text steigt ab hier im ersten Dreieck rechts aussen Zeile um Zeile nach unten.

$$
\begin{aligned}
& \text { النار والمظالم وآتنا اجمعين في الدنيا حسنة وفي الآخرة حسنة } \\
& \text { وقنا بفضل رحتك عذاب } \\
& \text { القبر وعذاب الفقر · وعذاب النار · وشر الخلايق اجمعين · } \\
& \text { اللهم كف عنا ايدي الظالمين } \\
& \text { وايدي المنافقين (؟) · برحمتك يا ارحم الراحمين · ولا حول الطمان } \\
& \text { ولا قوة الا بالله العلي العظيم }
\end{aligned}
$$

VI. Tahlīl al-Qurān wa-l-Ism al-a'zam:466 Überschrift in weissen, schwarz eingefassten und golden hinterlegten Buchstaben in einem Titelbalken mit rotem Hintergrund. Länge dieses Rechtecks: ca. $24.6 \mathrm{~cm}$ (inkl. Titelbalken). Auf der Höhe des Titelbalkens befindet sich am rechten Rand ausserhalb des Schriftspiegels ein handschriftlicher Eintrag, der sich nicht entziffern liess.

Auch in diesem Abschnitt lassen sich im Mittelstreifen drei Teile erkennen. Der Text ist am Anfang und am Schluss auf jeweils drei horizontalen Zeilen in normal grossem Nash kopiert (a. und c.). Dazwischen (b.) wurde Text in Ġubār-Schrift in komplexen Figuren angeordnet. Der Text folgt dem Verlauf der Figuren. Es lassen sich drei annähernd quadratische Abschnitte mit identischem Aufbau erkennen. Im Zentrum befindet sich ein goldener Zierpunkt. Den vier Seiten der einzelnen Quadrate entlang verlaufen Wirbellinien, die ineinander verschlungen sind, sich aber nie berühren. Sie lassen in den einzelnen Vierteln des Quadrats Kreisfiguren entstehen. Diese Wirbellinien werden durch Text in $\dot{G} u b a \bar{r}$-Schrift gebildet. Zwischen den drei Quadraten lässt sich in der Mitte jeweils ein Dreieck mit Text in $\dot{G} u b a \bar{r}$ erkennen. Im folgenden wird der Versuch angestellt, diesen Text zu entziffern:

Inhalt: a. Drei horizontale Zeilen in normal grosser Schrift: Q 2:255 (Thronvers, mit der Basmala als Einleitung):

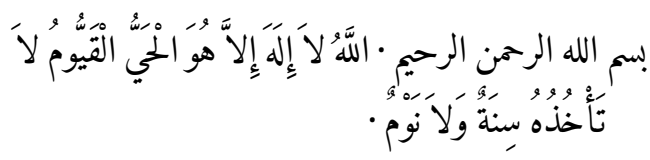

466 Abb. 12 der Rolle unter http://www.e-manuscripta.ch/ bau/content/pageview/837979. 


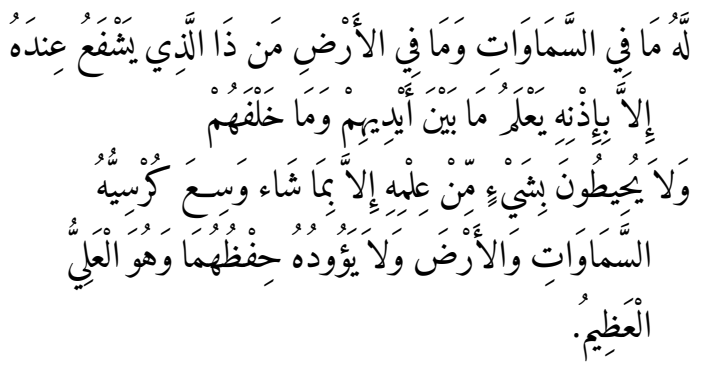

b. Abschnitt in $\dot{G} u b \bar{a} r$-Schrift mit den Quadraten b.1-3: Entzifferung offen.

c. Drei horizontal ausgerichtete Zeilen in normal grosser Schrift:

$$
\begin{aligned}
& \text { يا واحد يا احد يا واحد يا احد يا واحد يا احد يا واحد يا } \\
& \text { احد يا واحد يا احد } \\
& \text { يا جواد انصرني على من عاداني واجعل ثأري على من } \\
& \text { ظلمني واكفني ما أهمني من أحر الدنيا } \\
& \text { والآخرة انك على كل شي قدير وآخر دعوانا (؟) الحمد لله }
\end{aligned}
$$

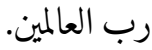

VII. Du'ä' as-safar:467 Überschrift in weissen, schwarz eingefassten Buchstaben in einem Titelbalken mit goldenem Rankenmuster auf blauem Hintergrund. Der Titel bedeutet „Reisegebet“. Von diesem Gebet sind nur noch ca. $10 \mathrm{~cm}$ erhalten. Die Rolle bricht danach ab. Am Anfang dieses Abschnitts fünf Zeilen Text in normal grossem Nash; sie sind horizontal ausgerichtet (a.). Danach folgt eine Stelle in $\dot{G} u b \bar{a} r$ (b.); davon sind nur noch etwa $3 \mathrm{~cm}$ erhalten. Der Text ist darin in schmalen Bändern angeordnet, die sich gegenseitig überschneiden. Die Leerräume zwischen den Textbändern sind mit einfachen Verzierungen (einzelne Blätter) ausgefüllt. Teilweise sind sie in einer Technik ausgeführt, die an den Siyāh Qalam-Stil erinnert.

Inhalt a.:468

$$
\text { بسم الله الرممن الرحيم •بسم الله العزيز • اللهم اسعدنا بهذه }
$$

467 Abb. 12 der Rolle unter http://www.e-manuscripta.ch/ bau/content/pageview/837979.

468 Siehe dazu http://www.haydarya.com/maktaba_mokta sah/o7/book_61/part6/11.htm (Stand 29. Dezember

$$
\begin{aligned}
& \text { الحركم • وامدنا بايمن والبركة • واكفناشر العدو • واعذنا من } \\
& \text { عناء } \\
& \text { السفر · وانزلنا خير المنازل · واعنا على طى المراحل · و قرب }
\end{aligned}
$$

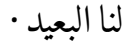

$$
\begin{aligned}
& \text { والنو[ا] هي (؟) • ويسر علينا السير والسرى • واحلنا فى ضمان } \\
& \text { السلامة (؟) •بلغنا فى امان } \\
& \text { العافية · ادفع عنا طوارق الليل وطوارق النهار الا طارقاً } \\
& \text { يطرق بخير. }
\end{aligned}
$$

Inhalt b.: Es wird kein Versuch angestellt, diese Stelle zu entziffern. Soweit ersichtlich handelt es um eine Stelle frommen Inhalts.

Schlussfolgerungen: Die Einordnung dieses äusserst komplexen Belegstücks ist nach wie vor mit grossen Unsicherheiten verbunden. Im Vordergrund steht eine Entstehung in NW-Iran oder NordMesopotamien (Nord-Irak, Nord-Syrien). Das Dokument dürfte um 1400 angefertigt worden sein. Auch auf diesem Belegstück lassen sich neben umfangreichen Stellen aus dem Koran zahlreiche Gebete nachweisen. Zumindest eines davon, die Du'ä'-i Ibrāhìm b. Adham wird mit einem bekannten Mystiker in Verbindung gebracht. ${ }^{469}$ Auf allfällige Bezüge zur Mystik könnte sodann die Wiederholung von $H \bar{u}$-Rufen an einer Stelle auf der Rolle hinweisen. ${ }^{470}$ Derartige Rufe sind von den in gewissen Derwischorden gepflegten Dikr-Übungen bekannt. Im Vordergrund stünde hier ein Bezug zur Rifāciyya, wobei sich dies nicht beweisen lässt.

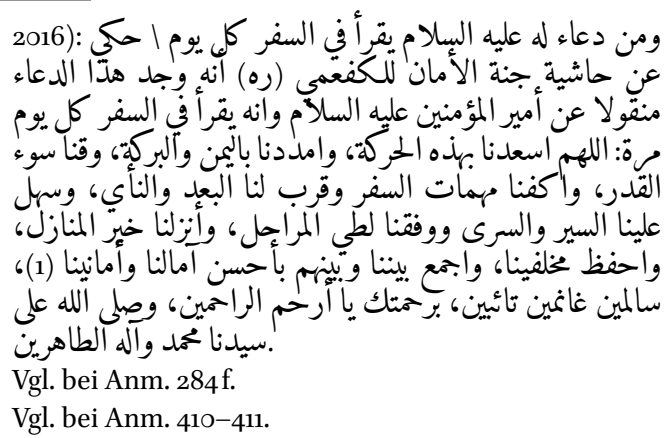


Ausserdem muss dieses Belegstück ursprünglich eine vollständige Abfolge des siebenteiligen Haykal-Gebets enthalten haben. ${ }^{471}$ Die Benennung dieses Gebets könnte implizit an die Sabäer von Harrān erinnern. Die Stadt Harrān liegt in so-Anatolien, östlich von Gaziantep, hart an der Grenze zu Syrien. Eine Untergruppe dieser Sabäer von Harrān ist in der islamischen Welt als Așhāb alhayākil, als „die Leute der Tempel“ bekannt; sie verehrten in ihren Tempeln (haykal, Pl. hayākil) u.a. die sieben Planetengottheiten. ${ }^{472}$

Dieses Belegstück ist sodann interessant, da es mehrfach Hinweise darauf enthält, dass es seinen Besitzer (șăhịb) vor allen Übeln schützen soll.. 43 An einer weiteren Stelle formuliert der Schreiber den Wunsch, dass Gott den Träger (hâmil) dieses Schriftstücks und seine Angehörigen im Besitz erhöhen möge. ${ }^{474}$ Auch lassen sich auf diesem Dokument besonders viele Elemente nachweisen, die aus der islamischen Magie (sihr) im engeren Sinn bekannt sind. So findet sich im 4. Haykal eine Anrufung Gottes mit „bi-ḥaqqi Āhiyā Šarāhiyā Adūnāy (?) Aṣbā’ūt". ${ }^{475}$ Dieselbe Anrufung figuriert später nochmals modifiziert auf der Rolle. ${ }^{476}$ Ausserdem enthält dieses Dokument mehrere Gebete für Situationen, für die sich auch in den Werken Būnīs und Tilimsānīs Schutzmittel nachweisen lassen. Gerade im Abschnitt $L i-d-$ duhūl 'alā s-Sulțān findet sich eine ganze Reihe

471 Vgl. bei Anm. 102 f. und die weiteren Bemerkungen zu den einzelnen Abschnitten des eigentlich siebenteiligen Gebets (auf der Rolle fehlt der erste Haykal).

Vgl. zu diesen impliziten Bezügen zu den Așhāb alhayākil ausführlich Kapitel 4.4 (bei und mit Anm. 82$89)$.

473 Vgl. nach Anm. 26o (Zeile 21 des 7. Haykal) und nach Anm. 263 (Zeile 31f. des 7. Haykal).

474 Vgl. bei Anm. $342 \mathrm{f}$.

475 Vgl. bei Anm. 183 und 337; siehe auch Kapitel 4.4, bei Anm. 113. Siehe zu dieser Formel Canaan, Decipherment $146 \mathrm{f}$.: „In most books on magic, as in several talismans we find [this formula in one or another version]. It is clearly taken from the Hebrew (Exodus 3.14)." Mit Verweis auf Goldziher, Hebräische Elemente 359. Auch Winkler, Siegel und Charaktere 20, 31-37, 78; Dorpmüller, Religiöse Magie 172 (Anm. 34).

476 Vgl. bei Anm. 337. von Elementen, die ebenso aus der Magie bekannt sind (Brillenbuchstaben, Buchstaben- und Zahlenfolgen etc.). ${ }^{477}$ Aber selbst auf dem vorliegenden Belegstück spielen all diese Elemente eine untergeordnete Rolle ${ }^{478}$ und dürfen nicht dazu verleiten, das Belegstück als Ganzes aus der Magie heraus erklären zu wollen.

Für die Kontextualisierung dieses Dokuments dürften vielmehr andere Bezüge relevant sein als jene zur Magie. So fallen am Anfang des erhaltenen Teils dieser Rolle zwei Medaillons auf, in denen der Name 'Alī dreifach notiert worden ist. ${ }^{479}$ Dieses dreifache 'Alī entsteht durch Abschriften von Q 112 und Q 2:255 in $\dot{G} u b \bar{a} r$. Im ersten Medaillon steht im Zentrum, wo die drei Begriffe 'Alı̄ aufeinandertreffen, drei Mal der Name Allāh. Die Figur könnte allenfalls als Nominalsatz „Alī Allāh“ gelesen werden. Dies würde bedeuten „Alī ist Allāh“. Die Ver-

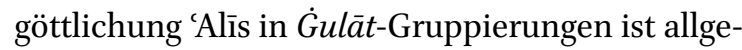
mein bekannt. ${ }^{480}$ Diese Vergöttlichung des ersten Imams der Schiiten hat den aus Iran bekannten 'Alì-Ilāhìs den Namen gegeben.

Eine ähnliche Interpretation könnten auch die beiden Buchstaben 'ayn und mim nahelegen, die zur Linken und Rechten eines Pfeils angebracht worden sind. Es handelt sich um den Abschnitt mit der Abbildung von zwei schussbereiten Bögen. ${ }^{481}$ Der Pfeil selbst könnte allenfalls als alif verstanden werden und würde damit auf Allāh anspielen. M. Moosa macht darauf aufmerksam, ${ }^{482}$ dass die Verehrung einer aus Allāh (alif), Muhammad (mìm) und 'Alī ('ayn) bestehenden Trinität ein zentrales Merkmal von Gulāt-Gruppierungen ist. Unter den Nuṣayriern spielt ausserdem Salmān alFārisī eine wichtige Rolle. Es sei üblich, dass die

\footnotetext{
477 Vgl. bei Anm. 367-370 und 433-440.

478 Sie lassen sich vielleicht auf $1-1,5 \%$ der Länge des Dokuments feststellen.

479 Vgl. bei Anm. 143-146.

48 o Vgl. dazu Moosa, Extremist Shiites IX, „Members of these [Ghulät] sects [...] share common religious beliefs, the most fundamental being that the Imam Ali [...] is God."

481 Vgl. bei Anm. 404.

482 Moosa, Extremist Shiites 50-65: „5. The Ghulat's 'Trinity'“.
} 
Buchstaben alif (Allāh), mìm (Muḥammad) und 'ayn ('Alī) auf diese Trinität anspielen. ${ }^{483}$

Diese hier ins Auge gefassten Bezüge würden zusätzlich auf ikonographischer Ebene eine Bestätigung finden. Es lassen sich auf diesem Belegstück mehrfach Verzierungen feststellen, die sich in späterer Zeit in modifizierter Form wiederholt auf Dokumenten aus dem Umfeld der Bektāšiyya nachweisen lassen. ${ }^{484}$ Auch in der Bektāšiyya wird 'Alī göttliche Verehrung zuteil.

Im Umfeld dieser Gulāt-Gruppierungen sind überdies Initiationszeremonien weit verbreitet, bei denen der Novize gegürtet wird. Es könnte gut sein, dass die Knoten auf der Basler Rolle indirekt auf jene Knoten anspielen, die der Meister bei diesen Riten in den Gürtel des Novizen bindet. Diese Knoten entstehen auf der Rolle an jenen Stellen, wo das dreiteilige Schriftband unter Umfahrung einer Abfolge von drei Medaillons (klein-grossklein) von der linken auf die rechte Seite des Dokuments bzw. vice versa wechselt. Es könnte gut sein, dass der Meister bei diesen Zeremonien dem Novizen auch ausgewählte Aussagen vorsagt, die auf einzelnen dieser Medaillons enthalten sind, z.B. „al-mulk li-[A]llāh“485 oder „Subhạana Allāh“.486 Und vielleicht spielt das Augenpaar am Anfang der Rolle auf den unwiderstehlichen Blick an, mit dem der Pir seine Novizen kontrolliert. ${ }^{487}$

Die soeben angestellten Überlegungen machen allerdings erst auf Möglichkeiten aufmerksam, die bei der Interpretation dieses komplexen Dokuments allenfalls zu berücksichtigen wären. Seine abschliessende Erklärung ist aber einstweilen offen.

483 Breebaart, Development 208 (mit Anm. 38) weist zusätzlich auf die Bedeutung der Buchstabenfolge 'ayn ('Alī), mìm (Muḥammad), lām (Ǧibrā̄ìl, letzter Buchstabe) und alif (Allāh) hin.

484 Vgl. dazu oben bei Anm. 371 und 432.

485 Vgl. bei Anm. 179.

486 Vgl. bei Anm. 205.

487 Vgl. bei Anm. 139. 


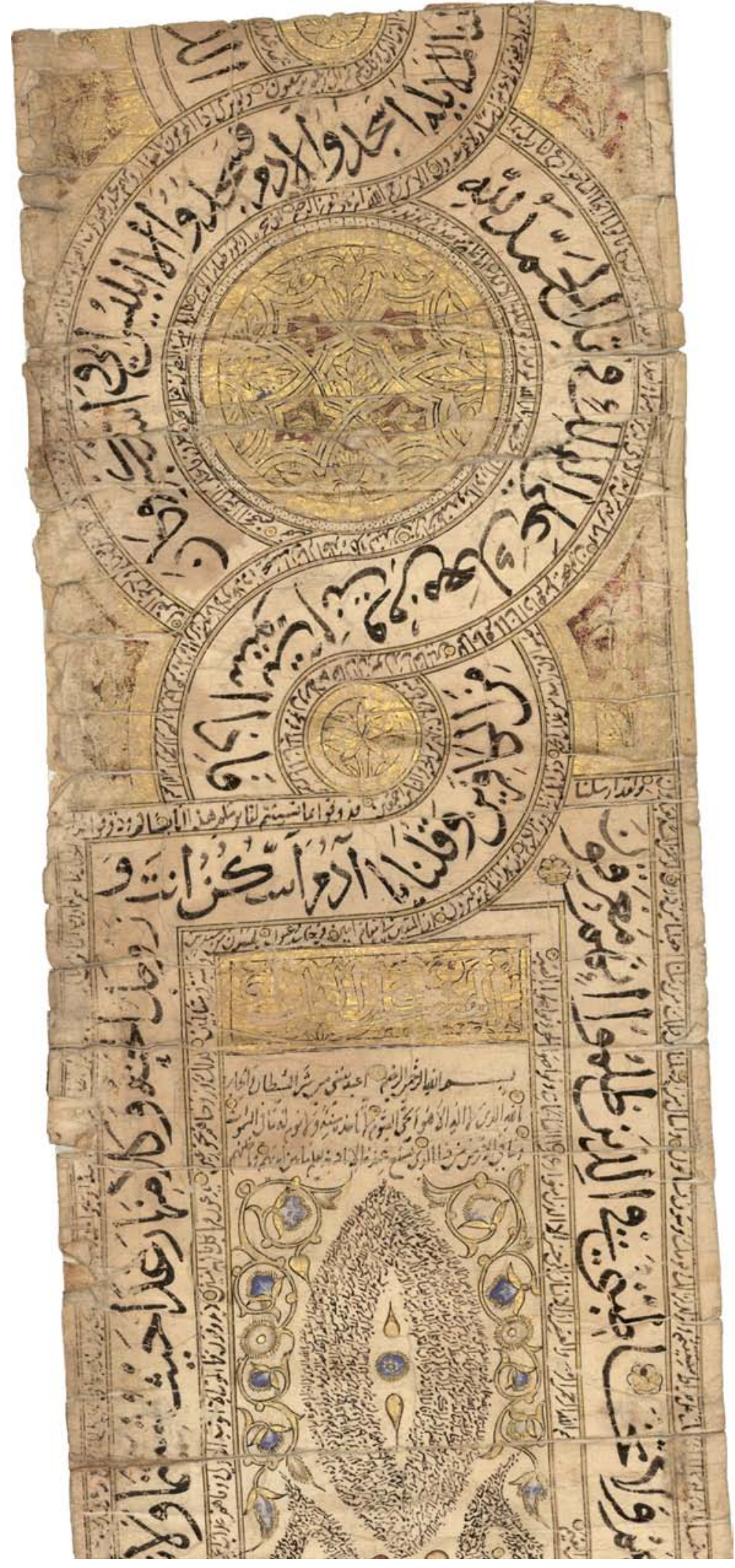

ABB. 71

Basel Universitätsbibliothek, M III 173 (vgl. bei Anm. 7-14 und 100104): Anfang des erhaltenen Teils der Rolle, wo in den Schriftbändern unterschiedliche Stellen aus dem Koran beginnen (für die Einzelheiten siehe die Beschreibungen). Nach der Abfolge der drei Medaillons folgt ein Titelbalken mit der Überschrift al-Haykal aț-tānī. 


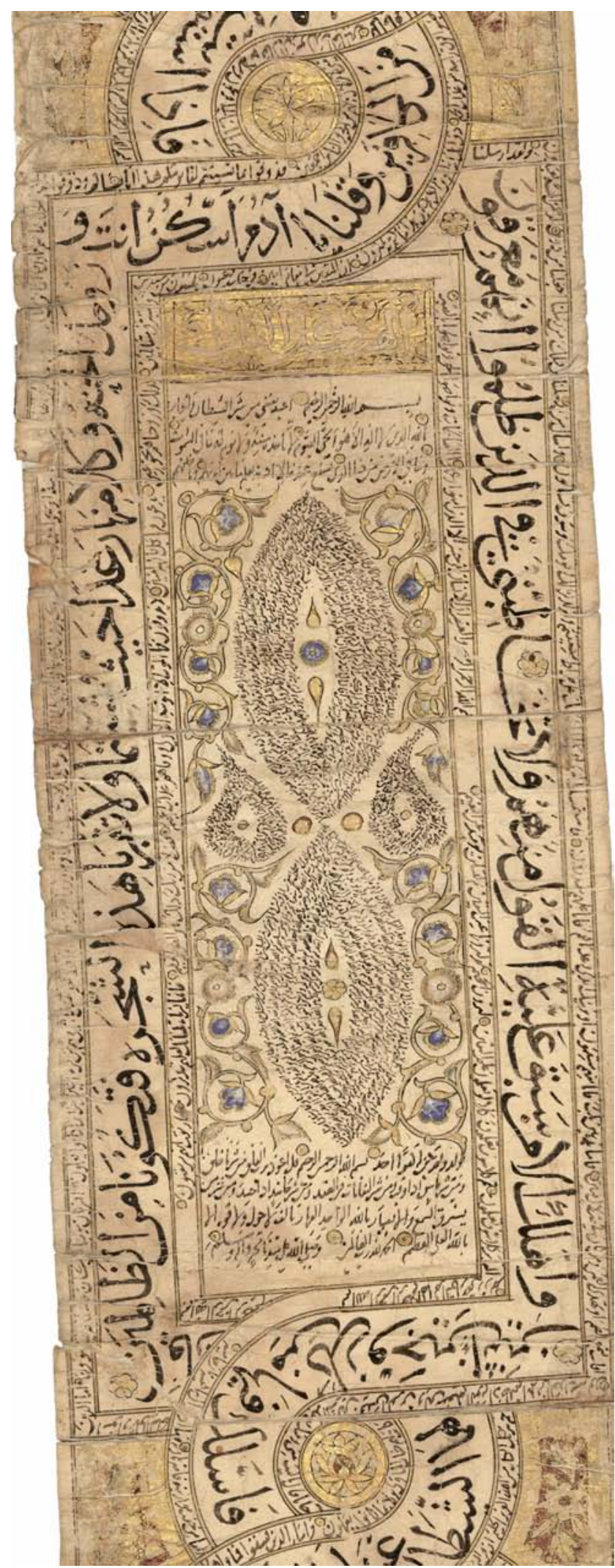

ABB. 72

Basel Universitätsbibliothek, M III 173 (vgl. bei Anm. 21-22 und 104-140): Abschnitt mit dem 2. Haykal (al-Haykal aț-tānī), der ein Gebet enthält. Der Text ist zuerst in grosser Schrift auf drei horizontalen Linien angeordnet. Danach wechselt der Schreiber zu $\dot{G} u b \bar{a} r$ und setzt die Abschrift in den senkrecht ausgerichteten mandelförmigen Figuren darunter fort. Wenn man den Abschnitt horizontal hinlegt, könnten die beiden Figuren ein Augenpaar darstellen. 


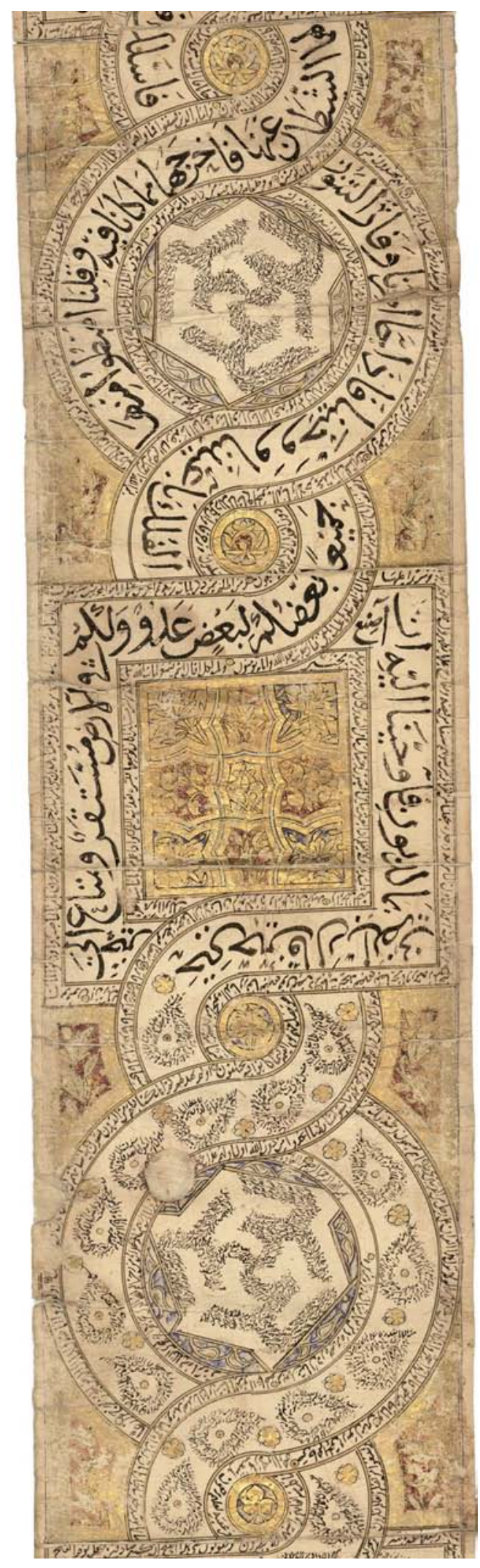

ABB. 73

Basel Universitätsbibliothek, M III 173 (vgl. bei Anm. 143-148): Auf der Rolle lassen sich zwei Medaillons feststellen, in denen Text in $\dot{G} u b \bar{a} r$-Schrift kopiert wurde. Diese Stellen sind derart angeordnet, dass als grosser Text ein dreifaches 'Alı entsteht. Beim mikroskopischen Text in den beiden Medaillons handelt es sich um Abschriften von Q 2:255 (Thronvers) und Q 112 (Sürat al-Iḥlāṣ). 


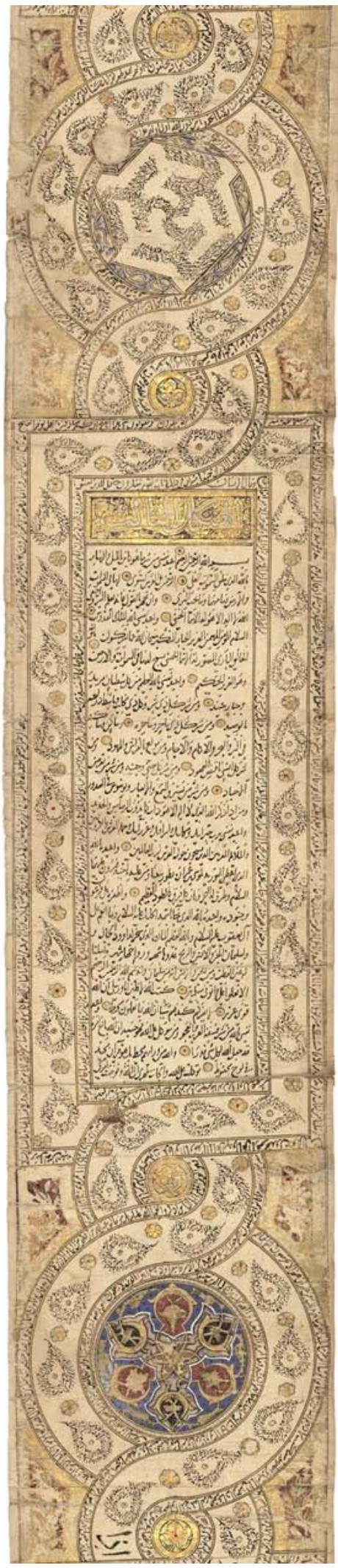

ABB. 74

Basel Universitätsbibliothek, M III 173 (vgl. bei Anm. 25-26 und 148-164): Abschnitt mit dem Anfang des 3. Haykal-Gebets (al-Haykal at-tāaliț). Im innern Textstreifen (senkrecht) lässt sich auf der Höhe der 6. Zeile des Haykal-Gebets ein Zwischenraum erkennen. Davor endet Q 98 (Sürat al-Bayyina); danach beginnt Q 99 (Sūrat az-Zalzala) mit der Basmala. 


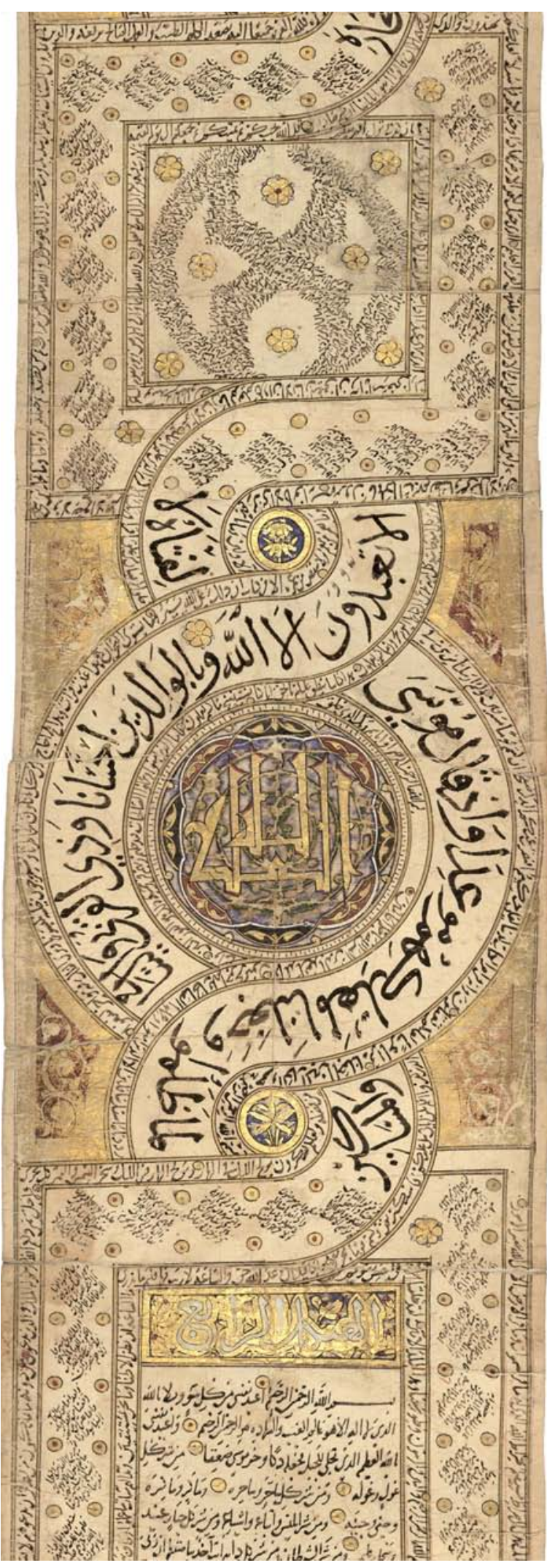

ABB. 75

Basel Universitätsbibliothek, M III 173 (vgl. bei Anm. 2832 und 179): Medaillon mit der Aussage al-Mulk li-[A]llāh („Die Macht ist Gottes“) in Zierkufi. Darunter beginnt nach einem Titelbalken der 4. Haykal. In den Schriftbändern um diese Figuren herum steht Korantext. 


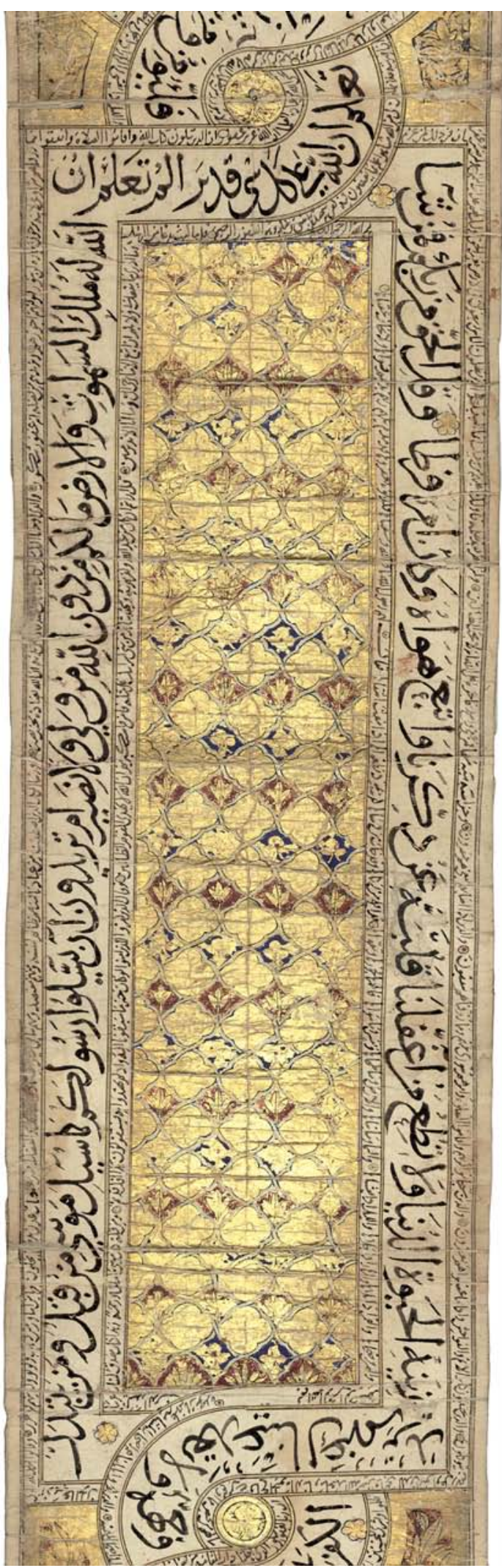

ABB. 76

Basel Universitätsbibliothek, M III 173 (vgl. bei Anm. 33-38 und 203-205): Goldenes Gitter von ca. 37 cm Länge. Es wird vermutet, dass in den einzelnen Zellen dieses Gitters ursprünglich die Schönen Namen Gottes standen. Man meint, am Ende dieses Abschnitts Reste von Buchstaben zu erkennen. 


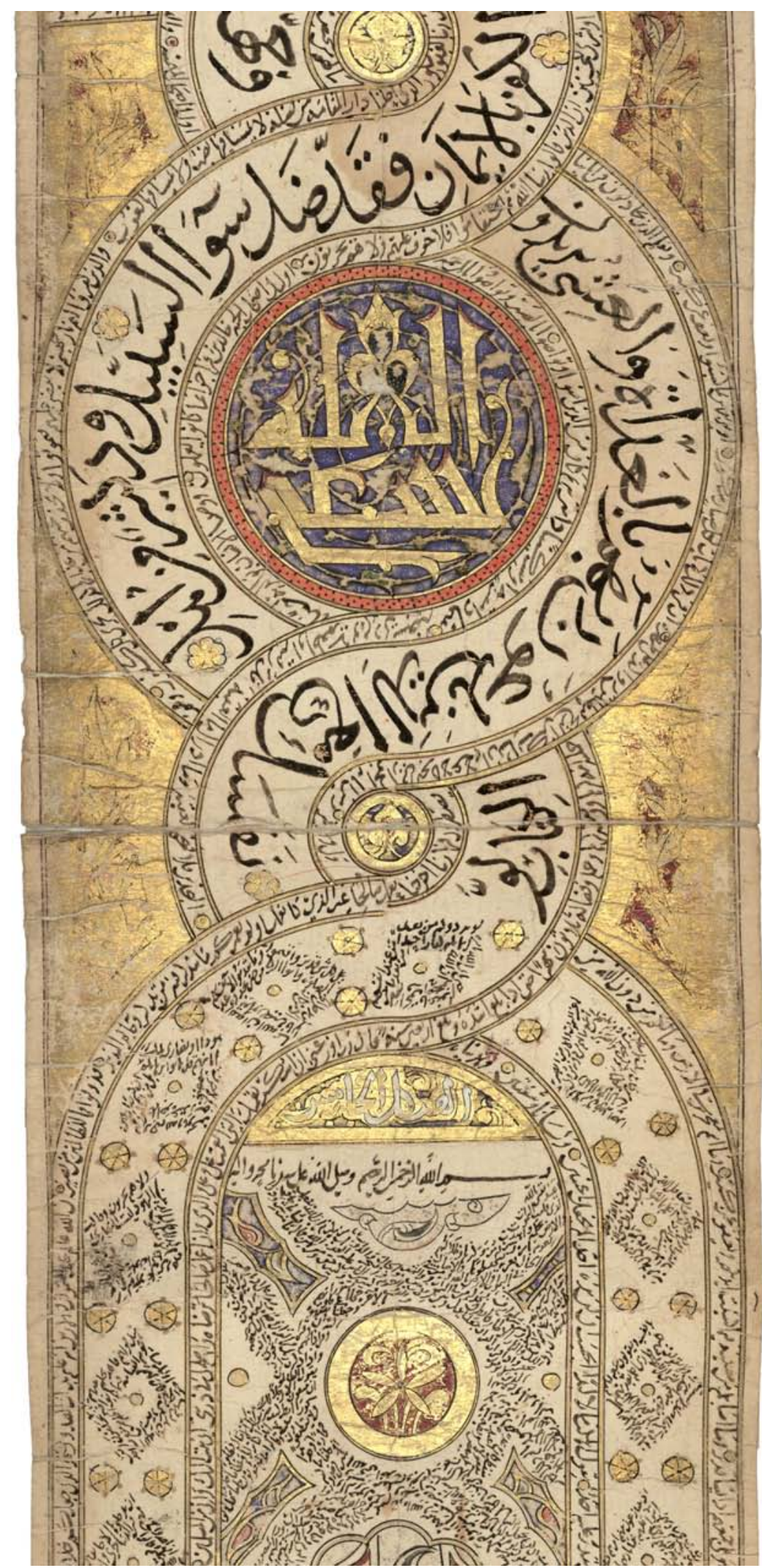

ABB. 77

Basel Universitätsbibliothek, M III 173 (vgl. bei Anm. 39 und 205): Medaillon mit der Anrufung Gottes mit Subhāna Allāh in goldenem Zierkufi auf blauem Hintergrund. Im nächsten Rechteck darunter (Federkastenform) steht der 5 . Haykal. 

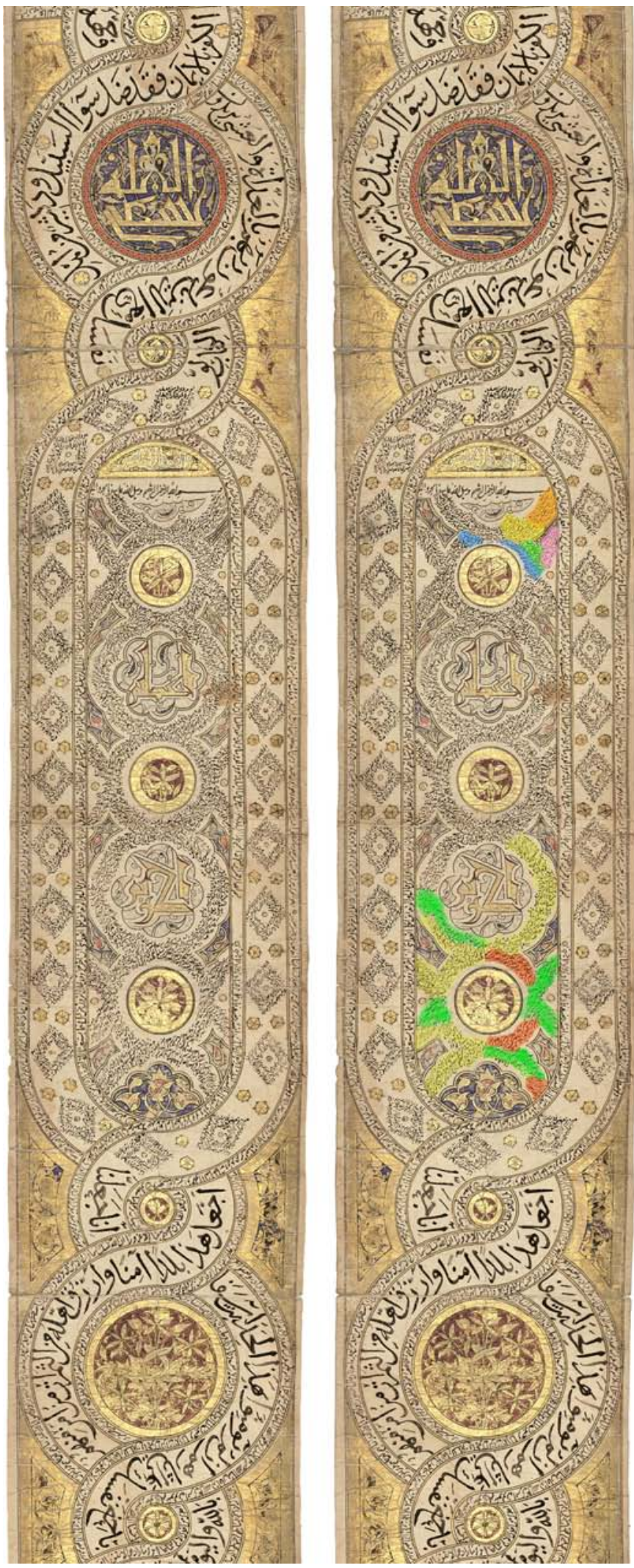

ABB. $78 \mathrm{~A}-\mathrm{B}$

Basel Universitätsbibliothek, M III 173 (vgl. bei Anm. 209-216): Beginn des 5. Haykals. Der Gebetstext wurde hier in $\dot{G} u b \bar{a} r$-Schrift notiert. Er besteht aus unterschiedlichen Textelementen, die sich teilweise identifizieren liessen. Der Text ist in diesem Abschnitt vertrackt angeordnet. 

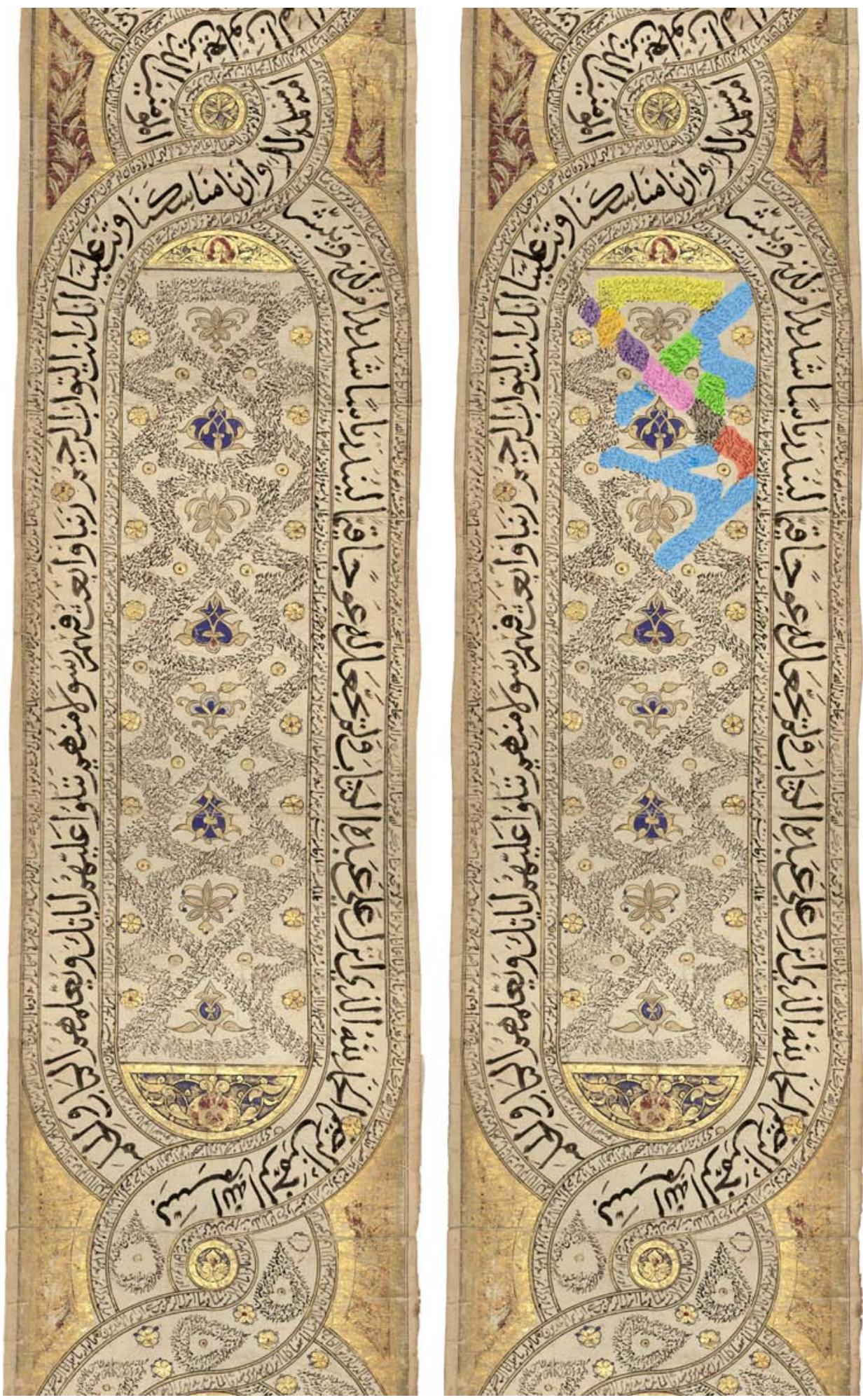

АВв. 79A-B Basel Universitätsbibliothek, M III 173 (vgl. bei Anm. 43-45 und 239-246): Auch in diesem Abschnitt aus dem 6. Haykal ordnete der Schreiber den Text komplex an. Unterschiedliche Stellen liessen sich lokalisieren und identifizieren. 


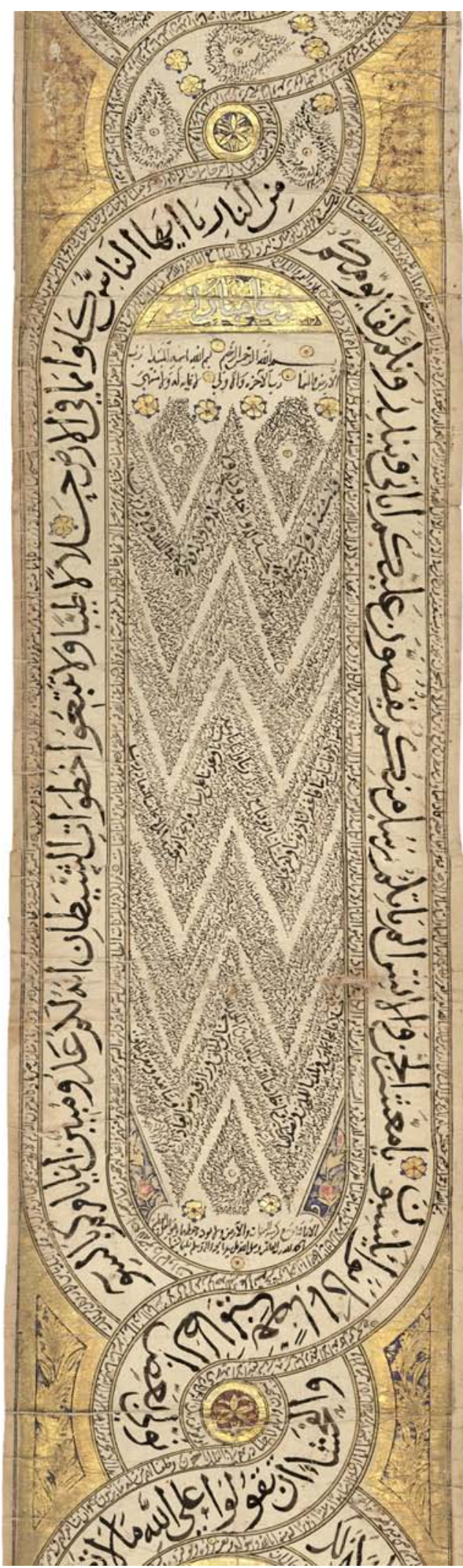

ABB. 80

Basel Universitätsbibliothek, M III 173 (vgl. bei Anm. 53-61 und 271279): Abschnitt mi einem weiteren Gebet, dessen Überschrift $D u^{\prime} \bar{a}$ ' mubārak lautet. Der Gebetstext wurde hier in W-Form angeordnet und oft in $\dot{G} u b \bar{a} r$ notiert. 

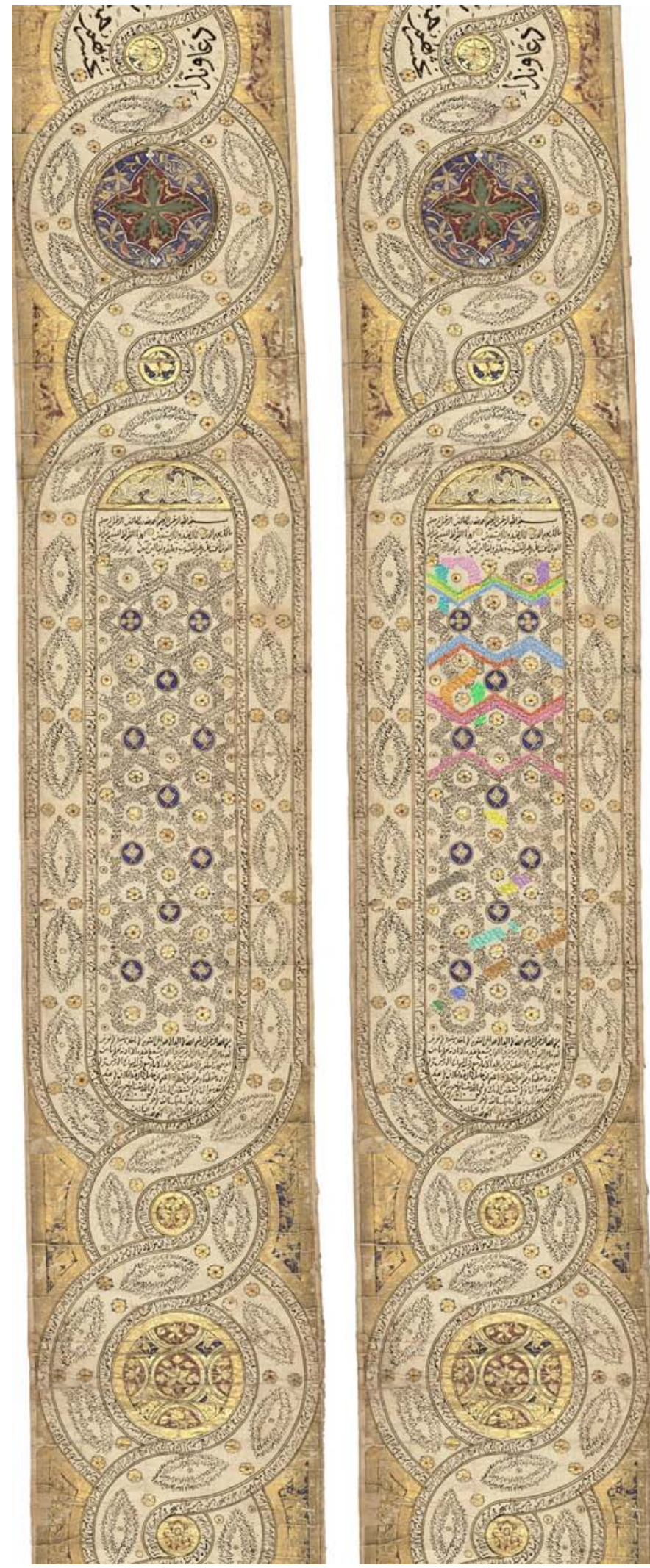

ABB. $81 \mathrm{~A}-\mathrm{B}$

Basel Universitätsbibliothek, M III 173 (vgl. bei Anm. 303-349): Abschnitt von ca. 34 cm Länge mit der Überschrift Du'ā’ mubārak mustağāa. In diesem Abschnitt liessen sich zahlreiche Stellen aus dem Koran (einzelne Verse bzw. Auszüge daraus) lokalisieren und identifizieren. 


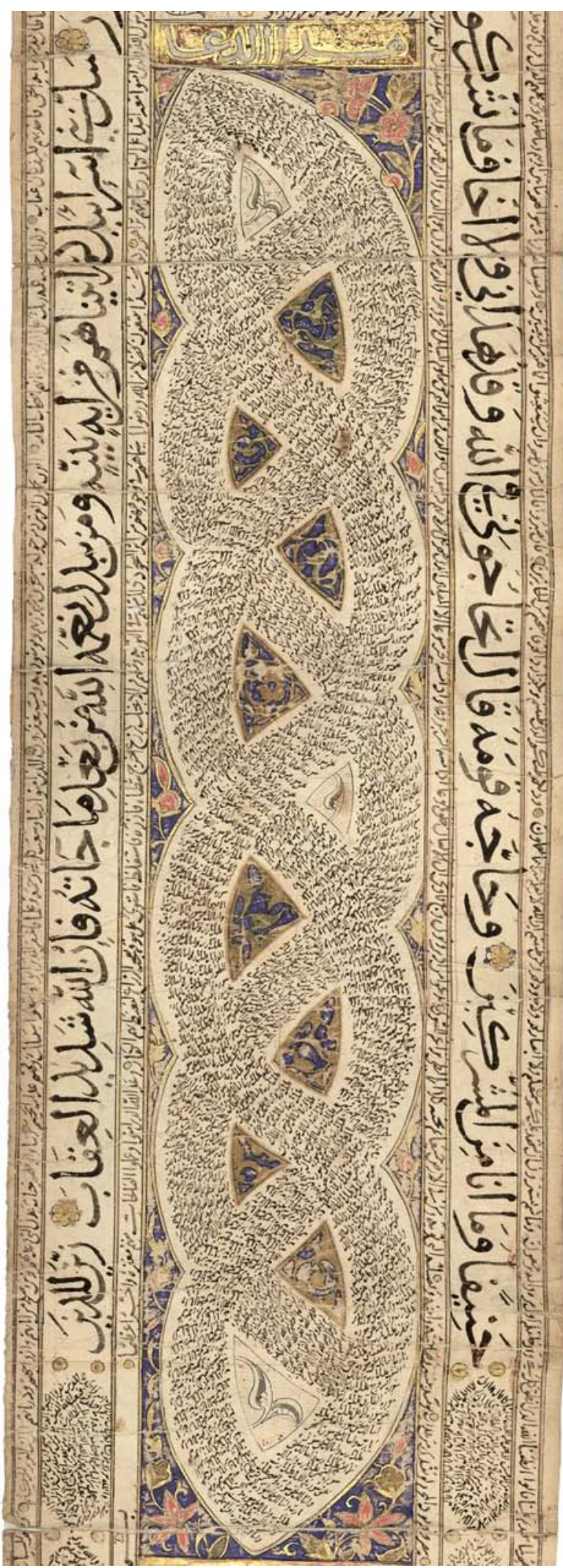

ABB. 82

Basel Universitätsbibliothek, M III 173 (vgl. bei Anm. 358366): Abschnitt mit Text in $\dot{G} u b \bar{a} r$-Schrift, der in ineinander verschlungenen Textbahnen angeordnet ist. Im Text lassen sich u. a. Stellen erkennen, in denen der Betende Gott bei den Namen der einzelnen Suren anruft. Auch wendet er sich an Gott, indem er die Namen der Propheten vor Muhammad anführt. 


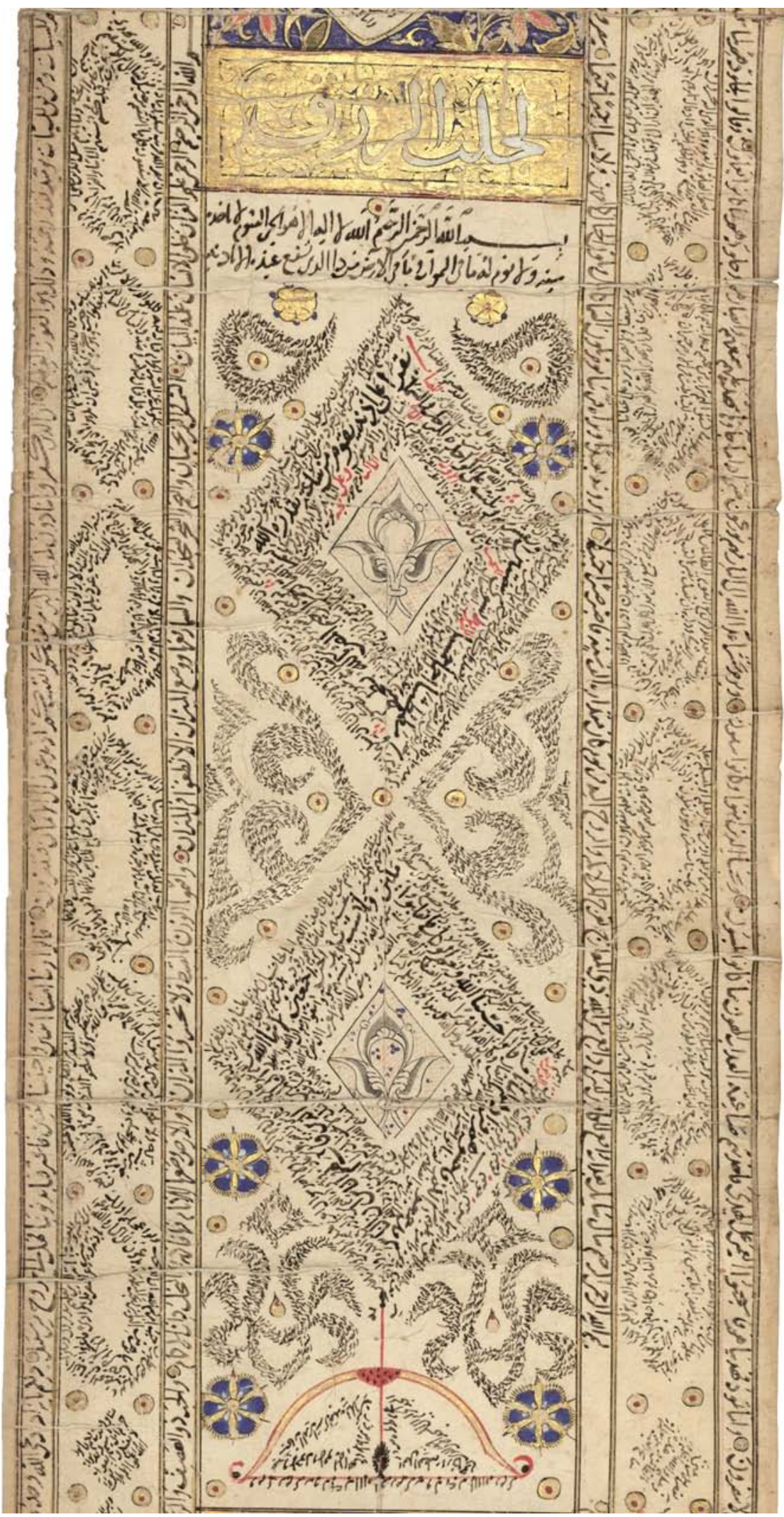

ABB. 83

Basel Universitätsbibliothek, M III 173 (vgl. bei Anm. 8385 und 370-40o): Abschnitt von ca. $34 \mathrm{~cm}$ Länge. Aus der Überschrift $L i$-Ğalb ar-rizq lässt sich schliessen, dass er dem Träger der Rolle einen gesicherten Lebensunterhalt garantieren soll. 


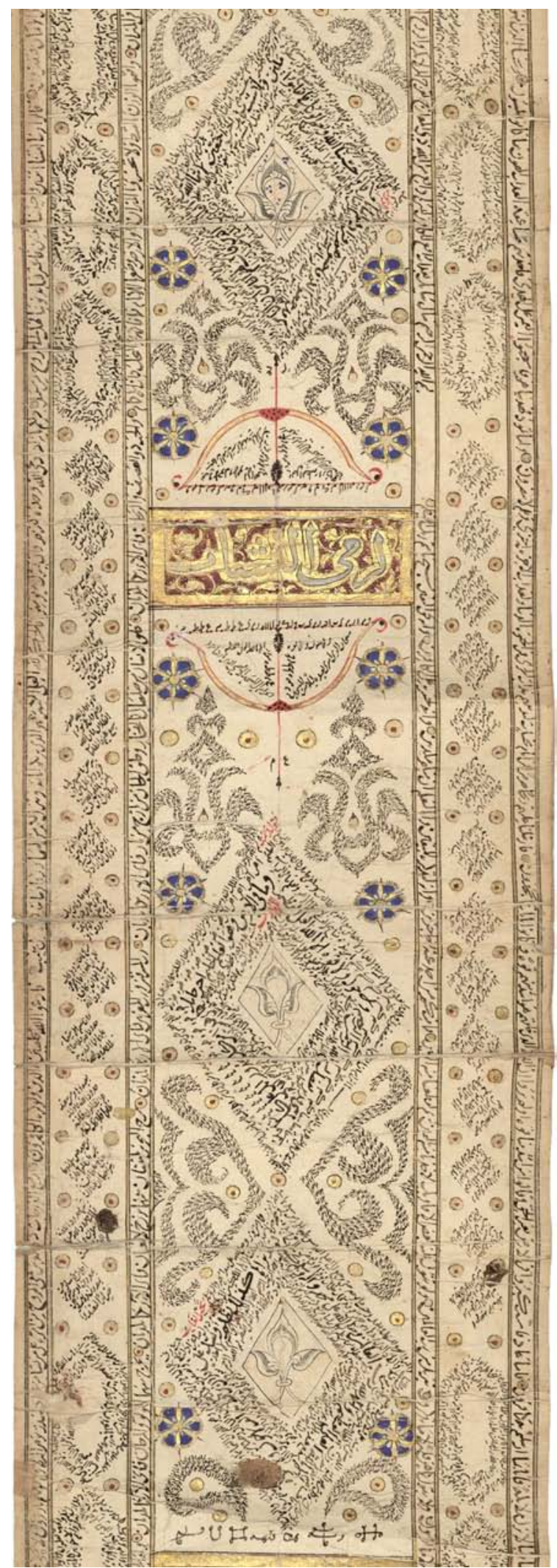

ABB. 84

Basel Universitätsbibliothek, M III 173 (vgl. nach Anm. 86 und bei Anm. 400-433): Abschnitt mit der Abbildung von zwei schussbereiten Bögen, die in entgegengesetzten Richtungen weisen. Aus der Überschrift Li-Ramy an-nuššāb lässt sich schliessen, dass dieser Abschnitt dem Besitzer der Rolle Erfolg beim Schiessen garantieren soll. Man beachte die beiden Buchstaben 'ayn und mim auf der rechten bzw. linken Seite des Pfeils. 


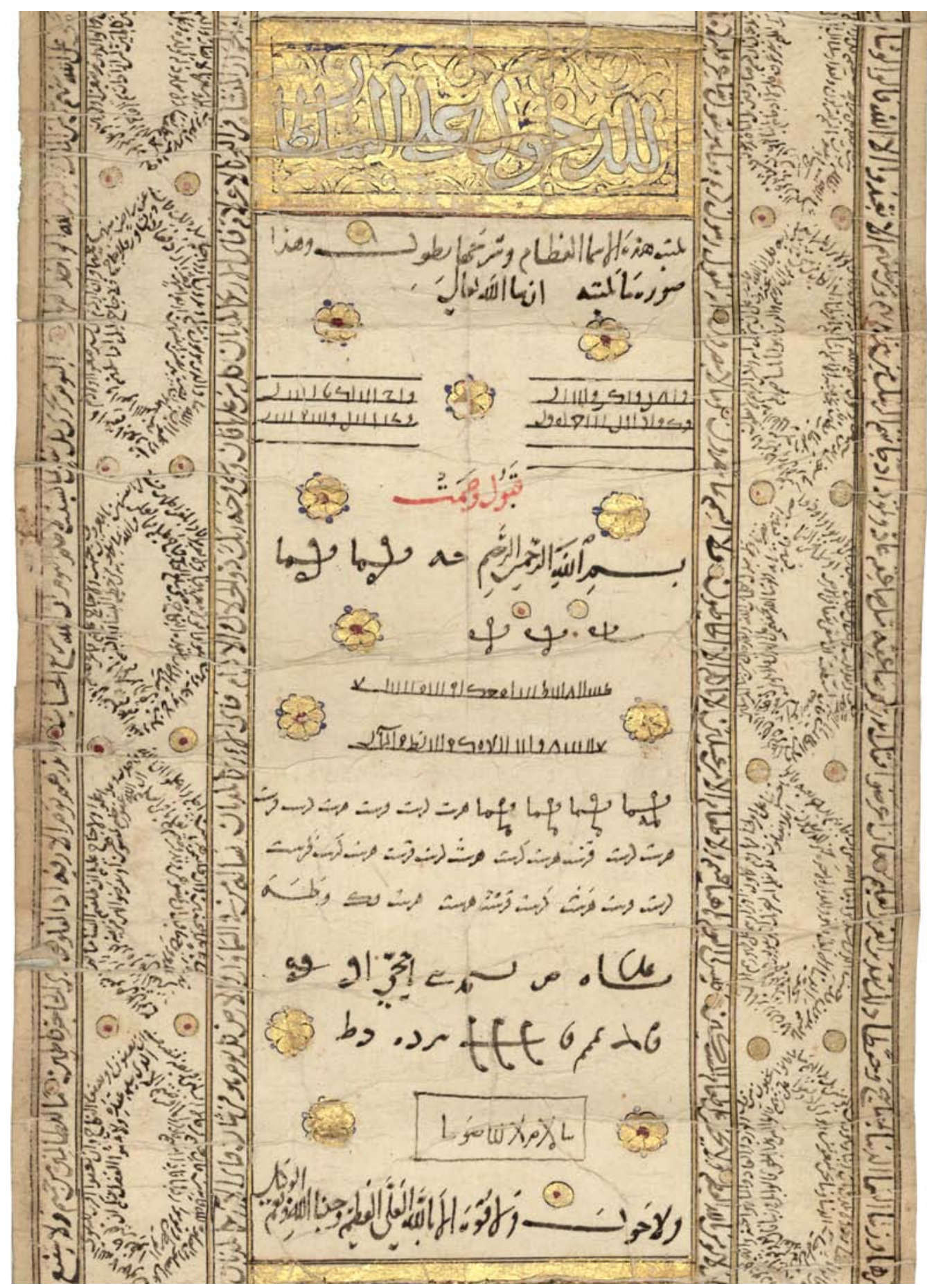

ABB. 85 Basel Universitätsbibliothek, M III 173 (vgl. bei Anm. 434-440): Abschnitt von ca. $17 \mathrm{~cm}$ Länge mit der Überschrift Li-Duhūl 'alā s-Sulțān. Er soll also Schutz verleihen, wenn man bei einer mächtigen Person eintritt. Man beachte, dass gerade dieser Abschnitt eine Reihe von Elementen enthält, die sonst aus der Magie bekannt sind: Brillenbuchstaben, Abfolge von Ziffern und Buchstaben etc. 
Vollständig erhalten; ${ }^{1} \quad$ Masse: $8.7 \times 744 \mathrm{~cm}$ (7.44 m; Bibliotheksmessung). ${ }^{2}$ Starkes Papier, das am Anfang auf grünen Stoff aufgezogen ist.

Das Belegstück wird am Anfang gegen aussen durch ein Lederstück (dunkelbraun) geschützt (Länge: $34.2 \mathrm{~cm}$ ). Es weist Verzierungen in Goldprägung auf: Wellenband dem Rand entlang; Zierelemente mit sieben goldenen Punkten (ein Punkt in der Mitte, sechs „Blätter“ darum herum, in drei Spalten angeordnet; dem Rand entlang jeweils drei Punkte zusammen; dazwischen zusätzlich einzelne Punkte). Ganz am Anfang ein grüner Stoffbändel (Länge: $69.3 \mathrm{~cm}$, Breite: $1.5 \mathrm{~cm}$ ) zum Zubinden der Rolle.

1 Kurze Beschreibung in Arberry, The Koran illuminated $5^{2}$ (Nr. 171).

2 Die Chester Beatty Library erstellte von der vorliegenden Rolle jeweils zwei Aufnahmen pro Meter. Die folgende Beschreibung stützt sich auf zusätzliche eigene Aufnahmen, die die restlichen Teile der Rolle abdecken. Diese zusätzlichen Aufnahmen wurden im Januar 2015 angefertigt. Bei den Verweisen auf Abbildungen zu diesem Belegstück wurde folgendes Vorgehen gewählt: Verweise mit den Ziffern 1 und 2 nach dem Punkt beziehen sich auf die von der Chester Beatty erstellten Abbildungen. Bei den Aufnahmen mit den Ziffern 3 und höher nach dem Punkt handelt es sich um eigenes Abbildungsmaterial. Folgende Übersicht erleichtert die Lokalisierung der einzelnen Aufnahmen auf dem Belegstück: Abb. o.1 ff. (Schutzstück aus Leder): keine Bibliotheksaufnahmen; Abb. 1.1ff.: o-1 m: Bibliotheksphotos 1 und 2 (Verweis hier als 1.1-2); Abb. 2.1ff.: 1-2 m: Bibliotheksphotos 3 und 4 (Verweis hier als 2.1-2); Abb. 3.1 ff.: 2-3 m: Bibliotheksphotos 5 und 6 (Verweis hier als 3.1-3.2); Abb. 4.1 ff.: 3-4 m: Bibliotheksphotos 7 und 8 (Verweis hier als 4.1-4.2); Abb. 5.1 ff.: 4-5 m: Bibliotheksphotos 9 und 10 (Verweis hier als 5.1-2); Abb. 6.1ff.: 5-6 m: Bibliotheksphotos 11 und 12 (Verweis hier als 6.12); Abb. 7.1 ff.: 6-7 m: Bibliotheksphotos 13 und 14 (Verweis hier als 7.1-2); Abb. 8.1 ff.: 7-8 m: Bibliotheksphotos 15 und 16 (Verweis hier als 8.1-2).

N.B.: Die Chester Beatty Library erstellte die im Abbildungsteil verwendeten Digitalisate der vollständigen Rolle erst 2019, als die vorliegende Untersuchung abgeschlossen war. Die hier in den Anmerkungen aufgeführten Stellenverweise beziehen sich auf im Lauf der Arbeit an diesem Belegstück in den Jahren 2014-2015 gemachte Aufnahmen; sie genügen professionellen Ansprüchen nicht (vgl. auch Einleitung zu Teil II, bei und mit Anm. 10).
Das Dokument weist keinen Kolophon auf, der eine zweifelsfreie geographische und chronologische Einordnung gestatten würde (АВВ. 92). Ganz am Schluss des Dokuments lassen sich zwar auf den goldenen Zierbändern zur Linken und Rechten Reste von Einträgen in weisser Schrift erkennen. Diese liessen sich allerdings nicht entziffern. Verschiedene Gestaltungselemente auf Is 1626 legen jedoch nahe, dass es in einem spättimuridischen, allenfalls früh-safawidischen Kontext entstanden sein könnte. Folgende Aspekte fielen bei der Untersuchung auf und könnten zu seiner geographischen und chronologischen Kontextualisierung beitragen:

a. Das Schutzstück aus Leder am Anfang des Dokuments weist grosse Ähnlichkeiten mit jenem von Ms. or. oct. 146 (Staatsbibliothek zu Berlin) auf. ${ }^{3}$ Dieses Vergleichsstück lässt sich der zweiten Hälfte des 16. Jh. zuordnen. ${ }^{4}$ Es ist unwahrscheinlich, dass Is 1626 und Ms. or. oct. 146 aus gänzlich verschiedenen Kontexten stammen. Diese Feststellung allerdings unter der Voraussetzung, dass das Schutzteil am Anfang von Is 1626 original ist.

b. Auch die breiten Goldbänder auf Is 1626 (Dublin) und Ms. or. oct. 146 (Berlin) bilden eine auffällige Gemeinsamkeit. Is 1626 dürfte tendentiell älter sein als Ms. or. oct. 146.

c. Für eine Zuordnung zu einem timuridischen Kontext spricht die grosse Bedeutung von Schriftstellen in Schachbrett-Küf $\iota$ auf diesem Dokument (Авв. 86-89). ${ }^{5}$ Stellen in Schach-

3 Dieser Hinweis setzt allerdings voraus, dass dieses lederne Schutzstück bereist bei der Anfertigung der Rolle selbst dazu gehörte. Es liesse sich ohne weiteres vorstellen, dass die Rolle Is 1626 ursprünglich nicht mit einem Schutzstück versehen war und dieses erst zu einem späteren Zeitpunkt hinzugefügt wurde.

4 Vgl. zu Ms. or. oct. 146 und dessen chronologischen Einordnung Kapitel 5.1, bei Anm. 1 und 89-92. Das für die Herstellung des Schutzstücks Ms. or. oct. 146 (Berlin) verwendete Leder ist rötlich gefärbt: jenes von Is 1626 ist braun.

5 Vgl. dazu die Beschreibungen Teil I, Figuren I.1-12 (ab Anm. 24) und bei Anm. 16-18. 
brett-Küfı sind zurVerzierunge von Bauwerken aus der Timuriden-Zeit gut bekannt. ${ }^{6}$

d. Zur Einordnung kann auch das Anfangszierfeld (Höhe $5 \mathrm{~cm}$ ) unmittelbar vor dem Beginn der Abschrift des Korans herangezogen werden (Ав в. 90). ${ }^{7}$ Das florale Muster auf blauem Hintergrund lässt sich in sorgfältigerer Ausführung in Handschriften aus timuridischen und safawidischen Kontexten mehrfach belegen. ${ }^{8}$

e. Auffällig ist sodann die Verzierung durch ein pflanzliches Rankenmuster ${ }^{9}$ als Hintergrund im ersten Abschnitt der Rolle (Länge: $66.2 \mathrm{~cm}$ ) vor dem Beginn der Abschrift des Korans im Mittelstreifen. Derartige Verzierungen lassen sich auch in Handschriften aus der späten Timuriden- und der Safawiden-Zeit in ähnlicher Ausführung belegen. ${ }^{10}$

Den soeben angestellten Überlegungen ist hinzuzufügen, dass sich der Aufbau dieses Belegstücks deutlich von den meisten zuvor untersuch-

6 Vgl. u.a. die folgenden Bauwerke (siehe bereits Kapitel 4.7, Anm. 7): 1. Qāẹīzāda-Rūmī-Mausoleum in Samarkand (errichtet um 1425): https://archnet.org/sites/2911 und https://archnet.org/sites/2911/media_contents/149o (Stand 29. September2017). 2. Mīr Čāqmāq-Moschee in Yazd: Golombek und Wilber, Timurid architecture I, 421423 (Nr. 226A, R. Holod) und II, Abb. 450-46o, v.a. Abb. 450, Pläne 145-147; 3. Ardabil, Grabturm Šayh Ṣafĩ ud-Dīns errichtet 1345 (also vor den Timuriden): https:// archnet.org/sites/1595/media_contents/40812 (Stand 29. September 2017).

7 Vgl. die Abb. 1.2 und 1.18; zu einer ausführlicheren Beschreibung vgl. unten, Teil II, vor Anm. 6o.

8 James, After Timur: Beachte u.a. die Frontispize mit dem Rankenmuster auf blauem Hintergrund: 150 (Nr. 39: Koran, einbändig: Shiraz, 952/1545-1546); 158f. (Nr. 40: Koran, einbändig; Shiraz, 1525-1550); 164f. (Nr. 41: Koran, einbändig; Shiraz, 1525-1550).

9 Vereinzelt lassen sich hier auch blaue Blätter erkennen.

10 Vgl. Lentz und Lowry, Timur and the princely vision 76f. (cat. no. 19: Frontispiz aus einem Koran, Iran, ca. 1400-1450); 82 f. (cat. no. 11: Frontispiz aus der Kalīla wa-Dimna-Handschrift des Niẓām ud-Dīn Abu lMaāāi Naṣrullāh, Herat, datiert Muharram 833/Oktober 1429). ten Dokumenten unterscheidet. Zwar lässt sich auch auf diesem Belegstück ein Schriftband, im vorliegenden Fall ist es zweiteilig, feststellen, das einen Mittelstreifen einfasst. Allerdings beginnt es erst mit der Abschrift des Korans in Teil II der Rolle. Auf Teil I fehlt ein derartiges Schriftband. Die beiden seitlichen Schriftbänder sind ausserdem erst am Ende des Dokuments miteinander verbunden. Sie wechseln nicht bereits zuvor von der einen auf die andere Seite der Rolle, wie sich dies auf unterschiedlichen Dokumenten aus dem 14. Jh. beobachten liess. Das Vorgehen des Herstellers des vorliegenden Dokuments ruft am ehesten jenes des Kopisten in Erinnerung, der für die Anfertigung des Belegstücks aus der David Collection (Kopenhagen) verantwortlich war. ${ }^{11}$

Die zuvor festgehaltenen Beobachtungen legen eine Entstehung des vorliegenden Dokuments am Ende des 15. Jh. oder im Lauf des 16. Jh. nahe. Vieles spricht für eine Zuordnung in einen iranischen Kontext. Eine Anfertigung in Tabriz lässt sich nicht a priori ausschliessen. Angesichts der hohen Mobilität von Schreibern, Kunsthandwerkern und Derwischen - letztere werden von J. Kissling gern als „die Reisigen“ bezeichnet ${ }^{12}$ - ist vor einer abschliessenden geographischen Zuordnung allerdings Vorsicht angezeigt.

Das Belegstück lässt sich in zwei Teile von ungleicher Länge einteilen (Teil I und II):

Teil I: ${ }^{13}$ Die Länge von Teil I beträgt ca. $66.2 \mathrm{~cm} .{ }^{14}$ Auf diesem Teil lassen sich unterschiedliche Elemente feststellen, die den Charakter des Dokuments prägen. Sie werden in der detaillierten Beschreibung festgehalten.

11 Vgl. dazu oben, Kapitel 4.2.

12 So auch Taeschner, Zünfte und Bruderschaften 279. Die entsprechende Stelle bei H.J. Kissling liess sich leider nicht mehr eruieren (vgl. Kapitel 3.1, Anm. 9o).

13 Vgl. Abb. 1.1-18.

14 In dieser Längenangabe ist das blaue Zierfeld eingeschlossen, das unmittelbar vor dem Beginn der Abschrift des Korans im Mittelstreifen eingefügt worden ist und somit eigentlich zu Teil II der Rolle gehört. 
Teil II: ${ }^{15}$ Dieser Teil umfasst den Rest der Rolle. Hier wurde im Mittelstreifen (Breite $4.2 \mathrm{~cm}$ ) die islamische Offenbarung auf horizontalen Zeilen in $\dot{G} u b \bar{a} r$-Schrift kopiert. Dieser Mittelstreifen wird zur Rechten und Linken auf seiner gesamten Länge von einem schmalen Textband eingefasst (Breite ca. $0.35 \mathrm{~cm}$ ), das Text in kleinem Nash (Höhe ca. $3 \mathrm{~mm}$ ) enthält. ${ }^{16}$ Dieser Text wurde in der Rollenrichtung kopiert. Gegen aussen schliesst sich auf beiden Seiten ein breiteres Schriftband (ca. $0.6 \mathrm{~cm}$ ) mit Text in schwarzem Schachbrett$K \bar{u} f \imath$ an. Der Text in Schachbrett-Küf $\iota$ verläuft in Rollenrichtung, einerseits vorwärts und anderseits rückwärts. Die Oberlängen der Buchstaben in den beiden Textrichtungen sind ineinander verzahnt. ${ }^{17}$

Ergänzend ist darauf hinzuweisen, dass ein breiter goldener Rand und ein schmaler roter Zierstreifen das Dokument auf seiner gesamten Länge einfassen (Teile I und II). Die Breite der beiden Goldstreifen beträgt je ca. $1.0 \mathrm{~cm}$. Auf diesem Goldstreifen lassen sich zwei parallel zueinander verlaufende feine Zierlinien erkennen. Gegen innen schliesst sich ein roter Zierstreifen (Breite ca. $0.2 \mathrm{~cm})$ an.

Der rote Zierstreifen, die goldenen Seitenbänder, das Band mit Text in Nash-Schrift und das breitere Band mit Text in Schachbrett-Küfi schliessen die Rolle auch ganz am Schluss ab. ${ }^{18}$ Das Dokument ist jetzt auf einem kleinen Rohr aufgezogen; dieses ist allerdings nicht ursprünglich.

TEIL I: I.O (АВB. 86):19 Ganz am Anfang des Dokuments fällt eine goldene Verzierung auf; sie wurde aufgeklebt (Blattgold?) und ruft eine Mütze in Erinnerung. ${ }^{20}$ Ihre Höhe beträgt ca. $3.2 \mathrm{~cm}$. Die Ver-

15 Vgl. ab Abb. 2.1.

16 Bei dieser Höhe kann eine Schrift gerade noch knapp als $\dot{G} u b \bar{a} r$ charakterisiert werden; ab $3 \mathrm{~mm}$ Schrifthöhe ordnet man eine Schrift aber zumeist nicht mehr als $\dot{G} u b \bar{a} r$ ein.

Vgl. zu diesem Vorgehen auch unten bei Anm. 7o.

Vgl. Abb. 16.3-4.

Diese Verzierung wird als I.o bezeichnet, da sie sich noch ausserhalb des Rahmens mit dem goldenen Rankenmuster als Hintergrund befindet.

20 zierung weist unten einen Ring auf, auf den der schmalere Oberteil aufgesetzt worden ist. Diese Verzierung ruft die unter Derwischen gebräuchlichen Kopfbedeckungen in Erinnerung. Es wurden Versuche angestellt, aufgrund der Form dieser Mütze eine Zuordnung zu einem bestimmten Derwischorden vorzunehmen. ${ }^{21}$ Die Details der Kopfbedeckung auf dieser Rolle lassen sich allerdings nur schlecht erkennen. Auffällige Ähnlichkeiten liessen sich jedoch mit der Ausbildung der Kopfbedeckung in den Derwischorden der Qādiriyya und Rifā'iyya feststellen. ${ }^{22}$ Gerade diese Kopfbedeckung war ein deutlicher Hinweis auf die Zuordnung dieser Dokumente in Rollenform ins Umfeld der Mystik ganz allgemein.

Diese Mütze befindet sich noch ausserhalb des Rahmens (schwarze Doppellinie und roter Zierstreifen), der das ganze Dokument einfasst. Danach schliesst sich der Abschnitt an (Länge ca. $62 \mathrm{~cm}$ ), dessen Hintergrund von einem goldenen Rankenmuster mit vereinzelten blauen Blättern ausgefüllt worden ist. Auf diesem Abschnitt lassen sich entlang der Längsachse 12 Elemente mit Textelementen in Schachbrett-Küfı erkennen: ${ }^{23}$

I.1: Als erstes Zierelement lässt sich ein auf der Spitze stehendes, rot eingefasstes Quadrat erkennen. ${ }^{24}$ Es enthält Text in blauem Schachbrett-Kūfi. Die leeren Felder erscheinen als von schwarzen Linien eingefasste Quadrätchen. ${ }^{25}$

Beim hier eingefügten Text handelt es sich um Q 72:8; der Vers lautet:

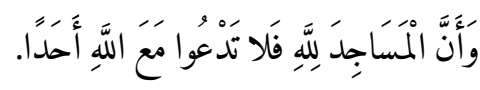

sich ein Schildchen mit einer alten Signatur; der Eintrag lautet (in arabischer Schrirft): țūmār / 6459 (obere / untere Zeile).

21 Zur Bedeutung der Kopfbedeckungen in den einzelnen Derwischgruppierungen und ihren Formen vgl. Frembgen, Kleidung und Ausrüstung, Kapitel „Mütze und Turban" 29-55.

Vgl. für zusätzliches Abbildungsmaterial: Anetshofer, Traktat über die Derwischmützen, beachte vorliegend v. a. Abb. 34 und 100.

23 Vgl. für eine Übersicht die Abb. 1.12-16.

24 Seitenlänge: $2.5 \mathrm{~cm}$.

25 Vgl. die Abb. 1.10 und 1.3. 
Dieser Text beginnt in der rechten Ecke des Quadrats und verläuft zuerst im Uhrzeigersinn dem Rand entlang. Mit dem Begriff ma'a springt der Text ins Innere dieses Quadrats.

I.2: Bei der zweiten Figur handelt es sich um einen Kreis von $5.3 \mathrm{~cm}$ Durchmesser. Er wird von zwei golden ausgefüllten Ringen eingefasst, zwischen die ein Schriftband mit Text in schwarzem Schachbrett-Küf $\iota$ eingepasst worden ist. Dieser Text besteht aus zwei Zeilen, die gegenläufig angeordnet sind; die Oberlängen der Buchstaben sind wiederholt ineinander verzahnt. Das Zentrum des Kreises (Innendurchmesser: $2.8 \mathrm{~cm}$ ) ist rot ausgefüllt und mit einem goldenen Muster versehen, das aus Pflanzenranken mit Blättern und Blüten besteht. In diesen innern Kreis wurde ein auf der Spitze stehendes Quadrat eingepasst, dessen Seitenlänge $2 \mathrm{~cm}$ misst.

In diesem Quadrat wurde Text in blauem Schachbrett-Küfı́ notiert. Die leeren Felder erscheinen als von schwarzen Linien eingefasste Quadrätchen. Der Text im Quadrat beginnt erneut in der rechten Ecke und lautet:

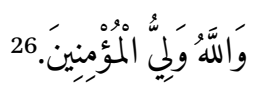

Die Entzifferung des Texts in schwarzem Schachbrett-Küfi im Ring um diese Figur herum gestaltet sich schwieriger; die folgenden Feststellungen sind hilfreich: Der Text verläuft auf der innern Zeile im Gegenuhrzeigersinn; er steht über der oberen Spitze des Quadrats aufrecht. Auf der äussern Zeile verläuft der Text jedoch im Uhrzeigersinn; er steht über der oberen Spitze des Quadrats auf dem Kopf. Dieser Ring mit Textstellen in gegenläufigem Schachbrett-Küf $\iota$ wurde in drei Abschnitte eingeteilt. Dies geschieht durch durchgehende Linien aus feinen Quadrätchen, die keinerlei Buchstabenteile enthalten. Diese durchgehenden leeren Linien trennen die drei folgenden Texteinheiten voneinander:

I.2 (Ring) Text 1: Direkt über der oberen Spitze des Quadrats im Innern des Kreises befindet sich

26 Die Aussage findet sich so am Schluss von Q 68:3. eine dieser durchgehenden Linien mit Kästchen ohne Buchstabenelemente. Die nächste durchgehende Linie mit leeren Kästchen folgt im Ring mit dem Text in gegenläufigem Schachbrett-Küf $\iota$ etwas links der Mitte der Linie, die die obere und die linke Ecke des Quadrats miteinander verbindet. In diesem ersten Abschnitt steht die Basmala; sie beginnt auf der Innenseite des Rings. Innerhalb des Ausdrucks ar-Rah-//-mān ${ }^{27}$ wechselt der Schreiber auf die Aussenseite und notiert den Rest der Formel rückläufig und auf dem Kopf stehend.

I.2 (Ring) Text 2: Die soeben vorgestellte Basmala gehört natürlich grundsätzlich zu einer Sure, die hier im Gegenuhrzeigersinn notiert auch sogleich beginnt. Die Basmala wurde als selbständiges Textelement vorgestellt, da der Schreiber innerhalb dieser Formel die Schriftrichtung wechselt und sie damit vom Rest des Surentexts abhebt.

Zwischen der oberen und der linken Ecke des Quadrats im Innern beginnt die Abschrift von Q 114. Diese Sure wurde im Gegenuhrzeigersinn notiert und beginnt auf dem Innenband. Der Schreiber wechselt innerhalb des Ausdrucks alhannās in Q 114:4 (Schluss) vom Innenband auf das gegenläufige Aussenband. ${ }^{28}$ Diese Übergangsstelle befindet sich wenig unterhalb der rechten Ecke des Quadrats und wird durch eine Linie von Kästchen ohne Textelemente markiert. ${ }^{29}$ Etwas oberhalb dieser Stelle verläuft eine gut sichtbare Bruchstelle im Papier.

27 Die Markierung // kennzeichnet den Übergang zum rückläufigen Teil.

28 Q 114 wurde vollständig notiert und lautet:

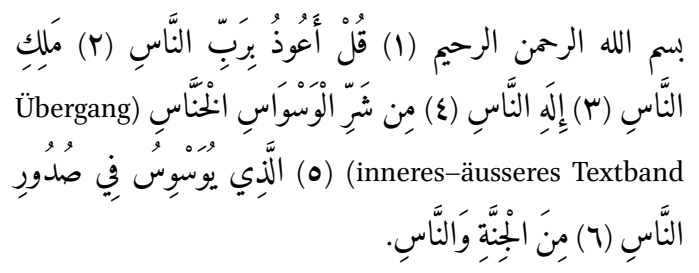

29 Ganz wenig unterhalb dieser oberen Linie mit leeren Kästchen ohne irgendwelche Buchstabenelemente befindet sich eine zweite solche Linie. Zwischen diesen beiden Linien hat der Schreiber den Ausdruck al-hannās notiert. 
I.2 (Ring) Text 3: Zwischen der rechten Ecke und der oberen Ecke des Quadrats im Kreisinnern hat der Schreiber im Ring eine dritte Stelle notiert. Sie beginnt erneut auf der innern Zeile im Gegenuhrzeigersinn; der Ausdruck an der Übergangsstelle (yașifüna) ist stark verderbt. Bei der kopierten Stelle handelt es sich um Q 37:180-181; sie lautet:

$$
\text { عَلَى المُرسَسَلِنَ. }
$$

Diese Koranstelle wurde übrigens an derselben Stelle auch in der identisch gestalteten Figur I.1O kopiert. ${ }^{31}$

I.3: Bei der dritten Figur handelt es sich erneut um ein auf der Spitze stehendes Quadrat, das rot eingefasst ist. Die Seitenlänge beträgt knapp $2 \mathrm{~cm}$. Es enthält Text in blauem Schachbrett-Küfi. Die leeren Felder erscheinen als von schwarzen Linien eingefasste Quadrätchen. Der Text beginnt auch hier in der rechten Ecke und lautet:

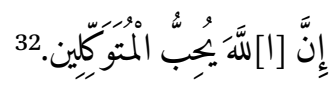

I.4 und I.8 (Авв. 87): Darunter schliesst sich eine fünfstufige Pyramide an, deren Spitze auf den Rollenanfang ausgerichtet ist. Oberhalb der letzten Stufe befindet sich ein auf der Spitze stehendes Quadrat. Diese erste Pyramide stellt Figur I.4 dar. Aufgrund des darin kopierten Texts lässt sich schliessen, dass sie inhaltlich zu einer zweiten Pyramide gehört, deren Spitze nach unten ausgerichtet ist (I.8). Die einzelnen Zierelemente werden in diesem Abschnitt der Rolle gewissermassen an einer weiteren Figur (I.6) gespiegelt, die später vorzustellen ist.

30 Wechsel innen-aussen innerhalb dieses Begriffs; er befindet sich oberhalb der oberen Ecke des Quadrats im Innern des Kreises.

31 Siehe dazu bei Anm. 57.

32 Es handelt sich um Q 3:159 (Schluss); das alif von Allāh fehlt soweit ersichtlich.
Die beiden Figuren I.4 und I.8 enthalten Text in Schachbrett-Küfi. Die unterste Stufe der oberen Pyramide (I.4) erstreckt sich nahezu über die gesamte Breite des Mittelstreifens. ${ }^{33}$ Die Pyramide verjüngt sich darauf nach oben. Auf den einzelnen Stufen der Pyramide ist der Text auf zwei Zeilen angeordnet. Der Text auf der unteren Zeile steht aufrecht und verläuft von rechts nach links, wie dies im Arabischen üblich ist. Der Text in der zweiten Zeile auf jeder Stufe steht hingegen auf dem Kopf und verläuft in der Gegenrichtung. Auch hier sind die Oberlängen der Buchstaben auf der unteren und oberen Zeile ineinander verzahnt. Der eingefügte Text lässt sich wie folgt entziffern:

I.4: ${ }^{34}$ Der Text in dem auf der Spitze stehenden Quadrat zuoberst und im Quadrat auf der obersten Stufe der Pyramide ist losgelöst vom restlichen Text in der Figur I.4 zu lesen. Mutmasslich steht in diesen beiden Quadraten u. a. der Ausdruck 'Alī.

Beim anschliessend auf den einzelnen weiteren Stufen der beiden Pyramiden I.4 und I.8 kopierten Text handelt es sich um eine Abschrift von Q 59:22-24. Die Abschrift wurde nach folgendem Schema angeordnet: Der Schreiber notierte Q 59:22 auf der unteren Zeile der einzelnen Stufen der oberen Pyramide; der Text steht hier aufrecht und verläuft Stufe um Stufe nach unten; er lautet:

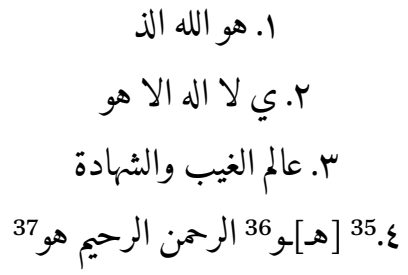

I.8: Der Schreiber setzt die Abschrift der Stelle in der unteren Pyramide (I.8) fort. Er tut dies, indem er an der breiten Basis der Pyramide beginnt und

33 Die untere Pyramide (I.8) ist einfach spiegelverkehrt aufgebaut; ihre Spitze ist nach unten gerichtet.

34 Vgl. Авв. 87.

35 Unterste Stufe der oberen Pyramide (Figur I.4).

36 Zeilenanfang verderbt.

37 Huwa: gehört bereits zu Q 59:23. 
die Abschrift Zeile um Zeile in Richtung Spitze der unteren Pyramide fortsetzt. Da die Spitze der unteren Pyramide (I.8) auf das Rollenende ausgerichtet ist, stehen die vier weiteren Zeilen innerhalb der Pyramide auf dem Kopf.

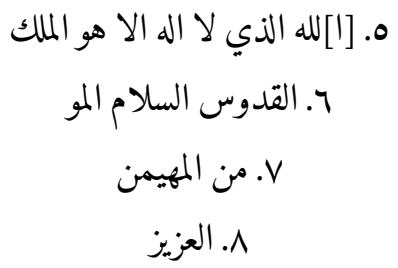

Die beiden Quadrate an der Spitze der unteren Pyramide enthalten wiederum separaten Text, der sich nicht mit Sicherheit entziffern liess.

Der Schreiber setzt die Abschrift von Q 59:23 danach in den gegenläufig ausgerichteten Zeilen der beiden Pyramiden fort (zuerst Pyramide I.8, darauf Pyramide I.4). Der weitere Text steht ab hier gegenüber der Rollenrichtung auf dem Kopf:

$$
\begin{aligned}
& \text { 9. الجبار } \\
& \text { •ا. المتكبر سبحان الله. } \\
& \text { 11. عما يشركون38 هو الله } \\
& \text { rا. الخالق البارئ المصور له [ا]لِ }
\end{aligned}
$$

Der Schreiber hat damit die breiteste Zeile der unteren Pyramide (I.8) erreicht; er setzt die Abschrift von Q 59:24 in der oberen Pyramide fort (I.4). Der Text steht hier gegenüber der Rollenrichtung weiterhin auf dem Kopf:

$$
\begin{aligned}
& \text { سا. لسما39 الحسنى يسبح له ما في } \\
& \text { عا. السموات وما في الا لاحئ }
\end{aligned}
$$

38 Ende von Q 59.23, Beginn von Q 59:24.

Dieser Ausdruck wurde zwischen den Pyramiden I.8 und I.4 aufgeteilt. Es handelt sich um den Begriff al-asmä; es ist nicht gänzlich klar, wo der Schreiber das Wort trennt.

$$
\text { 17. رض } 40 \text { هو العزيز } 14
$$

Der Schreiber ist jetzt wieder unmittelbar unterhalb der beiden Quadrate an der Spitze der oberen Pyramide (I.4) angelangt. Die beiden Figuren sind damit vollständig ausgefüllt. Der Text in den beiden Quadraten an der Spitze liess sich nicht mit Sicherheit entziffern.

I.5: Bei dieser Figur handelt es sich um ein Viereck, dessen Winkel nicht exakt $90^{\circ}$ betragen. Diese Figur wird von einem roten Rahmen eingefasst und enthält Text in blauem Schachbrett-Küfí. Die leeren Felder erscheinen als von schwarzen Linien eingefasste Quadrätchen.

Im Zentrum dieser Figur steht der Ausdruck Allāh (1 Mal). Den vier Kanten entlang steht sodann vier Mal der Name Muhammad, wobei das Anfangs-Mìm jeweils in den Ecken steht. In diesem Viereck befindet sich zwischen der äusseren Zeile und dem Begriff Allāh im Zentrum eine zusätzliche Linie mit Schriftelementen; hier wurde vier Mal der Ausdruck 'Alı̀ kopiert.

Diese Figur macht also auf die Trinität von Allāh, 'Alī und Muhamammad aufmerksam. Sie spielt für Gläubige alawitischer Ausrichtung eine bedeutende Rolle. ${ }^{42}$ Mit dieser Feststellung wird weder behauptet noch ausgeschlossen, dass das vorliegende Belegstück aus einem alawitischen Kontext stammt. Es wird aber in allgemeiner Form in Erinnerung gerufen, dass die 'Alī-Verehrung im 14. und 15. Jh. weit über die Schia hinaus verbreitet war. ${ }^{43}$

I.6 (Авв. 88): Diese Figur nimmt eine zentrale Stellung in Teil I der Rolle ein. Sie bildet die imaginäre horizontale Achse an der nicht nur die beiden Pyramiden I.4 und I.8, sondern auch die weiteren Figuren in diesem Abschnitt gespiegelt werden. Figur I.6 wird erneut aus Textstellen in gegenläu-

40 Zeilenumbruch innerhalb des Wortes al-ard.

41 Stelle verderbt; Ende von Q 59:24 (Schlussvers der Sure).

42 Vgl. Moosa, Extremist Shiites 50-65, Kapitel 5: „The Ghulat's 'trinity'".

43 Vgl. Kapitel 3.3: „Alid loyalty oder die Schiitisierung der Futuwwa-Bewegung". 
fig angeordnetem Schachbrett-Küfi gebildet, wie es der Schreiber bereits in den beiden Pyramiden I.4 und I.8 verwendet hat. Sämtliche Textstellen mit gegenläufig ausgerichtetem Schachbrett$K \bar{u} f \iota$ in schwarzer Schrift sind golden eingefasst.

Im Zentrum von Figur I.6 stehen fünf senkrecht, also in der Rollenrichtung, ausgerichtete Stäbe (I.6.2). Darüber und darunter befindet sich je eine fünfstufige Pyramide; die oberste Stufe der beiden Pyramiden wird durch ein auf der Spitze stehendes Quadrat gebildet. Die Spitze der oberen Pyramide (I.6.1) ist auf den Rollenanfang hin ausgerichtet; die Spitze der unteren Pyramide (I.6.3) weist auf das Rollenende hin. Im folgenden wird der Inhalt dieser Figur vorgestellt. Der Schreiber hat den Text in Schachbrett-Kūfı notiert und ähnlich angeordnet, wie er dies bereits in den beiden Figuren I.4 und I.8 getan hat.

I.6.1: Im auf der Spitze stehenden Quadrat auf der obersten Stufe der oberen Pyramide steht mit grosser Wahrscheinlichkeit der Name 'Alī.

I.6.1a: Auf den weiteren Stufen der oberen und unteren Pyramide (I.6.1 und I.6.3) folgt eine Abschrift von Q 102 (Sūrat at-Takātur). Der Schreiber kopierte den Text erneut zuerst auf den gegenüber der Rollenrichtung aufrecht stehenden Zeilen; danach wechselt er auf die gegenläufig ausgerichteten Zeilen, in denen der Text auf dem Kopf steht. Die Stelle ist gerade in den Balken 1 und 2 verderbt (vgl. АВВ. 88):

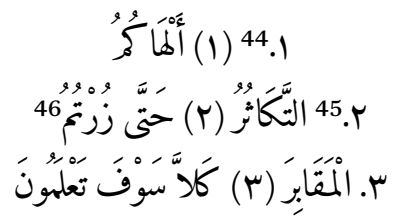

I.6.3: Der Kopist springt jetzt in den Teil I.6.3; er setzt die Abschrift von Q 102 dort auf den drei horizontal ausgerichteten Balken vor dem auf

44 Balken 1, unterhalb des auf der Spitze stehenden Quadrats. Bei den Ziffern in Klammern handelt es sich um die Versnummern.

45 Balken 2; untere Zeile, Schrift aufrecht.

46 Ausdruck zurtum am Ende dieser Zeile wohl teilweise gegenläufig notiert. der Spitze stehenden Quadrat fort. Der Text steht zuerst auf den unteren Zeilen und ist aufrecht ausgerichtet:

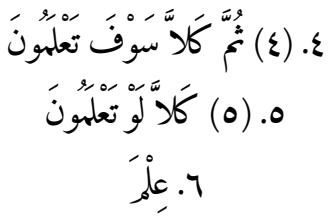

Der Schreiber hat jetzt den letzten Balken vor dem auf der Spitze stehenden Quadrat am Schluss erreicht. Er setzt die Abschrift von Q 102 in den oberen Teilen der einzelnen Balken fort; der Text steht darin gegenüber der Rollenrichtung auf dem Kopf:

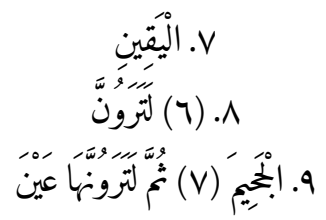

I.6.1b: Der Schreiber springt danach wieder in den oberen Teil und setzt die Abschrift in den gegenüber der Rollenrichtung auf dem Kopf stehende Zeilen fort: ${ }^{47}$

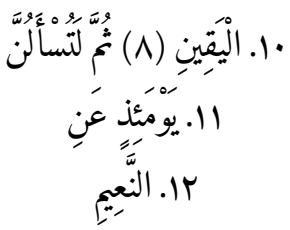

I.6.2: Die Figur I.6.2 befindet sich zwischen den beiden Figuren I.6.1 und I.6.3 (also zwischen den beiden Pyramiden, deren Spitzen nach oben bzw. nach unten weisen). Die Figur I.6.2 umfasst einerseits die in der Rollenrichtung selbst verlaufenden fünf (vertikalen) Stäbe. Zusätzlich gehören aber noch die beiden horizontalen - also quer zur Rollenrichtung verlaufenden - Balken direkt darüber bzw. darunter dazu. ${ }^{48}$

47 Vereinzelt ist die Zuordnung der verschiedenen Ausdrücke zu einer Zeile nicht gesichert. Die Stelle ist teils verderbt. Mehrfache dürften Wörter aufgetrennt worden sein.

48 Vgl. Abb. 1.13. 
In diesem Mittelteil von Figur I.6 wurden die beiden Schlussverse von Q 2 (Q 2:285-286) kopiert. ${ }^{49}$ Die Abschrift beginnt rechts unten auf dem horizontal ausgerichteten Balken unmittelbar vor den fünf vertikalen Stäben. Nach ilay-hi (Vers 285) springt der Schreiber in den ersten vertikal ausgerichteten Balken von links. Er notiert dort auf der inneren, absteigenden Zeile die Fortsetzung von Vers 285. Der Kopist springt darauf Stab um Stab nach rechts und setzt die Abschrift von Q 2:285 auf den absteigenden Zeilen fort. Gegen die Mitte des vertikalen Balkens rechts aussen erreicht er auf der absteigenden Linie den Schluss von Q 2:285 (Schluss: ilay-ka al-mașīr). Unmittelbar anschliessend beginnt Q 2:286. Nach Lā yukallifu Allāh nafasan illā wechselt der Schreiber in den horizontalen Balken darunter und setzt die Abschrift in der unteren Zeile fort (1. Begriff: $w u s^{\prime} a-$ $h \bar{a})$. Im Ausdruck wa-'alay-hā wechselt der Schreiber am Ende des Balkens in die obere Zeile in diesem Balken und setzt die Abschrift auf dem Kopf fort. Er wechselt dann mit in nasinā erneut in die vertikalen Balken und setzt Q 2:286 in den jeweils aufsteigenden Balkenteilen fort. Am Ende der letzten aufsteigenden Zeile links aussen steht der Imperativ fa-anșur-nā (Q 2:286). Der Schreiber notiert die Schlussbegriffe von Q 2:286 ('alāl-qawm al-kāfirin) darauf im horizontalen Balken darüber; der Rest des Verses steht auf dem Kopf. Der Kopist erreicht damit das Ende des horizontalen Balkens unmittelbar vor den fünf vertikalen Stäben (vgl. АвB. 88$) .50$

49 Vgl. Canaan, Decipherment 129, 131; Padwick, Muslim devotions $116 \mathrm{f}$.; die beiden Verse sind als Hawātim alBaqara bekannt.

50 Zur häufigen Verwendung von Q 2:285-286 auf Schutzmitteln siehe Canaan, Decipherment 129 und 131; die Verse lauten:

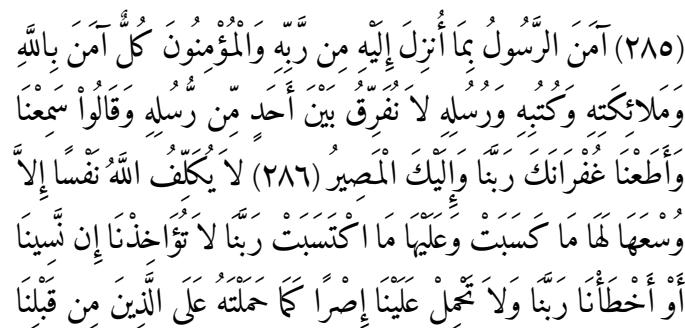

I.7: Die fünf Figuren I.7-11 stellen das Gegenstück zu den fünf Figuren I.1-I.5 dar und sind identisch aufgebaut. Die beiden Gruppen werden an der soeben beschriebenen Figur I.6 gespiegelt.

Bei Figur I.7 handelt es sich erneut um ein auf der Spitze stehendes Quadrat (Gegenstück zu I.5). Die Seitenlänge beträgt ca. $2.5 \mathrm{~cm}$. Diese Figur wird von einem roten Rahmen eingefasst und enthält Text in blauem Schachbrett-Kü $\tilde{\imath}$.

Der Text beginnt auch hier in der rechten Ecke des auf der Spitze stehenden Quadrats; es handelt sich um Q 10:1ob. Der Text lautet:

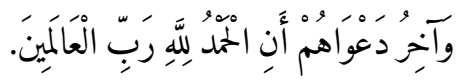

Das in der Ecke selbst notierte $w \bar{a} w$ ist klar erkenntlich. Als nächster Buchstaben folgt das alif direkt über dem auslaufenden $w \bar{a} w$. Darauf schliessen sich die Buchstaben $h \bar{a}^{2}-r \bar{a}$ an; sie sind entlang der rechts absteigenden Seitenlänge notiert. Auch der weitere Verstext folgt den Seitenlinien des Quadrats. Nach dem Ausdruck al-hamd - er ist entlang der von der oberen Spitze nach rechts absteigenden Seite notiert worden - springt der Kopist ins Innere des Quadrats. Jetzt folgt der Ausdruck li$[A] l l a \bar{h}$. Das alif davor gehört zur Wortfolge waăhir.

I.8: Diese Figur stellt sowohl formal als auch inhaltlich das Gegenstück zu Figur I.4 dar und ist deshalb zusammen mit ihr vorgestellt worden. ${ }^{51}$

I.9: Diese Figur stellt das Gegenstück zu Figur I.3 dar. Es handelt sich erneut um ein auf der Spitze stehendes, rot umrahmtes Viereck. Die Seitenlänge beträgt knapp $2 \mathrm{~cm}$. Es enthält Text in blauem Schachbrett-Küft. Der Text beginnt erneut in der rechten Ecke und lautet:
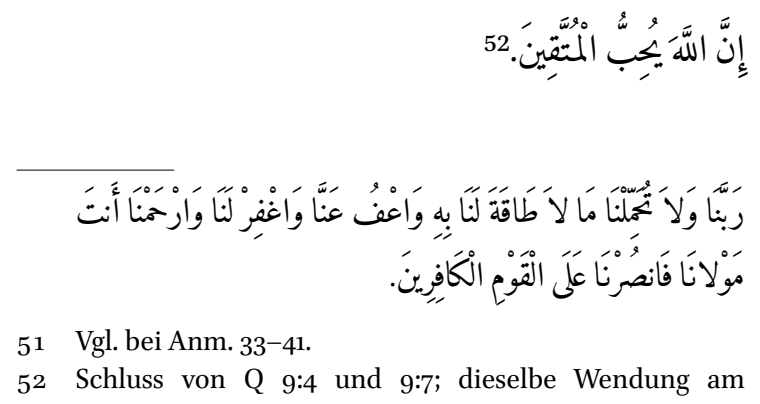
I.1O: Diese Figur stellt das Gegenstück zu Figur I.2 dar und ist wie sie aufgebaut. Im Zentrum dieser Figur befindet sich ein auf der Spitze stehendes Quadrat (Seitenlänge ca. $2 \mathrm{~cm}$ ). Hier erneut Text in blauem Schachbrett-Küft. Der Text im Quadrat beginnt in der rechten Ecke und lautet:

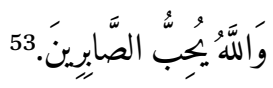

Um diese Figur herum verläuft ein Ring mit Text in gegenläufigem Schachbrett-Küft. Die Stelle ist analog aufgebaut wie im Ring um den Kreis in Figur I.2. ${ }^{54}$ Auch dieser Ring enthält drei Textstellen:

I.10 (Ring) Text 1: Der Text beginnt über der Spitze des Quadrats im Innern des Kreises und wechselt nach der Mitte der Seitenlinie, die die Spitze und die linke Ecke des Quadrates verbindet, die Schriftrichtung. Beim kopierten Text handelt es sich um die Basmala. ${ }^{55}$ Sie leitet den anschliessenden Surentext ein.

I.10 (Ring) Text 2: Es handelt sich um eine Abschrift von Q 106. Der Text beginnt direkt in Anschluss an die Basmala auf dem Innenband des Rings im Gegenuhrzeigersinn. Der Schreiber wechselt ganz wenig unterhalb der rechten Ecke des Quadrats die Schriftrichtung und notiert den Rest der Sure auf dem Aussenband im Uhrzeigersinn. Die Übergangsstelle wird durch eine Linie von Kästchen ohne Buchstabenelemente markiert. Q 106 (Sūrat Quray̌̌) lautet:

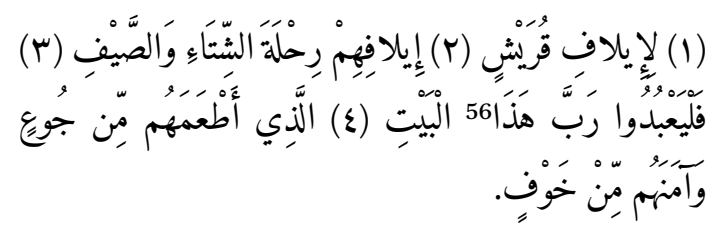

Schluss von Q 3:76 (wo modifizierte Einleitung):

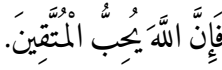

Vgl. Q 3:146 (Schluss).

54 Vgl. die Beschreibungen zum Aufbau der Figur oben vor Anm. 3 .

55 Die Schriftrichtung wechselt innerhalb des Ausdrucks arRaḥmān.

$5^{6}$ Wechsel innen-aussen und der Schriftrichtung in diesem Ausdruck.
I.10 (Ring) Text 3: Zwischen der rechten Ecke und der oberen Ecke des Quadrats hat der Schreiber eine dritte Stelle notiert. Sie beginnt erneut auf der innern Zeile und verläuft im Gegenuhrzeigersinn. Es handelt es sich um Q 37:180-181; sie lautet:

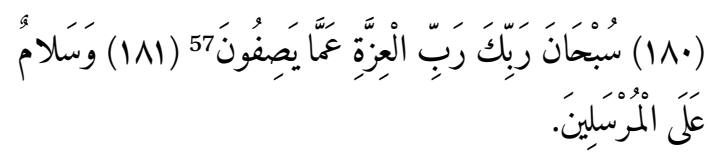

Diese Koranstelle wurde übrigens an derselben Stelle auch in der identisch gestalteten Figur I.2 kopiert. ${ }^{58}$

I.11: Die Figur I.11 bildet das Gegenstück zur Figur I.1 am Rollenanfang. Es handelt sich bei ihr um ein auf der Spitze stehendes Quadrat, das rot eingefasst wird (Länge der Seiten: $2.5 \mathrm{~cm}$ ). In diesem Quadrat erneut Text in blauem SchachbrettKüfi. Der Text beginnt in der rechten Ecke und lautet:

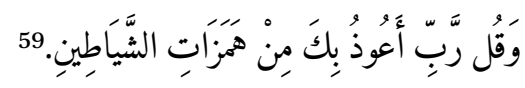

I.12 (АВв. 89): Figur I.12 gehört nicht mehr zur Abfolge von je fünf Figuren vor und nach dem Scharnierstück I.6. Sie stellt aber gewissermassen das Pendant zur Mütze am Rollenanfang dar. Bei Figur I.12 handelt es sich um ein Quadrat von $5.0 \mathrm{~cm}$ Seitenlänge. In dieses grosse Quadrat ist nach einem goldenen Rahmen ein zweites Viereck eingepasst. Der Rahmen ausserhalb des goldenen Bands und das Quadrat im Innern sind mit Text in

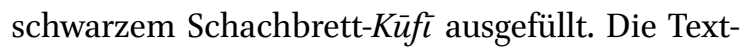
stellen beginnen in der rechten unteren Ecke:

a. Im innern Quadrat steht Q 2:255 (Thronvers). Er verläuft zuerst im Uhrzeigersinn den Seiten des innern Quadrats entlang. Kurz bevor der Schreiber zur unteren Ecke rechts zurückkehrt, setzt er die Abschrift nach links innen fort. Dies sieht im einzelnen wie folgt aus (der folgende Abschnitt folgt

57 Wechsel innen-aussen innerhalb dieses Begriffs; er befindet sich oberhalb der oberen Ecke des Quadrats im Innern des Kreises.

58 Siehe dazu bei Anm. 30.

59 Es handelt sich um Q 23:97 (ganz). 
dem arabischen Text von Q 2:255. Die Bemerkungen in lateinischer Schrift kommentieren den Textverlauf):

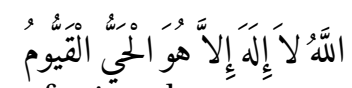

Text ab al-qayyūm links aufsteiğend

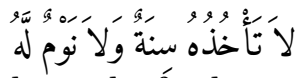

obere Horizontale, nach rechts verlaufend

Vertikale, rechts absteigend

$$
\text { مَا فِي السَّمَاوَاتِ وَمَاَفِي }
$$

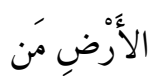

Text verläuft ab hier horizontal links nach innen

Text ab hier innen vertikal aufsteigend

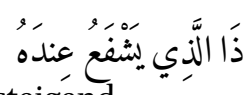

Text verläuft innen, horizontal

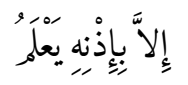

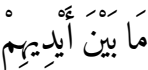

Text verläuft auf der nächsten Horizontalen nach links

Text erreicht das Zentrum
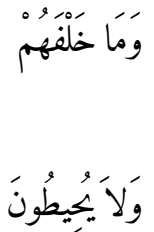

der Text verläuft ab hier wieder nach aussen

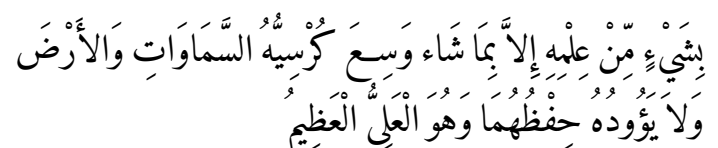

al-'azīm: dieser Begriff béfindet sich dírekt über dem Anfang von Q 2:255.

Der äussere Rahmen mit Text in SchachbrettKüfı enthält Q 105 und 108. In der Ecke rechts unten steht die Basmala. Der Schreiber notiert sie gegenläufig; er wechselt innerhalb des Worts arrah-mān in die obere Zeile und notiert den Rest der Basmala rückläufig auf dem Kopf.

Im unteren Rahmen beginnt darauf links neben der Basmala Q 105. Der Schreiber notiert deren Text zuerst auf der äusseren Zeile auf der unteren Horizontalen, dann auf der linken Vertikalen und zuletzt auf der oberen Horizontalen. Kurz bevor er die obere rechte Ecke des Quadrats erreicht, setzt er die Abschrift auf der inneren Zeile in der Gegenrichtung fort, bis er wieder den Anfang der Sure auf der unteren Zeile erreicht. Die Oberlängen der Textstellen auf der innern und äussern Zeile sind wiederholt ineinander verzahnt, wie sich dies bereits an andern Stellen beobachten liess.

Als zweiter Text wurde im restlichen Teil des äusseren Rahmens Q 108 kopiert. Dieser Text beginnt in der Ecke rechts unten, direkt über der Basmala. Der Text steigt zuerst auf der innern Zeile der rechten Vertikale nach oben; er verläuft an der rechten oberen Ecke kurz nach links. Er kehrt auf der äussern Zeile in gegenläufiger Richtung aber sogleich zum Anfang der Sure an der Ecke rechts unten zurück. Auch hier sind die Oberlängen der Buchstaben auf der innern bzw. äusseren Zeile ineinander verzahnt. Q 108 lautet:

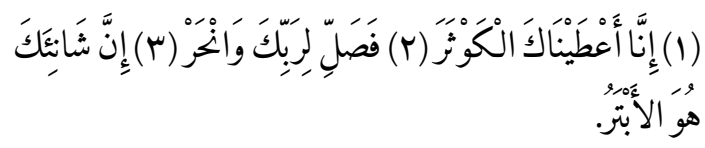

Der Schreiber wechselt am Ende von Vers 2 auf die äussere Zeile an der Ecke rechts oben.

TEIL II: Das Quadrat I.12 markiert den Schluss von Teil I der Rolle. Hier endet auch der Abschnitt mit dem goldenen Rankenmuster als Hintergrund. Es schliesst sich darauf ein Anfangszierfeld an, wie es ebenso von Handschriften in Kodex-Form bekannt ist. Dieses Anfangszierfeld legt es nahe, das vorliegende Dokument einem spät-timuridischen oder allenfalls früh-safawidischen Umfeld zuzuordnen:

Dieses Anfangszierfeld (АВв. 90) misst zusammen mit dem schmalen blauen und dem breiteren goldenen Rahmen $6.1 \times 5.0$ cm (Breite $\times$ Höhe); die 
Abmessungen des Innenteils mit dem blauen Hintergrund betragen $4.8 \times 4.0 \mathrm{~cm}$. Auf diesem blauen Hintergrund lässt sich ein goldenes Rankenmuster mit weissen und roten Blüten erkennen. Im Zentrum dieses Rechtecks befindet sich ausserdem eine grössere goldene Kartusche. Es ist zu vermuten, dass sie ursprünglich Text enthielt; ein solcher lässt sich jetzt darin aber nicht mehr erkennen. ${ }^{60}$ Zur Linken und Rechten dieser Hauptkartusche befinden sich zwei goldene, auf der Spitze stehende Quadrate. Dem Rand entlang lassen sich auf jeder Seite je zwei zusätzliche golden eingefasste Verzierungen erkennen.

Das Dokument wird in diesem Teil II weiterhin beidseits von einem goldenen Band und danach von einem roten Streifen eingefasst. Dieser Doppelstreifen markiert die Abgrenzungen des Schriftspiegels. Unterhalb des Anfangszierfelds lassen sich die folgenden Stellen erkennen:

$\mathrm{x}$. In der Mitte befindet sich ein Streifen von $4.2 \mathrm{~cm}$ Breite. Er enthält auf horizontalen Zeilen Text in $\dot{G} u b \bar{a} r$-Schrift.

A. und B.: Auf der rechten (A.) und linken (B.) Seite des Mittelstreifens verlaufen dem Rollenrand entlang zwei Schriftbänder mit Text in gegenläufigem schwarzem Schachbrett-Küfi. Diese Bänder sind am Rollenende miteinander verbunden. Die Breite dieser beiden Bänder beträgt ca. $0.7 \mathrm{~cm}$. Der Text auf den beiden Bändern A. und B. verläuft vorwärts (also in der Rollenrichtung); die beiden Texte stossen später aufeinander (АВ B. 91) ${ }^{61}$

C. und D.: Zwischen diesen beiden Bändern mit Text in Schachbrett-Küfı und dem horizontal notierten Text mit der Abschrift des Korans im Mittelstreifen (x.) wurde rechts (C.) und links (D.) je ein zusätzliches Band mit Text in kleinem Nash eingefügt. Die Breite dieser beiden Bänder

6o Häufig wurden auf den Dokumenten in Rollenform derartige inhaltliche Angaben in weisser Schrift auf goldenem Hintergrund angebracht. Es liess sich mehrfach feststellen, dass die Pigmente der weissen Farbe auf diesem goldenen Hintergrund schlecht haften. Dies führte gerade auf lange Zeit hinaus zu Textverlusten.

61 Vgl. bei Anm. 8gf. beträgt je ca. $0.5 \mathrm{~cm}$. Auch diese beiden Schriftbänder sind am Schluss der Rolle miteinander verbunden. Neben Text wurden in diese beiden schmalen Schriftbänder auch Kartuschen eingefügt. Sie sind golden ausgefüllt und rot oder blau eingefasst. Auch der Text auf den beiden Schriftbändern C. und D. verläuft vorwärts (also in der Rollenrichtung); die beiden Texte stossen später aufeinander. $^{62}$

Zu Teil II im einzelnen: $x$. Mittelstreifen: Soweit ersichtlich enthält der Mittelstreifen eine vollständige Abschrift des Korans in $\dot{G} u b \bar{a} r$-Schrift. ${ }^{63}$ Die einzelnen Suren sind mit einer Überschrift in grösserer goldener Schrift versehen, wie sich unterhalb des Zierfelds mit dem blauem Hintergrund aufzeigen lässt. ${ }^{64}$ Diese Überschriften erstrecken sich über die gesamte Breite des Mittelstreifens. Da die Suren am Ende des Korans kurz sind, folgen diese Überschriften dort rasch aufeinander. Goldene Verstrenner. Die Basmala am Anfang der einzelnen Suren erstreckt sich über die ganze Breite des Mittelstreifens. Der Schreiber erreicht dies, indem er die Verbindung zwischen den beiden Buchstaben sin und mìm im Ausdruck bism dehnt. Die Höhe der Buchstaben in den Stellen in $\dot{G} u b \bar{a} r$ Schrift beträgt ca. $1 \mathrm{~mm}$ (alif) ${ }^{65}$

In diesem Mittelstreifen mit der Abschrift des Korans liessen sich u.a. folgende Unregelmässigkeiten und Besonderheiten feststellen: Vor der Überschrift zu Q 36 (Sūrat Yā-sīn) im Mittelstrei-

62 Vgl. nach Anm. 242. Die beiden Texte treffen auf Aufnahme Is 1626.13.2 auf der rechten Seite aufeinander (unterhalb des Titels von Q 55, Sürat ar-Raḥmān, im Mittelstreifen).

63 Die Abschrift wurde nicht durchgehend auf allfällige Lücken überprüft. Eine Überprüfung fand nur auf der Ebene der Surentitel statt; diese sind auf der Rolle vollständig aufgeführt.

64 Diese Überschriften enthalten a. den Surennamen, b. Hinweise zum Offenbarungsort und c. Angaben zur Anzahl der Verse. Bei der Überschrift zu Q 2 vergass der Schreiber bei der Angabe der Anzahl Verse allerdings die Hunderter. So soll Q 2 nur 86, anstatt den tatsächlichen 286, Verse enthalten.

65 Zehn Zeilen Text auf ca. 1.5 cm Höhe. 
fen: Riss im Papier, der sich nahezu über die gesamte Breite der Rolle erstreckt. ${ }^{66}$ Ein Hinweis, dass das vorliegende Belegstück einen iranischen Hintergrund hat, könnte sich aus der Überschrift zu Q 39 (Sūrat az-Zumar) ableiten lassen.67 Dieser Titel wurde ohne den im Arabischen üblichen Artikel notiert. Dies lässt sich mit der persischen Grammatik erklären. Vor der Überschrift zu Q 42 (Sūrat aš-Šūrā) lässt sich erneut ein Riss im Papier feststellen, der sich über die ganze Breite der Rolle erstreckt. ${ }^{68}$ Der Titel von Q 71 wird auf diesem Belegstück Sürat an-Nūh (mit Artikel) geschrieben; üblich ist Sūrat Nūḥ; dies ist ein weiterer Hinweis, dass der Kopist nicht arabischer Muttersprache war. ${ }^{69}$

Die beiden Schriftbänder (A. und B.) mit Text in Schachbrett-Küfí: A. Dieses Schriftband beginnt auf der rechten Seite der Rolle. Im Abschnitt vor der ersten blau umrandeten goldenen Kartusche steht die Basmala in gegenläufigem Schachbrett$K \bar{u} f$. Der Schreiber ändert die Textrichtung innerhalb des Ausdrucks ar-Raḥmān. Die Oberlängen der Buchstaben auf den beiden gegenläufigen Zeilen sind ineinander verzahnt. Nach der blau umrandeten Kartusche beginnt auf der äusseren, vorwärtslaufenden Zeile Q 36 (Sūrat Yā-sīn). ${ }^{70}$ Auf der Gegenseite steht rückwärts, aufsteigend Q 36:83 (Schlussvers). ${ }^{71}$ Diese Anordnung lässt vermuten, dass der Schreiber auf diesem Schriftband A Q 36 vollständig kopiert hat. ${ }^{72}$ Der Schreiber

66 Vgl. Aufnahme Is 1626.10.4.

67 Vgl. Aufnahme Is 1626.11.2.

68 Vgl. Aufnahme Is 1626.11.4.

69 Vgl. Aufnahme Is 1626.14.4.

70 Q 36:1-4 ist deutlich zu erkennen, ebenso die Fortsetzung; Q 36.1-4 lautet:

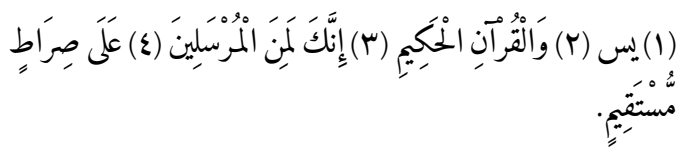

71 Q 36:83 lautet:

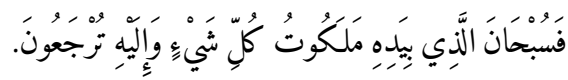

72 Q 36 ist auch im Mittelstreifen vorhanden, auf dem der Korantext fortlaufend notiert worden ist. Sie ist auf der vorliegenden Rolle somit zweimal kopiert worden. wechselt auf der Höhe von Q 13 (Sürat $\left.a r-R a^{\prime} d\right)$ im Mittelstreifen auf dem Seitenband A vom vorwärtslaufenden zum rückwärtslaufenden Text. ${ }^{73}$ An dieser Stelle steht Q 36:45. ${ }^{74}$ Diese Übergangsstelle vom vorwärtslaufenden zum rückwärtslaufenden Text ist gut erkenntlich: Hier befindet sich im Textband eine blau umrandete goldene Kartusche. ${ }^{75}$

Nach der soeben erwähnten Kartusche folgt ein nächster kurzer Abschnitt mit gegenläufigem Schachbrett-Küfí. Beim Text handelt es sich um die Basmala. In diesem Textband A. folgt darauf ein goldenes Quadrat. Nach diesem Quadrat beginnt die Abschrift von Q 48 (Sūrat al-Fath). ${ }^{76}$ Auf dem innern, rückläufigen Teil des Schriftbands lässt sich Q 48:29 (Schlussvers) erkennen. ${ }^{77}$ Auch diese Anordnung lässt vermuten, dass der Schreiber in diesem Textband bei der Abschrift von Q 48 vom vorwärtslaufenden zum rückwärtslaufenden Text wechselt. Diese Übergangsstelle befindet sich auf der Höhe von Q 38 (Sūrat Șād) im Mittelstreifen. ${ }^{78}$ Hier steht Q 48:17.79 An dieser Übergangsstelle befindet sich eine weitere blau umrandete goldene Kartusche.

73 Vgl. Aufnahme Is 1626.5.8 (bzw. Aufnahme 6 der Chester Beatty Library).

74 Q 36:45 lautet:

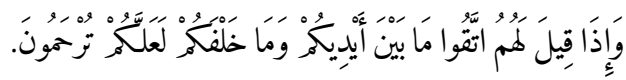

Die Abschrift von Q 36 in diesem Seitenband mit Text in Schachbrett-Küf $\iota$ wurde nicht auf der gesamten Länge auf Vollständigkeit überprüft.

76 Vgl. Aufnahme Is 1626.6.3 (auch Aufnahme 6 der Chester Beatty Library); Q 48:1 lautet:

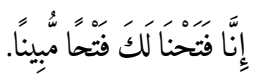
lautet:

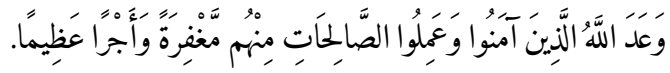

Vgl. Aufnahme Is 1626.10.5.

79

Q 48:17 lautet:

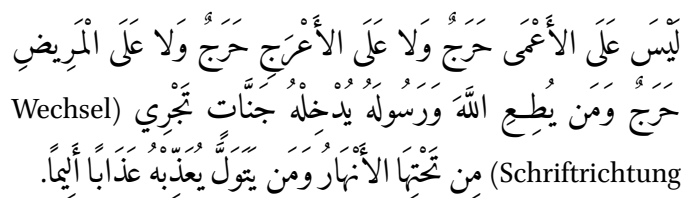

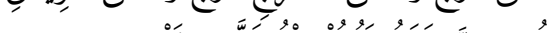

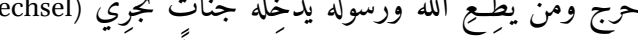

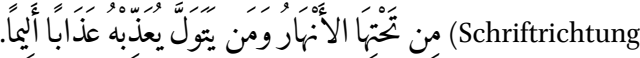


In der Abschrift von Q 48 in gegenläufigem Schachbrett-Kūfı ist auf eine Auffälligkeit aufmerksam zu machen. ${ }^{80}$ Hier wurde im Mittelstreifen Q 25 (Sūrat al-Furqān) kopiert; unmittelbar darauf folgt der Titel von Q 26 (Sūrat aš-Šu'rā'). Die Stelle in gegenläufigem Schachbrett-Küfı dem rechten Rollenrand entlang ist auf der Höhe dieser beiden Suren nahezu vollständig schwarz eingefärbt. Es lässt sich kein Text mehr erkennen. Da Passagen aus Q 48 auf weiteren hier untersuchten Dokumenten in Rollenform eine besondere Behandlung erfahren (vgl. CBL Is $1624,{ }^{81} \mathrm{BNF}$ Arabe $6088^{82}$ und CBL Is $1625^{83}$ ), stand die Vermutung im Raum, die vorliegende Stelle könnte absichtlich unleserlich gemacht worden sein, um allenfalls Einträge missliebigen Inhalts zu tilgen. Diese Vermutung liess sich allerdings nicht erhärten. Anfängliche Vermutungen, es könnte hier der Name eines Vorbesitzers der Rolle gestanden haben, haben sich als unwahrscheinlich erwiesen. Es dürfte sich im vorliegenden Fall einfach um eine Beschädigung handeln, wie sie sich auf handschriftlichen Dokumenten immer wieder feststellen lässt.

In Anschluss an die Stelle mit Q 48 folgt ein weiterer Abschnitt in gegenläufigem SchachbrettKüfı mit der Basmala. ${ }^{84}$ Nach einem golden ausgefüllten Quadrat beginnt Q 62 (Sürat al-Ğum'a). ${ }^{85}$

8o Vgl. die Aufnahmen Is 1626.8.5 und Is 1626.9.2 (und Aufnahme 9 der Chester Beatty Library; auf dieser Aufnahme ist allerdings nur noch der Schluss der im folgenden diskutierten Stelle erkennbar).

81 Vgl. Kapitel 4.6 bei Anm. 20-23.

82 Vgl. Kapitel 4.5 bei Anm. 17.

83 Vgl. Kapitel 4.7 bei Anm. 107-108.

84 Vgl. Aufnahme Is 1626.11.2 (und Aufnahme 11 der Chester Beatty Library).

85 Q 62:1 lautet:

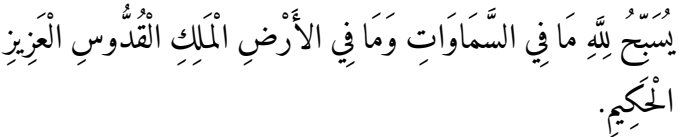

Q 62:11 (Schlussvers) lautet:

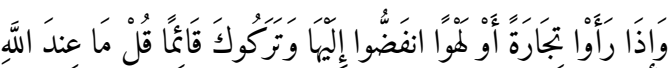

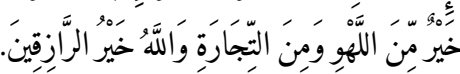

Der Übergang vom vorwärtslaufenden zum rückwärtslaufenden Text befindet sich unmittelbar vor dem Beginn von Q 49 (Sūrat al-Huğurāt) im Mittelstreifen. ${ }^{86}$ An der Übergangsstelle vom vorwärtslaufenden zum rückwärtslaufenden Text befindet sich Q 62:6. ${ }^{87}$

Nach einer blau eingefassten goldenen Kartusche $^{88}$ folgt eine nächste Basmala in gegenläufigem Schachbrett-Küfi. Nach einem golden ausgefüllten Quadrat schliesst sich die Abschrift von Q 76 (Sūrat al-Insān) in gegenläufigem Schachbrett-Kūf $\iota$ an. ${ }^{89} \mathrm{Im}$ Fall dieser Sure ist der Übergang vom vorwärtslaufenden zum rückwärtslaufenden Text nicht besonders kenntlich gemacht. Er befindet sich auf der Höhe des Endes von Q 88 (Sūrat al Ġāšiya) im Mittelstreifen. ${ }^{90}$ Im Seitenband befindet sich hier keine weitere Kartusche, da der im linken Band mit Text in Schachbrett-Küfi beginnende Text von unten aufsteigt. Innerhalb von Q 76 findet der Übergang vom vorwärts- zum rückwärtslaufenden Text in Vers ${ }^{16-17}$ statt. ${ }^{91}$ Von unten steigt hier die Fortset-

86 Vgl. Aufnahme Is 1626.12.4.

87 Q 62:6 lautet:

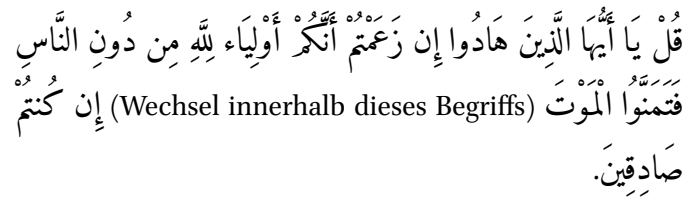

88 Man beachte, dass sich um diese Kartusche herum die für das Notieren der Stellen in Schachbrett-Kū $f$ i vorbereiteten Kästchen noch klar erkennen lassen.

89 Q 76:1 (vorwärtslaufend, absteigend) lautet:

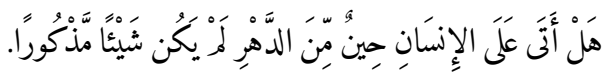

Q 76:31 (Schlussvers; rückwärts, aufsteigend) lautet:

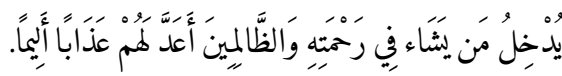

90 Vgl. Aufnahme Is 1626.15.2.

91 Q 76:16-17 lautet:

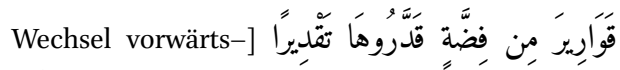

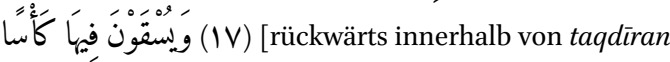

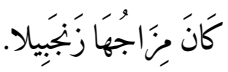


zung des Texts von Q 6 in Schachbrett-Küfı empor. Da sie aber auf der linken Seite nicht vollständig Platz fand, setzte der Schreiber ihre Abschrift fort, indem er unten das Rollenende umfuhr und im rechten Schriftband in Schachbrett-Küfı mit dem Text wieder emporstieg.

B. Dieses Schriftband mit Text in gegenläufigem Schachbrett-Küfı̀ beginnt auf der linken Seite auf der Höhe der Abschrift des Korans in $\dot{G} u b a \bar{r}$ Schrift im Mittelstreifen. Hier lässt sich zuerst die Basmala erkennen. Es schliesst sich eine blau eingefasste goldene Kartusche an. In Anschluss an diese Kartusche beginnt auf der inneren, vorwärtslaufenden Zeile des Schriftbands mit SchachbrettKüfı̀ die Abschrift von Q 6 (Sūrat al-An'ām). ${ }^{92}$ Auf der äusseren, aufsteigenden Zeile steht gegenüber von Vers 1 Q 6:165 (Schlussvers). ${ }^{93}$ Da in diesem auf der linken Seite beginnenden Schriftband nur Text aus Q 6 kopiert worden ist, fehlen Kartuschen zur Unterteilung der Abschnitte mit den Abschriften der einzelnen Suren auf gegenläufigen Zeilen.

Unregelmässigkeiten in der Textfolge unterhalb des Endes der Stelle mit Q 76 (Schriftband A) lassen darauf schliessen, dass Q 6 im Schriftband B und in dessen Verlängerung im untersten Teil von Schriftband A nicht vollständig kopiert worden ist. Diese Unregelmässigkeiten lassen sich direkt unterhalb der Stelle klar feststellen, wo der Schreiber beim Kopieren von Q 76 von der absteigenden in die aufsteigende Richtung übergeht: Hier lässt sich im Textband mit Schachbrett-Kü $\mathrm{i} \iota$ auf der inneren Zeile (aufsteigend) Q 6:6oa erkennen. ${ }^{94}$ Der Schreiber wechselt dann die Schriftrichtung

92 Q 6:1 lautet:

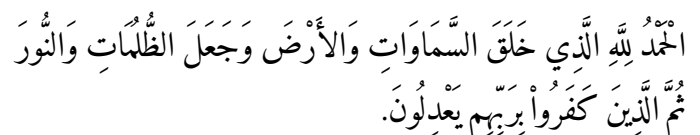

93 Q 6:165 lautet:

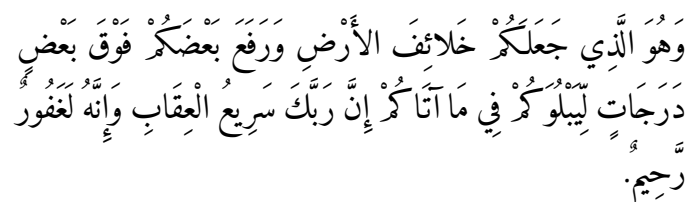

94 Q 6:6o lautet (der Text in eckigen Klammern, also der Schluss von Vers 6o, fehlt an dieser Stelle): und setzt Q 6 mit Vers 6:122b fort. ${ }^{95}$ Ab hier verläuft der Text im äusseren Teil des Schriftbands in gegenläufigem Schachbrett-Küfi. Diese Beobachtungen zeigen auf, dass die Verse 6ob-122a an dieser Stelle fehlen. Dem Kopisten stand für die vollständige Abschrift von Q 6 an dieser Stelle schlicht zu wenig Platz zur Verfügung. Das Auslassen von ca. 6o Versen erlaubte es ihm, das vorgegebene Layout dennoch zu respektieren.

Diese Lücke in der Textfolge von Q 6 lässt Rückschlüsse auf das Vorgehen des Kopisten beim Herstellen dieser Rollenteile in gegenläufigem Schachbrett-Küf $\iota$ zu: Q 6 beginnt und endet im Seitenband B am Anfang der Abschrift des Korans im Mittelstreifen. Der Schreiber hat dort mit dem Notieren von Q 6:1 ff. auf dem Innenband begonnen. Er setzte diese Abschrift fort, bis er in Vers 6oa auf die Stelle stiess, wo Q 76 die Richtung wechselt. Es sieht danach aus, dass der Schreiber die Sure 6 zugleich auf dem äusseren Schriftband links vom Ende her kopierte. Er erreichte schliesslich an der Stelle mit Q 76 den Vers 122b aus Q 6 und hatte keinen Platz mehr, um weiteren Text aus Q 6 hinzuzufügen. Diese Beobachtung gestattet einen interessanten Einblick in das Vorgehen des Schreibers beim Anfertigen der vorliegenden Rolle.

Überlegungen zur Kontextualisierung von Is 1626: Die bisherigen Ausführungen zu Is 1626 zeigen auf, dass darauf Zierelemente in Schachbrett$K u ̈ f \iota$ eine bedeutende Rolle spielen. Dies trifft bereits auf die 12 Elemente in Teil I des Dokuments zu. Das Anbringen von Verzierungen in

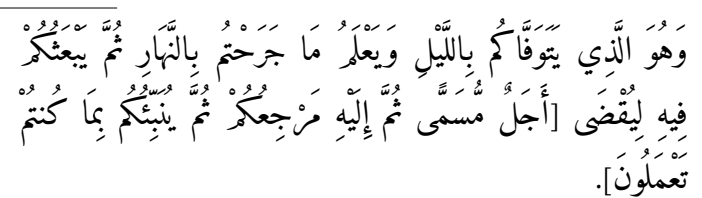

95 Q 6:122 lautet (der Text in eckigen Klammern, also der Anfang von Vers 122, fehlt an dieser Stelle):

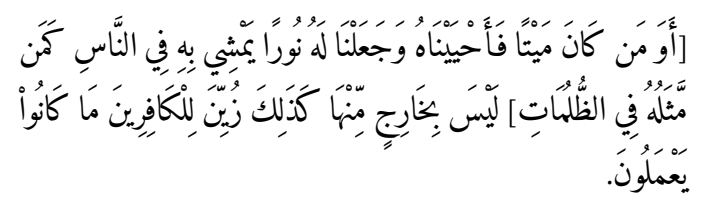


geometrisch angeordnetem $K \bar{u} f \grave{\imath}$ ist gerade von Bauten aus der Timuridenzeit gut bekannt. ${ }^{96}$ Es kann auf die Mīr Čāqmāq-Moschee in Yazd aufmerksam gemacht werden. Ebenso bekannt sind diesbezüglich verschiedene Bauwerke in Samarkand. Dazu zählen die Madrasa-Bauten um den Registān-Platz. Es kann überdies auf den dortigen Šāh-i Zinda-Komplex aufmerksam gemacht werden. Die soeben angeführten Bauwerke datieren im wesentlichen aus dem Ende des 14. oder aus dem Anfang des 15. Jh.

Diese Technik war in Iran allerdings bereits früher bekannt, wie sich u.a. anhand des ȘafawiyyaSchreins in Ardabil aufzeigen lässt. Seine Errichtung geht in ihrem Kern auf Șadr ud-Dīn, den Sohn des 1334 verstorbenen Begründers des Ordens, Šayh Ṣafì ud-Dīn, zurück. Auf seinem Grabtum wurde der Name Allāh insgesamt $132 \mathrm{Mal}$ in geometrisierendem $K \bar{u} f \imath$ angebracht. ${ }^{97}$ Es lässt sich ausserdem auf die Verzierungen am berühmten Schreinkomplex in Natanz verweisen (Anfang des 14. Jh., Ilkhaniden-Zeit). ${ }^{98}$ Ein weiteres interessantes Beispiel ist die Masğid-i-Ǧāmic in Aštarğān bei Isfahan, die ebenso aus der Ilkhaniden-Zeit datiert. ${ }^{99}$ Auch aus Sulțāniyya sind Verzierungen in

96 Die Belege für die folgenden Beispiele wurden bereits in Anm. 6 aufgeführt.

97 Vgl. Rizvi, Shrine 46-52 (mit Figure 8 und Plate 4); siehe auch http://archnet.org/sites/1595/media_contents/408 12 (Stand 27. Januar 2017). Siehe überdies H. Safavi, SOAS, University of London, Hermeneutic approach 4 und 10; Artikel aufrufbar unter http://www.nlai.ir/Portals/61/ pdf/Hermeneutic_Approach.pdf (Stand 23. Juli 2017).

98 Vgl. Blair, Natanz, darin z. B. Tafel 26 (Aufnahme des Mihrāb im Süd-Īwān der Moschee; man beachte die Quadrate in den oberen beiden Ecken der drei Bögen); siehe auch http://archnet.org/sites/1645/media_contents/42495 (Stand 26. Januar 2017); Blair, op. cit., Tafeln 58-6o: Textelemente am Minarett; siehe dazu auch http://archnet .org/sites/1645/media_conten

ts/4250o (Stand 26. Januar 2017).

99 Vgl. Blair, Natanz, Tafel 119 (Eingang zur Masğid-i Ğāmic in Aštarğān, datiert 715/1315). Vgl. auch die Informationen und Abbildungen unter http://archnet.org/sites/ 1597/media_contents/486 (Stand 26. Januar 2017). Zur Freitagsmoschee in Aštarğān siehe überdies Golombek und Wilber, Timurid architecture I, 365 (Nr. 140).
Schachbrett-Kūfı bekannt. ${ }^{100}$ Etwas anders ausgeführt worden sind die Inschriften in SchachbrettKūfi im Schrein von Šāh Ni`matullāh Walī in Māhān. ${ }^{101}$ Ein gutes Beispiel für die Verwendung von Textelementen in Schachbrett-Kūfi stellt überdies das unter Timur zwischen 1389 und 1405 errichtete Mausoleum für Huāğa Aḥmad Yasawī (gest. 565/1166), den Namensgeber des YasawiyyaOrdens, dar. Es befindet sich in Yasi im heutigen Kasachestan. ${ }^{102}$

Im folgenden sollen allerdings nicht die Beispiele von Zierelementen in Schachbrett-Küfı an den soeben angeführten Bauten weiter verfolgt werden, die ihre Parallelen gerade in den blauen Inschriften in den auf den Spitzen stehenden Quadraten in Teil I der Rolle Is 1626 finden. Die weiteren Ausführungen befassen sich vielmehr mit den Stellen in gegenläufigem schwarzem Schachbrett$K \bar{u} f \iota$, auf denen die Oberlängen der beiden Schriftbänder ineinander verzahnt sind. Sie lassen sich einerseits in den Bändern um die verschiedenen Medaillons herum in Teil I der Rolle feststellen (vgl. I.2 und I.10). Die Technik kam aber auch in den Elementen I.4, I.6, I.8 und I.12 zur Anwendung. Für die

100 Vgl. Blair, Natanz, Tafel 110 (Ülğäytü-Mausoleum, OstPortal, datiert 710/1310). Siehe auch http://archnet.org/ sites/1671/media_contents/42697 (Stand 26. Januar 2017).

101 Der Bau geht in seinem Kern auf das Jahr 1436 zurück. Es ist allerdings bekannt, dass 'Abbās I. 16o1 Renovationen durchführen liess. Davon war auch die Kuppel betroffen. Es lässt sich deshalb nicht beurteilen, ob die im folgenden angeführten allfälligen Parallelen noch aus dem 15. Jh. stammen. Siehe zum Schreinkomplex in Māhān im allgemeinen die Informationen unter http://archnet.org/sites/ 1637/media_contents/42361 (Stand 26. Januar 2017); beachte auch Golombek und Wilber, Timurid architecture I, 394f. (Nr. 184) und II, Abb. 401-404. Siehe auch folgende Einzelheiten des Mausoleums in Māhān (Schachbrett-Kū $\bar{\imath}$ ): a. Oberes und unteres Schriftband auf der Trommel unterhalb der Kuppel (vgl. http:// archnet.org/sites/1637/media_contents/942, Stand 26. Januar 2017); b. am Minarett: http://archnet.org/sites/ 1637/media_contents/40024.

102 Vgl.http://archnet.org/sites/3057/media_contents/1528 mit den Abbildungen (z.B.: http://archnet.org/sites/ 3057/media_contents/1528; Stand 30. Januar 2017). 
weiteren Ausführungen relevant sind jedoch v.a. die beiden Schriftbänder A und B, die Teil II der Rolle einfassen.

Diese beiden Schriftbänder sind am unteren Ende der Rolle miteinander verbunden. Sie rufen in auffälliger Weise das Eingangsportal zum bereits erwähnten Schrein in Erinnerung, der in Natanz am Anfang des 14. Jh. für den Sufi-Shaykh 'Abd aș-Ṣamad errichtet worden ist:103 Dieses Portal wird zu beiden Seiten von je zwei Schriftbändern in gegenläufigem Schachbrett-Kū $f \imath$ eingefasst. Sie werden durch ein Band von ähnlicher Breite voneinander getrennt. Oberhalb des Eingangsbogens befindet sich bloss ein einziges Schriftband in gegenläufigem Schachbrett-Kūfí. Auf beiden Seiten und oben wird das Eingangsportal durch ein zusätzliches Schriftband eingefasst.

Es ist ausgeschlossen, anhand von Fakten den Beweis erbringen zu wollen, dass der Eingang zum Heiligtum in Natanz dem oder den Herstellern der Rolle Is 1626 bekannt gewesen war. Allerdings sind die Parallelen zwischen den Gestaltungselementen auf der Rolle und dem Eingang des Heiligtums derart frappant, dass es zumindest als naheliegend angesehen werden muss, dass der Hersteller der Rolle Is 1626 von diesem Eingang gewusst hatte. Diese gestalterische Parallele gestattet indirekt Rückschlüsse auf das Umfeld, in dem die Rolle Is 1626 entstanden sein dürfte.

Wie Sh. Blair festhielt, wurde der SchreinKomplex in Natanz 707/1307-1308 von Zayn adDīn Mastarī errichtet. ${ }^{104}$ Er umfasst heute das Eingangsportal zu einem Hanāqāh, dahinter eine Moschee aus den 193oer-Jahren (sic), ein Minarett, das Grab des 'Abd aṣ-Ṣamad und eine VierIwan-Moschee mit einem achteckigen Heiligtum. Diese Einzelbauten sind lose miteinander verbunden. Sh. Blair zeigte auf, dass der Komplex in Natanz im wesentlichen in der ersten Dekade des

103 Vgl. Blair, Natanz, Tafeln 2 und 70-92. Siehe auch die Aufnahmen des Portals auf archnet, z. B. http://archnet .org/sites/1645/media_contents/42462 und http://arch net.org/sites/1645/media_contents/42466 (Stand 26 . Januar 2017).

104 Vgl. Blair, Natanz 2 und Figuren 2-5 (S. 104-107).
14. Jh., also unter den Ilkhaniden errichtet wurde. Sie sieht sich aufgrund der klaren Lokalisierung und Datierung des Heiligtums und dem Umstand, dass auch der Architekt bekannt war, in der glücklichen Lage, die Hintergründe aufzuzeigen, die zur Errichtung dieses Heiligtums für 'Abd aș-Ṣamad geführt hatten. Dies erlaubt es ihr, in ihrer Studie das Netzwerk an Beziehungen zwischen Angehörigen der ilkhanidischen Eliten und wichtigen Personen aus dem Umfeld des Sufitums aufzuzeigen. Ihre Erkenntnisse sollen an dieser Stelle nicht in extenso aufgegriffen werden. ${ }^{105}$ Allerdings wird hier die Auffassung vertreten, dass die in der vorliegenden Studie untersuchten Dokumente in Rollenform in ähnlichen Umfeldern entstanden sind wie z. B. das Heiligtum des 'Abd aș-Ṣamad in Natanz. Aus derselben Zeit sind gerade aus Iran auch weitere heilige Stätten bekannt, die L. Golombek in einem Aufsatz als little cities of God bezeichnet hat. ${ }^{106}$ L. Golombek geht neben 1. Natanz auf die Beispiele von ähnlichen kleineren Heiligtümern in 2. Ardabil, ${ }^{107}$ 3. Pīr-i Bakrān, ${ }^{108} 4$. Bisțām ${ }^{109}$ und 5. Turbat-i Šayh Ğām ${ }^{110}$ ein. Sie unterscheidet

105 Es wird hier in allgemeiner Form auf Blair, Natanz, verwiesen.

106 So S. 419 in ihrem folgenden Aufsatz: Golombek, Cult of saints.

107 In Ardabīl befindet sich der Schrein des Šayh Safī ud-Dīn, des Begründers des Derwischordens der Șafawiyya. Vgl. zu diesem Heiligtum Golombek, Cult of saints $422 \mathrm{f}$. Siehe jetzt auch die Untersuchung von Rizvi, Shrine.

108 Pīr-i Bakrān befindet sich in der Nähe von Isfahan; vgl. Golombek, Cult of saints 423 .

109 In Bisțām befindet sich das Heiligtum des bekannten Mystikers Abū Yazīd al-Bisțāmī (gest. ca. 875). Der Komplex mit dem Grab des Heiligen integriert ältere, vormongolische Bauwerke, wurde in seinen wesentlichen erhaltenen Teilen aber im frühen 14. Jh. erstellt; vgl. Golombek, Cult of saints $424 \mathrm{f}$.

110 Turbat-i Ğām befindet sich in No-Iran (Khorasan). Hier steht das Heiligtum des 1141 verstorbenen Šayh Ahmad. Der Schrein geht zwar in seinem Kern auf das Jahr 1236 zurück. Ebenso wie die andern von L. Golombek angeführten littles cities of God blühte aber auch dieses Heiligtum im 14. Jh. wieder auf. Damals wurden gemäss L. Golombek zwischen 1302 und 1362 um das Grab des Sufi-Heiligen Šayh Aḥmad weitere Bau- 
diese kleineren Heiligtümern (little cities of God) von den great cities of God, zu denen sie in Iran Qum und Mašhad zählt.

L. Golombek zeigte auf, dass diese kleineren Heiligtümer in der ersten Hälfte des 14. Jh. entstanden sind oder damals grundlegend erneuert wurden. ${ }^{111}$ Anhand der fünf soeben aufgezählten Schreine lässt sich aufzeigen, dass darin eine allgemeine Entwicklung zum Ausdruck kommt. Das zeitgleiche Entstehen dieser Schreine im 14. Jh. kann nur mit der Existenz von reichen und einflussreichen Sufi-Gemeinschaften erklärt werden. Die gewichtigsten Vertreter dieser SufiGemeinschaften konnten durchaus mit der feudalen Aristokratie rivalisieren. Vielfach unterhielten Sufis auch enge Beziehungen zu den Inhabern weltlicher Macht, wie anhand der Untersuchungen von M. Gronke ${ }^{112}$ oder Ch. Werner ${ }^{113}$ bereits aufgezeigt wurde. L. Golombek stützt ihre Feststellung zu den engen Beziehungen zwischen Sufis und weltlichen Machthabern ausserdem, indem sie auf die Forschungen von M. Mazzaoui, ${ }^{114}$ J.S. Trimingham ${ }^{115}$ und A.H. Zarrinkoob ${ }^{116}$ verweist. J.S. Tirmingham macht z.B. darauf aufmerksam, dass damals die Führung in religiösen Angelegenheiten von den dem traditionalistischen Islam verpflichteten 'ulama $\bar{a}$ an die Sufis überging. Es waren Sufis, die den Mongolen den Islam nahebrachten. Zu dieser Zeit war der Schrein (hāanaqāh), nicht mehr die madrasa, das Zentrum des religiösen Lebens. ${ }^{117} \mathrm{Zu}$ derselben Zeit lässt sich auch eine gewisse Institutionalisierung der von Sufis gepflegten Riten beobachten. Ausserdem

ten errichtet. Vgl. dazu Golombek, Cult of saints 427; http://archnet.org/sites/3887 (mit Abbildungen; Stand 27. Januar 2017).

Dies ist in Iran die Zeit der Ilkhaniden oder ihrer weniger bedeutenden Nachfolgedynastien; vgl. für die folgenden Ausführungen Golombek, Cult of saints 429. Gronke, Derwische 128-140 („Derwische und Machthaber").

113 Werner, Kuğuği-Stiftungen z. B. 30-40.

114 Mazzaoui, Origins.

115 Trimingham, Sufi orders.

116 Zarrinkoob, Persian Sufism.

117 Vgl. Trimingham, Sufi orders 67. weisen zahlreiche Belege auf eine enge Zusammenarbeit zwischen Sufis und weltlichen Eliten hin. ${ }^{118}$ Die Sufis waren nicht mehr länger gesellschaftliche Aussenseiter und Eigenbrötler, die in den Schreinen ein zurückgezogenes, Gott geweihtes Leben führten. Der Sufismus war vielmehr zu einem festen Bestandteil des urbanen Lebens geworden.

Sh. Blair konnte die von L. Golombek angestellten Beobachtungen am Beispiel des Schreins des 'Abd aṣ-Ṣamad in Natanz verdeutlichen. Ihre Erkenntnisse, gerade auch zu den Verbindungen zwischen den Sufis und den weltlichen Machthabern oder bedeutenden Händlern, sollen bei dieser Gelegenheit nicht wiederholt werden. Beachtung verdienen allerdings ihre Hinweise zur Person des Šayh 'Abd aṣ-Ṣamad, dem das Heiligtum in Natanz gewidmet ist. ${ }^{119}$ Die in Natanz bestattete Person lässt sich aufgrund von Inschriften eindeutig als Šayh Nūr ad-Dīn 'Abd aș-Ṣamad identifizieren. Er war ein Sufi-Shaykh und gehörte der Suhrawardiyya an, die zur Zeit der Ilkhaniden einen der beiden bedeutenden Orden in Iran darstellte. ${ }^{120}$ Der Suhrawardiyya-Orden geht auf Diyā' ad-Dīn Abu n-Naǧīb as-Suhrawardī (gest. 563/1168) und seinen Neffen Šihāb ad-Dīn Abu l-Ḥafṣ 'Umar (gest. 632/1234) zurück. Letzterer unterhielt bekanntlich enge Beziehungen zum Abbasiden-Kalifen anNāṣir li-Dīn Allāh. An-Nāṣir hatte für ihn in Bagdad einen ribāt errichtet, wo zahlreiche Sufis ausgebildet wurden. Ausserdem war es dieser Abu l-Hafș, der eine bedeutende Rolle bei der Reorganisation der Futuwwa unter an-Nāṣir li-Dīn Allāh gespielt hatte. ${ }^{121}$

Einer der wichtisgten Schüler dieses Abu lḤaf̣̦ war Nağīb ad-Dīn Buzgūš aus Shiraz (gest. 678/1279). Dieser Buzgūš wiederum initiierte 'Abd aș-Ṣamad in den Sufiorden der Suhrawardiyya. Es spricht vieles dafür, dass 'Abd aṣ-Ṣamad seine

\footnotetext{
118 Vgl. op. cit. 103.

119 Vgl. für die folgenden Ausführungen Blair, Natanz 5 .

120 Beim zweiten bedeutenden Sufiorden in Iran zur Zeit der Ilkhaniden handelt es sich um die Kubrāwiyya; vgl. Blair, Natanz 6.

121 Vgl. oben Kapitel 3.2.1.
} 
hirqa im hāanaqāh des Naǧīb ad-Dīn Buzgūš in Shiraz erhielt und danach nach Natanz übersiedelte. Dort scharte er seine eigenen Anhänger um sich. Seine beiden bedeutendsten Schüler waren 'Izz ad-Dīn Maḥmūd b. 'Alī b. Muḥammad b. Abī Ṭāhir al-Kāšānī an-Natanzī (gest. 735/1334-1335) und Kamāl ad-Dīn 'Abd ar-Razzāq b. Abi l-Ġanāim al-Kāšānī (gest. 736/1335). 'Abd aṣ-Ṣamad selbst soll 699/1299-130o gestorben sein. Seine beiden soeben erwähnten Schüler sollen ihren Lehrer übrigens an Bedeutung übertroffen haben. ${ }^{122}$

Es ist auch bekannt, dass der Hanaqāh in Natanz von Zayn ad-Dīn Halīfa b. Husayn b. 'Alī al-Mastarī errichtet worden ist, wie bereits erwähnt wurde. ${ }^{123}$ Aus historischen Quellen lässt sich schliessen dass Mastarī der Stellvertreter $(n \bar{a} i b)$ von Sa'd adDīn Sīwağ̄i, dem Hauptminister der Ilkhaniden, war. Ġazan-Hān ernannte Sa'd ad-Dīn zu seinem Hauptminister. Rašìd ad-Dīn war sein Assistent. Bei seiner Machtübernahme bestätigt Ülğäytü die beiden Minister in ihrem Amt.

Im Jahr 711/1312 wurde Sa'd ad-Dīn allerdings zusammen mit einigen seiner Statthalter, darunter auch Zayn ad-Dīn al-Mastarī hingerichtet. Sa'd adDīn hatte sich in Machtkämpfe und Intrigen mit Tāğ ad-Dīn 'Alī Šāh, einem seiner Gegenspieler, verwickeln lassen und dabei den Kürzeren gezogen. ${ }^{124}$

Zayn ad-Dīn al-Mastarī war nun jener Mäzen, der die Errichtung des Schreins in Natanz ermöglicht hatte. Sh. Blair weist bei dieser Gelegenheit darauf hin, dass reiche Persönlichkeiten aus dem Umfeld des Herrscherhauses zur Zeit der Ilkhaniden immer wieder als Mäzene des kulturellen und wissenschaftlichen Lebens in Erscheinung traten. Im Vordergrund standen Rašìd adDīn oder die Familie der Ǧuwaynīs. ${ }^{125}$ Zayn adDīn al-Mastarī spielte eine ähnliche Rolle, war allerdings einfach weniger bedeutend als die beiden soeben angeführten Parallelbeispiele. Dieser Zayn ad-Dīn al-Mastarī stiftete offensichtlich den

122 Vgl. Blair, Natanz 6.

123 Loc. cit.

124 Für die Einzelheiten siehe Blair, Natanz $6 \mathrm{f}$.

125 Vgl. dazu Blair, Natanz 8.
Bau des hānaqāh in Natanz und brachte damit seine Frömmigkeit zum Ausdruck. Zayn ad-Dīn alMastarī dürfte dem Sufi-Orden der Suhrawardiyya angehört haben und Schüler des 'Abd aș-Ṣamad gewesen sein, wie Sh. Blair aufzeigt. ${ }^{126}$ Diese Hinweise tragen indirekt auch zur Kontextualisierung von Is 1626 bei, dürfte diese Rolle doch in ähnlichen Umfeldern entstanden sein wie die angeführten Schreine. Nach diesem Exkurs ist auf die Erfassung der auf der Rolle kopierten Texte zurückzukommen:

TEIL II: Die Textbänder C und D: In den beiden Schriftbändern C und D wurde Text in kleinem Nash notiert, das gerade zu gross ist, um noch als $\dot{G} u b \bar{a} r$ eingestuft zu werden. Der Text beginnt in diesen beiden Bändern auf der rechten und auf der linken Seite je vorwärtslaufend. Die beiden Bänder treffen auf der Rolle später aufeinander. ${ }^{127}$ Die weiteren Ausführungen stellen die Textelemente in den beiden Seitenbändern näher vor:

Seitenband C (schmales Seitenband, rechts, mit Gebeten in kleinem Nash; Text absteigend und vorwärtslaufend; es befindet sich zwischen dem Schriftband A mit Text in gegenläufigem Schachbrett-Kū $f \imath$ auf der rechten Seite der Rolle und der Abschrift des Korans auf horizontalen Zeilen im Mittelstreifen).

II.C.1: Am Anfang stehen Sūrat al-Fātiha (Q 1 $)^{128}$ und Q 6:1-2. ${ }^{129}$ In diesen Abschnitt eingefügt sind zwei Kartuschen folgenden Inhalts; sie gehören zu einem zusätzlichen, unter Ziffer II.C.3 erwähnten Text. ${ }^{130}$ Dieser zusätzliche Text in den Kartuschen wird danach im Hirz Abı̄ Duğāna fortgesetzt und wird dort bei der Erfassung durch Fettsetzungen markiert.

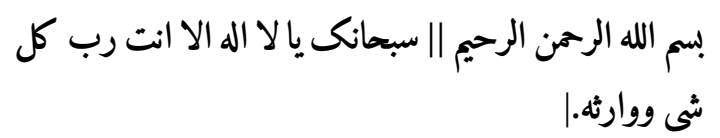

\footnotetext{
126 Op. cit. 11.

127 Vgl. Aufnahme Is 1626.13.2 und bei Anm. 301-302 und 551.

128 Vgl. die Aufnahmen Is 1626.2.1-4.

129 Vgl. die Aufnahmen Is 1626.2.5.

130 Vgl. unten bei Anm. 241.
} 


\section{II.C.2. Hịz Ab̄̄ Duğāna ${ }^{131}$}

هذا كتاب من محمد رسول132 الله .133 النبى العربي الهاشي

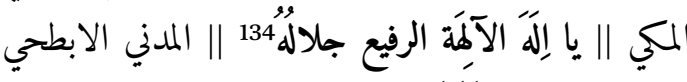
صاحب التاج والهَرَاوَّ135 • والقضيب والناقة والشفاعة • صاحب قول لا اله الا الله محمد رسول136 الله • الم من طرق

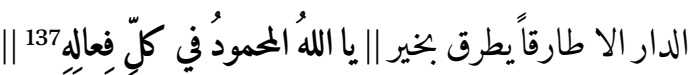
أما بعد 138 فإن لنا وركم في الحق سعة · فإن يكن طارقا مولعا أو داعيا مبطلا • أو مؤذيا مقتحما فاتركوا حملة القرآن

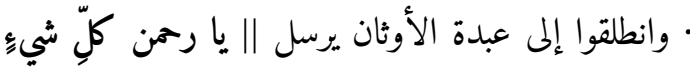
وراحمه139 || عليكما شواظ من نار ونحاس فلا تنتصران •بسم الله وبالله ومن الله وإلى الله 140 •.ولا غالب إلا الله ولا اله ا (؟) سوى الله · ولا شيء مثله الله (؟) || يا حي حين لا حي في ديمومة ملكه وبقائه1141 || بسم الله وأستفتح بالله وأتوكل على مئل

131 Vgl. http://roqia.khayma.com/DJANH.htm (Stand 20. Januar 2017). Siehe auch Abū Bakr al-Bayhaqī (9941066), Dalāil an-nubuwwa VII, 118-120 (Bayrūt, Dār alKutub al-ilmiyya, 1405/1985, siehe: http://lib.eshia.ir/ 44813/7/118; Stand 4. Oktober 2017); beachte ebenso: Mağlisī, Bihāar al-anwār 94, 220-224 (Nr. 19: http://lib .eshia.ir/110o8/94/220; Stand 4. Oktober 2017); siehe ausserdem: https://salawaat.wordpress.com/2015/o7/ 21/the-shield-hirz-of-abu-dujana-radiallahu-anhu-forprotection-against-the-jinn-and-shayateen/ (Stand 4. Oktober 2017).
Der Buchstaben sin wurde mit drei Punkten unterhalb der Zeile markiert.

Trennzeichen.

Diese Anrufung Gottes unterbricht den fortlaufenden Text; sie ist in eine rote Kartusche eingefügt. Man beachte die Wendung „O Gott der Götter, dessen Ehre erhaben ist". Sie ist bemerkenswert, stellt sie Allāh doch als einen Gott dar, der über einem Pantheon weiterer Gottheiten thront.

H. Wehr, Wörterbuch, vokalisiert hirāwa.

Sin erneut mit drei Punkten unterhalb der Zeile; vgl. Anm. 132.

Diese Anrufung Gottes erneut in einer roten Kartusche. Vgl. Aufnahme Is 1626.2.7-8.

Dieser Einschub in einer rot eingefassten Kartusche.

Fortsetzung auf Aufnahme Is 1626.3.2.

Dieser Einschub in einer schwarz eingefassten Kartusche; vgl. die Quellenangabe in Anm. 241. Er lässt
الله · وانت يا صاحب كّابي هذا في حرز الله وامانه · حيث

[ما] كان وحيثما توجه فلا تقربوه ولا تفزعوه ولا تضروه ||

يا قيوم فلا يفوته شيء من علمه ولايؤوده [حفظه يا قيوم] 142

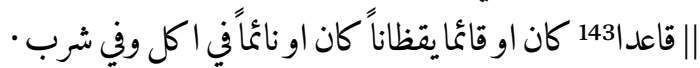
ولا في ثوب ولا عرياناً ولا في اغتسال وفي اي حال (؟) كان [فيه] · وفي اي مكان كان لا في الدار ولا في الارض || يا واحد الباتي (كذا) اول كل شيء وآخره الجبال ولا بالليل ولا بالنهار • وكلما145 سمعتم ذكر كتابي هذا

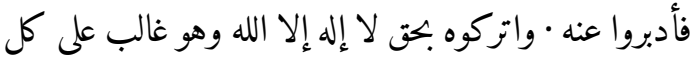
شيء وهو أعز || يا دائم فلا فناء ولا زوال لملكه يا حي 146 || من كل شيء وهو على كل شيء قدير

واعيذ صاحب كتابي بكلمة الله التامة · وباسم الذي هو مكتوب على سرادق العرش أنه لا إله إلا الله الغالب الذي 147

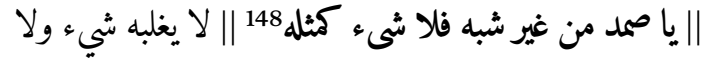

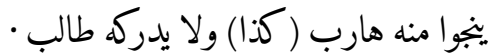

sich überdies nachweisen in الأنوار القادرية والأنوارئار ياحى-الأوار/الرمادية (Stand 20. Januar 2017).

142 Dieser Text in einer schwarzen Kartusche; vgl. die Quellenangabe in Anm. 241. Offensichtlich fehlte dem Schreiber der Platz, um die Aussage in der Kartusche vollständig zu notieren. Sie lässt sich u.a. überdies nachweisen unter http://fatin6.ibda3.org/t142 -topic (Stand 2o. Januar 2017).

143 Fortsetzung auf Aufnahme Is 1626.3.3.

144 Dieser Text in einer schwarzen Kartusche; vgl. Quellenangabe in Anm. 241.

145 Fortsetzung auf Aufnahme Is 1626.3.4.

146 Dieser Text in einer blauen Kartusche. Der Text wird in der Regel anders zitiert: زيا دائ فلا فناء ولائا زوال لملكم وبقائه يا دائح . Vgl. die Quellenangabe in Anm. 241.

Fortsetzung auf Aufnahme Is 1626.4.3.

148 Dieser Einschub in einer blauen Kartusche. Der Text lässt sich u.a. belegen unter http://www.alanwaralqadr

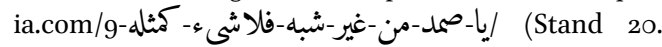
Januar 2017); vgl. aber v.a. die Quellenangabe in Anm. 241. 


$$
\begin{aligned}
& \text { وأعيذه بالحي الذي لا يموت وبالملك الذي لايزول ملكه } \\
& \text { •وبالقيوم الذي لا ينام وبالعزيز || يا بار فلا شيء كفؤه يدانيه } \\
& \text { ولا امكان لوصفه } 149 \text { || الذي لا يذل } \\
& \text { واعيذه بالاسماء المكتوبة في اللوح المحفوظ } 150 \text { • وبالاسم } \\
& \text { الذي هو مكتوب في التورية والانجيل والفرقان • وبالاسم }
\end{aligned}
$$

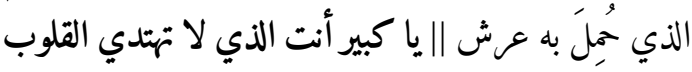

$$
\begin{aligned}
& \text { لصفة عظمته151 || بلقيس الى سليمان ابن داود عليهما السلام } \\
& \text { قبل ان يرتد اليه طرفه • وبالاسم الذي نزل به جبريل عليه } \\
& \text { السلام152 • المى محد صلى الله عليه وآله وسلم } 153 \text { || يا باري } \\
& \text { النفوس بلا مثال خلا عن غيره } 154 \text { || في يوم الإثنين وبالأسماء }
\end{aligned}
$$

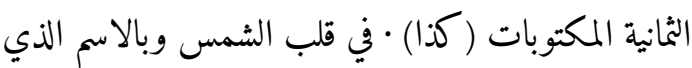

$$
\begin{aligned}
& \text { يسير به السحاب الثقال · وبالاسم الذي يسبح الرعد .بمده } \\
& \text { والملائكة || يا زاكي الطاهر من كل آفة بقدس } 155 \text { || من } \\
& \text { خيفته } 156 \text { وبالاسم الذي تجلى به ربنا وزّ وجل بموسى بن }
\end{aligned}
$$

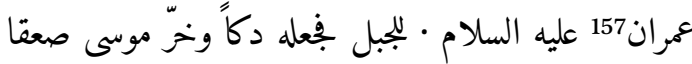

$$
\begin{aligned}
& \text { • وبالاسم الذي كتب على ورق || يا كافي الموسع لما خلق }
\end{aligned}
$$

149 Letzter Ausdruck (li-wasfi-hī) auf der Rolle kaum lesbar. Dieser Einschub in einer blauen Kartusche. Vergleiche dazu die Fatwā-Sammlung des Suyūțī (ausführliche Stellenangabe in Anm. 241): http://library.islamweb .net/newlibrary/display_book.php?flag=1\&paragraph id $=\& b k \_n o=130 \& I D=397 \& \% 2$ oBooks (Stand 4. Oktober 2017).

Vgl. Aufnahme Is 1626.4.5.

Dieser Einschub in einer roten Kartusche. Dieser Text lässt sich belegen in der in Anm. 241 (Text 3) angeführten Internetquelle.

Das $\sin$ wird hier weiterhin mit drei Punkten unterhalb der Zeile markiert.

Vgl. ab hier Aufnahme Is 1626.4.6.

Dieser Einschub in einer roten Kartusche. Dieser Text lässt sich belegen in der in Anm. 241 (Text 3) angeführten Internetquelle.

Dieser Einschub in einer roten Kartusche. Dieser Text lässt sich belegen in der in Anm. 241 (Text 3) angeführten Internetquelle. Der Text lautet in dieser Parallelstelle: يازاكي الطاهر من كل شيء بقد

Vgl. ab hier Aufnahme Is 1626.4.7.

Stark verderbt.

من عطاء فضله 158 || الزيتون وبالاسم الذي يمشي به الخضر على الملاء159 ولم تبتل قدماه وبالاسم الذي نطق 160 به عيسى

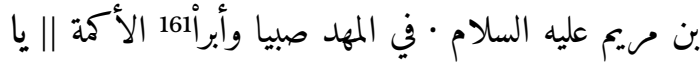
نقيا من كل جور لم يرضه ولم يخالط فعاله 162 || والأبرص وأحيى الموتى بإذن الله عز وجل · وبالاسم الذي نجا به ابراهيم عليه السلام 163 • من نار نمرود بن كنعان وبالاسم

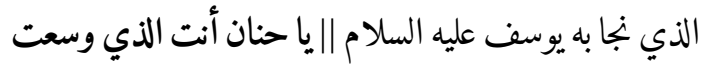
كل شيء رحمة وعلما164 || من الجب وبالاسم الذي نجا به يونس عليه السلام من الظلمات165 ـ وبالاسم الذي دعاء166 به موسى عليه السلام · على البحر فانفلق فكان كل فرق (؟) كالطود العظيم 167 || يا منان ذا الإحسان قد عم كل الخم الخلائق || 168 منه

واعيذه بالسبع المثاني والقران العظيم •وبمانزل نزل (كذا) على موسى عليه السلام بطور سينا • واعيذ صاحب كّابي هذا بهذه الاسماء من سى" كل عين ناظرة و ||| يا ديان العباد [ف]كل يقوم خاضعا لرهبته ورغبته 169 || آذان 170

$15^{8}$ Dieser Einschub in einer schwarzen Kartusche; der Text ist auf der Rolle verderbt. Er lässt sich belegen in der in Anm. 241 (Text 3) angeführten Internetquelle.

Vgl. ab hier Aufnahme Is 1626.4.9.

Auf der Rolle steht hier يظيق oder ähnlich, was keinen Sinn ergibt.

Auf der Rolle steht hier يبرى.

Dieser Einschub in einer schwarzen Kartusche; der Text ist auf der Rolle verderbt. Er lässt sich belegen in der in Anm. 241 (Text 3) angeführten Internetquelle.

Vgl. ab hier Aufnahme Is 1626.4.10.

Dieser Einschub in einer schwarzen Kartusche. Dieser Text lässt sich belegen in der in Anm. 241 (Text 3) angeführten Internetquelle.

Im Mittelstreifen beginnt hier Q 7 (Sūrat al-A'rā̃f).

Für دعاه.

Vgl. ab hier Aufnahme Is 1626.4.11.

Dieser Einschub in einer blauen Kartusche. Dieser Text lässt sich belegen in der in Anm. 241 (Text 3) angeführten Internetquelle.

Dieser Einschub in einer blauen Kartusche; letzter Ausdruck unsicher, er fehlt auch in der in Anm. 241 angeführten Internetquelle.

Vgl. ab hier Aufnahme Is 1626.4.13. 
سامعة وقدام ماشية ولسان ناطقة · وقلوب واعية وصدور

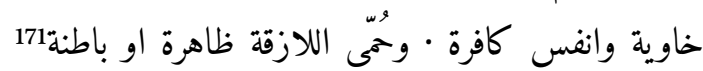

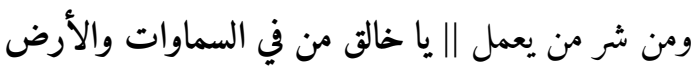
وكل إليه معاده172 || السوء والخطايا ويهم بها من ذكز او أنثى • من 173 الجن في الليل والنهار واعيذه من شر كل ذي شر • وعقدهم 174 وسلاحهم وكيدهم ومكرهم وبريق اعينهم || يا رحيم كل صريخ ومكروب وغياثه ومعاذه

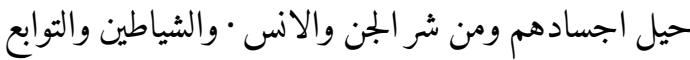

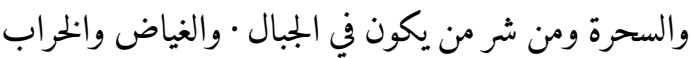

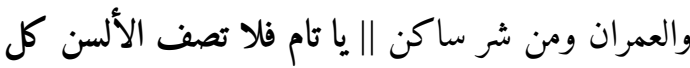
جلاله وعزه176 ||177 النواويس وساكن القبور وساكن البحار وساكن الطرق 178 • واعيذه من شر كل غول وغولة

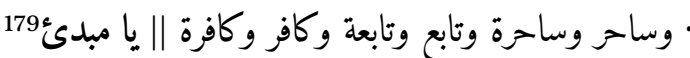

171 Die Vorlage liest hier وعين لازمة ظاهرة وباطنة. Vgl. Mağlisī, Bihār al-anwār 222 (http://lib.eshia.ir/11008/ 94/222, Stand 21. Januar 2017).

وأعيذ صاحب كخانى هذا من كل عين ناظرة، وآذان سامعة، وألسن ناطقة واقدام ماشية، وقلوب واعيلة هاعية، وصدور خاوية،

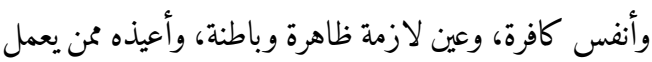
السوء ويعمل الخطايا، ويهم لما من ذكروانئ لاني.

Dieser Einschub in einer blauen Kartusche. Dieser Text lässt sich belegen in der in Anm. 241 (Text 3) angeführten Internetquelle.

Vgl. ab hier Aufnahme Is 1626.4.14

Im Mittelstreifen beginnt hier Q 8 (Sürat al-Anfäl).

Dieser Einschub in einer roten Kartusche. Dieser Text lässt sich belegen in der in Anm. 241 (Text 3) angeführten Internetquelle.

Dieser Einschub in einer roten Kartusche. Dieser Text lässt sich belegen in der in Anm. 241 (Text 3) angeführten Internetquelle.

Vgl. ab hier Aufnahme Is 1626.4.15.

Auf der Rolle steht hier wahrscheinlich at-taraf. Vgl. die Lesung at-țuruq bei Mağlisī, Biḥār al-anwār 222 (http://lib.eshia.ir/11008/94/222, Stand 21. Januar 2017).

Auf der Rolle: مبدو.

$$
\begin{aligned}
& \text { البدائع لم يبغ في إنشائها عونا من خلقه ||180 واعيذه181 من } \\
& \text { شرهم وشر ابائهم وامهاتهم وابنائهم · وذرياتهم ومن شر } 182
\end{aligned}
$$

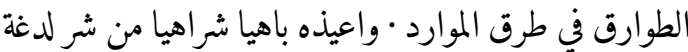

$$
\begin{aligned}
& \text { ناهش } 183 \text { || يا علام الغيوب فلا يئوده شيء من حفظه } 184 \\
& \text { || والاباليس ومن شر الفاعل والفاعل (؟)185 • ومن } 186 \\
& \text { شر كل عين ساحرة او خاطية ومن شر الخارج · والداخل } \\
& \text { ومن شر كل باغي وهادي (؟) وكل غاوي فاتك ومن || يا } \\
& \text { حليم ذا الأناة فلا يعادله شيء من خلقه بـ } 187 \text { || شر عفاريت } \\
& \text { الجن والانس } 188 \text { ومن شر الرياح والمياه • والنيران والجمادات } \\
& \text { والحيواناة ومن شر كل فصيح ·عجيم (؟) ونائم ويقظان }
\end{aligned}
$$

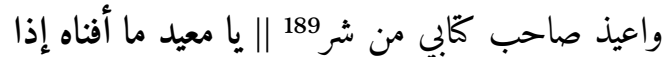

$$
\begin{aligned}
& \text { برز الخلائق لدعوته من مخافته } 190 \text { || ساكن الارض وساكن } \\
& \text { البيوتات والزوايا والمزابل } 191 \text { • ومن شر من يصنع } 192 \text { الخطيئة }
\end{aligned}
$$

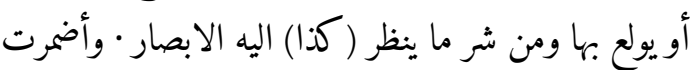

$$
\begin{aligned}
& \text { عليه القلوب وانقضت } 193 \text { || يا حميد الفعال ذا المن على جميع }
\end{aligned}
$$

180 Dieser Einschub in einer roten Kartusche. Dieser Text lässt sich belegen in der in Anm. 241 (Text 3) angeführten Internetquelle.

181 Vgl. ab hier Aufnahme Is 1626.4.16.

182 Dieser Ausdruck (šarr) unterhalb der Zeile hinzugefügt.

183 Auf der Rolle ناهيش.

184 Dieser Einschub in einer schwarzen Kartusche. Dieser Text lässt sich belegen in der in Anm. 241 (Text 3) angeführten Internetquelle.

ومن شَ القابل Bei Mağlisī, Biḥār al-anwār 222, steht (http://lib.eshia.ir/110o8/94/222, Stand 21. Januar 2017).

186 Vgl. ab hier Aufnahme Is 1626.5.2; im Mittelstreifen beginnt jetzt Q 10 (Sūrat Yūnus).

187 Dieser Einschub in einer schwarzen Kartusche; er ist schlecht leserlich. Dieser Text lässt sich belegen in der in Anm. 241 (Text 3) angeführten Internetquelle. Vgl. ab hier Aufnahme Is 1626.5.3.

189 Vgl. Aufnahme Is 1626.5.3; im Mittelstreifen beginnt hier Q 11 (Sūrat Hūd).

Dieser Einschub in einer schwarzen Kartusche. Dieser Text lässt sich belegen in der in Anm. 241 (Text 3) angeführten Internetquelle. Vgl. ab hier Aufnahme Is 1626.5.5.

192 Auf der Rolle allenfalls يضيع.

193 Auf der Rolle steht hier ein anderer Begriff: اتفقت (?). 
خلقه بلطفه194 || عليه العهود ومن شر من يولع بالفراش 195

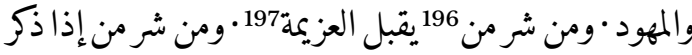
الله ذاب كما يذوب الرصاص والحديد على النار 198 واعيذه صاحب || يا ززيز المنيع الغالب على أمره فلا شيء يعادله 199

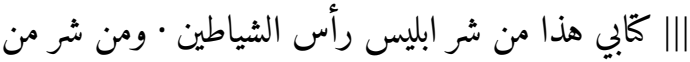
يعمل العقد ومن شر من يسكن في الهواء • والجبال والبحار ومن في الظلمات والنور200 ومن شر من يسكن في || يا قاهر ذا البطش الشديد أنت الذي لا يطاق انتقامه201 || العيون ومن شر من يمشي في الاسواق ومن يكون مع الدواب203 • والمواشي والوحوش ومن شر من يكون في الأرحام 204 . والأجام والا كام ومن شر من يوسوس في صدور الناس || يا قريب المتعالي فوق كل شيء علوه وارتفاعه السمع والابصار · وأعيذ صاحب كخابي من النظرة واللمحة

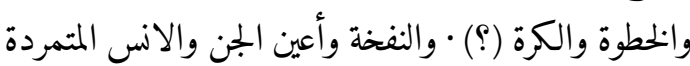
• ومن شر الطائف207 والطارق والغاسق || يا مذل كل

Dieser Einschub in einer roten Kartusche. Dieser Text lässt sich belegen in der in Anm. 241 (Text 3) angeführten Internetquelle.

Auf der Rolle بالفرش.

Vgl. ab hier Aufnahme Is 1626.5.6.

Mağlisī, Bihār al-anwār liest hier العزّ شر من لا يقبل العزيمة (vgl. http://lib.eshia.ir/110o8/94/222, Stand 22. Januar 2017).

Vgl. Aufnahme Is 1626.5.6; im Mittelstreifen beginnt hier Q 12 (Sürat Yūsuf).

Dieser Einschub in einer blauen Kartusche. Dieser Text lässt sich belegen in der in Anm. 241 (Text 3) angeführten Internetquelle.

Text verderbt.

Dieser Einschub in einer blauen Kartusche. Dieser Text lässt sich belegen in der in Anm. 241 (Text 3) angeführten Internetquelle.

Vgl. ab hier Aufnahme Is 1626.5.8.

Im Mittelstreifen beginnt hier Q 13 (Sürat ar-Ra'd).

Auf der Rolle wohl ohne $r \bar{a}$.

Dieser Einschub in einer blauen Kartusche; er ist teilweise stark verderbt. Dieser Text lässt sich belegen in der in Anm. 241 (Text 3) angeführten Internetquelle.

Im Mittelstreifen beginnt hier Q 14 (Sürat Ibrähīm); vgl. ab hier Aufnahme Is 1626.6.3.

So bei Mağlisī, auf der Rolle steht wohl الطابق.

جبار بقهر عزيز سلطانه 208 || والواقب والحاسد والطاغي والكاهن 209 ومن شر كل عقد · وسحر وفزع وهم وحزن واستيحاش ونكر (؟) وفك · ووسواس 210 واعيذه بالله من ونري شر كل داء يفترى لبني آدم وبنات || يا نور كل شيء وهداه أنت الذي فلق الظلمات نوره211 || حوا من قبل الدم والبلغم والمرة والحمراء212 . والصفراء والسوداء ومن النقصان ومن

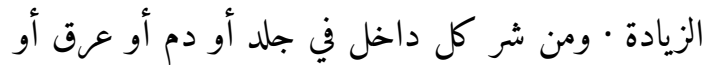
عصب أو نطفة أو عظم أو || يا عالي الشاخخ فوق كل شيء علوّ ارتفاعه || في سمع أو بصر أو ظهر أو بطن أو شعر أو أو أو أو

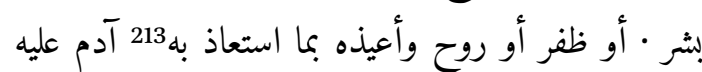
السلام · وشيت وهابيل وإدريس ونوح ولوط214 وإبراهيم وإسمعيل || يا قدوس الظاهر على كل شيء فلا شيء يعادله من خلقه 215 || وإسحاق ويعقوب والأسباط وعيسى وأيوب ويونس ·وموسى وهارون وداوود وسليمان وزكزيا • ويحيى ويوسف وهود وشعيب وإلياس وصالح واليسع ولقمان || يا مبدى البرايا ومعيدها بعد فنائها بقدرته ||216 وذو الكفل وذو القرنين وطالوت ووزير • والخضر ودانيال ومحمد صلى الله عليه

208 Im Mittelstreifen beginnt hier Q 14 (Sürat al-Hiğr). Dieser Einschub in einer roten Kartusche. Dieser Text lässt sich belegen in der in Anm. 241 (Text 3) angeführten Internetquelle.

209 Vgl. ab hier Aufnahme Is 1626.6.4.

210

211

212

213

214

215 einer schwarzen Kartusche; er ist teilweise schlecht leserlich. Dieser Text lässt sich belegen in der in Anm. 241 (Text 3) angeführten Internetquelle. 
وآله وسلم عليهم [السلام] أجمعين · وكل ملك مقرب ملك

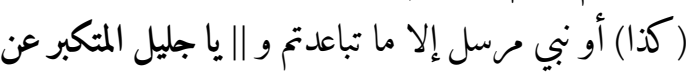

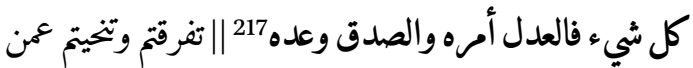
علق عليه كتابي · هذ|218 بسم الله الجليل الحميد المحسن الفعال لمايريد · وأعيذه بالله وبالاسم الذي أضاء به القمر و استنار به الشمس || يا محمود فلا تبلغ الأوهام كل ثنائه ومجده 219 || وهو مكتوب تحت العرش انه لا إله إلا الله محمد رسول الله220 • فسيكفيكهم الله وهو السميع العليم 221 • نفذت ججة الله وظهر سلطان الله وتفرق أعداء الله || يا كزيم العفو ذا لهاء العدل أنت الذي ملأ كل شيء عدله 222 || وبقي 223 وجه

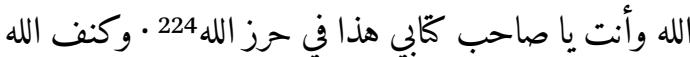
وجوار الله وامان الله وحفظ الله · جار عزيز وحفظه منيع الله جارك ووليك وحارسك || يا عظيم ذا الثناء الفاخر وذا العز والمجد والكبرياء فلا يذل عزه225 || وحافظك ووليك ما

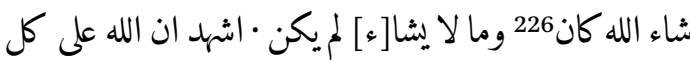

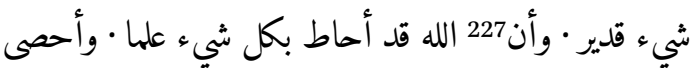

217 Dieser Einschub in einer blauen Kartusche; er ist teilweise schlecht leserlich. Dieser Text lässt sich belegen in der in Anm. 241 (Text 3) angeführten Internetquelle. Im Mittelstreifen beginnt hier Q 19 (Sūrat Maryam, hier Sūrat Kāf-hä'-y $\left.\bar{a}^{\prime}-{ }^{\prime} a y n-s ̦ a \bar{d}\right)$.

Im Mittelstreifen beginnt hier Q 20 (Sūrat Țā-hā'). Auf der Rolle wohl ein zusätzlicher, kaum leserlicher Begriff. Dieser Einschub in einer blauen Kartusche. Dieser Text lässt sich belegen in der in Anm. 241 (Text 3) angeführten Internetquelle.

Vgl. ab hier Aufnahme Is 1626.7.4.

Vgl. Q 2:137 (Schluss).

Dieser Einschub in einer blauen Kartusche. Dieser Text lässt sich belegen in der in Anm. 241 (Text 3) angeführten Internetquelle.

Im Mittelstreifen beginnt hier Q 21 (Sürat al-Anbiy $\bar{a}$ ).

Vgl. ab hier Aufnahme Is 1626.8.2.

Schluss schlecht leserlich; dieser Einschub in einer roten Kartusche. Dieser Text lässt sich belegen in der in Anm. 241 (Text 3) angeführten Internetquelle.

Im Mittelstreifen beginnt hier Q 22 (Sürat al-Hağğ).

Vgl. ab hier Aufnahme Is 1626.8.3.

كل شيء عددا إن الله وملائكته || يا بجيب (؟) فلا تنطق

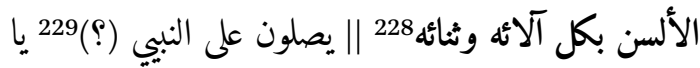

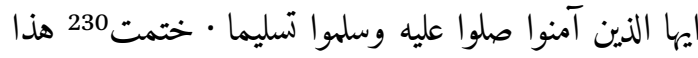
الختاب بخاتم الله الذي ختم به أقطار السموات والأرض الماليه

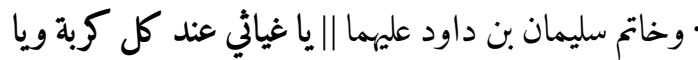
معاذي عند كل شدة وبميبي (؟) عندها232 || السلام وبخاتم

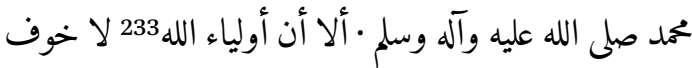
عليهم ولا هم يحزنون • الله لا اله الا هو رب العرش الع العظيم له معقبات من || [...] يصلي على محمد وآل محمد و [...] || بين يديه ومن خلفه يحفظونه من أمر الله 235 ـ. والله خير

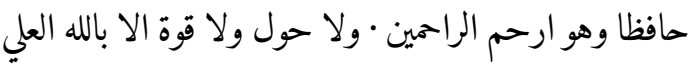

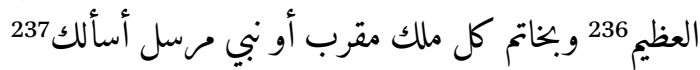
أمانا من عقوبات الدنيا والآخرة سبحان الله لا اله الاهو هو عليه توكلت وهو رب العرش العظيم • وصلى الله على محمد وآله 238

228 Anfang und Schluss schlecht leserlich; er wurde in die Kartusche gepresst. Dieser Text lässt sich belegen in der in Anm. 241 (Text 3) angeführten Internetquelle.

(1)

, wo der Text in gegenläufigem Schachbrett-Kūfī im rechten Seitenband stark verderbt ist. Rekonstruktion anhand der Parallele, wo die Passage verzeichnet ist; dieses Zitat befindet sich hier nicht in einer Kartusche. Dieser Text lässt sich belegen in der in Anm. 241 (Text 3) angeführten Internetquelle.

238 Im Mittelstreifen beginnt hier Q 26 (Sūrat aš-Šu'arā'). 


$$
\begin{aligned}
& \text { اجمعين الطيبين الطاهرين · برحمتك يا ارحم الراحمين وسلم } \\
& \text { تسليما كثيرا (؟)239 || برحتك يا ارحم الراحمين } 240 \text { || }
\end{aligned}
$$

An dieser Stelle endet das Gebet, das sich unter dem Titel Hirz Ab̄ Duğāna u.a. bei Mağlisī, Biḥār al-anwār, nachweisen lässt. Danach folgt ein nächster Text der mit der Basmala eingeleitet wird. Dieser nächste Text wird sogleich anschliessend erfasst (II.C.4).

II.C.3. Der Text in den farbigen Kartuschen liess sich mit geringen Abweichungen in der Fatwa Sammlung Suyūṭis nachweisen. ${ }^{241}$ Er wurde in Kartuschen ins soeben transkribierte Gebet des Abū Duğāna integriert. Diese Textstellen wurden in der vorangehenden Transkription des Hirz Abi Duğāna (II.C.2) fett hervorgehoben. Es handelt sich um Anrufungen und Lobpreisungen Gottes. Dieser Text stellt das Gegenstück zu den Lobpreisungen Muhammads im Schriftband D auf der gegenüberliegenden (linken) Seite der Rolle dar.

II.C.4, Gebet: ${ }^{242}$ Dieses Gebet folgt auf dem rechten Seitenband mit Text in Nash-Schrift. Es erstreckt sich von der Aufnahme Is 1626.9.2 bis zur Aufnahme Is 1626.13.2. Dort stösst aufsteigend das von der linken Seite her kommende Schriftband auf die Stelle mit dem vorliegenden Gebet. Die Stelle, wo die beiden Texte aufeinandertreffen ist klar ersichtlich, da die Schriftrichtung unterschiedlich ist (absteigend bzw. aufsteigend).

239 Die Stelle ist verderbt.

240 Dieser Text in einer schwarzen Kartusche.

241 Der Text in den Kartuschen liess sich nachweisen bei Ǧalāl ad-Dīn as-Suyūțī, al-Hāàw li-l-Fatāwā 440 f. Bayrūt, Dār al-Fikr li-n-našr wa-ț-tibā'a, 1424/2004. Siehe dazu: http://library.islamweb.net/newlibrary/display_book .php?flag=1\&paragraphid=\&bk_no=130\&ID=397\&\%20 Books (Stand 4. Oktober 2017). Auch abgedruckt in Suyūṭī, al-Hāwì li-l-Fatāwā I, $367 \mathrm{f}$. Bayrūt, Dār alKutub al-ilmiyya, 1395/1975. Derselbe Text mit grösseren Abweichungen grundsätzlich auch auf Ms. or. oct. 146 aus der Staatsbibliothek zu Berlin; vgl. Kapitel 5.1 bei Anm. 19-20.

$$
\begin{aligned}
& \text { بسم الله الرحمن الرحيم } 243 \text { • اللهم يا كثير النوال ويا حسن } \\
& \text { الفعال • اللهم ان دخل الشك في ايمانى بك • ولم244 اعلم } 245 \\
& \text { به تبّت عنه و || وصلى الله على محمد وآله اجمعين } 246 \text { || اقول لا لا } \\
& \text { اله الا الله محمد رسول الله • اللهم ان دخل الكفر فى اسلامي }
\end{aligned}
$$

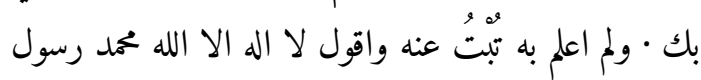

$$
\begin{aligned}
& \text { الله247 || اللهم صل على محمد مع من امن واتبع } 248 \text { || اللهم }
\end{aligned}
$$

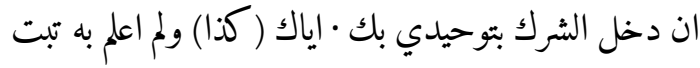

$$
\begin{aligned}
& \text { عنه واقول لا اله الا الله · محمد رسول الله اللهم ان دخل }
\end{aligned}
$$

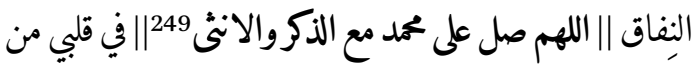

$$
\begin{aligned}
& \text { ذنوب الصغائر والبكائر } 250 \text { ـ ولم } 251 \text { اعلم به تبت عنه واقول لا لا } \\
& \text { اله الا الله محد رسول الله • اللهم ان دخل العجب والكبرياء } \\
& \text { وارياء || اللهم صل على [محد] مع البكور والعشي ( كذا) 252 }
\end{aligned}
$$

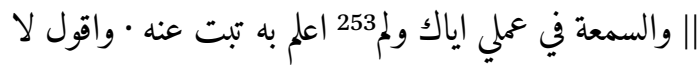

$$
\begin{aligned}
& \text { اله الا الله محمد رسول الله • اللهم ما عملت من سو ولم اعلم } \\
& \text { به تيت عنه } 254 \text { || اللهم صل على محمد مع الليل اذا يغشى } 255
\end{aligned}
$$

243 Vgl. Aufnahme Is 1626.9.2.

244 Vgl. ab hier Aufnahme Is 1626.9.3.

245 Im Mittelstreifen beginnt hier Q 27 (Sürat an-Naml).

246 Dieser Einschub in einer blauen Kartusche.

247 Im Mittelstreifen beginnt hier Q 28 (Sūrat al-Qișaṣ).

248 Dieser Text in einer blauen Kartusche; er steht gegenüber dem Text auf dieser Linie ausserhalb der Kartusche auf dem Kopf. Diese Anordnung des Texts in den weiteren Kartuschen in diesem Seitenband zeigt auf, wie der Kopist bei der Anfertigung der Rolle vorgegangen ist: Er dürfte diese Kartuschen zuerst geschrieben haben, da er vermutete, der vom linken Seitenband hier aufsteigende Text würde bis hierhin gelangen. Dies war dann aber offensichtlich nicht der Fall.

249 Dieser Text in einer blauen Kartusche; er steht gegenüber dem Text auf dieser Linie ausserhalb der Kartusche auf dem Kopf. (Sürat al-'Ankabūt) Die Stelle ist stark verderbt.

Dieser Text in einer roten Kartusche; er steht gegenüber dem Text auf dieser Linie ausserhalb der Kartusche auf dem Kopf.
Im Mittelstreifen beginnt hier Q 30 (Sürat ar-Rüm).

Vgl. ab hier Aufnahme Is 1626.10.2.

Dieser Text in einer roten Kartusche; er steht gegenüber 


$$
\begin{aligned}
& \text { || واقول256 لا اله الا الله محمد رسول الله • اللهم ان دخل } \\
& \text { الكذب والغيبة (؟)257 على لسانى • ولم اعلم به تيت عنه واقول } \\
& \text { لا اله الا الله258 || اللهم صل على محد مع النهار اذا على } 259
\end{aligned}
$$

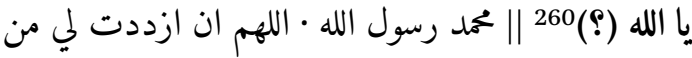

$$
\begin{aligned}
& \text { خير ولم اشكره • ولم اعلم به تبت عنه واقول لا اله الا الله }
\end{aligned}
$$

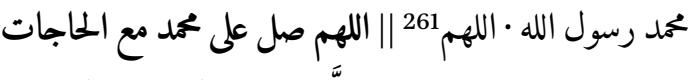

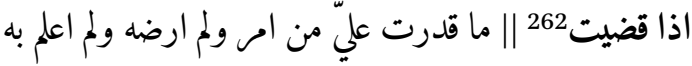

$$
\begin{aligned}
& \text { تبت عنه · واقول لا اله الا الله محمد رسول الله • اللهم } 263
\end{aligned}
$$

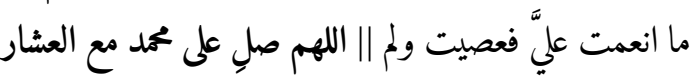

$$
\begin{aligned}
& \text { اذا عطلت } \\
& \text { محمد رسول الله } 266 \text { • اللهم ما اوليتني عن نعمائك فغفلت عن }
\end{aligned}
$$

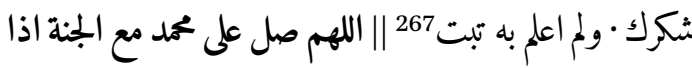

$$
\begin{aligned}
& \text { [268 || عنه واقول لا اله الا الله محمد رسول الله • اللهم }
\end{aligned}
$$

dem Text auf dieser Linie ausserhalb der Kartusche auf dem Kopf.

256 Im Mittelstreifen beginnt hier Q 31 (Sūrat Luqmān).

257 Im Mittelstreifen beginnt hier Q 32 (Sūrat as-Sağda).

258 Im Mittelstreifen beginnt hier Q 33 (Sūrat al-Aḥzāb).

259 Für le.

26o Dieser Text in einer roten Kartusche; er steht gegenüber dem Text auf dieser Linie ausserhalb der Kartusche auf dem Kopf.

261 Im Mittelstreifen beginnt hier Q 34 (Sūrat al-Aḥzāb).

262 Dieser Text in einer schwarzen Kartusche; er steht gegenüber dem Text auf dieser Linie ausserhalb der Kartusche auf dem Kopf.

263 Vgl. ab hier Aufnahme Is 1626.10.4.; im Mittelstreifen beginnt hier Q 35 (Sūrat al-Malāika).

264 Dieser Text in einer schwarzen Kartusche; er steht gegenüber dem Text auf dieser Linie ausserhalb der Kartusche auf dem Kopf.

265 Riss im Papier, der sich nahezu über die ganze Breite der Rolle erstreckt.

266 Im Mittelstreifen beginnt hier Q 36 (Sürat Yā-sīn).

267 Vgl. ab hier Aufnahme Is 1626.10.5; im Mittelstreifen beginnt hier Q 37 (Sūrat aș-Șâffāt).

268 Wohl: ازلفت. Die Stelle ist stark verderbt. Dieser Text in einer schwarzen Kartusche; er steht gegenüber dem Text auf dieser Linie ausserhalb der Kartusche auf dem Kopf.

$$
\begin{aligned}
& \text { ما اوليتني من احسان269 فلم اود حقه • ولم اعلم به تبت عنه } \\
& \text { واقول لا اله الا الله محمد رسول الله 270 || اللهم صل على محمد }
\end{aligned}
$$

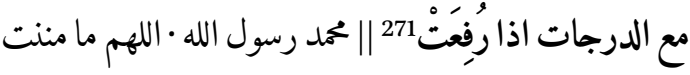

$$
\begin{aligned}
& \text { من الحسنى فلم احمدك • ولم اعلم به تبت عنه } 272 \text { واقول لا اله }
\end{aligned}
$$

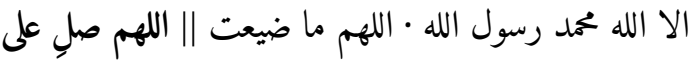

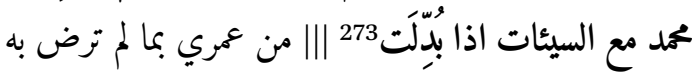

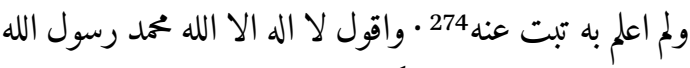

$$
\begin{aligned}
& \text { • اللهم } 275 \text { ما اوحيت عليَّ من النظر فيك ولم ولم اعلم به || اللهم } \\
& \text { صل على محمد مع الحسنات اذا ظهرت }
\end{aligned}
$$

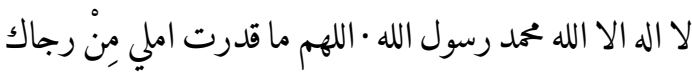

$$
\begin{aligned}
& \text { ولم اعلم به تبت عنه } 277 \text { ـ واقول لا اله الا الله محمد رسول الله }
\end{aligned}
$$

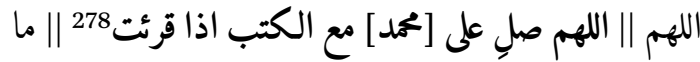

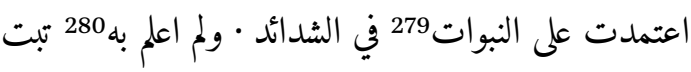

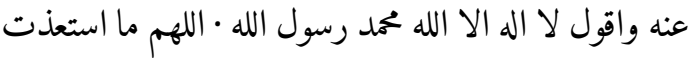

$$
\begin{aligned}
& \text { من غيرك في النوائب || اللهم صل على محد مع الصدور اذا }
\end{aligned}
$$

269 Dieser Begriff nachträglich verbessert; der ursprüngli-

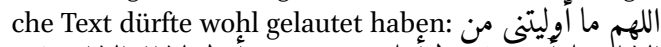
الائك فلم أؤديّيته ولم أعلم به تبت عنه وأقول لا اله اله الا الله محمد مسول الله.

270 Im Mittelstreifen beginnt hier Q 38 (Sürat Șād).

271 Dieser Text in einer blauen Kartusche; er steht gegenüber dem Text auf dieser Linie ausserhalb der Kartusche auf dem Kopf. Im Streifen mit gegenläufigem Text in Schachbrett-Kūfī endet hier Q 48. Im Mittelstreifen beginnt hier Q 39 (Sūrat az-Zumar).

Dieser Text in einer blauen Kartusche; er steht gegenüber dem Text auf dieser Linie ausserhalb der Kartusche auf dem Kopf.

hier Aufnahme Is 1626.11.3.

Im Mittelstreifen beginnt hier Q 40 (Sūrat al-Mu'min).

Dieser Text in einer blauen Kartusche; er steht gegenüber dem Text auf dieser Linie ausserhalb der Kartusche auf dem Kopf. Im Mittelstreifen beginnt hier Q 41 (Sūrat Hī'-mìm bzw. Fușşilat). Vgl. ab hier Aufnahme Is 1626.11.4.

Dieser Text in einer blauen Kartusche; er steht gegenüber dem Text auf dieser Linie ausserhalb der Kartusche auf dem Kopf.

279 Hier Riss im Papier, der sich über nahezu das ganze Dokument erstreckt.

280 Im Mittelstreifen beginnt hier Q 42 (Sūrat aš-Šūrā). 
حَصِلَتْ 281 || ولمَ اعلم به تبت عنه 282 واقول لا اله الا الله محمد رسول الله283 • اللهم ان زلت قدمي في السوال من غيرك

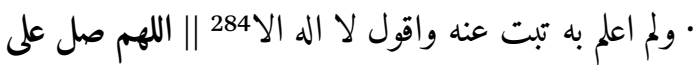

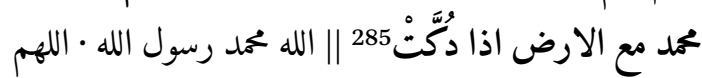
ما صلح ${ }^{286}$ به من شأني بفضلك فرأيته من غيرك · ولم اعلم به تبت عنه واقول لا اله الا287 الله محمد رسول الله || اللهم صل على محد مع القبور اذا بعثرت 288 || يا حي يا قيوم بمد الله وحسن توفيقه • وصلى الله على 289 خير خلقه محمد وآله الطيبين الطاهرين اجمعين · برحمتك يا ارحم الراحمين 290 وسلم تسليما

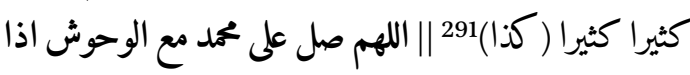

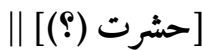

\section{II.C.5. Gebet (im schmalen Seitenstreifen) ${ }^{292}$}

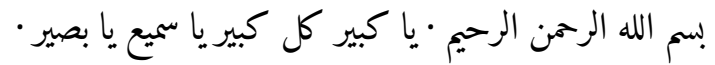
يا من 293 لا شريك له ولا وزير [له] ولا نظير [له] ·يا خالق مئم

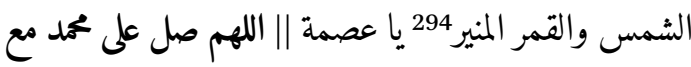

281 Dieser Text in einer roten Kartusche; er steht gegenüber dem Text auf dieser Linie ausserhalb der Kartusche auf dem Kopf.

282 Im Mittelstreifen beginnt hier Q 43 (Sūrat az-Zuhruf).

283 Vgl. ab hier Aufnahme Is 1626.12.2.

284 Im Mittelstreifen beginnt hier Q 44 (Sūrat ad-Duhān).

285 Dieser Text in einer roten Kartusche; er steht gegenüber dem Text auf dieser Linie ausserhalb der Kartusche auf dem Kopf.

286 Im Mittelstreifen beginnt hier Q 45 (Sūrat al-Ǧātiya). Vgl. ab hier Aufnahme Is 1626.12.3.

287 Im Mittelstreifen beginnt hier Q 46 (Sūrat al-Aḥqāf).

288 Dieser Text in einer schwarzen Kartusche; er steht gegenüber dem Text auf dieser Linie ausserhalb der Kartusche auf dem Kopf.

289 Im Mittelstreifen beginnt hier Q 47 (Sūrat Muham$\mathrm{mad})$.

290 Vgl. ab hier Aufnahme Is 1626.12.4.

291 Im Mittelstreifen beginnt hier Q 48 (Sürat al-Fath).

292 Dieses Gebet beginnt zwischen Q 48 und 49 im Mittelstreifen. Kurz danach treffen im rechten Seitenband in Schachbrett-Küfi Q 62 und 76 aufeinander (Trennung durch goldene Kartusche markiert). Im Mittelstreifen beginnt hier Q 49 (Sūrat al-Huğurāt).

$$
\begin{aligned}
& \text { الشمس اذا ادبرت295 || البأس الخائف المستجير } 296 \text { يا رازق } \\
& \text { الطفل الصغير297 ـ يا جابر العظم الكسير يا قاصم } 298 \text { كل } \\
& \text { جبار عنيد · اسئلك بمعاقد العز من عرشك وبمفاتيح || اللهم } \\
& \text { صل على محمد مع الشمس اذا تصـ[لدّعت (؟)]299 || الرحمة }
\end{aligned}
$$

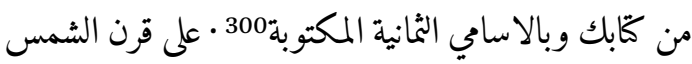

$$
\begin{aligned}
& \text { ان تقضي حاجاتي يا قاضي الحاجات وتكفي مهماتي يا مفتح } \\
& \text { الابواب. }
\end{aligned}
$$

Mit dem Ende dieses kurzen vierten Gebets schliesst der Schreiber das absteigende Schriftband mit Text rechts ab. Hier kommt von unten aufsteigender Text entgegen. Er stellt die Fortsetzung des linken Schriftbands mit Text in kleiner Schrift dar. Die Erfassung dieses Textes erfolgt deshalb in Ergänzung zum Teil mit dem linken Schriftband. ${ }^{301}$ Die Stelle, an der die beiden Texte aufeinandertreffen ist gut sichtbar, ändert hier doch auch die Schriftrichtung (absteigend bzw. aufsteigend). ${ }^{302}$

TEIL II: Seitenband D (schmales Seitenband, links, mit Gebeten in kleinem Nash; Text absteigend und vorwärtslaufend). In diese Seitenbänder mit Text in kleinem Nash sind in regelmässigen Abständen farbig eingefasste Kartuschen (rot, blau, schwarz) eingefügt worden. Sie enthalten ein zusätzliches, eigenständiges Gebet. Diese Kartuschen im rechten und linken Seitenband sind parallel zueinander und jeweils in derselben Farbe eingefügt worden.

295 Dieser Text ist stark verderbt. Er steht in einer schwarzen Kartusche; er steht gegenüber dem Text auf dieser Linie ausserhalb der Kartusche auf dem Kopf.

296 Im Mittelstreifen beginnt hier Q 51 (Sürat ad-Dāriyāt).

297 Vgl. Aufnahme Is 1626.12.5.

298 Im Mittelstreifen beginnt hier Q 52 (Sūrat aț-Ṭūr).

299 Im Mittelstreifen beginnt hier Q 53 (Sūrat an-Nağm). Dieser Text steht in einer blauen Kartusche; er steht gegenüber dem Text auf dieser Linie ausserhalb der Kartusche auf dem Kopf.

300 Im Mittelstreifen beginnt hier Q 54 (Sūrat al-Qamar).

301 Vgl. bei Anm. 534-551.

302 Vgl. Aufnahmen Is 1626.13.1-2. 
II.D.1, Gebet 1: Dieses Gebet lässt sich bei Ibn Țāwūs nachweisen. Es ist üblicherweise als Du'ä’ al-Ğawšan („Gebet des Schutzpanzers“) bekannt. ${ }^{303}$ Es wird in regelmässigen Abständen durch Kartuschen unterbrochen, die Anrufungen und Lobpreisungen Muhammads enthalten. ${ }^{304}$ Diese Einschübe sind in der folgenden Abschrift fett hervorgehoben. In diesen Einschüben sind gerade die entscheidenden Begriffe zur Charakterisierung Muhammads oft nur noch schlecht leserlich. Dem Kopisten stand in den Kartuschen zu wenig Platz zur Verfügung, um diesen Text klar zu schreiben.

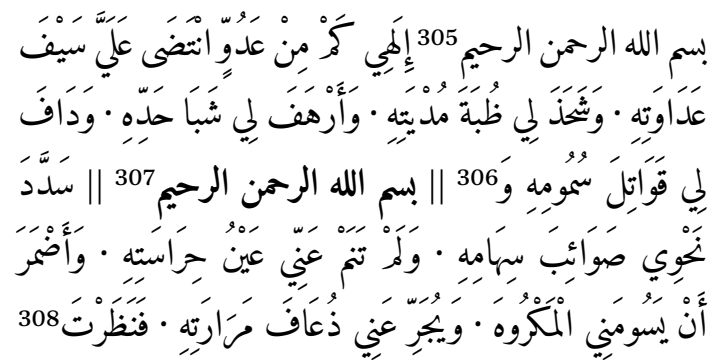

303 Ibn Țāwūs, Muhağ ad-da'wāt wa-manhağ al-ibādāt 22off.; vgl. http://lib.eshia.ir/71561/1/220 (Beginn Text; Titel: S. 217; Stand 24. Januar 2017). Es handelt sich um folgende Druckausgabe: Qum, Dār ad-Dahāāir, 1411 h.q.; man beachte folgende Bemerkung dazu:

ملاحظات: اين نسخه با طبع ججرى بسال 1323 هـ در زمان

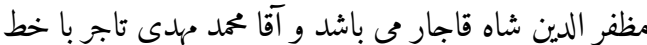

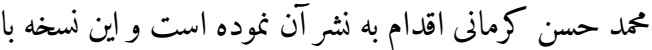

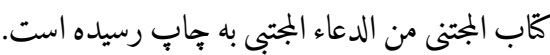

Anrufungen und Lobpreisungen Muhammads von derselben Art liessen sich nachweisen unter https://lasjan .page.tl/Salat_al_Kubra.htm (Stand 3. Oktober 2017). Das Gebet wird hier als Du'ā’ as-Salawāt al-kubrā bezeichnet. Siehe auch http://www.alsada.org/plus/ viewtopic.php? $\mathrm{f}=7 \& \mathrm{t}=8305^{1}$ (Stand 3 . Oktober 2017).

Es handelt sich also gewissermassen um eine Hilyat an-nabī; Lobpreisungen des Propheten lassen sich auch auf andern Dokumenten, gerade auf solchen aus osmanischen Kontexten, nachweisen; vgl. Kapitel 6.2.2.3 (bei Anm. 94-102).

Vgl. Aufnahme Is 1626.2.3 (schmales Seitenband, links).

Vgl. ab hier Aufnahme Is 1626.2.4.

Dieser Text in einer blauen Kartusche.

Vgl. ab hier Aufnahme Is 1626.2.5.

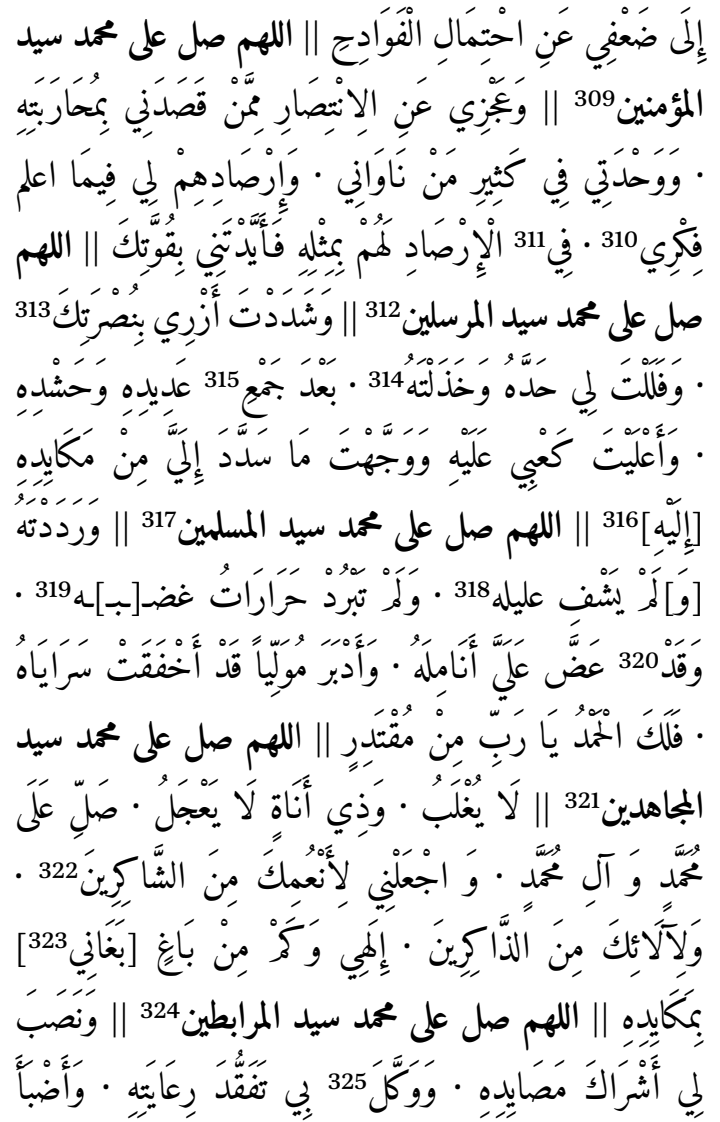

309 Dieser Text in einer blauen Kartusche.

Die Vorlage liest hier abweichend:

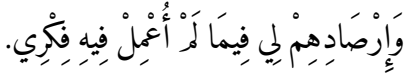

Vgl. http://lib.eshia.ir/71561/1/220 (Stand 24. Januar 2017).

Vgl. ab hier Aufnahme Is 1626.2.7
Dieser Text in einer roten Kartusche.

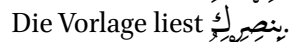

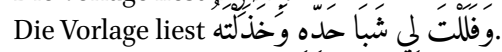

Auf der Rolle جميc.

Nur in der gedruckten Vorlage.

Dieser Text in einer roten Kartusche; schlecht leserlich.

Die Vorlage liest hier غُليله.

غنيظة غليله

Vgl. ab hier Aufnahmé Ís 1626.2.8.

Dieser Text in einer roten Kartusche.

Vgl. ab hier Aufnahme Is 1626.3.2. Im Mittelstreifen beginnt hier Q 3 (Sūrat Āl Imrān).

Dieser Ausdruck fehlt auf der Rolle: Kopistenfehler.

Dieser Text in einer schwarzen Kartusche.

Kāf mit drei Punkten unterhalb der Zeile. 


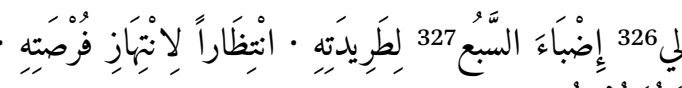

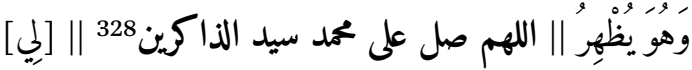

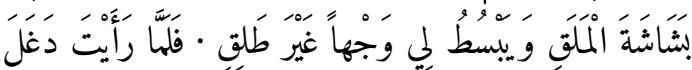

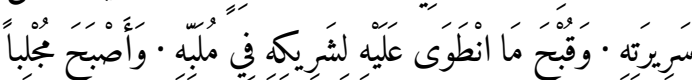

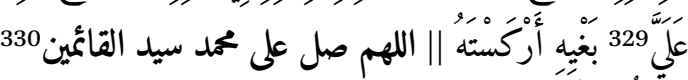

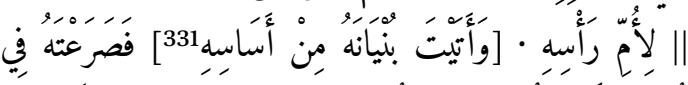

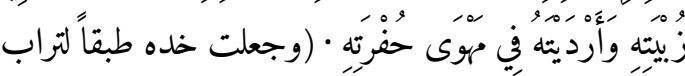
رجله • وشخلته332 في بدنه ورزقه 333) • ورَميته || اللهم

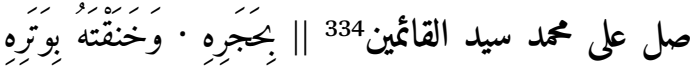

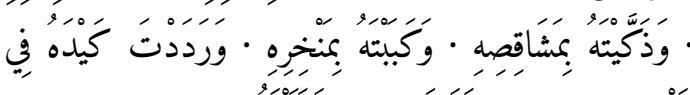

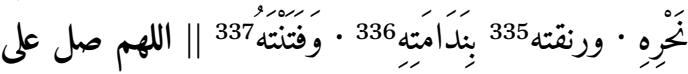

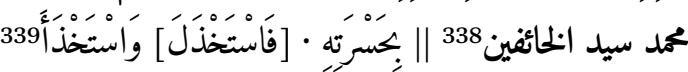

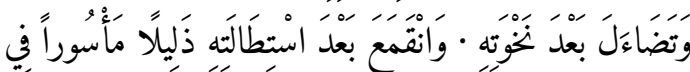

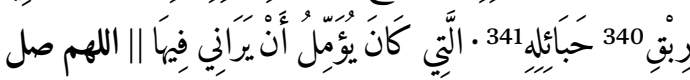

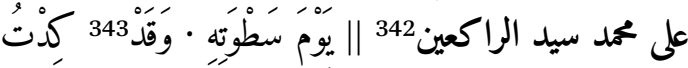

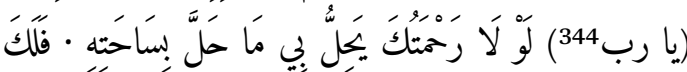

326 Die Vorlage liest hier إلى

327 Sin mit drei Punkten unterhalb des Buchstabens.

328 Dieser Text in einer schwarzen Kartusche. Letzter Ausdruck stark verderbt; er lässt sich nur erahnen.

Die Vorlage liest hier إلي

Dieser Text in einer sch̆warzen Kartusche.

Der Text in eckigen Klammern fehlt auf der Rolle.

Vgl. ab hier Aufnahme Is 1626.3.4.

Dieser Text nur auf der Rolle, nicht bei Ibn Țāwūs.

Dieser Text in einer blauge, Kartusche.

Die Vorlage liest hier ووبقته.

Vgl. ab hier Aufnahme Iś 1626.4.3.

Auf der Rolle steht hier ونتأته

Dieser Text in einer blauen Kartusche.

Auf der Rolle:

\section{وَاسْتَخْذَى.}

Auf der Rolle steht hier بريق. Ab hier Seite 221 bei Ibn Țāwūs, Muhağ ad-da'wāt wa-manhağ al-ibādāt; vgl. http://lib.eshia.ir/71561/1/221 (Stand 24. Januar 2017).

Auf der Rolle steht hier حبالته

Dieser Text in einer blauén Ḱartusche.

Vgl. ab hier Aufnahme Is 1626.4.5.

Nur auf der Rolle.

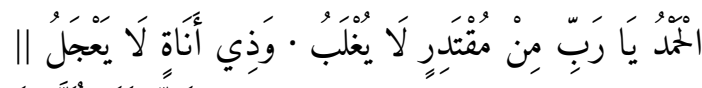

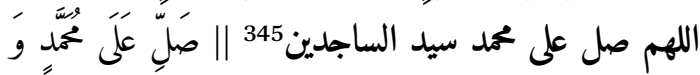

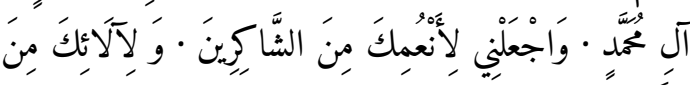
الذَّاَكرِنَ.

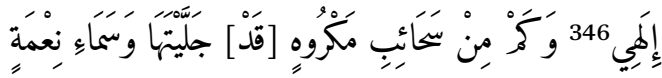

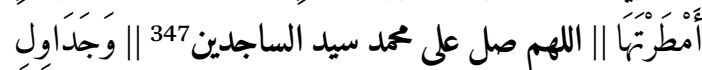

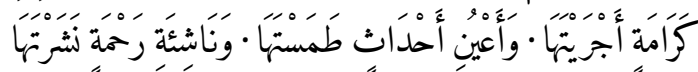

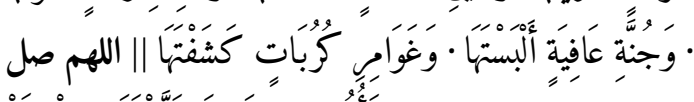

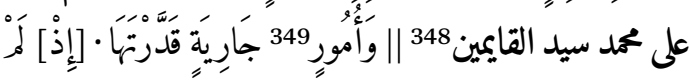

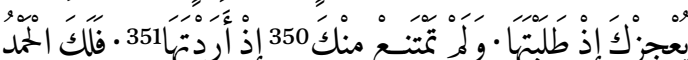

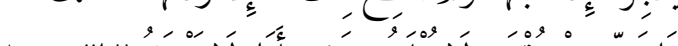

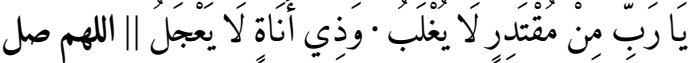

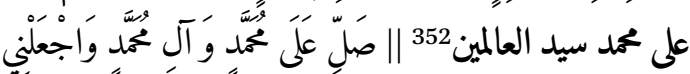

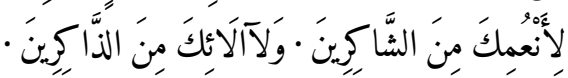

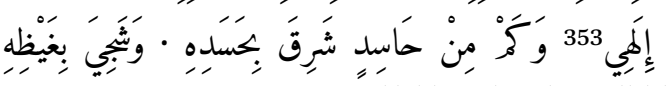

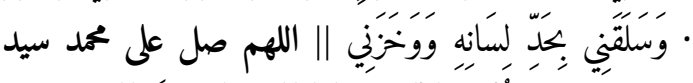

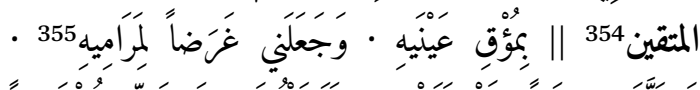

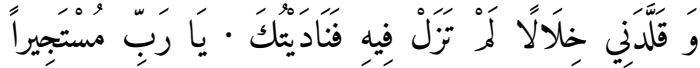

345 Dieser Text in einer blauen Kartusche.

346 Vgl. ab hier Aufnahme Is 1626.4.6. In der Vorlage bei Ibn Ṭāwūs folgt diese Stelle erst später.

347

Dieser Text in einer roten Kartusche; Entzifferung unsicher.

348 Dieser Text in einer roten Kartusche.

349 Vgl. ab hier Aufnahme Is 1626.4.7.

$35^{\circ}$ Die Vorlage liest hier:

عَلَككَ.
351

352

353

t. vor dem vorangehenden Abschnitt mit den Anm. 346$35^{2}$. verderbt.

Ibn Ṭāwūs liest hier:

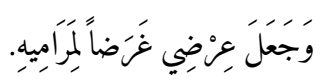




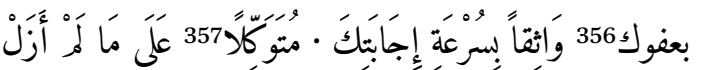

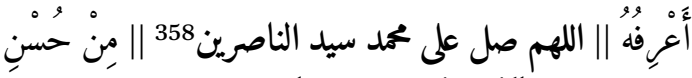

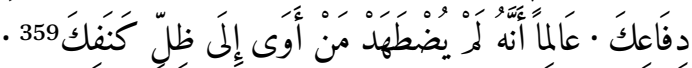

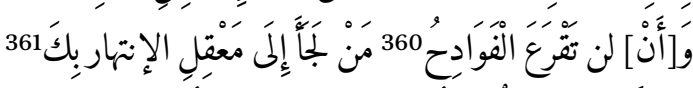

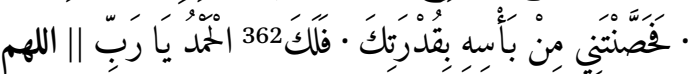

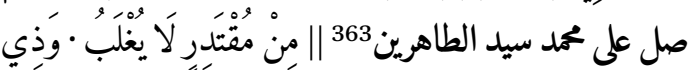

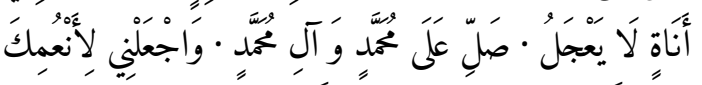

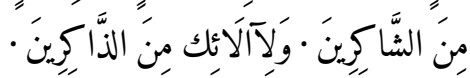

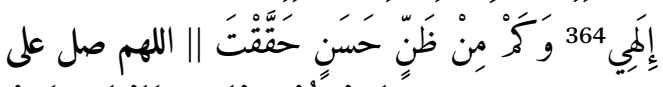

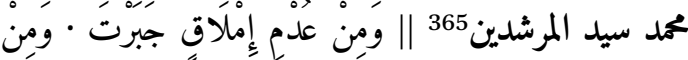

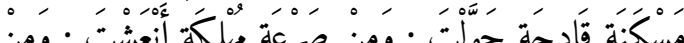

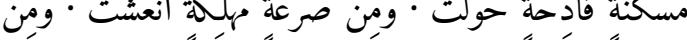

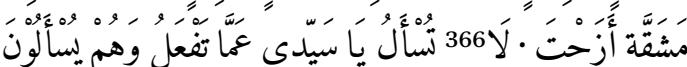

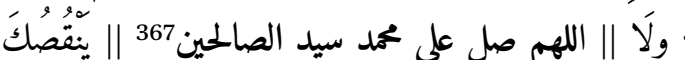

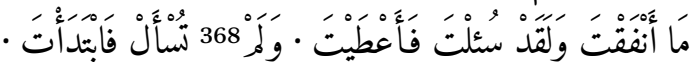

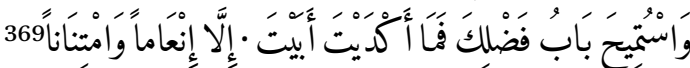

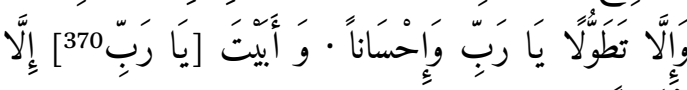

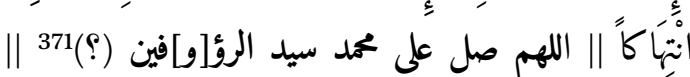

356 Ibn Ṭāwūs liest hier ك́ك.

357 Vgl. ab hier Aufnahme Is 1626.4.10.

358 Dieser Text in einer schwarzen Kartusche.

359

360

361 Im Mittelstreifen beginnt hier Q 7 (Sürat al-Árä $)$ ). Auf der Rolle steht hier الحوادث. Ibn Tāwūs liest hier:

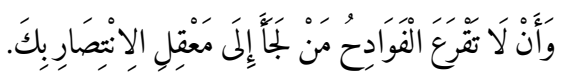

362 Vgl. ab hier Aufnahme Is 1626.4.11.

363 Dieser Text in einer blauen Kartusche; letzter Ausdruck verderbt und somit unsicher.

Vgl. ab hier Aufnahme Is 1626.4.13.

Dieser Text in einer blauen Kartusche.

Dieser Begriff auf der Rolle sehr undeutlich geschrieben: $\lg (?)$.

Dieser Text in einer blauen Kartusche.

Vgl. ab hier Aufnahme Is 1626.4.14. Im Mittelstreifen beginnt hier Q 8 (Sürat al-Anfäl).

Dieser Ausdruck fehlt auf der Rolle.

Dieser Text in einer roten Kartusche.

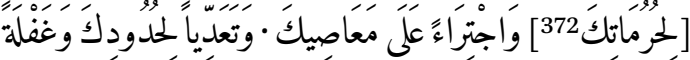

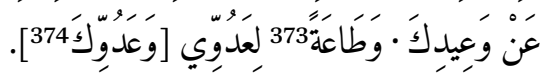

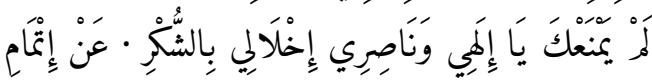

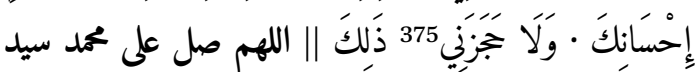

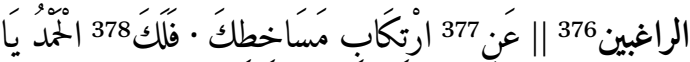

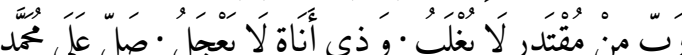

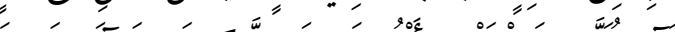

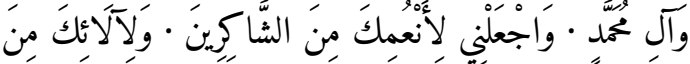

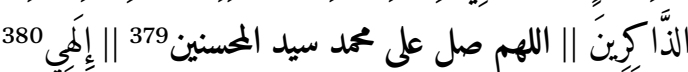

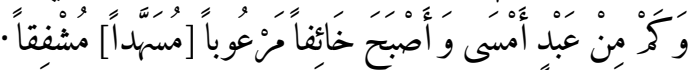

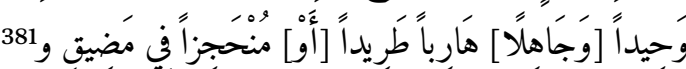

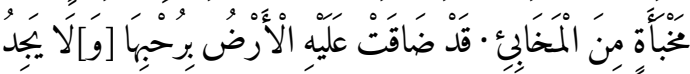

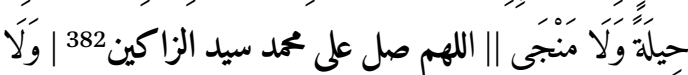

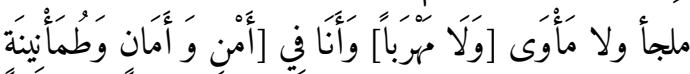

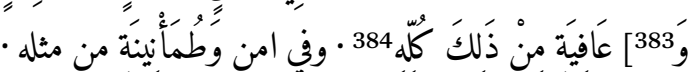

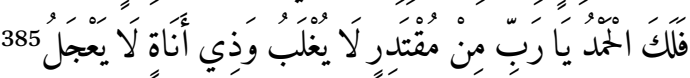

Dieser Ausdruck fehlt auf der Rolle.

$\mathrm{Ab}$ hier Seite 222 bei Ibn Țāwūs, Muhağ ad-da'wāt wa-manhağ al-ibādāt; vgl. http://lib.eshia.ir/71561/1/ 222 (Stand 24. Januar 2017).

Dieser Ausdruck fehlt auf der Rolle. Im Mittelstreifen beginnt hier Q 9 (Sürat at-Tawba). Dieser Text in einer roten Kartusche.

Vgl. ab hier Aufnahme Is 1626.4.15.

Abfolge der Texteinheiten auf der Rolle und in der Ausgabe des Texts von Ibn Ṭāwūs weichen voneinander ab.

Dieser Text in einer roten Kartusche.

Abfolge der Texteinheiten auf der Rolle und in der Ausgabe des Texts von Ibn Ṭāwūs weichen voneinander ab. In der Vorlage steht أَّ

Oder الذاكين. Dieser Text in einer schwarzen Kartusche.

Umstellung der Textfolge auf der Rolle.

Im Mittelstreifen beginnt hier Q 10 (Sürat Yünus).

$\mathrm{Ab}$ hier Seite 223 bei Ibn Țāwūs, Muhağ ad-da'wāt wa-manhağ al-ibādāt; vgl. http://lib.eshia.ir/71561/1/ 223 (Stand 24. Januar 2017). 


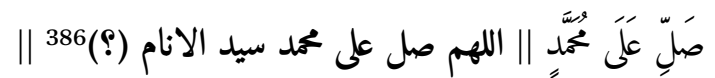

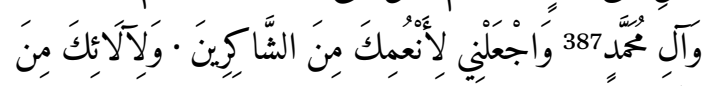
الذَّاكِكِينً

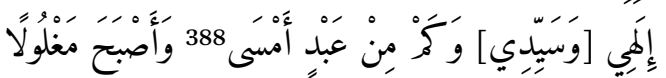

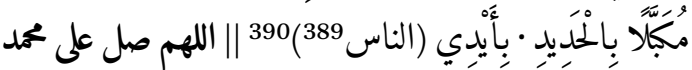

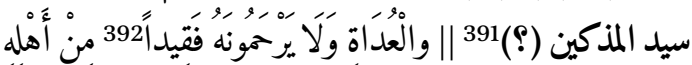

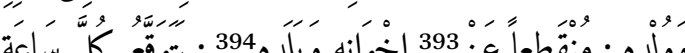

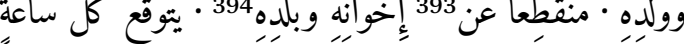

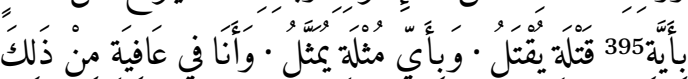

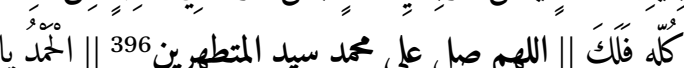

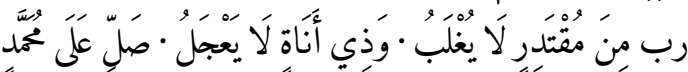

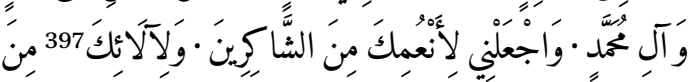
الذَّاكرِينَ"

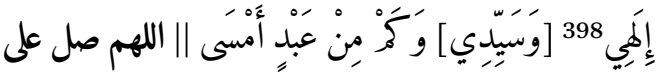

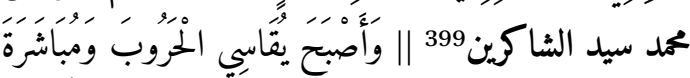

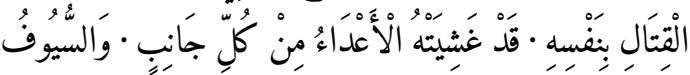

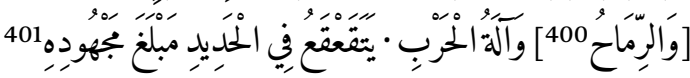

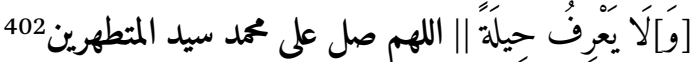

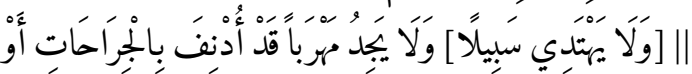

386 Dieser Text in einer schwarzen Kartusche; der letzte Ausdruck stark verderbt.

387 Vgl. ab hier Aufnahme Is 1626.5.3.

388 Das $\sin$ mit drei Punkten unterhalb der Zeile.

389 Dieser Ausdruck nur auf der Rolle.

390 Im Mittelstreifen beginnt hier Q 11 (Sūrat Hūd).

391 Dieser Text in einer schwarzen Kartusche.

392 Auf der Rolle wahrscheinlich بعِ

393 Auf der Rolle wohl على.

394 Vgl. ab hier Aufnahme Is 1626.5.6.

395 Auf der Rolle: باى.

396 Dieser Text in einer roten Kartusche.

397 Im Mittelstreifen beginnt hier Q 12 (Sürat Yüsuf).

398 Vgl. ab hier Aufnahme Is 1626.5.7.

399 Dieser Text in einer blauen Kartusche.

400 Fehlt auf der Rolle.

401 Auf der Rolle wohl:

Dieser Text in einer blauen Kartusche.

$$
\text { قد بلغ مَمهودوده. }
$$

414

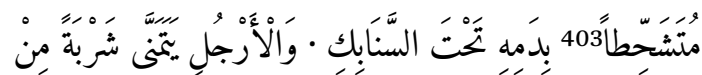

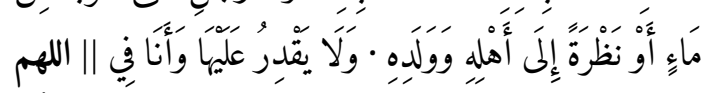
صل على محمد سيد الطاهرين 404 || 405 عَافَيَةِ

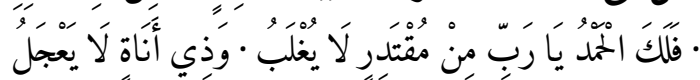

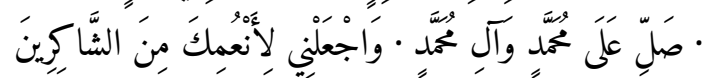

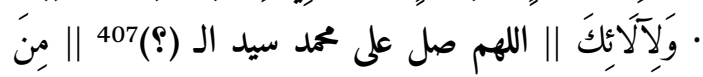
الذَّاَكِرِنَ

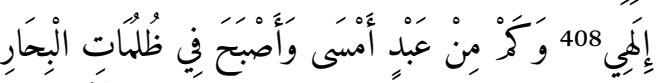

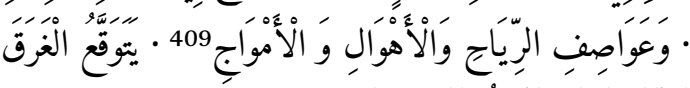

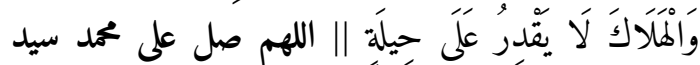

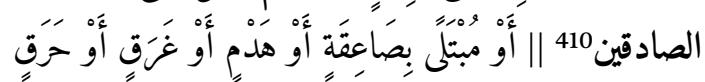

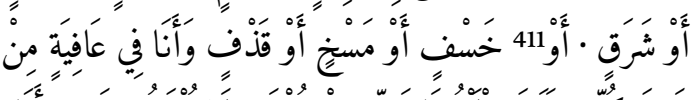

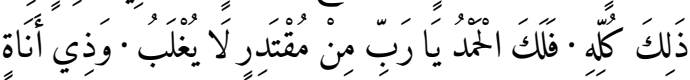

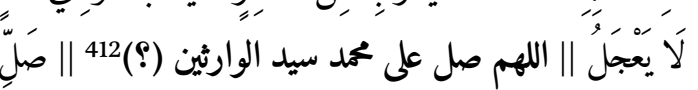

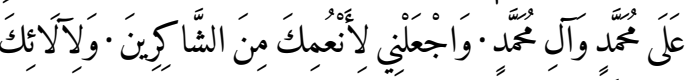

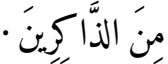

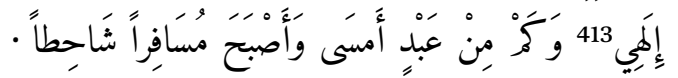

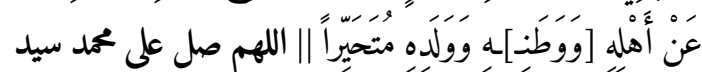

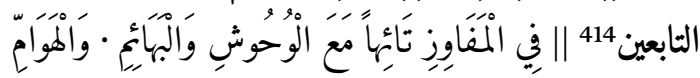

403 Im Mittelstreifen beginnt hier Q ${ }_{13}$ (Sürat ar-Ra'd).

404 Dieser Text in einer blauen Kartusche. Entzifferung des letzten Ausdrucks nicht gänzlich gesichert.

405 Vgl. ab hier Aufnahme Is 1626.6.3.

406 Im Mittelstreifen beginnt hier Q 14 (Sürat Ibrāhīm).

407 Ein Ausdruck unklar. Dieser Text in einer roten Kartusche. Im Mittelstreifen beginnt hier Q 15 (Sürat alHiğr $r$.

408 Vgl. ab hier Aufnahme Is 1626.6.4.

409 Im Mittelstreifen beginnt hier Q 16 (Sürat an-Nahl).

410 Dieser Text in einer roten Kartusche.

411 Vgl. ab hier Aufnahme Is 1626.6.5.

412 Dieser Text in einer schwarzen Kartusche.

Vgl. ab hier Aufnahme Is 1626.6.6. Im Mittelstreifen beginnt hier Q 17 (Sūrat al-Isrä). 


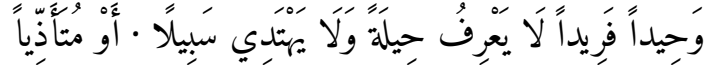

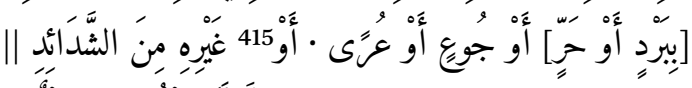

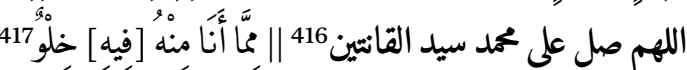

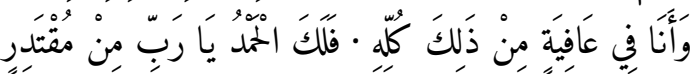

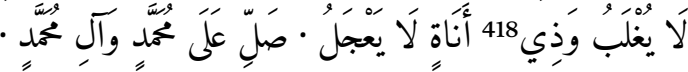

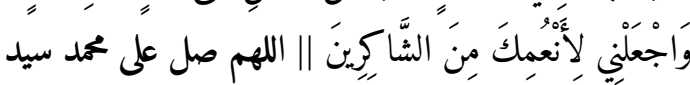

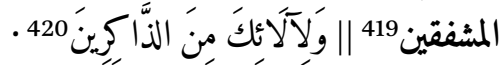

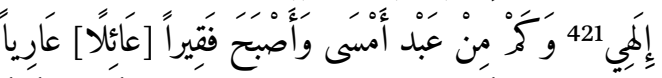

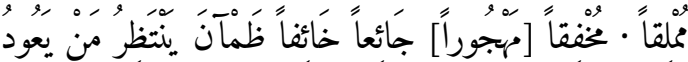

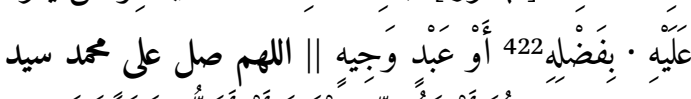

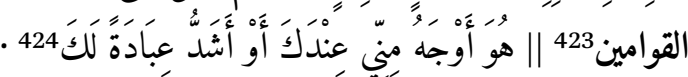

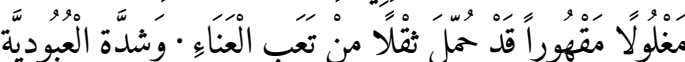

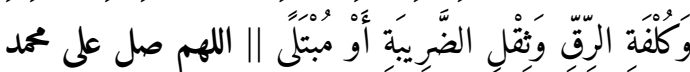

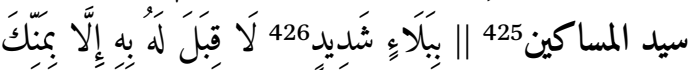

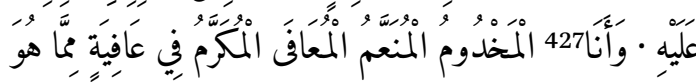

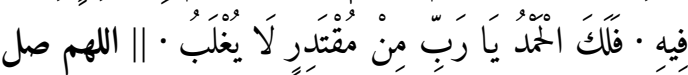

415 Vgl. ab hier Aufnahme Is 1626.6.7. Im Mittelstreifen beginnt hier Q 18 (Sürat al-Kahf).

416 Dieser Text in einer schwarzen Kartusche; letzter Ausdruck verderbt.

417 Die Stelle nach der Kartusche ist verderbt

$418 \mathrm{Ab}$ hier Seite 224 bei Ibn Țāwūs, Muhağ ad-da'wāt wa-manhağ al-ibādāt; vgl. http://lib.eshia.ir/71561/1/ 224 (Stand 25. Januar 2017).

Dieser Text in einer blauen Kartusche.

Im Mittelstreifen beginnt hier Q 19 (Sürat Maryam; hier: Sūrat Kāf-hā'-y $\left.\bar{a}^{\prime}-{ }^{\prime} a y n-s ̦ a \bar{d}\right)$.

Vgl. ab hier Aufnahme Is 1626.7.3.

Die Vorlage liest:

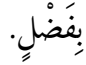

Dieser Text in einer blauen Kartusche. Im Mittelstreifen beginnt hier Q 20 (Sūrat Țầ-Hà $)$.

Vgl. ab hier Aufnahme Is 1626.7.4.

Dieser Text in einer blauen Kartusche.

Im Mittelstreifen beginnt hier Q 21 (Sūrat al-Anbiy $\left.\bar{a}^{\prime}\right)$.

Vgl. ab hier Aufnahme Is 1626.8.2.

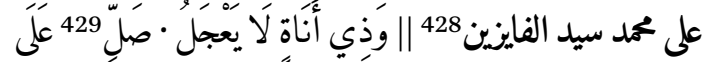

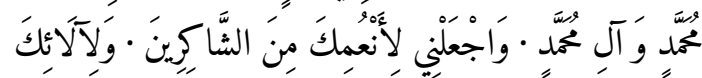

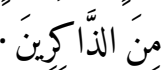

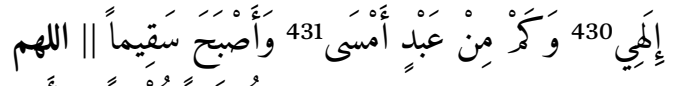
صل على محمد سيد المتصدقين 432 || مُوجَعَاً مُدْفَاً فِي أَنِينٍ

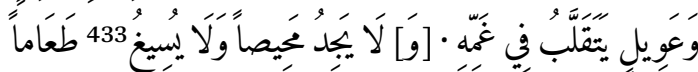

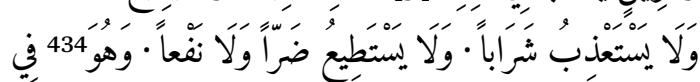

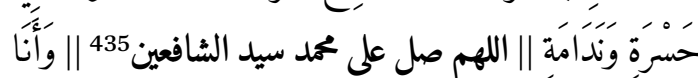

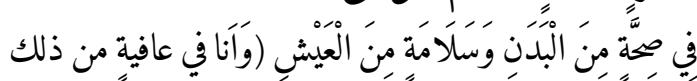

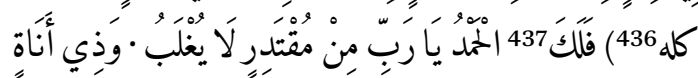

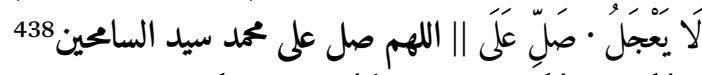

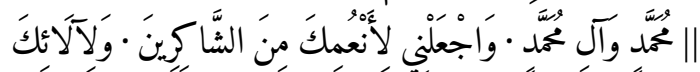
مَنَ الذَّاَكركِينَ.

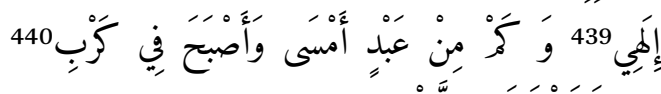

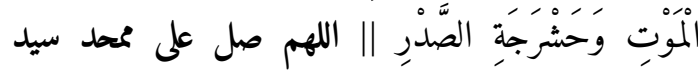

428 Dieser Text in einer roten Kartusche. Im Mittelstreifen beginnt hier Q 22 (Sūrat al-Haǧğ). Vgl. ab hier Aufnahme Is 1626.8.3; die Stelle befindet sich bei Ibn Ṭāwūs auf S. 222 (Umstellung der Textfolge): http://lib.eshia.ir/71561/1/222 (Stand 25. Januar 2017).

Der Ausdruck amsā stets mir drei Punkten unter dem $\sin$.

Dieser Text in einer roten Kartusche.

Im Mittelstreifen beginnt hier Q 23 (Sürat al-Mu'mi$n \bar{u} n)$.

Vgl. ab hier Aufnahme Is 1626.8.4.

Dieser Text in einer roten Kartusche.

Dies nur auf der Rolle; die Vorlage bei Ibn Țāwūs liest:

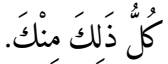

437 438 439
Im Mittelstreifen beginnt hier Q 24 (Sūrat an-Nūr). Dieser Text in einer schwarzen Kartusche.

Die Stelle befindet sich bei Ibn Ṭāwūs auf S. 222 und zwar vor dem vorangehenden Abschnitt über Krankheiten (Umstellung der Textfolge): http://lib.eshia.ir/ 71561/1/222 (Stand 25. Januar 2017).

Im Mittelstreifen beginnt hier Q 25 (Sūrat al-Furqān). 


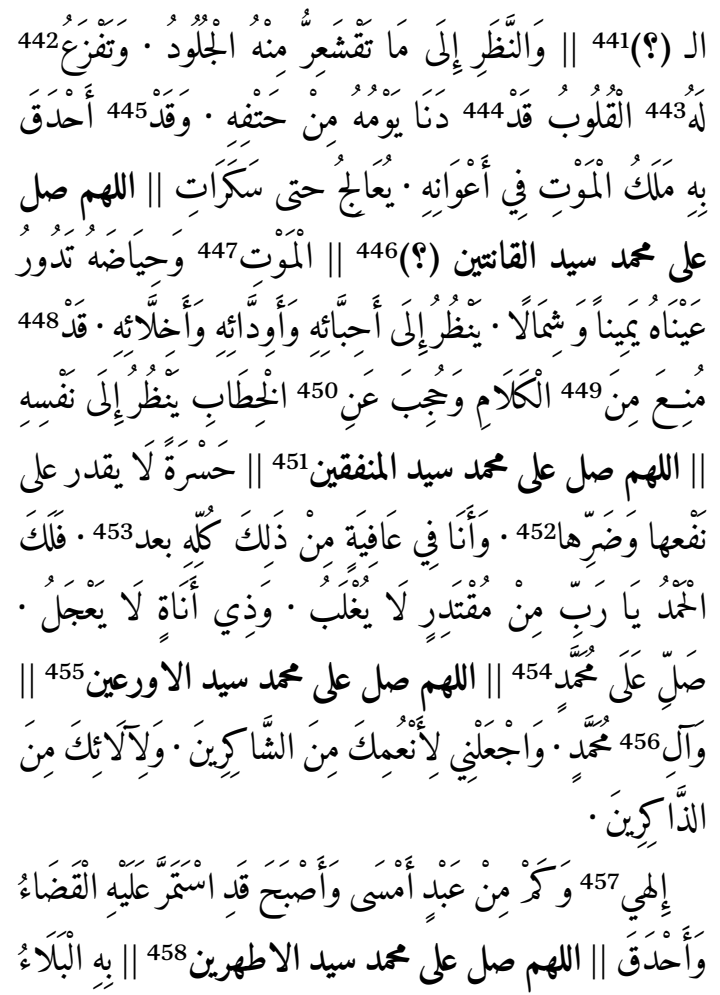

441 Dieser Text in einer schwarzen Kartusche. Hier weist die Rolle Beschädigungen auf; im Mittelstreifen wurde Surentext von anderer Hand später nachgeschrieben. Der letzte Ausdruck in der Kartusche lässt sich nicht mehr entziffern.

Vgl. ab hier Aufnahme Is 1626.9.2.
Die Vorlage bei Ibn Ṭāwūs liest إلي

Die Fortsetzung folgt bei Ibn Ṭāwūs erst beim Übergang S. 224-225; vgl. http://lib.eshia.ir/71561/1/224 (Stand 25. Januar 2017).

Im Mittelstreifen beginnt hier Q 26 (Sūrat aš-Šu'arā’).

Dieser Text in einer schwarzen Kartusche.

Die Stelle befindet sich bei Ibn Ṭāwūs auf S. 225: http:// lib.eshia.ir/71561/1/225 (Stand 25. Januar 2017).

Vgl. ab hier Aufnahme Is 1626.9.3.

Die Vorlage liest عن.

Im Mittelstreifen beginnt hier Q 27 (Sürat an-Naml).

Dieser Text in einer blauen Kartusche.

Die Vorlage liest hier:

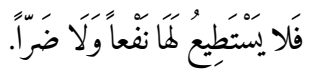

Dieser Abschnitt in der Druckausgabe abweichend. Im Mittelstreifen beginnt hier Q 28 (Sürat al-Qașaș). Dieser Text in einer blauen Kartusche.

Vgl. ab hier Aufnahme Is 1626.9.4.

Die Fortsetzung folgt bei Ibn Ṭāwūs auf S. 226; vgl. http://lib.eshia.ir/71561/1/226 (Stand 25. Januar 2017).

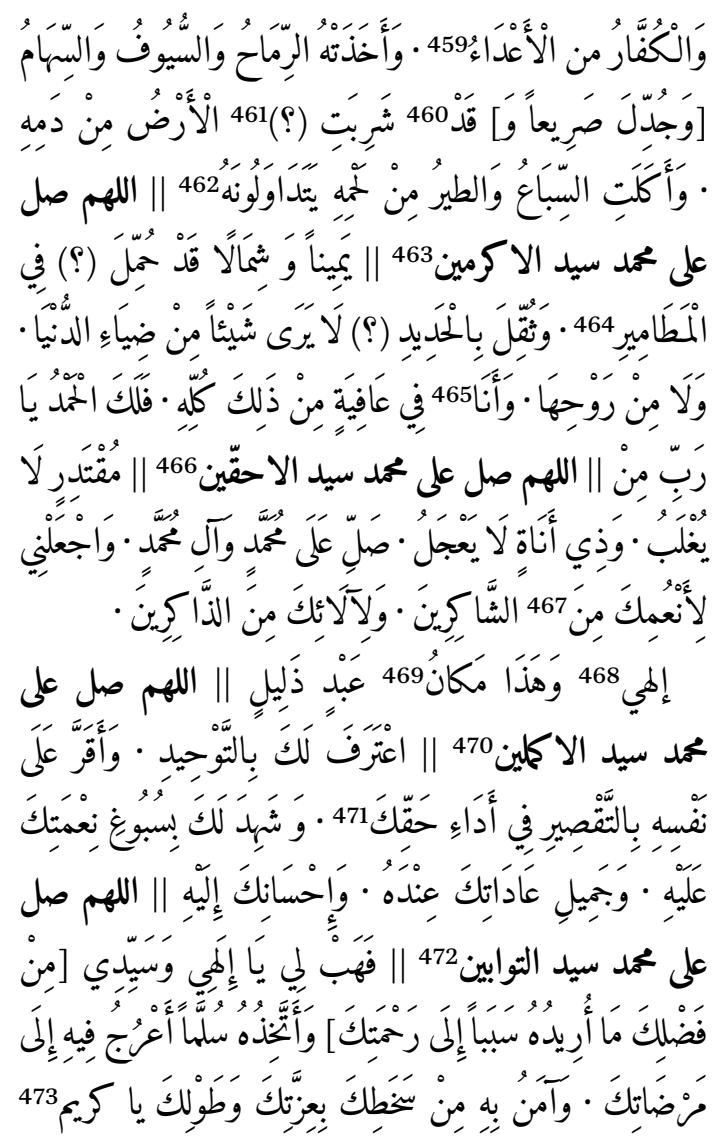

459 Im Mittelstreifen beginnt hier Q 29 (Sürat al-Ankabūt).

460 Vgl. ab hier Aufnahme Is 1626.9.5.

461 Auf der Rolle شربة.

462 Die Fortsetzung folgt bei Ibn Țāwūs auf S. 225 (unten); vgl. http://lib.eshia.ir/71561/1/225 (Stand 25. Januar 2017).

463 Dieser Text in einer roten Kartusche.

464 Im Mittelstreifen beginnt hier Q 30 (Sūrat ar-Rūm).

465 Ab hier erneut abweichend gegenüber Vorlage.

466 Dieser Text in einer roten Kartusche. Im Mittelstreifen beginnt hier Q ${ }_{31}$ (Sürat Luqmān).

467 Im Mittelstreifen beginnt hier Q 32 (Sürat as-Sağda).

468 Die Fortsetzung folgt bei Ibn Ṭāwūs mit einigen Abweichungen auf S. 222; vgl. http://lib.eshia.ir/71561/1/222 (Stand 25. Januar 2017).

469 Im Mittelstreifen beginnt hier Q 33 (Sūrat al-Ahzäb).
470

471

472

473 Dieser Text in einer roten Kartusche.

Vgl. ab hier Aufnahme Is 1626.10.3.

Dieser Text in einer schwarzen Kartusche. Im Mittelstreifen beginnt hier Q 34 (Sūrat as-Saba').

Im Mittelstreifen beginnt hier Q 35 (Sūrat al-Maläika, Sūrat Fātiri). Die Fortsetzung folgt bei Ibn Ṭāwūs mit einigen Abweichungen auf S. 226; vgl. http://lib.eshia .ir $/ 71561 / 1 / 226$ (Stand 25. Januar 2017). 


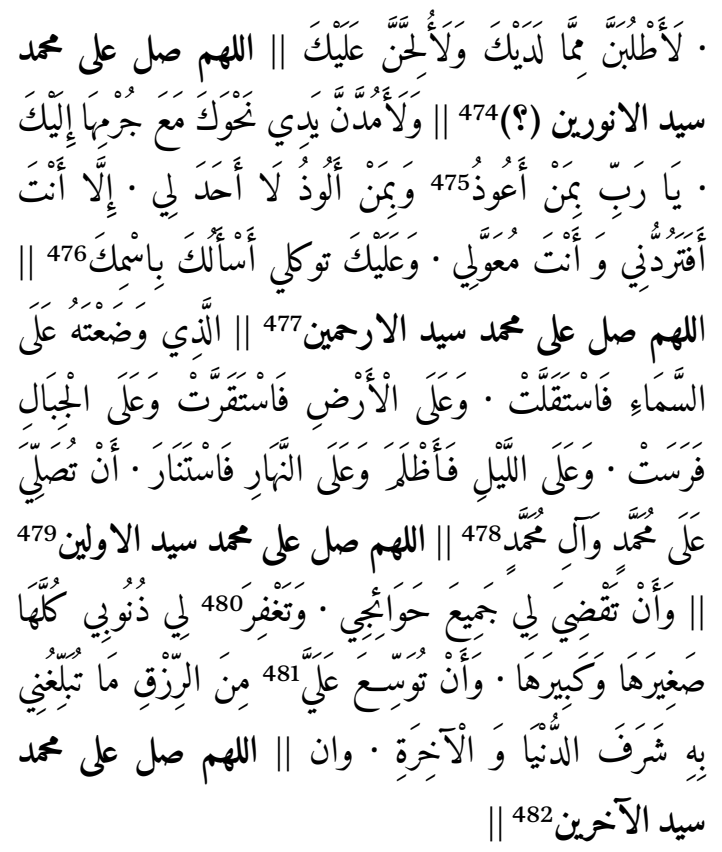

Ab hier weicht der Text des Gebets auf der Rolle deutlich von der Vorlage bei Ibn Ṭāwūs ab. Es ist nicht mehr einfach die Textfolge, die umgestellt wurde, sondern es handelt sich um einen andern Text. Es ist allerdings anzumerken, dass sich die meisten folgenden Texteinheiten auch in weiteren Quellen belegen lassen; allerdings stimmt die Textfolge dort nicht mehr mit jener auf der Rolle überein.

$$
\text { • وأن تببنين إلى المؤمنين والمؤمنات والمسلمين والمسلمات483 }
$$

474 Dieser Text in einer schwarzen Kartusche.

475 Im Mittelstreifen beginnt hier Q 36 (Sūrat Yā-sīn).

476 Vgl. ab hier Aufnahme Is 1626.10.5.

477 Al-arhamin: am wahrscheinlichsten, aber unklar. Dieser Text in einer schwarzen Kartusche. Im Mittelstreifen beginnt hier Q 37 (Sūrat aș-Șäffāt). Im Mittelstreifen beginnt hier Q 38 (Sūrat Șād). Dieser Text in einer blauen Kartusche. Vgl. ab hier Aufnahme Is 1626.11.2. Im Mittelstreifen beginnt hier Q 39 (Sūrat [az-] Zumar). Dieser Text in einer blauen Kartusche.

So auf der Rolle.

485 Im Mittelstreifen beginnt hier Q 40 (Sürat al-Mu'min; üblicherweise: $\dot{G} \bar{a} f(r)$.
في الاخرين وأن تجعلني عندك وجيها في الدنيا || اللهم صل

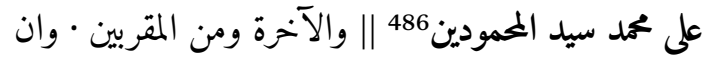
ترزقني هيبة المتقين وأن تجعل النور في بصري والبصيرة • في ديني واليقين 487 في قلبي والاخلاص في عملي والسلامة || اللهم صل على محمد سيد ولد آدم 488 || في نفسي والسعة في رزقي 489 والشكر لك أبدا ما أبقيتني 490 وأن ترضي عني أني أني وأن لا تخرجني من الدنيا إلا وانت عني راضٍ • وأن تحشرني في زمرة المتقين || اللهم صل على محمد سيد الـ (؟491 || والصالحين واولائك المخلصين 492 • الذين 493 لا خوف عليهم ولا هم يحزنون · بحق محد وآله الطيبين الطاهرين • ال طه يس وايس

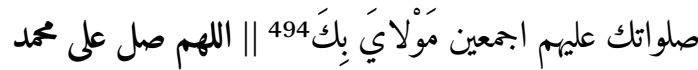

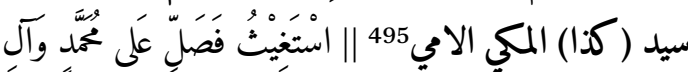

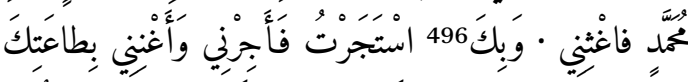

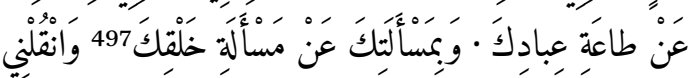

486 Dieser Text in einer blauen Kartusche.

487 Vgl. ab hier Aufnahme Is 1626.11.4. Im Mittelstreifen beginnt hier Q 41 (Sūrat Fușşilat).

488 Dieser Text in einer blauen Kartusche.

489 Hier Riss im Papier, der sich über nahezu die gesamte Breite des Dokuments erstreckt. Im Mittelstreifen beginnt hier Q 42 (Sūrat aš-Šūrā). Dieser Text in einer roten Kartusche; letzter Ausdruck unklar. Im Mittelstreifen beginnt hier Q 43 (Sūrat az-Zuhruf). Vgl. ab hier Aufnahme Is 1626.12.2.

Der Text lässt sich ab hier nachweisen bei 'Abbās alQumī, Mafātịh al-ğinān 164.5f. (siehe http://lib.eshia مجع إحياء الثقافة ;.ir/10505/1/164, Stand 28. Februar 2018. (الإسلامية. المطبعة: ياسدار إسلام . Siehe http://www.m -alhassanain.com/ad3yah/mafatih\%2oaljanan/mafa tifi2.htm (Stand 26. Januar 2017). Siehe auch 'Abbās alQumī, Hāăğğ Šayh 'Abbās (1876-1941), Kitāb-i mustațābi Mafātīh al-ǧinān 100-106 (aus Du'ā’ al-Ğawšan așșaġìr, hier S. 106.4f.). Ṭihrān, Kitābfurūšīi-i 'Ilmiyya-i Islāmiyya, 1381 h.q./1962 (vgl. Basel, Universitätsbibliothek, Meier 2453).

Dieser Text in einer roten Kartusche. Im Mittelstreifen beginnt hier Q 44 (Sūrat ad-Duhāan).

496 Vgl. ab hier Aufnahme Is 1626.12.3. Im Mittelstreifen beginnt hier Q 45 (Sūrat al-Ğātiya). 


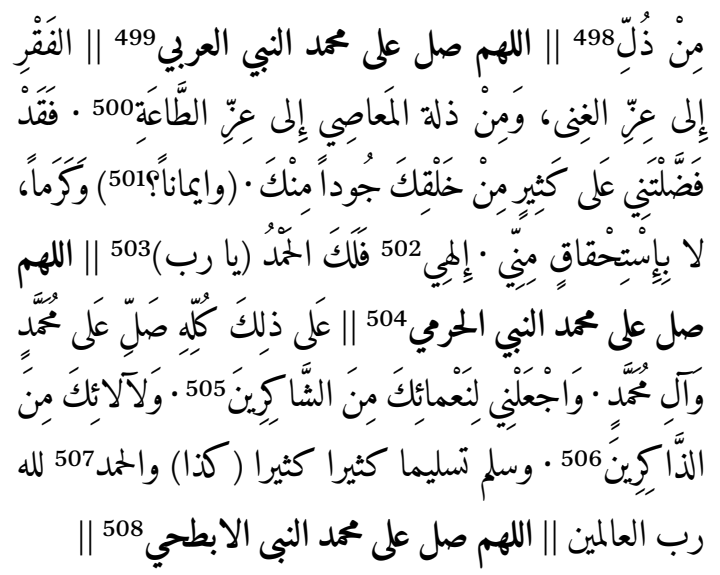

II.D.2, Gebet 2: Du'ä' Hizb al-Baḥr:509 Beim folgenden Text handelt es sich um die Du'ä’ Hizb al$b a h ̣ r$ von aš-Šādilīi.510 Der Text auf der Rolle weist gegenüber den angeführten Ausgaben des Texts immer wieder Abweichungen auf. Der Titel des Gebets steht auf der Rolle selbst.

$$
\begin{aligned}
& \text { دعاء حزب البحر • اعوذ بالله السميع العليم من الشيطان }
\end{aligned}
$$

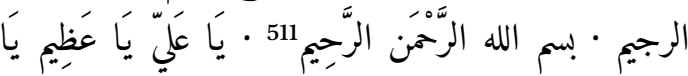

Auf der Rolle steht hier لذة; dies ergibt inhaltlich keinen Sinn.

Dieser Text in einer schwarzen Kartusche. Im Mittelstreifen beginnt hier Q 48 (Sūrat al-Fatḥ).
Im Mittelstreifen beginnt hier Q 47 (Sürat Muhammad).

Dieser Ausdruck nur auf der Rolle.

Vgl. ab hier Aufnahme Is 1626.12.4. Dieser Text in einer schwarzen Kartusche; verderbt. Im Mittelstreifen beginnt hier Q 49 (Sūrat al-Huğurāt). Hier endet der Text, der sich nachweisen lässt bei 'Abbās al-Qumī, Mafātị̣ al-ǧinān 106.8, vgl. Anm. 494. Im Mittelstreifen beginnt hier Q 5o (Sürat Qāf).

Dieser Text in einer schwarzen Kartusche.

Dieses Gebet beginnt auf der Aufnahme Is 1626.12.5 (links). Im Mittelstreifen beginnt hier Q 51 (Sürat adDāriyāt).

Siehe http://lib.eshia.ir/40289/21/142 (Stand 26. Januar 2017). Aș-Ṣafadī, al-Wāfı bi-l-wafayāt XXI, $142 \mathrm{ff}$. (ohne Jahr, ohne Ort). Siehe auch http://elislame.alafdal.net/ t34-topic (Stand 26. Januar 2017). Beachte überdies den Text und die Rezitation dieses Gebets auf http:// shadhili.nur.nu/en_GB/awrad/104/hizb-al-bahr-2/ (Stand 28. Februar 2018). Auch Ibn Baț̣uța, Riḥla 26 f., zitiert diesen hizb (Bayrūt, Dār Bayrūt, 198o).

Im Mittelstreifen beginnt hier Q 52 (Sürat aț-Ṭūr).
حَلِيم يَا عليم • أَنْت رَبِي وعلمك || اللهم صل على محمد النبي

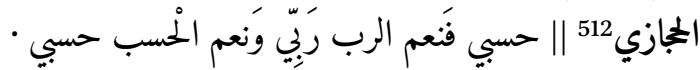

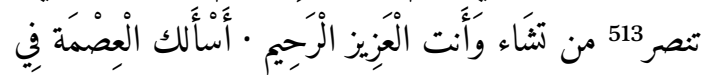
الحركات514 والسكات والكلمات والإرادات || اللهم صل تل على النبي الماشمي 515 || والخطرات 516 من الشكوك والظنون

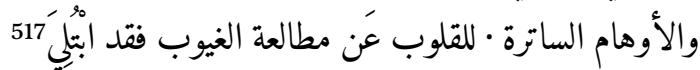

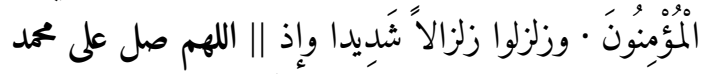

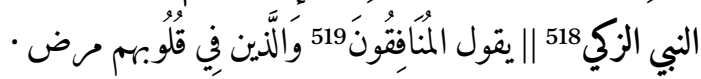

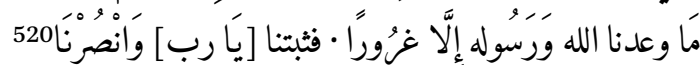

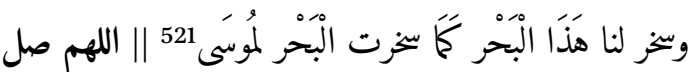

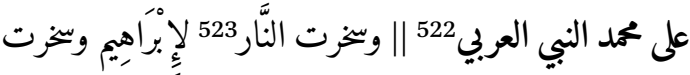

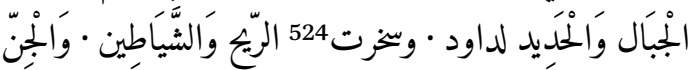

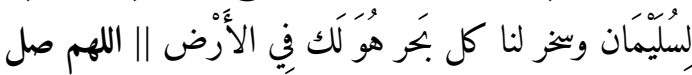

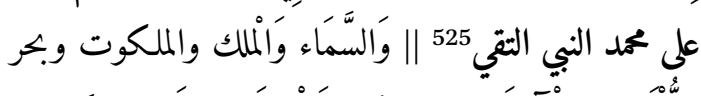

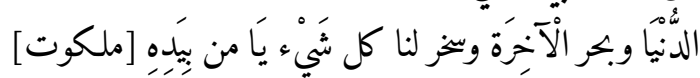
كل شَيْء · كهيعص كهيعص كهيعص انصرنا فإنَّك خير || اللهم صل على محمد النبي القرشي 526 || الناصرين وَافْتَحْ لنا

512 Dieser Text in einer blauen Kartusche. Im Mittelstreifen beginnt hier Q 53 (Sūrat an-Nağm). Im Mittelstreifen beginnt hier Q 54 (Sürat al-Qamar). Im Mittelstreifen beginnt hier Q 55 (Sürat ar-Raḥmān). Dieser Text in einer blauen Kartusche. Im Mittelstreifen beginnt hier Q 56 (Sürat al-Wāqi'a). Im Mittelstreifen beginnt hier Q 57 (Sürat al-Hadīd). Dieser Text in einer blauen Kartusche. Im Mittelstreifen beginnt hier Q $5^{8}$ (Sürat al-Muğă dala).

Im Mittelstreifen beginnt hier Q 59 (Sürat al-Hašrr). Vgl. ab hier Aufnahme Is 1626.14.2.

Dieser Text in einer roten Kartusche. Im Mittelstreifen beginnt hier Q 6o (Sürat al-Mumtahina).

Im Mittelstreifen beginnt hier Q 61 (Sürat aș-Șaff). Dieser Text in einer roten Kartusche. Im Mittelstreifen beginnen hier Q 62-64. Vgl. für die Fortsetzung nach der roten Kartusche Aufnahme Is 1626.14.3.

Dieser Text in einer roten Kartusche. Im Mittelstreifen beginnen bis hier die Q $65^{-68}$. 
فَإنَّك خير الفاتحين • واغفر 527 لنا فَإنَّك خير الغافرين وارحمنا

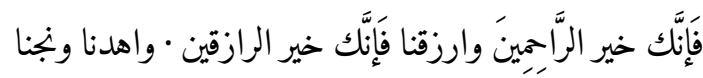

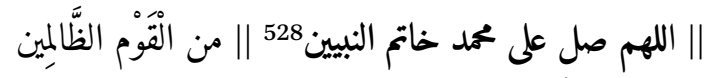

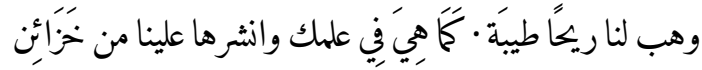

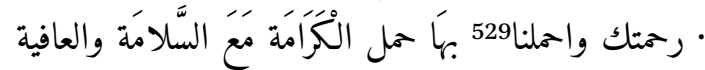
|| اللهم صل على محمد رسول العالمين 530 || فِي الدِينِ والدنّانَ

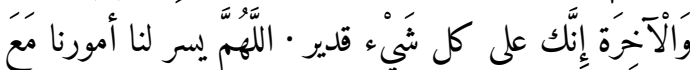

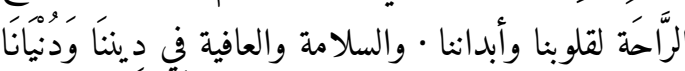

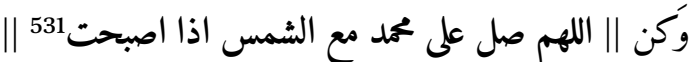

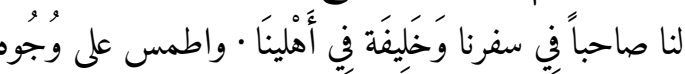

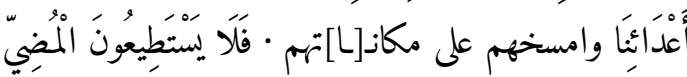

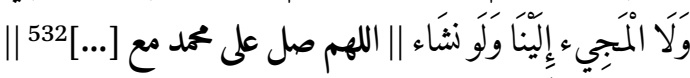

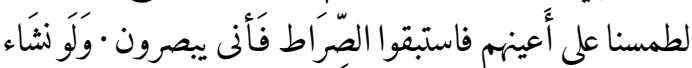

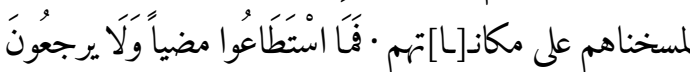

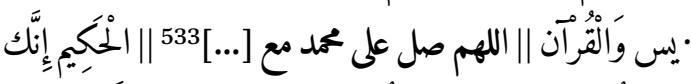

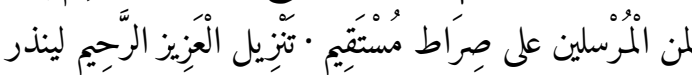

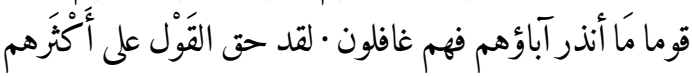

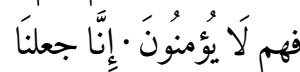

Der Schreiber erreicht jetzt das Ende der Rolle. Der folgende Text befindet sich im horizontalen Rahmenstück ganz am Schluss des Dokuments;

Dieser Text in einer blauen Kartusche (stark verderbt, am Schluss ein Ausdruck unleserlich). Im Mittelstreifen beginnt am Ende dieser Kartusche Q 88 (Sürat al$\dot{G} \bar{a}$ šiya). Vgl. ab hier Aufnahme Is 1626.15.4.

Dieser Text in einer blauen Kartusche; verderbt (am Schluss ein Ausdruck unleserlich). Vgl. ab hier die Aufnahmen Is 1626.16.2-4. er ist - gerade am Schluss der blauen Kartusche nur schlecht lesbar. Nach dieser Zeile steigt der Schreiber auf der gegenüberliegenden Seite im Seitenband $\mathrm{C}$ wieder nach oben.

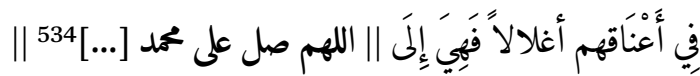

$$
\begin{aligned}
& \text { الأذقان فهم مقمحون }
\end{aligned}
$$

Ab jetzt verläuft der Text rechts aufsteigend:

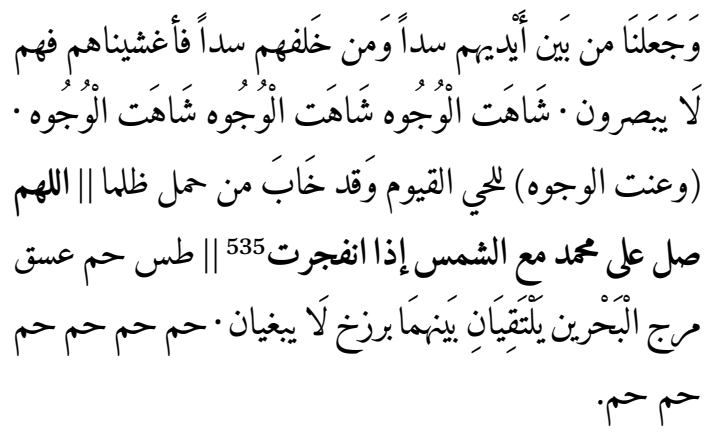

Es folgt jetzt auf der Rolle ein Einschub, der sich in den angeführten Ausgaben des Hizb al-Bahr so nicht nachweisen liess: ${ }^{536}$

$$
\begin{aligned}
& \text { اللهم لا تقتلنا بغضبك • ولا تهلكا بعذ ابك وعافنا || اللهم صل } \\
& \text { على محمد مع الشمس إدا انفطرت (؟537 || قبل ذلك اللهم } \\
& \text { ولا تؤاخذنا بسو (؟) اعمالنا ولا تسلط علينا · من لا يرحمنا } \\
& \text { وكف ايدي الظالمين عنا • يا حفيظ احفظنا اللهم يسر امورنا } \\
& \text { وحصل || اللهم صل على محمد مع الشمس اذا النقت } 538 \text { || } \\
& \text { مرادنا برحتك يا ارحم الراحمين }
\end{aligned}
$$

Danach kehrt der Kopist zur Vorlage zurück: ${ }^{539}$

534 Dieser Text in einer blauen Kartusche. Der Schlussausdruck liess sich nicht entziffern. Dieser Text in einer blauen Kartusche. Vgl. ab hier Aufnahme Is 1626.15.4 (aufsteigend). Vgl. ab hier Aufnahme Is 1626.15.2 (aufsteigend).

Dieser Text in einer blauen Kartusche.

Dieser Text in einer schwarzen Kartusche.

Vgl. ab hier Aufnahme Is 1626.14.5. Siehe http://lib.eshia .ir/40289/21/142 (Stand 26. Januar 2017). Aṣ-Ṣafadī, alWāfi bi-l-wafayāt 21, 142-143 (Übergang). Siehe auch 


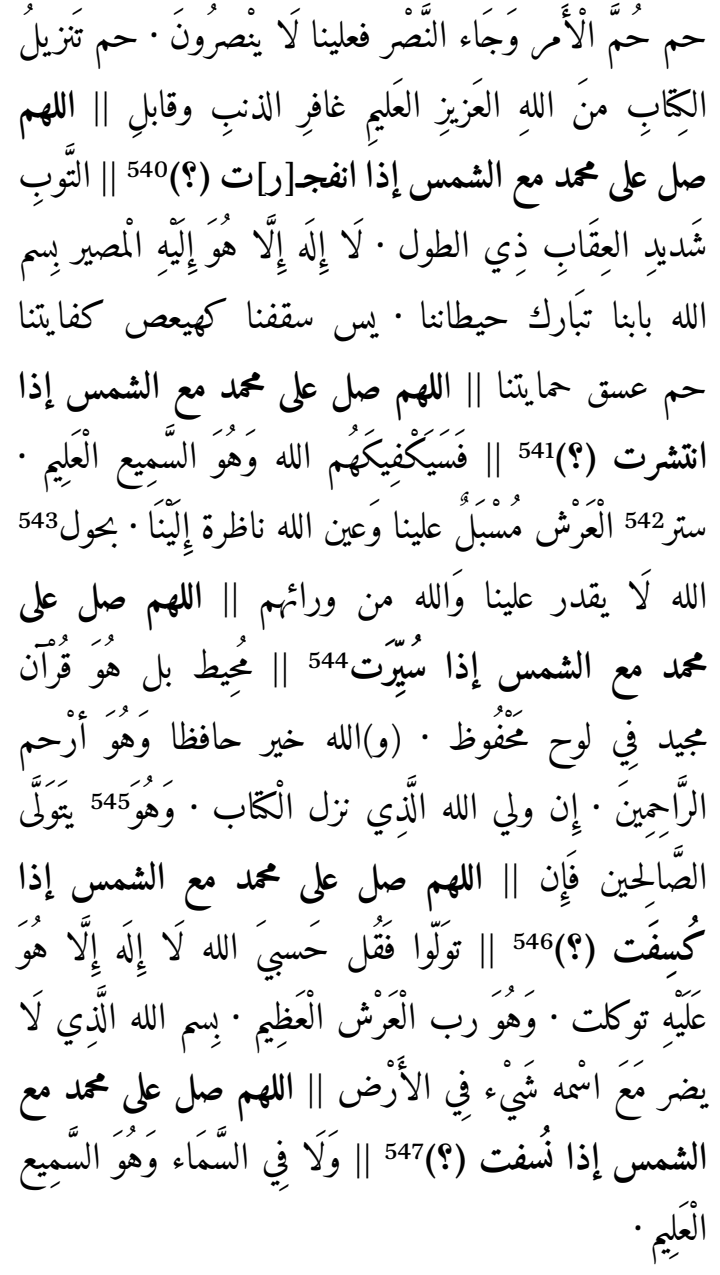

Hier erreicht der Hizb al-Bahr in der Version Șafadīs nahezu sein Ende; der Text auf der Rolle weicht jetzt ab. ${ }^{548}$

http://elislame.alafdal.net/t34-topic (Stand 26. Januar 2017).

540 Dieser Text in einer schwarzen Kartusche. Im Mittelstreifen befindet sich hier Q 76 (Sūrat ad-Dahr, üblicherweise Sūrat al-Insān). Vgl. ab hier Aufnahme Is 1626.14.4.
Dieser Text in einer schwarzen Kartusche. In der Vorlage steht hier die Metrumsangabe:من الوافر. Vgl. ab hier Aufnahme Is 1626.14.3.

Dieser Text in einer roten Kartusche.

Vgl. ab hier Aufnahme Is 1626.14.2.

Dieser Text in einer roten Kartusche.

Dieser Text in einer roten Kartusche.

Übereinstimmung aber gemäss http://elislame.alafdal

$$
\begin{aligned}
& \text { ولا حول ولا قوة إلا بالله العلي العظيم • إن الله وملائكته }
\end{aligned}
$$

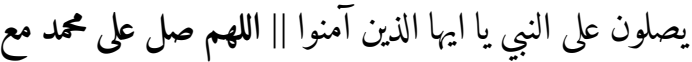

$$
\begin{aligned}
& \text { الشمس إذا كورت549 || صلوا عليه وسلموا تسليماً · وصلى لهلى }
\end{aligned}
$$

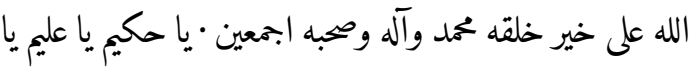

$$
\begin{aligned}
& \text { عظيم اسمع دعائي بخصايص لطفك || اللهم صل على محمد مع } \\
& \text { الشمس إذا ذكرت } 550 \text { || امين امين امين. }
\end{aligned}
$$

An dieser Stelle endet dieses Gebet, das im linken Seitenband begonnen hatte, dann aber am Rollenende zusammen mit dem Schriftband auf die rechte Seite der Rolle wechselte und von dort wieder nach oben stieg. Hier kommt jetzt von oben das Seitenband $\mathrm{C}$ mit absteigendem Text entgegen. Aufsteigender und absteigender Text treffen auf der Höhe von Q 55 (Sūrat ar-Raḥmān) im Mittelstreifen aufeinander. ${ }^{551}$

Schlussfolgerungen: Dieses Belegstück dürfte vor 1500 in Iran entstanden sein. Im Vordergrund steht eine Anfertigung in einem mystisch orientierten Umfeld. Dafür spricht insbesondere die goldene Mütze, die am Anfang des Dokuments aufgeklebt worden ist. ${ }^{552}$ Die häufige Anordnung von Textelementen in gegenläufigem SchachbrettKūfī ruft sodann den Eingang des Schreins des Suhrawardiyya-Shaykhs 'Abd aș-Ṣamad in Natanz in Erinnerung. ${ }^{553}$ Auch enthält die Rolle im Mittelstreifen von Teil II eine wohl vollständige Abschrift des Korans. Die Zierelemente in Teil I greifen ebenso Stellen aus der islamischen Offenbarung auf. 554

Wichtig ist sodann, dass in den Seitenbändern von Teil II weitere Texte kopiert worden sind. Es handelt sich häufig um Gebete, die in Sufi-Orden

.net/t34-topic (Stand 26. Januar 2017). Vgl. ab hier Aufnahme Is 1626.13.3. Dieser Text in einer blauen Kartusche. Dieser Text in einer blauen Kartusche.

$55^{1}$ Vgl. Aufnahme Is 1626.13.2.

$55^{2}$ Vgl. bei Anm. 20-23.

553 Vgl. bei Anm. 69-95 und 103.

554 Vgl. bei Anm. 63-69. 
beliebt waren. Diese Gebete werden hier der besseren Übersicht halber nochmals genannt: II.C.2: Hirz Ab̄̄ Duğāna; 555 II.C.3: Lobpreisungen Gottes, belegt in der Fatwā-Sammlung des Suyūțī; 556 II.C.4: weiteres Gebet; ${ }^{557}$ II.C.5: weiteres Gebet; ${ }^{558}$ II.D.1: Du'ă’ al-Ğawšan; ${ }^{559}$ II.D.2: Du'ä' Hizb al-Bahr des Šādilī̄;60 II.D.[3]: In Kartuschen eingeschoben sind ausserdem Anrufungen des Propheten; sie figurieren als Gegenstück zu den Lobpreisungen Gottes. ${ }^{561}$

\footnotetext{
555 Vgl. bei Anm. 131.

556 Vgl. bei Anm. 241.

557 Vgl. bei Anm. 242

558 Vgl. bei Anm. 292

559 Vgl. bei Anm. 303

560 Vgl. bei Anm. 509.

561 Vgl. bei Anm. 304; zu diesen Lobpreisungen Gottes siehe bei Anm. 556 (II.C.3).
} 


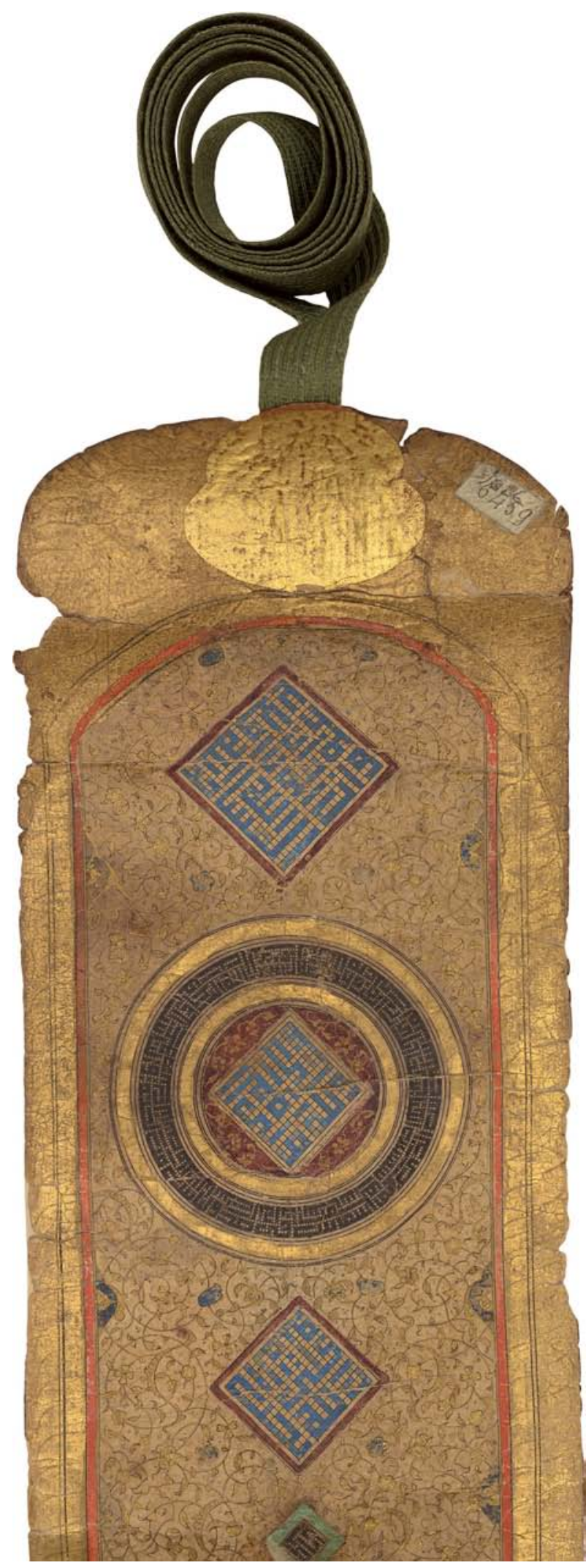

ABB. 86

Dublin, Chester Beatty Library, Is 1626 (vgl. bei Anm. 1932): Anfang der Rolle. Ganz zuoberst lässt sich ausserhalb des Schriftspiegels eine aufgeklebte Verzierung erkennen. Sie erinnert an die Mützen, wie sie von Derwischen getragen werden. Darunter schliessen sich drei Zierelemente mit Text in Schachbrettkufi an. Die kopierten Stellen werden in den Beschreibungen identifiziert.

(C) THE TRUSTEES OF THE CHESTER BEATTY LIBRARY, DUBLIN (CHESTER BEATTY, DUBLIN. CC BY-NC 4.0) 


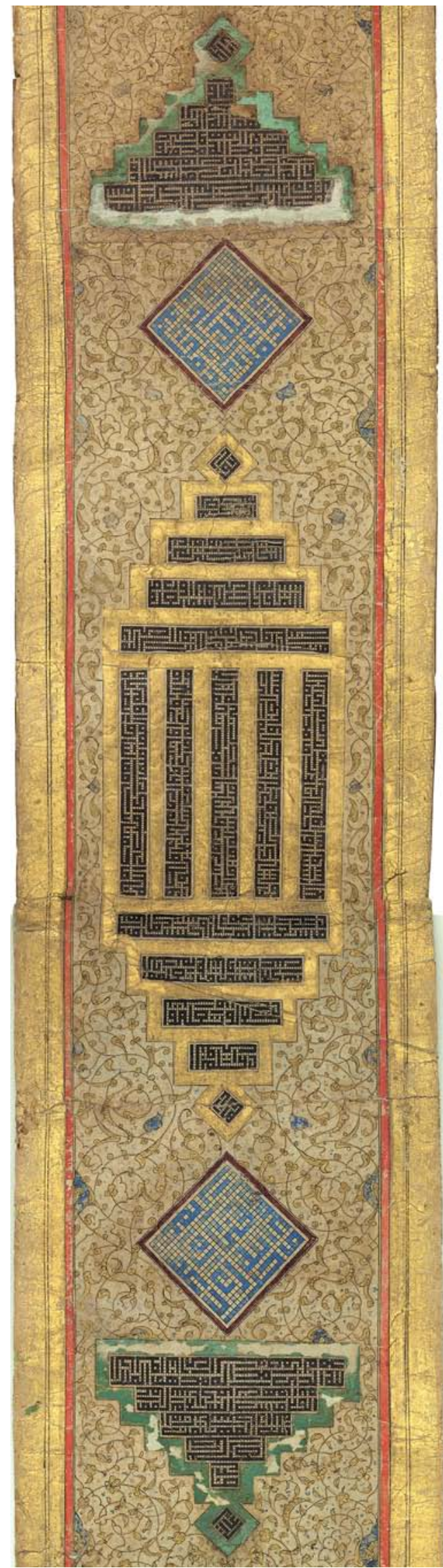

ABB. 87

Dublin, Chester Beatty Library, Is 1626 (vgl. bei Anm. 32-51): Die Elemente 4-8 im Mittelstreifen von Teil I. Die in den einzelnen Elementen kopierten Texte werden in den Beschreibungen bestimmt. (C) THE TRUSTEES OF THE CHESTER BEATTY LIBRARY, DUBLIN (CHESTER BEATTY, DUBLIN. CC BY-NC 4.0) 




ABB. 88

Dublin, Chester Beatty Library, Is 1626 (vgl. bei Anm. 43-50): Element 6 im Mittelstreifen von Teil I; an dieser Figur werden die Elemente 1-5 davor bzw. 7-11 danach gespiegelt. Die in Element 6 kopierten Textstellen werden in den Beschreibungen bestimmt.

(C) THE TRUSTEES OF THE CHESTER BEATTY LIBRARY, DUBLIN

(CHESTER BEATTY, DUBLIN. CC BY-NC 4.0) 


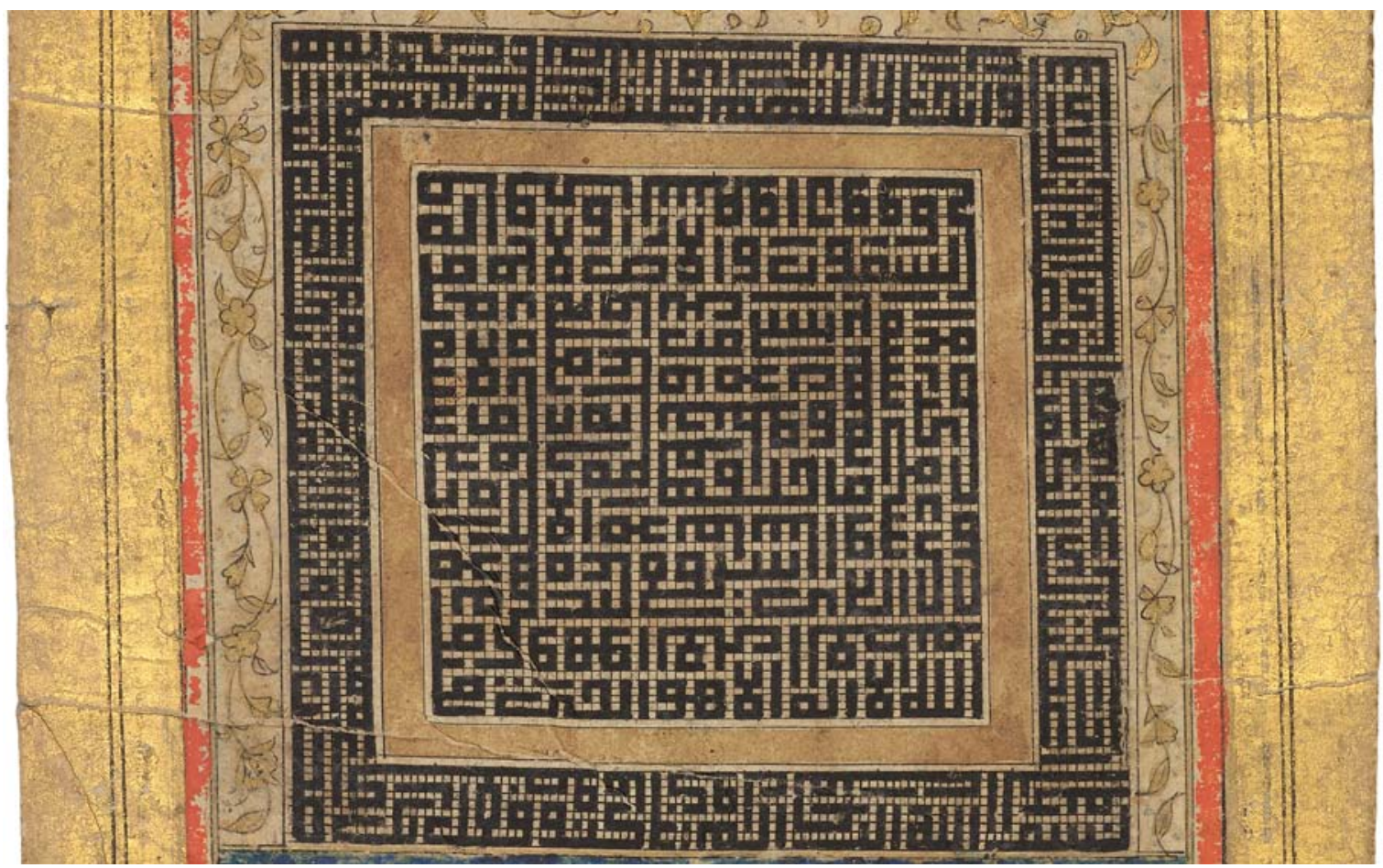

АВB. 89

Dublin, Chester Beatty Library, Is 1626 (vgl. nach Anm. 59): Der Schreiber hat in diesem Quadrat ausgewählte Stellen aus dem Koran kopiert. Im innern Viereck steht der Thronvers (Q 2:255, Beginn in der unteren Ecke, rechts). Der äussere Rahmen enthält Q 105 und Q 108. (C) THE TRUSTEES OF THE CHESTER BEATTY LibRARY, DUbLiN (CHESTER BEATty, DUBLIN. CC BY-NC 4.0) 


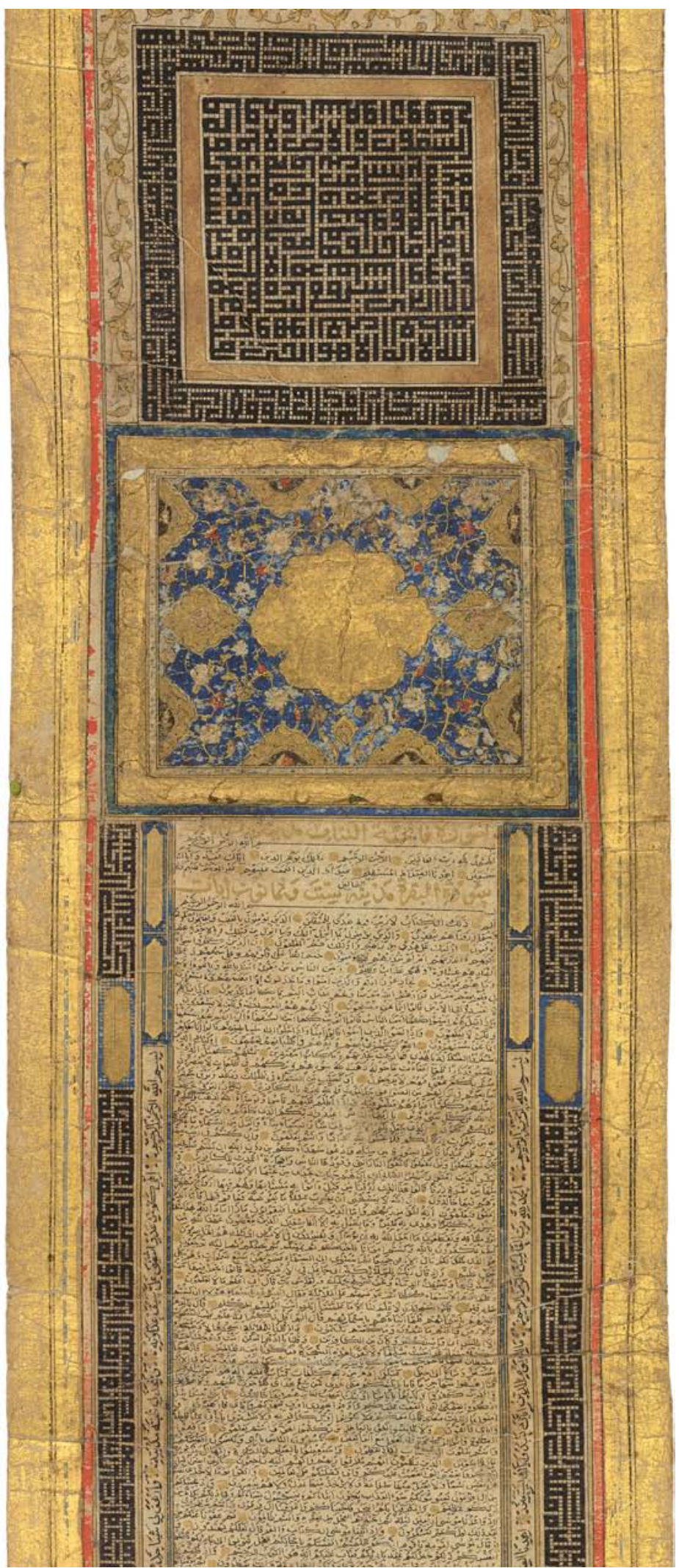

ABв. 90

Dublin, Chester Beatty Library, Is 1626 (vgl. bei Anm. 6o-62): Der Kopist hat im Mittelstreifen von Teil II den Korantext in $\dot{G} u b \bar{a} r$-Schrift auf horizontalen Zeilen notiert. Die Ausführung des blauen Zierfelds davor legt eine Zuordnung dieser Rolle zu spät-timuridischen bzw. frühsafawidischen Kontexten nahe. In den seitlichen Schriftbändern mit gegenläufigem Schachbrettkufi wurden ausgewählte Suren kopiert. Die beiden schmalen Textbänder mit Text in Nash enthalten mehrere Gebete. Sie liessen sich teilweise identifizieren (vgl. Anm. 555-561). Für die Einzelheiten siehe die Beschreibung.

(C) THE TRUSTEES OF THE CHESTER BEATTY LIBRARY, DUBLIN (CHESTER BEATTY, DUBLIN. CC BY-NC 4.0) 


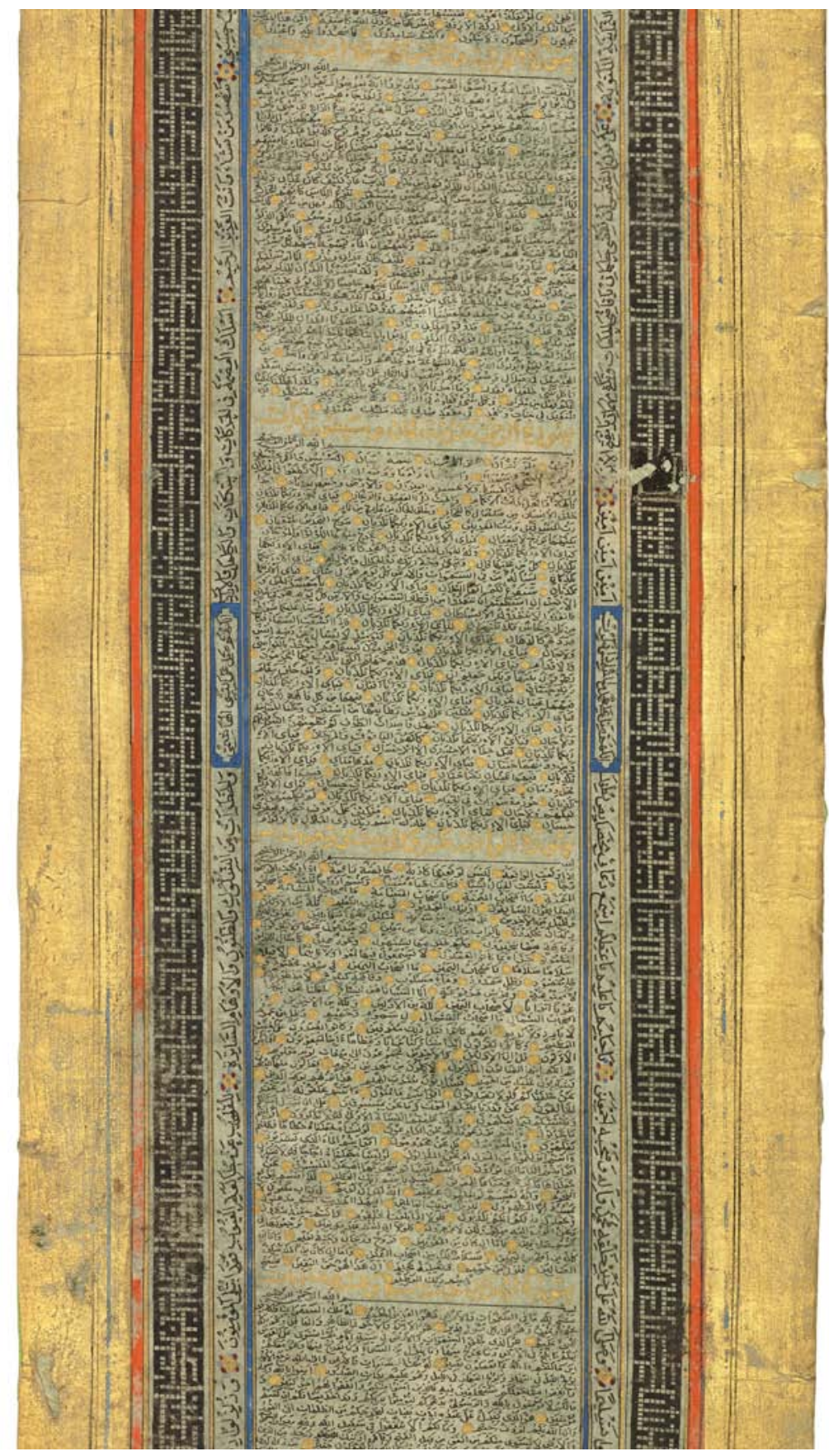

ABB. 91

Dublin, Chester Beatty Library, Is 1626 (vgl. bei Anm. 61 und 89): Im Mittelstreifen lässt sich die Überschrift von Q 55 (Sūrat arRaḥmān) erkennen. Im rechten Textband mit gegenläufigem Schachbrettkufi lässt sich etwas oberhalb der blauen Kartusche die Stelle erkennen, wo der rechts absteigende Text (Suren 36, 48 und 76) auf den aufsteigenden Text mit Stellen aus Q 6 trifft (vgl. in den Beschreibungen u.a. bei Anm. 61 und Anm. 70-95). (C) THE TRUSTEES OF THE CHESTER BEATTY LIBRARY, DUBLIN (CHESTER BEATTY, DUBLIN. CC BY-NC 4.0) 


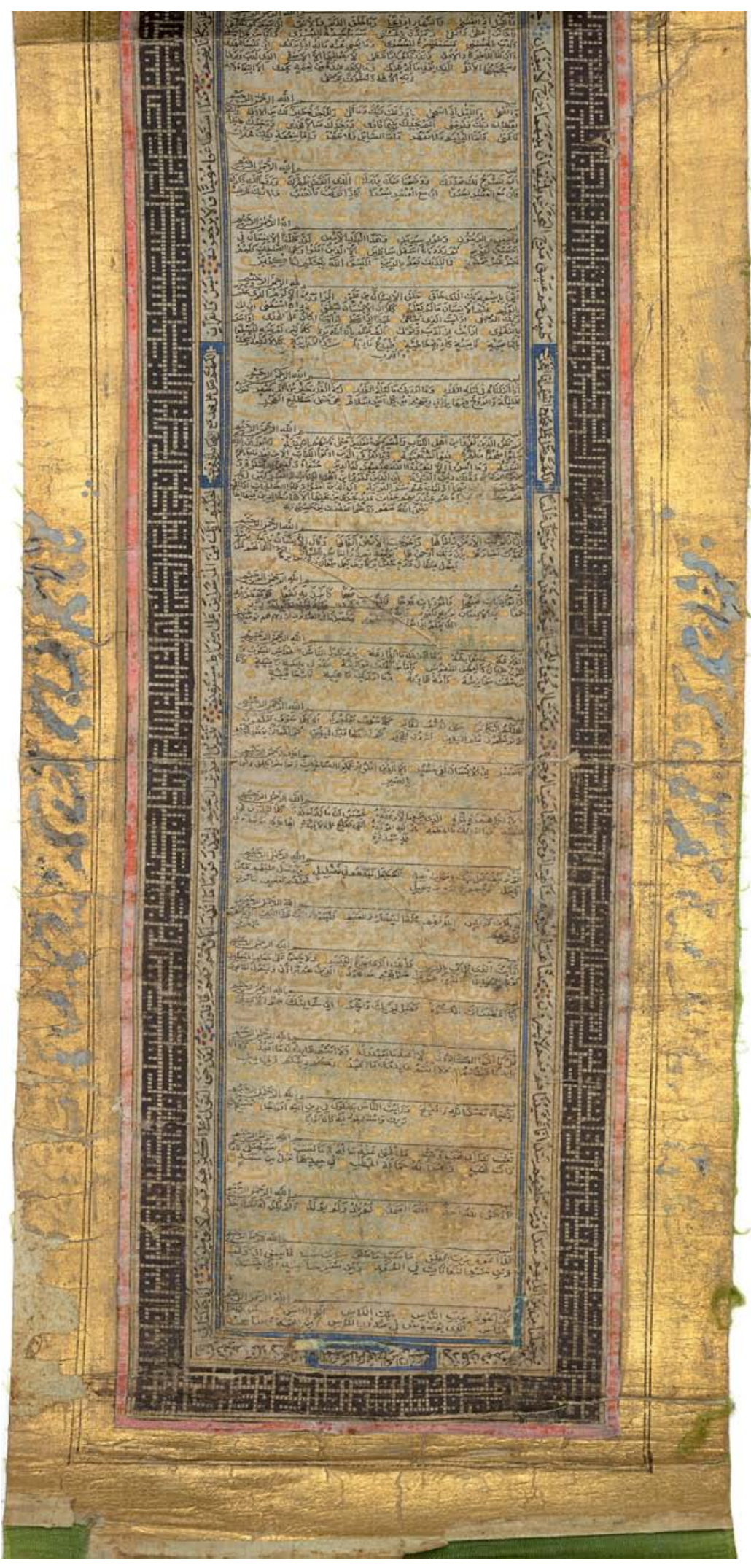

АBB. 92

Dublin, Chester Beatty Library, Is 1626 (vgl. zwischen Anm. 2 und 3): Schluss der Rolle, wo die seitlichen Textbänder den Mittelstreifen unten umfahren. Im Mittelstreifen sind die Suren am Ende des Korans zu erkennen. Ein Kolophon scheint zu fehlen. Auf dem goldenen Rand lassen sich auf der linken und rechten Seite Reste von Text in weisser Schrift erkennen. Dieser Text liess sich nicht entziffern. (C) THE TRUSTEES OF THE CHESTER BEATTY LIBRARY, DUBLIN (CHESTER BEATTY, DUBLIN. CC BY-NC 4.0) 
4.10

\section{Rolle des Ġiyāt ad-Dīn, Sultanat von Eretna (Ost-Anatolien)}

Diese Ausführungen machen im Sinn eines Exkurses auf ein im Jahr 754/1353-1354 hergestelltes Exemplar aufmerksam, das am 5. Oktober 2010 bei Christie's, London, hätte versteigert werden sollen, von seinem Besitzer aber wieder zurückgezogen wurde.

Die folgenden Ausführungen paraphrasieren das Katalogisat, das zu diesem Exemplar von Christie's erstellt worden ist. Nachdem das Exemplar vom Besitzer zurückgezogen wurde, konnte die Veröffentlichung dieser Beschreibung im gedruckten Katalog gerade noch verhindert werden. Allerdings muss der englische Text 2010 für mehrere Tage oder Wochen auf der Website des Auktionshauses aufgeschaltet gewesen sein. Von dort gelangte er auf invaluable.com, eine Metadatenbank für Objekte aus dem Kunsthandel. Da der Verfasser dieser Untersuchung dieses Exemplar nie sehen konnte, paraphrasiert der folgende Überblick die für den Auktionskatalog vorgesehenen Angaben: ${ }^{1}$

Aus dem von Christie's erstellten Katalogisat geht hervor, dass es sich bei diesem Dokument um eine Koranrolle [sic] handelt. Sie sei für Ġiyāt adDīn Muḥammad b. Sulțān Eretna angefertigt worden. Als Schreiber liess sich Mubārakšāh b. 'Abdallāh identifizieren. Das Belegstück stamme aus Ostanatolien und datiere aus dem Jahr 754/1353-1354.

Die Beschreibung hält danach fest, dass es sich beim Beschreibstoff um starkes Papier handle. Am Anfang lasse sich eine Reihe von abwechs-

1 Die englische Beschreibung war während langer Zeit einsehbar unter https:/www.invaluable.com/auction-lot/ quran-scroll-127-c-ce28dc7ef3 (Stand 29. September 2014). Es wurden Versuche angestellt, über das Auktionshaus einen Kontakt mit dem Besitzer dieses Dokuments herzustellen, um wenigstens Abbildungsmaterial davon zu erhalten. Das Auktionshaus teilte dem Verfasser allerdings in einer Nachricht vom 20. September 2015 mit, dass der Besitzer dieses Exemplar aktuell nicht für Studienzwecke zur Verfügung stelle. Es war anfänglich die Absicht, das englische Katalogisat hier vollständig als Quellentext abzudrucken. Darauf musste aber verzichtet werden. lungsweise runden und rechteckigen Zierfeldern erkennen. Sie seien aufwendig in Gold, Silber und weiteren Farben verziert worden. Beim kopierten Text am Anfang der Rolle handle es sich um fromme Anrufungen und Anführungen von ausgewählten Beinamen Gottes. An beiden Enden dieses Abschnitts lassen sich auffällig gestaltete Palmetten erkennen, die mit leuchtenden floralen Arabesken auf goldenem und silbernem Hintergrund verziert worden sind. Es schliessen sich darauf sechs- und mehrlappige Kartuschen an, die die englische Beschreibung als haykal bezeichnet. Sie enthalten ein Gitterwerk aus Text in $\dot{G} u b \bar{a} r$-Schrift. In fünf Fällen befinden sich unterschiedlich gestaltete, golden illuminierte Medaillons in der Mitte. In der siebten Kartusche (haykal) lassen sich drei kleine Rosetten erkennen; dieser siebte Abschnitt ist ebenso mit $\dot{G} u b \bar{a} r$-Schrift ausgefüllt und wird von einer Reihe von abwechslungsweisen langen Kartuschen mit kalligraphischen Elementen und kürzeren goldenen Kartuschen umrahmt.

Darauf beginnt die Abschrift des Korans. Der Korantext ist in einer Reihe von Rondellen mit Text in $\dot{G} u b \bar{a} r$-Schrift angeordnet worden. Die Zwischenräume wurden mit goldenen Rosetten ausgefüllt. Auf den Rändern lassen sich abwechslungsweise Rondellen mit kalligraphierten Textelementen und floralen Mustern erkennen. Die $\check{G} u z^{\prime}$-Vermerke wurden in weissem Tulut auf mehrfarbigen Feldern von unterschiedlicher Form angebracht. Der Kolophon wurde in weisser TulutSchrift auf goldenem Hintergrund notiert. Der Name des Schreibers und das Datum der Abschrift lassen sich unterhalb des Kolophons erkennen, dies in flüssigem schwarzem Nash. Beim ersten Zierfeld soll es sich um eine Ersetzung einer verlorenen Stelle aus osmanischer Zeit handeln. Das Dokument misst $11.9 \times 1572 \mathrm{~cm}(15.72 \mathrm{~m})$.

Die englische Beschreibung stuft diese Rolle als seltenes und eindrückliches Belegstück ein, das aus einem höfischen Umfeld in Anatolien stamme. Diese Koranrolle sei für Giiyāt ad-Dīn Sulțān Muhammad b. Sulțān Eretna angefertigt worden, dessen Name auf der Rolle steht. Es handle sich um eine wichtige Rolle, die von einem Schrei- 
ber kopiert worden sei, über den zwar wenig bekannt sei, der aber einen gefestigten Ruf habe. Der junge Sultan herrschte damals über den mächtigen, aber kurzlebigen Beylik-Staat von Eretna. Bei der Rolle handle es sich um ein ausgesprochen seltenes Überbleibsel aus der Produktion von Koranexemplaren an anatolischen Fürstenhöfen im 14. Jh.

Auf dem Belegstück sind unterschiedliche Texte kopiert worden; es fällt auf, dass sich diese Zitate oft auch auf andern hier vorgestellten Dokumenten feststellen lassen: Die Rolle beginnt mit einem Panel, in dessen vier Ecken und in der Mitte der Längsseiten je der Name Allāh notiert worden ist. Im Zentrum dieses Feldes steht Q 23:115 (Sūrat alMu'minūn). Es schliesst sich darauf ein weiteres Zierfeld an, das von Kartuschen eingefasst wird. Darin wurde Q 112 (Sūrat al-Ihlāṣs) kopiert. Auch lässt sich der Satz Fa-ittaqū Allāh („Fürchtet Gott“) erkennen. Darauf folgen Wiederholungen von Sure 112. Ein in eine Rosette eingepasstes Medaillon enthält Anrufungen Gottes. Es schliessen sich danach zehn vierblättrige Figuren mit weiteren Anrufungen an. Darauf lässt sich eine Rondelle erkennen, in deren Zentrum der Satz tawakkaltu 'alā Allāh („Ich setzte mein Vertrauen in Gott.“) steht. Um diese Rondelle herum wurde mehrfach der Ausdruck Allāh notiert. Es schliesst sich ein langes Textfeld an, in dem Q 57:3 kopiert wurde; um dieses Textfeld herum wurde Q 112 (Sūrat al-Ihlāṣ) wiederholt. In der nächsten Rondelle schliesst sich der Rest von Q 57 (Sūrat al-Hadìd) an. Auch hier wird die Rondelle von Wiederholungen des Begriffs Allāh eingefasst. Danach lässt sich ein Feld mit zehn Rosetten erkennen. In jeder Rosette steht eine Anrufung Gottes. Es schliesst sich darauf ein Zierelement an, unter dem sich in vergilbter Schrift der Eintrag tahrīr fi sana 47 (?) erkennen lässt [„Niederschrift im Jahr 47 (?)“].

Eine offensichtlich in Betracht gezogene Datierung ins 5. Jh. (?) muslimischer Zeitrechnung lässt sich gemäss den englischen Ausführungen nicht mit dem Stil der Illuminationen vereinbaren. Auch der Kolophon am Ende des Dokuments widerspreche einer solchen Einordnung. Dieses Datum muss deshalb später hinzugefügt worden sein. Es schliesst sich darauf ein Schutzgebet an, das als Hirz-i Yamānī bezeichnet wird. Es ist angeblich durch den Propheten an 'Alī übermittelt worden. Die einzelnen Gebete auf der Rolle sind nun in sieben haykal aufgeteilt. Der englische Text bezeichnet sie als protective prayers, Schutzgebete. Sie wurden in einer sehr kleinen Schrift (tiny script) kopiert; der Text verläuft diagonal über das Dokument. Jedes Einzelgebet ruft Gott um Schutz gegen unterschiedliche Gefahren an; auch enthalten alle Teile die basmala, die šahāda und Auszüge aus dem Koran. Bei den hier kopierten Koranstellen handelt es sich vornehmlich um Q 112 (Sürat alIhlāṣ), Q 2:255-256 (Sūrat al-Baqara), Q 65:3 (Sūrat aț-Talāq), Q 3:16 (Sūrat Āl Imrān). In einer Kartusche unter dem siebten Abschnitt des HaykalGebets steht Du'āy-i Hirz-i Yamānī. Es schliesst sich darauf eine ovale Kartusche an, in der ein Auszug aus Q 61:13 (Sūrat aș-Ṣaff) notiert wurde. Darauf beginnt die eigentliche Abschrift des Korans.

Am Schluss der Abschrift der islamischen Offenbarung steht der Kolophon in einer ovalen Kartusche. Die englische Beschreibung entziffert den Kolophon wie folgt: Bi-rasm hazānat mawlānā as-sulțān malik al-mulūk al-'arab wa-l-'ağam Gìyāt ad-Dunyā wa-d-Dīn Sulțān Muhammad b. Sulțān Eretnā hallada Allāhu mulka-hū („Im Auftrag des Schatzhauses unseres Herrn, des Sultans, des Königs der Könige der Araber und der Perser, Giyāt ad-Dunyā wa-d-Dīn, Sulțān Muhammad b. Sulțān Eretna, möge Gott seine Herrschaft ewig dauern lassen“).

Immer gemäss der englischen Vorlage, folgt danach ein zusätzlicher Tel des Kolophons, der festhält: Faraġa min tatmìm naqši-hī al-'abd alfaqīr al-muhtāă ilā raḥmat Allāh tacālà Mubārakšāh b. 'Abdallāh al-i (?) min ǧumlat 'abìd al-mawlā al-wazīr 'Abī Țālib dāma [wizāratu-hū?] fi l-bāqi fì t-tāmin wa-l-išrìn min Dū l-Hiğğat sanat arbac wa-hamsin wa-sab'mia („Die Abschrift wurde vollendet durch den armen und Gottes, des Erhabenen, Erbarmens bedürftigen Diener Mubārakšāh b. 'Abdallāh al-i (?), der zu den Dienern des Herrn und Wazīr Abū Ṭālib zählt, möge [sein Wesirat?] 
ewig dauern, am 28. Dū l-Ḥiğğa des Jahres 754“). Das genannte Datum entspricht dem 24. Januar 1354.

Im Kolophon nennt also Mubārakšāh b. 'Abdallāh, der Schreiber dieser Rolle, seinen Namen. Von ihm ist nur ein weiteres Werk erhalten geblieben, bei dem es sich um eine Prachthandschrift des Korans mit allen dreissig Teilen ( $\left.\check{g} u z^{\prime}\right)$ handelt. Das Katalogisat hält fest, dass dieses Exemplar dem Mamluken Amīr Șirgiitmiš an-Nāṣirī gehörte. Es wurde zwischen 1320-1330 in Bagdad oder Tabriz kopiert und befindet sich heute in Kairo; es wurde publiziert in D. James, Qur'ans of the Mamluks $148 \mathrm{f}$. D. James äussert sich anerkennend zur Hand des Mubārakšāh und vergleicht sie mit jener des Aḥmad b. as-Suhrawardī. James macht sodann auf ein Kalligraphie-Album aufmerksam, das sich heute in der Topkapi-Bibliothek befindet (Ms. H. 2310; James, S. 154). Dieses Album wurde für den Timuriden-Prinzen Bāyṣunğur angefertigt. Darin wird Mubārakšāh als einer der sitta aufgeführt. Allerdings zweifelt die englische Fassung des Katalogisats zu der hier diskutierten Rolle an, dass Mubārakšāh zu Recht zu den sitta gezählt wurde. Es ist dies aber nicht der Ort, diese Frage zu klären. Jedenfalls lässt sich feststellen, dass die vorliegende Rolle nur das zweite bekannte Werk des Mubārakšāh b. 'Abdallāh ist. Gewiss ist, dass Mubārakšāh ein ausserordentlich begabter Schreiber gewesen war.

In seinen Ausführungen zum Auftraggeber der Rolle stützt sich das englische Katalogisat auf C.E. Bosworth, The new Islamic dynasties 234: Der Kolophon hält fest, dass die Rolle für Giiyāt adDīn Muhammad (reg. 1352-1354 und 1355-1365) angefertigt wurde, als er noch jung war. Giyāt ad-Dīn herrschte später über den Beylik-Staat Eretna in Ost-Anatolien. Eretna, der Gründer dieser Dynastie, war ein Militärbefehlshaber uigurischer Abstammung; er kam ursprünglich aus OstTurkestan. Der Ilhānide Abū Sac̄īd ernannte Eretna 1327 als Gouverneur über Rūm. Eretna konnte sich nach Abū Sa īids Tod den Sultanstitel sichern (1335). Er errichtete seinen eigenen Beylik-Staat, der unter dem Schutz der Mamluken in Kairo stand. Unser
Ġiyāt ad-Dīn, der Auftraggeber der Rolle und Eretnas Sohn, war in seiner Machtausübung gänzlich von seinem Wesir Hwāḡa 'Alī abhängig; dieser wird auch auf der Rolle genannt. Als sich die Bevölkerung gegen ihn auflehnte, musste Giiyāt ad-Dīn in Konya Zuflucht suchen. Mit der Unterstützung der Karamanen in Kayseri konnte Ġiyāt ad-Dīn 1355 seine Macht zurückgewinnen und seinen älteren Bruder Ğa far ausschalten. Ġiyāta ad-Dīn konnte sich darauf bis 1365 an der Macht halten. Er fiel schliesslich einem Attentat zum Opfer, das eine Gruppe von Rebellen gegen ihn angezettelt hatte. Die hier diskutierte Rolle wurde also während der ersten Herrschaftszeit Giiyāt ad-Dīns angefertigt.

Das englische Katalogisat hebt die ausserordentliche Leuchtkraft der Farben hervor, die bei der Herstellung dieses Dokuments verwendet wurden. Üppige und naturnahe florale Motive würden die Rolle verzieren; sie seien in ähnlicher Ausführung von Illuminationen in Handschriften bekannt, die etwa zeitgleich im mamlukischen Ägypten, in Syrien und im Iraq angefertigt worden seien. Allerdings seien der Illuminator und der Schreiber auf dem vorliegenden Belegstück klar über die bis anhin bekannten Möglichkeiten bezüglich Farben, Motiven und Anordnung hinausgegangen.

Die Beschreibung macht zum Vergleich auf die Rolle aus der David Collection in Kopenhagen aufmerksam (Inv. no. 37/1996, K. von Folsach, Art from the World of Islam in the David Collection 6o, Fig. 9). ${ }^{2}$ Sie soll eng mit Giiyāt ad-Dīns Rolle verwandt sein. Ausserdem wird auf ein Exemplar aus malaysischem Privatbesitz hingewiesen, das um 1360 in Kairo angefertigt worden sein soll (Islamic Calligraphy, Ausstellungskatalog, Genf 1989, 98f., No. 22). Diese drei Rollen würden aus einer ähnlichen Tradition stammen. Gerade die Rolle aus der David Collection soll eng mit dem hier beschriebenen Belegstück verwandt sein, ist der Koran doch auf beiden Dokumenten in $\dot{G} u b \bar{a} r-$ Schrift kopiert worden. Auch würden sich auf beiden Rollen Zierfelder mit eleganten Illuminatio-

2 Siehe Kapitel 4.2 in dieser Untersuchung. 
nen finden, in denen einzelne Verse aus der islamischen Offenbarung hervorgehoben würden.

Gemäss dem englischen Katalogisat ist die Kontextualisierung dieser Rollen und weiterer Manuskripte mit vergleichbaren Verzierungen nicht gesichert. Dies lasse sich damit erklären, dass Kolophone mit klaren Ortsangaben und Datierungen fehlen. Aus dem 14. Jh. seien gerade aus Anatolien nur wenige klar datierte Koranabschriften bekannt. Viele Manuskripte befänden sich im Mawlānā-Museum in Konya und seien unveröffentlicht. Jedenfalls äussert sich D. James in diesem Sinn (The Master Scribes, S. 194). Da nun der Kolophon auf der hier diskutierten Rolle klar festhält, dass es sich um ein Dokument handelt, das für den Herrscher Giiyāt ad-Dīn aus dem BeylikStaat Eretna angefertigt worden sei, könnte die bei Christie's 2010 angebotene Rolle zur allgemeinen Einordnung dieser frühen Dokumente in Rollenform und auch weiterer Abschriften des Korans beitragen. 